
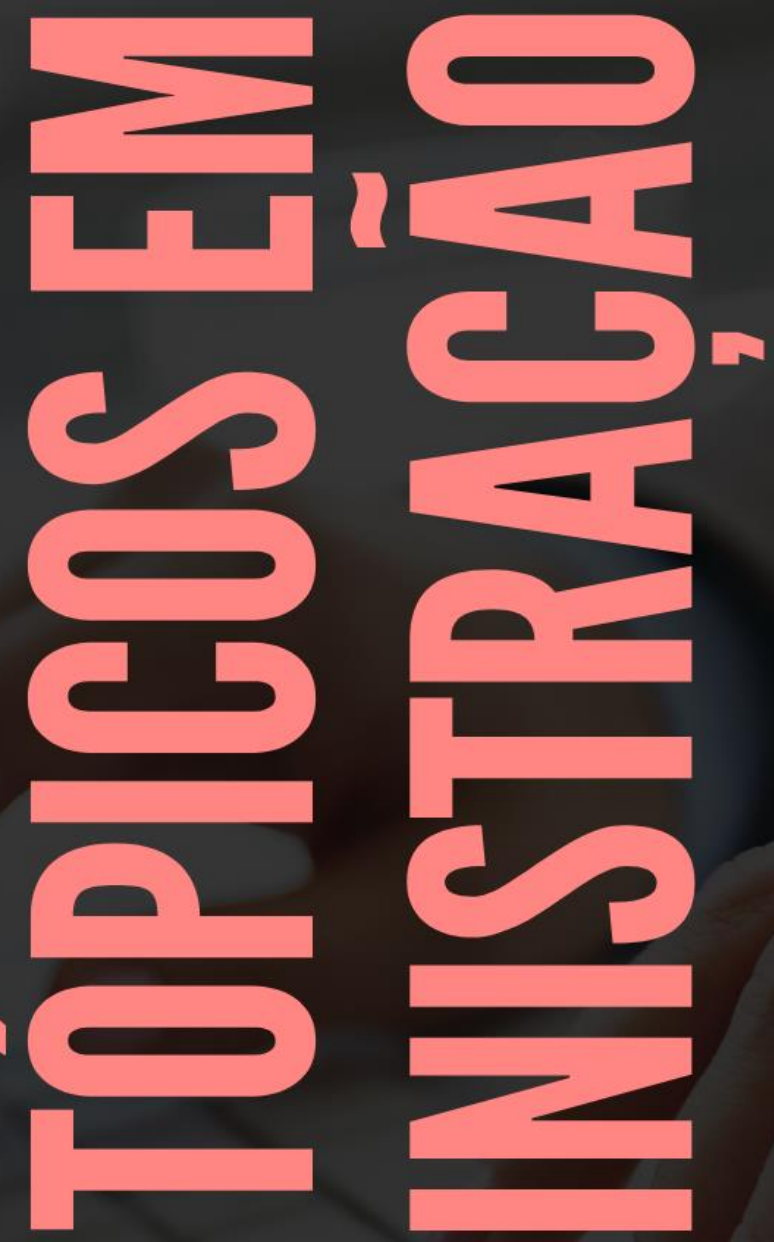

ELIZÂNGELA DE JESUS OLIVEIRA RUTE HOLANDA LOPES

MARIA ELIANE BARBOSA LACERDA

LÉIA MARIA ERLICH RUWER OSVALDO SENA GUIMARÃES (ORGANIZADORES)
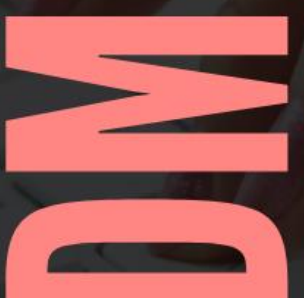

\title{
Volume 43
}


Elizângela de Jesus Oliveira

Rute Holanda Lopes

Maria Eliane Barbosa Lacerda

Leia Maria Erlich Ruwer

Osvaldo Sena Guimarães

(Organizadores)

\section{Tópicos em Administração Volume 43}

1a Edição

Belo Horizonte

Poisson

2022 


\section{Editor Chefe: Dr. Darly Fernando Andrade}

\section{Conselho Editorial}

Dr. Antônio Artur de Souza - Universidade Federal de Minas Gerais

Ms. Davilson Eduardo Andrade

Dra. Elizângela de Jesus Oliveira - Universidade Federal do Amazonas

Msc. Fabiane dos Santos

Dr. José Eduardo Ferreira Lopes - Universidade Federal de Uberlândia

Dr. Otaviano Francisco Neves - Pontifícia Universidade Católica de Minas Gerais

Dr. Luiz Cláudio de Lima - Universidade FUMEC

Dr. Nelson Ferreira Filho - Faculdades Kennedy

Ms. Valdiney Alves de Oliveira - Universidade Federal de Uberlândia

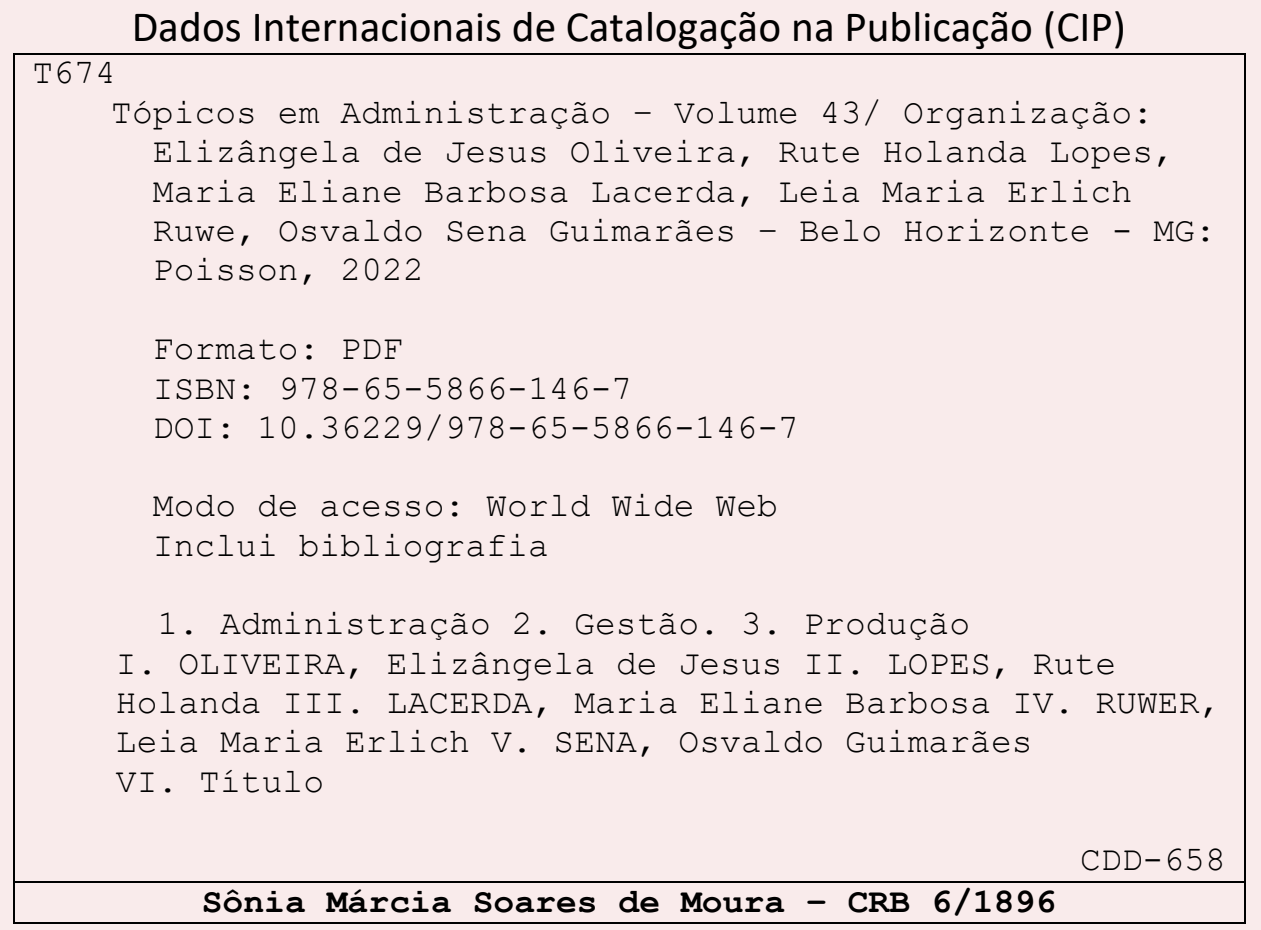

O conteúdo deste livro está licenciado sob a Licença de Atribuição Creative Commons 4.0.

Com ela é permitido compartilhar o livro, devendo ser dado o devido crédito, não podendo ser utilizado para fins comerciais e nem ser alterada.

O conteúdo dos artigos e seus dados em sua forma, correção e confiabilidade são de responsabilidade exclusiva dos seus respectivos autores.

www.poisson.com.br

contato@poisson.com.br 


\section{SUMÁRIO}

Capítulo 1: Ciência da administração: Uma análise a partir de diferentes abordagens paradigmáticas 07

Luciano Trentin

DOI: $10.36229 / 978-65-5866-146-7 . C A P .01$

Capítulo 2: Avaliação da produção cientifica sobre Indicadores Educacionais no Brasil, contidas na Base do Portal de Periódicos CAPES, entre 2011 e 2020. 18

Elinelson Pinheiro de Souza, Sérgio Henrique Arruda Cavalcante Forte

DOI: $10.36229 / 978-65-5866-146-7 . C A P .02$

Capítulo 3: Contabilidade Ambiental: Mulheres x Homens em uma década de produção científica 31

Alison Silva Ferreira, Mirian Gomes Conceição, Sonia Maria da Silva Gomes

DOI: $10.36229 / 978-65-5866-146-7 . C A P .03$

Capítulo 4: Educação a distância e a análise da tutoria no processo de aprendizagem dos cursos de Administração 46

Luciane Silva Franco, Monika Fritz, Sonia Luíza Bernet da Luz, Evelin Cristina de Goes

DOI: $10.36229 / 978-65-5866-146-7 . C A P .04$

Capítulo 5: Gastos em educação: Um estudo sobre a destinação de recursos no orçamento público na região metropolitana de Maringá

Roberto Rivelino Martins Ribeiro, Letícia Ribeiro Gasparini, Juliane Andressa Pavão, Kerla Mattiello DOI: $10.36229 / 978-65-5866-146-7 . C A P .05$

Capítulo 6: Compliance: A incidência de práticas éticas nas micro e pequenas empresas de Ponta Grossa - PR

Eliane Iara Bendix, Rosaly Machado, Alexsandra Camila Zagulski Iensen, Maria Paula Ferreira Machado DOI: $10.36229 / 978-65-5866-146-7 . C A P .06$

Capítulo 7: Marketing empresarial em escritório de contabilidade. 83

Amanda Eduarda da Silva, Natália do Amaral, Adriana Gresielly Fabrini

DOI: 10.36229/978-65-5866-146-7.CAP.07 


\section{SUMÁRIO}

Capítulo 8: A importância e a resiliência das instituições econômicas 97

Virgilius de Albuquerque

DOI: $10.36229 / 978-65-5866-146-7 . C A P .08$

Capítulo 9: Transporte individual por meio de aplicativo: Percepções do consumidor 104

Evelyn Cristina Silva, Jocelino Antonio Demuner

DOI: $10.36229 / 978-65-5866-146-7 . C A P .09$

Capítulo 10: Empreendedorismo e inovação: Um estudo do impacto da Pandemia do COVID-19 no comércio informal do município de Codó-MA

Pedro da Silva Sousa, Inácio Ferreira Façanha Neto

DOI: $10.36229 / 978-65-5866-146-7 . C A P .10$

Capítulo 11: Empreendedorismo Rural Feminino: Um estudo bibliométrico para o Brasil 136

Alessandra Bandeira da Rosa, Eduardo Leite de Souza, Wendelino Fang, Gabrielito Rauter Menezes DOI: $10.36229 / 978-65-5866-146-7 . C A P .11$

Capítulo 12: Análise de Viabilidade Econômica Financeira na bovinocultura de corte

Pedro Zorzetti de Paiva, Elis Regina de Oliveira, Brasilino José Ferreira Neto, Ronivaldo Alcebíades Ferreira

DOI: $10.36229 / 978-65-5866-146-7 . C A P .12$

Capítulo 13: Vantagens e desvantagens do home-office: Um estudo com profissionais da contabilidade. 156

Suzete Antonieta Lizote, Jessica Henequim, Julia Regina Martins, Luana Lia Schmitz, Shirley Vargas Vicente DOI: $10.36229 / 978-65-5866-146-7 . C A P .13$

Capítulo 14: Estudo comparativo dos modelos de gestão das Unidades de Atendimento Integrado (UAI) em Minas Gerais 169

Laura Cecília Rodrigues Reis, Luis de Paulo Costa, Carolina Gabarra Marques Gonçalves, Polyana Rodrigues do Carmo Silva

DOI: 10.36229/978-65-5866-146-7.CAP.14 


\section{SUMÁRIO}

Capítulo 15: Aplicação de Metodologia Ágil de Gestão de Projetos em pesquisa industrial aplicada.. 181

Caio Moldenhauer Peret

DOI: $10.36229 / 978-65-5866-146-7 . C A P .15$

Capítulo 16: A abordagem da gestão por competências para alocação de servidores técnico-administrativos recém-concursados em uma instituição federal de ensino superior.

Phelipe Augusto Marins, Fernando de Oliveira Vieira

DOI: $10.36229 / 978-65-5866-146-7 . C A P .16$

Capítulo 17: Primeiros passos em busca da vantagem competitiva: Construção da identidade organizacional para pequenas empresas

Cássia Jaqueline Theobald

DOI: 10.36229/978-65-5866-146-7.CAP.17

Capítulo 18: Planejamento estratégico em uma empresa de armazenagem de grãos no município de Amambai - Mato Grosso do Sul

220

Deisivani Carol Lima dos Santos, André Felipe Queiroz, Lesley Soares Bueno, Valéria Sun Hwa Mazucato

DOI: $10.36229 / 978-65-5866-146-7 . C A P .18$

Capítulo 19: Gestão e Estratégia: Os impactos da COVID-19 e os 10 passos para retomada.. 231

Marielle Ferreira Figueiredo, Andriéli Ferreira de Araujo, Rossana Veiga do Canto

DOI: $10.36229 / 978-65-5866-146-7 . C A P .19$

Autores: 


\section{Capítulo 1}

\section{Ciência da administração: Uma análise a partir de diferentes abordagens paradigmáticas}

\section{Luciano Trentin}

Resumo: A natureza da administração científica pode ser considerada como um produto fundamentalmente exógeno que, no perpassar dos séculos, tem experimentado influências endógenas, mais relevantes em determinadas áreas, por vezes prósperas a adaptação desse processo, outras vezes não. Nesse sentindo, a partir de uma pesquisa bibliográfica, a presente pesquisa tem por objetivo analisar os princípios epistemológicos da administração baseados em diferentes paradigmas de pesquisa. Os paradigmas tradicionais para a construção de teorias não são plenamente consistentes com os propósitos de paradigmas emergentes de pesquisa. Analisamos nesta pesquisa as abordagens paradigmáticas do diagrama de Burrell e Morgan, os estudos multiparadigmáticos apresentados por Lewis e Grimes, a metatriangulação de Gioia e Pitre e o círculo das matrizes epistêmicas proposto por Paula. Tais perspectivas podem conceber interpretações de fenômenos organizacionais que possibilitem aos pesquisadores assegurar os contrastes teóricos intrínsecos e não harmônicos, em compensação podem também incentivá-los a aderir uma lente paradigmática mais holística ao considerar essas diferenças.

Palavras-Chave: Ciência da Administração; Paradigmas; Epistemologia. 


\section{INTRODUÇ̃̃OO}

Os estudos da Administração possuem diversificadas personalidades, devido a orientação de variadas teorias e tendências que tem direcionado os pesquisadores e estudiosos da área na interpretação dos fenômenos estudados. Assim torna-se essencial para o pesquisador que pretende aprender ou atuar em um campo específico de conhecimento, compreender melhor os paradigmas predominantes desse campo.

De acordo com Martins (1996) o legado das perspectivas de investigação concebidas pela administração é oriundo de princípios diversos, tais como psicologia, sociologia e economia. Nesse sentido, a ciência da administração apesar de bem-conceituada como um campo de conhecimento com inúmeras obras contemporâneas, que contribuem para a compreensão do seu desenvolvimento e consolidação como campo científico, ainda assim, encontra-se diante de um campo de conhecimento por diversas vezes contestado, persistindo o paradigma habitual sobre a cientificidade da administração (Mattos, 2009; Raadschelders, 2011).

Contudo, os estudos da ciência da administração têm sido guiados por paradigmas e quadros teóricos vigentes reconhecidos pela comunidade científica. A administração, fundamentada, em clássicos da epistemologia das ciências, reúne múltiplos interesses nos paradigmas de pesquisa, contribuindo para a criação de um arcabouço de conhecimentos teórico-prático sobre a referida temática (Burrel \& Morgan, 1979; Caldas, 2005; Hassard, 2005). Motivo pelo qual a ciência busca enquadrar a natureza das pesquisas dentro das fronteiras preestabelecidas pelo paradigma predominante, isto é, adequar a resolução de novos problemas de acordo com os problemas similares.

Para Kuhn (2012) o conjunto de problemas similares e resultados-padrão que constituem o entendimento da comunidade científica deve ser solucionado com suporte nos resultados estudados previamente para problemas similares. De acordo com Ostermann (1996), Bird (2003) e Tozzini (2011), a imagem da ciência normal constituída por Kuhn, é excessivamente conservadora, por permanecer limitada a um paradigma, seja qual for, paradigma este admitido pela comunidade científica. Por outro lado Popper (1970) possui uma visão diferenciada, mais otimista, quanto a interpretação dos fenômenos organizacionais, com possibilidade de construir teorias a partir de múltiplos paradigmas. Segundo o autor, "somos prisioneiros de nossos modelos teóricos, porém se tentarmos, podemos escapar de nossos modelos a qualquer momento. Admitidamente nos encontraremos em um modelo novo, porém melhor e mais espaçoso; e poderemos escapar dele novamente a qualquer momento" (Popper, 1970, p.56).

Compreende-se que a evolução dos estudos organizacionais, necessitaria ser entendida como um processo dialético e de construção social, definido por diferenças e instigado por grupos de interesses. No ponto de vista de Morgan (1996), a insciência dessa diversidade paradigmática, assim como a aceitação tácita quase soberana do paradigma funcionalista (objetivista), inclina-se a reduzir o desenvolvimento dessa heterogeneidade.

Em alternativa, para contribuir com os pesquisadores na elaboração de teorias, por intermédio de visões teóricas e perspectivas epistemológicas dissemelhantes, Jasperson et al. (2002) e Saunders, Carte e Butler (2003) apresentam a metatriangulação como método de pesquisa. De acordo com os autores, o método proporciona ao pesquisador aprender a coexistir com teorias distintas e compreender os fenômenos a partir de múltiplos paradigmas à uma complexa e paradoxal realidade organizacional.

Na perspectiva de Pellegrinelli e Murray-Webster (2011) o desenvolvimento de concepções para a análise dos estudos organizacionais advém da utilização de um pluralismo teórico e metafórico. Em conformidade com os autores, na pesquisa multiparadigmática, os pesquisadores excedem a revisão da literatura, tencionando à aplicabilidade de paradigmas empiricamente divergentes, empregues de modo segregado ou em conjunto, na coleta e análise de dados e na criação de múltiplas representações de um fenômeno em ambientes complexos.

Considerada como uma promissora alternativa para a compreensão dos fenômenos organizacionais complexos, o círculo das matrizes epistêmicas proposto por Paula (2016), conforme Scussel (2017) e Santos (2017), propicia aos pesquisadores diferentes interpretações de um mesmo fenômeno orientado por distintos paradigmas, dependendo da posição em que se estabelecem os pesquisadores no círculo das matrizes epistêmicas, criando conhecimento fronteiriço da realidade social e do todo.

Evidencia-se que, entender e utilizar diversificadas abordagens em muitos paradigmas contribui para desprender e expandir os limites de estudiosos e pesquisadores. Assim, nesta pesquisa, por intermédio de diferentes abordagens paradigmáticas, defende-se a utilização de uma visão holística para com a cientificidade dos fenômenos observados na área da administração. 0 questionamento que orienta esta pesquisa, pode ser compreendido como: os paradigmas convencionais para a concepção de teorias são 
integralmente consistentes com a heterogeneidade e premência do mundo contemporâneo? Os paradigmas emergentes de pesquisa podem utilizar articulações e junções paradigmáticas de maneira discricionária?

Diante disso o presente artigo tem como objetivo analisar os princípios epistemológicos da administração baseados em diferentes paradigmas de pesquisa. Esta pesquisa sugere um olhar mais abrangente sobre o processo científico na criação de conhecimento, oportunizando diálogos entre diferentes visões e contribuindo para a área do saber em administração. Reflexões sobre as contribuições teóricas, arquétipos e compartilhamento do conhecimento podem coadjuvar para um processo renovação das pesquisas de administração em termos de harmonia, justeza, significância e finalidade.

O documento está estruturado da seguinte forma: a segunda seção analisa-se a epistemologia da administração e os modelos paradigmáticos que envolvem está ciência, na terceira seção apresenta as reflexões acerca da temática abordada, e por último, apresenta-se as considerações finais.

\section{EPISTEMOLOGIA DA ADMINISTRAÇÃO}

A geração de conhecimento conceituada como axiomática pela comunidade científica mundial, assim como percebida na atualidade, se originou no século XVII na Inglaterra. O marco científico moderno foi instituído pelo filósofo Francis Bacon (1979), sugerindo a secessão da ciência em três domínios: poesia - a ciência da imaginação, história - a ciência da memória, e filosofia - a ciência da razão. As categorias foram desdobradas em subcategorias para simplificar o dimensionamento da produção intelectual notória à época. Bacon (1979) contribuiu também para elucidar os conhecimentos considerados como verdadeiros os quais enraizados na cultura popular fossem desmistificados iniciando-se assim um ciclo de descobertas científicas.

Entre os séculos XIX e XX a prosperidade de conhecimento elaborados no campo da administração exteriorizou uma gama de inquietudes, desde os estudos de Max Weber, com a procura de racionalização da ação na sociologia e por decorrência nas organizações e, com Karl Marx que percebia a organização como um pensamento formado pela combinação de impressões passadas e presentes por intermédio da sociedade, cenário de domínio e fragmentação da ação humana (Marsden \& Towloy, 2001).

A origem da Teoria da Administração, no começo do século XX, vem arraigada nesse pensamento de racionalização proveniente da ciência moderna positivista associada a uma demanda por maior efetividade operacional que bem define o pensamento funcionalista (Mattos, 2009; França, 2004). Mesmo preterida por Max Weber na busca pela racionalidade técnica, as pesquisas que envolvem o homem e seus arbítrios e estímulos, ainda assim mantiveram um íntimo convívio com os efeitos econômicos da organização, substanciando a condição funcionalista das pesquisas. Nessa perspectiva, a condição científica pretendida pela administração apresenta-se perene no pensamento de que o conhecimento em modelos analíticos se torna capaz de inferir maior autenticidade no contexto social no qual possa ser empregue (Mattos, 2009).

Entretanto, exclusivamente a aplicabilidade dos conceitos positivistas às ciências sociais pode ser inapropriada dado a heterogeneidade dos objetos estudados. Demo (1985) contrapõe as ideias do objetivismo positivo, onde somente se pode produzir conhecimento com verificação, e uma tese somente torna-se teoria seguida de verificação. Isto é, compete "à ciência produzir teorias verificáveis" (Demo, 1985, p.107). O autor expõe que "o entusiasmo teórico por certas ideias encontraria numa dedicação empírica um corretivo salutar, porque nisto se descobriria que muitas das hipóteses brilhantes o são talvez porque se furtam ao teste" (Demo, 1985, p.110). Dessa forma, Demo (1985) previne que a dificuldade do empirista é considerar que um acontecimento seja meramente um fato, visto que não pode ser considerado essencialmente como um fato, mas principalmente interpretar o acontecimento.

Pack (2011) salienta que uma teoria não é tão somente um conjunto de preposições que se relacionam com a realidade e são capazes de serem averiguadas relativamente a ela. Tem uma percepção divergente ao declarar que teoria e prática, não se confrontam, mas necessitam inter-relacionar-se a realidade para o aperfeiçoamento da ciência. Outra forma de pensamento foi estabelecida por Popper (1980) apresentando a crítica à indução, que se define pelo processo de inferência com base nos experimentos específicos para questões generalizadas, expondo que a condição de falseabilidade coopera para que as teorias se harmonizem com a práxis. 0 autor especifica a metodologia para que se verifique uma teoria e esclarece as dificuldades e obstáculos das teorias científicas na desarmonia entre o objetivismo e subjetivismo, ou se preferir, no âmbito da objetividade científica e da convicção subjetiva (Popper, 1980). 
Entretanto, para Kuhn (2012) a ciência segue um modelo de desenvolvimento entre uma sucessão de ciclos através da ciência normal, em que o corpo de pesquisadores adota um paradigma, descontinuado por revoluções científicas (ciência extraordinária). Os acontecimentos extraordinários são evidenciados por anomalias ou crises paradigmáticas predominantes, findando com sua descontinuidade. 0 conceito fundamental proposto por Thomas kuhn para sua teoria é o paradigma. Em dissonância com Popper (1980), Kuhn (2012) critica os diferentes sentidos evidenciados quanto ao denominado método de falseamento. Para ele o método não deve ser generalizado, pois menciona basicamente o modo como persiste a ciência normal, e no interior de um paradigma encontram-se parâmetros convencionadas e reconhecidos, que possibilitam testar um enunciado teórico.

A administração, na conjuntura de campo científico, pronuncia-se com uma erudição interdisciplinar, um campo de conhecimento que se encontra ainda em estágio de amadurecimento (Shields, 1998). De acordo com Santos, Santos e Braga (2014) existem três consideráveis abordagens teóricas que assistem à produção científica no campo da administração, sendo:

a) os estudos ortodoxos da administração - entende-se por "toda produção científica aplicada às organizações produtivas mercantis, concebida nos moldes da ciência positivista, do método empirista, do liberalismo econômico, dos princípios de engenharia, tendo por fim elevar a eficiência produtiva do capital e do trabalho" (p.3);

b) os estudos organizacionais - entende-se que "todo conhecimento produzido na tentativa de descrever, interpretar e explicar o comportamento das e nas organizações, tendo como referência teórica as produções oriundas da psicologia, da sociologia, da antropologia, da economia, da ciência política, entre outras" (p.8); e

c) os estudos críticos em administração - são entendidos como "toda produção científica, alternativa à tradição da ciência moderna da administração e das organizações, cuja gestão das relações sociais de produção seja fundamentada em princípio não performático, desnaturalizado, reflexivo e emancipatório" (p.15).

Ainda que a produção científica na administração disponha de diferentes abordagens teóricas, Santos (2004) e Whetsell (2013) expõem uma carência de conformidade metodológica, peculiaridade relacionada à multidisciplinaridade da administração, posto que ela interatua com o ambiente e se beneficia do conhecimento de outros campos das ciências, como a psicologia, a sociologia, a economia, a ciência política e a antropologia, processo que resulta em um pluralismo metodológico interdependente.

Segundo Bernardes e Marcondes (2006), o campo administração estabelece um objeto de investigação definido, as organizações, como demonstra o avanço histórico do pensamento da administração. Walter e Augusto (2008) mencionam que as pesquisas em administração têm se consolidado em todos as partes do mundo e em especial no Brasil, com o aumento do número de estudos submetidos e publicados em eventos e periódicos da área, bem como no número de dissertações e teses desenvolvidas.

Entretanto, um dos fundamentos que norteiam a complexidade do campo da administração, é que no campo científico da administração o objeto de estudo "miscigena", ou diversas vezes se entrelaça, com o sujeito(s) ou participante(s) deste objeto. De acordo com Adorno (2009), os conceitos constituem parte de uma constelação que ilumina o que há de intrínseco no objeto e suas adjacências (p.140). A luz dos conceitos pode iluminar o objeto em análise, no entanto não é capaz de demonstrar com completa perfeição o que ele de verdade é. 0 que não está iluminado do mesmo modo está ali, mas não pode ser percebido. Nesse sentido, o objeto em todo o tempo é mais do que se consegue observar dele (Faria, Maranhão, \& Meneghetti, 2013).

A administração habitualmente esteve vinculada aos ambientes organizacionais manifestando-se fundamentalmente mediante a premência da prática. Para Giddens (2001) o reconhecimento amplo da cientificidade da administração, reside na ausência da legitimidade das conquistas científicas, devido a estreita relação entre a pesquisa e o objeto de pesquisa. Nesse contexto, de maneira habitual, pode ocorrer a aquisição dos conceitos pelos atores, de modo que a legitimidade não seja reconhecida com a adequada relevância científica.

Segundo Gomes et al. (2013) independentemente da ampla predominância de outras áreas do saber nos estudos da administração, isso não constitui um descrédito para a administração enquanto ciência. Pelo contrário, a administração define-se essencialmente como uma ciência pluralista, que conversa com diversas áreas do saber, propiciando novas e diversificadas concepções de mundo. Considerando esta perspectiva, fazendo jus a toda a multidisciplinaridade de teorias, o correto seria não mais denomina-la de administração, mas sim de Ciências da Administração. 
Em contrapartida Rocha e Zembo (2017) evidenciam que o campo da administração permanece ainda na fase pré-paradigmática, e pela condição atual deste campo de pesquisa, relativamente jovem, considera-se que a administração não pode ser conceituada como ciência. No ponto de vista dos autores, para o campo da administração alcançar a maturidade necessária a fim de obter status de ciência, faz-se necessário suplantar obstáculos, conscientizar-se de suas adversidades contemporâneas, reflexionar sobre suas bases epistemológicas, teóricas e metodológicas, aprofundando reflexões em seus pressupostos.

\subsection{MODELOS PARADIGMÁTICOS}

Ao que tudo indica persiste uma aquiescência no meio dos pesquisadores do campo da administração de que um paradigma preponderante neste campo ainda inexiste, e uma das explicações pode ser a natureza multidisciplinar do campo da administração. Esclarecidos pela ontologia e epistemologia, os paradigmas aparecem como perspectivas de uma cosmovisão ocasionalmente vistas como excludentes (Kuhn, 2012; Vergara \& Caldas, 2005), complementares e ainda como integradas (Morgan, 2007). De acordo com Kuhn (2012), os paradigmas podem ser sucedidos nas ciências, no momento que o paradigma dominante (ciência normal) se tornar refutado e exasperado por um paradigma contemporâneo, que o sucede e institui-se como novo paradigma.

Segundo Damke, Walter e Silva (2010) e Maciel e Silva (2011) com base na visão paradigmática de Kuhn (2012), não existe a possibilidade de definir se a administração é uma ciência. A justificativa dos autores para tal afirmação está constituída no fato de ainda não ter sido constatado com clareza um paradigma convincente, singular e válido no campo da administração. Kuhn (2012) elucida, na fase pré-paradigmática que, entre os pesquisadores, podem ocorrer inconsonâncias, a criação e instituição de princípios teóricos, a clarificação de propósitos, o estabelecimento de normas e critérios adequados, a existência de um detalhamento do objeto de estudo, além de um discernimento a respeito das inter-relações presentes entre as variáveis relacionadas.

Perante essa elucidação, Senff et al. (2015) apresentam que o campo de pesquisa da administração encontrou o seu paradigma e, consequentemente, trata-se de uma ciência. Os motivos elencados pelos autores, foram em função da imensa quantidade sucessiva de estudos na área e também pelas transformações no ambiente interno das organizações quanto na inconsistência do cenário socioeconômico. De outra forma, Rocha e Zembo (2017) evidenciam que o campo da administração permanece ainda na fase pré-paradigmática, dado que se trata de uma fase onde o campo do saber está pretendendo alcançar sua maturidade e intensidade metodológica de pesquisa e o delineamento do seu objeto de estudo, argumentando que a administração não deve ser considerada como ciência.

Diante de um ponto de vista mais aproximado das ciências sociais aplicadas, propriamente no campo de análise da administração, Burrell e Morgan (1979) apresentam duas relevantes contribuições: os autores reconhecem quatro paradigmas exequíveis na área das ciências sociais e, discordantes de Kuhn (2012), compreendem como verossímil a harmonia entre os distintos paradigmas. Desta maneira, o pensamento evolucionista de Kuhn (2012) é contraposto diante de uma oportunidade de múltiplos paradigmas que coabitam em um campo científico. Vergara (2005) e Kura e Sulaiman (2012) manifestam que independentemente do paradigma estudado pelo pesquisador, o fenômeno pode ser pesquisado tanto numa perspectiva positivista ou interpretativista.

O modelo evidenciado por Burrell e Morgan (1979) conta com duas dimensões, a sociologia da regulação e a sociologia da mudança radical, que são perpassadas pela contraposição objetividade e subjetividade, tornando-se um esboço com quatro paradigmas: o funcionalismo, o interpretativismo, o estruturalismo radical e o humanismo radical (Figura 1). 
Figura 1 - Diagrama de Gibson Burrell e Gareth Morgan

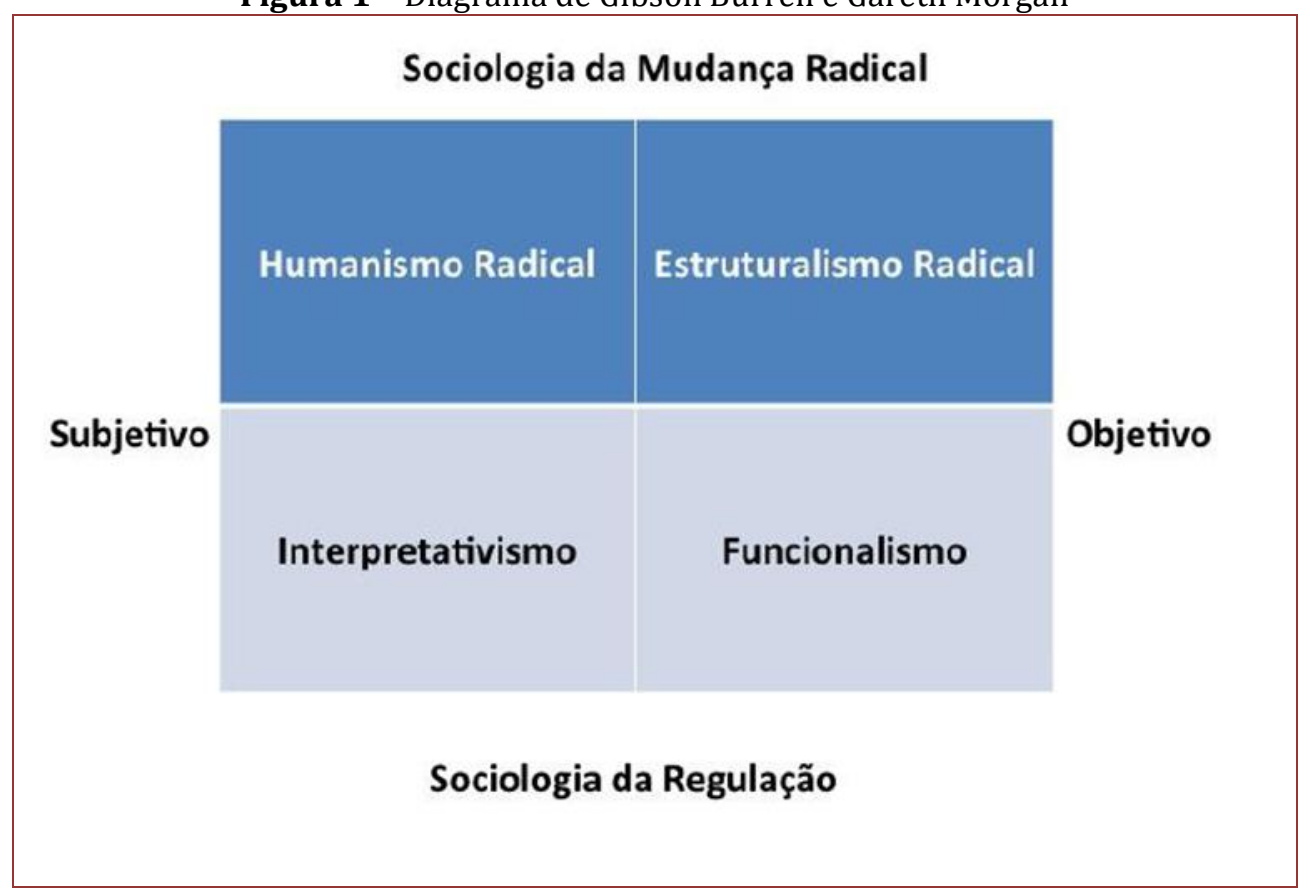

Fonte: Burrell e Morgan (1979, p.22).

Os autores conceberam o esboço com base em quatro pressuposições acerca da natureza das ciências sociais, classificados nos seguintes objetos de debate: realismo versus nominalismo (o debate ontológico), positivismo versus antipositivismo (o debate epistemológico), determinismo versus voluntarismo (o debate da natureza humana) e teoria nomotética versus teoria idiográfica (o debate metodológico) (Burrel \& Morgan, 1979).

Objetivando um comportamento integrativo da construção do conhecimento, Burrel e Morgan (1979), a despeito de estipular significativos contrastes entre os paradigmas, declaram que não os veem como opositores, mas como completivos e interativos. Outrossim, as duas linhas que constituem a sua matriz paradigmática são recomendadas como um continuum através dos dois extremos. Por conseguinte, os autores, de maneira indireta, identificam níveis de subjetividade e objetividade, da mesma forma os distintos níveis de mudanças sociais e regulação.

Caldas (2005) e Morgan (2007) na direção da colaboração integrativa, advêm os estudos multiparadigmáticos, fundamentados essencialmente em preferências metodológicas que poderiam repercutir de forma desarmônica de uma perspectiva paradigmática. Os estudos multiparadigmáticos surgem com o objetivo de tergiversar as demarcações das teorias monoparadigmáticas que envolveriam unicamente uma parcela da complexa realidade pesquisada. Os múltiplos paradigmas seriam neste caso aceitos como maneira de estabelecer comparação entre teorias distintas e de suas inquietudes deduzir teorias mais irrestritas com características variadas e peculiares, mais apropriadas à multidisciplinaridade do campo da administração (Gioia \& Prite, 1990; Lewis \& Grimes, 2005; Schultz \& Hatch, 1996).

Os limiares vão de encontro ao ponto de vista de incomensurabilidade paradigmática, reflexão que compreende os paradigmas como estanque e que foi amplamente disseminado logo após o trabalho de Burrell e Morgan (1979). Por meio de três abordagens distintas - revisões multiparadigmáticas, pesquisa multiparadigmática e construção multiparadigmática de teorias - as investigações multiparadigmáticas, de acordo com Lewis e Grimes (2005), podem ser empregues de modo segregado ou em conjunto.

As técnicas de agrupamento e ligação entre os paradigmas, consistem em caracterizar e revelar a ênfase da teoria estabelecida. A técnica de agrupamento busca determinar as distinções entre os paradigmas, propiciando a alternância de perspectivas e, a técnica de ligação possibilita a comunicação entre os paradigmas e retratam os fenômenos nas diferentes estratégias de pesquisa. Os estudos multiparadigmáticos investigam empiricamente as distintas perspectivas, também conhecidas como lentes paradigmáticas, ao contrário de uma simples revisão de diversas bibliografias. Deste modo, é capaz de existirem estudos que usem técnicas interpretativistas para aperfeiçoar previamente percepções funcionalistas, ou mesmo de maneira oposta, métodos positivistas para instrumentalizar e experienciar constructos com um viés interpretativista (Lewis \& Grimes, 2005). 
Pode-se ponderar também as abordagens retratadas por Gioia e Pitre (1990), tendo como principal propósito colaborar com os estudiosos na concepção de uma teoria, concebida como metatriangulação. Para os autores a metatriangulação trata-se de uma estratégia de aplicabilidade da multiplicidade paradigmática para proporcionar maior compreensão e inventividade. A multiplicidade paradigmática tem como propósito esclarecer princípios discrepantes, ensejando o conhecimento, a aplicação, a crítica e o vínculo entre concepções alternativas. Tenta sobrepor e mesclar percepções distintas em uma nova percepção (Bataglia, Meirelles, \& Barrella, 2007).

Metatriangulação propõe uma confiável aplicabilidade de paradigmas múltiplos para estudar suas relações e diferenças, assim assimilando e evidenciando o fenômeno de interesse, igualmente os paradigmas utilizados. Constituir os fundamentos da metatriangulação demanda a definição do fenômeno de interesse, o foco em lentes paradigmáticas, e da coleta de amostra metateórica. Não se pode entender a metatriangulação como um substituto para composição de teorias de paradigma único, mas como uma possibilidade de análise de fenômenos complexos a partir de perspectivas teóricas e epistemológicas discordantes. A metodologia é mais adequada as pesquisas de fenômenos multifacestados, tipificados por amplos e polêmicos campos de estudo (Lewis \& Grimes, 2005).

Os obstáculos de reconhecimento, assim como ponderações distintas ao diagrama de Burrel e Morgan (1979), fomentaram pesquisadores a refletirem diferenciadas maneires de harmonização do diagrama com aplicação de hipóteses díspares aos quatro paradigmas empregues pelos autores. Nesse sentido, Paula (2016) destaca em sua pesquisa que o círculo das matrizes epistêmicas, contribui com direcionamentos para os estudos da administração. A pesquisadora teve como base Jürgen Habernas, assumindo a tese da incompletude cognitiva, na qual indicou que o conhecimento sociológico e organizacional se amplifica conforme a tese das reconstruções epistêmicas.

O círculo das matrizes epistêmicas faz menção aos tipos de ciências pesquisados por Jürgen Habermas, indicando três categorias de interesse cognitivo: técnico, prático e emancipatório. No espaço desse círculo, trilham múltiplas abordagens sociológicas criadas por suas respectivas teorias e metodologias. As abordagens sociológicas remetem a um conjunto teórico-metodológico e não existe barreiras para a quantidade de abordagens sociológicas criadas na produção de conhecimento (Paula, 2016).

Habernas (1983;1989) sugere que o conhecimento como um tipo de experiência pode ser assimilado como defensor deste espaço e exercendo uma função de intérprete-mediador da filosofia em relação à ciência. Em resumo, Paula (2016) expõe que as abordagens sociológicas constituem suas teorias e metodologias, e se direcionam conforme três matrizes epistêmicas, que se influem em uma filosofia e lógica de sentidos peculiares: "a matriz empírico-analítica caracteriza-se por três elementos: o alinhamento com a filosofia positiva, o uso da lógica formal e a preferência pelo interesse técnico; a matriz hermenêutica, por sua vez, caracteriza-se pelo alinhamento com a filosofia hermenêutica, pelo uso da lógica interpretativa e pela preferência pelo interesse prático; e a matriz crítica caracteriza-se pelo alinhamento com a filosofia negativa, pelo uso da lógica dialética e pela preferência pelo interesse emancipatório" (Paula, 2016, p.36).

A Figura 2 ilustra a proposição constituída por Paula (2016), demonstrando a alternativa que se exprime por imagens sugerida pela autora.

Figura 2 - Círculo das Matrizes Epistêmicas, abordagens sociológicas, teorias e metodologias

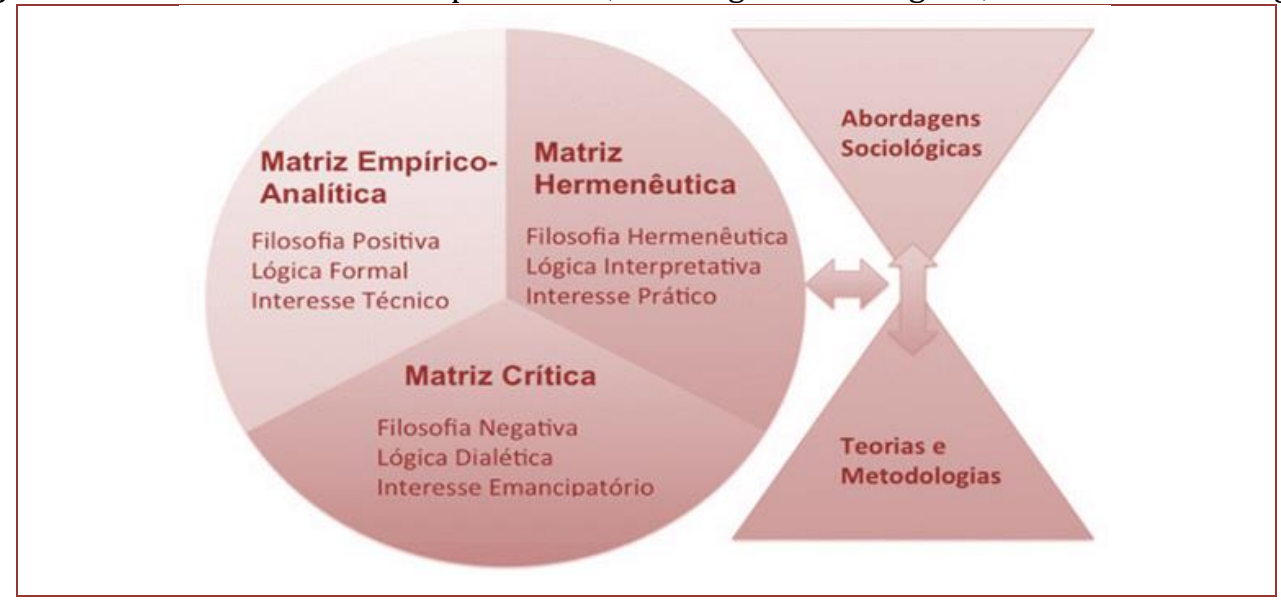


Fonte: Paula (2016, p.35).

Habermas (1968/1982) defende que as predileções dos mestres do conhecimento são responsáveis pela unicidade do sistema de ação e experiência, onde os elementos do sistema social e os interesses técnico e prático estão enlaçados com os elementos integrantes do sistema social, ao mesmo tempo que o interesse emancipatório assegura a ligação através do saber teórico e a práxis de vida. Medeiros e Marques (2003) evidenciam que independentemente do conflito entre teoria e práxis, o principal paradigma está associado a consciência dos pesquisadores, e que os estudos devem ser desenvolvidos com base no paradigma da razão.

De acordo com Paula (2016), as matrizes epistêmicas retratadas não podem ser entendidas como domínios que confinam as abordagens sociológicas, mas sim como partes integrantes de um todo constituído da criação de conhecimento. A autora ainda conclui que o trânsito das teorias e metodologias é capaz de conduzir reconstruções epistêmicas modernas que resultam em abordagens sociológicas híbridas, que possuem a domínio de transitar através das matrizes epistêmicas e compatibilizá-las.

Nesse cenário, a evolução científica do campo da administração, deve ser estimulada desde a formação inicial, despertando futuras gerações de pesquisadores, permeando as variadas áreas do conhecimento, valendo-se prudentemente dos pressupostos ontológicos, epistemológicos e metodológicos, assim possibilitando a ampliação paradigmática para a evolução dos debates teóricos.

\section{REFLEXÕES DA PESQUISA}

Mesmo com o crescimento de outras vertentes, como as interpretacionistas, as críticas e, mais recentemente, as pós-modernistas, a ortodoxia funcionalista tem sido preponderantemente empregada na elaboração de estudos organizacionais. Conforme Burrel e Morgan (1979), o funcionalismo e seus correlatos, validam a objetividade, presumem uma realidade mais tangível, recorrem ao que é perceptível, buscam singularizar o mundo para prevê-lo e comandá-lo. Burrel e Morgan (1979), inspirados por kuhn e apoiando-se na tese da incomensuralidade dos paradigmas, criaram o diagrama dos paradigmas sociológicos, porém sua aplicação vem instigando um conflito paradigmático. Diante de um olhar mais cuidadoso, os quatro paradigmas (o funcionalismo, o interpretativismo, o estruturalismo radical e o humanismo radical) criados pelos autores, apresentam posições contrárias, concebendo dicotomias que não se sustentam, direcionando os estudiosos e pesquisadores a buscar pontos de vista limítrofes dentro dos quadrantes para esclarecer as exceções (Paula, 2014).

As dificuldades de identificação, bem como considerações contrárias ao diagrama de Burrel e Morgan (1979), incentivaram estudiosos e pesquisadores a refletirem novas formas de adequação do diagrama com utilização de pressupostos diferenciados aos quatro paradigmas usados pelos autores. Morgan (1996) salienta que, novos paradigmas podem ser ainda articulados com cada um dos quatro paradigmas apresentados por Burrel e Morgan (1979), propiciando inúmeras formas de teorização e estudo das organizações.

Neste sentido, Paula (2016) demostrou em seus estudos proposta alternativa ao diagrama de paradigmas sociológicos para orientar as pesquisas organizacionais, constituindo matrizes que se guiam pelos três interesses cognitivos discutidos por Jürgen Habermas (1968/1982) em Conhecimento e Interesse: a matriz empírico-analítica (interesse técnico), a matriz hermenêutica (interesse prático) e a matriz crítica (interesse emancipatório), de forma circular, dividido em três partes iguais, nominada como: Círculo das Matrizes Epistêmicas. A autora expressa que "Não se tratam de rupturas paradigmáticas ou revoluções científicas, mas de criação de teorias e metodologias de fronteira, ou de abordagens sociológicas híbridas, que procuram superar a incompletude cognitiva" (Paula, 2016, p.41).

Pode-se considerar também as abordagens apresentadas por Gioia e Pitre (1990), tendo como objetivo contribuir com os pesquisadores na forma de construção de uma teoria, conhecida como metatriangulação. A metatriangulação utiliza-se de insights resultantes de múltiplos paradigmas, pesquisando perspectivas teóricas e epistemológicas distintas, estimulando hipóteses já definidas e evidenciando as adversidades organizacionais sob novas lentes paradigmáticas. Feyerabend (1975) já declarava que os teóricos precisam questionar incessantemente os limites das lentes que elegem e se seu empenho proporciona o crescimento ou a tenacidade dos paradigmas vigentes. Nessa perspectiva, Lewis e Grimes (2005) debatem a investigação multiparadigmática, que busca atender a demanda quanto à aplicação de paradigmas específicos, não obtendo constructos teóricos suficientes para resolver os problemas de maneira isolada. De acordo com os autores, na pesquisa multiparadigmática, os estudiosos e 
pesquisadores devem ir além da revisão da literatura, objetivando o emprego de paradigmas empiricamente distintos.

Entende-se que a pesquisa multiparadigmática ainda é pouco explorada e comedida, mas com imenso potencial para ampliar as perspectivas contemporâneas dos fenômenos organizacionais contraditórios e complexos. Teunissem (1996) afirma a necessidade de visões diferenciadas que contemplem as inquietudes organizacionais, a utilização de lentes paradigmáticas alternativas, ao contrário de racionalizá-las excessivamente. Nesta lógica, os pesquisadores Lewis e Grimes (2005) utilizaram paradigmas múltiplos na coleta e na análise dados e no aperfeiçoamento das variadas formas de um fenômeno em condições desfavoráveis. Segundo os autores, pode ocorrer pesquisas que utilizem métodos interpretativistas para certificar resultados funcionalista ou mesmo ao inverso; métodos positivistas para pôr em prática e experenciar constructos por um viés etnográfico.

Mintzberg, Ahlstrand e Lampel (2010) corroboram com o debate no momento em que apresentam o conto "Os cegos e o elefante", de John Godfrey Saxe (1816-1887). Os autores descrevem em sua obra que são cinco pessoas à volta de um elefante tocando somente uma das partes do animal, sem enxergá-lo por completo. 0 todo está na parte, assim como a parte está no todo. 0 conto narrado pelos autores destaca que o pesquisador em sua análise não deve ficar limitado exclusivamente nas partes sem ter a visão do todo. A percepção das partes, segundo os autores, "cega" e "limita" o pesquisador, induzindo a assimilar os problemas de maneira simplista, enquanto os problemas encontram-se interconectados, demandando a escolha e a conjunção de múltiplas "lentes" paradigmáticas.

\section{CONSIDERAÇÕES FINAIS}

Com base nas reflexões realizadas em torno das abordagens epistemológicas no campo de conhecimento da administração, observa-se, primeiramente, que a ortodoxia foi colocada sob suspeição no instante em que Burrel e Morgan (1979) fomentaram o debate sobre a aplicação de múltiplos paradigmas em estudos organizacionais. Salienta-se que a contribuição de Burrel e Morgan (1979) no campo de conhecimento da administração é incontestável, pois os autores promoveram a disseminação e convencionaram o uso da teoria crítica e interpretativa nos fundamentos da teoria organizacional.

De outro ponto de vista, Burrel e Morgan contribuíram igualmente para o crescimento de concepções opositoras. Assim, paradigmas emergentes se posicionaram como uma alternativa possível, essencialmente por abarcar lacunas não contempladas pelo paradigma hegemônico. Nessa perspectiva, compreende-se a necessidade de entender fundamentalmente as interações sociais vivenciadas em toda a sua heterogeneidade, bem como ampliar a possibilidade de desenvolvimento de novas abordagens paradigmáticas.

Independentemente da abordagem utilizada, identifica-se que a adesão de uma lente paradigmática mais abrangente, possibilita aos pesquisadores melhor entendimento de um fenômeno em ambientes que interagem entre si em numerosas relações de interdependência ou de subordinação. A realidade deve ser compreendida de várias maneiras, instituída sob o ponto de vista social e alicerçada nas práticas e interações experenciadas pelos envolvidos no processo. Incorporar um pluralismo teórico e metafórico permite a evolução de nossas concepções no que se refere a análise organizacional.

Devido a existência de um mundo mais contemporâneo, percebe-se a adversidade acerca de explicar fenômenos de forma consistente por intermédio de paradigmas convencionais. Os paradigmas propostos pelos autores não podem ser considerados como mutuamente excludentes, no entanto complementares. Hiatos suprimidos por determinado paradigma, podem ser aperfeiçoados por outro na compreensão do fenômeno pesquisado. Aceitar a diversidade, por intermédio da utilização de paradigmas emergentes de pesquisa, possibilita aos pesquisadores ampliar suas interpretações da realidade organizacional adversa e complexa.

Concebe-se que todas as harmonizações e conjunções paradigmáticas devem ser praticadas, uma vez que o pesquisador disponha incessantemente de referência e fundamentação, sustentando a coesão e credibilidade da temática investigada. Os resultados desta pesquisa compõem diversas contribuições para pesquisadores, estudiosos, universidades e instituições de pesquisa. Este estudo fornece um entendimento para os profissionais que desejam compreender a ciência da administração a partir de diversas abordagens paradigmáticas. 


\section{REFERÊNCIAS}

[1] Adorno, T. W. (2009). Dialética negativa. (MA Casanova, trad.). Rio de Janeiro, RJ: Jorge Zahar

[2] Bacon, F. (1979). (Viscount St. Albans) Novum organum ou Verdadeiras indicações acerca da interpretação da natureza. Nova Atlântida; tradução e notas de José Aluysio Reis de Andrade - 2ª ed. - São Paulo: Abril Cultural.

[3] Bataglia, W., Meirelles, D. S. E., \& Barrella, F. P. (2008). Rumo a um Modelo Integrativo entre a Ecologia Organizacional e a Economia Evolucionária. XXXII Encontro da Associação Nacional de Pós-Graduação e Pesquisa em Administração - ANPAD, p. 1-15.

[4] Bernardes, C., \& Marcondes, R. Teoria Geral da Administração: gerenciando organizações. Saraiva, São Paulo, 2006.

[5] Bird, A. (2003). Three conservative Kuhns. Social epistemology, 17(2-3), 127-133.

[6] Burrel, G., \& Morgan, G. (1979). Sociological paradigms and organisational analyses. London: Heinemann Educational Books.

[7] Caldas, M. P. (2005). Paradigmas em estudos organizacionais: uma introdução à série. Revista de Administração de Empresas, 45(1), 53-57.

[8] Damke, E. J., Walter, S. A., \& da Silva, E. D. (2010). A Administração é uma Ciência? Reflexões Epistemológicas acerca de sua Cientificidade. Ciencias da Administraçao, 12(28), 127-146.

[9] Demo, P. (1995). Metodologia científica em ciências sociais. 3ed. São Paulo: Atlas.

[10] Faria, J. H. D., Maranhão, C. M. S. D. A., \& Meneghetti, F. K. (2013). Reflexões epistemológicas para a pesquisa em administração: contribuições de Theodor W. Adorno. Revista de Administração Contemporânea, 17(6), 642-660.

[11] Feyerabend, P. (1975). Against Method. London: New Left Books.

[12] França, G. C. (2004). Para um olhar epistemológico da Administração: problematizando seu objeto. In: Santos, R. S. (Org.). A administração política como campo do conhecimento. Ed. Mandacaru: São Paulo/Salvador.

[13] Giddens, A. (2001). 0 que é ciência social? In: Gideens, A. Em defesa da sociologia: ensaios, interpretações e tréplicas. Tradução de Roneide Venancio Majer; Klauss Brandini Gerhardt. São Paulo: UNESP, p. 97-113.

[14] Gioia, D. A., \& Pitre, E. (1990). Multiparadigm perspectives on theory building. Academy of management review, 15(4), 584-602.

[15] Gomes, E. O., Amarante, J. M., Caldas, L. M., Basaglia, M. M., \& Cantagallo, M. V. (2013). Repensando a administração como ciência: Um ensaio teórico. Maringá Management, 10(3), 7-16.

[16] Habermas, J. A. (1983a; 1989). Filosofia como Guardador de Lugar e como Intérprete. In: Habermas, J. A. Consciência Moral e Agir Comunicativo. Rio de Janeiro: Tempo Brasileiro. p.17-35.

[17] Habermas, J. A. (1968; 1982). Conhecimento e Interesse. Com um Novo Posfácio. Rio de Janeiro: Zahar, 367 p.

[18] Hassard, J. (2005). Multiple paradigms and organizational analysis: A case study. Organization Studies, 12(2), 275-299.

[19] Jasperson, J. S., Carte, T. A., Saunders, C. S., Butler, B. S., Croes, H. J., \& Zheng, W. (2002). Power and information technology research: A metatriangulation review. MIS quarterly, 26(4), 397-459.

[20] Kuhn, T. S. (2012). The Structure of Scientific Revolutions. Chicago: University of Chicago Press.

[21] Kura, B., \& Sulaiman, Y. (2012). Qualitative and quantitative approaches to the study of poverty: Taming the tensions and appreciating the complementarities. The Qualitative Report, 17(20), 1-19.

[22] Lewis, M. W., \& Grimes, A. J. (2005). Metatriangulação: a construção de teorias a partir de múltiplos paradigmas. RAE-Revista de Administração de Empresas, 45(1), 72-91.

[23] Maciel, C. O., \& Silva, E. D. (2011). Administração como Ciência: Uma reflexão a partir de diferentes critérios de demarcação. Perspectiva Contemporânea, Campo Mourão, v.6, n.1, p. 80-104.

[24] Marsden, R., \& Towloy, B. (2001). A coruja de Minerva: reflexões sobre a teoria na prática. In: Clegg, S. R.; Hardy, C.; Nord, W. R. (Orgs.). Handbook de estudos organizacionais. Volume 2. Reflexões e novas direções. São Paulo: Atlas.

[25] Martins, G. A. (1996). Epistemologia da pesquisa em administração. IN: Encontro Anual Cladea - Reunião do Conselho de Escolas de Administração. Santiago, Chile. Anais... Santiago, Chile.

[26] Mattos, P. C. (2009). Administração é Ciência ou Arte? O que podemos apreender com esse mal-entendido? RAE - Revista de Administração de Empresas. São Paulo: n 3. v. 49, pp. 349-360.

[27] Medeiros, A. M. S., \& Marques, M. A. R. B. (2003). Habermas e a teoria do conhecimento. ETD - Educação Temática Digital, Campinas, v.5, n.1, p.1-24. 
[28] Mintzberg, H., Ahlstrand, B. R. U. C. E., \& Lampel, J. (2010). Safári de estratégias: um roteiro pela selva do planejamento estratégico. Porto Alegre: Bookman.

[29] Morgan, G. (1996). Imagens da organização. São Paulo: Atlas.

[30] Morgan, D. L. (2007). Paradigms lost and pragmatism regained: Methodological implications of combining qualitative and quantitative methods. Journal of mixed methods research, 1(1), 48-76.

[31] Ostermann, F. (1996). A epistemologia de Kuhn. Caderno Brasileiro de Ensino de Física, 13(3), 184-196.

[32] Pack, L. (2011). Necesidad e importância de La investigación empírica de La economia de La empresa em el sctor de la producción. Material de Leitura da Disciplina de Epistemologia da Administração. Doutorado em Administração, Curitiba/PR, Pontifícia Universidade Católica do Paraná - PUCPR.

[33] Paula, A. P. P. D. (2016). Para além dos paradigmas nos Estudos Organizacionais: o Círculo das Matrizes Epistêmicas. Cadernos Ebape. br, 14(1), 24-46.

[34] Paula, A. P. P. D. (2014). Para Além dos Paradigmas nos Estudos Organizacionais: 0 Círculo das Matrizes Epistemológicas. IV Colóquio Internacional de Epistemologia e Sociologia da Ciência da Administração. Florianópolis, SC, Brasil.

[35] Pellegrinelli, S., \& Murray-Webster, R. (2011). Multi-paradigmatic perspectives on a business transformation program. Project Management Journal, 42(6), 4-19.

[36] Popper, K. R. (1970). Normal science and its dangers. In: Lakatos, I.; Musgrave, A. (Eds.). Criticism and the Growth of Knowledge. Cambridge, UK: Cambridge University Press, p. 51-58.

[37] Popper, K. R. (1980). A lógica da investigação científica. In: Karl Popper, coleção os pensadores. São Paulo: Abril Cultural.

[38] Raadschelders, J. C. (2011). The future of the study of public administration: Embedding research object and methodology in epistemology and ontology. Public Administration Review, 71(6), 916-924.

[39] Rocha, C. F., \& Zembo, A. S. (2017). Administração é ciência? Reflexões sobre os desafios epistemológicos a partir de uma revisão sistemática de literature. Revista Contribuciones a las Ciencias Sociales, julio-septiembre, 2017.

[40] Santos, E. L. (2017). The scientific field of administration: an analysis from the circle of theoretical matrices. Cadernos EBAPE. BR, 15(2), 209-228.

[41] Santos, S. A. (2004). Existem paradigmas em administração? Uma análise sobre o uso do conceito. Disponível em: <www.fgvsp.br/iberoamerican/ Papers/0256>. Acessado em: junho de 2021.

[42] Santos, E. L., Santos, R. S., \& Braga, V. L. (2014). 0 campo científico da administração: percursos e percalços. Anais do Colóquio Internacional de Epistemologia e Sociologia das Ciências da Administração. Florianópolis, SC, Brasil, IV.

[43] Saunders, C., Carte, T. A., \& Butler, B. S. (2003). Lessons from the trenches of metatriangulation research. Communications of the Association for Information Systems, 11(1), 14.

[44] Schultz, M., \& Hatch, M. J. (1996). Living with multiple paradigms the case of paradigm interplay in organizational culture studies. Academy of management review, 21(2), 529-557.

[45] Scussel, F. B. C. (2017). Poder, paradigmas e domínio na pesquisa em marketing no Brasil: uma análise da produção nacional da disciplina a partir das matrizes epistêmicas. Administração: ensino e pesquisa, 18(3), 518-557.

[46] Senff, C. O., Veiga, C. P., Bendlin, L., Neto, E. E., Kudlawicz, C., \& Duclós, L. C. (2015). Uma contribuição para a celeuma sobre a cientificidade da administração. Revista ESPACIOS| Vol. 36 (№ 24).

[47] Shields, P. M. (1998). Pragmatism as a philosophy of science: a tool for public administration. Research in Public Administration, V.4, p.195-225.

[48] Teunissen, J. (1996). Paradoxes in social science and research. Contradictions in context, 17(1996), 38.

[49] Tozzini, L. D. (2011). Objetividade e racionalidade na filosofia da ciência de Thomas Kuhn. Dissertação de Mestrado em Filosofia, Curitiba/PR, Universidade Federal do Paraná - UFPR.

[50] Vergara, S. C. (2005). Método de pesquisa em Administração. São Paulo, Editora Atlas.

[51] Vergara, S. C., \& Caldas, M. P. (2005). Paradigma interpretacionista: a busca da superação do objetivismo funcionalista nos anos 1980 e 1990. Revista de Administração de Empresas, 45(4), 66-72.

[52] Walter, S. A., \& Augusto, P. O. M. O (2008). Status Científico da Pesquisa em Administração. Revista Negócios, Blumenau, v. 13, n. 4, p. 56 - 71, out./dez.

[53] Whetsell, T. A. (2013). Theory-pluralism in public administration: Epistemology, legitimacy, and method. The American Review of Public Administration, 43(5), 602-618. 


\section{Capítulo 2}

\section{Avaliação da produção cientifica sobre Indicadores Educacionais no Brasil, contidas na Base do Portal de Periódicos CAPES, entre 2011 e 2020}

\section{Elinelson Pinheiro de Souza \\ Sérgio Henrique Arruda Cavalcante Forte}

Resumo: Analisando os artigos científicos, publicados no período entre 2011 e 2020, cuja temática abordam os indicadores educacionais, verificou-se que a obrigatoriedade legal da aplicabilidade de tais indicadores na gestão de instituições de ensino gera demanda sobre o tema, evidenciando sua relevância. O período compreendido pela pesquisa abarca dois terços do tempo desde o início das metas do Índice de Desenvolvimento da Educação Básica (IDEB) até os dias atuais, haja vista que ocorreram mudanças na legislação sobre o tema. A seleção das publicações foi investigada na base de dados da Coordenação de Aperfeiçoamento de Pessoal de Nível Superior - CAPES, por meio das expressões em português "indicadores educacionais, métricas educacionais e índices educacionais", obtendo um total de 79 publicações com a abordagem pretendida. Para a análise das publicações foi utilizada a metodologia de estudo bibliométrico, com o apoio dos indicadores inerentes à classificação das publicações ao longo dos anos, das leis bibliométricas de Lotka e Bradford, da identificação dos periódicos, da autoria atrelada à sua produtividade, da relevância, das temáticas abordadas e da metodologia utilizada. De todos os artigos analisados, houve a vinculação de 164 autores, dentre os quais sete aparecem em mais de um artigo no período em análise. Os resultados dos últimos cinco anos indicam um crescimento do número de publicações, tanto que esse período atinge o percentual de 59,5\% de todas as publicações analisadas. Apesar do aumento, significativo, de publicações nos últimos anos, o número de publicações analisadas não apresenta concentração em temáticas de estudo ou de pesquisadores.

Palavras-chave: Indicadores Educacionais; Métricas Educacionais; Índices Educacionais; Estudo bibliométrico; IDEB. 


\section{INTRODUÇÃO}

A gestão consiste na administração de tarefas, por meio do estabelecimento de metas e métodos, com o intuito de atingir objetivos que devem ser cumpridos em tempo e modo necessários (Rios, 2009). Segundo Schultz (2016), o conceito de gestão é mais abrangente que o ato de administrar, pois enquanto a gestão compreende um conjunto de práticas, a administração abrange um conjunto de atividades, ou seja, a gestão se ocupa com as práticas administrativas e estas, por sua vez, atentam para a utilização eficiente e eficaz dos recursos seja humano ou materiais. Para a condução do processo de gestão é necessário, segundo Silva (2015), que o gestor atuando junto com outras pessoas da organização, para o alcance dos objetivos traçados, utilize os recursos disponíveis.

Como auxílio ao processo de gestão é salutar, o uso dos indicadores, os quais, segundo Brasil (2009), se constituem em um conjunto de regras que oportunizam informações sobre o desempenho de uma sequência de operações que se reproduzem com certa regularidade, ou seja, oportunizam informações sobre um processo. Existem conceitos de outros autores, como o de Caridade (2006), que define os indicadores como um conjunto de informações obtidos a partir da análise de um processo organizacional, de modo que tais informes possam ser comparados com os resultados de outra organização com atuação no mesmo ramo de atividades. Corroborando com as informações de Caridade, os autores Antico e Jannuzzi (2006) indicam que essa comparação de indicadores é fator decisivo para o bom desempenho de uma gestão, uma vez que tende a mostrar à organização qual o caminho a ser seguido, logo entende-se que os indicadores são ferramentas, cujo uso é importante no processo de gestão.

Com esse contexto, é possível afirmar que os indicadores não podem ser considerados simples números, uma vez que são dotados de três funções básicas: a descrição por meio numérico da situação de um processo, a geração de informações de desenvolvimento ou não de um processo, ao longo de sucessivas análises de um mesmo indicador no decorrer do tempo e a visibilidade transparente das informações dentro de uma organização Brasil (2009).

Nessa perspectiva, os indicadores são considerados como ferramentas que permitem às organizações, a mensuração de suas atividades, de modo que tenham a percepção de como seus serviços ou produtos estão atendendo os "clientes". Tais indicadores podem ser compostos por parâmetros quantitativos e qualitativos, sendo que os primeiros se preocupam com a mensuração de algo, caracterizando-se como objetivos e de fácil obtenção, bastando para tal, a criação de uma métrica bem definida; já os qualitativos, geralmente expressam as práticas dos atores de uma pesquisa ou de um processo avaliativo, afinal são eles, os geradores da interpretação do pesquisador, sobre diferentes aspectos (Paraná, 2015).

No campo da educação, o uso de indicadores, denominados de indicadores educacionais, se constitui como uma ferramenta para a avaliação da qualidade das instituições de ensino no país (Fonseca, 2010). Ainda sobre isso, tem o fato de que a adoção de indicadores educacionais assegura maior transparência as instituições, entendendo por transparência a disponibilização de dados de forma clara e acessível (Fonseca, 2010). Vale ressaltar que a falta de transparência em qualquer processo de gestão, pode gerar descrédito e comprometimento da eficiência sobre as decisões tomadas, assim, a transparência viabilizada pelo uso dos indicadores educacionais motiva todos os membros da instituição a participarem do processo de gestão, em específico, das tomadas de decisão (Silva \& Vacovski, 2015).

Ainda no âmbito educacional, tais instrumentos são passíveis de utilização em várias ações durante o acompanhamento dos sistemas educacionais, em prol da obtenção de dados, que possam subsidiar as tomadas de decisão e contribuir na avaliação da qualidade da educação e dos serviços ofertados pelas instituições de ensino, tais como, dentre outros: número médio de alunos por turma, percentual de docentes com formação superior e ou que tenham pós graduação, relação de aluno por função docente e não docente, taxas de rendimento escolar (taxa de aprovação, taxa de reprovação e taxa de abandono) e taxas de fluxo escolar (taxa de promoção, taxa de repetência e taxa de evasão). (Instituto Nacional de Estudos e Pesquisas Educacionais Anísio Teixeira (INEP, 2004).

Apesar de já existirem pesquisas envolvendo a análise de indicadores educacionais no Brasil (Erasmos, Duarte, Nunes, \& Mendes, 2018; Fonseca, 2010) elas focam na análise de quais indicadores são mais relevantes ou aplicáveis em uma dada instituição, não realizando a avaliação da temática ao longo de um determinado período. Já a pesquisa efetuada por Ribeiro et al. (2019) faz uma análise temporal, 2008 a 2017 na base Scopus, sobre a temática de "avaliação da educação" comparando o Brasil e o mundo, tendo concluído que a temática apresenta uma crescente evolução de pesquisa sobre essa temática ao longo dos últimos anos. Ressalta-se que os temas avaliação da educação e indicadores educacionais são diferentes, uma vez que o segundo se configura como uma ferramenta do primeiro, sendo portanto estudos 
complementares, ou seja, para a realização de pesquisas sobre avaliação da educação se faz necessario ter o entendimento sobre os indicadores educacionais, sendo esse o grande diferencial desse trabalho.

Diante do exposto, a questão de pesquisa que direciona este artigo é: Como está configurado o campo de pesquisas científicas sobre Indicadores Educacionais no Brasil? Dessa forma, tem-se como objetivo geral compreender a produção científica brasileira em Indicadores Educacionais nos artigos contidos na base de dados periódicos CAPES - Coordenação de Aperfeiçoamento de Pessoal de Nível Superior, nos anos de 2011 a 2020, portanto, em um período de 10 anos.

A contribuição desta pesquisa consiste no entendimento de como a temática dos Indicadores Educacionais está sendo desenvolvida pelos pesquisadores, bem como propõem um estímulo para futuras pesquisas nesta área.

Com a proposição de apresentar os resultados do estudo bibliométrico de artigos que abordam a questão dos indicadores educacionais, o presente trabalho, além da introdução que, entre outras funções procura situar o leitor no contexto do estudo sobre a temática, está estruturado em três tópicos. No primeiro tópico são apresentados o referencial teórico com comentários sobre a bibliometria, as origens e conceitos dos indicadores educacionais no Brasil, informações sobre a LDB e a apresentação de pesquisas anteriores, no segundo tópico é explicitado a metodologia utilizada na pesquisa, no terceiro são apresentados os resultados e as discussões sobre o estudo realizado. Seguem-se a eles, as conclusões e as referências.

\section{REFERÊNCIA TEÓRICO}

\subsection{INDICADORES EDUCACIONAIS NO BRASIL}

Desde a constituição de 1934, o termo Lei de Diretrizes e Bases - LDB é empregado, entretanto, somente em 1961, ele foi efetivamente utilizado na área educacional. Com a sanção da nova LDB em 1996, que estabelece as diretrizes e bases da educação nacional, a área educacional foi submetida a grandes transformações, uma vez que a proposição legal era a de consolidar medidas que ampliassem o acesso e melhorassem a forma de financiamento do ensino no país. (Lei n. 9.394, 1996). Vale ressaltar que, desde sua instituição, essa lei vem sofrendo alterações em seu texto base, sendo que a última foi realizada em 2019, onde foram incluídas alternativas aos alunos que necessitam se ausentar a aulas e a faltar provas em virtude de razões religiosas. (Lei n. 13.796, 2019).

Segundo o artigo 8o da lei 9.394, o sistema educacional brasileiro é de responsabilidade de todos os entes federativos, ou seja, a União, os Estados, o Distrito Federal e os Municípios. (Lei n. 9.394, 1996). Nos incisos V e VI do artigo 9o da mesma lei ficam estabelecidos a introdução de mecanismos de avaliação do ensino, os quais materializaram-se por meio dos indicadores educacionais, uma vez que propunham: a coleta, análise e disseminação de informações sobre a educação de modo a assegurar o processo de avaliação com o objetivo de definir as prioridades para a melhoria da qualidade do ensino (Lei n. 9.394, 1996).

Nesse sentido os principais indicadores educacionais utilizados são aqueles desenvolvidos pelo Instituto Nacional de Estudos e Pesquisas Educacionais Anísio Teixeira - INEP, onde destacam-se o Índice de Desenvolvimento da Educação Básica (Ideb) e o Censo Escolar (Fonseca, 2010).

Os indicadores educacionais caracterizam-se por ser um registro sistemático de informações, atualizados de forma periódica, com início de emprego no Brasil datado de 1906, momento em que as primeiras medições fizeram parte do Anuário Estatístico do Brasil, publicado até 1918, as quais se referiam ao ensino público e privado e continham informações sobre o número de escolas, de docentes, de matrículas e de retenções, dados coletados apenas na cidade do Rio de Janeiro que era, na época, a capital do país (Horta, 2007).

Em 1931, com o Decreto n. 19.560 (1931), foi criada a Diretoria Geral de Informações Estatísticas e Divulgação, como parte integrante do Ministério dos Negócios da Educação e Saúde Pública, com a responsabilidade pelo levantamento dos dados relativos à educação. Foi somente no ano de 1936, que os dados relativos aos indicadores educacionais voltaram a ser gerados, no momento, com informações de todos os estados do país (Horta, 2007).

No ano de 1934 é criado, via o Decreto n. 24.609 (1934), o Instituto Nacional de Estatísticas, que seria, posteriormente, o Instituto Brasileiro de Geografia e Estatística - IBGE, o qual, segundo o decreto de 
criação seria o responsável por toda coordenação de levantamento, registro e tratamento de informações com vistas â criação de estatisticas nacionais.

Em 1937, com a Lei n. 378 (1937), o Ministério dos Negócios da Educação e Saúde Pública passa a denominar-se de Ministério da Educação e Saúde. Já em 1938, por meio do Decreto-Lei n. 580 (1938) foi criado o Instituto Nacional de Estudos Pedagógicos - INEP, com a atribuição de ser o centro de estudos relativos à educação do Ministério da Educação e Saúde.

Já em 1953, por meio da Lei n. 1.920 (1953), houve o desmembramento do Ministério da Educação e Saúde em duas pastas, ou seja, o Ministério da Educação e Cultura e o Ministério da Saúde. Somente em 1961, a Lei de Diretrizes e Bases da Educação Nacional - LDB foi aprovada, tendo como um dos focos centrais, a qualidade da educação, utilizando para tal as estatísticas do ensino. (Lei n. 4.024, 1961).

No ano de 1972, via o Decreto n. 71.407 (1972), o INEP passa a ser denominado de Instituto Nacional de Estudos e Pesquisas Educacionais, com a atribuição de ser o centro de divulgação da pesquisa educacional do país.

Em 1990, foi proposto e aplicado o primeiro ciclo do Sistema de Avaliação da Educação Básica - SAEB com o objetivo de prover o estado brasileiro de informações referentes às escolas de primeiro grau. (Heck, 2018).

Já no ano de 1996, houve a promulgação da Lei n. 9.394 (1996) que instituiu a nova LDB e o Decreto n. 1.917 (1996), Anexo - I, que criou a Secretaria de Avaliação e Informação Educacional (SEDIAE), por meio da qual o Ministério da Educação realizaria o processo de avaliação do rendimento escolar. Mas, com o Decreto n. 2.146 (1997), Anexos - I e II, a SEDIAE foi extinta e suas atribuições foram repassadas para o INEP, que apesar do status alcançado por força do Decreto n. 71.407 (1972) manteve-se inexpressivo até o ano de 1997 quando passou novamente a ter destaque. (Horta, 2007).

No ano de 2001 foi aprovada a Lei n. 10.172 (2001) estabelecendo o Plano Nacional de Educação - PNE, que dentre outras ações, estabeleceu prioridades no âmbito educacional, dentre as quais, uma estabelecia o desenvolvimento de um sistema de informação e de avaliação para o ensino, bem como, um programa de monitoramento com o uso dos indicadores do Sistema Nacional de Avaliação da Educação Básica e outro que venha a ser implantado no Brasil.

Com a advento da nova LDB e do PNE ficou clara a importância dada aos indicadores educacionais como instrumentos de gestão da educação. Outro item a ser ressaltado incide no fato de que tanto a LDB quanto o PNE trazem a perspectiva descentralizadora do processo de avaliação da educação, uma vez que estabelecem a realização de tais programas de avaliação em todos os estados brasileiros, sob a supervisão da União.

\subsection{INDICADORES EDUCACIONAIS NO BRASIL}

As pesquisas anteriores que tratam sobre a temática dos indicadores educacionais tendem a focar na identificação de quais indicadores se adequam melhor a determinada instituição ou na análise de indicadores de forma isolada, ou seja, tratam do resultado da aplicação dos indicadores em um determinado local, não focando na análise das pesquisas existentes sobre o tema, isso pode ser verificado ao analisar as produções de Fonseca (2010), Erasmo et al. (2018). Já a pesquisa realizada por Ribeiro et al. (2019) faz uma análise bibliométrica sobre a temática da avaliação da educação.

Na pesquisa realizada por Fonseca (2010), sobre a qualidade dos indicadores educacionais, o autor traçou um paralelo sobre indicadores utilizados pela Organização para a Cooperação e Desenvolvimento Econômico - OCDE e pelo Centro Nacional de Estatísticas da Educação - NCDES (órgãos internacionais) e o INEP (órgão nacional) a fim de determinar quais os indicadores tinham mais qualidade e fossem mais adequados para retratar a realidade da educação nacional. Já na pesquisa realizada por Erasmo et al. (2018), os autores focaram na análise do resultado dos indicadores de desempenho institucional utilizados pelas Instituições Federais de Ensino Superior - IFES, mais precisamente a Universidade Federal do Tocantins - UFT, tendo concluído que os indicadores de gestão e desempenho são relevantes pois funcionam como elementos norteadores das ações da instituição.

A pesquisa efetuada por Ribeiro et al. (2019) faz uma análise temporal, 2008 a 2017 na base Scopus, sobre a temática de "avaliação da educação". Nessa pesquisa os autores identificaram o crescimento das publicações sobre o tema, os principais autores, as instituições e países que mais produzem artigos sobre a temática e as subáreas de maior interesse que estavam associadas sobre o tema avaliação da educação. 
Dessa forma a pesquisa resultou em um total de 515 artigos, considerando 49 publicações exclusivamente nacionais e 466 exclusivamente internacionais, com isso foi possível fazer comparativos entre as produções nacionais e internacionais, concluindo que o Brasil está em terceiro lugar entre os países que mais produziram publicações e que existe uma crescente nos estudos relacionados a temática nos últimos anos. Apesar da relevância do tema de avaliação educacional o foco do presente trabalho está na análise dos indicadores educacionais, sendo que estes se configuram como uma ferramenta de avaliação de modo que os estudos são complementares.

\section{METODOLOGIA}

\subsection{TIPOLOGIA}

Nesse trabalho, utilizou-se a metodologia de análise qualitativa, uma vez que focou em uma análise descritiva da produção de artigos sobre uma temática, em determinado período. Juntamente a análise qualitativa empregou-se uma análise documental. (Nascimento \& Sousa, 2015).

\subsection{COLETA DE DADOS}

A pesquisa foi realizada na base de dados periódicos CAPES, entre os dias 21 e 23 de agosto do ano de 2021, utilizando a opção de "Busca avançada", a qual apresentou, como resultado, publicações que continham o termo "Indicadores Educacionais" assim como seus sinônimos "Métricas Educacionais" e "Índices Educacionais", presente no título, no resumo ou nas palavras chaves. Ressalta-se que, em um primeiro momento, para a obtenção dos artigos foi utilizada a expressão chave em inglês "educational indicators" assim como "educational metrics" e "educational indexes", mas ao ser feito o uso das ferramentas de refinamento disponíveis na base de dados, foram retirados da pesquisa os artigos que não fossem integrantes de periódicos revisados por pares, que não tivessem com data de publicação inserida no período dos últimos 10 anos (01/01/2011 à 31/12/2020). Dessa forma, ao ser utilizado o termo em inglês e seus sinônimos foram encontradas 48 publicações e ao ser utilizado o termo em português "indicadores educacionais" e seus sinônimos, com os mesmos refinamentos, foram obtidas 79 publicações, com desconto de itens em duplicidade. Diante desse contexto, houve a decisão de utilizar o termo em português para a realização da pesquisa.

\subsection{ANÁLISE DE CONTEÚDO}

Decidiu-se, nesse trabalho, utilizar as etapas da técnica de Bardin (2006), segundo o qual, podemos dividir a análise de dados em três etapas: sendo a primeira uma análise preliminar, a segunda a exploração do material e a última a interpretação de resultados.

Dessa forma, procedeu-se com a primeira etapa onde todos os dados relativos aos 79 artigos encontrados foram compilados e transferidos para uma planilha do Software Microsoft Excel, versão 2010. 0 passo seguinte constituiu-se da leitura e análise dos artigos encontrados, e por fim foi realizado a etapa de interpretação de resultados fazendo a classificação das publicações ao longo dos anos, das leis bibliométricas de Lotka e Bradford separando-os pelos periódicos a qual pertencem, da verificação da autoria e sua respectiva produtividade, da relevância, das temáticas abordadas e da metodologia utilizada. Ressalta-se que além do Excel, o Software VOSviewer, versão 1.6.17, foi utilizado para a análise de dados.

\section{RESULTADOS E DISCUSSÃO}

Dessa forma e motivados pela importância e relevância da temática inerente aos indicadores educacionais, diversos pesquisadores se propuseram a analisá-la, tanto que, no intervalo amostral de 10 anos, período focalizado neste trabalho, foram ao todo 164 autores citados em um total de 79 trabalhos.

Segundo Richardson (1999), a pesquisa consiste em "um conjunto de etapas que tem por objetivo gerar novos conhecimentos". Assim, as pesquisas sobre indicadores educacionais auxiliam a compreensão sobre as preocupações dos pesquisadores, os desafios a enfrentar, os procedimentos a adotar e possibilidades de uso. Além disso, seus resultados são de grande valia para demonstrar, em função do tipo ou modelo utilizado, o desenvolvimento da educação vivenciada. 
Ressalta-se que o intervalo de 10 anos, 2011 a 2020, proposto no estudo, se enquadrou em um período histórico e importante para os indicadores educacionais no país, pois se considerarmos o ano inicial (2005) da fixação das metas trazidas pelo Índice de Desenvolvimento da Educação Básica (Ideb), e o último ano corrente (2020) teremos 16 anos ao todo, sendo que o estudo proposto analisa os 10 últimos anos, ou seja, dois terços do período de fixação das metas do Ideb até os dias atuais, importante lembrar que em 2016 houve a comemoração dos 20 anos de promulgação da LDB. (Lei n. 9.394, 1996).

A pesquisa teve como objetivo a identificação das produções de artigos que versam sobre a temática dos Indicadores Educacionais, no período de 2011 a 2020, possibilitando, por meio dos indicadores bibliométricos, o reconhecimento do crescimento dessas publicações, sendo que os últimos cinco anos, período de 2016 a 2020, foi o período de maior crescimento no número de artigos publicados, apresentando um número absoluto de 47 artigos, representando um total de 59,5\% de todas as publicações analisadas. Ressalta-se que a análise das publicações, ao longo dos anos, considerou, o ano em que os artigos foram publicados.

Figura 1 - Frequência dos artigos sobre indicadores educacionais e linha de tendência

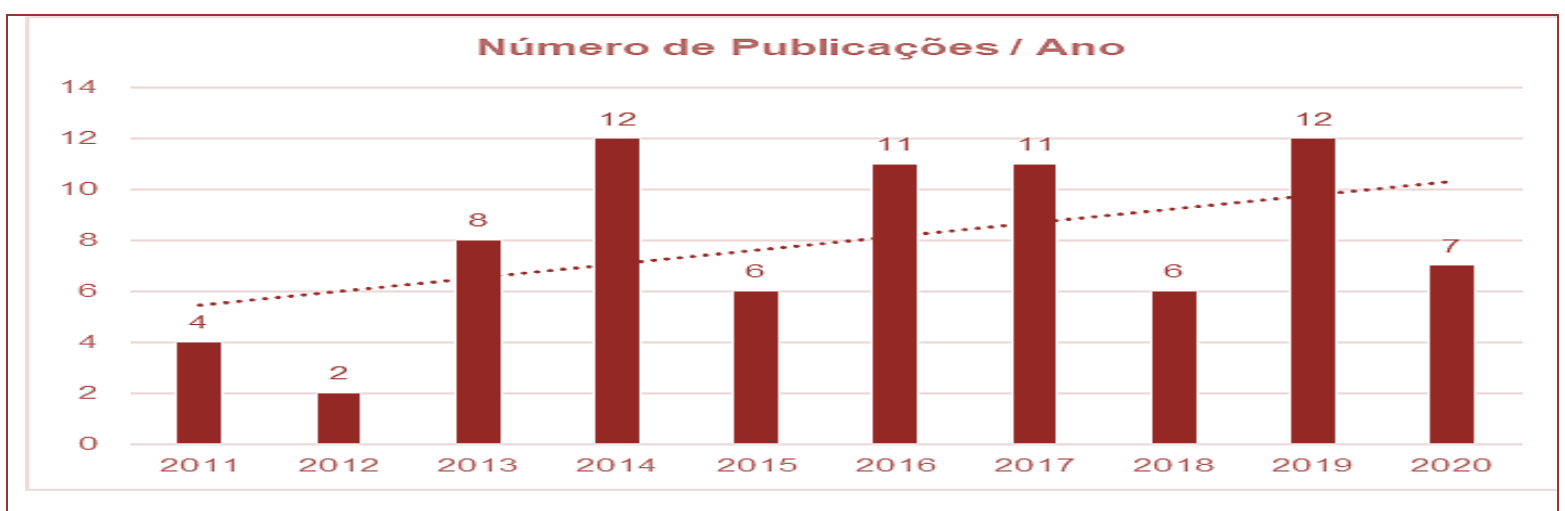

De acordo com o Figura 1 a produção média anual e de 7,9 artigos publicados, com um desvio padrão em relação à média de 3,2. Os anos de 2014 e 2019 apresentaram o maior número de artigos publicados em números absolutos, ressalta-se que o ano de 2016 apresentou um total de 11 artigos publicados, isso pode ser explicado pelo fato de que a Lei n. 9.394 (1996), que trata sobre a LDB, completou, em 2016, 20 anos de promulgação.Nesta seção ilustra-se o modo como devem ser efetuadas as citações e as referências bibliográficas, assim como sua formatação.

\subsection{LEIS BIBLIOMÉTRICAS}

Na Tabela 1 os autores identificados foram analisados conforme a Lei de Lotka.

Tabela 1 - Percentual de artigos versus Produtividade de Lotka

\begin{tabular}{|c|c|c|c|}
\hline $\begin{array}{l}\text { Número de Contribuições } \\
\text { por Autor }\end{array}$ & $\begin{array}{l}\text { Número de } \\
\text { Autores }\end{array}$ & $\%$ & Lotka \\
\hline 1 & 157 & $95,73 \%$ & $60,80 \%$ \\
\hline 2 & 4 & $2,44 \%$ & $15,20 \%$ \\
\hline \multirow[t]{2}{*}{3} & 3 & $1,83 \%$ & $6,76 \%$ \\
\hline & 164 & $100 \%$ & \\
\hline
\end{tabular}

Segundo a lei de Lotka, o número de autores que tem " $n$ " produções em determinada área do conhecimento em dado intervalo de tempo é aproximadamente $1 / \mathrm{n}^{2}$ daqueles autores que fazem apenas uma produção no mesmo intervalo de tempo e que a proporção desses que fazem apenas uma produção é mais ou menos igual a $60 \%$ do todo de autores que produziram nessa área do conhecimento no mesmo intervalo de tempo. (Cândido et al., 2018). Dessa forma, considerando as informações dispostas na tabela 1, temos que a exceção do percentual de dados relativos à produção de apenas um autor todos os outros percentuais encontram-se abaixo dos valores estimados por Lotka. 
A Tabela 2 apresenta os 79 artigos analisados, atrelados a 55 periódicos, divididos em 4 zonas em conformidade a Lei de Bradford.

Tabela 2 - Zonas de produtividade segundo a Lei de Bradford

\begin{tabular}{|c|c|c|c|c|c|c|}
\hline $\begin{array}{c}\text { A } \\
\text { Número de } \\
\text { Periódicos }\end{array}$ & $\begin{array}{c}\text { B } \\
\text { Número de Artigos } \\
\text { Dedicados ao Tema }\end{array}$ & $\begin{array}{c}\text { C } \\
\text { Periódicos } \\
\text { Acumulado }\end{array}$ & $\begin{array}{c}\text { D } \\
\text { Total de Artigos } \\
\text { Acumulado }\end{array}$ & $\begin{array}{c}E \\
\operatorname{Ln}(C)\end{array}$ & Zonas & $\begin{array}{l}\text { Multiplicador } \\
\text { Bradford }\end{array}$ \\
\hline 1 & 6 & 1 & 6 & 0,00 & \multirow{3}{*}{ Núcleo } & \multirow{3}{*}{1} \\
\hline 1 & 5 & 2 & 11 & 0,69 & & \\
\hline 1 & 3 & 3 & 14 & 1,10 & & \\
\hline 11 & 2 & 14 & 36 & 2,64 & Zona 2 & 4,67 \\
\hline 43 & 1 & 57 & 79 & 4,04 & Zona 3 & 4,07 \\
\hline
\end{tabular}

Pelo enunciado da lei de Bradford, tem-se que se os periódicos (Coluna A) forem ordenados em ordem decrescente de produtividade de artigos (Coluna B), em uma dada temática, poderão ser distribuídos em um núcleo e zonas (Coluna E), onde a quantidade de artigos produzidos por cada zona (Coluna D) será igual ou muito próxima ao núcleo, seguindo a proporcionalidade de 1:n:n² . (Bradford,1934).

Na Tabela 2 pode-se verificar a divisão dos periódicos em três zonas, sendo que ao analisar o multiplicador de Bradford, deve-se verificar qual a menor diferença entre eles, dados zonas sucessivas, será considerado o número de zonas ideal, para classificação, quanto menor for essa diferença entre os multiplicadores de Bradford das últimas zonas sucessivas. 0 ideal e que esse multiplicador seja constante, ou seja, diferença entre eles seja igual a zero, isso significa que as zonas contêm a mesma quantidade de artigos.

Pela análise dos periódicos, considerando os Indicadores Educacionais como o assunto central, foi possível estabelecer a dispersão do tema por nove áreas de avaliação, para a determinação da classificação Qualis utilizou-se o quadriênio 2013-2016, dessa forma obtivemos os seguintes valores. Verifica-se que do total de 79 artigos, o quantitativo de 29, em números absolutos, representa 37\% dos periódicos classificados com Qualis A1 (15) e A2 (14), os demais estão classificados em Qualis B1 (33), B2 (11) e B3 (6). É válido ressaltar que é possível, entre períodos de classificação Qualis, que periódicos sofram variação em termos de sua posição classificatória.

No que diz respeito a área de avaliação, tem-se que a área de Educação foi a mais representativa, contribuindo com 52 artigos no total, representando cerca de 65,8\% de todos os artigos do estudo, isso pode ser justificado tomando por base que o tema central do estudo faz referência a indicadores educacionais. Com relação aos periódicos que mais contribuíram com artigos para a pesquisa, o periódico Ensaio - Avaliação e Políticas Públicas em Educação contribuiu com seis artigos, representando 7,6\% do total de artigos, já o periódico Holos apresentou cinco, sendo seguido pela Estudos em Avaliação Educacional (impresso) com três artigos, já os demais periódicos apresentaram entre um a dois artigos cada.

\subsection{AUTORIA DOS ARTIGOS}

De todas as 79 publicações contabilizadas houve 164 autores vinculados, com sete deles aparecendo em mais de uma publicação no período de análise, enquanto os demais aparecem em apenas uma publicação, havendo, entretanto, artigos que contam com até 9 autores. Por meio da Tabela quatro é possível verificar que vinte e três artigos foram produzidos de forma individual, trinta em dupla, vinte em trio, três em quarteto, dois em quinteto e apenas um foi produzido por um total de nove autores. 
Tabela 3 - Quantidade de Autores nos Artigos Publicados

\begin{tabular}{|l|c|c|c|c|c|c|c|c|c|c|c|c|c|c|}
\hline \multirow{2}{*}{ Autoria } & \multicolumn{10}{|c|}{ Ano } & \multicolumn{1}{|c|}{ Total } & $\%$ \\
\hline Autoria Individual & 2011 & 2012 & 2013 & 2014 & 2015 & 2016 & 2017 & 2018 & 2019 & 2020 & & \\
\hline Dois Autores & 3 & 2 & 4 & 5 & & 3 & 2 & 1 & 2 & 3 & 23 & $29,1 \%$ \\
\hline Três Autores & & & 1 & 1 & 5 & 3 & 3 & 2 & 5 & & 20 & $25,3 \%$ \\
\hline Quatro Autores & & & & & & 1 & & 1 & 1 & & 3 & $3,8 \%$ \\
\hline Cinco Autores & & & & & & 1 & 1 & & & & 2 & $2,5 \%$ \\
\hline Nove Autores & & & & 1 & & & & & & & 1 & $1,3 \%$ \\
\hline Total Geral & 4 & 2 & 8 & 12 & 6 & 11 & 11 & 6 & 12 & 7 & 79 & $100,0 \%$ \\
\hline
\end{tabular}

No concernente à frequência de contribuições, houve três autores que tiveram três contribuições Andressa Santos Rebelo, Gilvan Luiz Machado Costa, Rodrigo Travitzki, quatro autores com duas contribuições José Francisco Soares, Maria Lília Imbiriba Sousa Colares, Taísa Grasiela Gomes Liduenha Gonçalves e Silvia Márcia Ferreira Meletti enquanto os demais contribuíram apenas uma vez. Ainda na análise de frequência é possível observar a falta de relação entre eles, de modo que não houve artigos compartilhados entre os autores.

Com base na frequência dos autores dos artigos e após a análise das publicações ao longo do tempo surgem as informações constantes na Tabela 4, onde verifica-se que a exceção do autor José Francisco Soares e Rodrigo Travitzki com apresentação de duas de suas três publicações em um mesmo ano, os demais autores publicaram um artigo por ano, sendo que o tempo médio entre uma publicação e outra e de no máximo quatro anos.

Tabela 4 - Distribuição ao longo dos anos das publicações dos autores mais frequentes

\begin{tabular}{|l|c|c|c|c|c|c|c|c|c|c|c|c|c|}
\hline Autor & 2011 & 2012 & 2013 & 2014 & 2015 & 2016 & 2017 & 2018 & 2019 & 2020 & Total \\
\hline Andressa Santos Rebelo & - & - & - & - & - & 1 & - & 1 & 1 & - & 3 \\
\hline Gilvan Luiz Machado Costa & - & - & 1 & 1 & - & - & - & - & - & 1 & 3 \\
\hline José Francisco Soares & - & - & 2 & - & - & - & - & - & - & - & 2 \\
\hline Maria Lília Imbiriba Sousa & - & - & - & - & - & - & 1 & - & - & 1 & 2 \\
\hline Rodrigo Travitzki & - & - & - & - & - & - & 2 & - & - & 1 & 3 \\
\hline Silvia Márcia Ferreira Meletti & - & - & - & 1 & - & 1 & - & - & - & - & 2 \\
\hline Taísa Grasiela Gomes & - & - & - & - & - & 1 & - & - & 1 & - & 2 \\
\hline Total Geral & - & - & 3 & 2 & & 3 & 3 & 1 & 2 & 3 & 17 \\
\hline
\end{tabular}

Ao fazermos uma análise entre os autores que mais produziram e as publicações nos periódicos constatamos que a exceção de Taísa Grasiela Gomes Liduenha Gonçalves que teve seus artigos publicados em apenas um períodico os demais fizeram suas publicações em periódicos distintos. Um ponto de destaque é que a exceção de Matia Lília Imbiriba Sousa Colares que teve um de seus dois artigos publicados em periódico com a classificação Qualis B2, os demais tiveram classificação A1 (5), A2 (3) e B1 (1), sendo bom frisar que dos autores com o maior número de contribuições apenas Rodrigo Travitzki, teve dois de seus três artigos publicados em periódicos de classificação A1, os demais Andressa Santos Rebelo e Gilvan Luiz Machado Costa Alves e Soares tiveram artigos em periódicos de classificação A2 ou B1. 


\subsection{RELEVÂNCIA DOS ARTIGOS}

Com o intuito de determinar o nível de relevância dos artigos, foi analisado quais artigos, contidos na lista de análise, foram citados em outras publicações. Dessa forma, dos 79 artigos do estudo foi observado que $17,7 \%$ deles, ou seja, 14 artigos, em números absolutos, foram citados em outras publicações, ou melhor, em 39 artigos em diferentes anos. Ao analisar os artigos, verifica-se que quatro artigos foram citados uma única vez por outros artigos, cinco tiveram duas citações, um teve três citações, dois tiveram quatro citações cada e dois arquivos tiveram sete citações cada um, o que deu a esses dois a configuração de artigos com maior número de citações dentre todos os verificados nessa pesquisa.

Considerando que o a temática de indicadores educacionais esteve presente em nove áreas de avaliação em cinquenta e sete periódicos diferentes podemos concluir que o número de citações em outras publicações ainda é baixo, entretanto isso pode ser explicado em função da baixa interação entre os autores, conforme demonstrado anteriormente.

\subsection{SOBRE AS TEMÁTICAS ABORDADAS}

Para a definição das temáticas abordadas foi utilizado a técnica de análise de conteúdo que segundo Silva et al. (2005), consiste em extrair o sentido dos textos em análise, essa extração é feita por meio de unidades de análise que podem ser palavras-chave, termos específicos, categorias ou temas. Dessa forma foi estabelecida uma categorização de temáticas, com definição prévia, nas quais os artigos analisados seriam alocados. Foram criadas nove temáticas básicas, sendo os artigos distribuídos, nessas temáticas, em função da similaridade e da compatibilidade dos temas. Houve algumas dificuldades no enquadramento dos artigos nas categorias, haja vista que, dentre os trabalhos, existiam aqueles que se identificavam com a inclusão em mais de uma temática, mas para solucionar a situação, foram analisados os objetivos dos artigos para a determinação de qual temática melhor se encaixavam.

Figura 2 - Distribuição dos Artigos por Temática Abordada

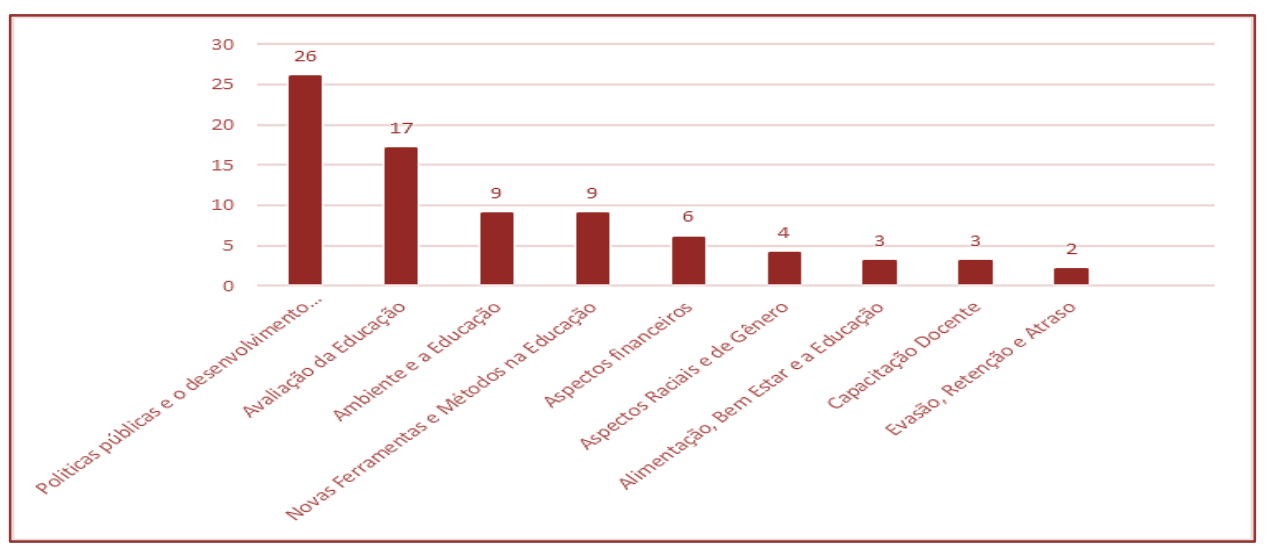

Dos 79 artigos da pesquisa vinte e seis foram classificados na temática de "Políticas públicas e o desenvolvimento socioeconômico"; dezessete em "Avaliação da Educação"; nove em "Ambiente e a Educação" e "Novas Ferramentas e Métodos na Educação", seis em "Aspectos Financeiros”, quatro em "Aspectos Raciais e de Gênero"; três em "Alimentação, Bem Estar e a Educação" e "Capacitação Docente" e apenas dois em "Evasão, Retenção e Atraso".

Com o objetivo de verificar se os autores mais produtivos figuram, seus artigos, em temáticas diferentes ou concentram suas pesquisas em temáticas específicas, chegou-se aos seguinte dados. 0 autor Gilvan Luiz Machado Costa apresentou suas três publicações em três temáticas distintas, já a autora Andressa Santos Rebelo e Rodrigo Travitzki que também contribuíram com três publicações figuram em apenas duas temáticas. Já os autores que contribuíram com duas publicações distribuem-se entre aqueles que estão concentrados em apenas uma temática, sendo o caso de Taísa Grasiela Gomes Liduenha Gonçalves e aqueles que se distribuem em duas temáticas como os autores Maria Lília Imbiriba Sousa Colares, Silvia Márcia Ferreira Meletti e José Francisco Soares. 


\subsection{SOBRE A METODOLOGIA UTILIZADA}

Segundo Zucolotto (2012) no resumo de textos científicos é preciso conter os seguintes itens: contexto da pesquisa, hiato de tempo onde se encaixa a pesquisa, objetivo dela, metodologia, resultados e conclusões. Apesar da contribuição do autor para a análise sobre a metodologia utilizada, para o trabalho foi adotada total incursão aos textos, ultrapassando os limites do resumo.

Em termos da determinação sobre a metodologia utilizada, foi adotada a classificação proposta por Nascimento e Sousa (2015) que estabelece os tipos de pesquisa quanto a abordagem, que pode ser qualitativa ou quantitativa..

A partir da análise dos 79 artigos coletados, Tabela 5, foi identificada a predominância de trabalhos resultantes de pesquisa qualitativa. Ainda de acordo com a tabela 10 verifica-se que a pesquisa quantitativa vem crescendo nos últimos cinco anos, 2016 a 2020, representando 85,0\% do total de artigos quantitativos, isso pode ser explicado pela comemoração, em 2016, dos 20 anos de promulgação da LDB.

Tabela 5 - Metodologia Utilizada

\begin{tabular}{|l|c|c|c|c|c|c|c|c|c|c|c|c|c|c|c|}
\hline & \multicolumn{10}{c|}{ Ano } \\
Tipo de Metodologia & 2011 & 2012 & 2013 & 2014 & 2015 & 2016 & 2017 & 2018 & 2019 & 2020 & Total & $\%$ \\
\hline Qualitativa & 4 & 2 & 8 & 10 & 5 & 8 & 8 & 2 & 8 & 4 & 59 & $74,7 \%$ \\
\hline Quantitativa & & & & 2 & 1 & 3 & 3 & 4 & 4 & 3 & 20 & $25,3 \%$ \\
\hline Total Geral & 4 & 2 & 8 & 12 & 6 & 11 & 11 & 6 & 12 & 7 & 79 & 79 \\
\hline
\end{tabular}

Estudo recente sobre o tema de avaliação da educação efetuada por Ribeiro et al. (2019), informa que o número de publicações sobre o tema vem aumentando desde 2007 tendo seu ápice no ano de 2015, apesar de ser diferente da temática de Indicadores Educacionais pode ser utilizado como parâmetro para justificar o crescimento das publicações sobre Indicadores Educacionais nos últimos anos, haja vista que estes se constituem como uma ferramenta para avaliação educacional.

\section{CONCLUSÃO}

O campo de pesquisas científicas sobre Indicadores Educacionais no Brasil é vasto e mostrou-se em pleno crescimento, isso fica claro pelo número de trabalhos em diferentes eixos temático e pelo crescimento das publicações nos últimos anos. Ressalta-se que o estudo de Indicadores Educacionais é uma temática relativamente nova dentro do campo da pesquisa cientifica, em decorrência do advento da avaliação educacional, atividade que norteou a introdução dos Indicadores Educacionais, iniciada com a promulgação da LDB, lei no. 9.394/1996. Nesse estudo, os 79 artigos selecionados serviram para identificar as principais áreas temáticas dentro dos Indicadores Educacionais, indicando que a análise temática é altamente útil para qualquer pesquisador, por apresentar uma visão geral dos diferentes subcampos de uma área de pesquisa.

Aliando o estudo dos Indicadores Educacionais a análise bibliométrica, instrumento muito útil por trazer uma série de informações sobre o campo de pesquisa científica. A principal contribuição deste artigo foi a de mostrar a importância do tema, via a apresentação dos resultados da análise realizada, algo claro com os dados que evidenciam o crescente número de publicações nos últimos 5 anos, 2016 a 2020, ou seja, um crescimento 46,9\% se compararmos com o quinquênio anterior, 2011 a 2015.

A partir do estudo dos Indicadores Educacionais é possível melhorar a compreensão do processo de tomada de decisão pelos gestores educacionais, o que, por sua vez, permitirá a concepção de iniciativas de educação de uma natureza mais eficaz, melhor compreensão do papel do contexto e das instituições, e a evolução ao longo do tempo do processo individual de cada instituição educacional, usuária de indicadores.

Vale ressaltar que o estudo não foi isento de limitações, pelo contrário elas estão associadas à metodologia utilizada e foram traduzidas pelo fato de que, apesar dos esforços envidados, a busca na literatura pode ter sido frágil, ou seja, não ter capturado todos os trabalhos, cuja temática versasse sobre Indicadores Educacionais, ou apesar de todas as precauções tomadas, tenha pairado uma subjetividade em termos da 
classificação temática dos artigos, fato que pode ter contribuído, negativamente, em alguns resultados das análises descritas.

A pesquisa não pretendeu esgotar o assunto, mesmo porque a temática é ampla, há muito espaço para novas análises, com diferentes enfoques, tanto que, após o trabalho foi identificada a existência de um grande potencial para a pesquisa sobre os Indicadores Educacionais em futuras pesquisas para se poder responder questionamentos como: Qual a relação entre os indicadores educacionais e a avaliação educacional? Qual a diferença entre os indicadores educacionais do Brasil com seus vizinhos da América do Sul, Qual a relação de citações dos principais pesquisadores da área em relação a outras publicações?

\section{REFERÊNCIAS}

[1] Antico, C., \& Jannuzzi, P. D. M. (2014). Indicadores e a gestão de políticas públicas. Fundação do Desenvolvimento Administrativo-FUNDAP. São Paulo. Debates.

[2] Araújo, R. F., \& Alvarenga, L. (2011). A bibliometria na pesquisa científica da pós-graduação brasileira de 1987 a 2007. Encontros Bibli: revista eletrônica de biblioteconomia e ciência da informação, 16(31), 51-70. Universidade Federal de Santa Catarina. Brasil.

[3] Bradford, S. C. (1934). Sources of Information on scientific subjects. Engineering, n. 137, p. 85-6. Cambridge,

MA.

[4] Brasil. (2009). Ministério do Planejamento, Orçamento e Gestão. Secretaria de Gestão. Guia referencial para medição de desempenho e manual para construção de indicadores. Brasília, 2009a. Disponível em: http://www.gespublica.gov.br/sites/default/files/documentos/guia_indicadores_jun2010.pdf. Acesso em: $30 \mathrm{abr}$. 2020 .

[5] Cândido, R.B., Garcia, F.G., Campos, A.L.S., \& Tambosi Filho, E. (2018). Lei de Lotka: um olhar sobre a produtividade dos autores na literatura brasileira de finanças. Encontros Bibli: revista eletrônica de biblioteconomia e ciência da informação, 23 (53), 01-15. Universidade Federal de Santa Catarina. Brasil.

[6] Caridade, A. V. D. S. (2006). Práticas de gestão estratégica e aderência ao método sigma: um estudo de caso no setor de celulose e papel (Doctoral dissertation, Universidade de São Paulo).

[7] Constituição da República dos Estados Unidos do Brasil de 1934. (1934) Brasília. Recuperado de https://www2.camara.leg.br/legin/fed/consti/1930-1939/constituicao-1934-16-julho-1934-365196publicacaooriginal-1-pl.html

[8] Bardin, L. (2006). Análise de conteúdo (L. de A. Rego \& A. Pinheiro, Trads.). Lisboa: Edições 70. (Obra original publicada em 1977).

[9] Decreto n. 1.917, de 27 de maio de 1996. Aprova a Estrutura Regimental e o Quadro Demonstrativo dos Cargos em Comissão e Funções Gratificadas do Ministério da Educação e do Desporto e dá outras providências. Recuperado de https://www2.camara.leg.br/legin/fed/decret/1996/decreto-1917-27-maio-1996-435693publicacaooriginal-1-pe.html.

[10] Decreto n. 19.560, de 5 de janeiro de 1931. Aprova o regulamento que organiza a Secretaria de Estado do Ministério da Educação e Saúde Pública. Recuperado de https://www2.camara.leg.br/legin/fed/decret/19301939/decreto-19560-5-janeiro-1931-515777-publicacaooriginal-1-pe.html.

[11] Decreto n. 2.146, de 14 de fevereiro de 1997. Aprova a Estrutura Regimental e o Quadro Demonstrativo de Cargos em Comissão e Funções Gratificadas do Instituto Nacional de Estudos e Pesquisas Educacionais - INEP, e dá outras providências. Recuperado de https://www2.camara.leg.br/legin/fed/decret/1997/decreto-2146-14fevereiro-1997-341858-publicacaooriginal-1-pe.html.

[12] Decreto n. 24.609, de 6 de julho de 1934. Cria Instituto Nacional de Estatística e fixa disposições orgânicas para a execução e desenvolvimento dos serviços estatísticos. Recuperado de https://www2.camara.leg.br/legin/fed/decret/1930-1939/decreto-24609-6-julho-1934-515214-publicacaooriginal1-pe.html.

[13] Decreto n. 71.407, de 20 de novembro de 1972. Dispõe sobre o Instituto Nacional de Estudos e Pesquisas Educacionais, do Ministério da Educação e Cultura, e dá outras providências. Recuperado de https://www2.camara.leg.br/legin/fed/decret/1970-1979/decreto-71407-20-novembro-1972-419786publicacaooriginal-1-pe.html.

[14] Decreto-Lei n. 580, de 30 de julho de 1938. Dispõe sobre a organização do Instituto Nacional de Estudos Pedagógicos. Recuperado de https://www2.camara.leg.br/legin/fed/declei/1930-1939/decreto-lei-580-30-julho1938-350924-publicacaooriginal-1-pe.html. 
[15] Erasmo, L.E.A.L., Duarte, M.S.L.T., Nunes, B.E.L.L.O., \& Mendes, R.N. (2018). Avaliação Institucional: uma análise de indicadores de desempenho educacional em uma IFES. Revista Observatório, 11(6), 845-877. Universidade Federal de Tocantins. Brasil.

[16] Fonseca, G.L.S.B. (2010). Qualidade dos Indicadores Educacionais para Avaliação de Escolas e Redes Públicas de Ensino Básico no Brasil. Dissertação de mestrado, Universidade Federal de Juiz de Fora, Juiz de Fora, MG, Brasil.

[17] Guedes, V. L., \& Borschiver, S. (2005). Bibliometria: uma ferramenta estatística para a gestão da informação e do conhecimento, em sistemas de informação, de comunicação e de avaliação científica e tecnológica. Encontro Nacional de Ciência da Informação, 6(1), 1-18.

[18] Hayashi, C. R. M. (2013). Apontamentos sobre a coleta de dados em estudos bibliométricos e cientométricos. Filosofia e Educação, Campinas, SP, v. 5, n. 2, p. 89-102, 2013. DOI: 10.20396/rfe.v5i2.8635396.

[19] Heck, M. F. (2018). Sistema nacional de avaliação da educação básica (SAEB): compreendendo a realidade educacional. Revista Eletrônica Científica Ensino Interdisciplinar. Mossoró, 4 (11), 410-422.

[20] Horta, J. L., Neto. (2007). Um olhar retrospectivo sobre a avaliação externa no Brasil: das primeiras medições em educação até o SAEB de 2005. Revista Iberoamericana De Educación, 42(5), 1-14. https://doi.org/10.35362/rie4252398.

[21] Instituto Nacional de Estudos e Pesquisas Educacionais Anísio Teixeira - INEP. (2004). Dicionário de Indicadores Educacionais fórmulas de cálculo. Recuperado em 30 abril, 2020, de http://portal.inep.gov.br/informacao-da-publicacao/-/asset_publisher/6JYIsGMAMkW1/document/id/486420.

[22] Lei n. 1.920, de 25 de julho de 1953. Cria o Ministério da Saúde e dá outras providências. Recuperado de https://www2.camara.leg.br/legin/fed/lei/1950-1959/lei-1920-25-julho-1953-367058-publicacaooriginal-1-pl.html.

[23] Lei n. 10.172, de 9 de janeiro de 2001. Aprova o Plano Nacional de Educação e dá outras providências. Recuperado de https://www2.camara.leg.br/legin/fed/lei/2001/lei-10172-9-janeiro-2001-359024publicacaooriginal-1-pl.html.

[24] Lei n. 13.796, de 3 de janeiro 2019. Altera a Lei no 9.394, de 20 de dezembro de 1996 (Lei de Diretrizes e Bases da Educação Nacional), para fixar, em virtude de escusa de consciência, prestações alternativas à aplicação de provas e à frequência a aulas realizadas em dia de guarda religiosa. Recuperado de https://www2.camara.leg.br/legin/fed/lei/2019/lei-13796-3-janeiro-2019-787598-norma-pl.html.

[25] Lei n. 378, de 13 de janeiro de 1937. Dá nova organização ao Ministério da educação e Saúde Pública. Recuperado de https://www2.camara.leg.br/legin/fed/lei/1930-1939/lei-378-13-janeiro-1937-398059publicacaooriginal-1-pl.html.

[26] Lei n. 4.024, de 20 de dezembro de 1961. Fixa as Diretrizes e Bases da Educação Nacional. Recuperado de https://www2.camara.leg.br/legin/fed/lei/1960-1969/lei-4024-20-dezembro-1961-353722-publicacaooriginal-1pl.html.

[27] Lei n. 5.692, de 11 de agosto de 1971. Fixa Diretrizes e Bases para o ensino de $1^{\circ}$ e $2^{\circ}$ graus, e dá outras providências. Recuperado de https://www2.camara.leg.br/legin/fed/lei/1970-1979/lei-5692-11-agosto-1971357752-norma-pl.html.

[28] Lei n. 9.394, de 20 de dezembro de 1996. Estabelece as diretrizes e bases da educação nacional. Recuperado de https://www2.camara.leg.br/legin/fed/lei/1996/lei-9394-20-dezembro-1996-362578-publicacaooriginal-1pl.html.

[29] Nascimento, F. P. D., \& Sousa, F. L. L. (2016). Metodologia da pesquisa científica teoria e prática: como elaborar TCC. Brasília: Thesaurus.

[30] Paraná. (2015). Secretaria da Educação. Semana Pedagógica: Anexo 2 - Indicadores Educacionais. Disponível em:http://www.gestaoescolar.diaadia.pr.gov.br/arquivos/File/sem_pedagogica/fev_2015/anexo2_indicadores_educa cionais_sp2015.pdf. Acesso em: 05 jun. 2020.

[31] Ribeiro, K. C. et al. Indicadores bibliométricos na base SCOPUS sobre o tema "avaliação da educação" no Brasil e no mundo. R. Tecnol. Soc., Curitiba, v. 15, n. 37, p. 311-331, jul./set. 2019. Disponível em: https://periodicos.utfpr.edu.br/rts/article/view/8436. Acesso em: 15 de abril de 2020.

[32] Richardson, R. J. (2012). Pesquisa social: métodos e técnicas. 3. ed. revista e ampliada, 14. Reimpressão. São Paulo: Atlas.

[33] Rios, D. R. (2009). Minidicionário escolar da língua portuguesa. São Paulo: DCL.

[34] Santos, P. D. M. L. dos. (2008). Paul Otlet: um pioneiro da organização das redes mundiais de tratamento e difusão da informação registrada. Ciência Da Informação, 36(2). Recuperado de http://revista.ibict.br/ciinf/article/view/1176.

[35] Santos, R. N. M. D. (2003). Produção científica: por que medir? O que medir? Revista digital de Biblioteconomia e Ciência da Informação, 1(1). 
[36] Schultz, G. (2016). Introdução à gestão de organizações. Rio Grande do Sul. UFRGS.

[37] Silva, D.C.V da \& Vacovski, E (2015). A transparência na administração pública como instrumento facilitador para o controle social. Caderno Gestão Pública, 7 (4), 67-86. Recuperado em 9 junho, 2020, de https://www.uninter.com/cadernosuninter/index.php/gestao-publica/article/view/592/497.

[38] Silva, M. D. (2004). Análise bibliométrica da produção científica docente do programa de pós-graduação em educação especial/UFSCar: 1998-2003 (Doctoral dissertation, Dissertação (Mestrado em Educação Especial) Universidade Federal de São Carlos, São Carlos).

[39] Silva, C. R.; Gobbi, B. C.; Simão, A. A. (2005). O uso da análise de conteúdo como uma ferramenta para a pesquisa qualitativa: descrição e aplicação do método. Organizações Rurais Agroindustriais, Lavras, 7 (1), 70-81.

[40] Zucolotto, V. (2012) Workshop de Capacitação em Escrita Científica. Disponível: http://www.escritacientifica.com/index.php?option=com_content\&view=article\&id=5\&IteMID=110. Acesso em: 14 abril 2020. 


\section{Capítulo 3}

Contabilidade Ambiental: Mulheres x Homens em uma década de produção científica

\section{Alison Silva Ferreira \\ Mirian Gomes Conceição \\ Sonia Maria da Silva Gomes}

Resumo: 0 objetivo desta pesquisa foi analisar uma década de produção científica sobre contabilidade ambiental, no Brasil, e a participação entre homens e mulheres acerca do tema, entre o período de 2009 a 2018. Utilizou-se a técnica bibliométrica aplicada nos quatro eventos brasileiros da área de Administração, Ciências Contábeis e Turismo, realizados anualmente e com maior número de publicações, sendo eles: Congresso Brasileiro de Custos (CBC), Encontro Nacional da Associação Nacional de Pós-Graduação e Pesquisa em Administração (ENANPAD), USP International Conference in Accounting e o Congresso da Associação Nacional de Programas de Pós-Graduação em Ciências Contábeis (ANPCONT). Os resultados demonstraram que apenas 176 do total de 14.300 artigos pesquisados se enquadram no objeto de investigação, ou seja, 1,23\%. O CBC foi o evento que mais publicou artigos relacionados. Acerca da discussão de gênero, nota-se que as mulheres têm publicado mais pesquisas nos últimos anos. Contudo, no geral, a diferença frequente nos dados informacionais por gênero encontrados na pesquisa é muito pequena, subentendendo que quanto as redes e características autoriais nas pesquisas em contabilidade ambiental, há uma igualdade de gênero presente. Assim, tanto os estudos sobre gênero quanto sobre a temática ambiental devem continuar a ser um assunto substantivo para a comunidade acadêmica contábil.

Palavras-chave: Contabilidade Ambiental; Gênero; Produção Científica. 


\section{INTRODUÇÃO}

A contabilidade ambiental é vista como uma parte circunstancial no que tange a responsabilidade social, sendo exigida no ambiente que estamos inseridos, nas organizações, no próprio estado, e entidades públicas e privadas e na sociedade em geral.

Pois, esta é a área de conhecimento que tem assumido o compromisso de reportar as ações de mitigação, adaptação das mudanças climáticas, de combate à pobreza, corrupção, fraudes e irresponsabilidade em relação as públicas para o cumprimento dos objetivos do desenvolvimento sustentável. Para além de criar valor aos acionistas, por meio do relato integrado.

Neste contexto, os profissionais de contabilidade desempenham um papel fundamental dentro das organizações, tanto no que diz respeito a sua contribuição para mensurar e auxiliar na redução dos impactos ambientais gerados pelas empresas quanto no ato de indicar caminhos para transformar investimentos ambientais em possibilidade de rentabilidade.

Neste universo contábil-ambiental, há indícios de que as mulheres tem se apresentado mais ativas que os homens, sobretudo nos últimos anos. Para Ortner (1974) e Salleh (1984) esse fato se deve a origens biológicas das mulheres que relacionam-se com o meio ambiente, o que confere uma ideia de ecofeminismo.

Contudo, Garcia (1992) ressalta que esse pensamento é comumente criticado por antropólogos sociais e é necessário ir mais adiante e examinar criticamente as bases materiais que são subjacentes a estas construções, ou seja, analisar o trabalho que a mulher e o homem produz.

Neste sentido, podemos inferir que o ramo da contabilidade ambiental é uma área de estudos interessante para avaliar os índices de participações entre homens e mulheres em eventos científicos.

Portanto, este trabalho pretendeu responder a seguinte questão de pesquisa: Qual o nível de publicações, entre homens e mulheres acerca do tema Contabilidade Ambiental nos principais Congressos de contabilidade do país?

Considerando a importância dos congressos para a pesquisa científica, o objetivo principal consiste em analisar uma década de produção científica sobre contabilidade ambiental, no Brasil, e a participação entre homens e mulheres acerca do tema.

Para subsidiar tal objetivo, foi traçado os seguintes objetivos específicos: verificar o foco central das discussões em contabilidade ambiental pelos autores; apresentar os principais autores engajados na temática e suas características acadêmicas; e mapear a diferença na produção científica nos congressos entre homens e mulheres e sua representatividade.

Dessa forma, podemos considerar que este trabalho se justifica por contribuir na ampliação dos estudos que promovam a igualdade de gêneros, pois busca a identificação e confronto da participação entre mulheres e homens na área contábil-ambiental, a partir da avaliação do índice de produção científica nos principais congressos da área.

Além disso, espera-se que essa pesquisa contribua para o conhecimento acerca da divulgação da proposta do tema nos periódicos nacionais, e também é de fundamental importância o desenvolvimento desta pesquisa no espaço acadêmico, uma vez que a discussão e a busca de respostas para o problema irá contribuir para o desenvolvimento da contabilidade ambiental. Entende-se também que pesquisas relativas ao contexto socioambiental são de fundamental importância para o desenvolvimento da economia do país e redução das disparidades sociais.

\section{REFERENCIAL TEÓRICO}

\subsection{CONTABILIDADE AMBIENTAL}

0 meio ambiente e tudo que nele há é um dos recursos mais importantes para o ser humano, tão circunstancial que é praticamente impossível mensurar o tamanho da sua representatividade. No entanto, esse ecossistema é composto por diversos outros seres vivos, portanto, cabe o homem como ser racional cuidar para que os recursos finitos do planeta perpetuem para as gerações futuras.

É neste contexto que Silva e Cruz (2007), entendem que o homem passa a reconhecer que faz parte do meio ambiente, do sistema, e que todo sistema faz parte de um sistema maior, com o qual mantêm 
relações, numa contribuição para o seu funcionamento, assim como dele recebendo elementos para a execução de suas próprias funções.

Para isso, os autores entendem que é necessário que haja harmonia entre o desenvolvimento e o meio ambiente, ou seja, alternativas para não degradar, ou ainda, minimizar ao máximo os impactos causados pelo homem, e também, buscar técnicas de mensuração dos custos, despesas, receitas e desempenho empresarial que possam conservar e manter o meio ambiente.

É baseado nessas características que surge o Tripé da Sustentabilidade ou triple bottom line, que busca analisar os resultados de uma organização sob a ótica Social, Ecológica e Financeira. Para Vellani e Ribeiro (2009), o conceito do TBL reflete sobre a necessidade de as empresas ponderarem em suas decisões estratégicas, mantendo: a sustentabilidade econômica ao gerenciar empresas lucrativas e geradoras de valor; a sustentabilidade social ao estimular a educação, cultura, lazer e justiça social à comunidade; e a sustentabilidade ecológica ao manter ecossistemas vivos, com diversidade.

Contudo, Para Gomes et al (2013) existe um grande desafio na sustentabilidade que está atrelado justamente a alcançar excelência no desempenho social, financeiro e ambiental simultaneamente, gerando um paradoxo nas métricas de avaliação.

Sendo assim, conforme Oliveira e Pereira (2014), contabilidade passa então a ocupar espaço importante na comunicação e informação dos fatos relacionados ao meio ambiente em relação às organizações, para que os registros das estratégias organizacionais sejam contabilizados e possam ser avaliados futuramente.

No entanto, para Freitas et al (2012), diferente dos gastos operacionais e administrativos da contabilidade tradicional, os gastos da contabilidade ambiental, não tornam seu objetivo especificamente em contabilizar eventos causados no meio natural, mas se constitui uma ferramenta para evidenciar e controlar os gastos da Gestão Ambiental.

Esse ramo da contabilidade é visto por Silva (2013), como um detentor de potencialidade para auxiliar os administradores na missão de aprimorar a utilização dos recursos naturais, sendo usada para evidenciar a responsabilidade ambiental da entidade, através da apresentação de relatórios contábeis onde devem ser demonstrados, de forma clara, e autêntica, os gastos realizados com controle ambiental.

Além disso, o surgimento desta nova área contábil veio para auxiliar os contadores no desenvolvimento de ferramentas voltadas à interação com o meio ambiente (VERONEZE et al, 2016).

Nas organizações, a contabilidade se destaca ainda na perspectiva em que oferece os indícios das boas práticas de governança coorporativa (RIBEIRO et al, 2017). Silva e Cruz (2007) entendem que os motivos que levam as empresas a adotar uma contabilidade ambiental vão desde gestão interna e exigências legais a demandas por participes, ainda que essa contabilidade também possa identificar, estimar, alocar, administrar e reduzir os custos, e também ser usada como estratégias de marketing ecológico.

\subsection{CONTAS CONTÁBEIS AMBIENTAIS}

Segundo Iudicibus, Marion e Faria (2017) o objetivo da contabilidade é de oferecer informações necessárias para a tomada de decisões, portanto, se utiliza dados não apenas de natureza econômica e financeira, mas também informações socioambientais, importantes para os usuários internos e externos (stakeholders).

Portanto, segundo Santos et al. (2001), A partir deste contexto, subentende-se que a contabilidade ambiental é a parte da contabilidade que pretende estudar o patrimônio ambiental (bens, direitos e obrigações ambientais) das entidades, objetivando fornecer aos stakeholders, informações sobre os eventos ambientais que causam modificações na situação patrimonial, bem como realizar sua identificação, mensuração e evidenciação.

Contudo, devido à necessidade de atender as Normas Internacionais de Contabilidade (IFRS), o conceito de ativo mudou e passou a ser visto como um recurso controlado pela entidade como resultado de eventos passados e do qual se espera que resultem futuros benefícios econômicos para a entidade, conforme o CPC 00 .

Neste contexto, o ativo ambiental é definido por Ribeiro (2010), como os bens e direitos, sem exceções, possuídos pelas entidades, que tenham capacidade de geração de benefício econômico em períodos futuros e que visem à preservação, proteção e recuperação ambiental. 
Conforme Santos et al. (2001), esses ativos podem se apresentar na forma de capital circulante (realizados ao longo prazo ou disponibilidades oriundos de receita ambiental ou gerenciamento de resíduos) ou em forma de capital fixo que podem ser investimentos ecológicos, imobilizados com redução de lançamento de poluição ou resíduos produtivos ou diferidos provenientes de gastos com pesquisas para melhoria de produtos e processos, visando tecnologias mais limpas ou aplicação de SGA's.

A receita ambiental, neste contexto, é, portanto, definida pelo International Accounting Standards Board (IASB) e traduzida por Iudicibus, Marion e Faria (2017) como as entradas de ativos ou decréscimo de exigibilidade decorrente de acréscimo de benefícios econômicos durante o período contábil que redunda num acréscimo do patrimônio líquido, outro que não o relacionado a ajustes de capital, podendo ser, por exemplo: prestação de serviços especializados em gestão ambiental ou venda de produtos elaborados a partir de sobras de insumos do processo produtivo.

O passivo ambiental, por sua vez, está relacionado com a agressão que a entidade promove ao meio ambiente, bem como aos gastos que ela terá para compensar tais danos (WELTER e SANTANA, 2011). Neste sentido, os impactos causados a terceiros relacionados ao meio ambiente, decorridos de atividades da entidade, devem ser reconhecidos neste grupo de contas (TINOCO e KRAEMER, 2011).

Por fim, os Custos e despesas ambientais são vistas por Brumati (2015) são gastos aplicados direta ou indiretamente no sistema de gestão ambiental do processo produtivo e em atividades ecológicas da empresa.

0 que vai diferenciar os dois é sua aplicabilidade, pois quando aplicados diretamente na produção, estes gastos são classificados como custos, e, se foram aplicados de forma indireta, são chamados de despesas. Isso por que, conforme afirma Iudicibus (2015) as despesas e por consequência, as despesas ambientais despesas, em sua essência, representam a utilização ou o consumo de bens e serviços no processo de produzir receitas.

\subsection{GÊNERO; CONTABILIDADE E PRODUÇÃO CIENTÍFICA}

Dados estatísticos divulgados através da pesquisa realizada por Castro e Abramovay (2005) informavam que as mulheres ganhavam, em média, dois a três quartos menos do que os homens; e nos Estados Unidos, por exemplo, apenas $5 \%$ do corpo executivo das 500 maiores corporações são formados por mulheres.

No Brasil, um levantamento realizado pelo Instituto Ethos de Empresas e Responsabilidade Social (2010), demonstrou que apenas $14 \%$ dos cargos de chefia nas maiores empresas brasileiras eram ocupados por mulheres. Com o mesmo objetivo, o estudo foi realizado novamente em 2016, e demonstrou uma redução ainda maior desses números, apontando 13,6\%, o que deixa claro a desigualdade entre os sexos e a subrepresentação das mulheres, tendo em conta os dados sobre sua presença na sociedade brasileira.

No espaço acadêmico, no entanto, as mulheres vêm adquirindo destaque, sobretudo na área contábil ambiental e de sustentabilidade. De acordo com a pesquisa publicada por Souza, Ribeiro e Côrrea (2011); dentre os anos 2007 a 2009, nas principais revistas de contabilidade e administração do país, as mulheres representavam $38 \%$ das publicações.

Acerca da participação de mulheres, Conceição et al (2016), avaliando os principais congressos da área contábil, demonstrou em seus resultados, que as mulheres publicaram duas vezes mais que os homens, com 69\% de participação, em um período entre 2012 a 2015.

Pesquisas divulgadas por Oliveira et al (2013), que realizaram um levantamento do estado da arte da temática gestão socioambiental, analisando os congressos de Gestão Socioambiental do Simpósio de Excelência em Gestão e Tecnologia (SEGeT) e dos Seminários em Administração (SemeAd) no ano de 2010, constataram que há uma prevalência de publicações femininas (53\%).

Já Silva, Lima e Oliveira (2018), concluíram que dos oito autores com maior número de produção científica sobre Gestão Ambiental nas áreas de Administração, Ciências Contábeis e Turismo, na última década (2006-2015), cinco são mulheres, sendo elas: Mônica Cavalcanti Sá de Abreu, Maria Tereza Saraiva de Souza, Elisete Dahmer Pfitscher, Simone Sehnem e Adriana Marques Rossetto, além disso, grande parte das autoras participa de redes de coautoria, o que confere maiores publicações.

Em termos gerais, pesquisas também vêm sendo divulgadas acerca da participação das mulheres nas publicações em congressos e periódicos no Brasil. Os resultados dispostos por Luca et al (2011), por exemplo, concluiu que pouco mais de $58 \%$ das publicações em contabilidade entre os anos de 2004 a 2009, foram de mulheres. 
O estudo de Silva, Anzilago e Lucas (2015) que buscou verificar a o perfil das publicações em periódicos brasileiros sobre gênero no campo da contabilidade, depreendeu que entre os anos de 2011 e 2012, 67\% das autorias são de mulheres.

Com isso, observa-se que o movimento de mulheres, na sua longa história de avanços e de amadurecimento, tornou-se muito rico, diversificado e multidisciplinar (CASTRO; ABRAVAMOVAY, 2005). Segundo os autores, esse fato colabora com o desenvolvimento será sustentável e este só será realmente equitativo quando homens e mulheres participarem de forma mais igualitária, em todos os níveis, do processo de tomada de decisões.

As pesquisas da área científico-acadêmicos são imprescindíveis, portanto para diminuir essas desigualdades, pois tem demonstrado o crescimento da atuação feminina na área contábil-ambiental. Neste sentido, na opinião de Silva et al (2017), os grandes eventos científicos, tais como congressos, encontros, palestras, seminários, simpósios, painéis, etc., são grandes oportunidades para os envolvidos debaterem, aprenderem e ensinarem novas técnicas desenvolvidas.

Estes eventos tornam-se não apenas matrizes de oportunidades para os profissionais, inclusive mulheres, disseminar novos conhecimentos, mas também de diminuir as disparidades sociais entre gêneros através da divulgação de pesquisas científicas.

A partir deste ponto, pesquisas, sobretudo de cunho bibliométrico tem surgido cada vez mais, principalmente publicadas por mulheres. Segundo Teixeira e Ribeiro (2014), a bibliometria é uma importante ferramenta para o estudo e a avaliação de estudos científicos, bem como para a avaliação da disseminação da informação.

Complementando este pensamento, Oliveira e Ribeiro (2015), salientaram que essa técnica é constitui-se um tipo de pesquisa metodológica que permitir a identificação das tendências e crescimento do conhecimento sobre o periódico escolhido.

\section{PROCEDIMENTOS METODOLÓGICOS}

Conforme Conceição (2013), pesquisas empíricas, tal como essa, com uso da bibliometria, visam coletar dados a partir de fontes diretas (pessoas). Portanto, do ponto de vista dos prodimentos técnicos, esse tipo de pesquisa é elaborado a partir de material já publicado, sobretudo livros e artigos de periódicos e congressos (GIL, 2010).

Ainda na opinião de autor, também se trata de um trabalho descritivo na medida em que se promove a avaliação de características de determinada população ou fenômeno ou, então, o estabelecimento de relações entre variáveis. Sendo, portanto, uma pesquisa qualitativa e também quantitativa, pois houve uma análise e captação de um volume grande de dados tabulados, posteriormente, através da ferramenta Microsoft Excel e analisados com estatística descritiva.

Assim, com o propósito de alcançar o objetivo da pesquisa, foi realizado uma investigação do tipo empírico-analítica baseado em análise documental. Para tanto, utilizou-se a técnica bibliométrica, com a qual foi analisado a produção científica acerca das publicações realizadas por mulheres e homens sobre contabilidade ambiental. Sendo 2009-2018 o período temporal compreendido na pesquisa.

Para selecionar os congressos, objetos da análise bibliométrica, foram considerados grandes eventos brasileiros da área contábil ou de administração e turismo, realizados anualmente, com volume extenso de publicações e que possuam as informações dos autores-pesquisadores nos anais dos eventos.

Portanto, concluiu-se, como amostra, quatro grandes eventos, sendo eles: Congresso Brasileiro de Custos (CBC), Encontro Nacional da Associação Nacional de Pós-Graduação e Pesquisa em Administração (ENANPAD), USP International Conference in Accounting e o Congresso da Associação Nacional de Programas de Pós-Graduação em Ciências Contábeis (ANPCONT).

O evento da Universidade de São Paulo possui anais de iniciação científica e, em alguns casos, chamadas internacionais ou excepcionais. Estes também foram considerados como aporte do conteúdo da análise desta pesquisa.

Contudo, até o primeiro semestre de 2020, estavam disponíveis no novo site do ANPCONT, apenas os anais do período de 2011-2019. Portanto foram considerados, para este trabalho, apenas os 8 anos (20112018) disponíveis deste evento, compreendidos dentro do filtro estrutural. 
Diante do contexto, para delimitação, contraindo como base metodológica das pesquisas de Souza et al (2011), os artigos selecionados devem conter relação direta com a temática proposta (contabilidade ambiental), portanto, para enquadramento, há necessidade que um dos termos apareçam, não simultaneamente, no título, no resumo e/ou nas palavras-chave de cada artigo.

Neste sentido, foram escolhidas como filtro todos os artigos que contiveram os termos relacionados aos Componentes Patrimoniais Ambientais ou da própria Contabilidade ambiental: Ativo Ambiental; Passivo Ambiental; Despesa Ambiental; Receita Ambiental; Ganho Ambiental; Custo Ambiental; Gasto Ambiental; Encargo Ambiental; Patrimônio Ambiental; Investimento Ambiental; Balanço Ambiental; Balanço Social; Balanço Socioambiental, Contabilidade de Gestão Ambiental; Contabilidade Socioambiental, além de termos que se constituam ou envolvam proximidade absoluta com a ideia central (contabilidade).

Para os artigos publicados em outro idioma (inglês e/ou espanhol) foram feitas as devidas traduções para o idioma local, considerando os respectivos ou semelhantes termos já mencionados anteriormente.

Ademais, ressalta-se que os termos: Disclosure Ambiental; Divulgação Ambiental; "Evidenciação Ambiental" e demais correlatos, não integraram o filtro deste trabalho, pois outros autores, em estudos recentes, já contribuíram com o desenvolvimento nesse campo de pesquisa na medida em que se propuseram a analisar especificamente publicações relacionadas a essa temática, a exemplo do trabalho de Kouloukoui et al. (2017).

Considerando o total de 14.300 artigos pesquisados durante o período, identificou-se que apenas 176 se enquadravam dentro da metodologia estipulada para a pesquisa. 0 que representa apenas $1,23 \%$ de toda a publicação do período, conforme a tabela 1.

Tabela 1. Resultados generalizados da pesquisa.

\begin{tabular}{|c|c|c|c|c|c|c|c|c|c|c|}
\hline \multirow{2}{*}{ Ano } & \multicolumn{2}{|c|}{$\mathrm{CBC}$} & \multicolumn{2}{|c|}{ USP Conference } & \multicolumn{2}{|c|}{ ENANPAD } & \multicolumn{2}{|c|}{ ANPCONT } & \multicolumn{2}{|c|}{ Geral } \\
\hline & Freq. (n) & Total & Freq. (n) & Total & Freq. (n) & Total & Freq. (n) & Total & Freq.(n) & Total \\
\hline 2009 & 15 & 248 & 5 & 68 & 10 & 879 & - & - & 30 & 1.195 \\
\hline 2010 & 12 & 273 & 2 & 101 & 9 & 854 & - & - & 23 & 1.228 \\
\hline 2011 & 14 & 198 & 0 & 104 & 10 & 873 & 2 & 100 & 24 & 1.275 \\
\hline 2012 & 12 & 235 & 0 & 105 & 2 & 867 & 2 & 99 & 16 & 1.306 \\
\hline 2013 & 8 & 196 & 1 & 54 & 3 & 856 & 5 & 120 & 17 & 1.226 \\
\hline 2014 & 12 & 225 & 0 & 134 & 5 & 867 & 3 & 110 & 20 & 1.336 \\
\hline 2015 & 4 & 189 & 0 & 132 & 3 & 1.042 & 2 & 122 & 9 & 1.485 \\
\hline 2016 & 5 & 152 & 0 & 112 & 3 & 1.163 & 1 & 165 & 9 & 1.592 \\
\hline 2017 & 6 & 174 & 1 & 222 & 3 & 1.160 & 3 & 245 & 13 & 1.801 \\
\hline 2018 & 4 & 163 & 3 & 290 & 2 & 1.288 & 4 & 115 & 13 & 1.856 \\
\hline Total & 92 & 2.053 & 12 & 1.322 & 50 & 9.849 & 22 & 1.076 & 176 & 14.300 \\
\hline
\end{tabular}

Fonte: Dados da pesquisa (2019)

Dessa forma, tendo em vista a metodologia proposta, as análises foram desenvolvidas considerando três blocos, sendo que o primeiro, acerca dos eventos e particularidades, possui três sub-tópicos: os aspectos da incidência do tema; incidência das palavras-chaves e distribuição de artigos por congresso, ressaltando sua evolução sobre a temática de acordo com cada ano; além da análise das abordagens metodológicas mais utilizadas pelos autores.

A segunda parte da análise compreende as características de autoria, relacionando os autores mais prolíficos em contabilidade ambiental durante o período estudado e as redes de coparticipação dos mesmos.

Não obstante, para alcance do objetivo da pesquisa, buscou-se, no terceiro bloco, verificar a quantidade de mulheres e homens com maior volume de publicação sobre o tema, ressaltando a afluência nas publicações. Portanto, esta fase foi considerada circunstancial para conhecer os artigos e o nível de publicação entre mulheres e homens sobre a temática abordada.

Vale salientar que essa metodologia escolhida já foi validada em diversas pesquisas, em destaque para os trabalhos publicados por Souza et al. (2011); Luca et al. (2011); Conceição et al. (2012); Silva, Anzilago e Lucas (2015) e Conceição et al. (2016). 


\section{RESULTADOS E DISCUSSÕES}

\subsection{OS EVENTOS E SUAS PARTICULARIEDADES}

Para cumprir os objetivos desta pesquisa, foi definida na tabela 2, a quantidade de artigos científicos publicados nos anais dos congressos, no período entre 2009 a 2018. A referente tabela também apresenta a incidência dos artigos em relação ao total pesquisado que preencheram os requisitos definidos na metodologia da presente pesquisa, devendo, portanto, possuir o termo: contabilidade ambiental ou os respectivos termos semelhantes.

Desse modo, foram identificados 176 artigos correlacionados com o tema. Esta quantidade representa apenas $1,23 \%$ do total de artigos publicados no período. Contudo, ressalta-se que, por questões de indisponibilidade dos anais, foram avaliados 8 anos de publicações do Congresso da Associação Nacional de Programas de Pós-Graduação em Ciências Contábeis.

Tabela 2. Incidência de artigos sobre o tema

\begin{tabular}{|l|c|c|c|}
\hline \multicolumn{1}{c}{ Congressos } & Amostra & Frequência (n) & Incidência (\%) \\
\hline Congresso Brasileiro de Custos & 2.053 & 92 & 4,48 \\
\hline USP International Conference in Accounting & 1.322 & 12 & 0,91 \\
\hline ENANPAD & 9.849 & 50 & 0,51 \\
\hline ANPCONT & 1.076 & 22 & 2,04 \\
\hline Total & 14.300 & 176 & 1,23 \\
\hline
\end{tabular}

Fonte: Dados da pesquisa (2019)

Segundo a análise bibliométrica realizada com base nos quatro congressos, se observa que há pouca produção encontrada no período relacionada a temática abordada, resultando em baixa incidência durante a década estudada.

Estes resultados inferem que se faz necessário maiores pesquisas em relação à contabilidade ambiental, pois segundo Oliveira e Pereira (2012), essa área da contabilidade tornou-se um ponto importante nos estudos, por se tratar temas relevantes para os profissionais da área contábil, pois com as mudanças nas entidades, se faz necessário registrar condições relacionadas aos ativos e passivos ambientais oriundos das operações das organizações.

Se observado a evolução do tema durante os anos, é constatado que o mesmo apresentou retrações. Segundo a tabela 3, a seguir, no geral, houve uma quantidade maior de publicações entre 2009 - 2014 , mas os anos finais (2015 a 2018) apresentaram o menor número de anais relacionados com os filtros da pesquisa.

Tabela 3. Destaque dos congressos

\begin{tabular}{|c|c|c|c|c|c|}
\hline Ano & CBC & USP & ENANPAD & ANPCONT & Total \\
\hline 2009 & 15 & 5 & 10 & - & 30 \\
\hline 2010 & 12 & 2 & 9 & 2 & 23 \\
\hline 2011 & 14 & - & 10 & 2 & 26 \\
\hline 2012 & 12 & - & 2 & 5 & 16 \\
\hline 2013 & 8 & 1 & 3 & 3 & 20 \\
\hline 2014 & 12 & - & 5 & 2 & 9 \\
\hline 2015 & 4 & - & 3 & 1 & 13 \\
\hline 2016 & 5 & - & 3 & 3 & 13 \\
\hline 2017 & 6 & 1 & 3 & 4 & 176 \\
\hline 2018 & 4 & 3 & 2 & 20 & \\
\hline Total & 92 & 12 & 50 & & \\
\hline
\end{tabular}

Fonte: Dados da pesquisa (2019)

Se comparados, por exemplo, o ano inicial (2009) e final (2018), observa-se que a retração no número de pesquisas publicadas acerca da temática supera 230\%. Este índice retrativo é ainda maior (333\%) relacionando o período inicial aos anos de 2015 e 2016, períodos pós-desastre da Barragem de Fundão, na cidade de Mariana - MG. 
Assim, analisando a evolução das publicações por ano, conforme a tabela 3, observa-se que os anos de 2009, 2011 e 2010, respectivamente, marcam o maior período com artigos publicados e 2015-2016 possuíram o menor número de achados. Além disso, nota-se que os primeiros três anos analisados concentram, sozinhos, $44,89 \%$ do volume total de artigos enquadrados.

O Congresso Brasileiro de Custos apresentou maior volume de publicações ( 92 trabalhos), enquanto o USP Conference, obteve apenas 12 pesquisas enquadradas, sendo o evento com menor número de publicações relativas ao tema, ainda que esse congresso tenha linhas específicas para publicações relacionadas a meio ambiente e sustentabilidade e um volume total grande de produção científica.

Observando as tabelas 2 e 3, nota-se que, apesar do ENANPAD ter apresentado um volume de 50 artigos enquadrados, a sua incidência individual é a mais baixa entre os quatro eventos, isso por que, este congresso possui um número alto de anais publicados por ano. Neste período estudado foram 9.849 trabalhos.

Portanto, se tratando de volume, o ENANPAD aduziu quase 5x mais artigos analisados que o Congresso Brasileiro de Custos. Denotou ainda pouco mais de 7x mais publicações que USP Conference e 9x mais anais que o evento da ANPCONT.

Os filtros metodológicos realizados também permitiram verificar as palavras chaves mais recorrentes durante a pesquisa. Assim, a tabela 4 apresenta o panorama geral dos termos mais recorrentes, ou seja, das palavras-chaves definidas metodologicamente que apareceram, ao menos, uma vez em cada um dos 176 artigos filtrados. A pesquisa encontrou 229 itens.

Tabela 4. Palavras-chaves mais recorrentes

\begin{tabular}{|l|c|c|}
\hline \multicolumn{1}{|c|}{ Palavras-Chaves (Elementos Contábeis) } & Frequência & Incidência (\%) \\
\hline Contabilidade Ambiental & 42 & 18,34 \\
\hline Balanço Social & 33 & 14,41 \\
\hline Patrimônio Ambiental & 6 & 2,62 \\
\hline Ativo Ambiental & 6 & 2,62 \\
\hline Passivo Ambiental & 22 & 9,61 \\
\hline Receita Ambiental & 4 & 1,75 \\
\hline Despesa Ambiental & 21 & 9,17 \\
\hline Custo Ambiental & 53 & 23,14 \\
\hline Investimento Ambiental & 42 & 18,34 \\
\hline Total & 229 & $100,00 \%$ \\
\hline
\end{tabular}

Fonte: Dados da pesquisa (2019)

Conforme a tabela os termos: Custo ambiental" $(23,14 \%)$; Contabilidade ambiental e Investimento ambiental $(18,34 \%)$ foram as palavras mais recorrentes nas pesquisas dentre aquelas apresentadas metodologicamente.

Diferentemente deste resultado, as palavras: Receita ambiental (1,75\%); Ativo ambiental e Patrimônio ambiental $(2,62 \%)$ apareceram com menor frequência nos trabalhos desta década. Este fato pode ser relacionado com a afirmação de Yamaguchi (2011) que entende que existem dificuldades, por parte das empresas em medir a utilidade econômica dos bens e serviços e o próprio bem-estar econômico causados.

Contudo, no geral, afirmam Zilber; Caruzzo e Campanário (2008) que as empresas têm dificuldades na separação e na valoração de todos os fatos ambientais. Bem como sua correta classificação e avaliação contábil (MARCONDES; CAMPOS, 2005).

\subsection{ABORDAGENS METODOLÓGICAS}

Gerhardt e Silveira (2009) definem o método científico como um conjunto de dados iniciais e um sistema de operações ordenado para a formulação de conclusões, em outras palavras, o corpo de regras e procedimentos estabelecidos para realização de uma dada pesquisa. Portanto, o melhor método é aquele que mais ajuda na compreensão do fenômeno a ser estudado (HAGUETTE, 2018). 
Neste sentido, foi realizado um procedimento com o objetivo de verificar as principais abordagens metodológicas utilizadas nas seis pesquisas filtradas, demonstrando a preferência pelo método qualitativo, quantitativo ou a inter-relação dos dois.

Tabela 5. Tipologia da Pesquisa quanto à abordagem por ano

\begin{tabular}{|c|c|c|c|c|c|c|c|c|c|c|c|c|c|} 
Tipologia & 2009 & 2010 & 2011 & 2012 & 2013 & 2014 & 2015 & 2016 & 2017 & 2018 & Total \\
\hline Quali-Quanti & 4 & 11 & 8 & 5 & 3 & 3 & 1 & - & 3 & 1 & 39 \\
\hline Qualitativa & 11 & 9 & 11 & 5 & 9 & 10 & 4 & 7 & 4 & 1 & 71 \\
\hline Quantitativa & 15 & 3 & 7 & 6 & 5 & 7 & 4 & 2 & 6 & 11 & 66 \\
\hline Total & 30 & 23 & 26 & 16 & 17 & 20 & 9 & 9 & 13 & 13 & 176 \\
\hline
\end{tabular}

A partir dos resultados indicados, se observa que o uso das abordagens é bastante variável entre os artigos avaliados, pois, no geral, $40,34 \%$ recorreram ao método qualitativo, enquanto outros $37,50 \%$ aplicaram métodos quantitativos e mais $22,16 \%$ dos pesquisadores optaram pelo uso das duas tipologias unificadas.

Contudo, se nota que em 2018 houve um crescimento exponencial no número de pesquisas de tipo quantitativo, representando $84,62 \%$ das pesquisas deste ano. Contudo, para Bachini e Chicarino (2018) a maioria das pesquisas publicadas nos periódicos de Ciências Sociais do Brasil se caracteriza pela ausência de números.

Ressalta-se que para realização desta análise, consideraram-se as informações fornecidas pelos próprios autores sobre a abordagem adotada em seus trabalhos. Portanto, não coube neste estudo julgar eventuais inconsistências, já que se trata de artigos aprovados em congressos que possuem procedimentos de avaliação (FERREIRA et al., 2018).

\subsection{CARACTERÍSTICAS DE AUTORIA}

Segundo Souza et al. (2011) a representatividade e as redes colaborativas dos autores são evidenciadas a partir da quantidade de pesquisados em cada artigo e na medida em que esses autores produzem material científico conjuntamente, torna-se mais perceptível que a área é investigada por grupos de pesquisa ao invés de autores individuais.

Portanto, complementando este pensamento Subramanyam (1983) afirmou que esse tipo de colaboração, realizada por grupos sempre foi entendido, inclusive internacionalmente, como um dos indicadores de qualidade da pesquisa, principalmente em temas interdisciplinares.

Neste contexto, as pesquisas em contabilidade ambiental que propõe um arcabouço multidisciplinar tornam-se fundamental para o desenvolvimento da ciência. A tabela 6 apresenta a frequência de artigos de autoria individual e com mais autores por artigo.

Tabela 6. Característica de autoria por artigo

\begin{tabular}{|l|c|c|}
\multicolumn{1}{c|}{ Quantidade de Autores } & Frequência (n) & Incidência (\%) \\
\hline Individual & 8 & 4,55 \\
\hline Dois Autores & 48 & 27,27 \\
\hline Três Autores & 62 & 35,23 \\
\hline Quatro Autores & 34 & 19,32 \\
\hline Cinco Autores & 20 & 11,36 \\
\hline Seis Autores & 4 & 2,27 \\
\hline Total & 176 & $100 \%$ \\
\hline
\end{tabular}

Fonte: Dados da pesquisa (2019) 
A tabela 6 demonstra que as redes de autorias prevalecem, pois houve poucos artigos publicados em autoria individual, representando apenas $4,55 \%$ do total. Assim, têm-se que $95,45 \%$ dos artigos têm, ao menos dois autores, demonstrando as redes de parcerias.

Ademais, $35,23 \%$ do total dos trabalhos possuíram artigos com três autores, enquanto $27,27 \%$ das pesquisas foram realizadas com dois escritores. Outros $32,95 \%$ obtiveram quatro a seis pesquisadores. Mas, é imprescindível destacar que, exceto o $\mathrm{CBC}$, os demais congressos da amostra limitam a quantidade máxima de quatro autores por artigo.

Além disso, a pesquisa buscou ainda verificar, especificamente, o número de pesquisas publicadas pelos autores. As informações estão disponíveis na tabela 7. Desse modo, foi possível conhecer os principais autores e coautores engajados nessa metodologia.

Tabela 7. Autores mais prolíficos

\begin{tabular}{|c|c|c|c|}
\hline $\begin{array}{l}\text { Volume de } \\
\text { Produção }\end{array}$ & Autores & $\begin{array}{l}\text { Frequência } \\
\qquad(\mathrm{n})\end{array}$ & $\begin{array}{c}\text { Incidência } \\
(\%)\end{array}$ \\
\hline 7 & Elisete Dahmer Pfitscher. & 1 & 0,22 \\
\hline 6 & Janaina Ferreira Marques de Melo. & 1 & 0,22 \\
\hline 5 & - & 0 & 0,00 \\
\hline 4 & $\begin{array}{l}\text { Barbara de Lima Voss, Dusan Schreiber, Eloy Antonio Fenker, José } \\
\text { Maria Dias Filho, Márcia Reis Machado. }\end{array}$ & 5 & 1,10 \\
\hline 3 & $\begin{array}{l}\text { Benilson Borinelli, Blênio César Severo Peixe, Carlos Alberto Diehl, } \\
\text { Fabricia Silva da Rosa, Luciano Gomes dos Reis, Luiz Alberton, } \\
\text { Márcio André Veras Machado, Neylane dos Santos Oliveira, } \\
\text { Nverson da Cruz Oliveira, Roseane Patrícia Araújo Silva, Sandra } \\
\text { Maria dos Santos, Sonia Maria da Silva Gomes, Vanessa Theis. }\end{array}$ & 13 & 2,86 \\
\hline 2 & $\begin{array}{l}\text { Alexandre Sanches Garcia, Ana Carolina Vasconcelos Colares, Ana } \\
\text { Cristina de Faria, André Fernando Hein, Aneide Oliveira Araújo, } \\
\text { Antonio Cezar Bornia, Antonio Zanin, Ariovaldo dos Santos, } \\
\text { Augusto Cézar Aquino Cabral, Célia Braga, Cleber Broietti, Daniela } \\
\text { Di Domenico, Edvalda Araújo Leal, Fabíola Graciele Besen, Fátima } \\
\text { de Souza Freire, Fernando Dal-Ri Murcia, Francisco de Assis } \\
\text { Soares, Laura Calixto, Luiz Carlos Augusto de Carvalho, Luiz } \\
\text { Henrique Figueira Marquezan, Maisa de Souza Ribeiro, Marcelo } \\
\text { Resquetti Tarifa, Marcos Andrade, Margareth Aparecida Moraes, } \\
\text { Maria da Glória Arrais Peter, Maria de Fátima Nóbrega Barbosa, } \\
\text { Maria de Fátima Sales de Souza Campos, Maria Naiula Monteiro } \\
\text { Pessoa, Marília Bonzanini Bossle, Martin Airton Wissmann, Mônica } \\
\text { Cavalcanti Sá de Abreu, Paulo Henrique Leal, Paulo Mauricio Selig, } \\
\text { Renato J. Orsato, Ricardo Laporta Pomi, Sidnei Vieira Marinho, } \\
\text { Sílvia Maria Dias Pedro Rebouças, Susana Pereira de Sousa, } \\
\text { Thaiseany de Freitas Rêgo, Thiago Alberto dos Reis Prado, Tiago } \\
\text { Nascimento Borges Slavov, Tiago Wickstrom Alves, Vânia Vilma } \\
\text { Nunes Teixeira Xavier Teixeira }\end{array}$ & 43 & 9,45 \\
\hline 1 & Outros autores e coautores com 1 artigo publicado no período & 392 & 86,15 \\
\hline Total & - & 455 & 100,00 \\
\hline
\end{tabular}

Fonte: Dados da pesquisa (2019)

Observou-se que dentre os 455 autores mapeados, Elisete Dahmer Pfitscher foi a pesquisadora com um maior número de artigos publicados considerando os 10 anos de pesquisa, totalizando 7 trabalhos. Seguido por: Janaina Ferreira Marques de Melo com 6 trabalhos. Outros 5 autores possuem (cada) 4 artigos publicados no período.

Ademais, outros 12 pesquisadores possuem três artigos, cada, representando, juntos, 2,86\% do total e mais 43 autores apresentaram-se com dois artigos dentro do filtro estabelecido, conferindo 9,45\% de participação total. Há ainda outros 392 autores ou coautores que publicaram um artigo científico nos congressos estudados dentro deste período. 


\subsection{MULHERES X HOMENS: PUBLICAÇÕES}

Chamon (2005) cita que na última década, houve uma expansão no volume de publicações científicas em periódicos e congressos brasileiros na área de contabilidade. Contudo, a inclusão da temática de gênero nas pesquisas contábeis é bastante recente e pouco expressiva. (SILVA, ANZILAGO e LUCAS, 2015).

Dessa forma, buscou-se verificar, a partir dos resultados obtidos, o relacionamento entre os sexos e a produção científica do período, analisando, inclusive a afluência a respeito de quem publica mais como autor principal e coautor.

Tabela 8. Volume de publicação anual entre homens e mulheres

\begin{tabular}{|c|c|c|c|c|c|}
\hline Ano & Total de Autores & $\begin{array}{c}\text { Frequência (n) } \\
\text { Mulheres }\end{array}$ & $\begin{array}{c}\text { Incidência (\%) } \\
\text { Mulheres }\end{array}$ & $\begin{array}{c}\text { Frequência (n) } \\
\text { Homens }\end{array}$ & $\begin{array}{c}\text { Incidência (\%) } \\
\text { Homens }\end{array}$ \\
\hline 2009 & 77 & 32 & 41,56 & 45 & 58,44 \\
\hline 2010 & 76 & 30 & 39,47 & 46 & 60,53 \\
\hline 2011 & 82 & 42 & 51,22 & 40 & 48,78 \\
\hline 2012 & 53 & 30 & 56,60 & 23 & 43,40 \\
\hline 2013 & 46 & 31 & 67,39 & 15 & 32,61 \\
\hline 2014 & 55 & 31 & 56,36 & 24 & 43,64 \\
\hline 2015 & 28 & 14 & 50,00 & 14 & 50,00 \\
\hline 2016 & 20 & 16 & 80,00 & 4 & 20,00 \\
\hline 2017 & 45 & 22 & 48,89 & 23 & 51,11 \\
\hline 2018 & 41 & 23 & 56,10 & 18 & 43,90 \\
\hline Total & 523 & 271 & 51,82 & 252 & 48,18 \\
\hline
\end{tabular}

Fonte: Dados da pesquisa (2019)

Analisando a tabela 8 infere-se que, no geral, o número de publicações entre homens e mulheres durante os anos demonstrou-se equilibrado, pois conforme os dados, 51,82\% do volume total de autores entre os 10 anos pesquisados é do sexo feminino, enquanto 48,18\% são homens.

Contudo, durante o período de 2009-2010, a participação masculina era superior, obtendo participação média de 59,45\%. No entanto, sobretudo em 2013 e 2016 as mulheres apresentaram maioridade no número de participação nas publicações com 67,39\% e 80,00\%, respectivamente.

Ressalta-se que para esta análise considera-se as quantidades totais dos autores, por sexo, que publicaram em cada ano, portanto, a contagem é feita de forma regular, ou seja, foram eliminados as duplicidades de pesquisadores que publicaram no mesmo ano em diferentes eventos para tornar a amostra homogênia no quesito: publicações anuais por sexo.

As pesquisas estatísticas apontadas por Luca et al (2011) relacionadas ao período de 2004 a 2009 nos congressos: ANPCONT, ENANPAD e USP sobre a participação feminina no mundo dos negócios e da academia apontaram que a participação das mulheres era significativamente pequena em relação à participação de autores do gênero masculino e costuma acompanhar o comportamento da quantidade total de autores.

Contudo, sabe-se que as mulheres já representam cerca de $46 \%$ dos profissionais de contabilidade no Brasil (CFC, 2019) e, ao menos, 59\% dos estudantes de Ciências Contábeis são do sexo feminino (ENADE, 2012). Considerando tal perspectiva, a tabela 9 pretende verificar o panorama atual das pesquisas por gênero nos Congressos definidos metodologicamente.

Tabela 9. Volume de publicação dos eventos entre homens e mulheres

\begin{tabular}{|c|c|c|c|c|c|c|}
\multirow{2}{*}{\begin{tabular}{c} 
Congresso \\
\cline { 6 - 7 }
\end{tabular}} & \multicolumn{2}{c|}{ Frequência(n) } & \multicolumn{2}{c}{ Mulheres } & \multicolumn{2}{c|}{ Homens } \\
CBC & 296 & 100,00 & 154 & 52,03 & 142 & 47,97 \\
\hline ENANPAD & 145 & 100,00 & 74 & 51,03 & 71 & 48,97 \\
\hline USP & 37 & 100,00 & 17 & 45,95 & 20 & 54,05 \\
\hline ANPCONT & 55 & 100,00 & 29 & 52,73 & 26 & 47,27 \\
\hline Total & 530 & 100,00 & 274 & 51,41 & 259 & 48,59 \\
\hline
\end{tabular}


Foi identificado 533 diferentes autores dentre os trabalhos da amostra por evento. Destes, 274 são mulheres e 259 homens. Dessa forma, têm-se que 51,41\% dos pesquisadores dos trabalhos publicados são do sexo feminino e $48,59 \%$ do sexo masculino.

Observa-se que a participação por sexo é praticamente uniforme em todos os Congressos, mas os homens são maioria no evento da USP, com $54,05 \%$. As mulheres tem um pouco mais de representatividade nos outros três grandes congressos avaliados, alcançando participação média de 51,93\%.

Ressalta-se que para esta análise foi considerado os dados extraídos sobre a quantidade de autores em cada evento, assim, foram desconsideradas quantidades superiores a um nos casos em que os pesquisadores obtiveram dois ou mais trabalhos publicados no mesmo evento.

Neste contexto, também pretendeu-se verificar através da tabela 10, a participação qualitativa por sexo, ou seja, foi feito uma análise com o objetivo de quantificar o número de pesquisas em que os homens e mulheres aparecem como autores principais e a participação por sexo sobre o total de artigos.

Tabela 10. Participação qualitativa dos autores nos anais

\begin{tabular}{|c|c|c|c|c|c|c|c|}
\hline Legenda & Geral & \multicolumn{3}{|c|}{ Mulheres } & \multicolumn{3}{|c|}{ Homens } \\
\hline Informação & $\begin{array}{l}\text { Total de } \\
\text { Artigos }\end{array}$ & $\begin{array}{c}\text { Autor } \\
\text { Principal }\end{array}$ & $\begin{array}{c}\text { Com } \\
\text { Participação }\end{array}$ & $\begin{array}{c}\text { Sem } \\
\text { Participação }\end{array}$ & $\begin{array}{c}\text { Autor } \\
\text { Principal }\end{array}$ & $\begin{array}{c}\text { Com } \\
\text { Participação }\end{array}$ & $\begin{array}{c}\text { Sem } \\
\text { Participação }\end{array}$ \\
\hline Frequência (n) & 176 & 95 & 141 & 35 & 81 & 130 & 46 \\
\hline Incidência (\%) & $100 \%$ & 53,98 & 80,11 & 19,89 & 46,02 & 73,86 & 26,14 \\
\hline
\end{tabular}

Fonte: Dados da pesquisa (2019)

Assim observa-se que em 53,98\% dos casos, as mulheres apareceram nos artigos como autoras principais, considerando o total de anais publicados nos eventos e enquadrados metodologicamente nessa pesquisa. Os autores de sexo masculino representam $46,02 \%$ do total.

Também têm-se que, em pelo menos $80,11 \%$ dos artigos há alguma mulher entre os autores. Tal como houve a contribuição masculina em $73,86 \%$ dos trabalhos. Diferentemente dos resultados da pesquisa de Luca et al. (2011), os dados atuais não demonstram grandes expressividades das mulheres em relação aos homens na área de pesquisa em contabilidade ambiental.

Salienta-se que os nomes dos autores estão na ordem em que aparecem nas respectivas pesquisas publicadas, portanto, o presente trabalho não realizou alterações e considerou, para os devidos fins, o autor principal dos anais, como o primeiro autor despontado.

\section{CONSIDERAÇÕES FINAIS}

O objetivo desta pesquisa foi analisar uma década de produção científica sobre contabilidade ambiental, no Brasil, e a participação entre homens e mulheres acerca do tema, entre o período de 2009 a 2018, assim como, verificar o foco central das discussões em contabilidade ambiental pelos autores; apresentar os principais autores engajados na temática e suas características acadêmicas; e mapear a diferença na produção científica nos congressos entre homens e mulheres e sua representatividade.

Para tanto, utilizou-se a técnica bibliométrica, com a qual se buscou analisar a produção científica sobre contabilidade ambiental e os termos enquadrados na pesquisa a partir da metodologia validada por Souza et al. (2011).

Os resultados demonstraram que apenas 176 do total de 14.300 artigos se enquadram nos procedimentos metodológicos, ou seja, $1,23 \%$ de toda a produção científica publicada nos congressos referem-se ao tema desta pesquisa. Portanto, se observa que no contexto brasileiro, as pesquisas envolvendo gênero e produção científica ainda é incipiente.

Inclusive, acerca disto, observa-se um decrescimento nas publicações entre 2015 a 2018. Fato contrário ao esperado, sobretudo, por que se esperava um número maior de pesquisas científicas com ênfase ao meio ambiente após os recentes desastres e escândalos coorporativos-ambientais ocorridos no Brasil, sobretudo os eventos dos rompimentos das barragens de Mariana e Brumadinho, em 2015 e 2018, respectivamente. 
Em relação à incidência e evolução do tema identificou-se pouca ocorrência de estudos relacionados à temática no período. Sendo o Congresso Brasileiro de Custos o evento com maior quantidade de pesquisas enquadradas, seguido pelo ENANPAD, que apesar de possuir 50 artigos enquadrados, o volume total de publicações deste congresso é muito alto, fazendo com que a incidência individual seja mais baixa que os demais.

A abordagem metodológica qualitativa possui destaque, sendo a mais utilizada, contudo, os autores também têm optado, sobretudo nos últimos anos pela utilização da metodologia quantitativa ou intercalada.

Apesar de que, relativamente, as mulheres têm publicado mais nos últimos anos, inclusive como autoras principais, representando as redes brasileiras de autoria e coautoria em contabilidade, a diferença frequente nos dados informacionais por gênero é muito pequena, assim, podemos entender que quanto ao número de publicações, redes de autorias e características autorias nas pesquisas em contabilidade ambiental, há uma igualdade de gênero presente.

Dessa forma, conforme Silva, Anzilago e Lucas (2015), os estudos sobre gênero na área devem continuar a ser um assunto substantivo para a comunidade acadêmica contábil, pois a mesma também sente os efeitos. Além deste fato, sugere-se a ampliação dos estudos com o objetivo de promover o desenvolvimento da Contabilidade enquanto ciência e das organizações e seu patrimônio, o seu objeto de estudo, de forma sustentável (CONCEIÇAO, 2013).

Para futuros estudos, sugerem-se ainda pesquisas que fomentem e especifiquem os conteúdos utilizados no referencial teórico juntamente com o exame das abordagens metodológicas, ademais, a continuidade das publicações dos estudos avaliando as redes de pesquisadores na área de contabilidade é fundamental para mapear os principais grupos de pesquisas em diversos temas da ciência contábil.

\section{REFERÊNCIAS}

[1] ANPCONT. Congresso ANPCONT Anteriores. Disponível em: <http://anpcont.org.br/congr esso-anpcontanteriores/>. Acesso em: 24 fev. 2020.

[2] BACHINI, N.; CHICARINO, T. S. Os métodos quantitativos, por cientistas sociais brasileiros: entrevistas com Nelson do Valle Silva e Jerônimo Muniz. Revista Sociedade e Estado, vol. 33, num. 1, Janeiro/Abril, 2018.

[3] BRUMATI, D. N. Contabilidade da gestão ambiental: ativos e passivos ambientais em empresas, em Alta Floresta/MT em 2014-2015. Rev. Faculdade Alta Floresta, v. 2, n. 4, 2015.

[4] CASTRO, M. G.; ABRAMOVAY, M. Gênero e Meio Ambiente. UNESCO, Editora Cortez, São Paulo: 2005.

[5] CHAMON, M. Trajetória de Feminização do Magistério: ambiguidades e conflitos. Belo Horizonte: Ed. Autêntica, 2005.

[6] CONCEIÇÃO, M. G. A influência dos fatores contingenciais no sistema de controle de gestão de resíduos sólidos das empresas baianas do setor de transformação industrial. Dissertação (Mestrado). Salvador - BA. 2013.

[7] CONCEIÇÃO, M. G.; FERREIRA, A. S.; GOMES, S. M. S.; RIBEIRO, R. J. Perfil e evolução da pesquisa em gestão de resíduos sólidos: uma análise bibliométrica. In: $20^{\circ} \mathrm{CBC}$, Fortaleza, 2016.

[8] CONSELHO FEDERAL DE CONTABILIDADE. Dados estatísticos. 2019. Disponível em: <https://cfc.org.br/registro/quantos-somos-2/>. Acesso em: 11 jul. 2019.

[9] EXAME NACIONAL DE DESEMPENHO DE ESTUDANTES. Relatório Síntese do curso de Ciências Contábeis. 2012. Disponível em: <http://download.inep.gov.br/educacao_superio r/enade/relatorio_sintese/2012/2012_rel_ciencias_contabeis.pdf>. Acesso: 11 jul. 2019.

[10] FERREIRA, A. S.; CONCEIÇÃO, M. G.; GOMES, S. M. S.; RIBEIRO, L. W. S.; RIBEIRO, R. J. Perfil e evolução da pesquisa em gestão de resíduos sólidos: uma análise bibliométrica. ReACFAT, v. 10, n², 2018.

[11] FREITAS, D. P. S. et al. Contabilidade ambiental: um estudo bibliométrico em revistas científicas brasileiras. Revista Ambiente Contábil, v. 4. n. 1, p. 72 - 88, jan./jun. 2012.

[12] GARCIA, S. M. Desfazendo os vínculos naturais entre gênero e meio ambiente. Estudos Feministas, n 92, p. 163-167, 1992.

[13] GERHARDT, T. E.; SILVEIRA, D. T. Métodos de pesquisa. Porto Alegre: Editora da UFRGS, 2009.

[14] GIL, A.C. Métodos e técnicas de pesquisa social. 6. ed. São Paulo: Atlas, 2010.

[15] GOMES, S. M. S. et al. Controladoria ambiental: gestão social, análise e controle. Atlas, São Paulo. 2013. 
[16] HAGUETTE, T. M. F. Metodologia qualitativa na sociologia. Petrópolis: Vozes, 2018.

[17] INSTITUTO ETHOS. Perfil social, racial e de gênero das 500 maiores empresas do Brasil e suas ações afirmativas. Bid: São Paulo, 2016.

[18] IUDICIBUS, S. Teoria da contabilidade. 11aㅡ Ed., São Paulo: Atlas, 2015.

[19] IUDICIBUS, S.; MARION, J. C.; FARIA, A. C. Introdução a teoria da contabilidade: para graduação. 6⿳a ed., São Paulo: Atlas, 2017.

[20] KOUlOUKOUI, D.; MARINHO, M. M. O.; GOMES, S. M. S.; KIPERSTOK, A.; TORRES, E. A. Estudo Bibliométrico sobre Disclosure Ambiental, Mudança Climática e Risco Climático: Periódicos Indexados na Scopus de 1982 a 2017. ReACFAT, vol. 10, $n^{\circ} .1$, p. 71-92, jan/abr, 2018.

[21] LUCA, M. M. M.; GOMES, C. A. S.; CORRÊA, D. M. M. C.; DOMINGOS, S. R. M. Participação Feminina na Produção Científica em Contabilidade Publicada nos Anais dos Eventos EnANPAD, Congresso USP de Controladoria e Contabilidade e Congresso Anpcont. Revista de Contabilidade e Organizações, vol. 5, n. 11, p. 145-164, 2011.

[22] MARCONDES, N. A.; CAMPOS, J. C. Contabilidade Ambiental. INIC 2005 - IX Encontro Latino Americano de Iniciação Científica. Anais... INIC, 2005.

[23] OLIVEIRA, R. A.; PEREIRA, L. F. Contabilidade ambiental: pesquisa sobre a importância do tema para o setor contábil. Revista de Contabilidade Dom Alberto, v. 1, n. 6, dez. 2014.

[24] OLIVERIA, M. R. C.; RIBEIRO, H. C. M. Um estudo bibliométrico na revista brasileira de contabilidade (RBC) de 2007 a 2011. GeCont, v.2, n. 1, Floriano-PI, Jan-Jun. 2015.

[25] ORTNER, S. Is Male to Female as Nature is to Culture?, In: Woman, Culture and Society. Editado por M. Z. Rosaldo e L. Lamphere. Stanford: Stanford University Press, 1974.

[26] RIBEIRO, M. S. Contabilidade Ambiental. São Paulo: Saraiva, 2010.

[27] RIBEIRO, V. C.; FERREIRA, E. A.; LYRA, J. R. M.; SANTOS, E. J.; SOUSA, J. G. Contabilidade ambiental: visão teórica, definição e tendências. Rev. FACIT, v. 1, n. 1, p 136-142, 2017.

[28] SALLEH, A. K. Deeper than Deep Ecology: The Eco-Feminist Connection. Environmental Ethics, v. 16, Winter, 1984.

[29] SANTOS, A. O.; SILVA, F. B.; SOUZA, S.; SOUSA, M. F. R. Contabilidade ambiental: um estudo sobre sua aplicabilidade em empresas Brasileiras. Rev. Contab. Finanç. vol.12, no. 27, São Paulo, Set./dez., 2001.

[30] SILVA, A. R.; CRUZ, C. V. O. A. A importância da Contabilidade Ambiental no mundo globalizado. Revista Unopar Cient., Ciênc. Juríd. Empres, v. 8, p. 81-87, Set. 2007.

[31] SILVA, C. M.; PEREIRA, V. H.; SILVA, J. R.; VALADARES, J. P. A. Análise das produções científicas sobre Contabilidade Ambiental publicadas nos Anais do Congresso ANPCONT, Congresso USP em Controladoria e Congresso Brasileiro de Contabilidade, no período de 2008 a 2015. RAGC, v.5, n.19, p.45-60, 2017.

[32] SILVA, C. N.; ANZILAGO, M.; LUCAS, A. C. A Mulher Contabilista nas Publicações Acadêmicas Brasileiras. In: XV Congresso USP de Controladoria e Contabilidade, SP, 2015.

[33] SILVA, C. R. M.; LIMA, D. S. V. R.; FARIAS, I. F.; OLIVERA, L. V. C. Produção científica sobre gestão ambiental no brasil: um estudo bibliométrico e de redes de coautoria. Rev. Gest. Sust. Ambient., Florianópolis, v. 7, n. 2, p.426-451, abr./jun. 2018.

[34] SILVA, I. C.; PEREIRA, A. C. T.; PESTANA, C. S.; SANTOS, F. H. G.; GARCIA, H. C.; SILVA, Stella L. A. A Contabilidade como instrumento de auxilio no controle do meio ambiente. Colloquium Humanarum, v. 10, n. Especial, p. 546-552, Jul./Dez. 2013.

[35] SOUZA, M. T. S.; RIBEIRO, H. C. M.; JUNIOR, C. M.; CORRÊA, R. Perfil e Evolução da Pesquisa em Sustentabilidade Ambiental: uma Análise Bibliométrica. In: XXXV EnANPAD, Rio de Janeiro, 2011.

[36] SUBRAMANYAM, K. Bibliometric studies of research collaboration: A review. Journal of information Science, v. 6, n. 1, p. 33. CILIP, 1983.

[37] TINOCO, E. P.; KRAEMER, M. P. Contabilidade e gestão ambiental. 3. ed. São Paulo: Atlas, 2011.

[38] VELLANI, C. L.; RIBEIRO, M. S. Sustentabilidade e contabilidade. Revista Contemporânea de Contabilidade, Florianópolis, v.1, n¹1, p. 187-206, Jan./Jun. 2009.

[39] VERONEZE, M. V.; SILVA, V. A.; OLIVEIRA, F. A; NUNES, E. S.; ROCHA, M. A. Percepção dos profissionais contábeis sobre a importância da contabilidade ambiental. Revista UNEMAT de Contabilidade, vol. 5, n. 10, Jul./Dez. 2016. 
[40] WELTER, A. L.; SANTANA, A. F. B. Contabilidade ambiental: a realização e a evidenciação contábil de ações ambientais pelas empresas moveleiras associadas à SIMOVALE/AMOESC - MEF17567 - IR. Revista Brasileira de Contabilidade, $\mathrm{n}^{\circ} 187,2011$.

[41] YAMAGUCHI, C. K. Contabilidade ambiental e o compromisso das organizações com a responsabilidade ambiental. IX Congresso Virtual Brasileiro de Administração. Anais... $9^{\circ}$ Convibra. 2011.

[42] ZILBER, S. N.; CARUZZO, M.; CAMPANÁRIO, M. A. Uso de contabilidade ambiental e seus reflexos nos resultados das empresas. Revista Alcance, v. 18, n. 1, Jan-Mar, 2011. 


\section{Capítulo 4}

Educação a distância e a análise da tutoria no processo de aprendizagem dos cursos de Administração

\section{Luciane Silva Franco \\ Monika Fritz \\ Sonia Luíza Bernet da Luz \\ Evelin Cristina de Goes}

Resumo: A educação a distância (EaD) é uma modalidade de ensino e aprendizagem que tem tido um crescimento rápido, uma vez que possibilita maior flexibilidade de tempo e espaço para aperfeiçoamento e aquisição de conhecimentos. Nos cursos de Administração destaca-se que a prática da tutoria torna-se parte de uma equipe colaborativa de sucesso, permitindo aos alunos que se envolvam efetivamente no processo de aprendizagem e possa ser útil na vida profissional como futuro Administrador. Este artigo tem como objetivo avaliar a prática da tutoria e a aprendizagem do aluno em cursos de Administração na modalidade de educação a distância. Para tanto, foi realizada uma revisão sistemática de literatura por meio da Methodi Ordinatio. Os softwares Mendeleye JabRef foram usados para gerenciamento de referência. Conclui-se que é importante a formação continuada para os ProfessoresTutores do curso de Administração. Além de atuar com mediador no processo de aprendizagem dos alunos, o Professor-Tutor de cursos de Administração necessita de competências que dependem não apenas do conhecimento técnico da profissão, mas principalmente de habilidades interpessoais. Desta forma, a mediação do ProfessorTutor é essencial para que os alunos permaneçam e finalizem os cursos com excelente nível de aprendizagem.

Palavras-chave: Educação a Distância; Qualificação; Administrador; Professor-Tutor. 


\section{INTRODUÇÃO}

A educação a distância (EaD) é uma modalidade de ensino e aprendizagem mediada por tecnologias de informação e comunicação em que professores e alunos estão separados espacial e/ou temporalmente. Tem tido um crescimento rápido, uma vez que possibilita maior flexibilidade de tempo e espaço para aperfeiçoamento e aquisição de conhecimentos.

A EaD acontece além dos limites de uma sala de aula convencional, havendo necessidade de novas habilidades na interação e na relação dialógica entre professor e aluno. Segundo Oblinger (2006) os recursos tecnológicos contribuem para redefinir os espaços de aprendizagem. Para o autor, a interatividade no desenvolvimento das atividades é um fenômeno importante, que precisa ser bem compreendido e ocorre de forma colaborativa e centrada no aluno.

É necessário considerar que a educação a distância é, em sua maioria, dirigida a pessoas adultas, geralmente a profissionais que se veem impulsionados a continuar sua formação, em virtude das exigências impostas pelo mercado de trabalho, que vem requerendo habilidades e competências a fim de atender as demandas de uma sociedade que tem como característica as mudanças aceleradas, levando os profissionais a enfrentarem situações diferentes a cadamomento (Saggiomo \& Pereira, 2019).

Atualmente, segundo dados do Instituto Semesp, o curso de Administração é o segundo mais procurado no Brasil na modalidade de educação a distância (rede privada), com 251.495 matrículas em 2021. A pesquisa mostra que desde 2017 a 2020 o curso de Administração é o quarto no Brasil mais buscado na internet, ficando atrás de Direito, Medicina e Psicologia (Semesp, 2021). Iniciar um curso de Administração na modalidade à distância, tornou-se cada vez mais frequente para muitos alunos que trabalham (Barboza-Robles, 2021). Ter aulas neste formato permite que as pessoas equilibrem sua vida profissional e familiar com a educação. Desta forma, o papel da tutoria é fundamental para proporcinar o apoio que o aluno necessita, aliado a flexibilidade que permite que os alunos trabalhem em seu próprio tempo (Martins, Terçariol \& Gebra, 2015).

A colaboração e a mediação da tutoria com os alunos são alcançados com o uso de habilidades de comunicação, planejamento e gestão, que são essenciais para o trabalho em equipe (Martins, Terçariol \& Gebra, 2015). Como resultado, os alunos buscam contribuições e esclarecimentos, motivando uns aos outros. Portanto, nos cursos de Administração destaca-se que a prática da tutoria torna-se parte de uma equipe colaborativa de sucesso, permitindo aos alunos que se envolvam efetivamente no processo de aprendizagem e possa ser útil na vida profissional como futuro Administrador (Barboza-Robles, 2021).

Conforme o presente contexto, o estudo apresenta o seguinte problema de pesquisa: como a prática da tutoria impacta na aprendizagem do aluno em cursos de Administração na modalidade de educação a distância? Baseando-se nessa problemática aplicada a um contexto específico, esta revisão sistemática de literatura teve como objetivo avaliar a prática da tutoria e a aprendizagem do aluno em cursos de Administração na modalidade de educação a distância. Para melhor compreensão, apresenta-se inicialmente o referencial teórico e na sequência é exposta a metodologia utilizada na realização da pesquisa, seguida pelos principais resultados e discussões, os quais levaram às considerações finais do estudo.

\section{O PAPEL DO PROFESSOR-TUTOR NA EAD}

Atualmente, a educação na modalidade a distância está em constante expansão. A educação é a necessidade básica do ser humano, sem a qual é altamente desafiador constriuir uma carreira profissional. Aulas online foram iniciadas a fim de tornar a educação mais acessível para o aluno que não têm condições de acompanhar as aulas presencialmente nas instituições para aprender (Barboza-Robles, 2021).

Nesta modalidade de ensino, Lévy (1999, p.58) denomina o professor como sendo "animador da inteligência coletiva".

A EaD explora certas técnicas de ensino a distância, incluindo as hipermídias, as redes de comunicação interativas e todas as tecnologias intelectuais da cibercultura. Mas, o essencial se encontra em um novo estilo de pedagogia, que favorece ao mesmo tempo as aprendizagens personalizadas e a aprendizagem coletiva em rede. Neste contexto, o professor é incentivado a tornar-se um animador da inteligência coletiva de seus grupos de alunos em vez de um fornecedor direto de conhecimentos.(LÉVY, 1999, p.58). 
De acordo com Franco et al. (2021), o papel do professor é considerado representativo para executar os objetivos da instituição e o seu desempenho impacta diretamente no aprendizado do aluno. Conforme Shelley et. al (2006) e Guldberg e Pilkingyon (2007), o professor deve oferecer condições para o debate amigável e construtivo diminuindo assim o sentimento de isolamento comum em cursos a distância, com o estabelecimento de regras para a colaboração e o encorajamento dos alunos para que participem e desenvolvam sua autonomia no processo ensino e aprendizagem. Desta forma, o Professor-Tutor atua como facilitador, guia, mentor, responsável por dar feedback e provedor de recursos.

Nos cursos à distância, o Professor-Tutor exerce um papel fundamental, atuando como mediador no processo de aprendizagem dos alunos. Borges e Fontana (2003) defendem que cabe ao Professor-Tutor o papel de acompanhar e orientar os alunos na busca constante pelo saber, proporcionando condições para que o aluno possa construir sua própria aprendizagem, por meio de sua autonomia e independência.

Neste contexto, a afetividade passa a ser uma das habilidades importantes na prática da tutoria. Para Longhi, Behar e Bercht (2009), as pesquisas sobre afetividade na educação a distância estão ainda em fase de exploração. Quando o processo está acontecendo a distância eé mediado pela Internet, deve ser feito por professores/mediadores com disposição e habilidade para construir laços de confiança. O ProfessorTutor deve ser o mediador que propicia de forma colaborativa a construção de conhecimentos significativos para cada um e para o grupo, independente do suporte tecnológico.

Entre as atribuições destacadas por Longhi, Behar e Bercht (2009) estão: incentivar a comunicação e a interação entre os participantes para potencializar a troca de experiências; propor ideias e lançar temas para debate; qualificar o debate e fortalecer o desenvolvimento do espírito crítico; perceber as necessidades do grupo; fazer com que todos se sintam envolvidos e pertencentes ao espaço; sistematizar conteúdo de debate, compondo um produto final a ser oferecido para os participantes; acompanhar e avaliar constantemente a participação dos componentes do grupo; bem como auxiliar os participantes em questões técnicas.

Na educação a distância os papéis do professor se multiplicam, diferenciam e complementam, exigindo uma grande capacidade de adaptação, de criatividade diante de novas situações, propostas e atividades. 0 professor que até pouco tempo atuava somente em salas de aula presenciais, na qual "expunha conteúdos", no contexto atual passa a se deparar com a possibilidade de transcender as "informações fechadas" em blocos, para caminhar livremente em um ambiente próprio para que professor e aluno revejam a posição de emissor-receptor informacional (Barboza-Robles, 2021; Moran, 2000).

É importante salientar que o Professor-Tutor deve ter na formação pessoal a capacidade de lidar com o heterogêneo quadro de alunos e ser possuidor de atributos psicológicos e éticos, maturidade emocional, empatia com os alunos, habilidades de mediar questões, liderança, cordialidade e capacidade de ouvir. Para tanto se torna fundamental sua capacidade de promover a interação com e entre os alunos e turmas, tema que será abordado a seguir.

\subsection{O PROCESSO DE COMUNICAÇÃO NA EDUCAÇÃO A DISTÂNCIA}

A comunicação na educação a distância ocorre basicamente em ambientes virtuais de aprendizagem por meio das ferramentas tecnológicas. Paulo Freire (2001) conceitua a comunicação como um diálogo, na medida em que não é transformação do saber, mas um encontro de sujeitos interlocutores que buscam a significação dos significados, e nesse sentido, a relação dialógica é indispensável ao ato do conhecimento. 0 autor defende que o diálogo na relação pedagógica, reforça a sua defesa da relação ensino e aprendizagem como um processo de busca e troca de saberes permanentes, sem que isso implique em descaracterizar o rigor teórico que deve permear o ato educativo.

Moore e Kearsley (2013) informam que a interação que ocorre no ensino a distância deve ser vista como um fenômeno pedagógico e não simplesmente como uma mera questão de distância geográfica. A distância física conduz a um hiato na comunicação, um espaço psicológico de concepções errôneas potenciais entre instrutores e alunos, que precisa ser suplantado por técnicas especiais de ensino. A superação da distância se dá por meio de procedimentos diferenciadores na elaboração da instrução e na facilitação da interação.

Conforme a análise de Freire (2001), a relação dialógica cria um clima que possibilita um processo de avaliação e autoavaliação da aprendizagem dos alunos sem traumas e bloqueios, permitindo assim a comunicação livre, clara e precisa. 0 diálogo na educação a distância refere-se à interação linguística direta e indireta que acontece entre professores-tutores e alunos, tornando-se componente essencial do 
aspecto social da aprendizagem.

Segundo Moore e Kearsley (2013) não basta o desenvolvimento de métodos diferenciados ou técnicas inovadoras se não são consideradas as particularidades, tanto do público-alvo ao qual o curso atende e/ou se destina, quanto das características peculiares dos elementos. Freire (2001) conceitua a comunicação como um diálogo, na medida em que não é transformação do saber, mas um encontro de sujeitos interlocutores que buscam a significação dos significados, e nesse sentido, a relação dialógica é indispensável ao ato do conhecimento. 0 autor defende que o diálogo na relação pedagógica, reforça a sua defesa da relação ensino-aprendizagem como um processo de busca e troca de saberes permanentes, sem que isso implique em descaracterizar o rigor teórico que deve permear o ato educativo.

\subsection{A MEDIAÇÃO DO PROFESSOR-TUTOR NOS CURSOS DE ADMINISTRAÇÃO}

Zuhairi, Adnan e Thaib (2007), definem o curso de Administração como um programa de estudos em uma faculdade ou universidade que fornece um conhecimento geral dos princípios e práticas de negócios. A taxa de evasão em cursos EaD de Administração registrou 36,5\% em 2021 no Brasil (Semesp, 2021). Isso ressalta a importância da atuação do professo-tutor frentea mediação com os alunos, que influencia na evasão ou sucesso do aluno. Desta forma, a tutoria precisa ser considerada como um dos fatores na evsão do aluno nos curso de EaD (Martins, Terçariol \& Gebra, 2015).

Destaca-se que a Administração de Empresas é uma área de estudo diversa, sendo assim, os alunos com conhecimentos adquiridos e habilidades desenvolvidas nesta área precisam estar aptos a atuarem em uma variedade de áreas de trabalho, desde Finanças e Gerenciamento até Produção e Logística (BarbozaRobles, 2021).

Em sua essência, os programas de graduação em Administração enfocam muitos aspectos da gestão de uma empresa e suas pessoas e processos. Sendo assim, na Administração, o Professor-Tutor precisa vivenciar as mudanças nas ações estabelecidas entre o mercado e os sujeitos participantes do ato educativo em sala de aula digital. 0 desenvolvimento do processode aprendizagem precisa estabalecer um ambiente apto para a interação entre o aluno e o Professor-Tutor (Bittencourt \& Mercado, 2014).

A literatura sobre educação a distância concentra-se principalmente em sua eficácia geral como uma ferramenta para apoiar a educação e a satisfação dos alunos (Tumbo, 2018). Em algumas disciplinas técnicas do curso de Administração, tais como Gestão de Projetos e Administração da Produção, que exigem trabalho sistemático, a abordagem de educação a distância pode ser pouco eficaz se houver falta de mediação por parte do Professor-Tutor, poisfica aquém da suficiência em termos de interação (BarbozaRobles, 2021; Chiu et al., 2008).

Por outro lado, Cantino, Denicolai e Parola (2018) constataram que os alunos a distância são mais preparados e ativos no que se refere a fazer perguntas do que seus colegas participantes de aulas presenciais, facitando o aprendizado em disciplinas comportamentais, tais como Comunicação Empresarial e Gestão de Recursos Humanos. Os alunos que aprendem remotamente também percebem o trabalho em grupo como mais satisfatório e consideram o processo de comunicação e a tomada de decisão mais eficaz.

De acordo com Zuhairi, Adnan e Thaib (2007), o Professor-Tutor precisa incentivar nos alunos a autonomia na aprendizagem individualizada, para que os mesmos sejam mais responsáveis pelo processo de aprendizagem. Portanto, na abordagem EaD, o Professor-Tutor que desenvolve atuação eficaz, é aquele que promove a aprendizagem centrada e prepara o aluno para a autoaprendizagem permanente, importante para o desenvolvimento profissional ea mobilidade no mercado de trabalho do Administrador.

Além de atuar com mediador no processo de aprendizagem dos alunos, o Professor-Tutor de cursos de Administração necessita de habilidades bem estabelecidas para se adaptar a várias áreas, como Marketing, Recursos Humanos, Gestão Financeira e Sustentabilidade. Percebe-se que, cada vez mais que as competências do Professor-Tutor dependem não apenas do conhecimento técnico da profissão, mas principalmente de soft skills, ou seja, habilidades interpessoais (Martins, Terçariol \& Gebra, 2015; Mendes et al., 2014).

Chiu et al., (2008) destacam que habilidades interpessoais, humanas, pessoais ou comportamentais são necessárias para aplicar habilidades técnicas e conhecimentos no localde trabalho. Martins, Terçariol e Gebra (2015) ressaltam que o Professor-Tutor pode ser excelente com habilidades técnicas específicas, mas se não desenvolve habilidades como a afetividade, gestão do tempo, comunicação e debates, pode não ter sucesso na mediação com os alunos. 
$\mathrm{Na}$ área da Administração, as habilidades interpessoais na mediação professor e aluno, impactam positivamente no processo de formação. Visto que um Administrador precisa desenvolver habilidades de comunicação, o compartilhamento de conhecimentos e experiências com outras pessoas e a cultura organizacional, considerados particularmente importantes no campo da Administração e possibilita formar um profissional apto a desenvolver relacionamentos com clientes, colegas e superiores (Cantino, Denicolai \& Parola, 2018).

Em função do isolamento que ocorre na educação a distância, é fundamental a mediação do ProfessorTutor nas discussões em grupo nos fóruns dedicados em plataformas online, onde asideias dos alunos são compartilhadas e discutidas, podendo influenciar positivamente a colaboração em um projeto, desenvolver o envolvimento dos alunos e melhorar seu desempenho acadêmico (Bittencourt \& Mercado, 2014).

Os fóruns online e grupos de discussão para alunos e Professores-Tutores também são representantivos para o desenvolvimento de competências como comunicação, o trabalho em grupo e habilidades de resolução de problemas. 0 avanço constante da educação a distância ea tecnologia geraram expectativas de que os Professores-Tutores devem demonstrar competências adicionais dada às capacidades e habilidades que permitem fazer o uso bem sucedido do conhecimento adquirido por meio da educação (Martins, Terçariol \& Gebra, 2015).

O sucesso da formação do Administrador exige do Professor-Tutor a inovação. A lacuna de confiança entre os alunos e a tutoria é devido à falta de comunicações consistentes (Barboza- Robles, 2021). Na área do empreendedorismo, por exemplo, cabe ao Professor-Tutor dar o suporte com feedbacks de atividades realizadas pelos alunos, tais como o plano de negócio e pesquisas de mercado. 0 empreendedorismo é fundamental na formação do aluno, visto que muitas pessoas desejam estudar Administração não para entrar no mundo corporativo, mas porque desejam iniciar seu próprio negócio ou contribuir com uma capacidade maior para uma empresa familiar. Na área de formação do empreendedorismo, o ProfessorTutor precisa mediar à inovação e dar o suporte para aprimorar a aprendizagem em tópicos como conceitos de negócios, planejamento de sucessão, finanças e marketing (Cantino, Denicolai \& Parola, 2018; Mendes et al., 2014).

\section{METODOLOGIA DE PESQUISA}

Para realizar esta revisão sistemática de literatura na seleção de artigos de alto impacto, foi utilizado o Methodi Ordinatio para construção do portfólio de estudo (Pagani, Kovaleski \& Resende, 2015). A pesquisa utilizou as bases de dados ERIC, Periódicos Capes, Scopus e Webof Science para pesquisar artigos.

Para a busca nas bases de dados foi definido um conjunto de palavras-chave e utilizaram-se símbolos de truncagem e operadores booleanos, sendo realizada a busca em junho de 2021. Nenhum recorte temporal foi definido e foram aplicados como critérios de busca somente artigos e artigos de revisão, eliminando livros e capítulos de livros.

Os softwares Mendeley $\AA^{\circledR}$, Jabref® e Excel® foram utilizados para organizar e agrupar os artigos importados das bases de dados. Em seguida, uma série de filtros foi aplicada ao portfólio bruto para a seleção dos artigos mais relevantes a serem avaliados de forma integral (Figura 1). 
Figura 1 - Resultados da pesquisa dos artigos nas bases de dados

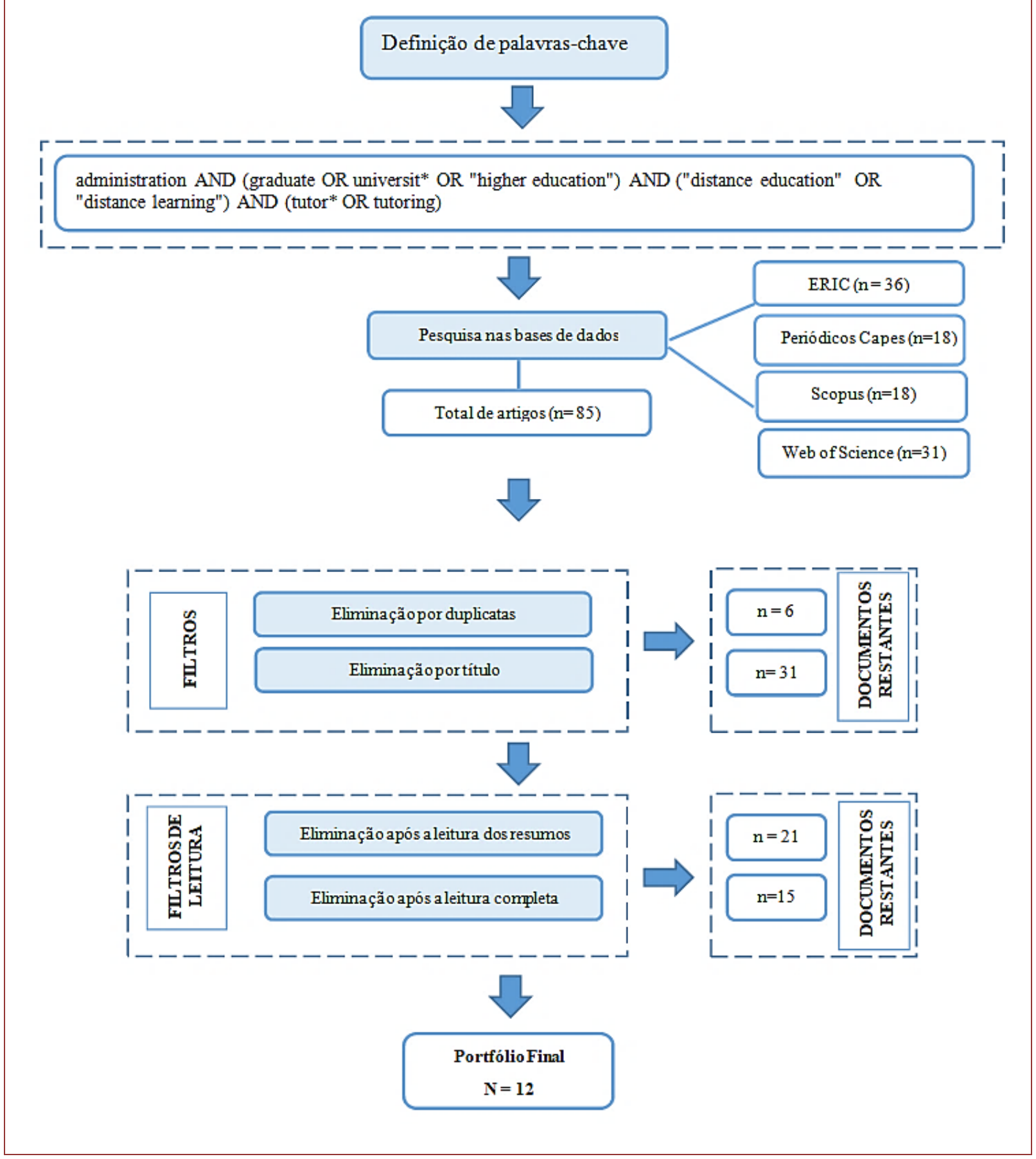


Após pesquisar as bases de dados, 85 artigos foram encontrados (conforme a Figura 1). Um total de 6 artigos duplicados foram eliminados, sendo assim, dos 85 permaneceram 79. Com a realização do filtro por títulos, alguns estudos sobre educação na modalidade presencial por não se enquadrarem no tema proposto já foram eliminados e, portanto, restaram 48. Outro filtro por resumo foi aplicado, e após a leitura dos resumos foram identificados estudos sobre tutoria de cursos não relacionados à área de Gestão, Négocios e Administração, portanto, mais 21 estudos foram eliminados, restando assim 27 artigos. Após a leitura integral, os autores analisaram que um total de 15 artigos não correspondia ao tema de comportamento organizacional, tendo como objeto de estudo a área de tecnologia na educação. Desta forma, após a exclusão dos mesmos, o portfólio final foi de 12 artigos.

Aplicou-se a Equação (1) para calcular o Index Ordinatio (InOrdinatio), o qual ajuda a ponderar o número de citações (CI) e o fator de impacto (FI) de cada artigo, e assim estimar a relevância para o estudo. Os artigos do portfólio final foram colocados e classificados na equação InOrdinatio. Para o fator de impacto (FI), foram utilizados os relatórios de citaçõesde periódicos (CiteScore - 2020). Para o número de citações (CI) foi utilizado com base o Google Scholar em julho de 2021.

O coeficiente InOrdinatio também relaciona o ano de publicação e solicita uma pontuação $(\alpha)$ que o autor pode atribuir entre 1 e 10, onde quanto mais próximo de 10 considera-se a importância da atualidade dos artigos com relação ao ano de publicação. Os autores optaram pelo escore 5, já que proporciona um equilíbrio no tempo, uma vez que o estudo não limitou recorte temporal. Para os 12 artigos, a seguinte fórmula foi utilizada:

$$
\text { InOrdinatio }=(\text { If } / 1000)+\alpha *[10-(\text { YearPesq }- \text { YearPub })]+\left(\sum \mathrm{Ci}\right)
$$

Onde:

Fi: fator de impacto periódico;

$\alpha$ : Coeficiente atribuído pelo pesquisador;YearPesq: Ano da pesquisa;

YearPub: Ano de publicação do artigo; e

Ci: número de citação do artigo em outros estudos.

Nenhum artigo foi excluído nessa etapa, pois com a aplicação da equação, não houve o retorno de nenhum artigo com índice negativo. O software VOSviewer foi utilizado para construção de um mapa visual, baseando-se em dados de texto dos títulos e resumos dos artigos extraídos do corpo de literatura (Van Eck \& Waltman, 2009).

\section{RESULTADOS E DISCUSSÃO}

Para realizar a análise, a Tabela 1 mostra características das categorias usadas na seleção dos artigos e o coeficiente InOrdinatio. A Tabela 1 é ordenada conforme a classificação determinada pela fórmula InOrdinatio. 
Tabela 1 - Portfólio final da revisão sistemática

\begin{tabular}{|c|c|c|c|c|c|c|c|}
\hline ID & Artigo & Ano & Periódico & $\mathrm{Ci}$ & $\mathrm{Fi}$ & InOrdinatio & Referência \\
\hline 1 & $\begin{array}{l}\text { Digital competence: analysis in teaching } \\
\text { staff of the School ofAdministration } \\
\text { Sciences of the UNED of Costa Rica }\end{array}$ & 2021 & $\begin{array}{l}\text { Revista electronica } \\
\text { calidad en la educacion } \\
\text { superior }\end{array}$ & 0 & 0 & 50 & $\begin{array}{l}\text { Barboza- } \\
\text { Robles (2021) }\end{array}$ \\
\hline 2 & $\begin{array}{l}\text { Analyzing learners behavior and } \\
\text { resources effectiveness in a } \\
\text { distancelearning course: A case study of } \\
\text { theHellenic Open University }\end{array}$ & 2019 & $\begin{array}{l}\text { Journal of Information } \\
\text { ScienceTheory and } \\
\text { Practice }\end{array}$ & 4 & 1 & 44 & \begin{tabular}{|l} 
Alachiotis, \\
Stavropoulose \\
Verykios(2019)
\end{tabular} \\
\hline 3 & $\begin{array}{l}\text { Learners' satisfaction level with online } \\
\text { sutdent portal as a support system inan } \\
\text { open and distance elearningenvironment } \\
\text { (ODeL) }\end{array}$ & 2015 & $\begin{array}{l}\text { Turkish Online Journal } \\
\text { of DistanceEducation }\end{array}$ & 21 & 2,2 & 41 & $\begin{array}{l}\text { Secreto e } \\
\text { Pamulaklakin } \\
(2015)\end{array}$ \\
\hline 4 & $\begin{array}{l}\text { Continuing education in de: reflections of } \\
\text { the tutor professor in aformative process }\end{array}$ & 2019 & $\begin{array}{l}\text { Brazilian Journal of } \\
\text { Education, Technology } \\
\text { and Societ }\end{array}$ & 0 & 0 & 40 & $\begin{array}{l}\text { Saggiomo e } \\
\text { Pereira (2019) }\end{array}$ \\
\hline 5 & $\begin{array}{l}\text { Digital technologies in higher education at } \\
\text { distance: mapping anduse by the tutors at } \\
\text { the pedagogicaluniversity of Mozambique }\end{array}$ & 2018 & $\begin{array}{l}\text { Brazilian Journal of } \\
\text { Education, Technology } \\
\text { and Societ }\end{array}$ & 1 & 0 & 36 & Tumbo(2018) \\
\hline 6 & $\begin{array}{l}\text { Using videos and multimedia tools in e- } \\
\text { learning experience of the business } \\
\text { administration bachelor at the } \\
\text { department of management (universityof } \\
\text { turin, Italy) }\end{array}$ & 2018 & $\begin{array}{l}\text { 11th International } \\
\text { Conference of } \\
\text { Education, Research } \\
\text { and Innovation }\end{array}$ & 0 & 0 & 35 & $\begin{array}{l}\text { Cantino, } \\
\text { Denicolai e } \\
\text { Parola (2018) }\end{array}$ \\
\hline 7 & $\begin{array}{l}\text { Conceptual maps for training tutors inthe } \\
\text { distance learning of business } \\
\text { administration course }\end{array}$ & 2014 & $\begin{array}{l}\text { International Journalon } \\
\text { E-Learning: Corporate, } \\
\text { Government, } \\
\text { Healthcare, andHigher } \\
\text { Education }\end{array}$ & 6 & 1,2 & 21 & $\begin{array}{l}\text { Mendes etal., } \\
(2014)\end{array}$ \\
\hline 8 & $\begin{array}{l}\text { Perceptions of the tutor: studentevasion } \\
\text { in a distance business administration } \\
\text { course }\end{array}$ & 2015 & $\begin{array}{l}\text { Revista Eletronica } \\
\text { Pesquiseduca }\end{array}$ & 0 & 0 & 20 & $\begin{array}{l}\text { Martins, } \\
\text { Terçariol e } \\
\text { Gebra }(2015)\end{array}$ \\
\hline 9 & $\begin{array}{l}\text { Dropout in courses in distance education: } \\
\text { Case study of the UFAL/UAB's pilot } \\
\text { administrationdistance education course }\end{array}$ & 2014 & Ensaio & 0 & 1,2 & 15 & $\begin{array}{l}\text { Bittencourt e } \\
\text { Mercado } \\
\text { (2014) }\end{array}$ \\
\hline 10 & $\begin{array}{l}\text { Towards ubiquitous communication } \\
\text { support for distance education withalert } \\
\text { management }\end{array}$ & 2008 & $\begin{array}{l}\text { Educational } \\
\text { Technology \&Society }\end{array}$ & 25 & 7,2 & 10 & $\begin{array}{l}\text { Chiu et al., } \\
(2008)\end{array}$ \\
\hline 11 & $\begin{array}{l}\text { A contribution to the Hellenic Open } \\
\text { University: Evaluation of the pedagogical } \\
\text { practices and the use ofICT on distance } \\
\text { education }\end{array}$ & 2008 & $\begin{array}{l}\text { International Reviewof } \\
\text { Research in Openand } \\
\text { Distance Learning }\end{array}$ & 21 & 5,8 & 6 & $\begin{array}{l}\text { Koustouraki, } \\
\text { Panagiotako } \\
\text { poulos, e } \\
\text { Vergidis(2008) }\end{array}$ \\
\hline 12 & $\begin{array}{l}\text { Provision of student learning support } \\
\text { services in a large-scale distance } \\
\text { education system at universitasTerbuka, } \\
\text { Indonesia }\end{array}$ & 2007 & $\begin{array}{l}\text { Turkish Online Journal } \\
\text { of DistanceEducation }\end{array}$ & 22 & 2,2 & 2 & $\begin{array}{l}\text { Zuhairi, Adnan } \\
\text { e Thaib (2007) }\end{array}$ \\
\hline
\end{tabular}

Os resultados são apresentados conforme o portfólio final dos 12 artigos de alto impacto, após terem passado pelos critérios no processo de seleção descritos na metodologia. Com a utilização de dados de texto, um mapa visual foi construído considerando título e resumo, método de contagem completa, com número mínimo de 4 ocorrências, sendo assim 36 termos de um total de 552 atenderam aos critérios, conforme apresentado na Figura 2. 


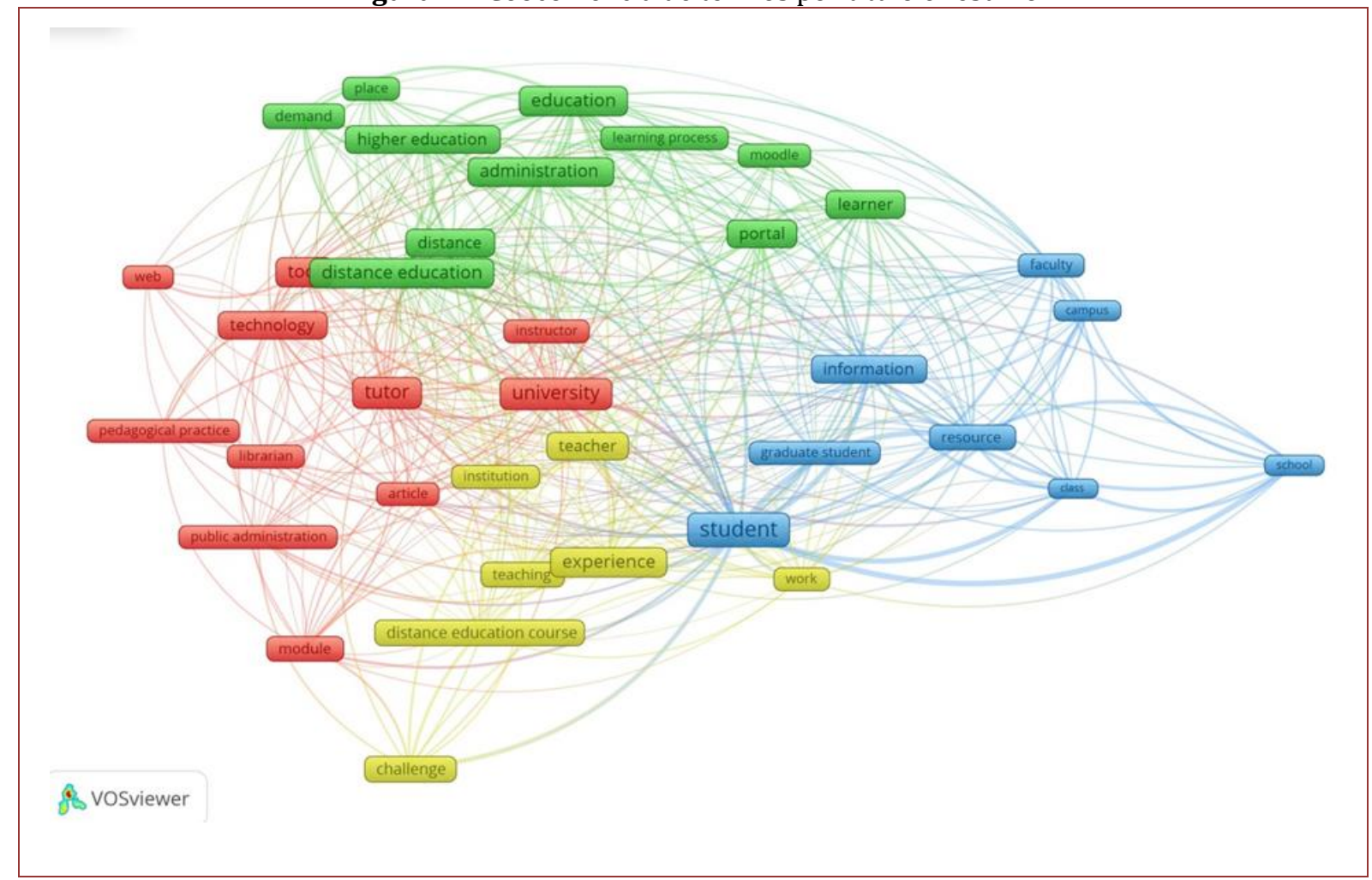

$\mathrm{Na}$ coocorrência de termos e suas inter-relações, pode-se observar que os dois maiores clusters são formados por 11 termos cada. 0 cluster verde apresenta os termos: "administration", "education", "higher education", "learning process", "distance", "distance education", "learner", "moodle”, "portal”, "demand" $e$ "place". Percebe-se que a educação a distância em cursos de Administração está relacionada com o desenvolvimento do processo de aprendizagem e ferramentas de ensino.

Estudos identificaram que a análise de aprendizagem é um campo emergente que aplica métodos e ferramentas de dados para a exploração de ambientes educacionais. Os sistemas de gestão de aprendizagem, como o Moodle, oferecem grandes quantidades de dados sobre a atividade, desempenho, comportamento e interação dos alunos com seus colegas e tutores. Os professores-tutores podem trabalhar com palestras ou discussões online, a fim de maximizar a participação dos alunos (Saggiomo \& Pereira, 2019; Tumbo, 2018). Resultados de pesquisas mostram o interesse dos alunos por cada componente estrutural, a dedicação ao curso, a participação nos fóruns e como isso afeta o envio das atividades. Esses resultados podem ser explorados de forma adequada nos cursos de Administração, com a finalidade de desenvolver uma formação completa, englobando tanto habilidades sociais (liderança e comunicação), quanto às habilidades técnicas para o desenvolvimento de know-how (Alachiotis, Stavropoulos \& Verykios, 2019; Mendes et al., 2014).

O cluster vermelho apresenta os termos: "university", "tutor", "technology", "instructor", "pedagogical practice", "tool", "librarian", "public administration", "module”, "web" e "article". Percebem-se análises de temáticas do papel do Professor-Tutor e a influência da tecnologia nas práticas pedagógicas (Secreto e Pamulaklakin, 2015). A tecnologia tem a capacidade de aprimorar o relacionamento entre ProfessorTutor e alunos. A tecnologia ajudaa tornar o ensino e a aprendizagem mais significativos, desta forma os alunos podem colaborar com seus próprios colegas por meio de aplicativos tecnológicos (Saggiomo \& Pereira, 2019; Cantino, Denicolai \& Parola, 2018).

Para complementar a análise, o Quadro 1 mostra os 12 artigos que foram selecionados na literatura conforme o método InOrdinatio, quanto a prática da tutoria e o impacto na aprendizagem do aluno em cursos de Administração na modalidade de educação a distância, além disso, apresentando a metodologia adotada nos estudos. 
Quadro 1 - Análise dos principais resultados das pesquisas: tutoria e a aprendizagem do aluno em cursos de Administração

\section{Principais resultados das pesquisas: tutoria e a aprendizagem do aluno em cursos de Metodologia Referência}

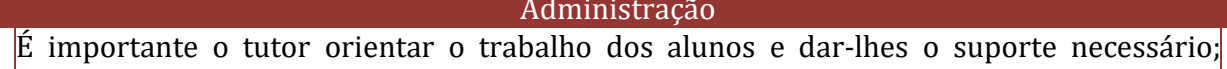
propor atividades de aprendizagem inovadoras principalmente nas áreas que envolvem 1 geração do conhecimento como Gestão e Empreendorismo. Conforme os autores, um dos objetivos estratégicos dos cursos, é redefinir o perfil do Professor- Tutor em educação a distância, o que inclui programas de formação que atendam a esse novo perfil de qualidade acadêmica para a formação de um Administrador preparado para o mercado.

A tutoria precisa buscar e compartilhar recursos complementares em diferentes formatos para esclarecer dúvidas no decorrer do assunto, de acordo com as características, objetivos e comentários do corpo estudantil. A gestão do fluxo de trabalho do Professor-

2 objetivos e comentários do corpo estudantil. A gestão do fluxo de trabalho do Professoratrasar as respostas esperadas pelos alunos. A elaboração de feedbacks é parte significativa das ações realizadas no cotidiano de trabalho dos tutores.

Por meio de uma pesquisa online com 147 alunos de graduação e pós-graduação a distância, os participantes identificaram o AVA como um local eficaz para obter

3 informações precisas sobre seu desempenho. Além deste recurso, como uma importante Questionário ferramenta de apoio ao aluno, foi identificada a importância da comunicação com a tutoria para aprimorar a experiência de aprendizagem.

O estudo destaca a importância da formação continuada para os Professores-Tutores do

4 curso de Administração modalidade EaD. Em cursos que lidam com comportamento

humano, é importante motivar a participação dos alunos de forma personalizada e grupal por meio das ferramentas da plataforma (fórum, e-mail).

A pesquisa ressalta a importância do Professsor-Tutor conhecer e fazer um manuseio

5 técnico adequado das ferramentas da plataforma em atividades de aprendizagem. Além

5 disso, fazer o uso de sites de armazenamento em nuvem e ferramentas de criação de documentos colaborativos.

Para a eficiência do curso de Bacharelado em Administração na modalidade EaD, é

6 necessário o apoio aos alunos em todas as suas atividades e processos educativos (tanto nas atividades educativas quanto no plano de carreira).

\section{(1)}

\begin{tabular}{|c|c|}
\hline Questionário & $\begin{array}{c}\text { Barboza- } \\
\text { Robles } \\
\text { (2021) }\end{array}$ \\
\hline $\begin{array}{c}\text { Estudo de } \\
\text { caso }\end{array}$ & $\begin{array}{c}\text { Alachiotis, } \\
\text { Stavropoulo } \\
\text { s e Verykios } \\
(2019)\end{array}$ \\
\hline Questionário & $\begin{array}{c}\text { Secreto e } \\
\text { Pamulaklaki } \\
\text { n (2015) }\end{array}$ \\
\hline Entrevista & $\begin{array}{c}\text { Saggiomo e } \\
\text { Pereira } \\
\text { (2019) }\end{array}$ \\
\hline
\end{tabular}

Como resultado de uma entrevista realizada com 30 Professores- Tutores de um curso de Administração, apontou-se que é necessária uma definição clara do papel destes profissionais. Percebeu-se que a maioria dos Professores-Tutores não tinham o

7 conhecimento e a experiência necessários em educação a distância, e faziam adaptações imediatas dos métodos presenciais. O Professor-Tutor de cursos de Administração necessita desenvolver habilidades para se adaptar a várias áreas, como Marketing, Recursos Humanos, Gestão Financeira e Sustentabilidade.

Nesta pesquisa com questionário aplicado a 16 tutores do curso de Administração, destacou-se que a interação entre o Professor-Tutor e aluno é essencial nos procedimentos aprendizagem e ensino da modalidade a distância. A interação deve partir 8 também do aluno, destacando que o mesmo necessita entender que o esperado é a interação, com envio de resposta às atividades propostas nas aulas, além da reflexão e respostas comentando a percepção dos colegas. 0 estudo destacou que há uma tendência da evasão dos alunos no primeiro ano do curso, na percepção dos tutores, devido à ambientação do aluno com as tecnologias, metodologia e motivos financeiros.

o estudo constatou no curso de Administração a distância investigado, que um dos 9 principais motivos de evasão foi a atitude comportamental relacionada de forma direta com a falta de satisfação com o tutor, além de problemas relacionados à plataforma.

Estudo de Denicolai e caso

Parola (2018)

Para melhorar e monitorar a qualidade da comunicação entre tutores e alunos, é 10 necessário uma infraestrutura de gestão da comunicação. As solicitações e mensagens nesses sistemas devem ser entregues e tratadas em tempo hábil para fornecer suporte $\mathrm{e}$ gerenciamento onipresentes de comunicação na educação a distância.

A comunicação e a colaboração são competências essenciais não só para a mediação com o Professor-Tutor, mas também para o sucesso profissional no mercado de trabalho do 11 aluno.

\begin{tabular}{|c|c|}
\hline & (2018) \\
\hline Entrevista & $\begin{array}{l}\text { Mendes et } \\
\text { al., (2014) }\end{array}$ \\
\hline Questionário & $\begin{array}{c}\text { Martins, } \\
\text { Terçariol e } \\
\text { Gebra } \\
(2015)\end{array}$ \\
\hline $\begin{array}{l}\text { Estudo de } \\
\text { caso e } \\
\text { Pesquisa } \\
\text { Documental }\end{array}$ & $\begin{array}{c}\text { Bittencourt } \\
\text { e Mercado } \\
\text { (2014) }\end{array}$ \\
\hline $\begin{array}{l}\text { Revisão de } \\
\text { lieratura }\end{array}$ & $\begin{array}{c}\text { Chiu et al., } \\
\text { (2008) }\end{array}$ \\
\hline $\begin{array}{l}\text { Revisão de } \\
\text { Literatura }\end{array}$ & $\begin{array}{c}\text { Koustourak, } \\
\text { Panagiotako } \\
\text { poulos, e } \\
\text { Vergidis } \\
(2008)\end{array}$ \\
\hline Questionário & $\begin{array}{c}\text { Zuhairi, } \\
\text { Adnan e } \\
\text { Thaib } \\
\text { (2007) }\end{array}$ \\
\hline
\end{tabular}


Dos artigos analisados, 42\% utilizaram questionário, 25\% estudo de caso, 17\% entrevistas eos demais 16\% utilizaram análise documental ou revisão de literatura. Percebe-se uma carência de pesquisas com abordagem qualitativa. De acordo com Mendes et al., (2014), a pesquisa qualitativa pode capturar a mudança de atitudes dentro de um grupo-alvo, podendo ser direcionada para temas de comportamento organizacional como o impacto da tutoria nos cursos de graduação na modalidade EaD.

Em disciplinas do curso tais como, Recursos Humanos e Comunicação Empresarial, a mediação de discussões por meio de fóruns e a afetividade do Profesor-Tutor são fundamentais para facilitar o aprendizado nas áreas comportamentais. Em disciplinas técnicas que exige tomada de decisão por parte do Administrador, tais como Planejamento Estratégico e Gestão de Projetos, atividades que envolvam a aplicação prática destas áreas precisam ser fortalecidas na educação a distância. Desta forma, é fundamental a mediação do Professor- Tutor para orientar e dar feedbacks, em função da dispersão física do professor que pode causar dúvidas em disciplinas técnicas do curso (Barboza-Robles, 2021; Cantino, Denicolai \&Parola, 2018; Chiu et al., 2008).

Os resultados do estudo de Martins, Terçariol e Gebra (2015) e Bittencourt e Mercado (2014), identificaram motivos que levam a evasão de alunos nos cursos de Administração na modalidade EaD. Dentre os motivos estão a falta de satisfação na comunicação com o Profeessor-Tutor, a falta de conhecimento e ambientação em tecnologias e razões financeiras.

De acordo Bittencourt e Mercado (2014), na evasão do curso de Administração, o importanteé preservar uma política para manter o aluno e compreender as principais dificuldades no desenvolvimento da aprendizagem, além de ter a preocupação em analisar as oportunidades do mercado de trabalho no campo da Administração.

\section{CONSIDERAÇÕES FINAIS}

O presente estudo apresentou como objetivo avaliar a prática da tutoria e a aprendizagem do aluno em cursos de Administração na modalidade a distância. 0 ensino a distância oferece maior flexibilidade de tempo e espaço para a capacitação e aperfeiçoamento do conhecimento, sendo hoje um formato essencial para o equilíbrio da vida profissional, pessoal, familiar e educacional. O processo de interação entre aluno e Professor-Tutor ocorre por meio dos canais de comunicação, e-mail, chat, fórum, ambiente virtual, sendo um processo fundamentalpara a construção de uma relação assertiva e afetiva.

O Professor-Tutor possui o papel de acompanhar, orientar e fazer o intermédio entre oconhecimento e os alunos. Pode-se dizer que, a qualidade na interação do aluno é parte essencial do trabalho dos professores-tutores, onde os mesmos precisam estar atentos ao que os alunos demandam tanto em particular quanto coletivamente, para que escolham estratégias, materiais e se necessário realizar intervenções pedagógicas adequadas. Tendo em vista o exposto, é importante enfatizar o papel de mediação entre o Professor-Tutor e aluno. Neste processo, os professores são tão importantes quanto os alunos, pois, dependendo do seu conhecimento técnico e de suas características afetivas, influenciam diretamente nas relações entre os participantes e nos resultados de todo o processo educativo, sendo de evasão ou no sucesso do aluno.

Os resultados da pesquisa concluem que, em relação à tutoria nos cursos de Administração, os seguintes fatores são necessários na aprendizagem do aluno: (i) propor atividades inovadoras principalmente em áreas como Gestão e Empreendedorismo; (ii) evitar o acúmulo de atividades e dar os feedbacks necessários; (iii) incetivar o uso de ferramentas de discussão como o fórum online; (iv) utilizar o armazenamento em nuvem e ferramentas de criação de documentos colaborativos; (v) ter formação e experiência necessárias na educação a distância; (vi) aprimorar a comunicação, pois uma das razões identificadas da evasão foi a falta de satisfação com o tutor; (vii) propor a participação do aluno e a flexibilidade para garantir que as atividades sejam eficientes no processo de aprendizagem; e (viii) dar o suporte necessário para o aluno ambientar-se com as tecnologias.

Como pesquisas futuras, sugere-se o desenvolvimento de estudos com abordagem qualitativa. Desta forma, será possível explorar por meio de pesquisa aplicada, os fatores identificados nesta revisão sistemática de literatura sobre a integração da prática da tutoria na aprendizagemdos alunos em cursos de Administração. 


\section{REFERÊNCIAS}

[1] Alachiotis, N., Stavropoulos, E. C., \& Verykios, S. V. (2019). Analyzing learners behavior and resources effectiveness in a distance learning course: A case study of the Hellenic Open University, Journal of Information Science Theory and Practice, (7:3), pp.06-20.

[2] Barboza-Robles, Y. (2021). Digital competence: analysis in teaching staff of the School of Administration Sciences of the UNED of Costa Rica, Revista electronica calidad en la educacion superior (12:1), pp. $26-53$.

[3] Bittencourt, I. M., \& Mercado, L. P. L. (2014). Dropout in courses in distance education: Case study of the UFAL/UAB's pilot administration distance education course. Ensaio, (22:83), pp.465-503.

[4] Borges, M. K. \& Fontana, K. B. (2003). Interatividade na prática: a construção do texto colaborativo por alunos da educação a distância. In: Congresso Internacional da ABED, 10, Porto Alegre. Anais... Porto Alegre.

[5] Cantino, V., Denicolai, L., \& e Parola, A. (2018). Using videos and multimedia tools in e-learning experience of the business administration bachelor at the department of management (university of turin, Italy), 11th International Conference of Education, Research and Innovation, pp.1-15.

[6] Chiu, D. K. W., Choi, S. P. M., Wang, M., \& Kafeza, E. (2008). Towards ubiquitous communication support for distance education with alert management, Educational Technology \& Society, (11:2), pp.92-106.

[7] Demo, P. Questões para Teleducação. Petrópolis: Vozes, 1998.

[8] Franco, L. S., Franco, A. C., Pilatti, L. A., \& Picinin, C. T. (2021). Equilíbrio da vida profissional e familiar dos professores do ensino superior. Competência, Porto Alegre, (14: 1), pp.1-12.

[9] Freire, P. (2001). Pedagogia da Autonomia. 17. ed. São Paulo: Paz e Terra.

[10] Guldberg, K., \& Pilkington, R. (2007). Tutor roles in Facilitating Reflection on Practice Throug Online Discussion. Education Technology \& Society, (10: 1), pp. 61-72.

[11] Instituto Semesp. (2021). Mapa do Ensino Superior no Brasil. Disponível em: https://www.semesp.org.br/mapa- do-ensino-superior/. Acesso em 2 de ago. 2021.

[12] Koustouraki, G., Panagiotakopoulos, C. T, \& e Vergidis, D. (2008). A contribution to the Hellenic Open University: Evaluation of the pedagogical practices and the use of ICT on distance education. International Review of Research in Open and Distance Learning, (9:1), pp.1-18.

[13] Lévy, Piere. (1999). Cibercultura. Trad. Carlos Irineu da Costa. São Paulo: Editora 34.

[14] Longhi, M. T., Behar, P., \& Bercht, M. (2009). A busca da dimensão afetiva em ambientes virtuais de aprendizagem. In: BEHAR, Patrícia e colaboradores. Modelos pedagógicos em educação à distância. Porto Alegre: Artmed, pp. 204-229.

[15] Martins, C. Z., Terçariol, A. A. de L., \& Gebra, R. A. (2015). Perceptions of the tutor: student evasion in a distance business administration course. Rev. Eletrônica Pesquiseduca, (7:14), pp. 1-23.

[16] Mendes, E., Carvalho, C. J. de., Gargiulo, V., \& Alves, J. B. da M. (2014). Conceptual maps for training tutors in the distance learning of business administration course, International Journal on E-Learning: Corporate, Government, Healthcare, and Higher Education, (13:4), pp.451-466.

[17] Moore. M. G. \& Kearsley, G. (2013). Educação a distância: sistemas de aprendizagem on-line. 3. ed. São Paulo: Cengage Learning.

[18] Moran, J. M. (2000). Ensino e aprendizagem inovadores com tecnologias audiovisuais e telemáticas. In: Novas Tecnologias e mediação pedagógica. Campinas, SP: Papirus, pp.11-66.

[19] Oblinger, D.G. (2006). Space as a change agent. In: Oblinger, D.G. Learning spaces. Educause. cap.1, pp.12-16.

[20] Pagani, R., Kovaleski, J., \& Resende, L. (2015). Methodi Ordinatio: a proposed methodology to select and rank relevant scientific papers encompassing the impact factor, number of citation, and year of publication. Scientometrics, (105:3), pp. 1-27.

[21] Secreto, P. V., \& Pamulaklakin, R. L. (2015). Learners' satisfaction level with online sutdent portal as a support system in an open and distance elearning environment (ODeL), Turkish Online Journal of Distance Education, (16:3), pp. 33-47.

[22] Saggiomo, L., \& e Pereira, E. C. (2019). Continuing education in de: reflections of the tutor professor in a formative process. Brazilian Journal of Education, Technology and Societ, (12:3), pp.236-244.

[23] Shelley, M., White, C., Baumann, U., \& Murphy, L. (2006). Its a unique role! Perspectives on tutor attributes and expertise in distance language teaching. The International Review of Research in Open and Distance Learning, 7(2), pp.1-15. 
[24] Tumbo, D. L. (2018). Digital technologies in higher education at distance: mapping and use by the tutors at the pedagogical university of Mozambique, Brazilian Journal of Education, Technology and Societ, (11:4), pp. 613-623.

[25] Van Eck, N. J., \& Waltman, L. (2009). How to normalize cooccurrence data? An analysis of some well-known similarity measures. Journal of the American Society for Information Science and Technology, (60:8), pp.1635-1651.

[26] Zuhairi, A., Adnan, I., \& Thaib, D. (2007). Provision of student learning support services in a large-scale distance education system at universitas Terbuka, Indonesia, Turkish Online Journal of Distance Education, (8:4), pp.112. 


\section{Capítulo 5}

Gastos em educação: Um estudo sobre a destinação de recursos no orçamento público na região metropolitana de Maringá

\section{Roberto Rivelino Martins Ribeiro \\ Letícia Ribeiro Gasparini \\ Juliane Andressa Pavão \\ Kerla Mattiello}

Resumo: Uma das reivindicações da população brasileira mais tem solicitado são melhorias e maiores investimentos em educação, nesse sentido, este estudo estabeleceu como objetivo investigar os gastos em educação a partir da destinação dos recursos previstos e realizados no orçamento público, na região metropolitana de Maringá abrangendo o período de 2013 a 2019, a qual contempla 26 municípios. Como plataforma teórica, se procedeu a apropriação do tema a partir de uma revisão bibliográfica que contempla o planejamento e orçamento público, sua aplicação na área da educação, e, também, uma breve revisão empírica de estudos realizados nessa perspectiva. Os aspectos metodológicos empregados fizeram uso da pesquisa descritiva, de natureza aplicada, com abordagem qualitativa e quantitativa, com procedimento técnico documental, dedutiva e pesquisa de campo; os dados são provenientes dos Relatórios Resumido da Execução Orçamentária (RREO), disponibilizados nos sites da Secretaria do Tesouro Nacional (STN) e do Tribunal de Contas do Estado do Paraná (TCE-PR) dos anos de 2013 a 2019. Os resultados apontaram que os gastos realizados pelos municípios da Região Metropolitana de Maringá não têm atendido ao disposto na Constituição Federal no período analisado; a exceção é o município de Paiçandu, que investiu a cima da média todos os anos totalizando uma média de 33,04\%; Mandaguari só não atinge em 2013 atingindo uma média de 26,19\%; Mandaguaçu atinge em 2018 (27,21\%) e 2019 (27,11\%) com média final de 23,90\% e Sarandi em 2015 (27,73\%) somente e atingindo uma média de 23,12\%; o demais municípios não cumpriram ao determinado pela legislação.

Palavras-Chave: Orçamento Público; Gastos em Educação; Região Metropolita de Maringá. 


\section{INTRODUÇÃO}

O orçamento público é o instrumento que evidencia a informação sobre a previsão de investimentos na administração pública. Configura-se como uma ferramenta fundamental para os governos, em que há o planejamento da utilização do dinheiro público e também a previsão das receitas e despesas futuras para a administração. No orçamento público deve conter a discriminação da receita e da despesa, de forma a evidenciar a política econômico-financeira e o programa de trabalho do governo, obedecidos os princípios de unidade, universalidade e anualidade, evidenciada no Art. 2o da Lei do Orçamento na Lei 4.320/64. Assim é possível saber o exato volume das despesas projetadas pelo governo, a fim de autorizar a cobrança de tributos necessários para atendê-las conforme disposto (Brasil, 1988).

A aplicação do orçamento se dá em todas as esferas da administração pública, aplicando-se a entes federativos, secretarias, empresas, enfim todas as entidades. Na área da educação, especificamente, a Constituição Federal (1988) obriga o poder público das esferas federal, estadual e municipal, por meio da Lei de Diretrizes e Bases da Educação (LDB), Lei no 9394 aprovada em dezembro de 1996, a aplicarem uma parte de sua receita resultante de impostos e transferências na manutenção e no desenvolvimento da educação. Consta na lei que a União precisa alocar 18\% de sua receita líquida para a área e os estados e municípios devem destinar 25\%; a lei atribui aos municípios a atuação prioritária no Ensino Fundamental e na Educação Infantil (Brasil, 1988). Além disso, a distribuição dos recursos públicos tem que dar prioridade ao atendimento das necessidades do ensino obrigatório e na garantia de padrão de qualidade, ou seja, o município não pode investir em outras áreas da Educação, por exemplo, construindo uma universidade municipal sem atender as prioridades (Brasil, 1996).

Para o aproveitamento do percentual investido, o parágrafo 3o da LDB no 9394/96, diz que o percentual mínimo a ser investido é calculado, não apenas sobre a previsão da receita de impostos contida na lei do orçamento, mas também com base na abertura de créditos adicionais resultantes de excesso de arrecadação. Por sua vez, o parágrafo 4⿳⺈ impõe que se o percentual mínimo obrigatório não for aplicado num trimestre, o Poder "Público" é obrigado a corrigir monetariamente o valor devido não gasto e aplicálo no trimestre seguinte. Esta disposição é fundamental para evitar os governos que gastam bem menos do que o percentual mínimo e empenha valores astronômicos com o objetivo de compensar, o que não foi aplicado em meses anteriores (Brasil, 1996).

O Fundo de Manutenção e Desenvolvimento da Educação Básica e de Valorização dos Profissionais da Educação (Fundeb), criado em 2007, também exerce um papel importante quanto à educação nos municípios. Este, financia as etapas da Educação Básica, distribuindo igualitariamente os recursos, dentro de cada estado, conforme o número de alunos matriculados no ensino público. Quando o valor investido por aluno não atinge o mínimo nacional, a União complementa. "O Fundeb reequilibra as desigualdades entre municípios e Estados. Aquilo que sobra do que deveria ser gasto é colocado no fundo. Para os municípios, o total é de 20\% das transferências" (Fernandes \& Gremaud, 2009, p. 1). 0 acompanhamento e o controle social sobre a distribuição, a transferência e a aplicação dos recursos do programa são feitas em escalas federal, estadual e municipal por conselhos criados especificamente para esse fim e é o Ministério da Educação que promove a capacitação dos integrantes dos conselhos.

Embora relevante o tema seja, escassos são os estudos que mostram discricionariamente como os governos têm desempenhado suas atribuições no período recente, tendo em vista que alguns municípios, no entanto, não cumprem a obrigação constitucional. Segundo o Ministério da Educação (MEC), os Tribunais de Conta dos municípios e o Ministério Público são os órgãos responsáveis por fiscalizar se o montante do investimento está de acordo com a lei. A experiência brasileira tem demonstrado que de nada adiantam leis boas se elas não forem cumpridas e se as autoridades não forem punidas pelo seu descumprimento. Diante do exposto, o objetivo desse estudo é investigar os gastos em educação a partir da destinação dos recursos previstos e realizados no orçamento público, na região metropolitana de Maringá abrangendo o período de 2013 a 2019.

Entende-se como relevante a realização desta pesquisa, pois os resultados encontrados a partir da investigação evidencia as previsões e realizações dos investimentos na área, assim, contribui para alertar a população do desenvolvimento educacional da região metropolitana de Maringá e também para que os mesmos estejam cientes da aplicação do dinheiro público mediante o orçamento realizado. Intui-se então que a pesquisa evidencie o montante de investimentos, se tem sido crescente ou não, se atende ao disposto na legislação ou não, enfim, traga luz a tal questão. 


\section{REVISÃO DE LITERATURA}

\subsection{PLANEJAMENTO E ORÇAMENTO PÚBLICO NO BRASIL}

O orçamento público, hoje em dia, reveste-se de diversas formalidades legais e é aperfeiçoado dentro e fora do Brasil devido sua saliência para a economia do país e mundial. O Governo é responsável por dispêndios sejam na aquisição de produtos ou serviços, na construção de grandes obras, contratações de empresas ou pagamentos de salários. Em contrapartida o Estado tende a recuperar parte desses gastos, na cobrança de impostos e nas contribuições pagas pelos que possuem renda. Por outro lado, a arrecadação de tributos tem a necessidade de gerir melhor os recursos de forma a satisfazer aos anseios e às necessidades da população (Ribeiro et al., 2019). Dessa forma, o orçamento público tem por objetivo fazer a alocação dos gastos públicos por meio de um planejamento, em que constam as despesas da administração pública para um ano, em equilíbrio com a arrecadação das receitas previstas (Kohama, 1996).

No início do ano de 1967 foi publicada a sexta constituição brasileira, o texto dessa constituição identifica uma preocupação com a "segurança nacional" e com tendência de centralização dos poderes do Presidente da República. Visto isso, o Decreto-lei 200, de 25 de fevereiro de 1967, vigente até os dias atuais, definiu pela primeira vez o planejamento no ordenamento jurídico, tendo como princípio fundamental nortear as atividades da administração federal, usando como base o orçamento-programa anual e outros programas. Em vista de melhorias, a constituição passou por muitas inovações, até receber sua oitava constituição em 5 de outubro de 1988, entre as inovações tem-se a exigência de, anualmente, o Executivo encaminhar ao Legislativo, o projeto de lei de diretrizes orçamentárias com o objetivo de orientar a elaboração da lei orçamentária. Segundo Horvath $(1999$, p. 69) classicamente, o orçamento é uma peça que contém a previsão das receitas e a autorização das despesas, sem preocupação com planos governamentais e com interesses efetivos da população.

Todos os anos os municípios e estados fazem o levantamento de suas despesas que serão ocorridas durante os próximos meses, dessa forma o Governo consegue planejar seus investimentos e as quantidades de verbas que serão distribuídas entre municípios e estados, contribuindo para o controle e fiscalização no uso e gasto do dinheiro público. Contudo o processo de planejamento envolve três etapas: a aprovação da Lei do Plano Plurianual (PPA), da Lei das Diretrizes Orçamentárias (LDO) e da Lei Orçamentária Anual (LOA), em que a LDO determina as prioridades e metas do PPA e assim é possível elaborar a LOA.

Com intuito de planejar os gastos e receitas públicas para médio prazo o Plano Plurianual (PPA) foi criado para estabelecer as diretrizes do governo, bem como os objetivos e metas para os projetos e programas de longa duração, para um período de quatro anos. Nenhuma obra grande ou cuja execução ultrapasse um exercício financeiro (01 de janeiro a 31 de dezembro) pode ser iniciada sem prévia inclusão no plano plurianual. A Constituição Federal em seu artigo 165, parágrafo 1o assim estabelece: "A lei que instituir o plano plurianual estabelecerá, de forma regionalizada, as diretrizes, objetivos e metas da administração pública federal para as despesas de capital e outras delas decorrentes e para as relativas aos programas de duração continuada". O PPA deve ser enviado pelo Poder Executivo ao Poder Legislativo até 31 de agosto e o Poder Legislativo tem até o dia 22 de dezembro para apreciar, emendar, votar, aprovar e devolver o plano plurianual ao Poder Executivo para fins de sanção e publicação (Brasil, 1988). 0 PPA, segundo Kohama (2010), é um Plano de médio prazo, por meio do qual procura-se ordenar as ações do governo para o atingimento dos objetivos e metas fixados para um período de quatro anos.

0 atual processo de elaboração, aprovação, execução, avaliação e controle do planejamento orçamentário pátrio compreende em um ciclo orçamentário que desempenha a possibilidade de o Estado interligar o planejamento à execução orçamentária, que tem as seguintes fases: planejamento (elaboração e aprovação), execução, avaliação e controle. Ao todo, o ciclo orçamentário atual não se destina somente a um exercício financeiro, que corresponde à previsão e execução da receita e fixação e execução da despesa do ano corrente.

Com objetivo de possibilitar a melhor administração, gerência, guarda e utilização dos recursos que entram na conta do governo, com o intuito de financiar as políticas públicas, que irão satisfazer aos anseios da sociedade brasileira a Constituição Federal descreve em seu artigo 71, "O controle externo, a cargo do Congresso Nacional, será exercido como o auxílio do Tribunal de Contas da União [...]" (Brasil, 1988).

Com a elaboração do PPA é possível estabelecer as metas e prioridades do exercício seguinte, para isso foi criado a LDO, dentre seus objetivos está estabelecido a orientação para elaboração da LOA, as políticas das 
agências de desenvolvimento, além de dispor sobre alterações na legislação tributária. A Lei de Responsabilidade Fiscal remeteu à LDO diversos outros temas, como política fiscal, contingenciamento dos gastos, transferências de recursos para entidades públicas e privadas e política monetária, com inclusão do Anexo de Metas Fiscais e do Anexo de Riscos Fiscais (Brasil, 2000).

A LDO é responsável pela interligação entre o que o governo planejou para os seus quatro anos de mandato e o que efetivamente vai realizar em cada ano, ou seja, é o elo entre o planejamento (PPA) e a ação governamental (LOA) (Brasil, 1988). Portanto, o projeto da LDO deverá ser enviado pelo poder Executivo ao Congresso Nacional até o dia 15 de abril, e este tem até o dia 17 de julho para apreciar, emendar, votar, aprovar e devolver ao Poder Executivo para fins de sanção e publicação. A Constituição traz em seu artigo 57 que o Congresso Nacional não poderá entrar em recesso parlamentar em julho enquanto não aprovar a LDO (Brasil, 1988).

Na elaboração da LOA, a lei 4.320/64 estabelece que estão estimadas as receitas que serão arrecadadas durante o exercício financeiro e as despesas que o Governo espera realizar. Essa lei deve ser elaborada pela Secretaria de Orçamento Federal e encaminhada ao Congresso Nacional pelo Presidente da República. A LOA contém três orçamentos, conforme previstos na Constituição Federal: o orçamento fiscal, o orçamento da seguridade social e o orçamento de investimentos das empresas estatais.

A LOA engloba receitas e despesas referentes aos poderes da união, incluindo seus fundos, aquisições, investimentos com direito de voto e todas entidades a ela vinculada direta ou indiretamente. Dessa forma é possível estabelecer a lei regida sobre o controle da União para evidenciar os trabalhos do Governo (Brasil, 1988).

\subsection{ORÇAMENTO PÚBLICO NA EDUCAÇÃO}

De acordo com a Lei 9.394/96, Art. 68, em que se refere aos Recursos Financeiros, serão recursos destinados à educação a "receita de impostos próprios da União, dos Estados, do Distrito Federal e dos Municípios; receita de transferências constitucionais e outras transferências; receita do salário-educação e de outras contribuições sociais; receita de incentivos fiscais; outros recursos previstos em lei".

Em complemento, no Art. 69 está descrito que a União deve aplicar no mínimo 18\% e os Estados, Distrito Federal e Municípios nunca menos que $25 \%$ das receitas resultantes de impostos, incluindo as transferências constitucionais, na manutenção e no desenvolvimento público (Ribeiro et al., 2020).

Levando em consideração o artigo 205 da Constituição Federal de 1988 está exposto que "A educação, direito de todos e dever do Estado e da família, será promovida e incentivada com a colaboração da sociedade, visando ao pleno desenvolvimento da pessoa, seu preparo para exercício da cidadania e sua qualificação para o trabalho". Visto isso, os preceitos dos ordenamentos jurídicos são responsáveis pela organização e funcionamento do sistema escolar brasileiro (Brasil, 1988).

A Emenda Constitucional noำ14, de 1996 e a Lei de Diretrizes e Bases da Educação Nacional (LDB), instituída pela lei no 9394, de 1996, criou o Fundo de Manutenção e Desenvolvimento do Ensino Fundamental e de Valorização do Magistério (Fundef, 1998). Sua criação foi vista como uma verdadeira revolução no ensino Fundamental, em 2007 foi substituída pela FUNDEB destacando-se o aumento dos recursos oriundos dos impostos (Brasil, 1996).

De acordo com a LDB, o Ensino Superior é de competência da União, podendo ser oferecido pelo Estado e Município, o ensino médio é responsabilidade do Estado, ensino fundamental é obrigatório e gratuito se inicia pelo município e os anos finais pelo Estado, a educação infantil é obrigação do município, assim como direcionar a faixa de zero a seis anos. 0 dever do Município é aplicar pelo menos $25 \%$ de sua receita de impostos e transferências na manutenção e no desenvolvimento da educação (Brasil, 1996).

O FUNDEB é um fundo de natureza contábil e de âmbito estadual, formado, por recursos provenientes dos impostos e transferências dos estados, Distrito Federal e municípios, vinculados à educação por meio do disposto no art. 212 da Constituição Federal. Além desses recursos, ainda compõe o FUNDEB, a fim de complementação, uma parcela de recursos federais, sempre que, seu valor por aluno não alcançar o mínimo definido nacionalmente. Independentemente da origem, todo o recurso gerado é redistribuído para aplicação exclusiva na educação básica. 


\subsection{PESQUISAS PRÉVIAS SOBRE INVESTIMENTOS EM EDUCAÇÃO}

A Constituição Federal de 1988, art. 205 define educação como um direito de todos e dever do Estado e da família, visando o desenvolvimento pessoal, preparo para exercer sua cidadania e qualificação no trabalho, deve ser promovida e incentivada com colaboração da sociedade. Visto isso, para que seja garantido os meios de acesso à esses direitos no âmbito municipal os gastos com educação devem ter um investimento mínimo por parte de seus dirigentes.

De acordo com Manual de Contabilidade Aplicada ao Setor Público (2018), as Receitas Orçamentárias são disponibilidades de recursos financeiros gerados durante o exercício com o intuito de aumentar o saldo financeiro do Estado, possibilitando que o mesmo execute programas de ações que atendam a necessidade e demanda da sociedade. Ainda assim, dispondo à face de suas necessidades. Segundo Silva (2011), o Estado dispõe de recursos que lhe são entregues pela contribuição da sociedade, esses recursos formam a Receita Pública e com esta é possível realizar a manutenções, custeio de serviços, segurança, desenvolvimento econômico e social e responsabilidade com seu próprio patrimônio.

Em contrapartida, para Iudícibus e Marion (2009), a despesa pública deve ser entendida como valores arrecadados por meio de impostos ou outras fontes para aplicação de valores e custeamento dos serviços voltados para sociedade ou para execução de investimentos. Araújo e Arruda (2004) definem despesa pública como um conjunto de gastos que depende da autorização legislativa com finalidade de atender as premissas contidas na LOA, desenvolvida conforme o PPA, LDO e LRF.

Com base na pesquisa de Cruz (2018) referente às despesas com pessoal e os impactos nos investimentos em educação e considerando os itens contidos na LRF, expõem-se a orientação, disciplina e limites dos gastos públicos, visando garantir o aproveitamento dos recursos públicos em outras áreas. Junto a isso, uma pesquisa feita pela Federação das Indústrias do Estado do Rio de Janeiro (FIRJAN), publicada em abril de 2019, destaca que a maioria dos estados brasileiros concentram a maior parte das suas despesas em pagamento de pessoal, com o crescimento dessa despesa os investimentos públicos como a educação podem ser prejudicados.

No que diz respeito à efeitos positivos no crescimento econômico, de acordo com Sen (2010), um país que investe mais em educação e saúde tem mais chances de alcançar resultados positivos na economia. Tendo em vista a China como exemplo, sua expansão se deu principalmente pelo alto investimento nos setores públicos, como na educação que resultou um alto grau de alfabetização e na saúde, sendo assim pode-se concluir que esses gastos contribuem para o crescimento econômico do país, de acordo com Sen (2010).

\section{PROCEDIMENTOS METODOLÓGICOS}

Neste trabalho foi utilizado o método de pesquisa descritiva, quanto à sua natureza é do tipo aplicada. Quanto a sua abordagem, foi utilizado o método qualitativo e o quantitativo, sendo assim classificada como mista. No que diz respeito ao método de abordagem da pesquisa, é caracterizada como dedutiva. Com relação aos procedimentos técnicos, trata-se de uma pesquisa documental, e se empregou o procedimento ex-post facto. Com relação ao ambiente de desenvolvimento do estudo, se trata de uma pesquisa de campo.

0 método de coleta de dados utilizado, refere-se à coleta documental. 0 estudo tem como objeto de pesquisa os recursos previstos e realizados no orçamento público, na região metropolitana de Maringá abrangendo o período de 2013 a 2019, sendo que os dados foram coletados dos Relatórios Resumido da Execução Orçamentária (RREO), disponibilizados nos sites da Secretaria do Tesouro Nacional (STN) e do Tribunal de Contas do Estado do Paraná (TCE-PR). Os dados documentados nesta pesquisa são analisados com finalidade de comparação ao mínimo que deve ser investido em educação em cada município ante ao que determina a legislação.

\section{APRESENTAÇ̃̃O E ANÁLISE DOS DADOS}

\subsection{DESCRIÇÃO DO OBJETO DE ESTUDO}

A Região Metropolitana de Maringá - RMM está no interior do país, cuja sede não se trata de uma capital de estado e está localizada na Região Norte Central do Estado do Paraná. A configuração espacial inclui 26 municípios, sendo Maringá (polo) o terceiro maior município do Paraná, mais oito municípios com população a partir de 20 mil até 100 mil habitantes, são eles Sarandi, Paiçandu, Marialva, Mandaguari, Nova Esperança, Astorga, Mandaguaçu, Jandaia do Sul. Santa fé como único município com até 12 mil habitantes e por fim os restantes que correspondem a maioria dos municípios (16) com população inferior 
a 10 mil habitantes, entre eles Cambira, Bom Sucesso, Floresta, Itambé, Doutor Camargo, São Jorge do Ivaí, Presidente Castelo Branco, Floraí, Lobato, Iguaraçu, Munhoz de Melo, Atalaia, Ourizona, Ivatuba, Ângulo e Flórida.

Os dados sobre a região abordada, utilizados nesta pesquisa foram obtidos do Relatório Resumido da Execução Orçamentária (RREO), composto por diversos demonstrativos que são disponibilizados nos sites da Secretaria do Tesouro Nacional e do Tribunal de Contas do Estado do Paraná, e exportados para planilhas do Excel. Após isso, foram selecionadas as informações que seriam utilizadas, organizadas em partes de receitas arrecadadas e despesas empenhadas na educação em formato de tabelas analíticas.

\subsection{DESCRIÇÃO DOS DADOS E APRECIAÇÃO DOS RESULTADOS}

A partir das informações coletadas se elaborou esquemas que retratam e possibilitam verificar informações a respeito do orçamento da Região Metropolitana de Maringá no período de abrangência dessa pesquisa. Na Tabela 1 se apresenta o Percentual do aumento/diminuição da receita total arrecadada entre 2013 e 2019.

Tabela 1 - Percentual do aumento/diminuição da receita total arrecadada entre 2013 e 2019

\begin{tabular}{|c|c|c|c|c|c|c|c|c|}
\hline \multicolumn{9}{|c|}{ AUMENTO/DIMINUIÇÃO DA RECEITA } \\
\hline & $\begin{array}{c}2013 / \\
2014\end{array}$ & $\begin{array}{c}2014 / \\
2015\end{array}$ & $\begin{array}{c}2015 / \\
2016\end{array}$ & $\begin{array}{c}2016 / \\
2017\end{array}$ & $\begin{array}{c}2017 / \\
2018\end{array}$ & $\begin{array}{c}2018 / \\
2019\end{array}$ & MÉDIA & RANKING \\
\hline Ivatuba & $21,91 \%$ & $1,36 \%$ & $19,28 \%$ & $118,03 \%$ & $53,12 \%$ & $-65,04 \%$ & $21,24 \%$ & 10 \\
\hline Floresta & $47,82 \%$ & $3,84 \%$ & $24,91 \%$ & $-5,06 \%$ & $7,12 \%$ & $7,85 \%$ & $12,35 \%$ & $2^{\circ}$ \\
\hline S. J. Do Ivaí & $16,41 \%$ & $5,50 \%$ & $14,98 \%$ & $3,72 \%$ & $29,41 \%$ & VNI & $11,67 \%$ & $3^{\circ}$ \\
\hline Sarandi & $17,52 \%$ & $-11,60 \%$ & $38,74 \%$ & $0,62 \%$ & $36,15 \%$ & $-9,08 \%$ & $10,33 \%$ & $4 \underline{0}$ \\
\hline Ângulo & $28,46 \%$ & $-3,60 \%$ & $27,96 \%$ & $3,54 \%$ & $14,23 \%$ & $-4,02 \%$ & $9,51 \%$ & 50 \\
\hline Bom Sucesso & $2,79 \%$ & $13,84 \%$ & $33,56 \%$ & $-11,57 \%$ & $26,71 \%$ & $0,46 \%$ & $9,40 \%$ & 60 \\
\hline Paiçandu & $17,54 \%$ & $9,34 \%$ & $13,91 \%$ & $21,22 \%$ & $-5,62 \%$ & $8,66 \%$ & $9,29 \%$ & $7 \underline{0}$ \\
\hline Santa Fé & $11,78 \%$ & $7,60 \%$ & $8,70 \%$ & $22,51 \%$ & $9,64 \%$ & $3,14 \%$ & $9,05 \%$ & $8^{0}$ \\
\hline Mandaguaçu & $23,11 \%$ & $10,28 \%$ & $2,46 \%$ & $21,22 \%$ & $-6,05 \%$ & $11,91 \%$ & $8,99 \%$ & 90 \\
\hline Flórida & $19,61 \%$ & $20,97 \%$ & $9,40 \%$ & $-6,19 \%$ & $22,35 \%$ & $-3,84 \%$ & $8,90 \%$ & $10^{\circ}$ \\
\hline Dr. Camargo & $24,35 \%$ & $16,58 \%$ & $9,56 \%$ & $6,16 \%$ & $12,13 \%$ & $-7,30 \%$ & $8,78 \%$ & $11^{\circ}$ \\
\hline P. C. Branco & $5,65 \%$ & $29,45 \%$ & $23,05 \%$ & $-3,20 \%$ & $0,84 \%$ & $4,99 \%$ & $8,68 \%$ & $12^{\circ}$ \\
\hline Iguaraçu & $1,16 \%$ & $27,86 \%$ & $13,73 \%$ & $-0,99 \%$ & VNI & VNI & $8,35 \%$ & $13^{\circ}$ \\
\hline Maringa & $12,32 \%$ & $10,74 \%$ & $11,91 \%$ & $3,07 \%$ & $19,22 \%$ & $0,00 \%$ & $8,18 \%$ & $14^{\circ}$ \\
\hline Lobato & $18,55 \%$ & $6,45 \%$ & $23,36 \%$ & $-3,95 \%$ & $13,11 \%$ & $-1,10 \%$ & $8,06 \%$ & $15^{\circ}$ \\
\hline Cambira & $12,29 \%$ & $6,64 \%$ & $9,95 \%$ & $8,16 \%$ & $15,22 \%$ & $1,37 \%$ & $7,66 \%$ & $16^{0}$ \\
\hline M. De melo & $1,75 \%$ & $17,37 \%$ & $11,63 \%$ & $4,63 \%$ & $21,50 \%$ & $-3,60 \%$ & $7,61 \%$ & $17^{\circ} \underline{0}$ \\
\hline Floraí & $14,43 \%$ & $15,53 \%$ & $4,89 \%$ & $2,17 \%$ & $7,62 \%$ & $8,45 \%$ & $7,58 \%$ & $18^{\circ}$ \\
\hline N. Esperança & $3,03 \%$ & $15,89 \%$ & $12,04 \%$ & $6,14 \%$ & $13,97 \%$ & $-0,91 \%$ & $7,17 \%$ & $19^{\circ}$ \\
\hline J. Do sul & $12,35 \%$ & $7,17 \%$ & $5,79 \%$ & $13,89 \%$ & $9,53 \%$ & $-0,51 \%$ & $6,89 \%$ & $20^{\circ}$ \\
\hline Atalaia & $-1,31 \%$ & $14,97 \%$ & $27,98 \%$ & $1,96 \%$ & $-0,18 \%$ & $0,04 \%$ & $6,21 \%$ & $21^{\circ}$ \\
\hline Ourizona & $11,99 \%$ & $8,30 \%$ & $7,22 \%$ & $3,26 \%$ & VNI & VNI & $6,15 \%$ & $22^{\circ}$ \\
\hline Mandaguari & $9,36 \%$ & $11,03 \%$ & $11,31 \%$ & $0,03 \%$ & $5,25 \%$ & $5,79 \%$ & $6,11 \%$ & $23^{\circ}$ \\
\hline Itambé & $17,47 \%$ & $4,11 \%$ & $13,02 \%$ & $3,01 \%$ & $14,67 \%$ & $-16,16 \%$ & $5,16 \%$ & $24^{\circ}$ \\
\hline Astorga & VNI & VNI & $16,82 \%$ & $2,21 \%$ & $5,78 \%$ & $-0,59 \%$ & $4,84 \%$ & 25 o \\
\hline Marialva & VNI & VNI & $14,52 \%$ & $-8,83 \%$ & $-7,90 \%$ & $23,53 \%$ & $4,26 \%$ & $26^{0}$ \\
\hline
\end{tabular}

Por detrimento, os dados faltantes da tabela estão representados pela abreviação VNI (valores não informados) por serem considerados valores indisponíveis nas bases de pesquisa utilizadas neste estudo. Por conta disso os valores de média foram calculados proporcionalmente aos anos que continham os dados para análise. De acordo com a tabela 1, se pode verificar os municípios que tiveram aumento na arrecadação, no período do estudo, em termos de acréscimo na arrecadação, de no mínimo 4\% dentro dos 7 anos analisados. 0 período de 2014 para 2015 destaca-se como o segundo período com menor aumento na arrecadação de receitas, visto que o Brasil se encontrava no início de uma crise econômica, marcada por uma recessão. No período de 2015 para 2016 houve uma recuperação desses valores, de acordo com 
os valores expostos na tabela ao analisa-la por período, sendo o período com maior aumento na arrecadação comparado ao período anterior, em seguida, ainda por reflexo dessa crise o período de 2016 para 2017, mas no geral, mantiveram as arrecadações positivas, não sendo tão discrepante quanto às dos anos de 2015 para 2016. Já em 2017 para 2018, os municípios voltam às normalidades de suas receitas, até que o ano de 2018 é marcado com a greve dos caminhoneiros que impactaram negativamente nas arrecadações de receitas e a maioria dos municípios regrediram diante disso, fazendo com o que o período de 2018 para 2019 fosse marcado com os menores percentuais de arrecadação de receitas dentro do período em questão.

Tendo em vista os quatro primeiros colocados do ranking, pode-se dizer que alguns dos menores municípios foram os que mais tiveram aumento na arrecadação de suas receitas, em destaque o município de Ivatuba que em média arrecadou 21,24\%, marcada por uma variação positiva discrepante de $118 \%$ entre o ano de 2015 e 2016 . Os outros municípios tiveram a média entre $10 \%$ e $12 \%$ de variação positiva. Em segundo lugar, Floresta atinge o percentual de 12,35 com destaque no período de 2013-2017, em que obteve um aumento de 47,82\%. 0 terceiro lugar é ocupado pelo município de São Jorge do Ivaí com média de 11,67\% com aumento em 2017 para 2018 de quase 30\%. Enfim, o quarto lugar com média de 10,33\% de aumento fica com município de Sarandi, em que destacam-se dois períodos com aumento para seu resultado final que são os períodos de 2015-2016 e 2017-2018 que atingem percentual entre 36 até 39.

Ao que se refere às outras colocações do quinto ao décimo quinto lugar ocupam os municípios que registram uma média de 8 a 10\% de aumento em suas receitas arrecadadas, Maringá ocupa o décimo quarto lugar com $8,18 \%$ tendo em vista que conseguiu manter o crescimento positivo em todos os períodos, em destaque o período de 2017-2018 com 19,22\%. Do décimo sexto até o vigésimo quarto lugar registram as porcentagens de 5 a 8\% tendo os municípios de Cambira, Floraí e Mandaguari com arrecadação positiva em todos os anos e o município de Itambé com a segunda maior queda de todas de 16,16\% no período de 2018 para 2019 decaindo assim sua média que vinha sendo positiva em todos os períodos. Por fim, dois municípios (Astorga e Marialva) tiveram um aumento na arrecadação em média de menos de 5\%, apesar de estarem com desfalque de dados, Astorga teve somente um período negativo (2018-2019) na média de 0,59, enquanto Marialva permanece com diminuição de arrecadação por dois períodos consecutivos, são eles de 2016 à 2018 variando entre 7 a 9\%.

Após apresentados os dados de aumento/diminuição da receita total arrecadados dos municípios, cabe analisar o item foco da pesquisa, o investimento na educação. No que tange a área de investimentos em educação, está estabelecido na Constituição Federal, art. 212, que deverá ser aplicado o mínimo de 25\% (vinte e cinco por cento) da receita resultante de impostos, sendo direcionadas para transferências, manutenção e desenvolvimento do ensino. 0 desempenho dos investimentos em educação da Região Metropolitana de Maringá pode ser analisado na Tabela 2.

Analisando os dados da tabela 2, pode-se concluir que os percentuais investidos variam bastante entre os municípios e entre os anos. Primeiramente se verifica os municípios que atingiram ou não a meta estabelecida pela legislação, sendo que em primeiro lugar o município de Paiçandu ultrapassou o percentual obrigatório em todos os anos, resultando numa média de 33\% de investimento sobre, com destaque em 2018 com 36\% da receita total arrecadada investida na educação, sendo o município que mais investiu em educação no período de tempo analisado. Na sequência, do segundo ao quinto lugar, todos os anos analisados de cada município, entre eles Mandaguari, Mandaguaçu, Astorga e Sarandi respectivamente, investiram mais de $20 \%$ da receita total arrecadada. 0 município de Mandaguari cumpriu a lei em quase todos os anos, ficando bem próximo em 2013 com 24,58\% e com destaque no ano de 2015 com 28,89\% investidos. Já Mandaguaçu ocupa o terceiro lugar com uma média de investimento próximo de $24 \%$, em que os anos de 2018 e 2019 investiu em torno de $27 \%$ e nos outros anos variou de 20 a $24 \%$ em seus investimentos na educação. Astorga encontra-se em quarto lugar com uma média de 23,35\% desconsiderando 2014 por falta de dados, não atingiu a meta em nenhum dos anos, variando entre 21 a $24 \%$, no caso de 2017 foi o ano que mais investiu. 
Tabela 2 - Percentual dos investimentos em educação entre 2013 e 2019.

\begin{tabular}{|c|c|c|c|c|c|c|c|c|c|}
\hline \multicolumn{10}{|c|}{ GASTO EM EDUCAÇÃO } \\
\hline & 2013 & 2014 & 2015 & 2016 & 2017 & 2018 & 2019 & MÉDIA & RANKING \\
\hline Paiçandu & $30,51 \%$ & $30,86 \%$ & $34,14 \%$ & $34,65 \%$ & $31,36 \%$ & $36,02 \%$ & $33,74 \%$ & $33,04 \%$ & $1^{0}$ \\
\hline Mandaguari & $24,58 \%$ & $26,30 \%$ & $28,89 \%$ & $26,06 \%$ & $25,88 \%$ & $25,15 \%$ & $26,50 \%$ & $26,19 \%$ & $2^{\circ}$ \\
\hline Mandaguaçu & $20,75 \%$ & $22,21 \%$ & $21,62 \%$ & $24,75 \%$ & $23,62 \%$ & $27,21 \%$ & $27,11 \%$ & $23,90 \%$ & $3^{0}$ \\
\hline Astorga & $21,45 \%$ & VNI & $23,90 \%$ & $22,78 \%$ & $24,04 \%$ & $23,95 \%$ & $23,96 \%$ & $23,35 \%$ & $4 \underline{0}$ \\
\hline Sarandi & $22,26 \%$ & $21,52 \%$ & $27,73 \%$ & $24,27 \%$ & $24,24 \%$ & $20,75 \%$ & $21,05 \%$ & $23,12 \%$ & $5^{\circ}$ \\
\hline Santa Fé & $19,45 \%$ & $20,44 \%$ & $23,54 \%$ & $23,03 \%$ & $20,99 \%$ & $21,44 \%$ & $18,61 \%$ & $21,07 \%$ & $6^{0}$ \\
\hline Floresta & $18,95 \%$ & $19,52 \%$ & $21,04 \%$ & $21,26 \%$ & $23,89 \%$ & $22,19 \%$ & $20,41 \%$ & $21,04 \%$ & 70 \\
\hline P. C. Branco & VNI & VNI & $20,48 \%$ & $20,79 \%$ & $21,21 \%$ & $20,65 \%$ & $20,89 \%$ & $20,80 \%$ & $8^{0}$ \\
\hline Cambira & $17,63 \%$ & $19,10 \%$ & $21,20 \%$ & $21,54 \%$ & $20,93 \%$ & $20,35 \%$ & $22,70 \%$ & $20,49 \%$ & 90 \\
\hline Dr. Camargo & $19,64 \%$ & $18,13 \%$ & $22,21 \%$ & $18,99 \%$ & $22,69 \%$ & $20,36 \%$ & $21,38 \%$ & $20,48 \%$ & $10^{\circ}$ \\
\hline Itambé & $17,83 \%$ & $18,41 \%$ & $22,23 \%$ & $19,98 \%$ & $21,14 \%$ & $18,89 \%$ & $24,12 \%$ & $20,37 \%$ & $11^{\circ}$ \\
\hline N. Esperança & $18,24 \%$ & $21,03 \%$ & $19,03 \%$ & $21,17 \%$ & $19,28 \%$ & $18,98 \%$ & $20,94 \%$ & $19,81 \%$ & $12^{\circ}$ \\
\hline J. Do sul & $15,71 \%$ & $18,26 \%$ & $20,01 \%$ & $21,59 \%$ & $20,35 \%$ & $20,85 \%$ & $21,78 \%$ & $19,79 \%$ & $13^{\circ}$ \\
\hline Atalaia & $17,75 \%$ & $21,81 \%$ & $22,35 \%$ & $19,14 \%$ & $18,02 \%$ & $18,99 \%$ & $19,68 \%$ & $19,68 \%$ & $14^{\circ} \mathrm{o}$ \\
\hline Marialva & $13,97 \%$ & VNI & $21,21 \%$ & $18,15 \%$ & $20,07 \%$ & $24,95 \%$ & $19,70 \%$ & $19,68 \%$ & $15^{\circ}$ \\
\hline Floraí & $17,88 \%$ & $20,18 \%$ & $17,67 \%$ & $16,63 \%$ & $20,51 \%$ & $17,56 \%$ & $24,79 \%$ & $19,32 \%$ & $16^{0}$ \\
\hline Iguaraçu & $18,84 \%$ & $19,49 \%$ & $17,55 \%$ & $17,68 \%$ & $21,11 \%$ & VNI & $19,90 \%$ & $19,09 \%$ & $17^{\circ}$ \\
\hline Maringa & $16,15 \%$ & $15,92 \%$ & $18,76 \%$ & $16,55 \%$ & $18,56 \%$ & $15,57 \%$ & $18,67 \%$ & $17,17 \%$ & $18^{\circ}$ \\
\hline S. J. Do Ivaí & $18,18 \%$ & $17,64 \%$ & $17,48 \%$ & $16,91 \%$ & $17,57 \%$ & $12,68 \%$ & VNI & $16,74 \%$ & 190 \\
\hline Lobato & $17,08 \%$ & $18,73 \%$ & $17,07 \%$ & $15,02 \%$ & $15,78 \%$ & $14,84 \%$ & $16,24 \%$ & $16,39 \%$ & $20^{\circ}$ \\
\hline M. De Melo & $12,87 \%$ & $19,87 \%$ & $15,71 \%$ & $15,49 \%$ & $17,47 \%$ & $16,07 \%$ & $14,28 \%$ & $15,97 \%$ & $21^{\circ}$ \\
\hline Ourizona & $14,47 \%$ & $14,85 \%$ & $14,55 \%$ & $15,69 \%$ & $14,82 \%$ & VNI & $20,46 \%$ & $15,81 \%$ & $22^{\circ}$ \\
\hline Bom Sucesso & $13,65 \%$ & $13,60 \%$ & $14,68 \%$ & $17,77 \%$ & $14,92 \%$ & $12,70 \%$ & $14,52 \%$ & $14,55 \%$ & $23^{\circ}$ \\
\hline Ângulo & $13,26 \%$ & $19,83 \%$ & $14,67 \%$ & $12,70 \%$ & $13,63 \%$ & $13,67 \%$ & $13,30 \%$ & $14,44 \%$ & $24^{\circ}$ \\
\hline Flórida & $13,22 \%$ & $15,43 \%$ & $11,86 \%$ & $12,88 \%$ & $15,27 \%$ & $12,40 \%$ & $13,62 \%$ & $13,52 \%$ & $25^{\circ}$ \\
\hline Ivatuba & $12,23 \%$ & $20,19 \%$ & $15,47 \%$ & $12,21 \%$ & $7,90 \%$ & $3,90 \%$ & $11,21 \%$ & $11,87 \%$ & $26^{\circ}$ \\
\hline
\end{tabular}

Do quarto lugar em diante nenhum dos municípios citados atingiram a meta de investimento estabelecida em algum dos anos, sendo assim é possível analisar as colocações no ranking. Entre o sexto e o décimo primeiro lugar, estão colocados os municípios que atingiram uma média de 20 a $21 \%$. Em sexto e sétimo estão respectivamente Santa Fé $(21,07 \%)$ e Floresta $(21,04 \%)$, sendo que em todos os anos ficaram acima de 18\% investido e o máximo atingido foi 23,89\% em 2017 pelo município de Floresta, seguido por 23,54\% em 2015 por Santa Fé. Com referência ao oitavo até décimo primeiro lugar, Presidente Castelo Branco (20,80\%), Cambira (20,49\%), Doutor Camargo (20,48\%) e Itambé $(20,37 \%)$, todos citados atingem em média 20\% investidos, com Cambira marcando menor percentual investido em 2013 com somente 17,63\% e Itambé registrando o maior percentual entre os outros municípios com 24,12\% em 2019. Seguindo a mesma linha de raciocínio, Cambira e Doutor Camargo resultam em 22,70\% (2019) e 22,69\% (2017) respectivamente. 
Dentro da décima segunda à décima oitava colocação, estão os municípios que investem entre 17 e $20 \%$ das suas receitas, atingindo a maior colocação Nova Esperança com 19,81\% de média, com variação de $18,24 \%$ (2013) a 21,17\% (2016). Até o décimo sétimo lugar, todos municípios investiram mais de 19\% em média, com pertinência nos investimentos pode-se citar os municípios de Atalaia (14º) com 22,35\% em 2015, Marialva (15ㅇ) e Floraí (16º) quase atingiram o percentual regido em lei, resultando em 24,95\% em 2018 e 24,79\% em 2019, respectivamente. No caso de Maringá, o município com maior território e mais populosa de toda região analisada, ocupa o décimo oitavo lugar com uma média de investimento de $17,17 \%$, sendo 2015 o ano que mais investiu (18,76\%) e 2018 o ano que menos investiu $(15,57 \%)$.

Os municípios de São Jorge do Ivaí e Lobato ocupam décimo nono e vigésimo lugar com as médias de $16,74 \%$ e 16,39\%, o ano que os dois menos investiram foi de 2018 com percentual de 12,68 e 14,84 nesta ordem. Por outro lado, São Jorge do Ivaí teve destaque em 2013 com 18,18\% e Lobato com 18,72\% em 2014. As seguintes colocações entre o vigésimo primeiro lugar e o vigésimo quarto variam entre as médias de 14 a 16\%. 0 município de Munhoz de Melo atinge o menor percentual de investimento na educação em 2013 com 12,87\% e a máxima em 2014 com 19,87\%, na seguinte posição Ourizona segue três anos (20132015) investindo na média 14,5\% e atinge seu pico no ano de 2019 com 20,46\%. Bom Sucesso e Ângulo investem uma média abaixo de 15\% (14,55\% e 14,44\%), mesmo assim em 2016 o ano que Bom Sucesso mais investiu 17,77\%, por outro lado fica abaixo da média (12 a 13\%) em 2013, 2014 e 2018 e na ordem Ângulo em 2014 alcança o percentual de 19,83\%, mas ficam abaixo da média (12 a 13\%) por quatro anos 2013, 2016, 2018 e 2019.

Por fim, os dois últimos municípios colocados no ranking são Flórida e Ivatuba, contam com um percentual de 13,52\% e 11,87\% investidos, Flórida conta com uma máxima em 2015 resultando em 15,43 e uma mínima de 11,86\% em 2014, foi o segundo município que menos investiu em educação dentre os anos analisados. Em primeiro lugar tem-se o município de Ivatuba, com as mínimas de 7,90 (2017) e 3,90 (2018), mas com maior valor investido em 2014 com 20,19\%. Contudo, depois de analisado os percentuais investidos, será demonstrado a relação ou não das receitas totais arrecadas e os investimentos, a fim de declarar uma relação entre o aumento/diminuição da receita e o percentual investido de cada município. Para este fim, a seguir a Tabela 3 demonstra o ranking analisados por uma média percentual dos municípios que mais e menos arrecadaram receitas, juntamente com a colocação dos investimentos.

Pode-se observar por meio dos dados coletados, que os investimentos em educação nos municípios analisados não acompanhou a evolução da arrecadação durante o período, pois, ao analisar o ranking das duas variáveis estudadas, não é possível estabelecer ligação direta do aumento/diminuição da receita total arrecadada com os investimentos em educação, mas que na maioria dos casos de aumento da receita arrecadada, houve uma diminuição do percentual investido em educação, por conta do percentual de aumento das receitas não estar relacionado com o volume investido na educação. Como a tabela 3 demonstra, é possível perceber um exemplo claro de como isso ocorre no município de Ivatuba, este ocupa o primeiro lugar com aumento de em média $21,24 \%$ de suas receitas totais e o mesmo ocupa o último lugar (vigésimo sexto) em investimento na educação, com uma média de 11,87\% investidos. Isto ocorre por conta dos investimentos não aumentarem de acordo com que aumenta-se a receita arrecada, assim acontece em 2017 em que consta um aumento de 118\% na receita total arrecadada no período de 20162017 e apenas 7,90\% investidos na educação.

O inverso acontece com o município de Mandaguari, este ocupa o vigésimo terceiro lugar com uma média de 6,11\% de aumento nas receitas, mas fica em segundo lugar nos investimentos com educação com percentual de 26,19, ou seja, ele continuou investindo uma média de 26,19\% mesmo não havendo um aumento proporcional de suas receitas. Alguns outros municípios com essa discrepância, pode-se citar Bom Sucesso em sexto lugar com um aumento de 9,40\% das receitas e vigésimo terceiro lugar nos investimentos com uma média de 14,55\% investidos, em contrapartida o município de Astorga ocupa o vigésimo quinto lugar nas arrecadações das receitas totalizando 4,84\% de aumento, já nos investimentos consegue manter um percentual de em média 23,35\% aplicados na educação se colocando em quarto lugar no ranking. 
Tabela 3 - Ranking em percentual das médias dos municípios em arrecadação e gastos

\begin{tabular}{|c|c|c|c|c|}
\hline \multirow[b]{2}{*}{ RANKING } & \multicolumn{2}{|l|}{ RECEITA } & \multicolumn{2}{|l|}{ GASTO EM } \\
\hline & ARRECADADA & MÉDIA & EDUCAÇÃO & MÉDIA \\
\hline $1^{o}$ & Ivatuba & $21,24 \%$ & Paiçandu & $33,04 \%$ \\
\hline $2^{o}$ & Floresta & $12,35 \%$ & Mandaguari & $26,19 \%$ \\
\hline $3^{\mathrm{o}}$ & São Jorge do Ivaí & $11,67 \%$ & Mandaguaçu & $23,90 \%$ \\
\hline $4^{\circ}$ & Sarandi & $10,33 \%$ & Astorga & $23,35 \%$ \\
\hline $5^{\mathrm{o}}$ & Ângulo & $9,51 \%$ & Sarandi & $23,12 \%$ \\
\hline $6^{0}$ & Bom Sucesso & $9,40 \%$ & Santa Fé & $21,07 \%$ \\
\hline $7^{\circ}$ & Paiçandu & $9,29 \%$ & Floresta & $21,04 \%$ \\
\hline $8^{o}$ & Santa Fé & $9,05 \%$ & P. Castelo Branco & $20,80 \%$ \\
\hline 9o & Mandaguaçu & $8,99 \%$ & Cambira & $20,49 \%$ \\
\hline $10^{\mathrm{o}}$ & Flórida & $8,90 \%$ & Doutor Camargo & $20,48 \%$ \\
\hline $11^{\mathrm{o}}$ & Doutor Camargo & $8,78 \%$ & Itambé & $20,37 \%$ \\
\hline $12^{\mathrm{o}}$ & P. Castelo Branco & $8,68 \%$ & Nova Esperança & $19,81 \%$ \\
\hline $13^{0}$ & Iguaraçu & $8,35 \%$ & Jandaia do Sul & $19,79 \%$ \\
\hline $14^{\mathrm{o}}$ & Maringa & $8,18 \%$ & Atalaia & $19,68 \%$ \\
\hline $15^{0}$ & Lobato & $8,06 \%$ & Marialva & $19,68 \%$ \\
\hline $16^{\mathrm{o}}$ & Cambira & $7,66 \%$ & Floraí & $19,32 \%$ \\
\hline $17^{\circ} \stackrel{0}{-}$ & Munhoz de Melo & $7,61 \%$ & Iguaraçu & $19,09 \%$ \\
\hline $18^{0}$ & Floraí & $7,58 \%$ & Maringa & $17,17 \%$ \\
\hline 190 & Nova Esperança & $7,17 \%$ & São Jorge do Ivaí & $16,74 \%$ \\
\hline $20^{\circ}$ & Jandaia do Sul & $6,89 \%$ & Lobato & $16,39 \%$ \\
\hline $21^{\circ}$ & Atalaia & $6,21 \%$ & Munhoz de Melo & $15,97 \%$ \\
\hline $22^{\circ}$ & Ourizona & $6,15 \%$ & Ourizona & $15,81 \%$ \\
\hline $23^{\circ}$ & Mandaguari & $6,11 \%$ & Bom Sucesso & $14,55 \%$ \\
\hline $24 \underline{0}$ & Itambé & $5,16 \%$ & Ângulo & $14,44 \%$ \\
\hline $25^{\circ}$ & Astorga & $4,84 \%$ & Flórida & $13,52 \%$ \\
\hline $26^{\circ}$ & Marialva & $4,26 \%$ & Ivatuba & $11,87 \%$ \\
\hline
\end{tabular}

Alguns municípios mantém uma distância menor entre o aumento de arrecadação das receitas com os investimentos, como no caso de Floresta que fica em segundo lugar com relação às receitas com média de 12,35\%, enquanto seus investimentos ficam na média de 21,04\% em sétimo lugar. Mandaguaçu mantém uma distância de seis colocações de um ranking para o outro, sendo suas receitas em nono lugar com $8,99 \%$ de aumento e em terceiro lugar nos investimentos totalizando $23,90 \%$. No caso de Sarandi, a distância no ranking diminui, apenas uma colocação de diferença, com 10,33\% ocupa o quarto lugar em relação às receitas e quinto lugar nos investimentos com $23,12 \%$, com isso nota-se que os investimentos acompanham a variação das receitas arrecadadas. No caso de Santa Fé também tem uma distância menor, de duas colocações, com 9,05\% de aumento nas receitas em oitavo lugar e nos investimentos ocupa o sexto lugar totalizando uma média de 21,07\%. Em décimo primeiro lugar, Doutor Camargo atinge 8,78\% de aumento nas receitas e em décimo lugar com 20,48\% nos investimentos, com uma posição de diferença. Seguindo este raciocínio o município de Ourizona é o único município que mais aproxima seus investimentos na educação com relação à receita que arrecada, não é o que mais investe, mas com relação 
à variação de arrecadação consegue manter seus investimentos na média de 15,81\% em vigésimo segundo lugar e com aumento de 6,15\%.

0 município que mais investe em educação é Paiçandu com 33,04\% de média, estando com uma distância de seis colocações do ranking das receitas, em que ocupa o sétimo lugar com 9,29\% de aumento, com isso pode-se verificar que o município continuou aplicando em educação de forma crescente mesmo com sua receita variando ao longo dos anos, alcançando um resultado positivo em todos os anos. Dentre os municípios que conseguem aproximar seus investimentos com a variação de suas receitas, numa média de investimento inferior encontra-se Floraí, com 7,58\% de aumento nas receitas estando em décimo oitavo lugar e com investimentos na média de 19,32\% em décimo sexto lugar. Iguaraçu e Munhoz de Melo mantém um intervalo de quatro posições de um ranking para o outro, o primeiro ocupa o décimo terceiro lugar com um aumento de 8,35\%, mas com investimento de 19,09\% em décimo sétimo lugar e o segundo investe uma média de 15,95\% estando em vigésimo primeiro lugar e com um aumento de 7,16\% em suas receitas atingindo a décimo sétimo lugar, nos dois casos os investimentos ficam estagnados e abaixo da média e as arrecadações das receitas variam no período. Com relação ao município de Lobato tem-se uma distância de cinco colocações, em décimo quinto lugar no aumento das receitas $(8,35 \%)$ e em vigésimo lugar nos investimentos (16,39\%), neste caso os investimentos também não acompanharam a variação positiva de receita no decorrer dos anos.

Há três municípios que mantém a mesma distância entre as colocações em sete posições, o primeiro município é o de Nova Esperança que ocupa o décimo segundo lugar com 19,81\% tratando-se de investimentos à educação, seguido por Jandaia do Sul em décimo terceiro com uma média de 19,79\% e Atalaia com 19,68\% em décimo quarto lugar. Com relação às receitas totais arrecadas, posicionam-se em décimo nono com $7,17 \%$ de aumento, vigésimo com $6,89 \%$ e por fim vigésimo primeiro com $6,21 \%$, seguindo a ordem citada anteriormente. Os três municípios conseguem manter seus investimentos na média, sem muito aumento e nem diminuição, mesmo com sua receita variando e não aumentando tanto.

São Jorge do Ivaí e Ângulo também mantém uma distância considerável de 16 e 19 colocações respectivamente, com um aumento considerável nas receitas ocupando o terceiro $(11,67 \%)$ e quinto (9,51\%) e com um investimento inferior, correspondente à média de $16,74 \%$ e $14,44 \%$ nesta ordem. Os municípios de Itambé e Flórida pode-se ver um distanciamento entre as variáveis de 13 e 15 posições, no caso de Flórida suas receitas variam 8,90\% em média ocupando o décimo lugar enquanto seus investimentos não são favorecidos ocupando o penúltimo lugar no ranking (25ㅇ) com 13,52\% investidos. Já em Itambé acontece o contrário, seus investimentos em educação são contínuos mesmo que sua receita tenha uma variação pequena, o que reflete em uma colocação de décimo primeiro lugar com $20,37 \%$ de investimentos em média e um aumento de receita de 5,16\% em vigésimo quarto lugar. Este caso também pode ser observado no município de Marialva, que apesar de não atingirem a meta de investimento, conseguem manter uma média de investimento de 19,68\% ocupando o décimo quinto lugar com um aumento apenas de $4,26 \%$ de suas receitas ficando em último lugar (26) neste quesito.

Visando as pesquisas prévias sobre investimentos em educação citados no tópico 2, de acordo com a Constituição Federal a educação é um direito de todos e incentivada com colaboração da sociedade, sendo assim é estabelecido um investimento mínimo por seus dirigentes de $25 \%$ das receitas totais arrecadadas, que são geradas para atender as necessidades e demanda da sociedade. Tendo isso em vista, dentre todos municípios analisados somente Paiçandu atinge o percentual exigido em todos os anos analisados alcançando uma média de 33,04\% referente às receitas totais arrecadadas pelos dirigentes por meio de impostos pagos pela sociedade. Pode-se citar também o município de Mandaguari que atinge o disposto em Lei em quase todos os anos, ficando abaixo somente em 2013 e com média de 26,19\%, no caso dos dois municípios seguintes suas médias não atingem os $25 \%$, mas nos respectivos anos conseguem fazer um investimento adequado, em Mandaguaçu atinge em 2018 com 27,21\% e 2019 com 27,11\% e Sarandi em 2015 com $27,73 \%$ somente.

No entanto, tem-se o estudo feito por Cruz (2018) em que dispõe sobre orientação e limites de gastos para garantir o aproveitamento dos recursos e em seguida uma pesquisa realizada pela FIRJAN (2019) destaca que a maioria dos estados brasileiros concentram suas despesas em pagamento pessoal o que prejudica os investimentos com educação. Por meio destes pode-se concluir que, exceto Paiçandu e Mandaguari, todos os outros municípios deixam de atingir o percentual mínimo obrigatório por lei, limites de gastos e direcionamento adequado às receitas arrecadas, ou seja, os pagamentos de impostos feitos pela sociedade não estão sendo aplicados de forma que haja um crescimento e aproveitamento econômico direto e relevante, como com a educação de todos. 
Portanto, com referência à um estudo feito por Sen (2010) ficou comprovado que os investimentos em educação contribuem no crescimento econômico de um país, no que diz respeito aos investimentos direcionados à educação a região Metropolitana de Maringá. Pode-se dizer que, 24 dos 26 municípios analisados não cumprem a Lei, demonstrando baixos índices de investimento em educação, visto que a sociedade está sendo penalizada sem obter o retorno esperado sobre os pagamentos de impostos (receitas).

\section{CONSIDERAÇÕES FINAIS}

A legislação brasileira foi promulgada pelo governo como instrumento de controle das contas públicas, visando melhorar a aplicação dos recursos, dentre as quais se tem a LRF, a Lei da Transparência, a Lei de Acesso à Informação e a própria Constituição Federal. O objetivo dessas legislações é de estabelecer metas, limites e uma ampla divulgação e transparência das informações, a fim de possibilitar a monitoria, fiscalização, e supervisionar os atos praticados pelos gestores públicos, exercendo um controle social. A aplicação dos recursos públicos deve ser feita de modo a atender a legislação e proporcionar maiores taxas de crescimento econômico, redução da desigualdade social e aumentar a qualidade de vida da população. Diante disso, o desenvolvimento desta pesquisa partiu do objetivo de investigar os investimentos em educação no período de 2013 a 2019 na região metropolitana de Maringá.

Os resultados do estudo evidenciaram, em relação às receitas totais arrecadadas dos municípios analisados dentro do período em questão, pode-se dizer que todos municípios houve um crescimento nas receitas, variando bastante entre anos, mas com no máximo dois anos de diminuição. Observa-se também que que a maioria (18 municípios) ficam entre as médias de 6 a 10\% de aumento, são eles Ângulo (9,61\%), Bom Sucesso (9,40\%), Paiçandu (9,29\%), Santa Fé (9,05\%), Mandaguaçu (8,99\%), Flórida (8,90\%), Doutor Camargo (8,78\%), Presidente Castelo Branco (8,68\%), Iguaraçu (8,35\%), Maringá (8,18\%), Lobato $(8,06 \%)$, Cambira (7,66\%), Munhoz de Melo (7,61\%), Floraí (7,58\%), Nova Esperança (7,17\%), Jandaia do Sul (6,89\%), Atalaia (6,21\%), Ourizona $(6,15 \%)$ e Mandaguari $(6,11 \%)$ os acima dessa média ficam Sarandi (10,33\%), São Jorge do Ivaí (11,67\%) e Floresta (12,35\%) e com destaque o município de Ivatuba $(21,24 \%)$ com média acima de $21 \%$ e por fim os abaixo de $6 \%$ estão Itambé $(5,16 \%)$, Astorga $(4,84 \%)$ e Marialva (4,26\%).

No que diz respeito aos investimentos, verifica-se que os pontos expostos nesta pesquisa se trata de variáveis que não tem natureza relacionada, já que cada município trata a aplicação de suas receitas totais arrecadas em investimentos de forma diferente, por mais que haja lei estabelecida pela Constituição Federal expondo o mínimo obrigatório de $25 \%$ da receita total arrecada investida em educação. Tal fato evidencia uma falha grave da gestão municipal, já que não atende à legislação atual e não se encontrou justificativas disponibilizadas para tal questão.

O resultado apontou que não há atendimento a tal determinação, pois, há municípios em que os investimentos em educação atendem e superam ao disposto na lei, como em Paiçandu, todos os anos foram destinados mais que o obrigatório, ainda que suas receitas não cresceram em todos os anos. Já Mandaguari também atinge o percentual em quase todos os anos, menos em 2013 e Mandaguaçu atinge em 2018 e 2019. Alguns outros municípios atingem em um ano ou outro, mas não conseguem manter os investimentos. Sendo assim, é possível visualizar que apenas 2 dos 26 municípios que foram objetos de estudo, atendem ao disposto na legislação, como evidencia a tabela 4.

Considera-se que foi possível verificar como tem ocorrido a destinação de recursos para a educação, considerado a evolução da arrecadação de cada município. Portanto, este estudo contribuiu para o avanço do conhecimento científico na área pública, para o esclarecimento da aplicação dos recursos públicos nos investimentos em educação dos municípios da Região Metropolitana de Maringá, para as futuras decisões e ações dos gestores em relação à destinação dos recursos públicos para a educação, e, despertar a consciência da população da importância da participação social na fiscalização dos recursos públicos.

Por fim, como sugestão para estudos futuros poderiam ser desenvolvidas pesquisas objetivando a análise de outros município e/ou regiões. Pode-se ainda, fazer comparações entre outros municípios, a fim de verificar se possuem a mesma tendência de crescimento ou se são casos particulares. Ainda assim, é possível que se pesquise o tema em outras abordagens ou períodos diferentes para um maior conhecimento e mais informações à sociedade com vistas a melhorias nos controles sociais e transparência das entidades públicas. 


\section{REFERÊNCIAS}

[1] Araújo, I., \& Arruda, D. (2004). Contabilidade Pública: Teoria e Prática. São Paulo.

[2] Brasil. (1988). Constituição da República Federativa do Brasil de 1988. Diário Oficial da União, 05 Outubro 1988. Brasília.

[3] (2020). Ministério da Educação. Fundeb: apresentação. Disponível em: <http://portal.mec.gov.br/fundeb>. Acesso em 15 de nov. 2020.

[4] (2012). Lei Complementar no 141, de 13 de janeiro de 2012. Presidência da República. Brasília. Disponível em: <http://www.planalto.gov.br/ccivil_03/leis/lcp/lcp141.htm>. Acesso em 15 de nov. 2020.

[5] Cruz, A. F. (2018). A gestão fiscal do estado do Rio de Janeiro: uma análise à luz da LRF e da sustentabilidade da dívida no período de 2001 a 2017. Revista de Administração Pública. Rio de Janeiro.

[6] Escola Nacional de Administração Pública - Enap. (2014). Orçamento Público: Conceitos básicos. Enap.

[7] Fernandes, R., \& Gremaud, A. (2009). Avaliação da qualidade da educação no Brasil. Fundação Santillana/INEP.

[8] Governo Federal. (2020). Portal da Transparência. Orçamento Público. Disponível em: http://www.portaltransparencia.gov.br/entenda-a-gestao-publica/orcamento-publico. Acesso em 01de nov. 2020.

[9] Horvath, R. F. O. E. (1999). Manual de Direito Financeiro. 3 ed. São Paulo: Editora RT.

[10] Iudícibus, S.; Marion, J. C. (2009). Introdução à teoria da contabilidade. 5a Ed. São Paulo: Atlas, 2009.

[11] Kohama, H. (2016). Contabilidade pública: teoria e prática. 15ª ed. São Paulo: Atlas, 2016.

[12] Ribeiro, R. R. M. et al. (2020). Investimentos em saúde e educação: um estudo das informações orçamentárias no município de Paiçandu - Paraná. Capítulo de livro. Sistematizando práticas para administrar 2 [recurso eletrônico] / Organizadores Grayce Kelly Bianconi, João Dallamuta. Ponta Grossa: Atena Editora

[13] Ribeiro, R. R. M. et al. (2019). Investimentos na educação infantil: um estudo sobre a destinação de recursos orçamentários em Maringá - Paraná. Congresso Internacional de Administração. Disponível em: <

http://admpg.com.br/2019/anais/arquivos/07282019_180703_5d3e110b7ae89.pdf>. Acesso em 15 de nov. 2020.

[14] Secretaria do Tesouro Nacional. Manual De Contabilidade Pública Aplicada Ao Setor Público (MCASP). 7. Ed. Disponível em: <Http://Www.Tesouro.Fazenda.Gov.Br/-/Mcasp>. Acesso em 30 jun. 2021.

[15] Sen, A. (2010). Desenvolvimento como liberdade. São Paulo: Companhia de Bolso.

[16] Silva, L. M. (2011). Contabilidade governamental: um enfoque administrativo da nova contabilidade pública. São Paulo: Atlas. 


\section{Capítulo 6}

\section{Compliance: A incidência de práticas éticas nas micro e pequenas empresas de Ponta Grossa - PR}

\section{Eliane Iara Bendix}

\section{Rosaly Machado}

Alexsandra Camila Zagulski Iensen

Maria Paula Ferreira Machado

Resumo: Este artigo verificou a percepção dos gestores de um grupo de micro e pequenas empresas atuantes na cidade de Ponta Grossa - PR, no que diz respeito à conformidade das práticas éticas em seus negócios. A metodologia utilizada empregou uma abordagem quanti-qualitativa, quanto aos seus objetivos se classifica como exploratória e fez uso do modelo de cenários de Longeneker et al. (2006). Os dados foram coletados via preenchimento voluntário de um questionário online com 16 questões que descrevem cenários hipotéticos sobre o comportamento ético e compliance. As respostas estavam organizadas conforme uma escala Likert. O link do questionário foi enviado a 39 gestores, clientes de umescritório de contabilidade da cidade, obtendo-se retorno de 12 questionários. Os resultados obtidos indicam que a violação a determinados aspectos de compliance, como desrespeito à gestão ambiental, sobreposição de interesse individual ao empresarial e a ocultação de informação relevante de clientes/associados teve um alto índice de rejeição. Porém, em outras situações, demonstraram não perceber que os pilares éticos são fundamentais para se atingir uma posição de estabilidade no mercado. Adicionalmente, notou-se que o favorecimento empresarial é mais facilmente admitido por estes gestores induzindo-os a um desalinhamento das práticas éticas.

Palavras-Chave: Compliance; Ética nos negócios; Micro e pequenas empresas. 


\section{INTRODUÇÃO}

Frequentemente, a mídia tem noticiado inúmeros escândalos de corrupção em diversos países, inclusive no Brasil, envolvendo empresas de diferentes portes, natureza e regime tributário. Em decorrência disso, o Congresso Brasileiro aprovou a Lei Anticorrupção, Lei 12.846/2013, que dispõem às empresas a estarem em conformidade em seus negócios, zelar pelos padrões éticos e transparência, oferecer treinamento periódicos aos colaboradores, manter canais de fácil acesso para possíveis denúncias, tanto de funcionários quanto de terceiros e que preservem o denunciante. Esta lei não se aplica somente às grandes empresas. As micro e pequenas empresas (MPEs) também têm sido alvo de fiscalização anticorrupção e são pressionadas por parceiros de grande porte a seguir determinados padrões de integridade. Adicionalmente, a negociação com empresas estrangeiras, se dá de forma mais intensa quando a organização apresenta um programa de compliance.

No caso das MPEs, isto se torna ainda mais relevante quando nota-se que o anuário do trabalho elaborado pelo Sebrae (2020) relata que nos últimos 30 anos a participação das MPEs na economia do país vem crescendo, assim como seu papel na geração de empregos, renda e arrecadação de impostos. No Brasil, estas empresas respondem atualmente por $54 \%$ dos empregos, sendo que a remuneração média real dos colaboradores destas instituições tem apresentado um valor superior ao das médias e grandes organizações. As MPEs são reconhecidas como a maioria no país. Segundo a Agência Brasil (2020) somente em 2020, foram abertas 626.883 empresas, $85 \%$ delas representando as micro e $15 \%$ a pequena empresa.

Devido às reflexões atuais sobre transparência e integridade nas condutas de agentes públicos e privados, o termo compliance se torna cada vez mais presente na realidade das empresas brasileiras, sejam elas grandes ou pequenas. "O compliance integra um sistema complexo e organizado de procedimentos de controle de riscos e preservação de valores intangíveis que deve ser coerente com a estrutura societária." (CARVALHO et al, 2018, p.39). Isto posto, observa-se que esta temática é relativamente nova, tanto no meio acadêmico quanto nas MPEs merecendo maior discussão e realização de pesquisas. Discutir sobre compliance, num contexto geral ou mais especificamente nas MPEs é possibilitar abertura para formas mais saudáveis de negociar, de se comportar frente aos problemas internos e externos e de se mostrar à sociedade.

Diante disto, este artigo teve como objetivo geral verificar a percepção dos gestores de um grupo de micro e pequenas empresas atuantes na cidade de Ponta Grossa - PR no que diz respeito à conformidade das práticas éticas em seus negócios. Para atingir o objetivo proposto aplicou-se um questionário com 16 cenários que apresentavam situações hipotéticas sobre o comportamento ético e práticas de compliance. Estes cenários foram elaborados por Longenecker et al (2006), traduzidos e aplicados no trabalho de Terra em 2015, portanto, validados por este. Há sugestão deste autor para a aplicação desses cenários em novas pesquisas, a fim de que a discussão sobre as práticas de compliance sejam melhor exploradas no meio acadêmico e, principalmente, envolvendo as MPEs, que possuem significativa representatividade no cenário nacional.

0 presente estudo traz sua contribuição à medida que possibilitou maiores informaç̧ões do mundo real sobre a temática abordada através da análise e interpretação dos resultados de um grupo de gestores, possibilitando a sondagem de suas percepções sobre o cenário atual das práticas de compliance.

\section{REFERENCIAL TEÓRICO}

\subsection{COMPLIANCE}

A busca pelo compliance é uma cultura recente, mas que vem crescendo no ambiente empresarial, trazendo como desafio, a mudança comportamental. 0 Compliance é a prática de cumprimento de regras e de leis, quer seja dentro ou fora das empresas, sejam elas públicas ou privadas. Segundo Candeloro, Rizzo e Pinho, (2012, p. 30), compliance é "[...] um conjunto de regras, padrões, procedimentos éticos e legais que, uma vez, definido e implantado, será a linha mestra que orientará o comportamento da instituição no mercado em que atua, bem como as atitudes de seus funcionários." Assim, entende-se por compliance o ato de estar de acordo com as obrigações legais empresariais e com os padrões éticos de conduta. Segundo Bertoccelli (2019, p. 36), o compliance vai além do cumprimento de regras formais, "seu alcance é muito mais amplo e deve ser compreendido de maneira sistêmica, como um instrumento de mitigação de riscos, preservação dos valores éticos e de sustentabilidade corporativa, preservando a continuidade do negócio e o interesse dos stakeholders." 
A filosofia do compliance surgiu no começo do século XX, com a criação do Banco Central dos Estados Unidos (FED), onde se objetivou "criar um ambiente financeiro mais seguro, estável e flexível por intermédio do aperfeiçoamento da regulação e supervisão das práticas financeiras.” (BARROS, 2020, p.61). Nos EUA, na década de 70, foi criada a Lei Anticorrupção Transnacional - Foreign Corrupt Practices Act (FCPA), que deixou mais rígida a punição para as empresas americanas envolvidas com atos de corrupção. No Brasil, segundo estudos da Federação das Indústrias do Estado de São Paulo (Fiesp), a corrupção, afeta aproximadamente 2,3\% do PIB representando uma perda de $\mathrm{R} \$ 200$ bilhões de reais anuais ao erário público, prejudicando o crescimento do país, um ambiente de negócios estável e o bem-estar social (SANTOS, 2019). Portanto, a adoção de práticas de compliance nas organizações é mais do que um diferencial competitivo, devendo ser utilizado de forma proativa, preservando a segurança jurídica da empresa, fortalecendo o controle interno organizacional, consequentemente, protegendo-a de práticas ilícitas e fraudes, garantindo os direitos dos consumidores e, principalmente, mantendo a reputação empresarial no mercado.

Segundo a Associação Brasileira de Bancos Internacionais, as organizações podem ser e estar em compliance. "Ser compliance é conhecer as normas da organização, seguir os procedimentos recomendados, agir em conformidade e sentir quanto é fundamental a ética e a idoneidade em todas as nossas atitudes" e, "estar em compliance é estar em conformidade com leis e regulamentos internos e externos." (ABBI, 2009, p.8). Portanto, ser e estar em compliance proporciona benefícios para a empresa, como a prevenção e redução dos problemas com sanções legais, economizando financeiramente e também diminuindo a chance de comportamentos antiéticos e ilegais dos colaboradores, mantendo assim a reputação organizacional ilesa.

\subsection{LEI ANTICORRUPÇÃO}

A corrupção é um destaque nos noticiários brasileiros. Conforme o último ranking organizado pela transparência internacional brasil, através do relatório índice de percepção da corrupção 2020, o brasil ocupa a 94a posição entre 180 países avaliados. Em 2019 ocupava a 106 ${ }^{\underline{a}}$ posição, ou seja, em apenas um ano a percepção de corrupção entre funcionários públicos e políticos brasileiros aumentou em 12 posições. Isso se deve aos vários casos de corrupção já deflagrados pela polícia federal e largamente noticiados pela imprensa, desde mensalão, operação lava jato (revista época negócios, 2015) até casos mais recentes como operação placebo e operação s.o.s, casos de corrupção deflagrados em meio à pandemia. (gazeta do povo, 2021).

Contudo, desde 2013 o brasil conta com a lei 12.846, chamada lei anticorrupção ou lei da empresa limpa. Teve sua origem no projeto de lei 6.826/10 que tramitou entre 2010 e 2013 e é considerada o marco da cultura do compliance no país. Segundo o tribunal de justiça do distrito federal e dos territórios, a lei 12.846:

trata da responsabilização administrativa e civil de pessoas jurídicas (empresas) pela prática de atos de corrupção contra a administração pública, nacional ou estrangeira, e atende ao pacto internacional firmado pelo Brasil. 0 objetivo é coibir a atuação de empresas em esquemas de corrupção e assim, evitar que grandes prejuízos sejam causados aos cofres públicos.

Lima (2014), comenta que as três maiores novidades nesta lei são a responsabilização objetiva para a empresa que pratica atos lesivos, irregulares ou ilícitos, punição para atos de corrupção contra a administração pública nacional ou estrangeira e o acordo de leniência. Este acordo tem por objetivo fazer com que as empresas colaborem com as investigações e com o processo administrativo de forma voluntária, comprometendo-se em romper com a prática de ilícitos. Em troca, a pessoa jurídica é isenta de algumas sanções, porém, continua respondendo juridicamente, civil e criminal, por seus atos.

O Decreto 8.420 de 2015 que regulamenta a Lei 12.846/13 valoriza os programas de compliance ou como denomina esta lei, programa de integridade, prevendo atenuantes de algumas sanções em decorrência de atos ilegais, ou seja, "a adoção de um programa de integridade não só previne que os atos ilícitos previsto nesta lei ocorram, como também pode resultar na diminuição das penalidades, caso sua empresa eventualmente for responsabilizada com base nesta lei." (Sebrae, 2017, p. 20). Salienta-se que a importância da implantação de um programa de integridade não se dá visando minimizar penalidades mas sim buscando fortalecer uma cultura ética empresarial, garantindo um mercado de negócios fortalecido pelas boas práticas, sustentado por regras íntegras que garantam o direito de todos. Corroborando com este pensamento, Simonsen (2016, p.32) relata que as principais vantagens para uma empresa que possui 
uma área de compliance além do benefício legal está na "proteção à marca, o aumento da sustentabilidade do negócio, a proteção financeira, o ganho de imagem, a ampliação da eficiência com foco no resultado, o incremento da credibilidade, o acesso a mais recursos financeiros e a proteção aos executivos."

\subsection{COMPLIANCE EM MICRO E PEQUENAS EMPRESAS}

Aos poucos a visão de compliance está se voltando para as micro e pequenas empresas, já que as mesmas não estão imunes à corrupção e, caso desejem manter negócios com a administração pública, acaba se tornando imperativo a implementação de um programa desta natureza, ou seja, cedo ou tarde as empresas terão que concretizá-lo. Segundo Costa (2019), os estados do Rio de Janeiro, Rio Grande do Sul, Amazonas e Goiás, foram pioneiros neste quesito, pois somente com um programa de compliance as empresas destes estados podem negociar com a administração pública. Isto garante a estas empresas um diferencial competitivo diante dos concorrentes.

A implementação de um programa de compliance ao contrário do que possa parecer não é um procedimento difícil de ser aplicado ou dispendioso. As exigências para as MPEs são reduzidas, permitindo uma versão mais branda do programa. Portanto, deve ser adaptado de acordo com a natureza do negócio, o porte empresarial, a estrutura organizacional, os riscos que a empresa está sujeita e seu modelo de negócio. (COSTA, 2019). Os parâmetros de integridade que devem ser avaliados para as MPEs estão dispostos no Decreto 8.420/2015, sendo estes parâmetros simplificados através da Portaria Conjunta CGU-SMPE no 2.279, de 9 de setembro de 2015.

Para que as MPEs implementem um programa de compliance não é necessário a criação de um departamento de Compliance ou a contratação de um profissional interno. Uma consultoria especializada pode estruturar as práticas empresariais e seus documentos e, com treinamento adequado, os próprios colaboradores "poderão fazer as vezes do setor de integridade." (SILVEIRA, D. B., 2019). Segundo este mesmo autor, são três os pilares que estruturam o programa de compliance para o pequeno negócio:

o apoio do(s) dono(s) da empresa, o qual precisa querer que sua empresa seja ética e que entenda essas novas exigências do mercado; a construção de um código de conduta, o qual orientará as boas práticas dos funcionários e eventuais procedimentos caso alguma fraude aconteça; e o treinamento desses colaboradores, os quais, difundindo a cultura interna da ética e da integridade, farão a empresa alcançar os padrões de exigências legais e de valores públicos necessários para fazer funcionar efetivamente o programa. (SILVEIRA, D. B., 2019).

A Controladoria Geral da União em parceria com o Sebrae (2015) elaboraram a cartilha 'Integridade para pequenos negócios' que discute a importância do compliance nas organizações, orientando o pequeno empreendedor no passo a passo da implantação de um programa de integridade e evidenciando as vantagens de sua aplicação além de seu ambiente interno.

\section{METODOLOGIA}

\subsection{CLASSIFICAÇÃO DA PESQUISA}

De acordo com Prodanov e Freitas (2013, p. 69-70), a pesquisa quantitativa "considera que tudo pode ser quantificável, o que significa traduzir em números opiniões e informações para classificá-las e analisá-las." Segundo estes mesmos autores a pesquisa qualitativa "considera que há uma relação dinâmica entre o mundo real e o sujeito, isto é, um vínculo indissociável entre o mundo objetivo e a subjetividade do sujeito [...].” Assim, quanto à abordagem esta pesquisa se classifica como quanti-qualitativa, pois traduziu as opiniões dos respondentes em dados sobre sua distribuição percentual e da moda de cada cenário. Ao mesmo tempo permitiu caracterizar a percepção dos respondentes no que diz respeito à conformidade de suas práticas em negócios.

Quanto aos seus objetivos, classifica-se como exploratória, pois, segundo Gil (2016, p.38), estas pesquisas "são desenvolvidas com o objetivo de proporcionar uma visão geral, do tipo aproximativo, acerca de determinado fato." Desta forma, buscou-se mais informações no mundo real sobre a temática abordada. 


\subsection{PROCEDIMENTOS DE COLETA DE DADOS}

A população da pesquisa contou com 39 micro e pequenas empresas que faziam parte da clientela de um escritório de contabilidade da cidade de Ponta Grossa - PR. A amostra é composta por 12 empresas com receita bruta igual ou inferior a $\mathrm{R} \$ 360.000,00$ classificadas como microempresas e, empresas com receita bruta entre $\mathrm{R} \$ 360.0001,00$ a $\mathrm{R} \$ 4.800 .000,00$ ao ano, classificadas como empresas de pequeno porte.

O convite de participação para a pesquisa foi enviado, via Whatsapp, em média, três vezes para cada responsável pela organização. Acredita-se que as dificuldades trazidas pela pandemia tenham prejudicado a participação destes. 0 questionário, disponibilizado pelo aplicativo Google Forms, conta com sete questões que observaram o perfil dos respondentes e 16 cenários apresentando situações hipotéticas sobre o comportamento ético e compliance passíveis de se encontrar no mundo corporativo. Estes cenários foram idealizados por Longenecker et al (2006), traduzidos e aplicados no trabalho de Terra em 2015. As respostas foram apresentadas em escala Likert de quatro pontos.

\section{ANÁLISE E RESULTADOS OBTIDOS}

\subsection{PERFIL DOS RESPONDENTES}

Dos 12 gestores que responderam ao questionário sete são do gênero feminino e cinco do gênero masculino. Cinco estão entre 41 a 50 anos, quatro entre 41 a 40 anos, dois entre 30 ou menos e um tem entre 61 ou mais. Com relação ao nível de escolaridade dos entrevistados, seis têm ensino superior, cinco, ensino médio e um possui ensino fundamental. Nove dos respondentes são proprietários e três exercem a função de gerência nas empresas. 0 ramo de atuação das entidades se divide em dois grupos, um, com oito empresas comerciais e o outro com quatro prestadores de serviço. Do quadro de funcionários das empresas, um respondente possui entre 10 a 19 colaboradores, sete deles possuem entre dois a nove colaboradores, dois respondentes possuem apenas um colaborador e um não possui colaborador.

\subsection{ANÁLISE E INTERPRETAÇÃO DA AMOSTRA EM TELA}

A seguir apresenta-se a análise das respostas dadas pelos 12 gestores respondentes da pesquisa em relação à percepção sobre as práticas éticas e de integridade em negócios. 0 quadro 1 lista as questões, as respostas e suas respectivas porcentagens em ordem decrescente da frequência de respostas inaceitáveis, por se entender que seria a resposta mais adequada às práticas de compliance. As respostas estão abreviadas da seguinte forma: I - Inaceitável, PVA - Poucas Vezes Aceitável, MVA - Muitas Vezes Aceitável, TA - Totalmente Aceitável e, M - Moda.

Inicialmente, é possível observar que os sete primeiros cenários que possuem um alto índice de rejeição (a porcentagem de respostas inaceitável é superior a 66.7\%) tratam de dois temas principais. 0 primeiro se refere a conflitos entre interesse individual sobre o empresarial na tomada de decisão (cenários 3, 11,12 e 14). O segundo diz respeito à ocultação/manipulação de informações fornecidas aos clientes e stakeholders (cenários 2, 10 e 13).

0 cenário 2, que expõe uma situação onde o gerente geral excede os limites legais de poluição ambiental, foi classificado como inaceitável por todos os respondentes. Esta questão foi a única cujo cenário foi rejeitado de forma unânime por todos os respondentes. Isto fornece um indício de que estes gestores se preocupam com as questões ambientais. A Lei 9.605/98 faz a tratativa sobre sanções penais e administrativas sobre estas questões.

No cenário 3, um corretor recomenda papéis que nem ele acredita ser um bom investimento e 11 participantes $(91,7 \%)$ afirmaram que isto é inaceitável enquanto 8,3\%, ou seja, um respondente marcou a alternativa poucas vezes aceitável. Esta questão demonstra conflito entre valores individuais e empresariais, podendo surgir, por exemplo, em decorrência da pressão por produtividade ou pelo cumprimento de metas. 0 ponto a ser observado aqui é que esta prática é incorreta não condizente com a atividade de uma empresa que gerencia investimentos de terceiros.

O cenário 13 descreve um empregador que recebeu currículo de duas pessoas qualificadas para posição de supervisor, no entanto, escolhe o candidato homem por acreditar que os colaboradores não se sentiriam bem sendo liderados por uma mulher. Dez $(83,3 \%)$ dos respondentes assinalaram a alternativa inaceitável. Nesta questão verifica-se a rejeição de práticas discriminatórias que impedem que homens e mulheres tenham oportunidades iguais de ascensão profissional. Esta prática é incompatível com as 
ideias de compliance e também com a Lei 9.029/95, que trata de algumas questões de práticas discriminatórias contra a mulher. Ao não aceitar o cenário 13, a maioria dos entrevistados mostra ter a percepção de que embora as mulheres tenham grande participação no mercado de trabalho, elas ainda possuem menor remuneração e menor chances em cargos de chefia. (G1 Economia, 2021).

Quadro 1: Cenários de situações hipotéticas sobre o comportamento ético e compliance

\begin{tabular}{|c|c|c|c|c|c|}
\hline CENÁRIOS & I & PVA & MVA & TA & M \\
\hline $\begin{array}{l}\text { Cenário 2. Para aumentar seus lucros, um } \\
\text { Gerente Geral utilizou um processo } \\
\text { produtivo que excedia os limites legais de } \\
\text { poluição ambiental. }\end{array}$ & $\begin{array}{l}100 \% \\
12 \\
\text { respostas }\end{array}$ & $0 \%$ & $0 \%$ & $0 \%$ & I \\
\hline $\begin{array}{l}\text { Cenário } 3 \text {. Devido a pressão de sua corretora } \\
\text { de valores, um corretor recomendou papéis } \\
\text { que nem ele acreditava ser um bom } \\
\text { investimento. }\end{array}$ & $\begin{array}{l}91,7 \% \\
11 \\
\text { respostas }\end{array}$ & $\begin{array}{c}8,3 \% \\
1 \\
\text { resposta }\end{array}$ & $0 \%$ & $0 \%$ & I \\
\hline $\begin{array}{l}\text { Cenário 13. Um empregador recebeu, para } \\
\text { uma posição de supervisor, o currículo de } \\
\text { duas pessoas qualificadas. No entanto, } \\
\text { escolheu o candidato homem por acreditar } \\
\text { que alguns colaboradores não se sentiriam } \\
\text { bem sendo liderados por uma mulher. }\end{array}$ & $\begin{array}{l}83,3 \% \\
10 \\
\text { respostas }\end{array}$ & $\begin{array}{l}16,7 \% \\
2 \\
\text { respostas }\end{array}$ & $0 \%$ & $0 \%$ & I \\
\hline $\begin{array}{l}\text { Cenário 14. Como parte da estratégia de } \\
\text { Marketing de um produto, o fornecedor } \\
\text { alterou sua cor e o comercializou como } \\
\text { "Novo e Melhorado", mesmo não tendo } \\
\text { alterado outras características do produto. }\end{array}$ & $\begin{array}{l}83,3 \% \\
10 \\
\text { respostas }\end{array}$ & $\begin{array}{l}16,7 \% \\
2 \\
\text { respostas }\end{array}$ & $0 \%$ & $0 \%$ & I \\
\hline $\begin{array}{l}\text { Cenário } 11 \text {. Um engenheiro descobriu uma } \\
\text { falha de projeto em um produto que poderia } \\
\text { vir a ser um risco de segurança. Sua empresa } \\
\text { se recusou corrigir a falha. O engenheiro } \\
\text { optou por manter-se calado a denunciar esta } \\
\text { situação fora da empresa. }\end{array}$ & $\begin{array}{l}83,3 \% \\
10 \\
\text { respostas }\end{array}$ & $\begin{array}{c}8,4 \% \\
1 \\
\text { resposta }\end{array}$ & $\begin{array}{c}8,3 \% \\
1 \\
\text { resposta }\end{array}$ & $0 \%$ & I \\
\hline $\begin{array}{l}\text { Cenário 12. Um Controller optou por um } \\
\text { método legal de relatório financeiro que } \\
\text { escondia alguns fatos financeiros } \\
\text { embaraçosos, que de outra forma se } \\
\text { tornariam de conhecimento público. }\end{array}$ & $\begin{array}{l}75 \% \\
\quad 9 \\
\text { respostas }\end{array}$ & $\begin{array}{c}25 \% \\
3 \\
\text { respostas }\end{array}$ & $0 \%$ & $0 \%$ & I \\
\hline $\begin{array}{l}\text { Cenário 10. Um executivo corporativo } \\
\text { promoveu a vice-presidente um gerente } \\
\text { competente, mas muito seu amigo, em } \\
\text { detrimento a um gerente melhor qualificado } \\
\text { com o qual não tinha relações pessoais. }\end{array}$ & $\begin{array}{c}75 \% \\
9 \\
\text { respostas }\end{array}$ & $0 \%$ & $\begin{array}{c}16,7 \% \\
2 \\
\text { respostas }\end{array}$ & $\begin{array}{c}8,3 \% \\
1 \\
\text { resposta }\end{array}$ & I \\
\hline $\begin{array}{l}\text { Cenário 1. Um executivo que ganha } \\
\mathrm{R} \$ 150.000,00 \text { por ano cobrou cerca de } \\
\mathrm{R} \$ 5.000,00 \text { a mais em seu relatório de } \\
\text { despesa. }\end{array}$ & $\begin{array}{c}66,7 \% \\
8 \\
\text { respostas }\end{array}$ & $\begin{array}{c}8,3 \% \\
1 \\
\text { resposta }\end{array}$ & $\begin{array}{c}8,3 \% \\
1 \\
\text { resposta }\end{array}$ & $\begin{array}{c}16,7 \% \\
2 \\
\text { respostas }\end{array}$ & I \\
\hline $\begin{array}{l}\text { Cenário 4. Uma pequena empresa recebeu } \\
\text { um quarto de sua receita bruta em dinheiro. } \\
0 \text { empresário declarou apenas a metade para } \\
\text { o imposto de renda a fim de pagar menos } \\
\text { impostos. }\end{array}$ & $\begin{array}{c}66,7 \% \\
8 \\
\text { respostas }\end{array}$ & $\begin{array}{c}8,3 \% \\
1 \\
\text { resposta }\end{array}$ & $\begin{array}{c}8,3 \% \\
1 \\
\text { resposta }\end{array}$ & $\begin{array}{c}16,7 \% \\
2 \\
\text { resposta } \\
\mathrm{s}\end{array}$ & I \\
\hline $\begin{array}{l}\text { Cenário 5. Uma empresa pagou } \mathrm{R} \$ 350.000 \\
\text { como "consultoria" a um funcionário público } \\
\text { de um país estrangeiro. Em troca, o } \\
\text { funcionário público prometeu ajuda para a } \\
\text { obtenção de um contrato que renderia um } \\
\text { lucro de } \mathrm{R} \$ 10 \text { milhões. }\end{array}$ & $\begin{array}{c}58,3 \% \\
7 \\
\text { respostas }\end{array}$ & $\begin{array}{c}25 \% \\
3 \\
\text { respostas }\end{array}$ & $\begin{array}{c}8,4 \% \\
1 \\
\text { resposta }\end{array}$ & $\begin{array}{c}8,3 \% \\
1 \\
\text { resposta }\end{array}$ & I \\
\hline
\end{tabular}


Quadro 1: Cenários de situações hipotéticas sobre o comportamento ético e compliance (Continuação)

\begin{tabular}{|c|c|c|c|c|c|}
\hline cenários & i & pva & mva & ta & m \\
\hline $\begin{array}{l}\text { Cenário } 15 \text {. Um produtor de cigarros lançou } \\
\text { uma campanha publicitária desafiando novas } \\
\text { evidências pesquisadas pela Secretaria de } \\
\text { Saúde no que diz respeito ao prejuízo } \\
\text { causado à saúde do fumante. }\end{array}$ & $\begin{array}{c}58,3 \% \\
7 \\
\text { respostas }\end{array}$ & $\begin{array}{c}25 \% \\
3 \\
\text { respostas }\end{array}$ & $\begin{array}{c}8,4 \% \\
1 \\
\text { resposta }\end{array}$ & $\begin{array}{c}8,3 \% \\
1 \\
\text { resposta }\end{array}$ & I \\
\hline $\begin{array}{l}\text { Cenário } 16 . \text { Um proprietário de uma empresa } \\
\text { conseguiu, gratuitamente, uma cópia de um } \\
\text { programa de computador de um amigo de } \\
\text { outra empresa ao invés de pagar } \mathrm{R} \$ 500,00 \\
\text { por um programa original, vendido por um } \\
\text { revendedor autorizado. }\end{array}$ & $\begin{array}{c}50 \% \\
6 \\
\text { respostas }\end{array}$ & $\begin{array}{c}33,3 \% \\
4 \\
\text { respostas }\end{array}$ & $\begin{array}{c}16,7 \% \\
2 \\
\text { respostas }\end{array}$ & $0 \%$ & I \\
\hline $\begin{array}{l}\text { Cenário 8. Um presidente de uma empresa } \\
\text { notou que ao oferecer presentes de Natal } \\
\text { caros para compradores (clientes) poderia } \\
\text { comprometê-los. No entanto, ele manteve } \\
\text { esta política, pois esta era uma prática } \\
\text { comum e, alterá-la, poderia reverter em } \\
\text { prejuízo ao seu negócio. }\end{array}$ & $\begin{array}{l}41,7 \% \\
5 \\
\text { respostas }\end{array}$ & $\begin{array}{c}33,3 \% \\
4 \\
\text { respostas }\end{array}$ & $\begin{array}{c}8,3 \% \\
1 \\
\text { resposta }\end{array}$ & $\begin{array}{c}16,7 \% \\
2 \\
\text { respostas }\end{array}$ & I \\
\hline $\begin{array}{l}\text { Cenário 9. Um diretor corporativo descobriu } \\
\text { que sua empresa iria desmembrar as ações e } \\
\text { distribuir os dividendos. Com esta } \\
\text { informação, ele comprou mais ações para } \\
\text { vendê-las com um ganho maior após o } \\
\text { anúncio. }\end{array}$ & $\begin{array}{c}41,7 \% \\
5 \\
\text { respostas }\end{array}$ & $\begin{array}{c}8,3 \% \\
1 \\
\text { resposta }\end{array}$ & $\begin{array}{c}25 \% \\
3 \\
\text { respostas }\end{array}$ & $\begin{array}{c}25 \% \\
3 \\
\text { respostas }\end{array}$ & I \\
\hline $\begin{array}{l}\text { Cenário 6. O presidente de uma empresa } \\
\text { descobriu que seu concorrente fez uma } \\
\text { importante descoberta científica e que esta } \\
\text { descoberta reduziria os lucros de sua } \\
\text { empresa. Com isso, ele contratou um } \\
\text { funcionário chave do concorrente com a } \\
\text { intenção de descobrir os detalhes desta } \\
\text { descoberta. }\end{array}$ & $\begin{array}{c}33,3 \% \\
4 \\
\text { respostas }\end{array}$ & $\begin{array}{c}25 \% \\
3 \\
\text { respostas }\end{array}$ & $\begin{array}{c}25 \% \\
3 \\
\text { respostas }\end{array}$ & $\begin{array}{c}16,7 \% \\
2 \\
\text { respostas }\end{array}$ & I \\
\hline $\begin{array}{l}\text { Cenário } 7 \text {. Um construtor de rodovias não } \\
\text { está de acordo com a situação caótica de } \\
\text { licitações e concorrência acirrada. Assim, ele } \\
\text { se alia com construtores maiores para } \\
\text { viabilizar licitações que forneçam / } \\
\text { permitam um lucro justo. }\end{array}$ & $\begin{array}{c}25 \% \\
3 \\
\text { respostas }\end{array}$ & $\begin{array}{c}16,7 \% \\
2 \\
\text { respostas }\end{array}$ & $\begin{array}{c}25 \% \\
3 \\
\text { respostas }\end{array}$ & $\begin{array}{c}33,3 \% \\
4 \\
\text { respostas }\end{array}$ & TA \\
\hline
\end{tabular}

Fonte: as autoras

A situação exposta no cenário 14, argumenta que como parte da estratégia de marketing, o fornecedor apenas altera a cor do produto e o comercializa como "novo e melhorado", mesmo não tendo realizado nenhuma modificação no mesmo. Dez $(83,3 \%)$ dos respondentes consideraram esta prática inaceitável. Assim, a maioria dos respondentes entenderam que o cliente está sendo enganado, logo, este cenário está relacionado a uma prática incorreta. Isto vem ao encontro das considerações de Machado $(2018$, p. 82) de que "os efeitos nocivos para a sociedade da falta de postura ética nos negócios tornaram urgente a necessidade de se questionar quais são as referências mais apropriadas para a constituição de uma ética nas organizações capaz de determinar as boas práticas e a boa conduta." A Lei 8.078/90, que dispõe sobre a proteção ao consumidor, aborda aspectos de compliance ligados ao cenário apresentado. 
No cenário 11, um engenheiro descobre uma falha no projeto de um produto que poderia ser um risco de segurança, como a empresa se nega a corrigir, o engenheiro opta por ficar calado a denunciar a situação. Dez respondentes (83,3\%) consideraram esta atitude inaceitável. Este índice de desaprovação mostra que quesitos como segurança no trabalho e segurança de terceiros são valorizados pela maioria dos gestores da amostra. Mais objetivamente, as respostas dadas sugerem uma concordância, mesmo que implícita, aos princípios que norteiam a Lei 6.514/77, que trata sobre a segurança e medicina do trabalho e as normas técnicas de segurança editados pelos Conselhos de Engenharia.

O cenário 12 expõe a situação de um controller que opta por um método legal de relatório financeiro que mascara alguns fatos financeiros embaraçosos, de outra forma se tornariam de conhecimento público. Nove (75\%) respondentes acharam esse fato inaceitável e três $(25 \%)$ poucas vezes aceitável. A conduta de ocultar informações vai contra os princípios éticos do profissional contábil, onde se deve exercer a profissão com zelo, diligência, honestidade e capacidade técnica, observando as Normas Brasileiras de Contabilidade e a legislação vigente, resguardando o interesse público, os interesses de seus clientes ou empregadores, sem prejuízo da dignidade e independência profissionais. (NBC PG 01).

O cenário 10 expõe um caso de privilégio, onde um executivo promove um amigo ao cargo de vicepresidente em detrimento de um funcionário competente. Nove (75\%) respondentes afirmaram ser inaceitável. Contudo, 25\% dos entrevistados consideraram a situação como muitas vezes aceitável (dois) e totalmente aceitável (um). No entender de Terra (2015, p.58) "quando as ações e os comportamentos dos administradores sofrem influência social, a permissividade para agir em não conformidade parece aumentar."

Os próximos cinco cenários, 1, 4, 5, 16 e 15, tratam de situações que foram associadas às respostas Inaceitável e Poucas Vezes Aceitável com uma frequência entre 75\% e 83\%. Três situações $(1,4,5)$ tratam de conflitos de interesse em que os agentes podem ter alguma vantagem financeira ao não realizar um pagamento devido ou ao cobrar por despesas não efetivadas. As outras duas se referem à corrupção ativa e a desqualificação de evidências científicas sem a realização de novos experimentos e analisar os estudos de controle. (SAGAN, 1997).

No cenário 1, um executivo que ganha $\mathrm{R} \$ 150.000,00$ por ano, cobrou cerca de $\mathrm{R} \$ 5.000,00$ a mais em seu relatório de despesa. Neste cenário, oito respondentes (66,7\%) consideram este ato inaceitável, um, poucas vezes aceitável, um, muitas vezes aceitável e dois (16,7\%) totalmente aceitável. A somatória das porcentagens de respostas que não optaram como inaceitável corresponde a 33\%. Tais respostas indicam uma aversão a desvios de conduta. Neste sentido, a Lei 12.843/13 pode ser aplicada como balizadora para estes conflitos de interesse.

No cenário 4, uma pequena empresa recebe um quarto de sua receita bruta em dinheiro e o empresário declara apenas a metade para o imposto de renda a fim de pagar menos impostos. Oito respondentes $(66,7 \%)$ classificaram essa atitude como inaceitável. A Lei 8.137/90 tem como principal objetivo analisar os crimes de sonegação fiscal praticados contra a ordem tributária. A prática prevê prisão de 6 meses a 1 ano.

0 cenário 5, traz o caso de uma empresa que paga um elevado valor a um funcionário público como "consultoria". Em troca ele facilitaria a obtenção de um contrato para esta sociedade. Esta prática propina - está prevista a sanções pela Lei do Compliance. Também, o Decreto 1.171/94 que aprovou o Código de Ética Profissional do Servidor Público, determina em sua Seção II, que é um dos deveres fundamentais a estes "resistir a todas as pressões de superiores hierárquicos, de contratantes, interessados e outros que visem obter quaisquer favores, benesses ou vantagens indevidas em decorrência de ações imorais, ilegais ou antiéticas e denunciá-las." A maioria dos respondentes rejeita este comportamento de forma geral. Para sete deles (58,3\%) esta atitude é inaceitável enquanto três (25\%) optaram por poucas vezes aceitável. Apesar do risco potencial desta ação, dois (16.5\%) dos respondentes disseram que o pagamento de propina é aceitável.

No cenário 15, um produtor de cigarros lança uma campanha publicitária desafiando novas evidências pesquisadas pela Secretaria de Saúde no que diz respeito ao prejuízo causado à saúde do fumante. Sete $(58,3 \%)$ dos respondentes acham esta atitude inaceitável, enquanto os demais $(41,7 \%)$ concordam com esta atitude. Segundo Machado (2018, p.46), "a carência de ética, uma das patologias mais agudas identificadas nas organizações contemporâneas, é conjecturada, muitas vezes, por uma prática linguisticamente mediada por uma comunicação sistematicamente distorcida" Esta questão trata da relação entre empresa e comunidade. A legislação que regulamenta as relações de consumo no Brasil é o código do consumidor (Lei 8.078/90). Adicionalmente, ao desacreditar arbitrariamente os resultados de 
pesquisas de um órgão de saúde, o produtor ignora os argumentos da racionalidade científica, independente de um risco potencial à saúde pública.

Um proprietário de uma empresa conseguiu, gratuitamente, uma cópia de um programa de computador de outra empresa através de um amigo, ao invés de pagar $\mathrm{R} \$ 500,00$ por um programa original, vendido por um revendedor autorizado. Esta é a descrição do cenário 16. Seis (50\%) dos respondentes consideraram esta hipótese inaceitável, quatro (33,3\%) classificaram como poucas vezes aceitável e dois $(16,7 \%)$ respondentes como muitas vezes aceitável. A Lei 9.609/98, dispõe sobre a violação de direitos autorais de software, prevendo pena contra este tipo de crime, podendo chegar, dependendo do caso, a quatro anos de reclusão e multa.

Os últimos quatro cenários de violação às práticas de compliance, de acordo com a ordenação préestabelecida, são os mais aceitos pelos respondentes. No Cenário 8, o presidente de uma empresa notou que ao oferecer presentes de Natal caros para compradores (clientes) poderia comprometê-los. No entanto, ele manteve essa política, pois esta era uma prática comum e, alterá-la, poderia reverter em prejuízo ao seu negócio. Dos 12 respondentes, cinco $(41,7 \%)$ demonstraram achar inaceitável tal hipótese, quatro (33,3\%) assinalaram a questão como poucas vezes aceitável, um respondente $(8,3 \%)$ afirmou ser muitas vezes aceitável e, dois $(16,7 \%)$ totalmente aceitável. Neste cenário, a moral e a ética profissional deveriam ser balizadoras, evitando assim possíveis constrangimentos até mesmo para quem é presenteado. Adicionalmente, no caso de negociações com o governo federal, a Lei 8.112/90 é bastante restritiva a respeito da entrega de presente ou brindes a funcionários públicos.

O cenário 9 apresenta um diretor corporativo que descobre que sua empresa iria desmembrar as ações e distribuir os dividendos. Com esta informação, ele comprou mais ações para vendê-las com um ganho maior após o anúncio. Cinco (41,7\%) dos respondentes consideram inaceitável enquanto um $(8,3 \%)$ assinalou poucas vezes aceitável, três (25\%) respondentes consideram muitas vezes aceitável e três (25\%) totalmente aceitável. Esse procedimento é considerado crime no Brasil chamado de "insider trading", conforme disposto na Lei 6.385/76, art. 27-D, uso indevido de informação privilegiada.

0 presidente de uma empresa descobriu que seu concorrente fez uma importante descoberta científica e que esta descoberta reduziria os lucros de sua empresa. Com isso, ele contratou um funcionário chave do concorrente com a intenção de descobrir os detalhes desta descoberta. Este é o cenário 6. Do total de respondentes quatro $(33,3 \%)$ consideram como inaceitável, três $(25 \%)$ poucas vezes aceitável, três $(25 \%)$ muitas vezes aceitável e, dois (16,7\%) totalmente aceitável. Apesar de três participantes considerarem a prática como inaceitável, nove deles não vê nenhum problema com a contratação do concorrente. Este fato vai em contradição com os procedimentos éticos, morais e legais definidos em um programa de compliance, que oferece fundamentos para sustentar os protocolos de boas práticas de conduta ética aos seus funcionários. (CANDELORO, RIZZO e PINHO, 2012).

Cenário 7, um construtor de rodovias não está de acordo com a situação caótica de licitações e concorrência acirrada. Assim, ele se alia com construtores maiores para viabilizar licitações que forneçam/permitam um lucro justo. As respostas obtidas foram, três (25\%) para inaceitável, duas $(16,7 \%)$ poucas vezes aceitável, três (25\%) muitas vezes aceitável e quatro $(33,3 \%)$ totalmente aceitável. A Lei 8.666/93 institui normas para licitações e contratos da Administração Pública.

Todos os cenários apresentados - de 1 a 16 - não atendem às práticas de Compliance. De acordo com as respostas obtidas, os gestores das MPEs demonstraram que não estão totalmente de acordo com as práticas éticas. Somente no cenário voltado ao meio ambiente se obteve uma resposta inaceitável. 0 pior cenário foi com relação à negociação de empresas privadas com a administração pública.

\section{CONSIDERAÇõES FINAIS}

Esta pesquisa teve por objetivo conhecer a percepção dos gestores das micro e pequenas empresas concernente à conformidade de práticas éticas em seus negócios. As respostas obtidas denotam a forma como os gestores desse grupo de empresas se comportam com relação às questões éticas. Em alguns cenários, percebeu-se que os respondentes refutam os atos não éticos, porém, no decorrer das situações hipotéticas observou-se a diminuição das porcentagens em fatos inaceitáveis e a aceitação dos respondentes para algumas questões eticamente questionáveis.

0 padrão das respostas indica que a adoção de programas de compliance é uma necessidade premente para que as atividades empresariais estejam em acordo com os preceitos da ética em negócios. Gestores que ignoram o programa de compliance, correm o risco de assumir a responsabilidade pessoal e 
empresarial, no âmbito judicial, ao desconhecer ou rejeitar tais preceitos. Além disso, entidades que não dispõem de programas de compliance deixam de desfrutar dos benefícios disponíveis sob as novas diretrizes das leis federais para as organizações responsabilizadas por atos ilícitos.

Os resultados obtidos sugerem algumas direções para trabalhos futuros. Entre elas, a análise de uma amostra maior e a diferenciação das respostas dadas por micro e pequenas empresas. Também sugere-se aplicar esta pesquisa em outros estados do país, a fim de conhecer as práticas de integridade em outras regiões.

\section{REFERÊNCIAS}

[1] Associação Brasileira de Bancos Internacionais ABBI. Função do Compliance, http://www.abbi.com.br/download/funcaodecompliance _ 09.pdf (11 de março de 2021).

[2] Barros, B. S. (2020). A importância do compliance nos municípios brasileiros. Revista do Ministério Público de Contas do Estado do Paraná, 7, 13, 58-76.

[3] Basílio, A. (2015). Os maiores escândalos de corrupção do Brasil, 2015. Revista Época Negócios, https://epocanegocios.globo.com/Informacao/Dilemas/noticia/2015/03/os-maiores-escandalos-decorrupcao-do-brasil.html (04 de abril de 2021).

[4] Bertoccelli, R.D.P. In: Carvalho, A. C. et al. (Coord.) (2019). Manual de Compliance. Forense.

[5] BRASIL, Decreto no 1.171, de 22 de junho de 1994. Aprova o Código de Ética Profissional do Servidor Público Civil doPoder Executivo Federal, http://www.planalto.gov.br/ccivil_03/decreto/d1171.htm, (01 de abril de 2021).

[6] Decreto no 8.420, de 18 de março de 2015. Regulamenta a Lei 12.846 de $1^{\circ}$ de agosto de 2013, http://www.planalto.gov.br/ccivil_03/_ato2015-2018/2015/decreto/d8420.htm (29 de março de 2021).

[7] Lei $n^{\circ} 6.385$ de 7 de dezembro de de 1976. Dispõe sobre o mercado de valores imobiliários e cria Comissão de valores imobiliários, http://www.planalto.gov.br/ccivil_03/leis/16385.htm (25 de março de 2021).

[8] Lei no 6.514 de 22 de dezembro de 1977. Altera o Capítulo V do Título II da Consolidação das Leis do Trabalho, relativo a segurança e medicina do trabalho e dá outras providências, http://www.planalto.gov.br/Ccivil_03/LEIS/L6514.htm (29 de julho de 2021).

[9] Lei no 8.078, de 11 de setembro de 1990. Dispõe sobre a proteção do consumidor e dá outras providências, http://www.planalto.gov.br/ccivil_03/leis/18078compilado.htm (29 de julho de 2021).

[10] Lei no 8.112, de 11 de dezembro de 1990. Dispõe sobre o regime jurídico dos servidores públicos civis da União, das autarquias e das fundações públicas federais, http://www.planalto.gov.br/ccivil_03/leis/18112compilado.htm (29 de julho de 2021).

[11] Lei no 8.137 de 27 de dezembro de 1990. Define crimes contra a ordem tributária, econômica e contra as relações de consumo, e dá outras providências, http://www.planalto.gov.br/ccivil_03/leis/18137.htm (29 de julho de 2021).

[12] Lei no 8.666, de 21 de junho de 1993. Regulamenta o art. 37, inciso XXI, da Constituição Federal, institui normas para licitações e contratos da Administração Pública e dá outras providências, http://www.planalto.gov.br/ccivil_03/leis/18666compilado.htm (29 de julho de 2021).

[13] Lei $\mathrm{n}^{\circ} 9.605$ de 12 de fevereiro de 1998. Dispõe sobre sanções penais e administrativas derivadas de condutas e atividades lesivas ao meio ambiente, http://www.planalto.gov.br/ccivil_03/leis/19605.htm (29 de março de 2021).

[14] Lei no 9.609 de 19 de fevereiro de 1998. Dispõe sobre a proteção da propriedade intelectual de programa de computador, sua comercialização no País, e dá outras providências, http://www.planalto.gov.br/ccivil_03/leis/19609.htm, (29 de março de 2021).

[15] Lei $\mathrm{n}^{\circ} 12.846$ de $1^{\circ}$ de agosto de 2013. Dispõe sobre a responsabilização administrativa e civil de pessoas jurídicas pela prática de atos contra a administração pública, nacional e estrangeira, http://www.planalto.gov.br/ccivil_03/_ato2011-2014/2013/lei/112846.htm (25 de março de 2021).

[16] Resolução CFC no1.328 de 18 de março de 2011. Dispõe sobre a Estrutura das Normas Brasileiras de Contabilidade. Normas Brasileiras de Contabilidade, http://www.portaldecontabilidade.com.br/nbc/ (20 de março de 2021).

[17] Candeloro, A. P., Rizzo, M. B. M. \& Pinho, V. (2012). Compliance $360^{\circ}$ : riscos, estratégias, conflitos e vaidades no mundo corporativo. Trevisan Editora Universitária.

[18] Carvalho, A. C; et al. (Coord) (2018). Manual de compliance. Forense. 
[19] Costa, A. F. A. (2019) Compliance e sua obrigatoriedade para a contratação com a administração pública. Aline Fonseca Advocacia, https://alinefonsecaadvocacia.adv.br/2019/11/05/compliance-por-que/ (29 de junho de 2021).

[20] Desideri, L. (2021). Corrupção na pandemia: um panorama do que já aconteceu no Brasil. Gazeta do Povo, https://www.gazetadopovo.com.br/republica/corrupcao-na-pandemia-um-panorama-do-que-ja-aconteceu-nobrasil/ (29 de junho de 2021).

[21] Gandra, A. (2021). Mais de 620 mil micro e pequenas empresas foram abertas em 2020. Agência Brasil, https://agenciabrasil.ebc.com.br/economia/noticia/2021-04/mais-de-620-mil-micro-e-pequenas-empresasforam-abertas-em-2020 (30 de Junho de 2021).

[22] Gil, A. C. (2016). Como Elaborar Projetos de Pesquisa. 6. ed., Atlas.

[23] Lima, F. L. A. (2014) Lei Anticorrupção: responsabilidade objetiva das pessoas jurídicas que pratiquem ilícitos perante a administração. Revista Jus Navigandi, nº4.125, 17/10/2014. Disponível em: https://jus.com.br/artigos/30260. (01 setembro de 2021).

[24] Machado, R. (2018). Ética nas organizações: reflexões sobre a prática contábil a partir da ética discursiva. Tese (Doutorado em Administração), Universidade Positivo.

[25] Prodanov, C. C. \& Freitas, E. C. (2013). Metodologia do trabalho científico: métodos e técnicas da pesquisa e do trabalho acadêmico. 2. ed., Feevale.

[26] Santos, L. (2019) Corrupção e má gestão. Revista Brasileira de Administração, n. 131, 18-20, 2019.

[27] SEBRAE (2020). Anuário elaborado pelo Sebrae traça perfil dos trabalhadores no país. Agência Sebrae de Notícias, https://www.agenciasebrae.com.br/sites/asn/uf/NA/anuario-elaborado-pelo-sebrae-traca-perfil-dostrabalhadores-no-pais,6e3eea2f7b666710VgnVCM1000004c00210aRCRD (30 de junho 2021).

[28] SEBRAE (2017). Integridade para pequenos negócios, https://www.sebrae.com.br/Sebrae/Portal\%20Sebrae/Anexos/Integridade\%20para\%20pequenos\%20neg \%C3\%B3cios.pdf (29 de março de 2021).

[29] Sagan, C. (1996) 0 mundo assombrado pelos demônios: a ciência vista como uma vela no escuro. Companhia das Letras.

[30] Silveira, D. (2021). Participação de mulheres no mercado de trabalho tem 50 ano de alta, mas remuneração segue menor que dos homens, diz IBGE, https://g1.globo.com/economia/noticia/2021/03/04/participacao-demulheres-no-mercado-de-trabalho-tem-5o-ano-de-alta-mas-remuneracao-segue-menor-que-dos-homens-dizibge.ghtml (29 de junho de 2021).

[31] Silveira. D. B. (2019). Compliance e integridade para pequenos negócios, https://www.hojemais.com.br/aracatuba/noticia/opiniao/compliance-e-integridade-para-pequenosnegocios (31 de julho de 2021).

[32] Simonsen, R. (2016). Os desafios do Compliance. Cadernos FGV Projetos. 11, 28, 31-37.

[33] Terra, D. M. (2015). Compliance: percepção de administradores de MPEs. Dissertação (Mestrado em Administração), Faculdade Campo Limpo

Paulista, http://www.faccamp.br/new/arq/pdf/mestrado/Documentos/producao_discente/donizete.pdf (22 de Novembro de 2020).

[34] Terra, D. M \& Bianchi, E. M. P. G. (2018) Compliance nas Micro e Pequenas Empresas: percepção de seus administradores, Revista de Empreendedorismo e Gestão de Pequenas Empresas, 7, 3, 58-66

[35] TRANSPARÊNCIA INTERNACIONAL BRASIL (2020). Índice de Percepção da Corrupção 2020, https://comunidade.transparenciainternacional.org.br/ipc-indice-de-percepcao-da-corrupcao-2020 (29 de março de 2021).

[36] TRIBUNAL DE JUSTIÇA DO DISTRITO FEDERAL E DOS TERRITÓRIOS - TJDFT (2018). Lei

Anticorrupção, https://www.tjdft.jus.br/institucional/imprensa/campanhas-e-produtos/direito-facil/edicaosemanal/lei-anticorrupcao (25 de março de 2021). 


\section{Capítulo 7}

Marketing empresarial em escritório de contabilidade

\section{Amanda Eduarda da Silva}

\section{Natália do Amaral}

\section{Adriana Gresielly Fabrini}

Resumo: 0 presente trabalho tem como objetivo principal demonstrar como adaptar as estratégias de marketing para serem implantadas em uma empresa prestadora de serviços, como um escritório de contabilidade. para a análise foi observado e estudado o marketing da microempresa delta assessoria contábil, do munícipio de andirá no estado do paraná. esta pesquisa classifica-se como aplicada do ponto de vista de sua natureza, quanto a abordagem do problema apresenta-se como qualitativa, da perspectiva da observação dos objetivos apresentados enquadra-se como explicativa, e ao que tange aos procedimentos técnicos, são esses: pesquisa bibliográfica, estudo de caso e pesquisa documental. os resultados obtidos demonstraram que existe uma defasagem na gestão de marketing de pequenos escritórios contábeis, em relação ao planejamento de aplicação de estratégias favoráveis. após análises considera-se extremamente eficiente para os tempos hodiernos em atuação no nicho estudado, o marketing de conteúdo em redes sociais.

Palavras-Chave: Marketing; Contabilidade; Microempresa; Estratégia. 


\section{INTRODUÇ̃̃O}

Segundo dados da Secretaria Especial de Comércio Exterior e Assuntos Internacionais, no país existem 6,4 milhões de empreendimentos, desse total, 99\% são micro e pequenas empresas (MPE). Apenas no ano de 2020, foram abertas 626.883, onde 535.126 eram microempresas (85\%) e 91.757 (15\%) eram empresas de pequeno porte (BRASIL, 2021).

À vista dos dados citados, nota-se o crescimento da competitividade e concorrência no mundo dos negócios, principalmente entre empresas de micro e pequeno porte. Esse cenário, exige, das organizações privadas, diferenciação e estratégias para ter vantagens competitivas sobre os concorrentes e, assim, manter-se no mercado.

Quando se analisa a microempresa, verifica-se que diversos são os seus desafios, e um deles é o marketing, foco de estudo deste trabalho. 0 micro e pequeno empresário acredita que a elaboração de um plano de marketing é complexo, cansativo e repleto de teoria, às quais normalmente pouco tem acesso, e por consequência acaba negligenciando esta etapa fundamental (LENZ, 2017). Porém, a falta de um planejamento diferencial competitivo, aumentará o risco de insucesso do negócio.

Para Kotler (1999), o marketing tem como função aumentar os recursos da empresa, além de estabelecer quais são as necessidades e oportunidades indispensáveis para constituir um bom plano estratégico para que a organização tenha relevância no mercado e possa obter vantagem competitiva sobre a concorrência.

Por isso, notando a importância do marketing para as empresas, o presente trabalho dedicou-seao tema em uma microempresa de prestação de serviços, aplicado ao escritório de contabilidade.

A presente pesquisa será abordada de forma explicativa, com o objetivo de demonstrar de que maneira as estratégias de marketing podem ser adaptadas e implantadas em um escritório de contabilidade. 0 objetivo geral dessa pesquisa é demonstrar por meio de fundamento investigativo científico das teorias de estratégias de marketing, como as suas ferramentas e características podem ser adaptadas para uma microempresa prestadora de serviços do ramo de contabilidade. Ou seja, serão buscados elementos referentes à teoria de marketing tais como, suas particularidades, ferramentas, vantagens e desvantagens, que contribuam com a explicação de como pode ser adequado e executado o marketing, em uma microempresa prestadora de serviços contábeis, de maneira que aumente, por exemplo, o número de clientes, faturamento ealcance de divulgação.

Desta forma, pretende-se demonstrar como adaptar as estratégias de marketing para serem implantadas em uma empresa prestadora de serviços, como um escritório de contabilidade.

Este trabalho está dividido em sete itens, incluindo esta introdução. No segundo item encontra- se o objetivo geral da presente pesquisa, em seguida os objetivos específicos. No quarto item, o referencial teórico, posteriormente a metodologia. No sexto item, encontra-se a descrição do caso e análise e por último, como sétimo item, a conclusão.

\section{REFERENCIAL TEÓRICO}

\subsection{MARKETING APLICADO EM MICROEMPRESA}

Diante dos avanços tecnológicos, a cada dia aumenta a busca por soluções de marketing para as microempresas, pois se posicionar no mercado se tornou uma questão de sobrevivência para o negócio (LENZ, 2017).

Segundo o Serviço Brasileiro de Apoio às Micro e Pequenas Empresas - SEBRAE - (2019), o enquadramento de microempresa (de acordo com o faturamento) é o empreendimento que possui receita bruta anual inferior ou igual a $\mathrm{R} \$ 360$ mil (trezentos e sessenta mil reais). Já conforme o número de funcionários, o setor de comércio e serviços pode ter, no máximo, 9 empregados e na indústria, o número permitido é maior, no máximo de 19 empregados. (SEBRAE, 2013). Esse conceito é exposto pela Lei complementar no 123/06, que define os critérios para o enquadramento das empresas no SIMPLES.

0 número de Microempresas no país partiu de 2,65 milhões, em 2009, para 4,14 milhões, em 2017, e de acordo com projeções do SEBRAE (2018), deve atingir 4,66 milhões, em 2022, o que representa um crescimento de 75,5\% nesse período de 23 anos, a uma taxa média anual de 2,47\%.

Nota-se que é crescente a quantidade de microempresas em território nacional, o que consequentemente aumenta a concorrência entre elas; uma ferramenta que auxilia no enfrentamento de um cenário altamente competitivo é um bom plano de marketing (FACIMA,2016). 
O plano de marketing compõe o planejamento estratégico de uma empresa e é utilizado para que a empresa tenha sabedoria do tamanho e posicionamento de mercado, e planeje como encaixar-se em cada segmento (LIMA; CARVALHO, 2011). Conforme estudo feito por Torres(2010), a empresa necessita definir uma vantagem competitiva permanente possuindo assim uma estratégia coerente, eficiente e eficaz, e é neste contexto que se verifica a importância da existência do marketing e as estratégias de negócios para a microempresa.

Esse planejamento de marketing, segundo Kotler (2000) é influenciado e refere-se a análise deaspectos internos e externos à microempresa, identificando maneiras pelas quais os interesses da organização se unam às oportunidades presentes no mercado. Magalhães e Sampaio (2007), delimitam esse processo em três partes: "Conhecer: levantar todas as informações sobre o ambiente, o mercado e a organização", "Decidir: definir os objetivos e estratégias de negócios para o produto ou serviço objeto de plano em sintonia com objetivos da empresa e preparar as condições a serem implantadas" "Agir: um processo de averiguação da validade e pertinência das decisões tomadas em relação a cada quadrante da matriz de marketing" (MAGALHÃES; SAMPAIO 2007,125).

Além disso, Born e Hartz (2013) complementam que esse plano deve conter as principais informações da organização com vistas a fornecer subsídio para a tomada de decisões e para a criação do cronograma de atividades e seu respectivo orçamento, dessa forma, é composto por quatro etapas: análise, decisões, implementação e controle. Ademais, Kotler e Armstrong (2003) afirmam que isso ajuda os gestores das microempresas e empresas em geral a prever situações e determinar como preveni-las ou enfrentá-las.

Portanto, a microempresa que agrega valor à sua marca, ou aos seus produtos e serviços atravésdo plano de marketing, consequentemente atende às demandas dos clientes; e se sobressai em relação a outras empresas. (SPAREMBERGER; ZAMBERLAN, 2008).

\subsection{MARKETING APLICADO EM EMPRESA PRESTADORA DE SERVIÇOS}

Atualmente, existe no mercado uma quantidade significativamente grande de empresas prestadoras de serviços, dos mais variados âmbitos, e que vem movimentando cada vez mais a economia. Segundo o Instituto Brasileiro de Geografia e Estatística - IBGE - (2017), havia mais de 1,3 milhão de empresas prestadoras de serviços em operação, no ano de 2017, e essas,representam quase 70\% do PIB do país.

Conforme a Organização Mundial do Comércio - OMC - as empresas prestadoras de serviçosrecebem uma classificação a qual faz possível mensurar sua influência no comércio e economia,dividindo as mesmas em 12 categorias de setores de serviços, nomeado como "w120", são eles: serviços profissionais; comunicação; construção e serviços relacionados a engenharia; distribuição; educacionais; meio ambiente; financeiros; saúde e sociais; turismo e relacionados; diversão, cultural e esportivos; transportes; e outros serviços não inclusos anteriormente.

Em consequência dos dados expostos, essa demasiada quantidade acarreta uma grande competitividade nessa esfera, entre empresas que prestam serviço do mesmo ramo, sendo assim,é de extrema importância que os profissionais prestadores de serviços tenham em mente a necessidade de conseguir oferecer e fazer visível ao público, o seu diferencial, através do marketing, e juntamente a isso, saber a forma certa de aplicá-lo quando o assunto se direciona a prestação de serviços (ALMEIDA, 2018).

Não obstante, é importante destacar a diferença entre empresas que ofertam produto e serviço,conforme Berry (1988), um produto pode ser um objeto, um aparelho ou uma coisa, enquanto o serviço é uma ação, um desempenho, isto é, é o resultado de um esforço. Complementarmente,Paladini e Bridi (2013), dividem os bens e serviços como tangíveis e intangíveis, ou seja, o produto palpável, concreto e que possui existência física, um bem tangível, já os produtos que não possuem essas características seriam os intangíveis.

Consoante a isso, de acordo com Grönroos (2006), é necessário afirmar que cada categoria de empreendimento precisa de uma aplicação do marketing específica, sendo assim, as empresas prestadoras de serviço necessitam de práticas voltadas para as mesmas, diferenciando-as das empresas que ofertam produtos, focando então, principalmente em saber o que os clientes querem, entender o que eles avaliam como importante na relação da empresa com o público, epossuir relatórios de qualidade de serviço, o qual é um dos itens mais importantes, pois, Kotler(1996) afirma que existe uma ligação direta entre a qualidade do serviço, a satisfação do consumidor e a rentabilidade da empresa. Esse método que abrange tais fatores, é o chamado "marketing de serviços", criado por McCarthy em 1960. 
O marketing de serviços faz referência aos 4Ps do marketing básicos, que todas as empresas deveriam possuir em sua estratégia, porém, quando se refere a prestação de serviços, são incorporados outros 3, totalizando 7Ps, sendo eles: produto; praça; preço; promoção; processo, ambiente físico (physical environment); e pessoas. Esses, segundo Lovelock, Wirtz e Hemzo (2011), são a base da execução do marketing de serviços, e representam as decisões gerenciais desse, necessárias para criar estratégias viáveis, voltadas ao atendimento das necessidades dos clientes de modo lucrativo em um mercado competitivo.

Portanto, utilizando o marketing de serviços as empresas são capazes de desenvolver estratégias especificadas ao setor de serviços, sendo eficazes para a obtenção de resultados, em meio a um mercado competitivo (LAS CASAS, 2006).

\section{METODOLOGIA}

Do ponto de vista da natureza a pesquisa desenvolvida classifica-se como aplicada. Pois conforme Menezes e Silva (2001, p. 20), tal pesquisa "objetiva gerar conhecimentos para aplicação prática dirigidos à solução de problemas específicos. Envolve verdades e interesses locais”. Ademais, a pesquisa aplicada é motivada pela necessidade de resolução de problemas concretos, mais imediatos. Possui finalidade prática (VERGARA, 2005).

Quanto a abordagem do problema da pesquisa aqui abordada classifica-se como qualitativa. Visto que de acordo com Vieira (1996) apud Zanella (2013, p. 35), a pesquisa qualitativa podeser definida como a que se fundamenta principalmente em análises qualitativas, caracterizando-se, em princípio, pela não utilização de instrumental estatístico na análise dos dados. Esse tipode análise tem por base conhecimentos teóricoempíricos que permitem atribuir-lhe cientificidade.

Para Gil (1999), a utilização dessa abordagem oportuniza o aprofundamento da investigação das questões relacionadas ao fenômeno em estudo e das suas relações, com valorização do contato direto com o caso estudado, considera que há uma relação dinâmica entre o mundo real e o sujeito, busca-se o que era comum, mas permanece aberta para perceber a individualidade e os significados múltiplos. Além disso, Menezes e Silva (2001), acrescentam que o ambiente contextual do caso em questão é a fonte direta para coletar dados, e o pesquisador é o instrumento-chave; este tende a analisar os dados indutivamente. 0 processo e seu significadosão os pontos centrais da abordagem.

Da perspectiva de observação dos objetivos apresentados nessa pesquisa, a mesma se caracteriza como pesquisa explicativa. Pois segundo Zanella (2013), pesquisa explicativa é aquela que tem o foco em identificar fatores determinantes ou de contribuição no decorrer dosfenômenos, explicando a razão pela qual ocorre determinadas conjunturas. Consoante a isso, Lakatos e Marconi (2001), pontuam que essa pesquisa visa estabelecer relações de causa-efeito por meio do estudo direto das variáveis relativas ao objeto de estudo, e que sua realização geralmente, é maior em laboratório do que em campo.

Em relação aos procedimentos técnicos referentes a atual pesquisa, classifica-se como pesquisa bibliográfica. Tendo em vista que uma pesquisa se categoriza como tal "Quando elaborada a partir de material já publicado, constituído principalmente de livros, artigos de periódicos e atualmente com material disponibilizado na Internet." (GIL, 1991). Ademais, Nascimento (2017) aponta que a pesquisa bibliográfica apresenta divergências ou análises realizadas em diferentes perspectivas, apontando os consensos e divergências sobre um determinado fenômeno.

Classifica-se também como estudo de caso, pois segundo Yin (2001), esse procedimento técnico é caracterizado pelo estudo aprofundado e exaustivo de um ou de poucos objetos, de maneira a permitir o seu conhecimento amplo e detalhado da realidade e dos fenômenos pesquisados. Para a realização de um estudo de caso podem ser utilizadas diferentes fontes de investigação, como: entrevistas, questionários e observação (GIL, 1999; YIN, 2001). Assim, para se analisar este caso busca-se, então, indicações de melhorias do processo de marketing empresarial, portanto, os dados são coletados por meio de entrevista estruturada aplicada na empresa de assessoria contábil estudada.

Caracteriza-se além das classificações supracitadas, como pesquisa documental. Conforme Gill(1991), essa é a pesquisa elaborada através de materiais que não receberam tratamento analítico,ou que ainda podem ser reelaborados de acordo com os objetivos da pesquisa. Nascimento $(2016$, p. 6) complementa tal pensamento citando que a pesquisa documental, ou histórica, consiste, de modo geral, na procura, leitura, avaliação e sistematização, objetivamente, de provas para clarificar fenômenos passados e suas relações com o tempo sócio-cultural- cronológico, visando obter conclusões ou explicações para o presente. 
Sendo assim, para fins desta pesquisa, foram utilizadas para análise as métricas das redes sociaisFacebook e Instagram do escritório Delta Assessoria Contábil, que é o caso abordado na presente pesquisa.

\section{DESCRIÇÃO E ANÁLISE DO CASO}

A microempresa Delta Assessoria Contábil é atuante na área contábil, fiscal e trabalhista. Se localiza no município de Andirá, no estado do Paraná. 0 escritório iniciou como sociedade em 1990, entre o Wesley James do Amaral (atual dono), sua mãe (Leonor Furlan) e um tio (Osvaldo Moraes). Houve uma separação empresarial e da sociedade em 1996. Assim, foi modificado e deu origem a um segundo escritório, de propriedade de Osvaldo Moraes e o outro entre WesleyJames do Amaral e Leonor Furlan, permanecendo com o nome Delta Assessoria Contábil.

A empresa inicialmente instalada em uma garagem, era pequena e possuía um número significativo de inadimplência por parte dos clientes. Após a abertura, aproximadamente um ano de funcionamento, foram feitas negociações e a inadimplência diminuiu em torno de $75 \% .0$ que possibilitou à empresa se solidificar no mercado.

A entrevista foi realizada com Renata Biancardi (esposa de Wesley James do Amaral), que até 1998 auxiliava em processos empresariais, e a partir do ano de 2000 veio a compor o quadro societário. Esta tem 44 anos de idade, é formada como técnico em contabilidade, cumpre o cargo financeiro, gestacional e abertura e encerramento de empresas. Além da formação acadêmica, realizou diversos cursos de capacitação contábil e de gestão. Antes da abertura do escritório, trabalhou em outras empresas, também do ramo administrativo, contábil e de gestão,o que conferiu a ela experiência no ramo.

Wesley James do Amaral, sócio fundador do escritório Delta Assessoria Contábil, tem 54 anos de idade, possui formação em ciências contábeis pela Universidade Estadual do Norte Pioneiro (UENP). Cumpre a função empresarial de folha de pagamento e setor contábil. Trabalhou em outras empresas também do ramo contábil e em áreas administrativas antes de se tornar sócio da organização. Possui cursos de capacitação contábil em áreas de recursos humanos, contabilidade gerencial, imposto de renda de pessoa física, área tributária e atendimento ao cliente.

Em entrevista, Renata afirmou que até o ano de 2002 "A empresa ainda se encontrava em evolução lenta e não era totalmente consolidada". Naquele ano houve um pedido de demissão de uma das funcionárias e Leonor Furlan passou sua parte da sociedade ao Wesley; houve entãoa demanda de contratação de outros dois funcionários (Ana Paula e Franciely). Nesse mesmo período iniciou um aumento de demanda e clientela e começaram a ser mais reconhecidos no mercado local e regional.

A empresa em estudo é definida, segundo Chiavenato (2001) e suas definições de tipos de organizações, como uma organização funcional, pois a autoridade é relativa e baseada na especialização, as comunicações entre os órgãos/cargos na organização são efetuadas diretamente, sem necessidade de intermediação; busca rapidez nas comunicações e ações. Ainda segundo o autor há também a descentralização das ações, as decisões são delegadas aos órgãos/cargos especializados que possuem conhecimento necessário para melhor implementá-las, ou seja, é a especialidade que promove as decisões; e as responsabilidades são delimitadasconforme as especializações.

A microempresa de contabilidade possui clientes do setor terciário, ou seja, de comércio e serviços. Oferece serviços de contabilidade, setor fiscal, folha de pagamento, abertura eencerramento de empresa, imposto de renda de pessoas físicas, assessoria para MEI e certificação digital.

A equipe é composta por cinco pessoas, Igor Gustavo do Amaral, que cumpre o cargo de auxiliar de escrita fiscal e marketing, e realiza confecção de certificado digital; Jussara Aguiar,cumpre a função de escrita fiscal e contábil; Matheus Santana, auxiliar contábil e office boy; Renata Biancardi (sócia), financeiro, abertura e encerramento de empresas; Wesley James do Amaral (sócio fundador), folha de pagamento e setor contábil.

Em entrevista realizada, a primeira pergunta feita à Renata com relação ao tema aqui abordado, o marketing, foi a partir de quando a empresa começou a se preocupar com essa área. A entrevistada relatou, então, que desde a fundação do escritório apresentam preocupação com o setor de marketing empresarial, entretanto, expos que para o setor de contabilidade, altos investimentos na área não são rentáveis. Essa crença é justificada segundo Barr e Mcneilly (2003) apud Sarquis et al. (2019), por haver poucos estudos em marketing que focalizem especialmente em empresas de contabilidade. Assim, devido a carência de estudos nessa área em organizações contábeis, há dificuldade, por parte das empresas, em realizar planejamentos e investimentos em marketing. Porém é notório e relevante a preocupação 
empresarial para comeste setor desde o início de sua prospecção no mercado, pelo fato que, de acordo com Dias e Santos (2015) apud Sarquis (2019), a alta competitividade em serviços de contabilidade demanda a necessidade de novas ferramentas de gestão e práticas de marketing, principalmenteao fim da década de 1990.

Ademais, dados da FENACON (Federação Nacional das Empresas de Serviços Contábeis) acrescentam que o marketing contábil é pouco praticado; e quando praticado é uma vantagem competitiva no mercado de prestação de serviços (PELEIAS et. al., 2007). Por isso a importância e relevância da preocupação do escritório Delta Assessoria Contábil.

Posteriormente, foi perguntado sobre quais eram as abordagens iniciais utilizadas no marketing da empresa. A entrevistada afirmou que no início faziam exposições e propagandas em cardápios de bares e restaurantes, e envio de mensagens de felicitações de fim de ano, tanto diretamente aos clientes como também por meios de comunicação em massa como o rádio.

Ao que tange sobre o início da implementação do marketing na organização, a ação de enviar mensagens de felicitações de fim de ano aos clientes, tanto direta como indiretamente, é considerado efetivo, pois se encaixa com o pensamento de Gabriel (2010) o qual diz que o processo de troca com o cliente, colocando o mesmo como centro de todas as ações, e fazê-lo sentir de tal maneira é uma das funções do marketing, pois isso reforça o relacionamento entrecliente e empresa, o que é um processo essencial dentro da jornada do cliente. Os meios utilizados, que no caso estudado eram principalmente os cardápios e propaganda no rádio, são,segundo Camargo (2019), fonte do marketing de massa, que é uma estratégia com foco exclusivo em impactar o maior número possível de clientes em potencial, sem nenhum tipo de diferenciação considerando nicho, persona ou público-alvo, ao longo do século XX era uma estratégia muito eficiente.

Quando questionada sobre quais eram os impactos das abordagens de marketing utilizadas no início da implementação, Renata informou que não apresentavam um retorno significativo paraa empresa e não era mensurável financeiramente. Porém, conforme Honorato (2004), essa é uma atividade voltada à conquista e manutenção de clientes por meio de processos de trocas, a empresa atende às necessidades e expectativas do cliente visando conquistar a fidelidade dessepara com a sua empresa e serviço e, assim, obtém lucro. Portanto, o marketing não impactará somente na área financeira, a métrica adotada para análise de efetividade deste deve ser além de quantitativa, deve atingir a qualitativa. Pois a efetividade pode se dar na perspectiva relacional, ou seja, na criação, desenvolvimento ou manutenção de relacionamentos duradouroscom clientes.

Em relação às ferramentas e estratégias de marketing, atualmente utilizam as redes sociais (Instagram e Facebook) para divulgação e não possuem uma estratégia de estruturada para isso.Conforme Canto e Corso (2017, p.101).

'A Internet, uma vasta rede pública de computadores, conecta, no mundo inteiro, usuários de todos os tipos uns aos outros e a um repositório de informações incrivelmente amplo' (KOTLER e ARMSTRONG, 2007 , p. 444). As vastas mudanças provocadas pela tecnologia criaram uma nova era digital causando um impacto ainda maior nas relações entre as empresas (sejam elas pequenas, médias ou grandes) e seus clientes. Ainda de acordo com Kotler e Armstrong (2007, p. 444), 'grande parte dos negócios no mundo hoje em dia é conduzida por meio de redes digitais que conectam pessoas e empresas'. Os autores (2007, p. 444) ainda afirmam que 'A Internet proporcionou uma maneira completamente nova de criar valor para osclientes e de construir relacionamento com eles'.

Mediante aos fatos expostos, a escolha da empresa na utilização de redes sociais para sua divulgação é uma característica essencial nos tempos hodiernos, pois a tecnologia está atrelada no dia a dia do ser humano em praticamente todas as suas ações. O Brasil, por exemplo, era em 2015 o quinto país do mundo em uso de Internet, com mais de 80 milhões de usuários conectados (FAGUNDES, 2015 apud CANTO e CORSO, 2017). Sendo assim, é possível notar que construir uma presença no digital é imprescindível às empresas.

Considerando o crescimento e avanço tecnológico da internet, as oportunidades existentes no mercado são ainda mais numerosas. Assim, o marketing tradicional da comunicação, da publicidade e da propaganda física deu espaço ao marketing digital. Segundo Torres (2010) apud Canto e Corso (2017) e Torres (2009) apud Boaira (2014) a definição de marketing digital é o conjunto de estratégias de marketing, aplicadas a Internet, se baseando no novo comportamento do consumidor atualmente. Consoante a isso, Boaira (2014) afirma que o marketing digital tem sido cada vez mais utilizado no ambiente das empresas através da adoçãode estratégias que permitam uma aproximação maior do público consumidor através do digitalem todas as suas facetas. 
Conforme supracitado, hodiernamente as redes sociais são essenciais, e assim se tornam o principal canal de comunicação para atrair novos clientes, assim como construir um relacionamento com os clientes existentes e conseguir melhor atender as suas necessidades. As redes sociais tiveram um impacto significativo na relação entre organizações e consumidor, assim, elas se tornam importantes instrumentos estratégicos para empresas de todos os portes ede todos os setores do mercado, vantagens (Torres, 2009).

No início da entrevista sobre o marketing, foi afirmado que o impacto e retorno não era significativo e impossibilitado de mensurar financeiramente, então, foi questionado se há impacto gerado através do marketing atual da empresa, já que houve migração dos meios de comunicação em massa para os meios virtuais e digitais, com maior foco nas redes sociais. A sócia-fundadora entrevistada relatou que não existe um retorno ou impacto notável gerado pelasações de marketing atualmente utilizadas.

Essa exposição de falta de retorno gerado pelas ações de marketing pode ser justificada por nãoexistir uma estratégia de marketing, e isso afeta diretamente se será obtido resultados para o negócio. Pois conforme uma pesquisa realizada para analisar o marketing em escritórios de contabilidade, o uso de marketing pelas empresas é ainda intuitivo e embrionário, e que os gestores possuem uma escassez de um melhor conhecimento sobre a área (SARQUIS et. al., 2019).

Os resultados da implementação de estratégias de marketing digital não são mensuráveis necessariamente por indicadores quantitativos, pois conforme Peleias et. al (2007) ao contrário da situação em que o consumidor compra produtos e vincula sua satisfação ao bem adquirido, os consumidores de serviços podem perceber os benefícios da contratação de maneiras e em momentos distintos, cabe notar como e quando uma melhoria deve ser oferecida ao cliente, é preciso saber o que o cliente sente sobre o serviço prestado, e manter a busca permanente pelamelhoria contínua, pois a melhor forma de atender, satisfazer e encantar o cliente é condição essencial para o progresso do negócio.

Conforme Kotler e Armstrong (1998) apud Carvalho (2017), empresas pequenas ou que estão iniciando seus negócios acabam não dando a devida atenção ao planejamento, por pensar que somente as grandes organizações precisam de um planejamento efetivo, porém, independentemente do porte, é necessário o planejamento, já que é a base para uma parte significativa da consolidação no mercado. Ainda segundo os autores, as empresas criam o escopo e uma missão traçado com objetivos para dar direção às ações. Para Compomar e Ikeda (2006, p.84) apud Carvalho (2017) o planejamento de marketing é "o processo de antecipar eventos e condições futuras e determinar cursos de ação necessários para alcançar objetivos de Marketing". Enquanto Rocha e Christensen (1999) referem-se a planejamento de marketing apenas como o início, já que posteriormente virá a fase prática.

Desse modo, para se implantar os processos do marketing digital em uma organização, a metodologia dos 8Ps é uma das medidas facilitadoras.

Abordado o exposto, foi indagado ainda se é feito o monitoramento das publicações em redes sociais e se há análise da repercussão destas. Renata afirmou que realizam monitoramento das postagens feitas, porém não possuem uma periodicidade ou critério para isso. Como supracitado, a metodologia dos 8Ps descrita por Vaz (2011) apud Cruz e Silva (2014), possui como o oitavo P, a precisão, isto é, a empresa realizar o monitoramento e analisar os resultados que foram obtidos no marketing digital aplicado. Notase, assim, a necessidade do monitoramento periódico e da mensuração dos resultados obtidos.

Visto que como meio de divulgação utilizam as redes socais, e estas possuem a possibilidade de impulsionar a publicação através de pagamento, foi perguntado se fazem uso de propagandas pagas ou gratuitas e o porquê utiliza uma ou a outra, ou ainda, ambas. A entrevistada relatou que utilizam propagandas pagas em ambas as redes sociais (Instagram e Facebook), realizam isso através de impulsionamento de publicações onde apresentam os serviços prestados pelo escritório, usam desse recurso para que alcancem maior visibilidade. Porém outras categorias de publicações como conteúdo que auxiliam o público, não são utilizadas de trafego pago. Poispossuem preferência em promover publicações que apresentem promoções e informações de serviços prestados.

Em vista do elencado, o trafego pago é uma forma de crescer estrategicamente nas redes sociaise que pode alavancar resultados, tanto para a obtenção de novos clientes, como fortalecer a comunidade existente. Entretanto, é importante ressaltar que não é necessário o uso de propagandas pagas para se alcançar resultados no digital, pois o crescimento orgânico (que nãoutiliza de custos para divulgação, propagandas em redes sociais, entre outras opções) é uma opção viável e considerada dentro da esfera do marketing 
digital. Nesse caso são utilizadas outras maneiras de conseguir visibilidade e alcance ${ }^{1}$, atrelada a demais estratégias. A tendência do crescimento orgânico é que exista um prazo maior para os resultados começarem a ser notados, todavia um trafego pago que não receba acompanhamento adequado sendo utilizado de forma assertiva, não irá gerar a reação esperada (CACHEL et. al., 2020).

Para uma melhor análise conclusiva do caso, foi indagado se realizam pesquisa para saber como o cliente conheceu a empresa. A entrevistada afirmou que questionam diretamente o cliente afim de saber como novos clientes tiveram conhecimento da empresa, e em sua majoritariedade é através de indicações espontâneas dos clientes já existentes.

Em relação a isso, uma pesquisa realizada em 259 escritórios de contabilidade do Estado de São Paulo apontou que os mesmos buscavam manter um bom atendimento aos clientes, pois isso é extremamente importante para conquistar a confiança dos consumidores, o que pode vira aumentar a propaganda "bocaa-boca", a qual é um meio de divulgação eficaz para empresas prestadoras de serviços (PELEIAS et. al., 2007). Sendo assim, a obtenção de novos clientes através de indicações é extremamente válida e importante para a empresa, pois remete que os clientes estão satisfeitos com os serviços prestados a ponto de considerarem recomendar a empresa para outras pessoas que eventualmente se tornarão clientes também. Porém, apesar do marketing relacional, ou seja, a gestão de relacionamentos de longo prazo ser a essência do marketing contemporâneo (ROCHA e LUCE, 2006 apud SARQUIS, 2019); o crescimento da Internet e seu impacto no dia a dia das pessoas trouxeram aos pequenos empreendedores oportunidades interessantes para alavancar os negócios. Sendo assim, os consumidores têm acesso a uma grande quantidade de informações, o que mudou totalmente a forma como eles descobrem, pesquisam, aprendem, avaliam e recomendam produtos e serviços e por isso há necessidade de focar além do marketing relacional (ENDEAVOR, 2016 apud CANTO e CORSO 2017).

Como já abordado, as redes utilizadas são Instagram e Facebook, e Renata nos informou que quem é responsável pelo setor de marketing, ou seja, realizar o monitoramento dessas redes sociais é majoritariamente o Igor, (o qual possui formação em direito) porém ela também tem participação no setor.

Em relação ao exposto segundo Carson e Gilmore (2000) apud Nascimento et. al. (2012) o perfil de empresários de pequenas empresas é em sua majoritariedade generalista, ou seja, ao invés de serem especialistas em uma determinada área, tomam decisões sobre todos os aspectos que envolvem a sua empresa. Isso remete a Renata, a qual cumpre o cargo financeiro, gestacional, abertura e encerramento de empresas e na resposta anterior também informou que tem participação nos processos de marketing da empresa. Desta forma, no que se trata a pequenas empresas não se espera que os mesmos sejam especialistas em marketing, mas considera-se que seria ideal para os empresários das mesmas ao menos possuir um conhecimento prévio e de qualidade sobre o assunto (TORLAK, 2005 apud NASCIMENTO et.al.; 2012).

Foi questionado a partir de qual data fizeram a inscrição em ambas redes sociais. Foi exposto, então, que o Facebook foi em meados de 2017, e que este existe há mais tempo que o Instagram, mas o movimento era mínimo antes da entrada do Igor na empresa, em 2019. Portanto, pode- se dizer que as duas redes sociais foram introduzidas ao marketing empresarial em 2019.

Foi documentado que o número de seguidores ${ }^{2}$ do Facebook totaliza 324, e no Instagram o número total é de 143. Por parte da entrevistada, foi relatado que apesar do Facebook apresentar maior número de seguidores, o alcance, número de curtidas e engajamento em geral é similar entre as duas redes socais. Por esse motivo, será utilizada para avaliação de métricas, a rede social Instagram, além de esta apresentar um alto grau de informação em relação ao desempenho como um todo do perfil em relação ao público.

A entrevistada disse ainda que as mesmas publicações são postadas nas duas redes sociais, portanto, há 18 publicações em ambas até a data de 01 de março de 2021. É importante ressaltar que todos os dados técnicos referentes às redes sociais do escritório Delta Assessoria Contábil supracitados e que serão apresentados são da data de 01 de março de 2021.

Analisando o perfil no Instagram da Delta Assessoria Contábil acima, é possível notar que o número de

${ }^{1}$ Alcance é uma estimativa do Instagram de quantas contas visualizaram a postagem pelo menos uma vez, com essa métrica, é possível entender quantas pessoas foram atingidas por uma publicação, mesmo que não tenham interagido diretamente com esse conteúdo (MAGALHÃES, 2020).

2 No meio digital, pode-se dizer que seguidor é uma pessoa possui conta virtual e segue outro perfil, pois demonstra compatibilidade e interesse no conteúdo deste. 
publicações no perfil até a data foram 18, relacionando tal dado com informações anteriores onde a entrevistada relatou que o perfil começou a ser movimentado ativamente em2019, há uma defasagem na constância das postagens.

Em relação a isso, Cachel et. al (2020) afirma que não é efetivo um planejamento de marketing,ou qualquer ação pensada para tal se não houver primeiramente constância nas postagens de conteúdo em redes sociais da empresa. Não obstante a isso, em um estudo realizado por Luca et. al em 2019 em uma empresa prestadora de serviços, apontou que a defasagem de alcance nos posts ${ }^{3}$ do Instagram de tal empresa tinha como uma de suas razões a falta de constância em suas postagens, se tornando algo prejudicial para o desenvolvimento do marketing digital do negócio.

A partir de demais dado coletados, as publicações de menor alcance, 8 em ambas, apresentadas pelo perfil da empresa estudada foram publicadas, respectivamente, em 25 e 27 de março de 2019, e possuindo respectivamente, 8 e 14 curtidas. Tais publicações foram as primeiras feitasno perfil.

Ao que tange sobre as duas publicações acima elencadas, nota-se que ambas trazem frases motivacionais, esse tipo de publicação pode gerar resultados de engajamento satisfatórios se entregados a uma interação com o público e relacionado ao nicho da empresa em um momentoestratégico, pois conforme Weber et. al. (2015) a empresa Dove realizou uma campanha em 2004 em relação ao dia internacional das mulheres, onde publicavam mensagens motivacionais de autoestima, e faziam uma ligação destas, aos produtos da marca.

Porém, somente essa forma de publicação não garante resultados, afinal como já supracitado, dentre os 8Ps do marketing digital, se encontra $2^{\circ}$ P, o qual é o "planejamento", nesse, conforme Cintra (2018) a empresa define e traça suas metas, e este $\mathrm{P}$ se faz intensamente relevante, pois é nesse momento que se define e explica minuciosamente as estratégias aplicadas que irão interferir nos demais passos. Consoante a isso Silva, (2018) apud Venture (2019, p.49) afirma que "quando se agrega o marketing ao planejamento, amplia-se fortemente o escopo de trabalhoda empresa; além de orientá-la para o mercado, tornando-a mais competitiva".

No dia da Black Friday de 2020, 17 de novembro, houve a postagem ${ }^{4}$ de uma publicação sobrea mesma, na qual continha uma chamada para a promoção de certificados digitais com $10 \%$ de desconto. Essa publicação foi a que obteve maior número de alcances, um total de 2609, e é relevante apontar que esta, utilizou tráfego ${ }^{5}$ pago. Outro post que pode ser feito uma comparação com o anterior, é o publicado em 1 de março de 2021, esse teve um total de 96 alcances, e não foi utilizado de tráfego pago, e diferentemente do anterior, esse foi feito em estilo post carrossel $^{6}$.

De acordo com as publicações apresentadas acima, pode-se notar que existem duas principais diferenças entre elas, a primeira, se trata sobre uma utilizar trafego pago e a outra trafego orgânico, e a segunda, é sobre os estilos, uma de post único e a outra em post carrossel.

Consoante ao primeiro ponto supracitado, é importante ressaltar a diferença entre trafego pagoe trafego orgânico, o primeiro se trata ao investimento de um valor monetário em uma determinada fonte em um determinado local da internet e isso faz com que mais visitantes cheguem até a página, o segundo se refere a uma conjuntura onde não possui nenhum custo direto, assim os visitantes chegam até a página de forma natural (GOMES, 2021). Tendo o exposto em vista, é observável que a publicação que utilizou de trafego pago teve $2617 \%$ de alcance a mais do que a que não usou, isso ocorre por conta da utilização do trafego pago aumentar o alcance da publicação aplicada para usuários específicos que são o público alvo do negócio (PATEL).

Ao que tange sobre o segundo ponto de diferença supracitado, o post carrossel é uma aposta que é mais vantajosa do que o post único, pois conforme Cachel et. al (2020) esse formato de postagem mantêm a audiência por um tempo maior visualizando a mesma, e isso é extremamente favorável para o algoritmo do Instagram, o que favorece que a postagem seja entregue para mais pessoas que não conhecem seu perfil, além de ser um formato mais dinâmicoe de fácil leitura.

${ }^{3}$ Post é uma palavra estrangeira, sendo a forma original da palavra em inglês, e indica uma publicação numapágina da Internet (NEVES, 2005).

${ }^{4}$ A palavra postagem é usada para indicar uma publicação numa página da Internet (NEVES, 2005).

5 A palavra tráfego diz respeito a acessos na página, e o trafego pago é o investimento de determinada quantia monetária em uma fonte (seja ela página, rede social ou site) para atrair visitantes para a fonte desejada (GOMES,2021).

6 Post carrossel é uma sequência de fotos na mesma postagem COSSETTI (2017). 
Analisando as publicações feitas na rede social do perfil sem a utilização de trafego pago (por se tratar de um fator que foi supracitado e analisado anteriormente) a média de curtidas foi de 6,5, enquanto a média de alcance das publicações foi calculada em 62,3.

Em relação a isso, é notável que a média respectiva do alcance é maior em comparação à médiade curtidas, isso significa que os posts chegaram a um determinado número de pessoas, e dessasque visualizaram o post pelo menos uma vez apenas uma parcela executou a ação de curtir. Essa conjuntura pode ocorrer por razão de o conteúdo das postagens não estarem conectando com o público de forma assertiva e o suficiente para que as pessoas queiram curtir o post, pois as métricas (curtidas, comentários, salvamentos e compartilhamentos) seguem como consequência dessa conexão (CACHEL, 2020).

\section{CONCLUSÃO}

De acordo com Grönroos (2006), é necessário afirmar que cada categoria de empreendimento precisa de uma aplicação específica do marketing, sendo assim, as empresas prestadoras de serviço necessitam de práticas voltadas para as mesmas, diferenciando-as das empresas que ofertam produtos, focando então, principalmente em saber o que os clientes querem, entender o que eles avaliam como importante na relação da empresa com o público, e possuir relatórios de qualidade de serviço, o qual é um dos itens mais importantes, pois, Kotler (1996) afirma que existe uma ligação direta entre a qualidade do serviço, a satisfação do consumidor e a rentabilidade da empresa.

Conforme mencionado no subitem 5, este projeto teve como objetivo principal demonstrar como adaptar as estratégias de marketing para serem implantadas uma empresa prestadora de serviços, como um escritório de contabilidade. A metodologia utilizada demonstrou ser eficaz para este plano, bem como os dados coletados e analisados, viabilizou o cumprimento dos quatro objetivos específicos apresentados anteriormente.

Primeiramente foi realizado um levantamento teórico de estratégias de marketing para microempresas prestadoras de serviços. Concluiu-se que há escassez de conteúdo nacional e metodologias na área de marketing aplicado em empresas prestadoras de serviços, principalmente contabilidade, e especialmente em países emergentes com o Brasil. Porém, há teorias, estratégias e metodologias que podem ser adapatadas para que seja definida uma vantagem competitiva permanente possuindo, assim, estratégias coerentes, eficientes e eficazes voltadas a prestação de serviço e ao atendimento das necessidades dos clientes de modo lucrativo em um mercado competitivo.

Posteriormente ao levantamento teórico, realizou-se a análise empírica das ferramentas e estratégias de marketing do caso em estudo. Assim, nota-se que as estratégias de marketing sereestruturam conforme os desejos e as necessidades dos indivíduos. A área de estudo (marketing) demanda condições a serem conhecidas para a estruturação de um plano, que são: o marketing é processo gerencial, baseia-se nas necessidades e desejos de grupos e no conceito de troca, além de eleger um mercado de atuação, deve atender às demandas da clientela e satisfazê-la com os serviços prestados, e por último, desenvolver vínculos econômicos e sociais sólidos para obter sucesso a longo prazo. Esse plano deve conter as principais informações da organização afim de fornecer subsídio à tomada de decisões e à criação do cronograma de atividades e seu respectivo orçamento, dessa forma, é composto por quatro etapas: análise, decisões, implementação e controle.

É necessário também conhecer o contexto que está inserido para definir o plano de marketing, assim, observa-se que a tecnologia está presente no cotidiano da população. Portanto, construiruma presença em plataformas digitais é imprescindível às empresas e é uma tendência no mundo globalizado contemporâneo. Nessa área de marketing digital foi analisado a metodologia dos 8Ps. Sequencialmente, essa metodologia traz o primeiro $\mathrm{P}$ sendo a pesquisa, posteriormente o planejamento, produção, publicação, promoção, propagação, personificação, e a precisão. Consoante a isso há outra metodologia para a base da execução do marketing de serviços, dessa vez contemplam os 7Ps, sendo eles: produto; praça; preço; promoção; processo,ambiente físico (physical environment); e pessoas.

Deste modo, embasados principalmente nas teorias, estratégias e metodologias supracitadas, compararam-se as realidades teórica e empírica estudadas, o terceiro objetivo específico da presente pesquisa. Para a comparação entre ambas as realidades, foram utilizadas respostas de perguntas feitas a uma entrevistada sócia fundadora da empresa, capturas de telas de publicações assim como seus respectivos dados de métricas disponibilizadas pelo perfil no Instagram do escritório de contabilidade estudado. 
Em consequência, tais análises permitiram visualizar implicações ao que tange sobre o marketing do escritório de contabilidade em questão. Dentre elas, foram elencadas: monitoramento irregular e sem critério de observação das postagens feitas; falta de constância nas postagens na rede social, pois em um período de 2 anos houve somente 18 publicações; escassez de planejamento para os posts feitos na rede social, pois nota-se a presença de frases motivacionais não relacionadas com o nicho do negócio; conteúdo que gera pouca conexão com os seguidores, pois apesar de haver um alcance notável em determinadas postagens, o número de curtidas não acompanha o mesmo padrão; e a inexistência de uma estrutura formada de marketing digital aplicável e direcionada para utilizar em redes sociais.

Tendo em vista tais pontos, a partir das análises obtidas por meio da comparação da realidade empírica e teórica, foi possível encontrar motivos pelos quais foi relatado em entrevista que as aplicações de marketing realizadas na empresa não entregavam um retorno significativo. A partir de tal conjuntura, com embasamento teórico foram apontadas ações, estratégias e ferramentas que favorecem o marketing, principalmente digital, direcionadas especificamente para as implicações atuantes no âmbito do escritório estudado. Dentre tais, incluem-se: elaboração de um plano de marketing detalhado; definição de quais estratégias serão aplicadasno perfil da rede social analisada; monitoramento constante de como tem sido o desempenho das ações aplicadas e existência de constância nas postagens feitas e a avaliação da efetividade das estratégias planejadas para que estas sejam constantemente aperfeiçoadas e modernizadas. Conforme isso, foi contemplado o quarto objetivo específico da presente pesquisa: demonstrara aplicabilidade e adaptabilidade das estratégias de marketing a microempresa em estudo.

Mediante os fatos expostos, esta pesquisa obteve êxito ao demonstrar por meio de fundamento investigativo científico das teorias de estratégias de marketing, como as suas ferramentas e características podem ser adaptadas para uma microempresa prestadora de serviços do ramo de contabilidade.

A pesquisa foi desenvolvida a nível explicativo, sendo assim, sugere-se que em trabalhos futuros sejam elaborados a nível exploratório, verificando os impactos que as análises e sugestões aqui abordadas apresentariam na praticabilidade do marketing referente a uma microempresa do ramo de contabilidade.

\section{REFERÊNCIAS}

[1] ABRAHAM MASLOW. Motivation and Personality. Nova York: Harper \& Row, 1954.

[2] AGENCIA BRASIL. Mais de 620 mil micro e pequenas empresas foram abertas em 2020. 2021. Disponível em: < https://agenciabrasil.ebc.com.br/economia/noticia/2021-04/mais-de-620-mil-micro-e-pequenas- empresasforam-abertas-em-2020> Acesso em: 30 jul. 2021

[3] BORN, R.; HARTZ, A. M. Plano de Marketing: roteiro, técnicas e recomendações. Porto Alegre: Meridional,2013.

[4] BRASIL. Classificação dos setores de Serviços. Disponível em: http://www.mdic.gov.br/index.php/comercioexterior/negociacoes-internacionais/217-negociacoes-internacionais-de-servicos/1942-ni-classificacao- dos-setoresde-servicos. Acesso em: 17 dez. 2020.

[5] CACHEL, C.; LUIZA, B. Guia Engajamento. 2020. Disponível em: < https://biolinky.co/guriasdomarketing> Acesso em: 15 mar. 2021.

[6] CACHEL, C.; LUIZA, B. Guia Estratégias. 2020. Disponível em: < https://biolinky.co/guriasdomarketing> Acesso em: 15 mar. 2021.

[7] CAMARGO, G. Descubra se realmente vale a pena trabalhar como o Marketing de Massa. 2019. Disponívelem: < https://rockcontent.com/br/blog/marketing-de-massa/> Acesso em: 07 mar. 2021.

[8] CANTO, L. C.; CORSO, K. B. Marketing na Era Digital: Um Estudo Sobre o Uso da Rede Social Facebookpor Pequenos Empreendedores. 2017. Disponível em: <http://www.ijbmkt.org/index.php/ijbmkt/article/view/83/64> Acesso em: 05 mar. 2021.

[9] CHIAVENATO, I. Teoria geral da administração. 6 edição. Rio de Janeiro: Elsevier Editora Ltda, 2001. CINTRA, A. O que são os 8 PS do Marketing Digital? Disponível em <https://www.postdigital.cc/blog/artigo/o-quesao-os-8-ps-do-marketing-digital> Acesso em: 15 mar.2021.

[10] COSSETTI, M. C.. Instagram libera até 10 fotos e vídeos no mesmo post com carrossel. 2017. Disponívelem: < https://www.techtudo.com.br/noticias/noticia/2017/02/instagram-libera-ate-10-fotos-e-videos-em- post-unicocom-carrossel-

veja.html\#: :text=Instagram\%20libera\%20at\%C3\%A9\%2010\%20fotos\%20e\%20v\%C3\%ADdeos\%20 no\%20mesmo\%20post $\% 20$ com $\% 20$ carrossel,por\%20Melissa\%20Cruz\&text=\%22Com\%20a\%20atualiza\%C3\%A7\%C3\%A3o\%2C\%20voc\%C3\%A A\%20n\%C3\%A3o,eles\%22\%2C\%20informa\%20o\%20Instagram.> Acesso em: 07 mar. 2021. 
[11] CRUZ, C. A. B.; SILVA, L.L. Marketing Digital: Marketing para o novo milênio. 2014. Disponível em: < https://assets.unitpac.com.br/arquivos/Revista/72/1.pdf> Acesso em: 01 mar. 2021.

[12] FACIMA. A importância do marketing empresarial para micro e pequenas empresas. 2016. Disponível em: <http://www.facima.edu.br/instituto/revista/ano1_2016.asp>. Acesso em: 15 jun. 2021

[13] GABRIEL, M. Marketing na Era Digital: conceitos, plataformas e estratégias. 2010. Disponível em: https://books.google.com.br/books?hl=pt-

BR\&lr=\&id=Cp2YDQAAQBAJ\&oi=fnd\&pg=PT6\&dq=GABRIEL,+Martha.+Marketing+na+Era+Dig

ital:+conceitos,+plataformas+e+estrat\%C3\%A9gias\&ots=ehisaaZauE\&sig=Z_Y05jNKtgj-

P01M5ezxbYZFikk\#v=onepage\&q=GABRIEL\%2C\%20Martha.\%20Marketing\%20na\%20Era\%20Dig ital\%3A\%20conceitos\%2C\%20plataformas\%20e\%20estrat\%C3\%A9gias\&f=false. Acesso em: 19 nov.2020.

[14] GIL, A. C. Como elaborar projetos de pesquisa. São Paulo: Atlas, 1991.

[15] GIL, A. C. Métodos e técnicas de pesquisa social. 5.ed. São Paulo: Atlas, 1999.GIL, A. C. Métodos e técnicas de pesquisa social. São Paulo: Atlas, 1999.

[16] GOMES, D. Tráfego pago: o que é, quais as vantagens e como utilizar no seu projeto. 2021. Disponível em: <https://sambatech.com/blog/insights/trafego-

pago/\#: :text=De\%20forma\%20bem\%20simples\%2C\%20tr\%C3\%A1fego,seja\%2C\%20o\%20tal\%20tr\%C3\%A1fego \%20pago.> Acesso em: 07 mar. 2021

[17] GRÖNROOS, C. Um modelo de qualidade de serviço e suas implicações para o Marketing. 2006. Disponívelem: https://rae.fgv.br/sites/rae.fgv.br/files/um_modelo_de_qualidade_de_servico_e_suas implicacoes_para_o_marketing_0.pdf. Acesso em: 16 dez. 2020.

[18] HONORATO, G. Conhecendo o Marketing. 2004. Disponível em: https://books.google.com.br/books?hl=ptBR\&lr=\&id=0gPl2zsdqpcC\&oi=fnd\&pg=PA1\&dq=HONORAT0,+Gilson.+Conhecendo+o+Marketin g\&ots=OxqPV_sGoi\&sig=FCxYUaovLo3kvTel7Ug7BKom744\#v=onepage\&q=HONORAT0\%2C\%2 0Gilson.\%20Conhecendo\%20o\%20Marketing\&f=false. Acesso em: 19 nov. 2020.

[19] KOLB, J. J. Estrutura Organizacional Linha-Staff. 2018. Disponível em: < http://jkolb.com.br/estruturaorganizacional-linha-staff/> Acesso em: 21 fev. 2021.

[20] KOTLER, et al. Marketing de serviços profissionais: estratégicas inovadoras para impulsionar sua atividade, sua imagem e seus lucros. 2.ed. São Paulo: Manole, 2002.

[21] KOTLER, P. Administração de marketing: a edição do novo milênio. São Paulo: Prentice Hall, 2000. KOTLER, P. Administração de marketing: análise, planejamento, implementação e controle. 1998. Disponível em: https://biblioteca.isced.ac.mz/bitstream/123456789/959/1/PDF-Marketing-Kotler-2000.pdf. Acesso em: 19 nov. 2020.

[22] KOTLER, P. O marketing sem segredo: Philip Kotler responde as suas dúvidas / Philip Kotler; trad. Bazan Tecnologia e Linguística. 2005. Acesso em: 19 nov. 2020.

[23] KOTLER, P.; REIN, I. J.; STOLLER, M. Marketing de Alta Visibilidade. Makron, 1a edição, 1999. KOTLER, P; ARMSTRONG, G. Princípios de marketing. 9ed.São Paulo. Pearson Pretice Hall. 2003. LAKATOS, E. M.; MARCONI, M. A. Fundamentos metodologia científica. 4.ed. São Paulo: Atlas, 2001.

[24] LENZ, D. S. Planejamento de marketing digital para a microempresa hazlo acessórios. 2017. Disponível em: https://www.riuni.unisul.br/handle/12345/4903. Acesso em: 15 dez. 2020.

\section{[25] LIMA, G. B.; CARVALHO, D. T. PLANO ESTRATÉGICO DE MARKETING: PROPOSTA DE UMA}

[26] ANÁLISE TEÓRICA. Revista Brasileira de Marketing. São Paulo, v. 10, n.2, p. 163-187. 2011. Disponível em: <http://www.spell.org.br/documentos/ver/5420/plano-estrategico-de-marketing- proposta-de-uma-analiseteorica>. Acesso em: 15 jun. 2021.

[27] LIMA, H. A. Marketing Contábil: Um Estudo em Escritórios de Contabilidade do Município de Icó, CearáBrasil. Disponível em: <https://idonline.emnuvens.com.br/id/article/view/1486/2250\#> Acesso em: 12 mar. 2021.

[28] LOVELOCK, C; WIRTZ, J; HEMZO, M. Marketing de serviços: pessoas, tecnologia e estratégia. 7a ed. SãoPaulo: Pearson Prentice Hall, 2011.

[29] LUCA, D.; GALEAZZI, T. L. O Instagram como Estratégia de Marketing Digital na empresa nutriativa. 2019. Disponível em:

<https://repositorio.ifsc.edu.br/bitstream/handle/123456789/1289/PI\%20Daniela\%20e\%20Tais.pdf?sequ ence=1\&isAllowed=y $>$ Acesso em: 16 mar. 2021

[30] MAGALHÃES, A. L. O que é alcance no Instagram e dicas para aumentá-lo. 2020. Disponível em: $<$ https://canaltech.com.br/redes-sociais/o-que-e-alcance-no-instagram-e-dicas-para-aumentalo/\#: :text=0\%20alcance\%20\%C3\%A9\%20uma\%20estimativa,interagido\%20diretamente\%20com\%2 0esse\%20conte\%C3\%BAdo.> Acesso em: 07 mar. 2021. 
[31] MAGAlHÃES, M. F.; SAMPAIO, R., Planejamento de marketing, São Paulo, Pearson Pretice Hall, 2007. MARTTINS, F. Teorias de marketing e balanced scorecard: Um ensaio teórico. 2010. Disponível em: http://www.portalcatalao.com/painel_clientes/cesuc/painel/arquivos/upload/temp/8218e526d008490491 b27e55110f7ec9.pdf. Acesso em: 26 nov. 2020.

[32] MENEZES, E. M.; SILVA, E. L. Metodologia da Pesquisa e Elaboração de Dissertação. 2001. Disponível em: < http://cursos.unipampa.edu.br/cursos/ppgcb/files/2011/03/Metodologia-da-Pesquisa-3a- edicao.pdf> Acesso em: 08 fev. 2021

[33] MINISTÉRIO DA ECONOMIA. Governo destaca papel da Micro e Pequena Empresa para a economia do país. 2020. Disponível em: < https://www.gov.br/economia/pt-br/assuntos/noticias/2020/outubro/governo-destacapapel-da-micro-e-pequena-empresa-para-a- economia-do-pais> Acesso em: 30 jul. 2021

[34] NASCIMENTO, F. P. Classificação da Pesquisa. Natureza, método ou abordagem metodológica, objetivos e procedimentos. 2016. Disponível em:

<http://franciscopaulo.com.br/arquivos/Classifica\%C3\%A7\%C3\%A3o\%20da\%20Pesquisa.pdf> Acessoem: 09 fev. 2021.

[35] NASCIMENTO, M. C. R.; TEIXEIRA, J. C. O Marketing na literatura versus o Marketing nas pequenas empresas concepções de empresários de pequenas empresas de um munícipio de Minas Gerais. 2012. Disponível em: < http://portaldeperiodicos.unisul.br/index.php/EeN/article/view/621> Acesso em 12 mar. 2021

[36] NEIL PATEL. Trafego pago: Como funciona, Que ferramentas usar e 5 dicas. Disponível em: < https://neilpatel.com/br/blog/trafego-pago/> Acesso em: 16 mar. 2021.

[37] NEVES, F. Postagem ou post. 2005. Disponível em: < https://duvidas.dicio.com.br/postagem-oupost/\#: :text=As\%20palavras\%20postagem $\% 20 \mathrm{e} \% 20$ post,dicionarizadas $\% 20 \mathrm{e} \% 20 \mathrm{~s} \% \mathrm{C} 3 \% \mathrm{A30} \% 20$ con sideradas\%20corretas> Acesso em: 07 mar. 2021.

[38] PALADINI, E. P.; BRIDI, E. Gestão e avaliação da qualidade em serviços para organizações competitivas. 1.ed. São Paulo: Atlas, 2013

[39] PARASURAMAN, A.; ZEITHAML Valarie A.; BERRY, Leonard L. SERVQUAL: a multiple-item scale formeasuring consumer perceptions of service quality. Journal of Retailing, v.64, n.1, p.12-40, Spring. 1988.

[40] PELEIAS, I. R.; HERNANDES, D. C. R.; GARCIA, M. N.; SILVA, D. Marketing Contábil: pesquisa com escritórios de contabilidade no Estado de São Paulo. 2007. Disponível em: <https://www.revistacgg.org/contabil/article/view/149> Acesso em: 05 mar. 2021.

[41] PRESIDÊNCIA DA REPÚBLICA CASA CIVIL SUBCHEFIA PARA ASSUNTOS JURÍDICOS. Lei complementar $\mathrm{n}^{\circ} 123$, de 14 de dezembro de 2006. Disponível em:http://www.planalto.gov.br/ccivil_03/leis/LCP/Lcp123.htm. Acesso em: 15 dez. 2020.

[42] ROBBINS, S. P. Comportamento Organizacional. 2005. Disponível em: https://admdotunisa.files.wordpress.com/2019/03/robbins_2009_livro_comportamento_organiz.pdf. Acesso em: 19 nov. 2020

[43] SANTOS, E. S. D. et al. Estratégias de marketing no contexto da contabilidade. 2019. Disponível em: http://revistas.icesp.br/index.php/FINOM_Humanidade_Tecnologia/article/view/668. Acesso em: 15 dez. 2020.

[44] SEBRAE. Definição de porte de estabelecimentos segundo o número de empregados. 2013. Disponível em: https://www.sebrae.com.br/Sebrae/Portal\%20Sebrae/UFs/SP/Pesquisas/MPE_conceito_empregados.pdf. Acesso em: 15 dez. 2020.

[45] SEBRAE. Microempresa, Empresa de Pequeno Porte e Microempreendedor Individual: diferenças e características. 2019. Disponível em: https://atendimento.sebrae-sc.com.br/blog/epp-microempresa-mei/.Acesso em: 15 dez. 2020.

[46] SEBRAE. Perfil das microempresas e empresas de pequeno porte. 2018. Disponível em: https://www.sebrae.com.br/Sebrae/Portal\%20Sebrae/UFs/RO/Anexos/Perfil\%20das\%20ME\%20e\%20EPP\%20\%2004\%202018.pdf. Acesso em: 15 dez. 2020.

[47] SILVA, C. R. A utilização do marketing digital para o benefício das organizações: estudo aplicado a microempresas de Capanema-Pa. 2019. Disponível em:

http://bdta.ufra.edu.br/jspui/bitstream/123456789/538/1/A\%20utiliza\%c3\%a7\%c3\%a3o\%20do\%20marketing\% 20digital\%20para\%20o\%20benef\%c3\%adcio\%20das\%20organiza\%c3\%a7\%c3\%b5es\%20estu do\%20aplicado\%20a\%20microempresas\%20de\%20capanema-pa..pdf. Acesso em: 26 nov. 2020

[48] SPAREMBERGER, A.; ZAMBERLAN, L. Marketing Estratégico. Rio Grande do Sul: Unijuí, 2008. TORRES, C. Guia Prático de Marketing na Internet para Pequenas empresas. 2010. Disponível em <http://www.cairu.br/biblioteca/arquivos/Marketing/Marketing_Internet_TORRES.pdf>.Acesso em: 15 jun 2021.

[49] VERGARA, S. C. Métodos de pesquisa em administração. São Paulo: Atlas, 2005 
[50] VIEIRA, M. M. F. V. A comparative study on quality management in the brazilian and the Scottish prison service. 1996. Tese [Doutorado PhD on Business Studies] - Scotland, University of Edinburg, Edimburgo, 1996.

[51] WHITELEY, R. C. A empresa voltada totalmente para o cliente: do planejamento à ação. Rio de Janeiro, Campus, 1992.

[52] YIN, R. K. Estudo de caso: planejamento e métodos. 2.ed. Porto Alegre: Bookman, 2001.

[53] ZANELLA, L. C. Metodologia de Pesquisa. 2013. Disponível em:

<http://arquivos.eadadm.ufsc.br/EaDADM/UAB_2014_2/Modulo_1/Metodologia/material_didatico/Li vro\%20texto\%20Metodologia\%20da\%20Pesquisa.pdf> Acesso em: 08 fev. 2021. 


\section{Capítulo 8}

\section{A importância e a resiliência das instituições econômicas}

\section{Virgilius de Albuquerque}

Resumo: Este trabalho problematiza a construção e a manutenção de instituições, em especial, aquelas de natureza econômica, a partir de algumas experiências brasileiras, em particular o Programa de Ação Econômica do Governo (PAEG), lançado em 1964. Analisa-se o papel das instituições, em especial, as instituições econômicas, a partir da exposição da doutrina do laureado com o Nobel de Economia, em 1993, Douglass North. A exposição da abordagem institucional é complementada com entendimentos desenvolvidos por outros renomados autores, Stephen Krasner e Robert Keohane, que discorrem sobre pontos não enfatizados por North. São apresentadas considerações acerca de mudanças institucionais, bem como de instituições domésticas e internacionais. Este trabalho é um pequeno ensaio acerca da criação e funcionamento das instituições e objetiva expressar alguns pontos de reflexão acerca do processo de mudança institucional.

Palavras-chave: instituições, mudança institucional, isomorfismo institucional, path dependence. 


\section{INTRODUÇÃO}

Uma das principais concepções teóricas de North (1996) consiste no argumento de que o desenvolvimento econômico é condicionado pelas instituições existentes. Pastore (2021), ao discorrer sobre os equívocos das políticas econômicas brasileiras incorridos desde a década de 1960, aborda as reformas institucionais efetuadas no âmbito do Programa de Ação Econômica do Governo (PAEG). Segundo ele, o PAEG, implementado antes da publicação dos mais reconhecidos trabalhos de North, continha diversos elementos de mudança institucional direcionados para o crescimento econômico.

O PAEG, que foi implementado no governo do ex-Presidente Humberto Castelo Branco, em 1964, procurou estabelecer as diretrizes estratégicas da política econômica abrangendo, inter alia, o controle da inflação, o crescimento e desenvolvimento econômico, a política salarial, a política habitacional, o equilíbrio das contas externas, a implementação de uma política de incentivos à exportação e a internacionalização da economia brasileira. Dentre as organizações e regras institucionais contidas no escopo daquele programa, foram instituídos o Banco Central e o Conselho Monetário Nacional, o Sistema Financeiro da Habitação e o Banco Nacional da Habitação, o Fundo de Garantia do Tempo de Serviço (FGTS), a correção monetária, a correção salarial anual e as minidesvalorizações cambiais (SANTOS, 2000).

No entendimento do economista brasileiro, foram criadas boas regras, instituições e organizações. Todavia, Pastore tece críticas sobre a institucionalização do Banco Central, a correção monetária e a política de minidesvalorizações cambiais concebidas no escopo do PAEG.

O Banco Central não detinha o monopólio de autoridade monetária, uma vez que esse papel também era exercido pelo Banco do Brasil. Ademais, a inexistência de mandatos fixos para seus gestores e a falta de autonomia em relação ao Executivo inviabilizaram a independência da política monetária. As decisões acerca da política monetária para combate da inflação eram deliberadas no Conselho Monetário Nacional, cujo colegiado era composto por empresários nacionais, inclusive. Esses arranjos institucionais, expressos em organizações e regras, foram capturados por grupos de interesse que representavam a elite política e econômica nacional. Por conseguinte, suas funções não eram destinadas para o controle da inflação nem para a promoção das exportações e o aumento do nível de competitividade da economia nacional, por exemplo, mas para o fomento do crédito doméstico e para a proteção da indústria brasileira.

A criação do mecanismo de indexação monetária - correção monetária, aliada à inoperância do Banco Central e à inexistência de uma âncora monetária, cambial ou fiscal para contenção dos preços engendrou o fenômeno da espiral inflacionária, apenas mitigada com a implantação do Plano Real, na década de 1990, da Lei de Responsabilidade Fiscal, em 2000, e do efêmero e maleável Teto dos Gastos Públicos, no final de 2016. Tanto a desvalorização monetária (inflação) como a cambial (minidesvalorizações) representam custos econômicos e custos de bem-estar social, que refletem instituições mal concebidas e ineficientes.

A instituição da indexação monetária e o modelo de minidesvalorização cambial são alguns exemplos de como a concepção e implementação de instituições econômicas podem afetar o crescimento econômico doméstico. Essas duas práticas institucionais contribuíram para a manutenção da inflação em níveis elevados, denotada pela expressão inflação inercial, que ocasionou o processo hiperinflacionário da década de 1980, bem como para a proteção do empresariado brasileiro contra a competitividade internacional.

O II Plano Nacional de Desenvolvimento (II PND), lançado em 1974, com o objetivo de fomentar a produção de insumos básicos, bens de capital, e energia, não levou em consideração o regime internacional de taxas de câmbio flutuantes. Portanto, as taxas de juros internacionais eram mais condicionadas pela expansão monetária do que pela estabilidade cambial. 0 endividamento externo incorrido a juros flutuantes para o financiamento do II PND levou o Brasil à moratória, em 1982, após a elevação acentuada das taxas de juros internacionais, em 1979.

O papel desempenhado pelas instituições para o crescimento econômico deve ser enfatizado. A criação, a manutenção e o eventual desfazimento de instituições demandam processos complexos e de longa maturação. Na dimensão econômica, as instituições não conduzem necessariamente a maior eficiência na distribuição e alocação de recursos sociais e econômicos em prol do desenvolvimento social. Formulações e funcionamentos inapropriados afetam a operacionalidade e os resultados de políticas públicas.

Desse modo, para melhor compreensão sobre a densidade e resiliência institucional, passa-se a discorrer sobre conceitos imanentes das instituições, abordando-se instituições domésticas, processos de mudanças institucionais e instituições internacionais. 


\section{INSTITUIÇÕES E MUDANÇA INSTITUCIONAL}

North (1996) tece comentários, essencialmente, sobre instituições domésticas. Nessa dimensão, pode-se tipificar, basicamente, duas naturezas de instituições, quais sejam, as instituições socioeconômicas e as políticas. As de natureza socioeconômica organizam os interesses do setor privado e interferem nos tipos de demandas distributivas requeridas pelos atores societais aos governantes, além de influenciar as condições macroeconômicas norteadas pelo governo.

Por outro lado, as instituições políticas agregam os interesses privados na esfera pública e conduzem o processo de barganha entre o setor privado e o Estado. Essas instituições podem apresentar diferentes gradações quanto ao tipo de regime (democrático, autoritário e totalitário), forma de representação política (proporcional, distrital e federativa), arquitetura dos sistemas executivo e legislativo, poderes do legislativo (estabelecimento da agenda, apresentação de emendas, ratificação, veto, referendo, barganhas políticas) e o grau de autonomia burocrática do executivo.

A abordagem das instituições econômicas de North é constituída a partir de uma teoria do comportamento humano combinada com uma teoria dos custos de transação, que acrescida de uma teoria de produção é capaz de analisar o papel das instituições no desempenho das economias. 0 autor compreende por custos de transação, os custos incorridos para a aferição do valor dos atributos que será transacionado, como, também, os custos decorrentes da proteção dos direitos, da fiscalização e da aplicação dos acordos. Tratase de uma concepção contratualista que pressume a existência de informações assimétricas na economia. Evidencia-se a sua ênfase denotada às instituições econômicas.

Sua rationale problematiza as premissas clássicas do comportamento racional do agente econômico, porquanto esses preceitos não se coadunam com a realidade empírica. Dentre os pressupostos comportamentais do ator racional, o mais controverso é a premissa de que os atores econômicos possuem sistemas cognitivos que fornecem verdadeiros modelos dos mundos sobre os quais fazem suas escolhas. De outra forma, esses atores recebem informações de problemas divergentes que levam à convergência de soluções. Ou seja, os modelos constituídos a partir de uma abordagem individual-utilitarista oferecem sérias restrições porquanto a realidade humana é caracterizada, também, por dissonâncias cognitivas, não-transitividade e mutabilidade de preferências, assimetrias e limitações informacionais, escolhas em ambientes de incerteza, e influências de natureza estrutural. Deste modo, o autor sugere um outro programa de pesquisa cuja ontologia reside nas instituições, a partir das quais pode-se derivar a análise de desempenho econômico das sociedades.

O laureado economista endossa o entendimento de que as instituições são constrições socialmente construídas que modelam as interações humanas, e que as mesmas podem ser distinguidas em restrições de natureza formal e informal. Enquanto as primeiras correspondem às regras e normas explícitas - ainda que advindas de uma commom law - as restrições informais provém da cultura social, ou seja, da transmissão de valores, conhecimentos e costumes que influenciam o comportamento de gerações.

Sinteticamente, o processo de institucionalização pode ser assim representado:

Percepção subjetiva $\rightarrow$ processamento e utilização de informações $\rightarrow$ comunhão de interesses $\rightarrow$ constituição de instituições formais e informais $\rightarrow$ formatação de preferências $\rightarrow$ comportamento humano.

Uma vez que as instituições estruturam o comportamento de seus membros, as estruturas institucionais reduzem o grau de incerteza de uma sociedade. Esse constitui um de seus pressupostos básicos. Enfatizase que a perspectiva institucional não prescreve que as instituições sejam funcionalmente eficientes para maximizar a utilidade esperada. Nesse mesmos diapasão, é a estrutura institucional vigente que condiciona a determinação do custo de transação e do custo de produção ou transformação.

Cabe observar que North apresenta conceituações distintas entre instituições e organizações. As organizações derivam do constructo institucional, bem como de fatores tecnológicos e de preferências dos consumidores. Sua organicidade corresponde a um grupo de indivíduos interligados por um propósito comum, que estão estruturados organizacionalmente para a consecução de objetivos definidos, mediante o uso combinado de recursos, habilidades, estratégias e capacidade de coordenação. Deve-se destacar, também, a importância da função empreendida pela estrutura institucional instituída. Caso, por exemplo, sua constituição priorize - em termos de oportunidade econômica - a redistribuição de renda, ela será menos efetiva que as instituições destinadas a promover o incremento de produtividade. 
Uma outra definição importante desse economista refere-se à mudança institucional. Ele ressalta a sua natureza incremental, em vez mudanças abruptas. Sustenta que um novo devir institucional pode ser explicado a partir (i) da relação simbiótica entre instituição e organização, em que esta última, juntamente com os empreendedores, conforma novas formas de relações institucionais, e (ii) do processo de contínua retroalimentação com que os indivíduos percebem e reagem a mudanças nas práticas e regras sociais, que são mais resilientes que as constrições institucionais formais.

O fenômeno do path dependence ajuda a explicar por que o processo de mudanças institucionais que transformam e geram novas instituições não são necessariamente mais eficientes. A sua constituição é influenciada pelas externalidades ambientais - positivas e negativas - pelo processo de aprendizagem das organizações, pelo processo histórico de auto reforço das percepções, e pela existência de organizações e grupos de coalizões com interesses distintos.

Norton menciona dois politólogos que contribuíram com profícuas discussões para seus trabalhos acerca das instituições: Stephen Krasner e Robert Keohane. Passa-se a sintetizar o entendimento desses dois autores sobre mudanças institucionais.

De acordo com Krasner (1988), a institucionalização exprime a tendência de manutenção dos padrões de comportamento, normas e estruturas formais. Esse autor assevera que a capacidade de resiliência das instituições a mudanças institucionais pode ser representada pela composição de dois vetores. 0 primeiro vetor é relativo ao nível de profundidade da instituição e representa o grau de intensidade com que a estrutura institucional define os agentes - vetor vertical. 0 outro vetor expressa o nível de relações que uma atividade particular mantém com outras atividades - vetor horizontal. Essa segunda dimensão permite avaliar a extensão das mudanças a serem empreendidas, caso ocorram alterações em uma determinada atividade.

O primeiro vetor expressa o enraizamento das instituições nos indivíduos. Nesse sentido, quanto mais intensa for a influência da estrutura institucional na autodefinição dos agentes, menor será a possibilidade de ocorrência de mudança estrutural. Fazendo menção à cidadania como exemplo de intensidade institucional conferida pela instituição Estado, observa-se que ela varia tanto internamente como entre os Estados.

A outra dimensão existente para avaliar o nível de resiliência de uma instituição, aos processos de mudança oriundos do ambiente externo, é a rede de associações que uma instituição particular mantém com outras. Portanto, presume-se que quanto maior for a densidade relacional de uma instituição, menor será a probabilidade de serem implementadas mudanças institucionais, porquanto será necessário, também, a imposição de mudanças nas demais instituições conexas. Ilustrativamente, a implementação de uma política de governo que objetive constituir um novo arranjo institucional, só auferiria eficácia caso fosse acolhida pelo sistema jurídico, pela estrutura burocrática, pelas barganhas políticas e pelos arranjos dos diversos grupos de interesse que se imiscuem na instituição Estado.

Krasner (1988; 1995) afirma que o fenômeno da durabilidade ou inércia das instituições pode ser explicado a partir dos seguintes elementos: (i) habilidade das instituições, mediante a adoção de políticas conscientes, de alterarem o ambiente externo ou de reforçar os padrões de comportamento existentes que as sustentam; (ii) manutenção de um contínuo processo de recrutamento de pessoal - formação de comunidades epistêmicas, por exemplo - coadunado com as instituições vigentes; (iii) capacidade das instituições de minimizar os problemas decorrentes de informações imperfeitas, diminuindo as possibilidades de free-riding; (iv) atributo de path-dependent, ou seja, elas têm uma tendência em manter o caminho inicial para o qual foram constituídas, obstaculizando alternativas - mesmo que essas alternativas sejam mais eficientes e efetivas a longo prazo - assumindo, consequentemente, um processo de retroalimentação; e (v) processo de isomorfismo institucional, decorrente de coerção, mimetismo, ou imposições normativas.

A arquitetura institucional doméstica é, portanto, resultante de diferentes tradeoffs entre a eficácia política e a eficiência econômica. Essa variedade com que as instituições domésticas são constituídas, consolidadas e entrelaçadas entre si, explicam a existência do heteromorfismo institucional, bem como, da inércia e dos elevados custos de mudança institucional. Cada sociedade apresenta suas tipicidades e, desse modo, a configuração das instituições decorre de situações relacionais idiossincráticas (MILNER, 1997).

No mesmo diapasão, o renomado cientista político Keohane (1988) entende que instituição pode ser conceituada como um padrão de atividade, ou, de outra forma, um arranjo particular socialmente constituído. Nesse sentido, exemplifica alguns padrões de comportamento, tais como, a religião, o casamento, soberania, neutralidade e reciprocidade. Ou seja, esse conceito expressa um conjunto, formal 
ou informal, de regras e normas persistentes e interconectadas que (i) prescrevem funções; (ii) constrangem as ações; e (iii) formatam as expectativas dos agentes.

Uma contribuição de Keohane, trazida para este trabalho, corresponde ao seu posicionamento sobre instituições internacionais. No plano internacional, as instituições são arranjos que possibilitam aos Estados equacionarem os problemas de ação coletiva decorrentes de situações de interdependência, mediante a criação e manutenção de organizações, regimes e convenções para fomentar a coordenação e cooperação entre eles (KEOHANE, 1989; 1993; 1993a). As instituições internacionais encontram-se manifestadas sob três formas: (i) organizações intergovernamentais formais ou não-governamentais - que correspondem a organizações burocráticas com regras e funções específicas; (ii) regimes internacionais regras específicas que formatam o comportamento dos Estados, como, por exemplo, o regime monetário internacional; e (iii) convenções - instituições informais, com regras implícitas, mas que, assim como os regimes, também, configuram as expectativas dos agentes, uma vez que facilitam os processos de coordenação de ações.

Os regimes compreendem, em uma hierarquia institucional, princípios, normas, regras e procedimentos decisórios. No que tange aos processos de mudança, essa hierarquia pode ser segmentada em dois níveis: (i) alterações de princípios e normas: provocam uma mudança de regime; e (ii) modificações de regras e processos decisórios: mudança dentro do regime existente.

Por sua vez, atinente às convenções, fazemos referência a um outro politólogo, Bull (1977) que ao rejeitar a hipótese de que o sistema internacional é anárquico cita as instituições como elementos constitutivos da interdependência entre os Estados. Menciona a guerra, o direito internacional, a diplomacia, a balança de poder e a doutrina da grande potência, como as principais instituições da sociedade internacional.

Deste modo, ao considerarmos o nível de análise internacional, as políticas de um Estado são entrelaçadas com as instituições internacionais, de sorte que as ações governamentais que estejam na mesma área de influência abarcada por princípios, normas e regras internacionais têm menores graus de liberdade. Por exemplo, a alteração de políticas tarifárias em um contexto de união aduaneira, apresenta menor possibilidade de implementação do que em acordos bilaterais de comércio, pois, no primeiro caso, ela possui uma estrutura institucional mais extensa. Da mesma forma, a implantação de políticas industrial e de tecnologia são constrangidas por regimes e convenções sustentadas pelos países mais desenvolvidos sob a forma de patentes e proteção à propriedade intelectual.

Norton sustenta que a desigualdade de crescimento econômico entre o Primeiro e Terceiro Mundo é explicada pela arquitetura institucional desses países. Em tradução livre, afirma que a "(...) incapacidade das sociedades para desenvolverem uma aplicação eficaz e de baixo custo dos contratos é a fonte mais importante tanto da estagnação histórica como do subdesenvolvimento contemporâneo no Terceiro Mundo. Estende este raciocínio para a fragilidade institucional de proteção dos direitos de propriedades existentes nos países em desenvolvimento. Reafirmando, conclui que "os países do Terceiro Mundo são pobres porque os constrangimentos institucionais definem um conjunto de pagamentos às atividades políticas e econômicas que não encoraja a atividade produtiva" (NORTON, 1996: 54, 110).

\section{CONSIDERAÇÕES FINAIS}

A consistência epistemológica da abordagem institucional é reforçada pela natureza estrutural das instituições, mormente em um ambiente de dissonâncias cognitivas, assimetrias de informações, volatilidade das preferências individuais, e de extensa diversidade cultural das sociedades.

O enraizamento das instituições nos indivíduos e a extensão das redes de associações mantidas por uma instituição com as demais existentes denotam o seu grau de resiliência e, por conseguinte, a possibilidade de implementação de mudanças institucionais. As características de path dependence e isomorfismo institucional são imanentes da inércia institucional. Ademais, as convenções ou regras informais que emergem dos valores e costumes sociais enfatizam a dimensão cultural das instituições. Além disso, a interdependência existente entre os estados nacionais constituída, inter alia, pelas instituições balança de poder e doutrina da potência hegemônica, inclusive na sua vertente econômica, condiciona o comportamento dos países no arranjo institucional da sociedade internacional.

0 atributo de resiliência das instituições confere dimensão explicativa quanto ao desenvolvimento das nações. 0 desenho institucional pode ser distorcido por ocasião de sua implementação, o que resulta no funcionamento de instituições ineficazes e ineficientes, porém de elevada capacidade autopoiética capaz de sustentar sua sobrevivência. E os mecanismos de path dependence e isomorfismo institucional podem 
resultar em instituições noveis igualmente contrapoducentes.

Nesse sentido, as críticas efetuadas à institucionalização de um Banco Central no Brasil com autonomia restrita, bem como dos mecanismos de correção monetária e desvalorizações cambiais para a manutenção de um câmbio subapreciado mostram-se pertinentes. Uma maior autonomia do Banco Central ocorreu, apenas, em 2021, a atualização monetária de ativos e de contratos ainda é observada, assim como a manutenção de um câmbio desvalorizado que arrefece a elevação da produtividade nacional e a competitividade internacional da indústria brasileira. As instituições apresentam, inegavelmente, um grande potencial de legado político, social e econômico.

Quanto ao arranjo institucional como elemento explicativo da desigualdade de crescimento econômico entre os países de economia desenvolvida e em desenvolvimento, cabe uma consideração. As instituições internacionais influenciam diretamente a condução de mudanças institucionais domésticas. 0 estudo das causas do subdesenvolvimento não pode ficar circunscrito na análise das instituições domésticas e internacionais de comércio e crédito, apenas. Ademais, se por um lado reconhece-se a dimensão do poder nos processos de constituição e mudança institucional doméstico, por outro, deve-se, também, fazer referência ao poder exercido pelos estados nacionais na configuração da ordem internacional. A composição estrutural centro-periferia, em que a gravitação hegemônica exercida pelos países desenvolvidos induz à transferência de recursos financeiros e aviltamento dos termos de troca dos países em desenvolvimento, é uma convenção cujo exame não pode ser desprezado. Da mesma forma, o fenômeno da dependência incentivada pelos grupos de interesse dos países desenvolvidos que se articulam com grupos periféricos dominantes (PREBISH, 1988).

Adicionalmente, salienta-se que as instituições tanto dos países em desenvolvimento como das nações desenvolvidas não são isomórficas. Há diferenças clássicas nos modelos regulacionistas das atividades econômicas e sociais entre os países do Primeiro Mundo - tais como, por exemplo, modo de produção, organização das empresas, mercado do fator de produção trabalho, e proteção à indústria nacional. À guisa de ilustração, o modelo organizacional estadunidense é nitidamente distinto do francês e do alemão. $\mathrm{E}$, no que concerne às instituições socialmente construídas, os valores e costumes da cultura japonesa são, analogamente, bastante diversos de seus pares desenvolvidos do ocidente.

Essa evidência pode, também, ser observada nas organizações, que, em conjunto com os empreendedores, correspondem ao dei ex machinis do processo de mudança institucional segundo o entendimento de North. As economias capitalistas apresentam modelos regulacionistas distintos. A concepção orgânica, a abrangência e o papel desempenhado pelas grandes organizações nos estados desenvolvidos originam-se de diferentes peculiaridades institucionais e interagem com as instituições sob diferentes modalidades. As corporations dos EUA, os keiretsus do Japão e as empresas estatais francesas são alguns exemplos que evidenciam a diversidade constitutiva das organizações e as diferentes funções que empreendem no dinâmico processo interativo com as instituições domésticas.

O estudo comparado do processo de mudança de instituições deve considerar que a premissa de isomorfismo institucional é frágil. Se por um lado, é possível evidenciar e comparar as instituições formais, por outro, o estudo dos arcabouços informais requer cuidados redobrados, em face da existência de instituições tácitas, concebidas e desenvolvidas dentro de um tecido social e intersubjetivamente incorporadas pelos indivíduos. 0 estudo do processo de formação de preferências dos atores societais é um dos grandes temas de pesquisa da perspectiva sociológica das ciências sociais.

A apresentação dos fatores que explicam a resiliência das instituições relaxa a abordagem racionalistafuncionalista de que as instituições são intencionalmente instituídas para desempenhar uma determinada função ou atividade. Da mesma forma, atenua o processo de extrapolação da tendência histórica. Fenômenos tais como path dependence obrigam a realização de estudos preditivos mais cuidadosos e aprofundados.

Apesar da conveniência metodológica de que seja privilegiado um determinado nível de análise, o estudo de fenômenos sociopolíticos e econômicos, efetuados a partir de uma abordagem institucional, não deve descuidar das dimensões doméstica e internacional. Igualmente necessária, é a avaliação das relações de poder e dos grupos de influência. Entende-se que um estudo de economia política que não abarque estes pontos seria, no mínimo, reducionista. Consequentemente, sua capacidade explicativa ficaria restrita ou enviesada.

As abordagens racionalista, sociológica e histórica apresentam densidades ontológicas distintas acerca do estudo da instituição. Enquanto a perspectiva racionalista enfatiza o caráter funcional e a natureza taken for granted da instituição, a abordagem sociológica enfoca a natureza social da instituição e o seu papel de 
formação de preferência e interesse, possuindo maior envergadura analítica para explicar os processos de mudanças institucionais. De outro modo, o institucionalismo histórico, ao incorporar a característica path dependence das instituições, detém a capacidade de explicar a persistência de instituições supostamente ineficientes. Estas duas últimas perspectivas são, portanto, capazes de analisar outcomes não-previstos pelos teóricos racionalistas, assim como, resultados não-intencionais, conquanto previsíveis.

\section{REFERÊNCIAS}

[1] BULL, Hedley. The Anarchical Society: A Study of Order in World Politics. London: Macmillan, 1977.

[2] KEOHANE, Robert. International Institutions: Two Approaches. International Studies Quarterly, vol. 32(4), 1988.

[3] _ Instituciones Internacionales y Poder Estatal: Ensayos sobre la Teoria de las Relaciones Internacionales. Buenos Aires: Grupo Editor Latinoamericano, 1993.

[4] _ Institutional Theory and the Realist Challenge After the Cold War in Neorealism and Neoliberalism: The Contemporary Debate, editado por David Baldwin. New York: Columbia University Press, 1993a.

[5] KRASNER, Stephen. Sovereignty: An Institutional Perspective. Comparative Political Studies, vol. 21, no. 1, April, p. 66-94, 1988.

[6] __ Power Politics, Institutions and Transnational Relations in Bringing Transnational Relations Back in: Non-State Actors, Domestic Structures and International Institutions, editado por Thomas Risse-Kappen, p. 257279. Cambridge: Cambridge University Press, 1995.

[7] MILNER, Helen. Interests, Institutions and Information: Domestic Politics and International Relations. Princeton: Princeton University Press, 1997.

[8] NORTH, Douglass C. Institutions, Institutional Change and Economic Performance, 7a ed. Cambridge: Cambridge University Press, 1996.

[9] PASTORE, Affonso C. Erros do Passado, Soluções para o Futuro: a herança das políticas econômicas brasileiras do século XX. São Paulo: Portfolio-Penguin, 2021.

[10] PREBISH, Raúl. Dependencia, Interdependencia y Desarrollo. Revista de la CEPAL, no. 34, p. 205-212, 1988.

[11] SANTOS, Marcelo Henrique P. Roberto de Oliveira Campos: homem de ação do governo Castelo Branco. Política brasileira. São Paulo: Perspectiva, 14 (2), 2000. 


\section{Capítulo 9}

Transporte individual por meio de aplicativo: Percepções do consumidor

\section{Evelyn Cristina Silva \\ Jocelino Antonio Demuner}

Resumo: 0 objetivo desse estudo é identificar a percepção dos consumidores que utilizam o serviço de transporte de pessoas intermediado por tecnologia via aplicativo. A satisfação de um consumidor está diretamente relacionada a um produto ou serviço e geralmente é definida através de uma resposta positiva ou negativa direcionada a necessidade ou expectativa do cliente. 0 trabalho constitui-se de uma pesquisa analíticaempírica com abordagem de caráter quantitativo e qualitativo. Para a coleta dos dados, foi utilizado como instrumento questionários com perguntas fechadas e abertas. 0 resultado mostrou que de forma geral, os usuários percebem grande importância no serviço transporte de pessoas intermediado por aplicativo, por consequencia, pode-se notar que há um elevado nível de satisfação contra um inexpressivo quantitativo de insatisfeitos com o serviço. 0 trabalho indica maior percepção de importância por parte das mulheres $(71,4 \%)$ contra $26,0 \%$ dos homens, logo, são elas as mais satisfeitas com o serviço. A despeito de 97,4\% dos usuários perceberem o serviço como muito importante, alguns fatores foram citados como pontos a melhorar, tais como, segurança, preço e conformidade com as diretrizes estabelecidas para usuários com necessidades físicas.

Palavras-Chave: Percepção do cliente; Serviço; Inovação; Aplicativos Móveis 


\section{INTRODUÇÃO}

O avanço da tecnologia no mercado tem sido um grande fator para as inovações na área de prestação de serviços, isso faz com que a concorrência entre prestadores de serviços fique ainda maior, dessa forma, o concorrente que investe na inovação mais atual terá maior vantagem. Segundo MORAES, T. A; FREIRE, A. A. Q; BACHMANN, T. H. B; ABREU apud (ROACH, 2009, PERSAUD; AZHAR, 2012)a mudança na forma de consumir tem sofrido influência da inovação incorporada nos dispositivos móveis, já reconhecidos pelos profissionais como um canal de marketing para atender os consumidores em qualquer lugar e momento, e por estes como uma forma de aprimorar sua experiência social e privacidade. 0 mercado de transporte vive de inovações, seja por novos veículos inventados, até novas técnicas e facilidades oferecidas no transporte de alimentos, animais e pessoas.

Nos últimos anos, ocorreu um elevado crescimento na economia de compartilhamento, um mercado que visa desagregar a utilização de um bem ou serviço de sua obtenção. 0 compartilhamento ocorre entre o detentor e terceiros. Alugar, emprestar e ceder bens de consumo é uma técnica antiga, porém com as plataformas tecnológicas o mercado ganhou espaço, pela facilitação promovida entre ofertantes e consumidores. (CODAGNONE, BIAGI, ABADIE, 2016).

O crescimento do desemprego tem levado muitos usuários para esses aplicativos e com isso, o mercado de serviço de transporte tem tomado cada vez mais espaço, deste modo, conforme uma estimativa feita em 2017 pelo coordenador do Centro de Estudos em Negócios do Insper, Paulo Furquim de Azevedo, realizado nas duas maiores cidades do país - São Paulo e Rio de Janeiro -, mostrou que os motoristas de aplicativos já movimentavam entre $\mathrm{R} \$ 1,5$ milhão à $\mathrm{R} \$ 3$ milhões por dia. Com a evolução da tecnologia os aplicativos se tornaram uma unanimidade no mundo atual. Sendo assim, surge o seguinte problema de pesquisa: Qual o nível de percepção dos consumidores em relação serviço de transporte de pessoas intermediado por tecnologia via aplicativo?

0 estudo objetiva identificar a percepção dos consumidores que utilizam esse serviço, mais especificamente, à pesquisa procurou, com base na percepção dos usuários: a) identificar principais reclamações e elogios em relação ao serviço prestado; b) verificar quais são os principais fatores que influenciam o consumidor a optar pelo uso de transporte pessoal por aplicativo.

Este estudo pode ser justificado por sua contribuição para outros estudos, seja para discentes ou docentes, ou até mesmo para demais interessados aos temas abordados. Também poderá servir para outras instituições de ensino, como base para elaboração de conteúdo ou para comparação de resultados. Além de poder contribuir fornecendo informações às empresas, essa pesquisa também pode colaborar com empresários que pensam em investir no ramo de transporte de pessoas por meio de aplicativo móvel.

Este artigo se estrutura em três partes: inicialmente há uma breve revisão da literatura sobre serviços, inovação em serviços, satisfação do consumidor e aplicativos móveis, em seguida é apresentada a metodologia proposta e por fim, a análise dos resultados da aplicação do questionário aos usuários de transporte por aplicativo.

\section{REFERENCIAL TEÓRICO}

\subsection{SERVIÇOS}

O desenvolvimento da TI (Tecnologia da informação) possibilitou que softwares fossem criados para dispositivos acordando com o novo contexto de conexão e interação criando assim, novos serviços como o dispositivo móvel. Segundo KOTLER (1988) Serviço está associado a qualquer contribuição ou atividade que uma pessoa física ou jurídica possa oferecer a outra, e que seja especialmente intangível, ou seja, que não seja algo físico e palpável.

O termo AppEconomy está relacionado aos serviços, fundamentados em aplicativos, que tem e utilizam uma estratégia particular vinculada à monetização dos serviços, no qual,são concedidos por meio de aplicação ou de acordo com a utilização dos elementos adicionais do próprio aplicativo (MIDIATISMO, 2013). Essa nova matriz de prestação de serviços age conectando os motoristas que prestam serviços comerciais de transporte de passageiros aos usuários que precisam locomover-se de um lugar a outro. (SALA 313 LAB, 2016).

De acordo com Esteves (2015), a evolução da tecnologia, especificadamente no tocante à internet e os telefones celulares, colabora com a origem de um novo tipo de prestação de serviço - transporte de passageiros via aplicativos móveis -, no qual, o serviço faz a locomoção dos passageiros de um ponto de origem ao outro (BUBICZ E SELLITTO, 2009). 


\subsection{INOVAÇÕES EM SERVIÇOS}

Segundo PAVITT (1984) inovação pode ser definida, como um produto ou como algum processo renovado, desde que possa ser utilizado ou comercializado com sucesso por uma organização trazendo mais eficiência. Esse conceito pode ser reforçado por meio da teoria de UTTERBACK (1994) de que a inovação é um determinante central de sucesso ou fracasso nas empresas manufatureiras. A inovação pode ser aplicada em todos os setores dentro de uma organização. Nos dias atuais a tecnologia em termos técnicos, instrumentais e de conhecimento é uma ferramenta indispensável no mundo organizacional, pois ela possibilita as empresas a perpetuarem-se em um mercado cada vez mais competitivo e instável.

A abordagem baseada em serviços foca nas especialidades de inovação de serviços e mostra inovações particulares, principalmente nas inovações interativas construídas entre clientes e organizações. 0 autor explica ainda que esta abordagem é especialmente definida por uma distinção entre serviços essenciais e serviços periféricos. Por serviços primordiais compreende-se a parte intangível, ou seja, intocável ou palpável do serviço que representa a explicação de sua existência, por serviço periférico entende-se serviço agregado ao essencial de pouca importância ou sem importância independente, podendo apresentar uma evidência tangível (SHOSTACK, 1982).

\subsection{SATISFAÇÃO DO CONSUMIDOR}

As empresas têm como objetivo principal, ao oferecer algum produto ou serviço, as prioridades exigidas pelos clientes, ou seja, satisfazer certa necessidade ou desejo requisitado ou demonstrado pelo consumidor. De acordo com HEPP (2006), a satisfação do consumidor é o objetivo principal de todos os negócios, ou seja, não é somente fornecer, não é vender, não é servir, mas sim satisfazer de forma eficaz as necessidades que levam os consumidores a fazer novos negócios. A percepção do consumidor é elevada quando ele está muito satisfeito. MATSUKUMA E HERNANDEZ (2006) acreditam que a satisfação é como um termômetro que possibilita conhecer melhor os clientes e, juntamente com outras considerações, indicar se o cliente é leal à empresa ou não, se pretende migrar para o concorrente ou, ainda, se pretendo abandonar o mercado. Neste sentido, a satisfação é estabelecida como a resposta do consumidor a uma avaliação da discrepância notada entre as suas expectativas e a performance após o consumo de um produto ou serviço (BLACKWELL et al., 2005).

O paradigma da desconformidade apresentado por OLIVER (1980) concebe a satisfação e a insatisfação como o resultado de uma comparação entre expectativas anteriores à compra ou consumo e o desempenho percebido pelo consumidor. 0 resultado de avaliação de um consumidor se está satisfeito ou insatisfeito é gerado através da comparação seja ela feito com um produto ofertado pela concorrência, por uma experiência ou pelo atendimento de uma necessidade.

Pessoas que estão altamente satisfeitas com o produto ou serviço visam a valorizar os atributos de um produto ou serviço e a manter a estrutura de recompra sobre ele (MILAN E TREZ, 2005). Um consumidor satisfeito opta pela compra e utiliza do mesmo produto ou serviço, pois aquele produto ou serviço atenderam a necessidade ou expectativa posta sobre ele, podendo até recomendar para futuros clientes, participando também ativamente da empresa no processo de melhoria do produto ou serviço ofertado.

ZEITHAML et al. (1993) afirmam que as necessidades e motivações pessoais são antecedentes da expectativa em relação ao serviço. Um cliente pode definir como satisfeito ou insatisfeito através da percepção de em que nível sua necessidade foi atendida. Quando o desempenho se mostra superior às expectativas formadas anteriormente, surge a desconformidade positiva, e consequentemente a satisfação. Quando o resultado mostra ser menos que o esperado, ocorre a divergência negativa, chamada insatisfação (OLIVER, 1980).

\subsection{APLICATIVOS MÓVEIS}

Os aplicativos móveis se tornaram peças fundamentais para uso pessoal e profissional nos dias atuais, Segundo a Agência Nacional de telecomunicações (NEGÓCIOS, 2019) há cerca de 230 milhões de telefones celulares em todo o Brasil, o avanço desta tecnologia vem crescendo rapidamente. Vale ressaltar que o país ocupa a $7^{\circ}$ colocação no mercado de internet, e o $5^{\circ}$ lugar quando se avalia as horas que os usuários permanecem conectados à rede.

Os aplicativos podem concomitantemente substituir tarefas de diversas tecnologias anteriormente criadas. 0 mercado de aplicativos móveis está em fase de crescimento, e não se pode ter certeza do 
caminho que tomará, ou das suas proporções, as tecnologias apresentadas pelos smartphones apresentam uma forma tradicional de se fornecer informações e serviços, dispondo assim de uma capacidade de modificar o comportamento individual dos usuários. (TSENGM KNPCKAERT e VERHOEF, 2013).

KHOO e ASITHA (2014) destacam que os aplicativos de transporte de pessoas instalados em smartphones se dividem em três categorias, a) os que auxiliam o usuário se deslocar, fornecendo informações de rotas, utilizando GPS e mapeando o trajeto a ser percorrido, b) os que funcionam fornecendo informações sobre o tempo de espera de um itinerário ou de um determinado transporte público, c) e, aqueles que ofertam um serviço, disponibilizando transporte individual ou dando acesso a uma rede de compartilhamento de veículos. Conforme a quantidade de usuários dessa nova tecnologia cresce, novas empresas e interessantes oportunidades aparecem, o sistema possibilita aos usuários um vasto acesso a informações anteriormente indisponíveis.

\section{ASPECTOS METODOLÓGICOS}

Desenvolveu-se a pesquisa com o método analítico-empírico que, segundo FRAGA (2009) se "dispõe a codificar olhar mensurável da realidade ou existência, priorizam estudos mais práticos, seu procedimento tem caráter técnico, forte preocupação com a relação casual entre variáveis". VERGARA (2005) acrescenta que a análise empírica é efetivamente feita no local onde de fato ocorre ou ocorreu um fenômeno ou que dispõe elementos para explicá-lo.

O universo envolveu os habitantes de Cariacica - ES. A amostra utilizada foi composta por usuários de transporte pessoal por aplicativo móvel. 0 cálculo da amostra levou em consideração dados das empresas de transporte por aplicativo revelados na última atualização em setembro de 2018, na página Fatos e Dados da Uber. Lá está disposto que a empresa tinha no Brasil 600 mil motoristas cadastrados e havia 22 milhões de usuários aptos a solicitar corrida no país, o que indica uma proporção de cerca de $10 \%$ dos brasileiros aptos a usar os serviços da Uber. Dessa forma, considerando que não se conhece a exata população de usuários de aplicativos em Cariacica, essa proporção foi usada na fórmula abaixo:

$$
n=\frac{Z_{\alpha / 2}^{2} \cdot p \cdot q}{E^{2}}
$$

Onde, o elemento a ser calculado, n, é o tamanho da amostra desejada, Z é o valor crítico que corresponde ao grau de confiança desejado, p equivale à proporção populacional de indivíduos que pertence a categoria dos aptos a usar os serviços de transporte pessoal, qé a proporção populacional de indivíduos que não pertence à categoria dos aptos, E é a margem de erro ou erro máximo de estimativa. Com base nesses números pode-se calcular o tamanho da amostra (n) para que a pesquisa tenha 95\% de confiança e um erro máximo de $5 \%$, a proporção dos aptos $\mathrm{p}=10 \%$ e a proporção complementar $\mathrm{q}=90 \%$. Assim, o tamanho do elemento n procurado é 139 usuários, que corresponde ao tamanho da amostra.

Os dados coletados foram obtidos pelo uso de questionários aplicados aos consumidores de transporte pessoal por aplicativo, os dados foram coletados por meio da plataforma de formulários do Google. 0 link do formulário foi enviado via WhatsApp, Instragram e Facebook. Vale ressaltar que a pesquisa teve como foco os moradores de Cariacica e o link do formulário foi enviado somente para eles. Para isso utilizou-se um dado do próprio Facebook, que informa a localização/endereço do seu afiliado de maneira pública (se o usuário permitir), sendo assim, procurou-se moradores da região de Cariacica para assim, enviar o link do formulário do Google. Depois dos ajustes necessários, essa pesquisa usou 168 questionários válidos contendo perguntas abertas e fechadas, o que está de acordo com o cálculo do tamanho da amostra, posto que maior que os 139 respondentes previstos para garantir a qualidade da pesquisa. Dentre as diversas maneiras de análise de dados, nesta pesquisa foi utilizada a forma qualitativa e quantitativa.

Os dados coletados foram tabulados e apresentados de forma analítica e estruturada. Além disso, eventos como a repetição de apontamentos nas perguntas abertas foram considerados, pois evidenciam uma percepção comum pelos diferentes consumidores. 


\section{ANÁLISE DOS DADOS}

Quanto à caracterização dos respondentes a idade, gênero e escolaridade são variáveis importantes nesse trabalho sobre percepção dos consumidores, especialmente sobre os serviços de transporte de pessoas. E, mais particularmente ainda, devido à inovação disruptiva ${ }^{7}$ a qual esses serviços foram submetidos com a chegada dos Serviços de Transporte por Aplicativos. A idade pode ser um fator de maior ou menor adesão à inovação, interferindo assim na percepção dos respondentes. Nesse sentido, a variável idade, quando segmentada por gênero, mostra que o público feminino é mais homogêneo do que o público masculino posto que $50 \%$ das mulheres encontram-se numa faixa etária entre 23 e 30 anos enquanto que os mesmos $50 \%$ dos homens, mais heterogêneos, estão distribuídos entre 24 e 37 anos. Já, quando a idade é segmentada por escolaridade, pode-se identificar que os respondentes com nível de escolaridade do ensino fundamental apresentam maior heterogeneidade que os demais grupos. A idade de $50 \%$ deles varia entre 19 e 45 anos com mediana de 34 anos. Por outro lado, a menor heterogeneidade se encontra nos respondentes do ensino médio onde se nota que 50\% deles estão na faixa etária de 20 a 29 anos. Os respondentes que informaram ter ensino superior como nível de escolaridade apresentam-se na faixa etária entre 22 e 33 anos com mediana de 25 anos, significando, ao todo, uma amostra jovem que se utiliza do serviço de transporte de pessoas intermediado por tecnologia, via aplicativo.

A variável idade, em anos, mostra que, 59 mulheres têm 24 anos ou menos e 61 das 168 respondentes têm mais de 24 e menos de 46 anos. Quanto aos homens, apenas um tem mais de 46 anos, 28 estão na faixa de 24 a 46 anos e por fim, apenas 17 têm menos de 24 anos. Interessante notar que as mulheres são maioria, nessa amostra, para qualquer faixa etária. Ao observar a idade sumarizada por escolaridade entende-se melhor que os 168 respondentes da pesquisa estão distribuídos de acordo com essas variáveis. 0 estudo mostra que a maioria (97, que corresponde a $57,7 \%$ ) possui ensino superior enquanto que 63 (que corresponde a $37,5 \%$ ) dos respondentes ainda não atingiram esse nível escolar, portanto, permanecem no Ensino Médio. Esses números indicam que essa amostra se encontra bastante qualificada para responder a pesquisa. Observa-se ainda uma pequena quantidade (8) de respondentes que se mantiveram no Ensino fundamental. Foi possível verificar também que entre as respostas mais comuns sobre a atual profissão dos entrevistados, grande parte dos respondentes são profissionais que atuam no setor administrativo outra boa parte que são estudantes, enquanto o restante, possui outros tipos de atividades como, policial militar, mecânico, professor, servidor público, designer de sobrancelha e entre outros que não se repetem com frequência quanto ao ramo de administração.

Ao inquirir os usuários sobre sua percepção em relação aos serviços de transporte por aplicativos, de forma geral os entrevistados mostraram-se satisfeitos, sendo que $48,52 \%$ estão muito satisfeitos e $48,21 \%$ parcialmente satisfeitos. Além disso, é possível apontar que 48,36\% do público (por gênero) feminino está muito satisfeito e $50 \%$ que corresponde a 61 pessoas do gênero feminino encontram-se parcialmente satisfeitas. ZEITHAML et al. (1993) afirmam que as necessidades e motivações pessoais são antecedentes da expectativa em relação ao serviço. Um cliente pode definir como satisfeito ou insatisfeito por meio da sua percepção de qual nível sua necessidade foi atendida.

Outro fator considerado quanto ao perfil dos usuários é a escolaridade, sendo assim, obteve-se as seguintes informações, $51,54 \%$ que equivale a 50 pessoas, possuem ensino superior e encontram-se muito satisfeitos com os serviços prestados, $45,36 \%$ que equivale a 44 pessoas, também possuem ensino superior e estão muito satisfeitos deixando assim, os demais dados como irrelevantes. Os que possuem ensino fundamental, 47,61\% encontram-se muito satisfeitos, e $49,20 \%$ parcialmente satisfeito. Os que possuem ensino fundamental, de forma geral os usuários estão satisfeitos com os serviços. Quando o desempenho se mostra superior às expectativas formadas anteriormente, surge a desconformidade positiva, e consequentemente a satisfação. Já quando o resultado mostra ser menos que o esperado, ocorre a divergência negativa, chamada insatisfação (OLIVER, 1980), no entanto, dos 168 entrevistados, apenas um respondente do ensino médio estava muito insatisfeito com o serviço, isso quer dizer que de maneira geral independente da escolaridade, os usuários percebem elevada importância no serviço de transporte pessoal por aplicativo, logo, estão satisfeitos com os serviços ofertados. Na categoria idade, destaca-se que dos 89 entrevistados $51,68 \%$ estão parcialmente satisfeitos e $44,94 \%$ estão muito satisfeitos com os serviços. Dos 76 entrevistados, 51,31\% que equivale a 39 correspondentes encontram-se muito satisfeitos e $46,05 \%$ que equivale a 40 , estão parcialmente satisfeitos. De forma geral, independente da idade os

7 "inovação disruptiva" é um termo cunhado pelo professor de Harvard Clayton M. Christensen em seu livro "O Dilema da Inovação: quando as novas tecnologias levam empresas ao fracasso". Significa que uma tecnologia pode transformar um produto ou serviço em algo novo, conveniente, mais simples e acessível de tal forma que pode tornar obsoleto o seu antecessor. 
usuários estão satisfeitos com os serviços, apenas um usuário respondeu estar muito insatisfeito.

Considerando a categoria por gênero, os muito satisfeitos, nessa amostra, 35,1\% são mulheres e 13,1\% são homens. Já os parcialmente satisfeitos são representados por $36,3 \%$ de mulheres e $12,5 \%$ de homens. Observou-se que segmentando a amostra por idade e por escolaridade esses percentuais se mantém assemelhados, o que, em certa medida responde ao problema de pesquisa. Pessoas que estão altamente satisfeitas com o produto ou serviço visam valorizar os atributos de um produto ou serviço e a manter a estrutura de recompra sobre ele (MILAN E TREZ, 2005). Isso quer dizer que os serviços de transporte por aplicativo vêm fazendo um trabalho satisfatório para os seus usuários atingindo assim, todos os níveis de escolaridade, idade e gênero.

0 termo AppEconomy está relacionado aos serviços, fundamentados em aplicativos, que tem e utilizam uma estratégia particular vinculada à monetização dos serviços, no qual,são concedidos por meio de aplicação ou de acordo com a utilização dos elementos adicionais do próprio aplicativo (MIDIATISMO, 2013). Dessa forma o aplicativo de transporte é uma das inovações que vem crescendo de forma extraordinária no mundo e cada vez mais se tornando mais popular no mercado de transportes de passageiros, nesse sentido, ao verificar quais são os principais fatores que influenciam o consumidor a optar pelo uso de transporte pessoal privado por aplicativos, o resultado obtido foi que: $29,2 \%$ (49) optam utilizar o aplicativo pela agilidade, $13,7 \%$ (23) pelo conforto, $44,0 \%$ (74) pela praticidade e $13,1 \%$ (22) pela segurança. Sendo assim o principal fator, de acordo com o resultado se concentra na praticidade que esse aplicativo proporciona aos seus usuários.

Dentro desses resultados o gênero feminino continua sendo predominante tendo uma porcentagem maior nos resultados e o masculino com uma diferença considerável de $28 \%$ a menos. Já o comparativo dos fatores de decisão por idade as respostas obtidas demonstram que 11,9\% (20) são pessoas com 24 anos ou menos e $17,3 \%$ (29) pessoas com idade maior que 24 anos a 46 anos ou menos, quanto ao quesito agilidade, nos dados coletados não houve respondentes com idade maior que 46 anos. Quanto ao motivo do conforto teve respondentes com idade de 24 anos ou menos sendo 5,3 \% (9) e com idade de 24 anos a 46 anos ou menos sendo 8,3\% (14), para esse quesito também não houve resposta de pessoas com idade acima de 46 anos. Além da maior porcentagem nos resultados, a praticidade também foi o único motivo que teve respondentes com idade maior que 46 anos sendo 1,8\% (3), diante disso vemos que esse é o motivo predominante em todas as escalas de idade, e a opção pela segurança os dados resultou em 10,7\% (18) que optam pelo uso tem idade entre 24 anos ou menos e 2,4\% (4) tem idade maior que 24 anos a 46 anos ou menos.

Quando segmentado o fator conforto por escolaridade 0,5\% (1) ensino fundamental, 5\% (8) ensino médio e $8 \%$ (13) ensino superior. Praticidades por escolaridade tiveram algumas porcentagens iguais comparada com a agilidade, na praticidade temos 2\% (3) ensino fundamental, $13 \%$ (22) ensino médio e $29 \%$ (49) ensino superior, pode-se observar que a maior população que utiliza o aplicativo de transporte por praticidade no perfil de escolaridade é do ensino superior. No fator segurança por escolaridade apresentase $0,5 \%$ (1) do ensino fundamental, $5 \%$ (8) do ensino médio e 7\% (12) ensino superior. Pode-se observar que a maioria da população entrevistada opta pela utilização por causa da praticidade e em seguida pela agilidade. Sendo assim, a satisfação é estabelecida por meio da percepção do consumidor a uma avaliação da discrepância notada entre as suas expectativas e a performance após o consumo de um produto ou serviço (BLACKWELL et al., 2005).

A despeito de 97,4\% dos usuários perceberem o serviço como muito importante, alguns fatores foram citados como pontos a melhorar, tais como, segurança, preço e conformidade com as diretrizes estabelecidas para usuários com necessidades físicas.

O questionário aplicado também buscou verificar se o serviço pode ser melhorado e juntamente identificar as principais reclamações. Os entrevistados acreditam que o serviço de transporte pessoal por aplicativo (Uber) pode ser melhorado. A análise dos dados coletados indica que a maioria acredita que o serviço pode, sim, ser melhorado no critério de segurança, atendimento, não deixar que os motoristas cancelem as viagens, melhorar os preços que ficam oscilando em horários específicos do dia. Uma percepção levantada foi a de elevada importância de aumentar a atenção aos passageiros surdos, cegos e cadeirantes, além disso, o usuário percebe a necessidade de manter um padrão de conservação para os veículos.

A pesquisa também capturou a percepção do consumidor quanto a sua preferência por transporte pessoal por aplicativo ou por taxi: Resultado aponta para 1,8\% (3) pessoas do gênero feminino preferem o táxi e $0,6 \%$ (1) do gênero masculino também preferem ir de táxi. Por outro lado, 70,8\% (119) das mulheres e 26,8\% (45) dos homens preferem utilizar o serviço de transporte pessoal por aplicativo. Esse achado está 
de acordo com o pensamento de (BABCZ e SELLITTO, 2009) que afirmam que esses serviços possibilitam mais conforto e rapidez para os consumidores já que não dependem das mesmas ligações telefônicas para centrais ou horas de espera para ser atendido, provocando assim, um serviço com mais facilidade e flexibilidade através do dispositivo móvel.

\section{CONCLUSÃO}

O presente estudo teve como objetivo identificar a percepção dos consumidores que utilizam o serviço de transporte de pessoas intermediado por tecnologia via aplicativo, na região de Cariacica-ES, buscando verificar o quanto os usuários estão satisfeitos com o serviço prestado. Desta forma, foi ressaltado no referencial teórico a inovação atual do mercado e seus efeitos, e a importância da satisfação do cliente no ato da prestação de um serviço. E de acordo com o resultado da pesquisa foi possível constatar que o grau de satisfação é maior do que o grau de insatisfação.

0 perfil dos entrevistados foi analisado através das respostas obtidas por meio dos 168 questionários respondidos e os resultados foram descritos usando análises qualitativas. Conclui-se que a maioria dos entrevistados é do gênero feminino (72,6\%), com faixa etária maior que 24 a 46 anos, ou menos (53\%) e a maioria com ensino superior completo (58\%).

Nos dados quantitativos foi analisado qual o aplicativo mais utilizado pelos respondentes que resultou a satisfação quanto aos serviços prestados pelos aplicativos de transportes privados. Os motivos pelos quais eles optam pelo serviço, qual tipo de transporte eles preferem utilizar, público ou privado, com qual frequência eles utilizam o aplicativo de transporte privado, se em algum eles já se sentiram insatisfeitos no ato da prestação do serviço e qual a preferência entre táxi e transporte por aplicativo. Já a análise qualitativa buscou verificar o que pode ser melhorado na prestação desses serviços, em qual ocasião os usuários costumam solicitar o carro por aplicativo e qual a insatisfação do consumidor quanto ao serviço prestado.

De acordo com o problema de pesquisa proposto no presente estudo: "Qual o nível de percepção dos consumidores em relação serviço de transporte de pessoas intermediado por tecnologia, via aplicativo?" obteve-se elevado nível de percepção de valor confirmado por nível de satisfação dos consumidores de $97,4 \%$, ou seja, 163 respondentes se encontram satisfeitos, mas com opiniões de melhorias na prestação do serviço. Foi possível identificar que 29,2 \% dos usuários optam em usar o serviço pela agilidade, 13,7\% pelo conforto, $44,0 \%$ pela praticidade e $13,1 \%$ pela segurança.

Pode-se concluir ainda que, mediante a pesquisa, os consumidores mesmo estando satisfeitos com muitos aspectos, ressaltam que é necessário realizar melhorias constantes na segurança, no atendimento ao cliente, no valor do serviço e no estado de conservação dos veículos, além de estabelecer o ponto de atenção de elevada importância para a lide com os passageiros surdos, cegos e cadeirantes adequandosecada vez mais ao perfil do cliente, posto que cada cliente tem uma necessidade, e todos eles esperam que tais necessidades e expectativas pessoais sejam realizadas de acordo com seus desejos.

\section{REFERÊNCIAS}

[1] Blackwell, R.D., Miniard, P.W., e Engel, J.F. (2005) Comportamento do consumidor. São Paulo.

[2] Bubicz, M. E., e Sellitto, M. A. (2009). Qualidade em Serviço de Transporte de passageiros: um estudo de caso no sistema urbano de Porto Alegre. Revista Produção Online, 9 (4).

[3] CODAGNONE. C.; BIAGI. F.; ABADIE. F. The passions and the interests: Unpacking the "Sharing Economy". Institute for Prospective Technological Studies. JRC Science for Policy Report, v. 1, n. 1, p. 1-60, 2016.

[4] Esteves, L. A. (2015). Uber: o mercado de transporte individual de passageiros - regulação, externalidades e equilíbrio urbano. Revista de Direito Administrativo, 270, 325-361, Rio de Janeiro.

[5] FRAGA, Marcelo Loyola. Metodologia para Elaboração de Trabalhos Científicos. Rio de Janeiro: Editora Fundo de Cultura, 2009. P. 2-2.Edição 01.

[6] Hepp, C..Envolvimento e satisfação do consumidor: um estudo no varejo de vestuário em Curitiba. Dissertação (Mestrado em Administração). Curitiba: Universidade Federal do Paraná, 2006. Houston, A Survey Handbook. Disponível em <http://www.uiowa.edu/ cqi/surveybk.pdf>. Acesso em dezembro de 2019.

[7] KHOO, H.L.: ASITHA, K.S. User requirements and route choice response to smart phone traffic applications (apps).Travel behavior rand Society, p. 59-70, 2014.

[8] Knockaert, J. S. A., Tseng, Y., e Verhoef, E. T. (2013). A revealed-preference study of behavioural impacts of 
real-time traffic information. Transportation Research Part C: Emerging Technologies, 30, 196-209. https://doi.org/10.1016/j.trc.2011.11.006.

[9] Kotler, P. Administração de marketing: análise, planejamento, implementação e controle. 5.ed. São Paulo: Atlas, 1998.

[10] Matsukuma, C.; Hernandez, J. Escalas e métodos de análise em pesquisa de satisfação de clientes. Revista de Negócios, 11, 2006.

[11] Midiatismo (2013). AppEconomy - Quando os aplicativos se transformam em negócios. Disponível em: <http://www.midiatismo.com.br/appeconomy-quando-aplicativos-se-transformam-em-negocios>. Acesso em março de 2020 .

[12] Milan, G.S. eamp; Trez, G. (2005). Pesquisa de satisfação: um modelo para planos de saúde. Revista da Administração de Empresas - versão eletrônica, 4(2), Art17.

[13] MORAES, T. A; FREIRE, A. A. Q; BACHMANN, T. H. B; ABREU, N. R. Qualidade em Serviços e Dispositivos Móveis: Uma Análise a Partir da Aplicação do Modelo SERVQUAL. Rev. FSA, Teresina, v.14, n.4, art. 2, p. 19-39, jul./ago. 2017.

[14] Oliver, R.L. (1980) A cognitive modelo fantecedents and consequences of satisfaction decisions. Journal of Marketing Research, 17, 460-469.

[15] PAVITT, Keith. Sectoral patterns of technical change: towards a taxonomy and a theory. Research Policy. v.13, 1984. p.343-373.

[16] Revista Época Negócios, 2019. Brasil tem 230 milhões de smartphones em uso. Disponivel em:<https://epocanegocios.globo.com/Tecnologia/noticia/2019/04/brasil-tem-230-milhoes-de-smartphones-emuso.html>. Acesso em novembro de 2019.

[17] Roach, G. (2009). Consumer perceptions of mobile phone marketing: a direct marketing innovation. Direct marketing: na international journal, 3(2), 124-138.

[18] SALA 313 LAB. Disponível em: <https://sala313.com/tag/ehailin/>. Acesso em novembro de 2019.

[19] SHOSTACK, G. How to design a service. European Journal of Marketing. v.16, 1982. p.49-63.

[20] UTTERBACK, James. Mastering the Dynamics of Innovation. How companies can seize opportunities in the face of technological change. Boston, Massachusetts: Harvard Business School Press, 1994.

[21] VERGARA, S. C. Métodos de pesquisa em administração. São Paulo: Atlas, 2005.

[22] Zeithaml, V.A.; Berry, L.L. e Parasuraman, A. (1993) The nature and determinants of customer expectations of service, Journal of academy of marketing science, 21 (1), 1-12. 


\section{Capítulo 10}

Empreendedorismo e inovação: Um estudo do impacto da Pandemia do COVID-19 no comércio informal do município de Codó-MA

\section{Pedro da Silva Sousa}

\section{Inácio Ferreira Façanha Neto}

Resumo: Em vista da crise sanitária causada pelo coronavírus e suas repercussões nas atividades econômicas, neste trabalho pesquisa-se sobre os impactos da pandemia de covid-19 na atuação de empreendedores do município de Codó-MA, em especial, nas atividades informais, com a finalidade de analisar as principais adversidades enfrentadas assim como as oportunidades surgidas nesse contexto. Para tanto, se faz necessário identificar a prática empreendedora e inovadora como fatores importantes para a continuidade do comércio municipal na pandemia, caracterizar no cenário pandêmico principais desafios enfrentados e oportunidades surgidas para os empreendedores e verificar principais implicações resultadas da pandemia no empreendedorismo informal de Codó-MA. Realiza-se, então, uma pesquisa bibliográfica juntamente com uma de campo através de questionário direcionado a empreendedores no município para coleta de dados primários, ambas com abordagem qualitativa. Diante disso, verifica-se que a maior parte dos participantes da pesquisa concorda, seja parcial ou totalmente, que as medidas para evitar aglomerações afetaram negativamente suas atividades e desempenho profissional, 40,9\% afirmam ter sofrido mudanças de funcionamento no trabalho devido à crise sanitária e 88,3\% disseram que investir em atividades online é uma das melhores formas de superar as dificuldades diante dessa crise.

Palavras-chave: Empreendedorismo. Impactos. Inovação. Pandemia. 


\section{INTRODUÇÃO}

O mundo atual vive uma grave crise sanitária ocasionada pela pandemia do coronavírus (SARS-CoV-2), as suas repercussões afligem a sociedade de forma intensa e em diversos aspectos. Seus impactos afetam muito além da ordem epidemiológica global, repercutindo em âmbitos sociais, culturais, econômicos, políticos e históricos cuja gravidade supera outras crises epidêmicas já vistas pelo mundo. Em meio às diversas classes e grupos impactados com a situação, há o comércio com os pequenos negócios, na figura dos empreendedores e seus empreendimentos, que sentem os efeitos causados em suas atividades em virtude das medidas de restrição de circulação, mudanças no consumo entre outras questões em decorrência da pandemia, o que é comprovado por estudo realizado pelo IBGE (2020), entre diversos outros feitos, apontando que das 3,2 milhões de empresas funcionando no Brasil, 38,6\% delas afirmaram que as suas atividades sentiram efeitos negativos devido a pandemia no segundo semestre de 2020.

Os empreendedores seguem enfrentando as repercussões da crise como algo jamais vivenciado antes, contudo, apesar das adversidades e prejuízos, muitos empreendedores e negócios conseguiram contornar a situação sabendo se reinventar para se adaptarem às novas condições, enxergando em meio às adversidades as oportunidades surgidas com a nova realidade exercendo uma postura de inovação. Frente a isso, surge os brasileiros como personagens centrais usando da criatividade como um meio seguindo transformando hábitos novos em chances de negócios (COSTA, 2021). Em razão disso, a pandemia também trouxe novos horizontes para os empreendedores que souberam absorver as chances e se reinventar para se adaptar ao novo contexto.

Diante de tal cenário, a importância desse trabalho se justifica pela necessidade de focar nos impactos da crise em um determinado grupo na sociedade, os empreendedores, em especial os informais, tendo consciência de que a pandemia é uma problemática sentida em escala global e comumente se trata de suas repercussões de forma generalizada. Ademais, direcionar um estudo a essa classe, faz jus à sua imensa importância para as sociedades em diversos aspectos além do econômico contribuindo para enriquecer ainda mais o que se conhece a respeito. Justifica-se a relevância ainda, por buscar conhecer mais sobre o assunto em determinada parcela desse grupo, os empreendedores de Codó-MA, de modo a fomentar perspectivas sobre sua situação vislumbrando pelas repercussões na vida de todos, investigar para ter noção de suas respostas ante a pandemia, possibilitando dar suporte para novos estudos sobre os impactos da pandemia no empreendedorismo, especialmente, na cidade de Codó, Maranhão.

Nesse sentido, esse trabalho buscou responder ao seguinte questionamento: Quais os principais desafios e oportunidades existentes com o surgimento da pandemia do Covid-19 no comércio informal do município de Codó-MA? Seguindo esse problema de pesquisa, toma-se como objetivo geral: Analisar os principais desafios e oportunidades existentes com o surgimento da pandemia do Covid-19 no comércio informal do município de Codó-MA. Para objetivos específicos: Identificar a prática do empreendedorismo e inovação, enquanto fatores essenciais à sobrevivência no comércio do respectivo município na atual situação pandêmica; Caracterizar diante do atual cenário de pandemia as principais oportunidades e desafios enfrentados no comércio informal do município de Codó-MA e; Verificar os principais impactos da pandemia do Covid-19 no empreendedorismo informal do município de Codó-MA.

A metodologia utilizada neste trabalho consistiu em uma pesquisa bibliográfica por meio de buscas em fontes como artigos científicos, dissertações, monografias, periódicos, matérias jornalísticas, entre outros para fundamentar e situar-se acerca da temática. Em razão dos objetivos do trabalho foi realizado também uma pesquisa de campo para fornecimento e confirmação dos dados primários através da aplicação de um questionário via Google Forms composto por 14 perguntas fechadas com quantidade de alternativas dicotômicas e/ou múltipla escolha tendo como alvo pequenos empreendedores do município de Codó-MA com a finalidade de compreender melhor sua situação na pandemia segundo os objetivos do presente estudo, onde 137 empreendedores responderam às perguntas. Devido aos meios adotados para coleta e tratamento de dados para esse trabalho - levantamento bibliográfico e pesquisa de campo - houve uma interpretação das informações obtidas relacionando os dados e contribuindo com eles por meio de análise e assimilação. Nesse sentido, "a interpretação dos fenômenos e a atribuição de significados são básicas no processo de pesquisa qualitativa" (PRODANOV; FREITAS, 2013), dessa forma, esse estudo para a análise dos dados utilizou-se de uma abordagem qualitativa.

0 trabalho dividiu-se em cinco seções: nesta primeira apresentou-se a introdução com contextualização do tema, problema de pesquisa, objetivos e metodologia usada. Na segunda apresentou-se o referencial teórico trazendo robusta pesquisa sobre o assunto com diversos autores e estudos publicados. Na terceira, uma descrição detalhada da metodologia adotada para realização do trabalho. Na quarta seção, a 
apresentação e análise dos resultados da pesquisa de campo. E por fim, na quinta seção, as considerações finais.

\section{REFERENCIAL TEÓRICO}

\subsection{CONCEITO DE EMPREENDEDORISMO E INOVAÇÃO}

Existem os mais multímodos conceitos para tentar-se delimitar o que seria empreendedorismo, pois este entendimento não se trata de um conceito restrito com fácil delineamento, e o trabalho para explicá-lo foi se dando com o decorrer do tempo e ganhando mais abrangência e complexidade, onde diversos autores e teóricos buscaram através de seus entendimentos traduzir com seu entendimento e palavras o que viria a ser o empreendedorismo juntamente do ato, em si, de empreender. Especulações sobre origem do papel do indivíduo empreendedor e a natureza do empreendedorismo têm sido feitas por um considerável número de autores (Parker, 2009, p. 39, apud VALE, 2014, p. 876). É correto afirmar que empreendedorismo é identificar e buscar transformar situações e oportunidades em soluções para o meio no qual se vive, tais quais sejam com objetivos econômicos, pessoais ou mesmo sociais, utilizando-se do que estiver ao alcance. Empreendedorismo é, ainda, buscar de forma inovadora transformar utilizando-se dos recursos materiais e de conhecimento disponíveis, ideias em soluções para atender necessidades percebidas na sociedade.

Na visão de Schumpeter (1997), o empreendedorismo seria uma destruição combinada com criatividade, ou seja, um caminho no qual se destrói métodos de produção e/ou produtos já existentes para que sejam substituídos por outros, os quais sejam tidos como novidades. Nesse entendimento é possível já visualizar o elemento inovação e a toda sua ligação com a ação de empreender. A característica de inovação é intimamente ligada ao empreendedorismo, é uma base de concretização do ato na qual o indivíduo permite-se ter como algo essencial para se manter sempre acompanhando a evolução do meio no qual se atua e as necessidades que mudam e surgem com o tempo. Para Chiavenato (2007), o indivíduo que empreende é o que dá início e/ou conduz um negócio tendo como fim a concretização de uma ideia ou projeto, afirmando também que para adiante dos riscos inerentes ao ato de empreender, a pessoa assume o papel de inovar continuamente.

Desse modo, a preocupação em estar se reinventando dentro da vivência de empreender e, dessa forma, inovando, garantirá o sucesso tendo em vista que trazendo novas atitudes e ideias constituíra-se a maneira por meio da qual o empreendedorismo possa seguir se adaptando e se mantendo tão importante em benefício das pessoas e da sociedade como uma totalidade tal como a iniciativa capaz de buscar sempre entender as necessidades para solucioná-las.

0 quadro 1 demonstra a definição de empreendedor partindo da visão de alguns importantes autores.

Quadro 1 - Conceitos do termo empreendedor

\begin{tabular}{|c|c|}
\hline Autores & Conceito de empreendedor \\
\hline Schumpeter (1982) & $\begin{array}{l}\text { Indivíduo responsável por promover nova ascensão e impedir o declínio da } \\
\text { geração de riquezas, garantindo resultados positivos ao negócio. Criador de } \\
\text { oportunidades. }\end{array}$ \\
\hline Drucker (1986) & Indivíduo inovador e maximizador de oportunidades. \\
\hline Dolabela (2006) & $\begin{array}{l}\text { Aquele que provê o próprio sustento, de forma independente. Oferece valor } \\
\text { positivo para os outros, não estando assim submetido à outra pessoa, possui } \\
\text { certo grau de liberdade. }\end{array}$ \\
\hline $\begin{array}{l}\text { Farah, Cavalcanti e } \\
\text { Marcondes (2008) }\end{array}$ & $\begin{array}{l}\text { Individuos com capacidade de criar, aproveitar oportunidades, melhorar } \\
\text { processos produtivos, desenvolver inovações que geram riquezas e } \\
\text { aumentam o bem-estar das pessoas. }\end{array}$ \\
\hline $\begin{array}{l}\text { Lemes e Pisa } \\
\quad(2010)\end{array}$ & $\begin{array}{l}\text { Individuo que enxerga as oportunidades, leva adianta e torna viável os } \\
\text { projetos, faz sacrifícios pessoais para criar e manter seu empreendimento, } \\
\text { com tal entusiasmo que convence os demais a ajudá-lo. }\end{array}$ \\
\hline $\begin{array}{l}\text { Salim e Silva } \\
\qquad(2010)\end{array}$ & $\begin{array}{l}\text { Aquele que acredita em algo, sabe avaliar riscos e possibilidades, age } \\
\text { normalmente de forma audaciosa e sagaz. Em certas ocasiões, possui sonhos } \\
\text { prematuros para tecnologia e cultura de sua época, mas não são impossíveis. } \\
\text { Às vezes, não se transforma em sucesso econômico, mas melhora a vida de } \\
\text { outras pessoas. }\end{array}$ \\
\hline $\begin{array}{l}\text { Hisrich, Peters e } \\
\text { Shepherd (2014) }\end{array}$ & $\begin{array}{l}\text { Aquele que pensa de modo diferente dos outros indivíduos, toma decisões } \\
\text { em ambientes inseguros, com altos riscos, pressões de tempo intensas e } \\
\text { considerável investimento emocional. }\end{array}$ \\
\hline
\end{tabular}

Fonte: Fernandes et al. (2020) adaptado pelo autor 
Face ao exposto, é possível conceber a inovação como elemento chave dentro do empreendedorismo, uma parte constituinte de tal ato, pois traz sempre consigo as novas ideias, novos métodos, novas soluções e novas propostas como resolução para uma determinada necessidade identificada pela pessoa que deseja empreender. Em consonância com o Manual de Oslo (2005), a inovação pode ser separada como inovação em processo, inovação em produtos, e também inovação em produto e processo.

Inovar representa não somente criar algo sem precedentes, mas significa também repensar, remodelar, reinventar algo já existente, quer seja um produto, serviço, processo ou alguma estratégia do empreendedor e sempre a introdução de algo novo precisa na prática ser viável, caso contrário pode resultar em fracasso. 0 ato de buscar novos modos de realizar algo, de atender a necessidade de alguém, de conduzir uma organização é o caminho a ser seguido para aquele que deseja continuidade com sucesso na sua caminhada empreendedora.

Empreender e inovar são dois lados de uma mesma moeda. Nesta assertiva é possível enxergar a inovação como a força para fomentação e o dinamismo do ato de empreender e nessa perspectiva, vislumbrar a inovação como ingrediente de caráter primordial para o empreendedorismo (DRUCKER, 1989). Portanto, inovar se faz tão somente o elemento que compõe o espírito do empreendedorismo, enxerga-se a ideia do conceito basilar que traz a possibilidade do sucesso juntamente de outros que mantêm arrojada as empreitadas que, dessa forma, proporcionarão sempre ótimas contribuições para, integralmente, a sociedade atendida.

\subsection{IMPORTÂNCIA DO EMPREENDEDORISMO E INOVAÇÃO PARA O COMÉRCIO}

O movimento de empreendedores sem dúvidas exerce um papel muito importante na sociedade, especialmente no comércio onde fomenta o aquecimento do sistema econômico e juntamente do mercado de empregos, além de coadjuvar para o avanço de produtos e serviços oferecidos uma vez que a busca por inovação faz parte intrinsecamente do empreendedorismo. No que se refere ao Brasil, a abundância de capacidade empreendedora do brasileiro demonstra o valor e potencial do país nesse aspecto (BAGGIO, 2015). De fato, a população brasileira agracia o país com sua forma empreendedora que se faz uma das maiores do mundo. A riqueza na capacidade reflete na sobrepujança que essa força exerce no país.

Pelo comércio muitos benefícios apenas com os empreendedores e seus serviços e produtos já são ofertados para a sociedade, todavia, diversos outros aspectos positivos chegam com as empreitadas, como a propiciação de empregos e, por consequência, distribuição de renda. Certamente, é um papel de grande importância para a promoção do bem-estar social muito por mérito, inclusive, de características específicas dos empreendedores como criatividade, percepção de oportunidades, motivação, flexibilidade, iniciativa além de ter a capacidade de compreender a mudança como oportunidade (LEITE, 2001). Desse modo, vislumbra-se o conjunto de atributos do empreendedor e é constatado a sua pertinência para que sejam tão capazes de fazer tanta diferença para o seu meio social.

O comércio faz parte da base fundamental para que a economia continue com seu fluxo o mais saudável possível, beneficiando a sociedade no tocante à promoção do desenvolvimento socioeconômico do país. De fato, grande parte do peso que o comércio tem no desenvolvimento social assim como no econômico se deve aos pequenos empreendedores cuja maioria atua no comércio dos produtos e serviços, conforme pode ser observado no caso do estado mais rico do Brasil e ponto de referência, o estado de São Paulo, acrescentando a isto, a participação dos pequenos negócios na economia que conta ótimos índices (SEBRAE, 2018). Sendo assim, temos que a participação dos pequenos comerciantes é fundamental no mercado de serviços e produtos e traz o oxigênio e dinamismo na economia necessários para mantê-la em movimento minimamente adequado.

Dessa forma, é possível conjecturar a relevância para todos os que participam do processo. 0 empreendedorismo ao lado da inovação traz para o comércio o combustível necessário para que o mesmo possa de forma contínua estar se inovando e reinventando, ao passo que, contribui para a modernização dos produtos, serviços e demais frutos para a sociedade através dos atributos dos empreendedores como positividade, energia, autoconfiança, determinação e perspicácia para atingir seus objetivos correndo riscos calculados, com pragmatismo e independência (THOMPSON, 1999), tudo isso constituindo um corpo de apoio para o alavanque da qualidade no comércio e economia. 


\subsection{EMPREENDEDORES INFORMAIS E SUA IMPORTÂNCIA PARA UMA ECONOMIA LOCAL}

A atividade empreendedora possui grande importância em qualquer economia onde exista e nos ecossistemas financeiros locais, em especial, os de regiões com pouco desenvolvimento, outrossim, percebe-se ainda mais o papel fundamental para o cotidiano do local e da vida das pessoas. A atividade informal, por vezes, acaba sendo relacionada com ilegalidade. 0 que é algo equivocado, pois economia informal não se trata de comércio ilegal ou algo que o valha para comparação. Como é exemplificado no artigo da plataforma Inovação SEBRAE Minas (2018), pode-se citar como exemplo alguns pequenos negócios informais que agem em pleno acordo com a Lei, como o caso de mercadinhos de bairro, oficinas mecânicas, movelarias, lanchonetes e pequenas indústrias. Estes são trabalhadores que por força do desemprego, falta de estrutura socioeconômica veem no empreendedorismo informal uma optação para vencer tais barreiras e terem sua renda e se tornando, para além disso, importantes fornecedores de serviços e produtos naquela economia local ajudando a fomentá-la.

Além das influências econômicas que os empreendedores informais exercem, diversas outras vantagens são verificadas, como a oportunidade de as pessoas em situação de vulnerabilidade social e econômica terem ao seu alcance uma forma de obter renda, pessoas sem experiência profissional que não conseguem oportunidade no setor de trabalho formalizado, e são absorvidas pelo informal tendo a chance de acumular experiência e ainda ter uma fonte de renda. Portanto, observa-se a relevância da atividade empreendedora informal, em especial em locais pouco desenvolvidos, e que se expande de forma mais acentuada nestas economias onde predomina o desemprego e outras instabilidades sociais, o que acaba por se tornar locais bastante oportunos para iniciar um negócio próprio (FONSECA, 2003), como já mencionado anteriormente. Ao que parece, a iniciativa de um negócio que quase sempre permanece informal por um bom tempo ou mesmo por todo tempo que existir tem maior incidência em regiões mais carentes e pouco assistidas pelo poder público onde os cidadãos têm menos instrução e, por consequência, maior dificuldade em ter acesso a orientação profissional e interesse na mesma.

Na opinião de Camargo (2009) a grande dissemelhança entre a renda do trabalhador e o custo da mão-deobra para quem emprega figura como causa tida como uma das mais importantes para explicar a ampliação nas taxas de informalidade no mercado ocupacional trabalhista do Brasil. De certo é que isso desempenha uma grande atuação para a comunidade brasileira que se beneficia, apesar das dificuldades, dos benefícios de uma população engajada com o empreendedorismo e sua contribuição para o desenvolvimento.

Ao passo em que é notória a importância econômica do empreendedor informal observando-se a influência na economia e na vida de quem trabalha e consome, também é possível observar a grande significância refletida nos números para a economia. Cerca de 41,6\% dos trabalhadores estavam na informalidade em 2019 segundo estudo realizado pelo Instituto Brasileiro de Geografia e Estatística (CAMPOS, 2020), representando cerca de 39,3 milhões de laboriosos informais (Tabela 1). A escalada do número de atuação profissional é significativa e demonstra como o meio informal tem força no país, haja vista como as reverberações econômicas e sociais têm o poder para mudar a realidade de uma região com o desenvolvimento e geração de emprego e renda. Existem várias modalidades de atuação informal que andam crescendo nos últimos anos e vários estudos constatam o fato que, por conseguinte, traz à tona como as pessoas estão mudando o cenário profissional.

0 crescente aumento do labor em condição informal no Brasil já é uma clara realidade desde antes do período pandêmico, mas que, naturalmente, se acentuou com a crise de saúde. A Tabela 1 a seguir mostra com mais detalhes a progressão no número de trabalhadores informais com separação por categoria de ocupação informal com dados de até um pouco antes do primeiro ano da oficialização da pandemia: 
Tabela 1 - Valores absolutos e proporção da população de 14 anos ou mais de idade ocupada informalmente, segundo os tipos de ocupações informais - Brasil - 2012-2019

\begin{tabular}{|c|c|c|c|c|c|c|c|c|}
\hline \multirow{2}{*}{$\begin{array}{l}\text { Tipos de } \\
\text { ocupações } \\
\text { informais }\end{array}$} & \multicolumn{8}{|c|}{ População de 14 anos ou mais ocupada informalmente } \\
\hline & 2012 & 2013 & 2014 & 2015 & 2016 & 2017 & 2018 & 2019 \\
\hline \multicolumn{9}{|c|}{ Valores absolutos ( 1000 pessoas) } \\
\hline Total & 37021 & 36562 & 35906 & 35918 & 35410 & 37087 & 38294 & 39347 \\
\hline $\begin{array}{l}\text { Empregado } \\
\text { sem carteira }\end{array}$ & 13320 & 13109 & 12878 & 12587 & 12650 & 13392 & 14034 & 14482 \\
\hline $\begin{array}{l}\text { Trabalhador } \\
\text { doméstico } \\
\text { sem carteira }\end{array}$ & 4303 & 4249 & 4083 & 4119 & 4184 & 4319 & 4495 & 4486 \\
\hline $\begin{array}{l}\text { Conta própria } \\
\text { não } \\
\text { contribuinte }\end{array}$ & 15548 & 15451 & 15356 & 15751 & 15398 & 16032 & 16288 & 17060 \\
\hline $\begin{array}{l}\text { Empregador } \\
\text { não } \\
\text { contribuinte }\end{array}$ & 1092 & 1044 & 967 & 939 & 982 & 1116 & 1347 & 1235 \\
\hline $\begin{array}{c}\text { Trabalhador } \\
\text { familiar } \\
\text { auxiliar }\end{array}$ & 2758 & 2709 & 2622 & 2522 & 2196 & 2228 & 2129 & 2084 \\
\hline \multicolumn{9}{|c|}{ Proporção por ocupação informal (\%) } \\
\hline Informal & 41,5 & 40,3 & 39,1 & 39,0 & 39,0 & 40,7 & 41,5 & 41,6 \\
\hline
\end{tabular}

Fonte: IBGE - PNAD Contínua 2012-2019 (2020) adaptado pelo autor

Como observa-se na Tabela 1, o estudo visualizou a crescente do mercado informal de trabalho verificando as cindo categorias de informalidade, desse modo percebe-se que medindo desta forma os resultados obtidos expressam de forma bem mais precisa a situação da realidade. 0 estudo mostra como em 2012 o percentual de informais era semelhante ao de 2019 e como houve uma pequena diminuição nos anos de 2014, 2015 e 2016 voltando a subir a partir de 2017.

Os conjuntos definidos como as ocupações informais (empregado sem carteira, trabalhador doméstico sem carteira, conta própria não contribuinte, empregador não contribuinte, trabalhador familiar auxiliar) expressam como está dividida a parcela que constitui a informal e permite uma análise mais assertiva na medida que é possível examinar cada uma delas de forma isolada.

\subsection{O EMPREENDEDORISMO E A PANDEMIA: DESAFIOS E OPORTUNIDADES}

No atual momento em que se vive e enfrenta uma pandemia do novo coronavírus, a situação trouxe impactos na civilização de tal modo não visto anteriormente. Os desafios que surgiram com esta situação única foram os mais diversos e impactaram a vida das pessoas em todos os aspectos praticamente. Uma calamidade como essa tem o poder de afetar a economia em geral, e os empreendedores e trabalhadores informais são um grupo que sente muito as consequências do momento pois estão mais vulneráveis às instabilidades em decorrência de estarem na margem de uma proteção social do Estado - ou seja, o conjunto de atos praticados pelo Estado com a finalidade de proteger as pessoas e a sociedade como um todo, proteger de ameaças econômicas, sociais e naturais - e em uma situação como essa vivenciada, uma assistência desse tipo seria de grande importância.

A OIT em uma análise já revela as repercussões do cenário pandêmico para o trabalho que ainda segundo a mesma, cerca de 305 milhões de indivíduos podem ficar sem suas ocupações devido a pandemia e também destaca as consequências para 1,6 bilhão de pessoas na informalidade ocupacional em situação vulnerável na América Latina e no Caribe (OIT, 2020). Com relação ao Brasil, o quadro situacional dos trabalhadores mais atingidos é bastante claro: para alguns, as alternativas para contornar as dificuldades podem ser alcançadas com mais facilidade, para outros, a pandemia afetou de forma crucial suas atividades. Os que mais sentiram podem ser facilmente identificados, sendo eles os trabalhadores na informalidade, domésticas, desempregados, entregadores delivery, camelôs dentre outros que formam um grupo de trabalhadores que em muitas das vezes trabalham na precariedade (RIBEIRO; OLIVEIRA; SANTOS, 2020). Importante ressaltar que esses trabalhos dependem, de forma crucial, da circulação e do contato e proximidade física com seus públicos, em razão disso a significativa implicação da crise pandêmica. 
A Tabela 2, com dados de uma pesquisa produzida pelo SEBRAE em trabalho conjunto com a FGV (2020), contribui para ratificar a asserção de que as repercussões da diminuição da livre circulação populacional em função das medidas sanitárias contra o coronavírus refletem de forma negativa em considerável parcela das empresas, primordialmente das que dependem muito dos atendimentos presenciais.

Tabela 2 - Sua empresa consegue funcionar neste momento de restrição de circulação de pessoas?

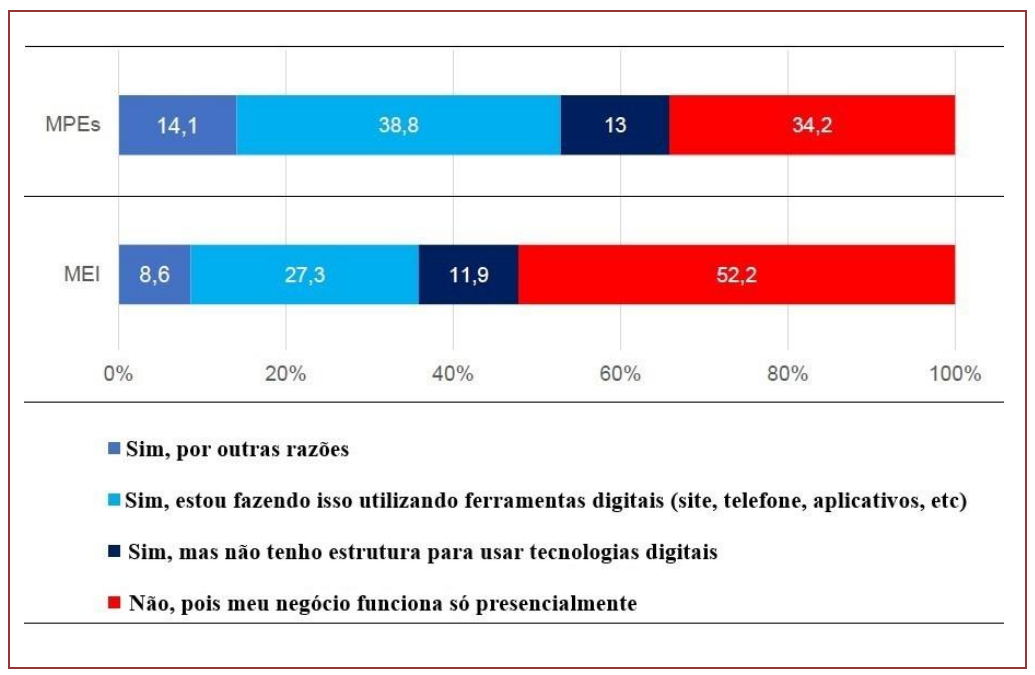

Fonte: SEBRAE/FGV (2020)

O estudo do SEBRAE em parceria com a FGV foi realizado no primeiro semestre de 2020, no período de 30 de abril a 05 de maio, portanto, em um momento importante e tenso no início da crise pandêmica e das restrições impostas. Mostra a preocupação das MPEs e MEIs com a situação vivida e as medidas tomadas para tentar conter a disseminação tendo em vista que 34,2\% das MPEs e 52,2\% dos MEIs responderam que não conseguem funcionar por consequência das medidas de restrição na circulação pois acreditam só conseguir funcionar de modo presencial. Isso reflete de forma taxativa o potencial de afetar das formas mais abrangentes e profundas o meio comercial.

A cadeia de efeitos da crise sanitária do Covid-19 atingiu de forma generalizada a roda da economia, o lado da oferta (empreendedores, trabalhadores) como também o da demanda (consumidores). A circulação de pessoas sendo restrita devido as medidas tomadas para combater a disseminação do vírus causa impactos nos negócios que dependem da circulação da população para atendimento pessoal, como lojas físicas, shoppings, lanchonetes, restaurantes entre outros causando queda no consumo que acaba por desaguar os empreendedores, seja informais ou formais, em um dilema que envolve comprometer sua renda para sobrevivência devido as restrições e arriscar se expor ao vírus e contaminar a si e a outras pessoas ao irem trabalhar (SILVA, 2020). Logo, estes se veem num estado difícil de contornar pois, de fato, para algumas atividades, a alternativa para não desrespeitar as medidas de segurança sanitária mais rígidas é paralisar a atividade.

Por fim, nos aspectos das adversidades na pandemia, algo que tem chamado atenção pela sua intensificação nesse período é o trabalho autônomo realizado por trabalhadores para grandes empresas plataformas como a Uber. O fenômeno da "uberização" corresponde a esse novo modelo de negócio que nada mais é que a conexão dos consumidores aos fornecedores de produtos e serviços por meio da tecnologia móvel. É o caso de empresas como a Uber, iFood entre outras, mas, contudo, esse aumento considerável já existia mesmo antes da crise sanitária e que só veio a se ampliar e ganhar mais notoriedade com a mesma. Houve aumento exponencial de pessoas trabalhando nesse tipo de empresas e sujeitadas aos termos da "uberização" por consequência (FRANCO; FERRAZ, 2019). É um grande número de trabalhadores - desde motoristas de carro, entregadores de delivery ciclistas e motociclistas entre outros ramos - que estão submetidos às regras dessas empresas, assumindo todos os custos decorrentes das prestações de serviços e recebendo por produtividade.

Por outra perspectiva, há as oportunidades que surgem em meio ao caos da crise e os aspectos positivos dos empreendedores em saber aproveitá-las. Diversos setores se viram obrigados a se adaptarem e se reinventarem para superar as dificuldades e conseguir manter suas atividades normalmente estimulando desenvolvimento de serviços e produtos para a nova vivência de hábitos e condições no mundo. A nova 
realidade que se impõe causou mudanças de forma generalizada, dessas mudanças surgem também novos hábitos de consumo e, consequentemente, novas oportunidades de negócios. Diante disso, surge os personagens principais se utilizando da criatividade, os brasileiros, que converteram os novos hábitos do contexto em possíveis negócios (COSTA, 2021). Em outras palavras, o pequeno empreendedor do Brasil possui uma das grandes qualidades que devem existir em tal agente, esse traço profissional faz o vislumbre da oportunidade na dificuldade vir para a adequação com a situação, ora, sendo absolutamente conveniente para as partes que se envolverem e desenvolverem no contexto.

Determinados produtos passam a ter seu comércio super aquecido, sendo um deles, o caso de produtos de higiene como álcool em gel, desinfetantes entre outros. Segundo Costa (2021) o comércio de produtos voltados para o entretenimento também viu suas demandas dispararem, como acontece com instrumentos musicais como violões, teclados e guitarras.

0 e-commerce é uma área que tem ganhado bastante impulsionamento em virtude da pandemia do Covid19 e as mudanças de hábitos consumistas da população. Seu crescimento que já vinha acompanhando a tendência natural de ampliação mesmo antes do coronavírus obteve uma alavancagem a mais com os consumidores obedecendo medidas de restrição de circulação e, consequentemente, comprando mais via internet. De acordo com análise realizada pelo Movimento Compre \& Confie em parceria com a ABComm (CHAUSSARD, 2020), no início de 2020 foi observado expressivo aumento nas vendas online impulsionado pela pandemia se comparado com o ano anterior, 2019, auferindo um crescimento de $28 \%$ do faturamento. Esse estudo comparou o período de fev-mar de 2019 com o de 2020.

A Tabela 3 mostra dados de outro estudo mais recente da ABComm/Movimento Compre\&Confie, dessa vez englobando um período maior, janeiro a agosto de 2020 atualizando a situação. Nela, observa-se o aumento da participação de cada região do país no comércio digital e faturamento em comparação com o mesmo período no ano de 2019.

Tabela 3 - Vendas no comércio eletrônico por região em 2020 em comparação a 2019

\begin{tabular}{|ccc|}
\hline Regiões do país & $\begin{array}{c}\text { Participação no } \\
\text { e-commerce } \\
\text { jan-ago/2020 }\end{array}$ & $\begin{array}{c}\text { Variação em \% do } \\
\text { faturamento }\end{array}$ \\
\hline Norte & $2,7 \%$ & $44,1 \%$ \\
\hline Nordeste & $15,3 \%$ & $60,9 \%$ \\
\hline Sul & $13,2 \%$ & $39,2 \%$ \\
\hline Sudeste & $62,2 \%$ & $54,9 \%$ \\
\hline Centro-oeste & $6,6 \%$ & $47,1 \%$ \\
\hline
\end{tabular}

Fonte: ABComm/Movimento Compre\&Confie (2020) elaborado pelo autor

Na Tabela 3, tem-se que a região do nordeste obteve aumento de 60,9\% na receita, isso proporcionalmente, corresponde ao maior faturamento entre todas as regiões comparado ao desempenho em 2019, e a receita correspondeu a 15,3\% do faturamento total do e-commerce brasileiro. Nas demais regiões, a sudeste foi outro destaque entre os maiores faturamentos, notabilizando-se também na participação no total de vendas no setor com $62,2 \%$ da receita.

O comércio de máscaras como equipamento de proteção individual (EPI) foi mais uma oportunidade a surgir em decorrência da pandemia. Pequenos autônomos observando a altíssima demanda pelo produto e tendo mentalidade empreendedora frente à necessidade de manter a renda familiar puseram negócios pequenos de produção e venda de máscaras para atender a demanda (BRASILEIRO; SOUZA, 2020). Em que se faça conspícua a gravidade do momento, para muitos a palavra que definiu o lado profissional de suas vidas foi a "reinvenção" sabendo tirar das dificuldades, as chances de fazer a diferença na vida dos demais e da sua própria, e corroborando mais uma vez a habilidade de extrair da adversidade a solução. 


\subsection{TRABALHO INFORMAL ENQUANTO FATOR ESSENCIAL À SOBREVIVÊNCIA}

Não existe uma definição consensual e única para se definir trabalho informal, mas sim, existem diversas formas de conceituar a condição informal de um serviço. É possível afirmar que trabalho informal consiste naquele cuja realização das suas atividades se dão sem qualquer vínculo empregatício devidamente formalizado, sem quaisquer registros formais. Conforme Cerqueira (2017, p. 126), "o termo 'informal' foi caracterizado pela primeira vez pela Organização Internacional do Trabalho (OIT), após conferência realizada em 1969". Nesta ocasião foram definidas condições específicas para se caracterizar "informal". Observou-se que os elementos para o definir são perfeitamente aceitáveis até hoje, apesar de no transcorrer desse tempo, terem surgido diversas outras formas para conceituar, até mesmo em função das mudanças conjunturais naturais do tempo e sociedade.

No Brasil a taxa de ocupados informais é grande e isso se deve a diversos fatores decisivos para esse quadro. Países emergentes e menos modernos como o Brasil possuem características que impulsionam o trabalho informal como forma única de renda e sobrevivência. Os indivíduos iniciam seu empreendedorismo informal em virtude da necessidade de sobreviver ou como uma tentativa de ampliar a renda da família frente a insuficiência e/ou diante de crises que causam o desemprego (NUNES, 2020). Em suma, é o que se torna real em locais de baixo desenvolvimento, a chance mais viável, muitas vezes, de garantir a sobrevivência.

Ainda conforme Nunes (2020, p. 34) citando Dornelas (2014), tratando da relevância da ocupação informal para a sobrevivência, afirma que:

Quem exerce ou tem um negócio na informalidade precisa ganhar dinheiro para a sua sobrevivência; tem uma alta autonomia, mas sem garantia de resultados; tem um nível de risco muito baixo, pois vive numa situação já limítrofe; dedica-se ao trabalho parcialmente, trabalha o suficiente para o sustento diário; trabalha geralmente com a ajuda da família ou mesmo sozinho; não possui recursos para o negócio, apenas tem conhecimento tácito e não tem objetivos mais concretos, apenas crê que qualquer dia sua destino pode mudar.

Partir para a informalidade é a alternativa mais viável para aqueles que enfrentam as adversidades que um país assolado por desemprego, além de uma educação deficiente e, ainda, crises como a causada pela pandemia do Covid-19 resulta. É válido ressaltar, ainda que de forma suscinta, algumas vantagens do trabalho informal pois à estas também pode ser atribuída alguma responsabilidade no fato de indivíduos estarem optando gradativamente mais pela informalidade. Entre elas, é possível citar algumas mais comuns como: a liberdade para produzir ao próprio gosto e criar; a autonomia; menos ou quase nenhuma questão burocrática; rendimentos imediatos e rápidos; adaptabilidade nos horários, entre outros.

\subsection{PANDEMIA DE COVID-19 E IMPACTOS NEGATIVOS NO COMÉRCIO E MERCADO DE TRABALHO}

Em contrapartida aos pontos positivos sentidos em alguns determinados nichos do comércio se valendo das oportunidades enxergadas na pandemia como já visto anteriormente, há também as repercussões negativas da crise sentidas em setores do comércio muito mais que em outros. Segundo dados da pesquisa Pulso Empresa realizada pelo IBGE, das 3,2 milhões de empresas em funcionamento no país, 38,6\% declararam para a pesquisa que suas atividades sofreram efeitos negativos causados pela pandemia na primeira metade de agosto de 2020.

As repercussões negativas cresceram da segunda metade do mês de julho que estava em $37,5 \%$ para a primeira de agosto ficando em 38,6\% (IBGE, 2020). 0 estudo constatou ainda que dentro dessas empresas que reportaram prejuízos em suas atividades, $47,9 \%$ são do setor de construção e $46,3 \%$ do comércio, os maiores índices na quinzena do estudo, primeira de agosto (IBGE, 2020). Foram as empresas no país que mais sentiram os impactos negativos da pandemia. Ademais, as empresas do setor da indústria relataram efeitos negativos pequenos ou mesmo inexistentes (38,9\% das empresas), no setor de serviços a ocorrência foi de 41,9\% e de comunicação de 61,5\% (IBGE, 2020). Como é possível observar, os efeitos da crise sanitária se disseminam de modo profuso pelos diversos setores da economia e do comércio, alguns sentindo mais que outros por questões específicas como o fato de alguns dependerem mais das pessoas circulando normalmente, algo que obviamente foi afetado com as medidas de restrição impostas com base nas recomendações das autoridades de saúde.

Naturalmente o mercado ocupacional vem sofrendo com os impactos de toda a situação econômica enfrentada na crise pandêmica, com as mudanças drásticas nas dinâmicas de funcionamento do meio 
social, das empresas, da movimentação das pessoas e de seus hábitos. Trabalhadores sofrem com as taxas de desocupação altas, com o assolamento do mercado de trabalho com indicadores disso, como o aumento do número de trabalhadores na informalidade, sem carteira profissional assinada e por contra própria (KREIN; OLIVEIRA, 2019). Os trabalhadores com menos proteção social do Estado e com menos escolaridade sofreram consequências mais profundas. Em entendimento com Veloso (2021), empregos de pouca escolaridade sofreram mais, com uma diminuição de 20,6\% em ocupações de indivíduos com 3 anos de estudo, até.

Percebe-se a vulnerabilidade nos trabalhadores informais e baixa escolaridade que em diversas situações de crise ou instabilidade tendem a sofrer mais. A crise pandêmica intensificou os efeitos que indivíduos nesse contexto já eram mais propensos a vivenciar, os efeitos colaterais de uma crise como esta ocorrem em cascata e provoca diversas situações desde o aumento dos informais até mesmo o desemprego. Como relata Costa (2020), "além da crise sanitária, uma das consequências da pandemia é o aumento do desemprego e, portanto, a elevação da informalização do trabalho, dos terceirizados, dos subcontratados". As desigualdades são postas em maior notoriedade e logo é possível observar que para poucos as possibilidades de contornar a situação foram mais alcançáveis.

\section{METODOLOGIA}

Para a realização desse trabalho, utilizou-se como procedimento de pesquisa um levantamento bibliográfico por meio de buscas em fontes como artigos científicos, dissertações, monografias, livros, periódicos, matérias jornalísticas, entre outros, pela necessidade de se obter aporte teórico sobre a temática do trabalho para melhor compreensão da situação. Também conhecida como pesquisa de fontes secundárias, a bibliográfica engloba todo material já publicado sobre o tema estudado e objetiva colocar o pesquisador em comunicação com o conteúdo produzido a respeito do tema (MARCONI; LAKATOS, 2003). Em virtude dos objetivos do trabalho, juntamente da pesquisa bibliográfica foi realizado um estudo de campo (fonte primária) através da aplicação de um questionário via Google Forms (Ferramenta de formulários para pesquisas do Google) composto por 14 perguntas fechadas com quantidade de alternativas dicotômicas e/ou múltipla escolha tendo como alvo pequenos empreendedores do município de Codó, Maranhão, portanto, caracterizando os objetivos do trabalho como descritivo, pois com a pesquisa bibliográfica buscou-se descrever o assunto estudado apresentando características e conceitos para analisá-los; e exploratório, pois foi-se além do estudo bibliográfico investigar sobre a situação dos empreendedores codoenses na pandemia buscando novas informações por meio de questionário inédito aplicado.

O questionário foi respondido por 137 empreendedores, onde objetivou-se com as perguntas compreender melhor a situação destes na pandemia, bem como suas atividades em meio aos impactos da crise sanitária.

Em razão dos meios adotados para coleta e tratamento de dados para esse trabalho - o levantamento bibliográfico e a pesquisa de campo - houve uma interpretação das informações obtidas relacionando os dados e contribuindo com eles por meio de análise e assimilação. Nesse sentido, "a interpretação dos fenômenos e a atribuição de significados são básicas no processo de pesquisa qualitativa" (PRODANOV; FREITAS, 2013). Portanto, neste estudo, para a análise dos dados utilizou-se de uma abordagem qualitativa.

\section{ANÁLISE E DISCUSSÃO DE RESULTADOS}

Nesta seção são apresentados os resultados e discussão da pesquisa de campo realizada em Codó-MA através da aplicação de questionário eletrônico cujo público-alvo foram pequenos empreendedores do município com o objetivo de buscar compreender melhor o perfil e a situação destes diante do cenário de pandemia que atinge a sociedade atualmente. A pesquisa foi conduzida conforme metodologia e objetivos pré-determinados para que se pudesse obter informações dos participantes com a finalidade de entender e ter noção da atuação do empreendedorismo no município, bem como as novas condições e reveses com a pandemia.

Os dados coletados na pesquisa são apresentados a seguir, iniciando pelo Gráfico 1 que informa o seguinte: 
Gráfico 1 - Percentual de gênero dos participantes

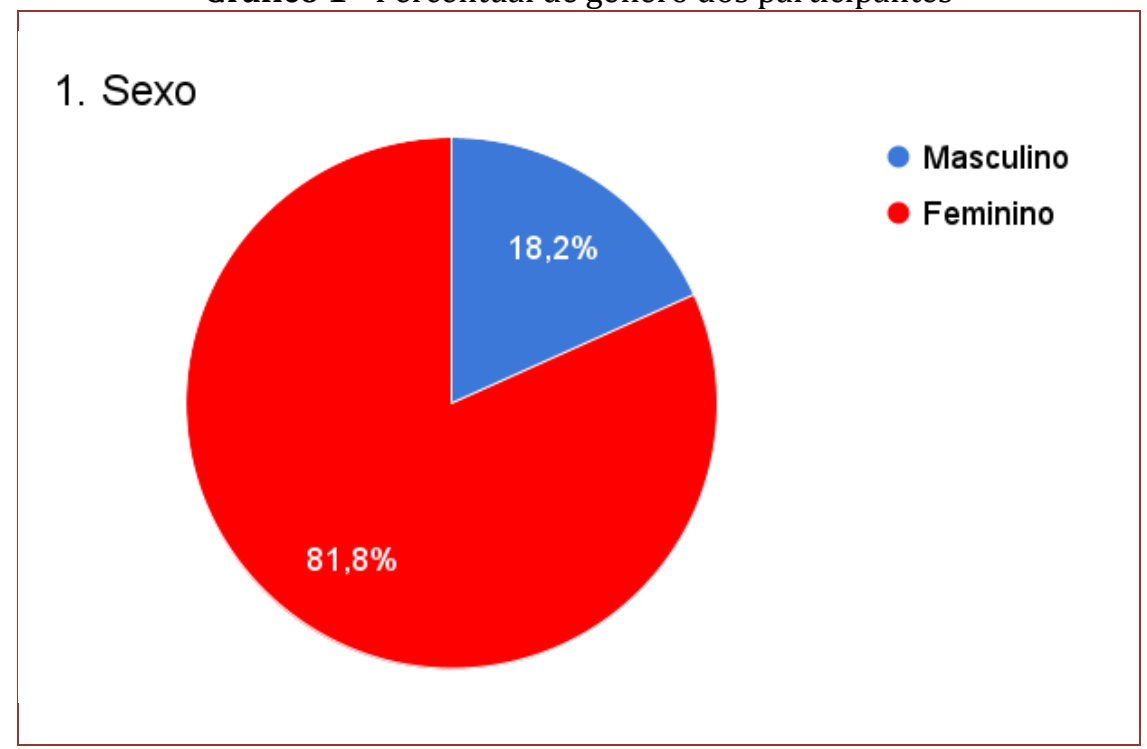

Fonte: Elaborado pelo autor a partir de dados coletados (2021)

De acordo com o Gráfico 1, é possível observar grande diferença na quantidade de empreendedores por gênero no município de Codó-MA, onde as mulheres apresentam grande vantagem com 81,8\% em relação aos homens com apenas 18,2\% do total de participantes da pesquisa. Ainda no âmbito sociodemográfico, o Gráfico 2 traz mais um dado importante para compreensão do perfil dos empreendedores.

Gráfico 2 - Perfil de faixa etária dos participantes

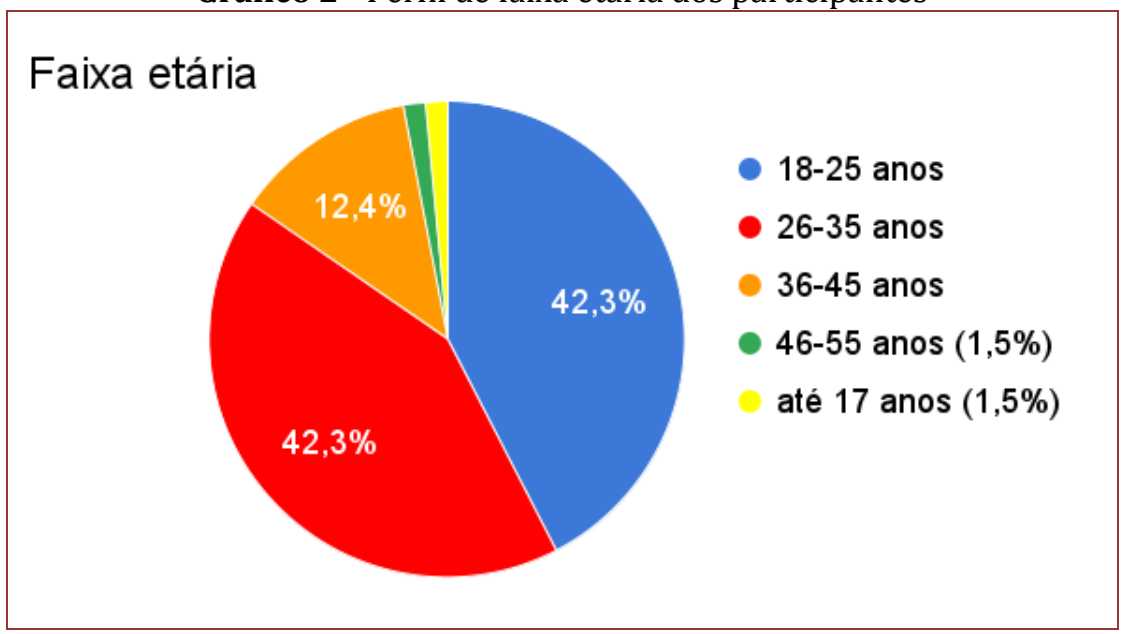

Fonte: Elaborado pelo autor a partir de dados coletados (2021)

Conforme os dados apresentados no Gráfico 2 acima, observa-se que os maiores percentuais de faixa etária correspondem as faixas de 18-25 anos e 26-35 anos, ambas com 42,3\% dos empreendedores que responderam à pesquisa, indicando que a maior parte dos empreendedores é composta de adultos jovens. As demais faixas trazem indicativos de outras faixas de idade, 12,4\% dos indivíduos responderam que pertencem a faixa de 36-45 anos, já os que estão na faixa de 46-55 anos somam 1,5\% dos participantes da pesquisa e os que pertencem a faixa de "até 17 anos" também somaram apenas 1,5\% dos participantes. Portanto, pelos dados observa-se uma maior participação de adultos jovens (18-35 anos) nas iniciativas empreendedoras na cidade, enquanto que pessoas mais velhas estão em número bem menor em relação.

Em referência ao nível de escolaridade dos empreendedores munícipes, o Gráfico 3 indica o percentual de cada um dos níveis desde o básico até os mais altos. 
Gráfico 3 - Nível de escolaridade dos participantes

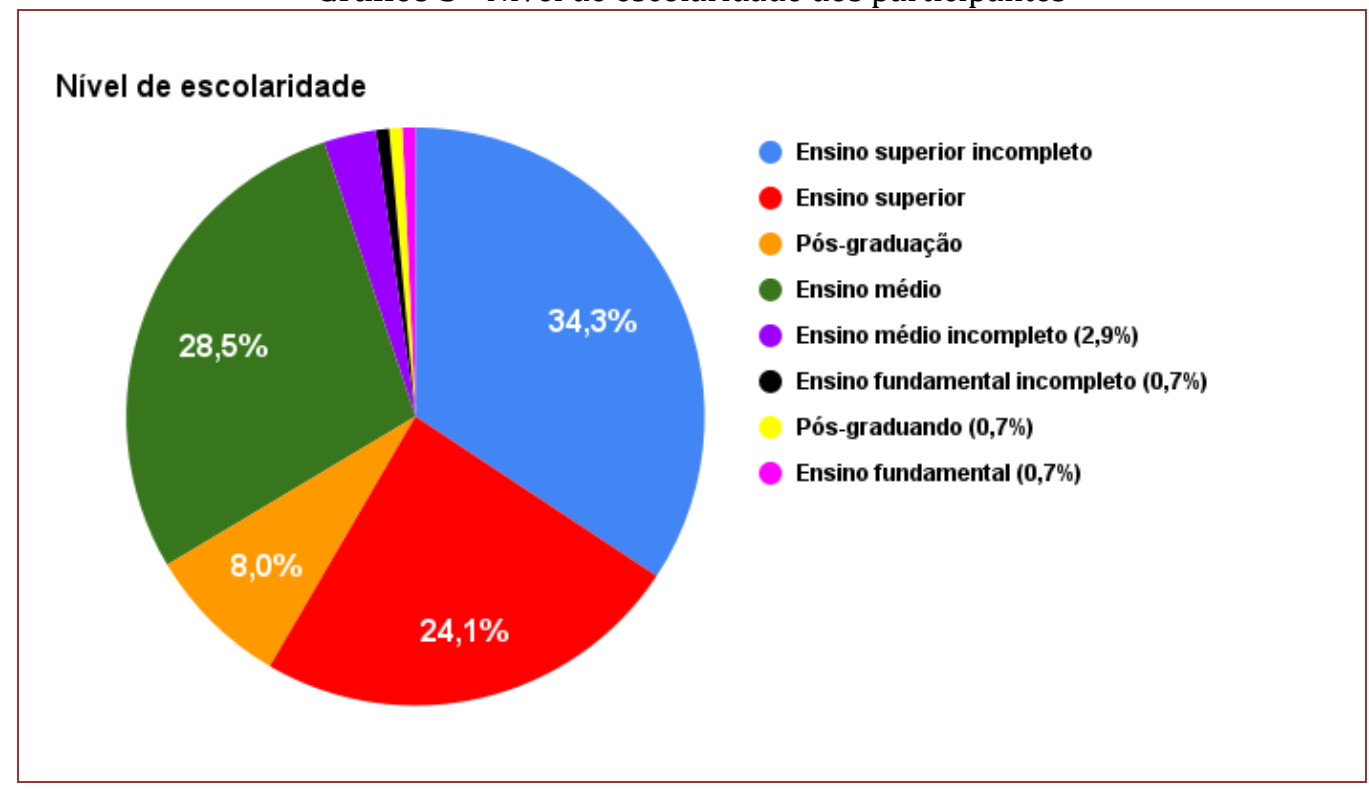

Fonte: Elaborado pelo autor a partir de dados coletados (2021)

Mais um dado importante sobre o perfil dos empreendedores do município participantes da pesquisa, o Gráfico 3 mostra que 24,1\% possui ensino superior completo, 34,3\% possui ensino superior incompleto, $28,5 \%$ possui ensino médio completo e, ainda, $8 \%$ com pós-graduação completa. Com isso é possível concluir que a maior parte dos participantes possui relativo bom nível educacional. Os demais níveis de escolaridade somam percentuais baixos: 2,9\% com ensino médio incompleto, 0,7\% com ensino fundamental incompleto, pós-graduando e ensino fundamental completo com $0,7 \%$ cada.

Referente ao local no qual os empreendedores realizam suas atividades, o Gráfico 4 traz dados bastante relevantes para se compreender a respeito de como ocorre os negócios.

Gráfico 4 - Local do empreendimento/negócio dos participantes

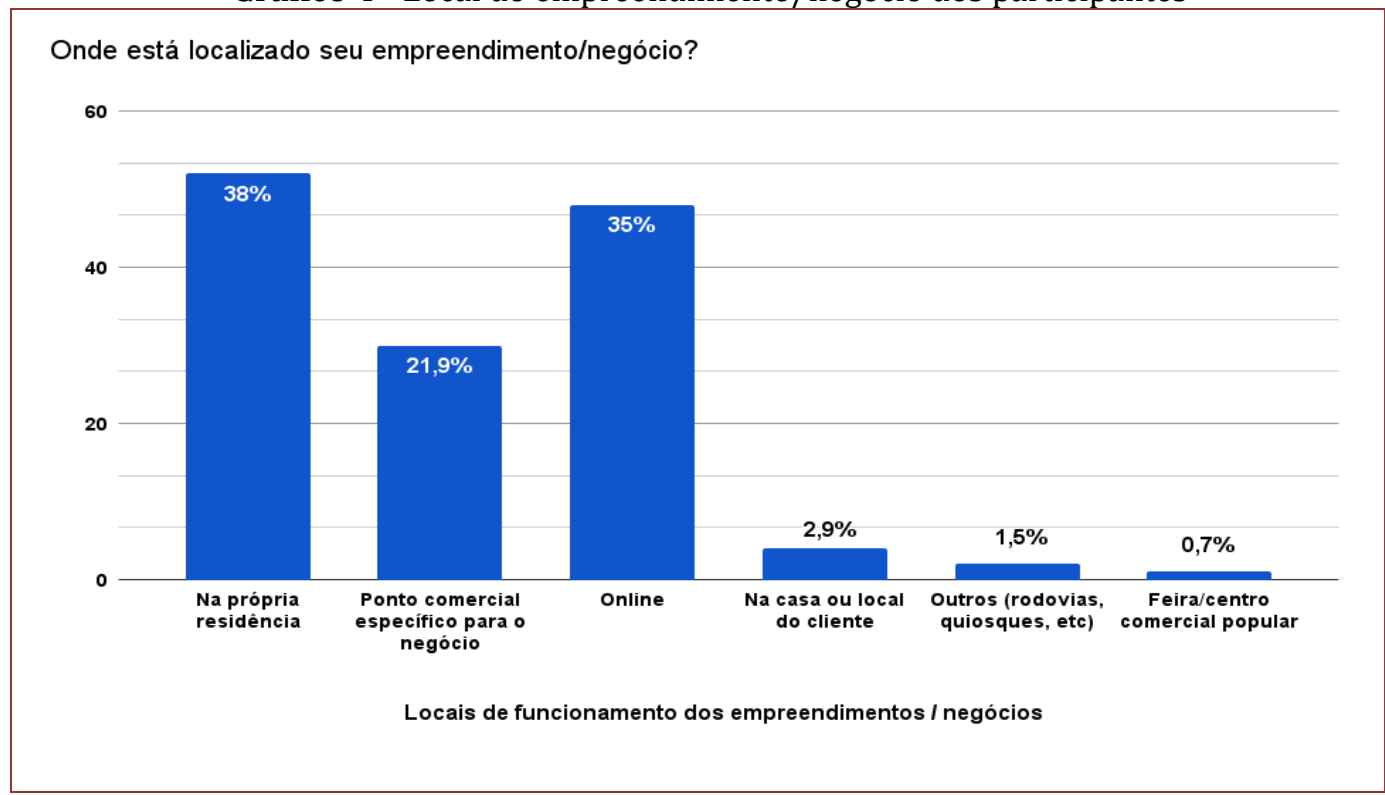

Fonte: Elaborado pelo autor a partir de dados coletados (2021) 
Conforme o Gráfico 4 aponta, a maior parte dos empreendedores que fizeram parte da pesquisa responderam que têm sua residência como local de funcionamento de seu empreendimento, 38\% dos participantes. Em segundo lugar, 35\% responderam que possuem seu negócio com funcionamento em meio online, em seguida, $21,9 \%$ afirmaram que possuem ponto comercial específico para trabalhar. Ademais, 2,9\% disseram que realizam seu trabalho na casa/local do cliente, 1,5\% em outros locais como quiosques, etc. e $0,7 \%$ em feira ou centro comercial popular.

Dessa forma, pode-se inferir que essa maior parte de pessoas com seus negócios funcionando na própria residência esteja relacionada com a pandemia e a necessidade de se manter em casa, portanto, tendo esta opção juntamente com atividade online - visto que é o segundo maior resultado apontado no Gráfico 4 um meio para complementar seu trabalho com a realização de anúncios, negociações e vendas.

O Gráfico 5 a seguir mostra o percentual de empreendedores que trabalham com prestação de serviços, venda de produtos e serviços e produtos.

Gráfico 5 - Com o que trabalham

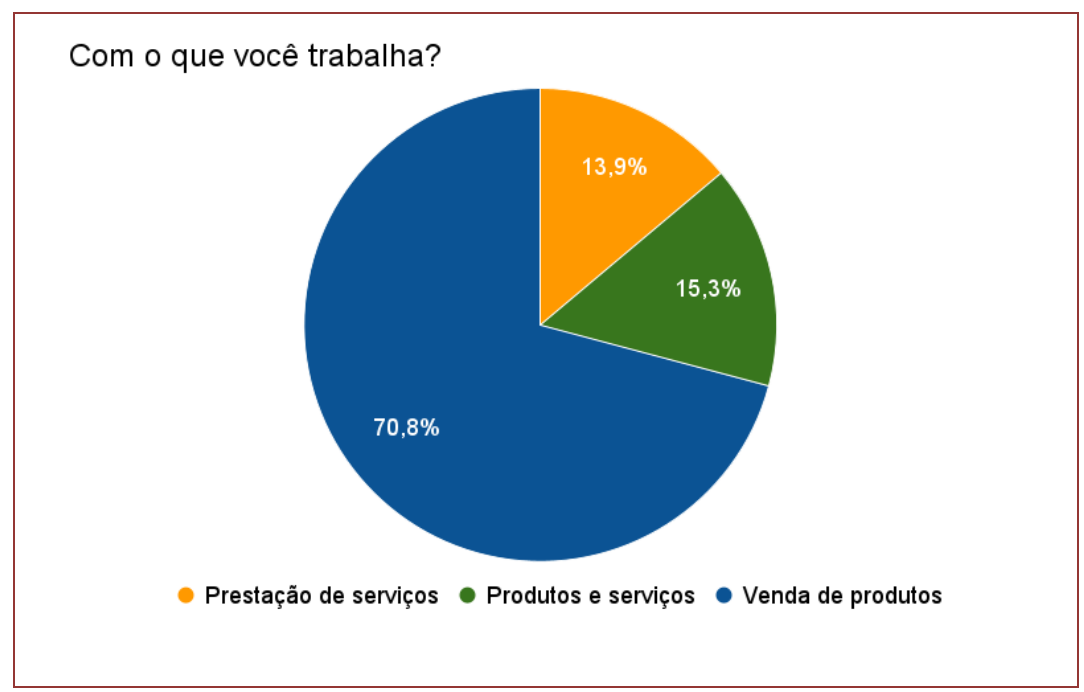

Fonte: Elaborado pelo autor a partir de dados coletados (2021)

Conforme observado no gráfico acima, 70,8\% dos participantes da pesquisa responderam que trabalham com venda de produtos, enquanto que 15,3\% informaram que trabalham com prestação de serviços e venda de produtos. Apenas 13,9\% afirmaram trabalhar somente com prestação de serviços. Concluir-se, portanto, que na atividade empreendedora, de acordo com as respostas dos participantes da pesquisa, o comércio de produtos predomina com certa folga. Com as novas condições impostas pela crise sanitária, a venda de produtos, sobretudo, de forma online, tem mais condições de ser realizada tendo em vista que diferente da prestação de serviços, a venda não requer tanto contato e proximidade do empreendedor com o cliente pois pode ser realizada por meios digitais.

Seguindo as informações coletadas, o gráfico abaixo demonstra o percentual dos empreendedores codoenses com relação a situação em que se encontravam antes da chegada da pandemia de covid-19. 
Gráfico 6 - Situação dos negócios antes da pandemia

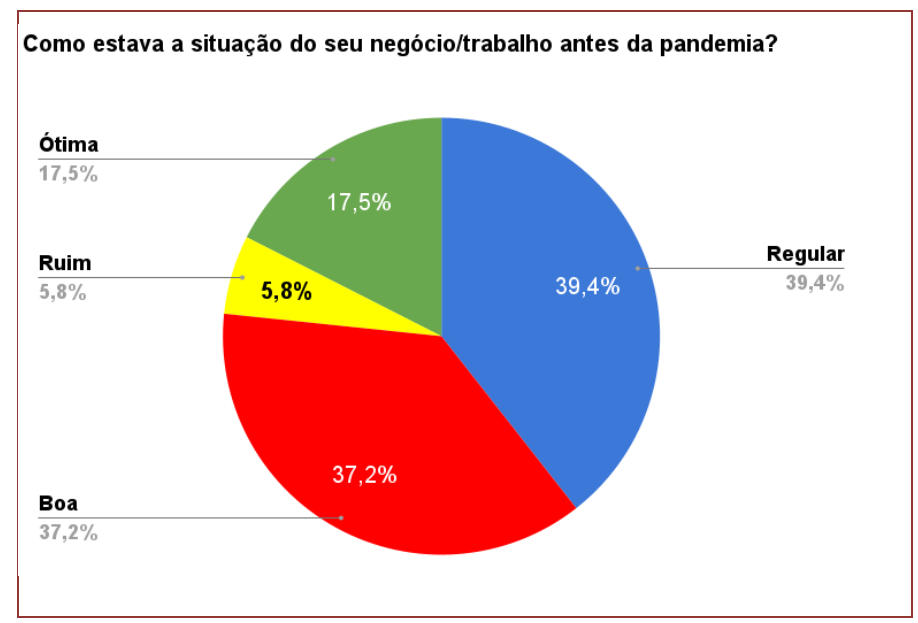

Fonte: Elaborado pelo autor a partir de dados coletados (2021)

O questionário indagou os pequenos empreendedores participantes sobre sua situação antes da chegada da crise sanitária, algo bastante agregador no sentido de se compreender o contexto do empreendedorismo impactado pela pandemia observando como se encontravam antes. Conforme o Gráfico 6 acima, 39,4\% dos participantes responderam que estavam em situação regular antes da pandemia, 37,2\% disseram estar antes da crise em situação boa, 17,5\% consideraram estar em situação ótima e 5,8\% em situação ruim antes da chegada da crise.

De modo geral, a situação dos negócios teve alterações devido as novas condições impostas na crise, a maioria considera que estava em situação positiva antes e que agora já não pode dizer o mesmo. Além da fragilidade financeira e estrutural, grande parte disso se deve também pela deficiência na preparação dos mesmos para contornar situações desse tipo.

0 Gráfico 7 a seguir ilustra isso trazendo dados sobre uma das principais consequências da pandemia, e que influencia muito no desempenho dos pequenos negócios.

Gráfico 7 - A restrição de circulação das pessoas devido a pandemia e o desempenho dos negócios

\section{A restrição de circulação das pessoas devido a pandemia afetou suas atividades e/ou desempenho do seu negócio.}

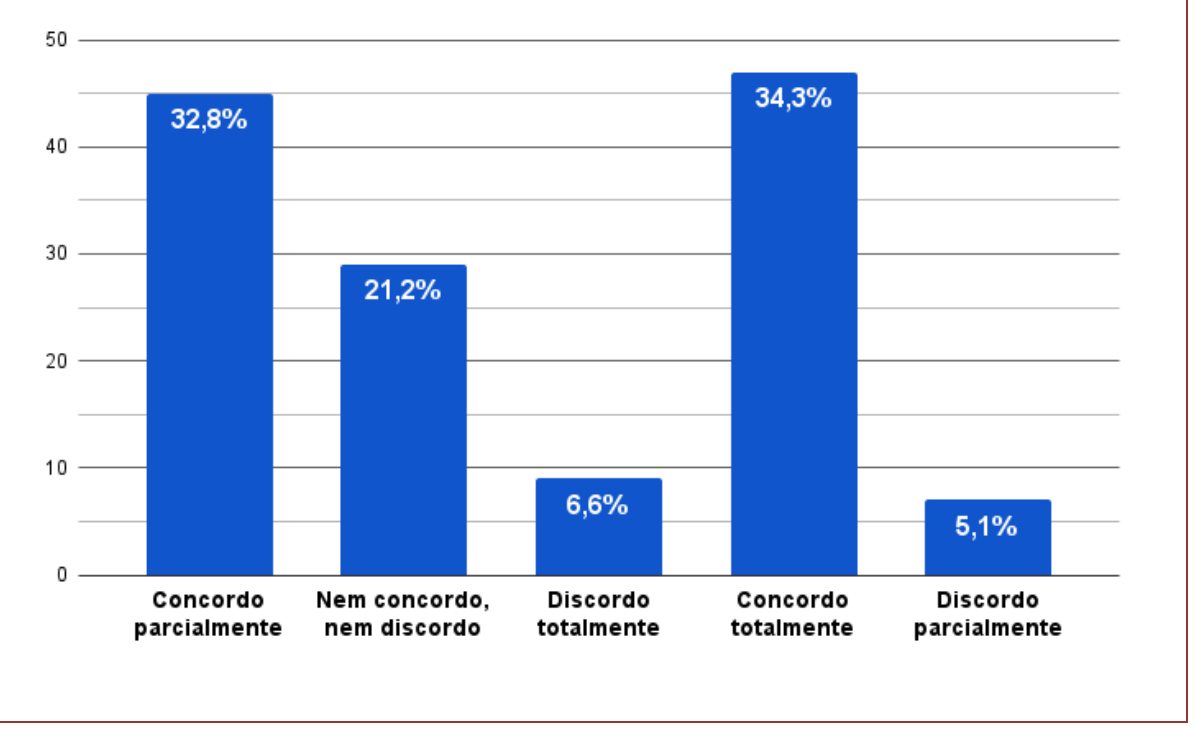

Fonte: Elaborado pelo autor a partir de dados coletados (2021) 
De acordo com o Gráfico 7, perguntados sobre a restrição de circulação das pessoas como uma medida contra a pandemia e se isso afetou o desempenho das atividades dos negócios, 34,3\% disseram concordar totalmente, $32,8 \%$ responderam que concordam em parte, 21,2\% disseram nem concordar, nem discordar, 6,6\% discordam totalmente e 5,1\% discordam em parte. É possível concluir, assim, que as medidas de restrições de circulação das pessoas como medida de segurança devido a pandemia para a maior parte dos participantes afetaram sim, em algum grau, suas atividades e desempenho em seus negócios. Pode-se inferir, que grande parte depende, de forma essencial, do contato mais próximo das pessoas para suas atividades.

Logo abaixo, o Gráfico 8 demonstra mais um aspecto de mudança em razão da crise sanitária no cotidiano empreendedor.

Gráfico 8 - Seu negócio teve que sofrer mudanças no funcionamento em algum momento devido à crise sanitária?

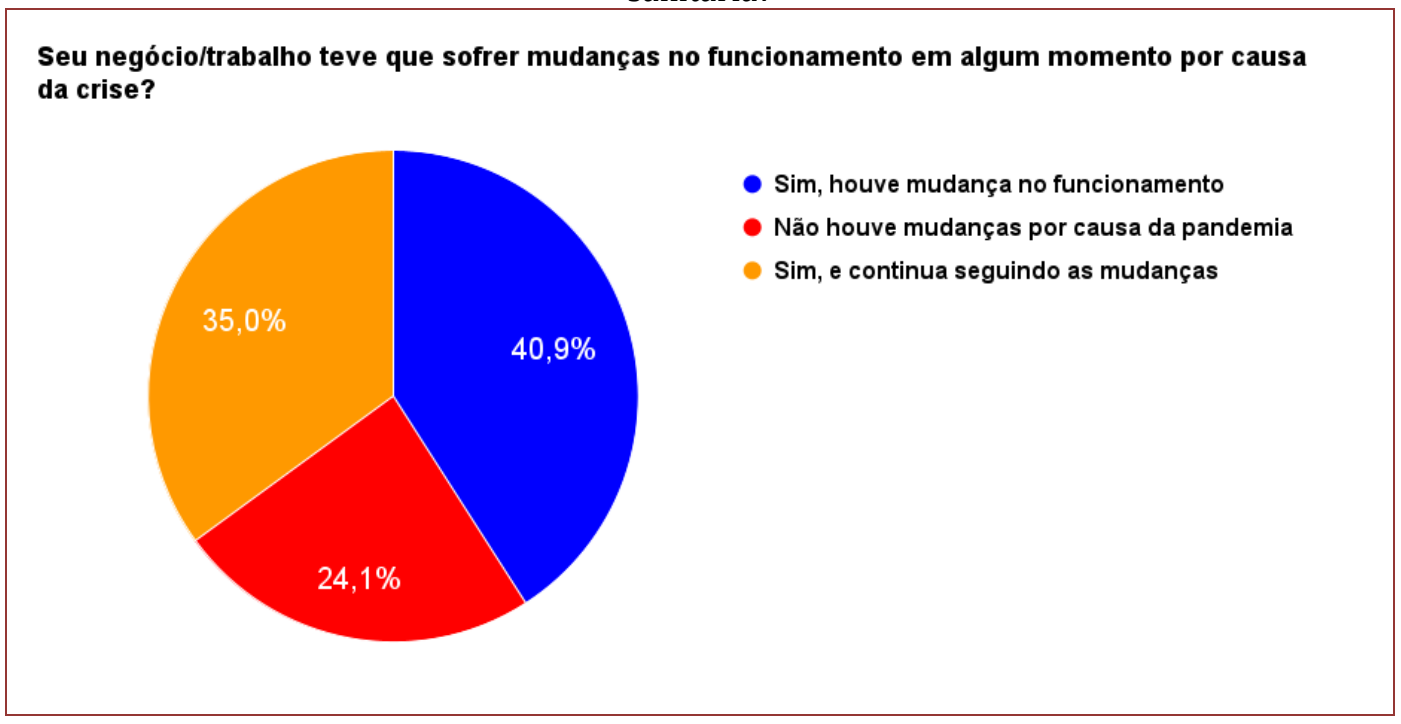

Fonte: Elaborado pelo autor a partir de dados coletados (2021)

O Gráfico 8 releva o quanto os pequenos negócios foram afetados no que diz respeito ao seu funcionamento. Perguntados sobre alterações no funcionamento normal das atividades nos empreendimentos, $40,9 \%$ dos participantes da pesquisa responderam que sim, ocorreram mudanças no funcionamento; $35 \%$ disseram que houve mudanças e que essas mudanças continuam vigorando. Outros participantes correspondentes à $24,1 \%$ informaram que não houve mudança em razão da pandemia.

Gráfico 9 - Concorda que buscar meios de inovar nos negócios é fundamental para enfrentar crises como a pandemia?

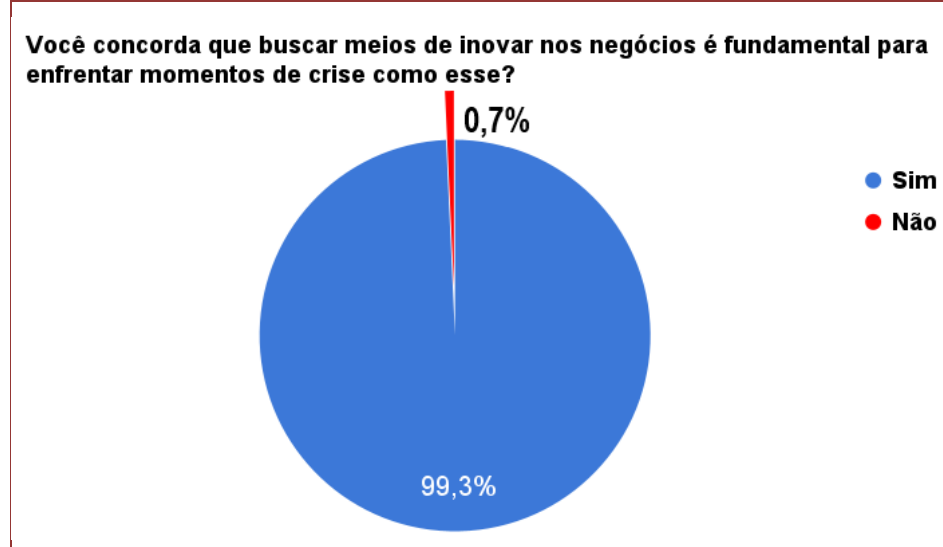

Fonte: Elaborado pelo autor a partir de dados coletados (2021) 
Neste trabalho buscou-se, entre outros, demonstrar como o quesito inovação pode ser importante e decisivo no que concerne o empreendedorismo e o empreendedor enquanto sujeito atuante na sociedade. Indagados através do questionário sobre ser fundamental procurar meios de inovar para enfrentar momentos difíceis, os empreendedores participantes dessa pesquisa concordaram que sim, 99,3\% concordaram que é fundamental a inovação para confrontar crises; 0,7\% disseram não (Gráfico 9).

A quase unanimidade dos participantes concordando com a importância da inovação nos negócios em crises demonstra a consciência destes a respeito das condutas de sucesso na área além de estarem podendo vivenciar na prática uma crise geral forçando muitos a tomarem iniciativas inovadoras para se adaptarem às mudanças e contornar as dificuldades para manterem seus negócios bem.

Gráfico 10 - Seu negócio/trabalho hoje é sua principal fonte de renda?

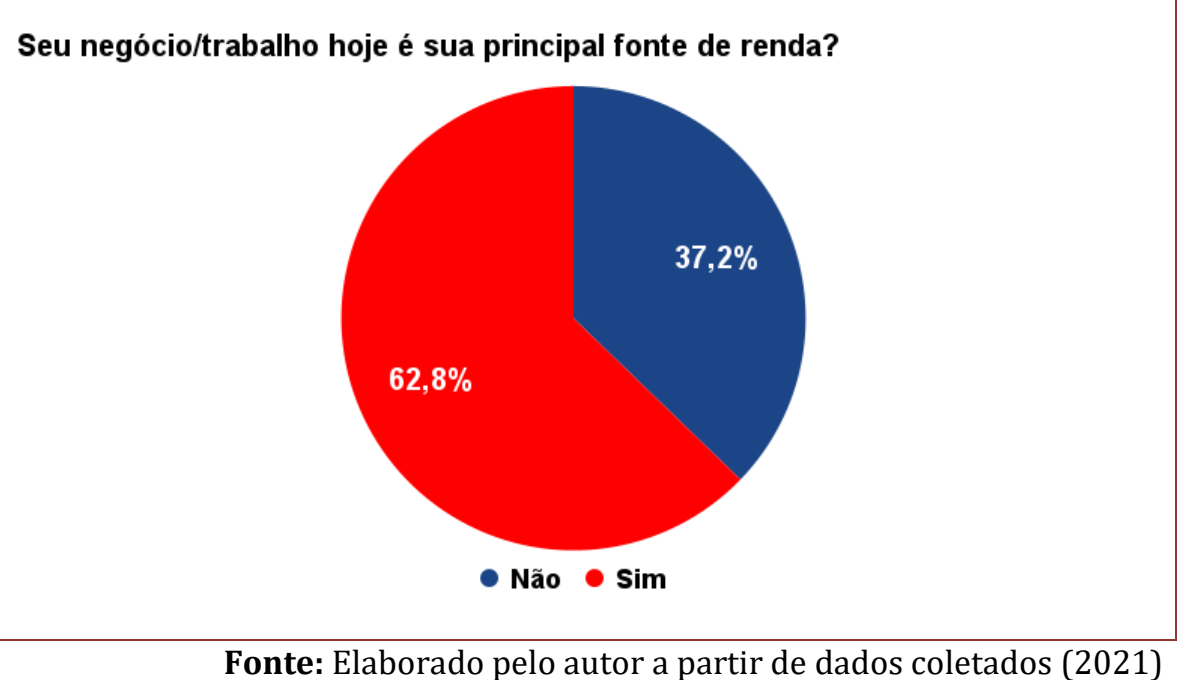

Conforme demonstrado no Gráfico 10, a maior parte dos participantes têm hoje seu empreendimento/trabalho como sua fonte principal de renda $(62,8 \%)$. Em vista disso, é possível inferir a relevância dos problemas ocasionados pela crise para esse grupo, uma vez que seu principal meio de sobrevivência se vê ameaçado, expondo-os à riscos econômicos e sociais.

Gráfico 11 - Quais dessas são as melhores formas de superar as dificuldades nessa crise?

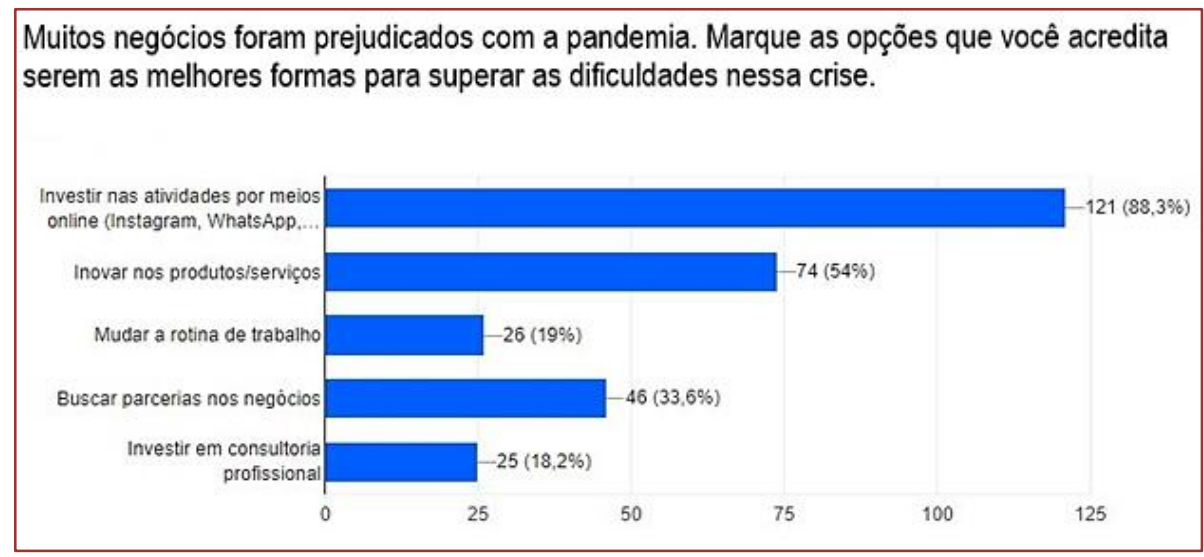

Fonte: Elaborado pelo autor a partir de dados coletados (2021)

Os participantes responderam à pesquisa sobre as formas que consideram ser melhores opções na busca por superação das dificuldades na pandemia elegendo dentre as opções apresentadas na questão as que consideram ser as melhores alternativas, podendo marcar uma ou várias opções. De acordo com o Gráfico 
11 acima, 88,3\% do total dos participantes marcaram a opção "investir nas atividades por meios online (Instagram, WhatsApp, etc.)"; 54\% selecionaram "inovar nos produtos/serviços"; 19\% marcaram "mudar a rotina de trabalho"; 33,6\% indicaram "buscar parcerias nos negócios"; e 18,2\% do total de participantes marcaram "investir em consultoria profissional".

Como observa-se, mais uma vez os meios online em um momento de afastamento social mostram o peso de sua importância para a manutenção das atividades dos empreendedores. A necessidade aliada a um meio que já existia provocou uma evidenciação nesse tipo de ferramenta, abrindo portas para a inovação.

Gráfico 12 - Motivos principais de trabalhadores informais sentirem mais os impactos da pandemia segundo os participantes

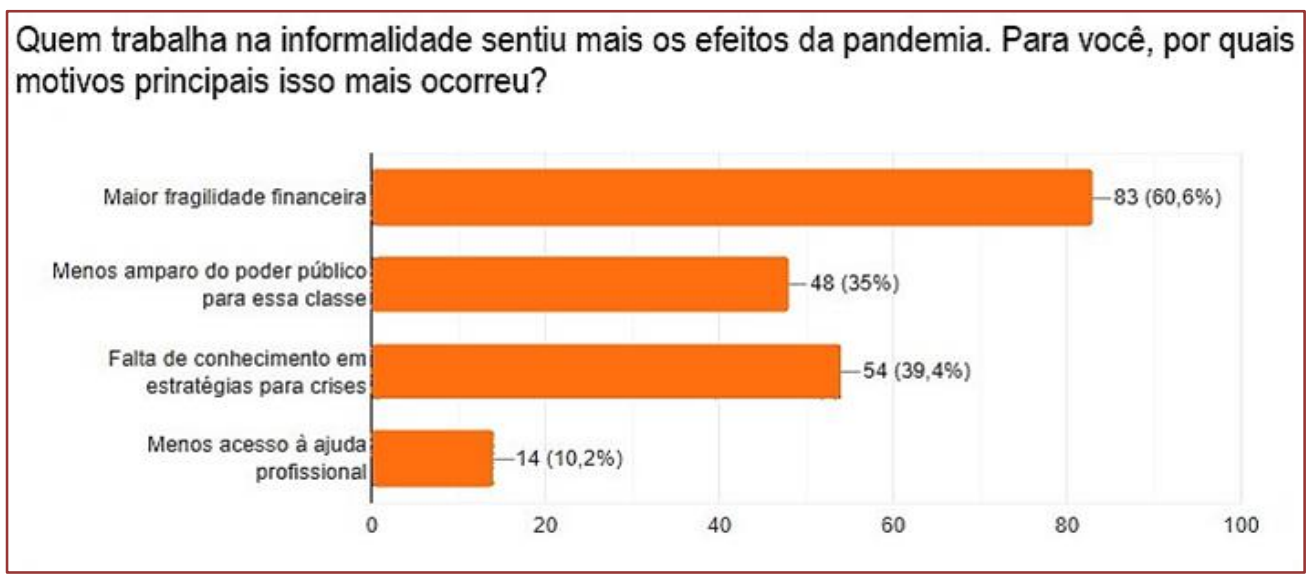

Fonte: Elaborado pelo autor a partir de dados coletados (2021)

O Gráfico 12 acima traz um questionamento a respeito de motivos que mais levaram trabalhadores informais a serem um dos grupos que mais sentiram e estão vulneráveis aos impactos da crise sanitária segundo os participantes. 60,6\% dos participantes elegeram a "maior fragilidade financeira" desses trabalhadores como um dos principais motivos de estarem mais expostos as problemáticas causadas pela pandemia. 35\% afirmaram que "menos amparo do poder público para essa classe" se configura um dos principais motivos; "falta de conhecimento em estratégias para crises" e "menos acesso à ajuda profissional" tiveram votação de 39,4\% e 10,2\% dos participantes, respectivamente.

Tendo em vista as respostas coletadas, percebe-se o fator financeira ainda como uma das principais causas da fragilidade dessa classe na opinião dos empreendedores participantes, seguida de menos amparo do poder público, que seguramente seria um auxílio determinante para que essa classe pudesse ter mais base financeira e social para contornar as adversidades.

Gráfico 13 - Melhores opções para ajudar a combater a falência de negócios devido a pandemia na opinião dos participantes

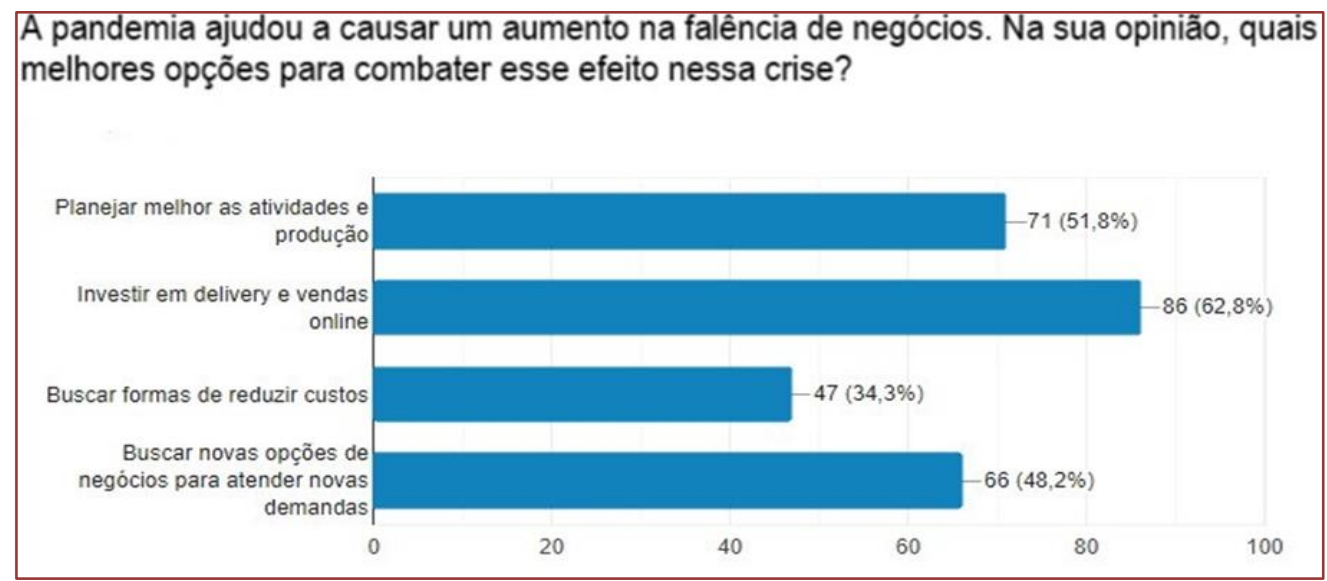

Fonte: Elaborado pelo autor a partir de dados coletados (2021) 
O fechamento de negócios em razão das dificuldades nesse período também é mais um reflexo do peso enfrentado pelos empreendedores na pandemia, sobretudo, os informais que estão sujeitos a sentirem mais. As alternativas para tentar contornar os efeitos negativos quase que invariavelmente passam pela busca por inovar em algo nos negócios. No Gráfico 13 encontra-se os resultados de uma questão da pesquisa onde os participantes indicaram as melhores alternativas para ajudar no combate aos casos de falência que tiveram aumento no período pandêmico na sua opinião. A maioria $(62,8 \%)$ marcou "investir em delivery e vendas online" como uma das melhores opções; seguida de "planejar melhor as atividades e produção" com $51,8 \%$ de indicações.

A restrição de circulação de pessoas para evitar aglomerações como forma de combate ao aumento dos casos de Covid-19 figura como uma das principais marcas do período pandêmico, o que ajuda a entender a alternativa mais votada. Investir em atividades por meios online assim como serviços de delivery nesse contexto, conquistou grande adesão por parte dos empreendedores que viram isso como um importante caminho para vencer as barreiras impostas às suas atividades.

Conforme o Gráfico 14 mostra, a maior parte dos empreendedores participantes da pesquisa concordam total ou parcialmente sobre as adversidades em decorrência da pandemia ajudar as pessoas a melhor servirem-se das oportunidades bem como identificá-las, além de fomentar incentivos a inovação. 56,9\% concordam totalmente com a afirmativa na questão, 33,6\% parcialmente. Isso demonstra como a situação de adversidade evidenciou para muitos a importância dessas condutas, sobretudo, para a adaptação às novas condições da realidade para garantir que se mantenham.

Gráfico 14 - As dificuldades como motivação para empreendedores aproveitarem melhor as oportunidades e inovar

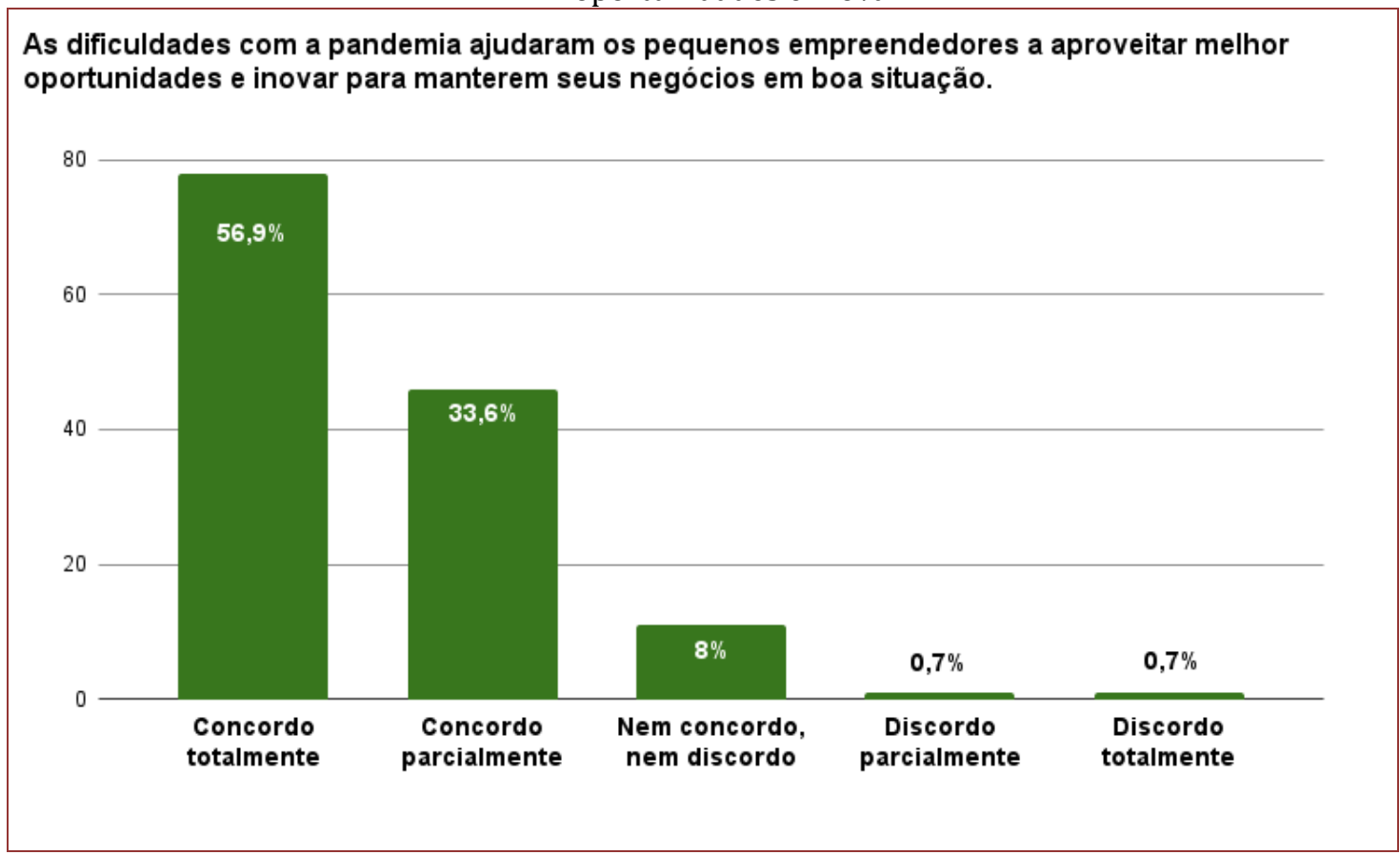

Fonte: Elaborado pelo autor a partir de dados coletados (2021)

\section{CONSIDERAÇÕES FINAIS}

Diante do atual cenário onde o mundo enfrenta uma crise sanitária em decorrência de uma pandemia de covid-19, onde a sociedade como um todo enfrenta consequências jamais vistas, verificou-se uma necessidade em focar esforços de estudo em uma classe fundamental para a sociedade codoense que enfrenta dificuldades na pandemia, os pequenos empreendedores da cidade de Codó-MA, com o intuito de entender sua situação na pandemia, de como estão enfrentando-a em vista de sua grande importância para o município em vários aspectos e da novidade da situação vivida, o que, por conseguinte, levou à escolha do tema aqui tratado.

Seguindo esses preceitos, de acordo com o tema definido, a pesquisa teve como objetivo geral analisar os principais desafios e oportunidades existentes com o surgimento da pandemia do Covid-19 no comércio 
informal do município de Codó-MA. Em vista dos resultados da pesquisa, pode-se constatar que o objetivo geral foi alcançado, pois o trabalho conseguiu identificar e demonstrar as principais consequências da crise através de dados obtidos em pesquisa bibliográfica e de campo com empreendedores do município; bem como identificou pontos positivos pelas oportunidades advindas, como investimento em serviço de delivery e incentivo à inovação.

Em relação aos objetivos específicos, o primeiro consistiu em identificar a prática do empreendedorismo e inovação, enquanto fatores essenciais à sobrevivência no comércio do respectivo município na atual situação pandêmica e foi atendido, pois a pesquisa de campo constatou a sua importância para a renda de acordo com os participantes e atividade empreendedora.

O segundo objetivo específico foi caracterizar diante do atual cenário de pandemia as principais oportunidades e desafios enfrentados no comércio informal do município de Codó-MA. Este, por sua vez, também foi atendido pois a pesquisa permitiu conhecer as principais oportunidades para a atividade empreendedora surgidas na crise, assim como as barreiras causadas pelo momento através de questionamentos direcionados à tal sentido, aliado a pesquisa bibliográfica corroborando com mais dados.

Em seguida, o terceiro consistia em verificar os principais impactos da pandemia do Covid-19 no empreendedorismo informal do município de Codó-MA, que foi alcançado por meio da pesquisa de campo tendo como alvo pequenos empreendedores do município, pois questões contidas no questionário tratavam dessa temática que foi atendida pelas respostas obtidas.

Tais direcionadores da pesquisa, tema e objetivos, buscaram responder ao seguinte problema: Quais os principais desafios e oportunidades existentes com o surgimento da pandemia do covid-19 no comércio informal do município de Codó-MA? Diante da pesquisa bem como os dados apresentados como resultado das pesquisas realizadas, conclui-se que o problema foi respondido. Os participantes informaram sobre questões essenciais para se entender a situação de sua atividade e vida empreendedora como situação antes da pandemia, o impacto da restrição de circulação das pessoas em suas atividades e desempenho no negócio, mudanças de funcionamento devido a crise, inovação diante do cenário atual, entre outros, que permitiram compreender sua conjuntura atual.

0 trabalho foi realizado se utilizando de robusta pesquisa bibliográfica acerca do atual contexto vivido, trazendo dados pertinentes aos direcionamentos definidos para a pesquisa. Além desta, foi realizado uma pesquisa de campo, por meio da aplicação de questionário via Google Forms tendo como público-alvo pequenos empreendedores do município de Codó-MA, obtendo 137 participantes.

Diante das definições da metodologia aplicada e o contexto no qual a pesquisa foi realizada, percebeu-se limitações com relação ao público-alvo que se demonstrou um tanto restrito na etapa de aplicação do questionário na pesquisa de campo por se tratar de público específico aliado à rotina dos participantes deste público no que diz respeito ao número de participantes que responderam ao questionário enviado. Aliado a isto, o prazo provou-se curto para a execução da coleta do máximo de respostas possíveis em vista das demais etapas da pesquisa ainda estando por fazer.

Face a essas observações visando auxiliar futuras pesquisas para obtenção de dados com uma amostra mais ampla e com dados mais relevantes, recomendações para uma maior atenção aos prazos para realização de pesquisas com esse público são válidas. Por fim, mais questionamentos a respeito de condutas nas suas atividades empreendedoras superando indagações de caracterização socioeconômica.

\section{REFERÊNCIAS}

[1] ABCOMM. Faturamento do e-commerce cresce 56,8\% neste ano e chega a R \$ 41,92 bilhões. Notícias. São Paulo, outubro de 2020. Disponível em: https://abcomm.org/noticias/faturamento-do-e-commerce-cresce-568-nesteano-e-chega-a-r-4192-bilhoes/. Acesso em: 26 maio 2021.

[2] BAGGIO, Adelar Francisco; BAGGIO, Daniel Knebel. Empreendedorismo: Conceitos e definições. Revista de Empreendedorismo, Inovação e Tecnologia, Passo Fundo, v. 1, n. 1, p. 25-38, jan. 2015. ISSN 2359-3539. Disponível em: https://doi.org/10.18256/2359-3539/reit-imed.v1n1p25-38. Acesso em: 10 maio 2021.

[3] BRASILEIRO, Gabriel Bernardes; SOUZA, Diego Silva. Oportunidades durante a pandemia: custeando e analisando os preços de venda de máscaras caseiras. In: Congresso de Gestão, Negócios e Tecnologia da Informação CONGENTI. 2020

[4] CAMARGO, J. M. C. Desemprego, informalidade e rotatividade: reformas que fazem a diferença. In: GIAMBIAGI, F.; BARROS, O. (Org.). Brasil Pós crise: agenda para a próxima década. Campus, 2009. 
[5] CAMPOS, Ana Cristina. IBGE: informalidade atinge 41,6\% dos trabalhadores no país em 2019. Agência Brasil. Brasília, 12 nov. 2020. Economia. Disponível em: https://agenciabrasil.ebc.com.br/economia/noticia/2020-11/ibgeinformalidade-atinge-416-dos-trabalhadores-no-pais-em-2019. Acesso em: 12 maio 2021.

[6] CERQUEIRA, Eder da Silva. Considerações acerca do conceito de informalidade. Produção Acadêmica. v. 3, n. 01, p. 123-133, 2017.

[7] COSTA, Daniela. As oportunidades de negócios que surgiram durante a pandemia. Revista Encontro. Economia. 14 março 2021. Disponível em: https://www.revistaencontro.com.br/canal/revista/2021/03/asoportunidades-de-negocios-que-surgiram-durante-a-pandemia.html. Acesso em: 13 maio 2021.

[8] COSTA, Simone da Silva. Pandemia e desemprego no Brasil. Revista de Administração Pública, Rio de Janeiro v. 54, n. 4, p. 969-978, agosto 2020. Disponível em: https://doi.org/10.1590/0034-761220200170. Acesso em: 14 maio 2021.

[9] CHAUSSARD, Cristiano. Com e-commerce em expansão, é hora de arrumar a casa! Associação Brasileira de Comércio Eletrônico - Abcomm. Mercado Digital. São Paulo, 22 maio 2020. Disponível em: https://abcomm.org/noticias/com-e-commerce-em-expansao-e-hora-de-arrumar-a-casa/. Acesso em: 12 maio 2021.

[10] CHIAVENATO, Idalberto. Empreendedorismo: dando asas ao espírito empreendedor. 2. ed. rev. São Paulo: Saraiva, 2007.

[11] DRUCKER, Peter. Desafios gerenciais para o século XXI. São Paulo: Pioneira, 1989.

[12] FERNANDES, Nicoline Pinheiro et al. Quem é o empreendedor? A busca por uma definição do conceito através da produção científica brasileira | Who is the entrepreneur? The search for a definition of the concept through brazilian scientific production. Revista Brasileira de Gestão e Inovação (Brazilian Journal of Management \& Innovation), v. 7, n. 3, p. 26-62, 2020

[13] FONSECA, I. F. Capacitação solidária: uma análise crítica da perspectiva de empregabilidade e empreendedorismo. 2003. 107 f. Dissertação (Mestrado em Serviço Social) - Departamento de Serviço Social, Pontifícia Universidade Católica do Rio de Janeiro, Rio de Janeiro: 2003.

[14] FRANCO, David Silva; FERRAZ, Deise Luiza da Silva. Uberização do trabalho e acumulação capitalista. Cad. EBAPE.BR. Rio de Janeiro, v. 17, n. spe, p. 844-856, nov. 2019. Disponível em: https://doi.org/10.1590/1679395176936. Acesso em: 14 maio 2021.

[15] IBGE - Instituto Brasileiro de Geografia e Estatística. Pesquisa Pulso Empresa. Agosto 2020. Disponível em: https://covid19.ibge.gov.br/pulso-empresa/. Acesso em: 14 maio 2021.

[16] ___. Síntese de indicadores sociais: uma análise das condições de vida da população brasileira. 2020. Coordenação de População e Indicadores Sociais. Rio de Janeiro: IBGE, 2020.

[17] INOVAÇÃO SEBRAE. Economia Informal: Importância e Soluções. Empreendedorismo. Ecossistema. MG, 2018. Disponível em: https://inovacaosebraeminas.com.br/economia-informal/. Acesso em: 02 jun 2021.

[18] KREIN, José. Dari; OLIVEIRA, Roberto Véras de. Os impactos da Reforma nas condições de trabalho. In: KREIN, J. D; VERAS DE OLIVEIRA, R.; FILGUEIRAS. V. Reforma trabalhista no Brasil: promessas e realidade. Campinas: Curt Nimuendaju, 2019.

[19] LEITE, Emanoel F. O fenômeno do empreendedorismo e as empresas de base tecnológica. SOUZA, ECLS Empreendedorismo: Competência Essencial para Pequenas e Médias Empresas. Brasília: Anprotec, p. 84-102, 2001.

[20] MANUAL DE OSLO. Diretrizes para Coleta e Interpretação de Dados sobre Inovação. Produção: ARTI e FINEP. 3. ed. 2005.

[21] MARCONI, Mariana de Andrade; LAKATOS, Eva Maria. Fundamentos da Metodologia Científica. 5. ed. São Paulo, SP: Atlas S.A., 2003

[22] NUNES, Daniel Oliveira. Sobrevivência no mundo do trabalho: um estudo sobre empreendedorismo informal em um mercado público na cidade de João Pessoa-PB. 2020. Trabalho de Conclusão de Curso.

[23] OIT - Organização Internacional do Trabalho. COVID-19 e o mundo do trabalho. Disponível em: https://www.ilo.org/brasilia/temas/covid-19/lang--pt/index.htm. Acesso em: 12 mai. 2021.

[24] PRODANOV, Cleber Cristiano; FREITAS, Ernani Cesar de. METODOLOGIA DO TRABALHO CIENTÍFICO: Métodos e Técnicas da Pesquisa e do Trabalho Acadêmico. - 2. ed. - Novo Hamburgo: Feevale, 2013.

[25] RIBEIRO, Bruno Andrade; OLIVEIRA, Vanessa Dias de; SANTOS, Josefa de Lisboa. EXPRESSÕES DA PRECARIEDADE DO TRABALHO NO QUADRO PANDÊMICO DA COVID-19. PEGADA - A Revista da Geografia do Trabalho, v. 21, n. 2, p. 302-332, maio. 2020

[26] SCHUMPETER, J. A. Teoria do Desenvolvimento Econômico: uma investigação sobre lucros, capital, crédito, juro e o ciclo econômico. Tradução: Maria Sílvia Possas. Os Economistas, São Paulo: Nova Cultural, 1997. 
[27] SEBRAE e FVG. Crédito no Brasil Para MPEs em tempo de Covid-19. FGV Projetos: Distrito Federal, 2020. Disponível:

https://fgvprojetos.fgv.br/sites/fgvprojetos.fgv.br/files/cra0dito_no_brasil_para_mpes_em_tempo_de_covid19_format acaosite.pdf. Acesso em: 25 maio 2021.

[28] SEBRAE. Panorama dos pequenos negócios 2018. São Paulo, 2018. Disponível em: https://www.sebrae.com.br/Sebrae/Portal\%20Sebrae/UFs/SP/Pesquisas/Panorama_dos_Pequenos_Negocios_2018_ AF.pdf. Acesso em: 11 maio 2021.

[29] SILVA, Pedro Henrique Isaac. 0 mundo do trabalho e a pandemia de covid-19: um olhar sobre o setor informal. Caderno de Administração, v. 28, n. Edição esp., p. 66-70, 2020.

[30] THOMPSON, J. L. The world of the entrepreneur - a new perspective. Journal of Workplace Learning, Bradford, v. 11, n. 6, p. 209-224, 1999.

[31] VALE, Gláucia Maria Vasconcellos. Empreendedor: origens, concepções teóricas, dispersão e integração. Revista de Administração Contemporânea, Rio de Janeiro, v. 18, n. 6, p. 874-891, nov./dez. 2014.

[32] VELOSO, Fernando. O impacto da pandemia no mercado de trabalho. Instituto Brasileiro de Economia - IBRE. Fundação Getúlio Vargas - FGV. março 2021. Disponível em: https://blogdoibre.fgv.br/posts/o-impacto-dapandemia-no-mercado-de-trabalho. Acesso em: 14 maio 2021. 
APÊNDICE A

Pesquisador: Pedro da Silva Sousa

Título do trabalho: EMPREENDEDORISMO E INOVAÇÃO: um estudo do impacto da Pandemia do Covid19 no comércio informal do município de Codó-MA

\section{QUESTIONÁRIO}

\section{1ㅇ) Sexo}
( ) Masculino
( ) Feminino

\section{2º) Faixa etária}

( ) até 17 anos ( ) 18-25 anos ( ) 26-35 anos

( ) 36-45 anos ( ) 46-55 anos ( ) acima de 55 anos

\section{3ํ) Nível de escolaridade}

( ) Ensino fundamental

( ) Ensino fundamental incompleto

( ) Ensino médio

( ) Ensino médio incompleto

( ) Ensino superior

( ) Ensino superior incompleto

( ) Pós-graduação

( ) Pós-graduando

( ) Não frequentou a escola

\section{4º) Onde está localizado seu empreendimento/negócio?}

( ) Na própria residência

( ) Ponto comercial específico para o negócio

( ) Online

( ) Feira/centro comercial popular

( ) Ambulante

( ) Na casa ou local do cliente

( ) Em veículo (bicicleta, moto, carro, etc.)

( ) Outros (rodovias, quiosques, etc.) 
5o) Com o que você trabalha?

( ) Venda de produtos

( ) Prestação de serviços

( ) Produtos e serviços

69) Como estava a situação do seu negócio/trabalho antes da pandemia?

( ) Ruim

( ) Regular

( ) Boa

( ) Ótima

$7^{\text {o) }}$ A restrição de circulação das pessoas devido a pandemia afetou suas atividades e/ou desempenho do seu negócio.

( ) Concordo totalmente

( ) Concordo parcialmente

( ) Nem concordo, nem discordo

( ) Discordo totalmente

( ) Discordo parcialmente

8) Seu negócio/trabalho teve que sofrer mudanças no funcionamento em algum momento por causa da crise?

( ) Sim, houve mudança no funcionamento

( ) Sim, e continua seguindo as mudanças

( ) Não houve mudanças por causa da pandemia

9o) Você concorda que buscar meios de inovar nos negócios é fundamental para enfrentar momentos de crise como esse?
( ) Sim
( ) Não

10ㅇ) Seu negócio/trabalho hoje é sua principal fonte de renda?

( ) Sim

( ) Não 
11ㅇ) Muitos negócios foram prejudicados com a pandemia. Marque as opções que você acredita serem as melhores formas para superar as dificuldades nessa crise.

( ) Investir nas atividades por meios online (Instagram, WhatsApp, etc.)

( ) Inovar nos produtos/serviços

( ) Mudar a rotina de trabalho

( ) Buscar parcerias nos negócios

( ) Investir em consultoria profissional

12º) Quem trabalha na informalidade sentiu mais os efeitos da pandemia. Para você, por quais motivos principais isso mais ocorreu?

( ) Maior fragilidade financeira

( ) Menos amparo do poder público para essa classe

( ) Falta de conhecimento em estratégias para crises

( ) Menos acesso à ajuda profissional

13으 A pandemia ajudou a causar um aumento na falência de negócios. Na sua opinião, quais melhores opções para combater esse efeito nessa crise?

( ) Planejar melhor as atividades e produção

( ) Investir em delivery e vendas online

( ) Buscar formas de reduzir custos

( ) Buscar novas opções de negócios para atender novas demandas

14$^{\circ}$ ) As dificuldades com a pandemia ajudaram os pequenos empreendedores a aproveitar melhor oportunidades e inovar para manterem seus negócios em boa situação.
( ) Concordo totalmente
( ) Concordo parcialmente
( ) Nem concordo, nem discordo
( ) Discordo totalmente
( ) Discordo parcialmente 


\section{Capítulo 11}

\section{Empreendedorismo Rural Feminino: Um estudo bibliométrico para o Brasil}

\section{Alessandra Bandeira da Rosa}

Eduardo Leite de Souza

Wendelino Fang

Gabrielito Rauter Menezes

Resumo: 0 presente trabalho, tem como objetivo, fazer um levantamento bibliométrico da produção científica sobre empreendedorismo rural feminino no Brasil. Para tanto foram consultadas as bases de dados Spell, Sciello e Web of Science que tratam sobre o tema, no período de 2006 a 2019, totalizando 57 artigos. Observou-se uma carência de artigos sobre empreendedorismo rural feminino, o indica a necessidade de um maior esforço e dedicação nesta importante e nova agenda de pesquisa.

Palavras-chave: Empreendedorismo Feminino; Rural; Bibliometria. 


\section{INTRODUÇÃO}

As mudanças cada vez mais aceleradas, tanto no contexto econômico, político ou social têm o poder de influenciar a maneira como os indivíduos conduzem os seus negócios. Nesta direção, é de grande importância que se tenha uma gama de habilidades para perceber necessidades, tendências, motivações ou preferências dos consumidores.

Esta não é uma tarefa fácil para aqueles indivíduos que exercem papel de gestão no seu próprio negócio, mais difícil ainda quando, além de assumir o poder de tomador de decisões de uma empresa, independentemente do seu tamanho, percebe-se que estes também integram a sociedade e que possuem suas próprias características, motivações e necessidades.

Ainda sobre esta perspectiva, poderia caber mais uma posição de decisão, como uma chefe de uma família, por exemplo. Estas transformações têm trazido novas necessidades que vão se somando de maneira mais forte àqueles indivíduos que já são capacitados naturalmente a ter uma simultaneidade entre decisões, sejam profissionais ou pessoais. Junto a isto, começa a surgir uma questão potencial que é ainda pouco discutida em relação à outras temáticas sobre empreendedorismo, mas que tem fundamental importância e precisa ter a relevância que lhe é justa.

Por esta razão, este trabalho tem o objetivo principal de realizar um estudo bibliométrico sobre a percepção dos estudiosos sobre o empreendedorismo rural feminino no período analisado de setembro à dezembro de 2019 e este estudo pretendeu verificar: (1) Identificar as publicações científicas na base Spell, Sciello e Web off Science que tratam sobre o tema empreendedorismo rural feminino; (2) apresentar os autores que mais estão publicando sobre o assunto; (3) e verificar o período que houve maior número de publicações sobre o assunto, entre os anos de 2006 à 2019.

Na sequência deste artigo, apresenta-se a revisão de bibliografia referente ao empreendedorismo rural feminino. Na terceira seção, apresentam-se os procedimentos metodológicos. Na quarta seção os resultados são apresentados, enquanto na quinta, são apresentadas as considerações finais.

\section{REVISÃO DE BIBLIOGRAFIA}

Tendo em vista atender o objetivo do presente artigo, a revisão de literatura foi dividida em duas subseções. A primeira contempla a literatura sobre empreendedorismo, num contexto geral. Já a segunda, apresenta o empreendedorismo rural feminino.

\subsection{EMPREENDEDORISMO}

O empreendedorismo no Brasil aparece na literatura a partir de 1964 e de acordo com Gimenez et al. (2017) os autores que iniciaram este estudo foram: Bresser Pereira (1964), Marcovitch et al. (1986) e Santos (1984). Mas o tema começou a ganhar força entre os pesquisadores brasileiros a partir de 2000. Os autores citados anteriormente, ainda acrescentam que até 2016 foram publicados mais de 1.000 textos sobre o tema empreendedorismo, em 307 periódicos brasileiros.

Segundo Kruger et al. (2017), para ser empreendedor o indivíduo requer certos comportamentos e atitudes. As quais foram descritas e classificadas por McClelland (1987), como: realização, planejamento e poder que referem-se as características: busca de oportunidade e iniciativa; persistência; comprometimento; exigência de qualidade e eficiência; correr riscos calculados; estabelecimento de metas; busca de informações; planejamento e monitoramento sistemáticos; persuasão e rede de contatos e; independência e autoconfiança.

No meio rural, o empreendedorismo tem um papel crucial para o desenvolvimento territorial. Como por exemplo o turismo, o qual é uma das atividades que vem se desenvolvendo e crescendo. Salienta-se, que existem alternativas consideradas não tradicional para o desenvolvimento econômico, destacando o papel do turismo rural, como oportunidade de negócio tanto para pousadas, atividades agrárias e comércio de produtos rurais (DIEGUEZ-CASTRILLON et al., 2012).

\subsection{EMPREENDEDORISMO RURAL FEMININO}

A partir dos anos 90 começam a ser feitos estudos sobre empreendedorismo feminino no Brasil. Como por exemplo o artigo "Empreendedorismo feminino no Brasil: gênese e formação de um campo de pesquisa". Tal trabalho chega à conclusão de que os estudos sobre empreendedorismo feminino no Brasil tiveram o 
predomínio de abordagens interpretativas, e que existem diversos aspectos da ação empreendedora. Destacando a percepção do exercício do papel empreendedor e sua importância, dificuldades enfrentadas e resultados obtidos e a presença de conflito relacionados aos múltiplos papéis desempenhados pelas empreendedoras, no trabalho, família e lar (GIMENEZ; FERREIRA; RAMOS, 2017).

Com relação ao empreendedorismo rural feminino no Brasil, os trabalhos são mais escassos. Isto se deve provavelmente ao difícil acesso as informações de dados sobre as mulheres empreendedoras no meio rural e por estas representarem um pequeno número no campo. De acordo com Serviço Brasileiro de Apoio às Micro e Pequenas Empresas (SEBRAE) em 2018, estima-se que o total de produtores rurais no Brasil tem cerca de 4,4 milhões de produtores rurais, e as mulheres representam apenas $15 \%$ desse total, as quais moram e trabalham no campo.

Embora a quantidade de mulheres empreendedoras no campo, sejam muito inferior, quando comparada ao sexo masculino, os dados mostram que elas vêm ganhando espaço em cargos de comando no campo. Saindo de 10\% em 2003 para 30\% dos cargos em propriedades rurais, e que uma em cada quatro destas tem nível superior, superando os homens que é um em cada cinco (GAVRAS, 2018).

Dentro deste contexto, as mulheres têm características distintas do que os dos homens em relação ao empreendedorismo. No universo feminino não tem como separar a seus papéis dentro da sociedade, mãe, esposa e coordenadora do lar. No artigo sobre "Mulheres e Suas Histórias: Razão, Sensibilidade e Subjetividade no Empreendedorismo Feminino" fica perceptível essa diferenciação. E através de relatos de mulheres nota-se que prevalece na sociedade brasileira uma visão natural dos gêneros e ser mulher demonstra condição biológica e não social. Mas a realidade é que a empreendedora feminina é um ser social, modificada subjetivamente pelo meio que vive, trabalha e a cultura que é inserida (FERREIRA; NOGUEIRA, 2013).

\section{METODOLOGIA}

De acordo com a questão central de pesquisa, orientadora deste trabalho adotou-se uma estratégia de pesquisa de caráter descritivo, que segundo Gil (2017), tem por proposito fazer um levantamento de um conjunto de dados já publicados, registrá-los e analisá-los sem interferência do pesquisador, usando como técnica de analise a bibliometria. A bibliometria, conforme Araújo (2006) é uma técnica quantitativa direcionada para a medição de índices de produção e disseminação do conhecimento. Sendo que esta técnica surgiu no início do século passado como resposta a necessidade de avaliação da produção e comunicação do conhecimento científico.

Quanto aos procedimentos, os estudos bibliométricos se desenvolvem a partir de três leis empíricas básicas, definidas por Araújo (2006) como as três leis clássicas sobre a abordagem e o dimensionamento da produção cientifica: a lei de Lotka, dispersão de Bradford, e a de Zipf.

A primeira lei, conhecida como lei de Lotka, foi formulada em 1926, produzida a partir de um estudo sobre a produtividade de literatura cientifica de um grupo restrito de autores. Já a lei de dispersão de Bradford foi desenvolvida no início da década de 1930. Estabelecendo que há uma correlação entre um grupo de periódicos, quando estes tratam do mesmo tema. 0 qual existe sempre um grupo, ou núcleo menor de periódicos que tratam do mesmo tema. 0 restante da produção, muitas vezes menos cientifica, está dispersa em um grupo maior de periódicos.

E no final da década de 1940, foi elaborada a lei de Zipf, a qual considera que existe uma correlação entre o número de palavras diferentes e a frequência de uso delas. Conforme Araújo (2006), um pequeno número de palavras empregado com maior frequência define o assunto do documento.

O emprego destas técnicas bibliométricas de forma isolada, por si só, não permite uma avaliação precisa da qualidade dos trabalhos publicados. De acordo com Beghis at. al (2014) estas técnicas são relevantes por identificarem os autores e os periódicos mais referenciados. Além disso, a Coordenação de Aperfeiçoamento de Pessoal de Nível Superior (CAPES), utiliza estes estudos para avaliar o impacto da produção cientifica dos programas de pós-graduação no país.

Os termos mulheres empreendedores foram definidos como ponto de partida do presente estudo. Pois, sintetizam o objeto de análise relativo ao objetivo do estudo bibliométrico aqui proposto. Visando alcançar um número representativo de publicações cientificas acerca do tema foram realizadas buscas e eletrônicas. As mesmas foram centralizadas nas publicações relativas à produção cientifica nacional. 0 período de análise foi de 2006 a 2019 por ser a partir desta época que começaram a surgir com mais vigor a questão da participação feminina em diversas áreas no empreendedorismo, disponibilizada nas bases 
de dados Spell, SciELO e Web off Science. Foram obtidas 57 publicações, sendo escolhidas as 45 publicações mais relevantes para compor a presente análise.

Inicialmente os artigos foram estudados individualmente e classificados conforme sua autoria, título da publicação, periódico da publicação, objetivo das publicações, palavras chaves e quanto ao tipo de pesquisa, qualitativa e ou quantitativa.

\section{RESULTADOS E DISCUSSÕES}

Através da pesquisa bibliométrica, e com base nos 45 artigos analisados, verificou-se que o tema "empreendedorismo rural feminino" não foi encontrado na busca feita nas bases de dados Spell, Sciello e Web off Science. Os assuntos relacionados, na pesquisa nas bases de dados, foram empreendedorismo feminino e mulheres empreendedoras. Embora esta questão seja importante e relevante para o mercado de trabalho e para a sociedade em geral, notou-se uma enorme lacuna, que demonstre e investigue a mulher que está no campo, que produz, que se mantêm a si e sua família.

De acordo com os artigos analisados, verificou-se que mais de $61 \%$ foram escritos por mulheres (76 autoras) e 47 homens, o que possuía menos autores tinha 2 e o que possuía mais 6 autores. Do total, 9 artigos foram escritos só por mulheres e as que produziram mais foram Hilka Vier Machado com 9 artigos e Rivanda Meira Texeira com 5, entre os anos de 2009 e 2018. 0 interesse sobre este assunto, tanto por homens quanto por mulheres demonstra a importância e relevância do tema.

Nessa relação demonstra a Lei de Lotka que afirma Araújo 2006 que alguns pesquisadores publicam muito e que muitos autores publicam pouco, sobre algum tema específico. E sobre o tema Empreendedorismo feminino conseguimos constatar esta lei. As autoras Hilka Vier Machado e Rivanda Meira Texeira, forma as que mais publicaram, enquanto o restante dos autores publicou poucos e a maioria apenas um artigo.

Gráfico 1 - Quantidade de publicações de 2006 a 2019

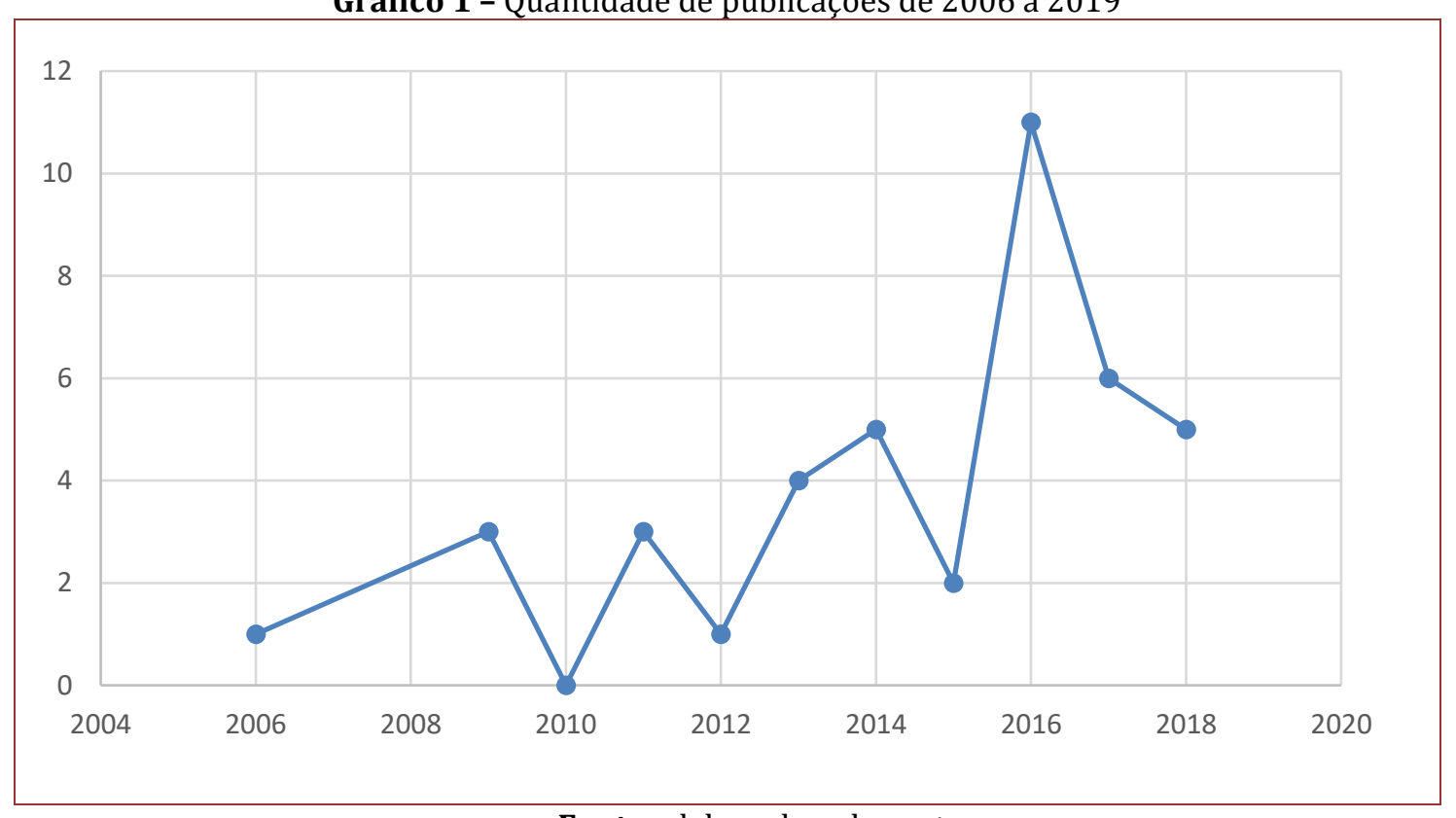

Fonte: elaborado pelos autores.

0 gráfico 1, mostra o período de maior produção de artigos, no intervalo dos anos de 2006 a 2019. Como podemos observar, o ano de 2016 se destacou com 11 publicações dobre o tema de empreendedorismo feminino. As revistas que mais publicaram foram as da área administrativa, economia e gestão.

Ainda sobre esses achados, destaca-se os títulos destes trabalhos. Vale salientar que se tratava do empreendedorismo feminino em diversos setores da economia. Muitos deles abordavam as características femininas, suas dificuldades, sensibilidade e gênero feminino. Os artigos relatam que as características femininas são de grande importância na tomada de decisão no empreendedorismo feminino e a maneira de agir das mulheres é demonstrada no seu modo de empreender. 


\subsection{PALAVRAS-CHAVE}

Face aos resultados apurados, pode-se afirmar que as palavras-chave representam uma fonte valiosa para prospectar, ou checar o conteúdo dos artigos indexados pelas bases de dados analisadas (Spell, SciELO e Web off Science).

Foram identificadas 292 palavras-chave nos 45 artigos, das quais foram descartadas 224 por não terem relação específica com tema de análise proposto neste estudo. Restando um total de 68 palavras que foram relacionadas, por possuírem afinidade, ou alguma relação que caracteriza o empreendedorismo feminino, conforme apresentado na tabela 1.

\subsection{OBJETIVOS E TIPOS DE PESQUISA}

Seguindo a análise de conteúdo, dos objetivos dos artigos que compõe o presente estudo, permitiu-se a identificação de dois grupos: os artigos que foram colocados no grupo I. Os quais tem por objetivo principal evidenciar aspectos pessoais das mulheres empreendedoras. Os artigos classificados no grupo II, aqueles que têm maior ênfase na gestão (administração) ou gerenciamento de atividades empreendedoras das mulheres empreendedoras.

Os 45 artigos analisados no presente estudo apresentam abordagem predominantemente qualitativa, apenas 4 artigos tiveram uma abordagem qualitativa e quantitativa e foi utilizada diversas metodologias, sendo entrevista e estudo de caso o mais frequente. $\mathrm{E}$ a característica fundamental dos artigos foi entender o universo feminino e seu modo de empreender diferente do masculino.

Quanto ao propósito dos artigos, os mesmos podem ser classificados de caráter exploratório-descritivo. Uma vez que, evidenciam, analisam ou procuram estabelecer relação entre o perfil do empreendedorismo feminino com aspectos peculiares, importância, sustentabilidade e dos negócios geridos por mulheres.

Os aspectos gerencias também são bastante evidenciados, exigindo estratégias capazes de fazer frente as dificuldades das atividades empreendedoras de maneira geral, tendo em vistas, um contexto macroeconômico muitas vezes desfavorável.

Por fim, os objetivos são diversos: expandir as discussões na literatura, sobre o papel da mulher, uma vez que os estudos no campo do empreendedorismo feminino são bastante recentes e uma área que ainda necessita ser explorada no contexto brasileiro.

\section{CONSIDERAÇÕES FINAIS}

O objetivo deste trabalho, foi analisar os artigos sobre empreendedorismo rural feminino, através de uma pesquisa bibliométrica no período de 2006 a 2019, identificando seus maiores autores, anos de publicação, assuntos e palavras-chave. Na busca por esse tema, foram realizadas pesquisas nas bases de dados Spell, SciELO e Web off Science. Verificou-se, que não foram encontrados nenhum artigo e a busca por empreendedorismo feminino e mulheres empreendedoras nos 45 artigos consultados.

Os autores que mais publicaram, na temática analisada, foram Hilka Vier Machado com 9 artigos e Rivanda Meira Texeira com 5 e o ano que mais houve publicações sobre o assunto foi 2016.

Concluiu-se que embora o tema empreendedorismo rural feminino seja muito importante para as mulher e sociedade em geral, ainda muito pouco está sendo estudado, de acordo com as buscas realizadas. Mostrando a necessidade de um direcionamento de pesquisa, para cobrir essa lacuna na temática brasileira. Já sobre o empreendedorismo feminino, este assunto está bem divulgado. Dentre os artigos selecionados notou-se que a questão de gênero, sensibilidade e outros atributos feminino são o que motivam estas mulheres empreendedoras. 


\section{REFERÊNCIAS}

[1] ALMEIDA NETO, F. S.; SIQUEIRA, E. S.; BINOTTO, E. Empreendedorismo feminino: o caso do setor salineiro Mossoró/RN. Revista de Administração da Unimep, v. 9, n. 2, p. 153-175, 2011.

[2] ALPERSTEDT, G. D.; FERREIRA, J. B.; SERAFIM, M. C. Empreendedorismo feminino: dificuldades relatadas em histórias de vida. Revista de Ciências da Administração, v. 16, n. 40, p. 221-234, 2014.

[3] AMARAL, D. G.; BRUNSTEIN, J. Aprendizagem Social para Sustentabilidade: A Experiência de um Programa Empresarial de Mulheres Empreendedoras em Situação de Pobreza. Revista de Gestão Social e Ambiental, v. 11, n. 3, p. 2-20, 2017.

[4] ARAUJO. A. Bibliometria: evolução histórica e questões atuais. Em Questão, v.12, n.1, p.11-32, 2006.

[5] ARROYO, Matilde Ruiz; FUENTES, María del Mar Fuentes; JIMENEZ, Jenny María Ruiz. Um estudo internacional sobre os fatores que explicam a expectativa de alto crescimento em novos empreendimentos: uma perspectiva de gênero. Rev. bras. gest. neg., São Paulo, v. 18, n. 60, p. 171-190, Apr. 2016. Available from <http://www.scielo.br/scielo.php?script=sci_arttext\&pid=S1806-48922016000200171\&lng=en\&nrm=iso>. access on 02 Feb. 2020. http://dx.doi.org/10.7819/rbgn.v18i60.1947.

[6] BARBOSA, F. C.; CARVALHO, C. F.; SIMÕES, G. M. M.; TEIXEIRA, R. M. Empreendedorismo feminino e estilo de gestão feminina: estudo de casos múltiplos com empreendedoras na cidade de Aracaju - Sergipe. Revista da Micro e Pequena Empresa, v. 5, n. 2, p. 124-141, 2011.

[7] BERGIS, H. S.M.; Arend, S.C.; Estivalete, V.F. Em frente ao espelho: A produção do conhecimento em cooperativas na RESR. Revista Economia Social Rural vol.52 no.1; Brasília.janeiro/março 2014.

[8] BERTOLAMI, Mariana. ARTES, Rinaldo. GONÇALVES, Pedro João. HASHIMOTO, Marcos. LAZZARINI, Sergio Giovanetti .Sobrevivência de Empresas Nascentes: Influência do Capital Humano, Social, Práticas Gerenciais e Gênero. RAC - Revista de Administração Contemporânea [en linea]. 2018, 22 (3), 311-335 [fecha a Consulta 2 de fevereiro de 2020]. ISSN: 1415-6555. Disponível em: https://www.redalyc.org/articulo.oa?id=84057857002.

[9] BRESSER PEREIRA, L. C. (1964). Origens étnicas e sociais do empresário paulista. Revista de Administração de Empresas, 4(11): 83-106.

[10] CAMARGO, R. A. M. M.; LOURENÇO, M. L.; FERREIRA, J. M. Mulheres Empreendedoras no Brasil: Quais seus Medos? . Revista Brasileira de Gestão de Negócios, v. 20, n. 2, p. 178-193, 2018.

[11] CARREIRA, S. S.; FRANZONI, A. B.; ESPER, A. J. F.; PACHECO, D. C.; GRAMKOW, F. B.; CARREIRA, M. F. Empreendedorismo feminino: um estudo fenomenológico . NAVUS - Revista de Gestão e Tecnologia, v. 5, n. 2, p. 6-13, 2015.

[12] CORTEZ, A. E. G.; FERREIRA, T. B.; FERREIRA, C. M.; ARAÚJO, A. G. Cognição e Afetividade nas Trajetórias Empreendedoras das Mulheres da Cidade do Natal - RN. Revista de Empreendedorismo e Gestão de Pequenas Empresas, v. 5, n. 2, p. 1-27, 2016.

[13] CORTEZ, Ana Eliza Galvão; DE ARAÚJO, Afrânio Galdino; PEREIRA, Fernando Antônio de Melo. A Influência dos Aspectos Cognitivos e Afetivos de Mulheres Empreendedoras nas Diferentes Fases de Desenvolvimento de um Negócio. Revista de Empreendedorismo e Gestão de Pequenas Empresas, [S.l.], v. 6, n. 2, p. 234-262, ago. 2017. ISSN 2316-2058. Disponível em: <https://www.regepe.org.br/regepe/article/view/446>. Acesso em: 02 fev. 2020. doi:http://dx.doi.org/10.14211/regepe.v6i2.446.

[14] DATA SEBRAE. Disponível em: < https://datasebrae.com.br/perfil-do-produtor-rural/\#houve> Acesso em: $15 / 06 / 2019$.

[15] DIEGUEZ-CASTRILLON, M. I. et al. Turismo rural, empreendedorismo e gênero: um estudo de caso na comunidade autônoma da Galiza. Revista de Economia e Sociologia Rural, v. 50, n. 2, p. 371-381, jun. 2012.

[16] FABRÍCIO, J. S.; MACHADO, H. V. Dificuldades para criação de negócios: um estudo com mulheres empreendedoras no setor do vestuário. Revista Gestão \& Planejamento, v. 13, n. 3, p. 515-529, 2012.

[17] FERNANDES, T. D. S.; LOPES, G. S. C.; WATANABE, M.; YAMAGUCHI, C. K.; GODOI, C. K. Dimensões do Empoderamento Feminino: Autonomia ou Dependência? . Revista Alcance, v. 23, n. 3, p. 391-413, 2016.

[18] FERREIRA, J. M.; NOGUEIRA, E. E. S. Mulheres e suas histórias: razão, sensibilidade e subjetividade no empreendedorismo feminino. Revista de Administração Contemporânea, v. 17, n. 4, p. 398-417, ago. 2013.

[19] FIGUEIREDO, Marina Dantas de et al. Empreendedorismo feminino no artesanato: uma análise crítica do caso das rendeiras dos morros da Mariana. Revista Eletrônica de Ciência Administrativa, [S.l.], v. 14, n. 2, p. 110-123, may 2015. ISSN 1677-7387. Disponível em: <http://www.periodicosibepes.org.br/index.php/recadm/article/view/2172>. Acesso em: 02 feb. 2020. doi:https://doi.org/10.21529/RECADM.2015010.

[20] FREITAS, R. K.; TEIXEIRA, R. M. Identificação de Oportunidades Empreendedoras por Mulheres. Revista Economia \& Gestão, v. 16, n. 44, p. 81-108, 2016. 
[21] GAVRAS, D. Mulheres ganham espaço no campo e ocupam 30\% dos cargos de comando. O Estado de São Paulo. Disponível em:

<https://www2.senado.leg.br/bdsf/bitstream/handle/id/542776/noticia.html?sequence=1\&isAllowed=y>. Acesso em: 20 out. 2019.

[22] GIL, Antonio C. Como Elaborar projetos de Pesquisa, 6ª ed. Altlas, São Paulo, 2017.

[23] GIMENEZ, F. A. P.; FERREIRA, J. M.; RAMOS, S. C. Empreendedorismo Feminino no Brasil: Gênese e Formação de Um Campo de Pesquisa. Revista de Empreendedorismo e Gestão de Pequenas Empresas, v. 6, n. 1, p. 40-74, 1 abr. 2017.

[24] GOMES, A. F.; SANTANA, W. G. P.; ANTONIALLI, L. M.; CORREIA, E. L. F. Trajetórias e estratégias de mulheres: um estudo conquistense. Revista de Gestão, v. 16, n. 1, art. 4, p. 69-87, 2009.

[25] GOMES, A. F.; SANTANA, W. G. P.; ARAÚJO, U. P.; MARTINS, C. M. F. Empreendedorismo feminino como sujeito de pesquisa. Revista Brasileira de Gestão de Negócios, v. 16, n. 51, p. 319-342, 2014.

[26] GOMES, A. F.; SANTOS, R. A.; SILVA, J. S. F.; SILVA, P. L. O.; BACELAR, A. S. Satisfação com o Trabalho e Dedicação ao Trabalho: Um Estudo com Empreendedoras no Interior Baiano. Perspectivas em Gestão \& Conhecimento, v. 8, n. 3, p. 67-89, 2018.

[27] GONÇALVES, G. V.; VIEIRA, S. F. A.; MELATTI, G. A.; GIMENEZ, F. A. P.; NEGREIROS, L. F. Configurações Estratégicas em MPEs: Uma Análise da Atuação de Mulheres Empreendedoras do Setor de Serviços de Londrina - PR . Revista de Administração da UFSM, v. 10, n. 4, p. 652-667, 2017.

[28] GUARIDO FILHO, E. R.; MACHADO-DA-SILVA, C. The development of institutional theory in the field of organization studies in Brazil. Cadernos EBAPE.BR, v. 8, n. 2, art. 6, p. 278-301, 2010.

[29] JESUS, M. F.; MACHADO, H. V. A trajetória de uma rede de empreendedoras e sua institucionalização. Revista Alcance, v. 18, n. 1, p. 94-107, 2011.

[30] KRUGER, C.; PINHEIRO, J. P.; MINELLO, I. F. As características comportamentais empreendedoras de David McClelland. Disponível em: <http://www.eumed.net/rev/caribe/2017/01/mcclelland.html>. Acesso em: 20 out. 2019.

[31] LOMAZINI, A.; VICENTE, R. C. C.; SANTOS, S. A. F. Tecnologia para produzir chuva: Competências de uma Mulher Empreendedora Social. Revista de Tecnologia Aplicada, v. 3, n. 3, p. 27-41, 2014.

[32] MACHADO, H. P. V.; GAZOLA, S.; FABRÍCIO, J. D. S.; ANEZ, M. E. M. Women Entrepreneurs: Reasons and Difficulties for Starting in Business. Revista de Administração Mackenzie, v. 17, n. 3, p. 15-38, 2016.

[33] MACHADO, H. P. V.; GUEDES, A.; GAZOLA, S. Determinantes e Dificuldades de Crescimento para Mulheres Empreendedoras . Revista Pensamento Contemporâneo em Administração, v. 11, n. 1, p. 85-99, 2017.

[34] MACHADO, H. V.; CRUBELlATE, J. M.; SOUZA, M. J. B. A Constituição de Associações de Mulheres de Negócios na Perspectiva da Teoria Ator Rede . Revista Economia \& Gestão, v. 18, n. 49, p. 141-157, 2018.

[35] MACHADO, H. V.; GAZOLA, S.; ANEZ, M. E. M. Criação de empresas por mulheres: um estudo com empreendedoras em Natal, Rio Grande do Norte. Revista de Administração Mackenzie, v. 14, n. 5, p. 177-200, 2013.MACHADO, H. V.; JESUS, M. F.; GREATTI, L.; LEAL, L. E. B. B. Efeitos da imersão de empreendedoras em redes: casos de Associações de Mulheres de Negócios do Estado do Paraná. GESTÃO.Org - Revista Eletrônica de Gestão Organizacional, v. 9, n. 3, p. 486-504, 2011.

[36] MAIA, T. S. T.; MAIA, F. S. O poder do batom: estratégias de empreendedoras de salão de beleza. Reuna, v. 16, n. 3, p. 45-60, 2011.

[37] MARCOVITCH, J., SANTOS, S. A., \& DUTRA, I. (1986). Criação de empresas com tecnologias avançadas: as experiências do PACTO/IA-FEA-USP. Revista de Administração, 21(2): 3-9.

[38] MELO, F. L. N. B.; SILVA, R. R.; ALMEIDA, T. N. V. Gênero e Empreendedorismo: Um Estudo Comparativo entre as Abordagens 'Causation e Effectuation' . Brazilian Business Review, v. 16, n. 3, p. 273-296, 2019.

[39] MELO, M. C. O. L.; LOPES, A. L. M.; RODRIGUES, R. B. Gênero Feminino no Empreendedorismo de Sucesso em Minas Gerais: Estudo de Casos . Revista Organizações em Contexto, v. 12, n. 23, p. 143-172, 2016.

[40] SANTOS, S. A. (1984). A criação de empresas de tecnologia avançada. Revista de Administração, 19(4): 81-83.

[41] WEBQUALIS ACESSE o LINK: http://qualis.capes.gov.br/webqualis. Acesso em 20 de outubro 2019. 


\title{
Capítulo 12
}

\section{Análise de viabilidade econômica financeira na bovinocultura de corte}

\author{
Pedro Zorzetti de Paiva \\ Elis Regina de Oliveira \\ Brasilino José Ferreira Neto \\ Ronivaldo Alcebiades Ferreira
}

Resumo: Este estudo tem por objetivo verificar a viabilidade econômico-financeira da implantação de sistema produtivo de bovinos de corte, com baixo consumo de suplemento no período de seca, em Ipameri-GO. Para análise do projeto foi considerado período de 15 anos, considerando existência da terra nua, portanto, necessários investimentos em cercas, formação de pastagens, benfeitorias e aquisição de rebanho. Criação do gado em pastejo com suplementação em até 500 gramas por animal/dia, no período de seca, para os animais em fase de terminação. Técnicas de pesquisas utilizadas: quantitativa, descritiva, bibliográfica conjugada com estudo de caso exemplo, com preços dos fatores de produção obtidos por meio de consulta a diversos agentes da cadeia produtiva no município. Foram utilizados os indicadores de análise de projeto: valor presente líquido, taxa interna de retorno, margens bruta e líquida, e ponto de equilíbrio físico. Os resultados indicaram a inviabilidade para implantação do projeto, em especial devido ao alto investimento inicial ( $\mathrm{R} \$ 4.242 .176,29)$. Principais resultados: VPL (R\$-835.806,59), TIR (1,27\%); Receita ( $\$$ \$714.321,13); Custo operacional total ( $\mathrm{R} \$ 417.690,34) ;$ Margem bruta ( $\mathrm{R} \$ 356.140,11) ;$ Margem líquida ( $\mathrm{R} \$ 296.630,79$ ); excedente de 872,33 arrobas ao ponto de equilíbrio; lucratividade (11,60\%) e rentabilidade $(2,59 \%)$.

Palavras-chave: Rentabilidade; Custos de Produção; Pecuária; Análise de Projeto. 


\section{INTRODUÇÃO}

Com grandes áreas agricultáveis, clima favorável e disponibilidade de água o Brasil apresenta viabilidade para pecuária, em especial a criação de bovinos (Capetti, 2017). De acordo com a Associação Brasileira das Indústrias Exportadoras de Carne [ABIEC] (2019) o país ocupa o segundo lugar no ranking internacional em rebanho bovino, atrás da Índia; o segundo em produção de carne, atrás dos Estados Unidos, e o primeiro lugar em exportação de carne bovina. E em 2019, o agronegócio do ramo da pecuária contribuiu com 6,8\% do PIB do país, conforme Centro de Estudos Avançados em Economia Aplicada e Confederação Nacional da Agricultura e Pecuária [CEPEA \& CNA] (2020). A cadeia produtiva da bovinocultura de corte apresenta relevância para a economia brasileira, por meio da geração de divisas, postos de trabalho e arrecadação, com tendência de crescimento em decorrência do aumento estimado para a demanda nos próximos anos (ABIEC, 2019; Capetti, 2017). Assim, a bovinocultura tem por finalidade atender questões de segurança alimentar, fortalecer a cadeia produtiva de carne, contribuindo com o saldo da balança comercial.

A maior participação do Brasil no cenário internacional decorre do aumento de produtividade, com maior investimento em tecnificação dos sistemas produtivos de bovinos de corte, que exigiu maior profissionalismo dos gestores, que precisam ter conhecimentos da interação entre nutrição, sanidade e bem-estar animal, logística e comercialização. 0 preço médio da arroba do boi gordo é orientado pelo mercado, então o maior poder de gestão sobre os resultados financeiros está relacionado ao gerenciamento dos custos, para todos os níveis de tecnificação (Capetti, 2017). Assim, a entrada de novos investidores ou a própria manutenção das atividades requer análise econômico-financeira, substanciadas por dados estimados ou registrados pelo gestor.

Assim, realizar estudos de viabilidade para implantar ou decidir pela continuidade da atividade, considerando os resultados econômico-financeiros, torna-se ferramenta importante de análise, para subsidiar o investidor na tomada de decisão se deve investir e estimar qual será a rentabilidade, possibilitando à propriedade sustentabilidade operacional e eficiência econômica (Pedrozo, 2016).

Neste contexto, essa pesquisa está norteada pela seguinte questão: Qual a viabilidade econômicofinanceira para implantação de sistema de produção de gado de corte em ciclo completo? Logo, direcionado por esse problema esta pesquisa tem por objetivo verificar a viabilidade econômicofinanceira da implantação de sistema produtivo de bovinos de corte, com baixo consumo de suplemento no período de seca, em Ipameri - Goiás. Para tanto serão identificados, estimados e classificados os gastos, receitas e investimentos inerentes a atividade, com duração do projeto prevista para 15 anos.

Ao analisar as contribuições desta pesquisa para a literatura existente, ratifica-se que ela mostra a relevância de investimentos realizados por meio estudo técnico, que propicia a mitigação dos riscos de decisões equivocadas por parte do investidor, bem como o orienta na implantação, caso seja essa a opção do mesmo. Segundo Mendes (2018), a cada ano que se passa o profissionalismo no campo é mais importante e, independente da estrutura da propriedade, deve-se ter estudo econômico-financeiro, para orientar a sustentabilidade econômica e produtiva.

No âmbito acadêmico, esse projeto se faz relevante, pois viabiliza a integração entre ambiente acadêmico e setor agropecuário, retornando aos interessados os resultados da pesquisa, como serviço de extensão universitária. Contribui, também, para fortalecer aplicações prática de elaboração de projetos, ratificando sua importância para orientar investidores.

\section{REFERENCIAL TEÓRICO}

\subsection{ANÁLISE GERENCIAL DE CUSTOS}

O arcabouço teórico desta pesquisa está baseado na Contabilidade de Custos em sua interação com a Contabilidade Gerencial, ao propiciar a classificação e métodos de custeio voltado para a análise gerencial de custo, com vista ao planejamento, controle e subsidio à tomada de decisão dos gestores (Martins, 2018). Nessa direção utilizaram-se, também, indicadores de análise econômica de projetos de investimentos (Assaf Neto \& Lima, 2017), para nortear o objetivo desta pesquisa.

A identificação dos custos tornou-se imprescindível, assim, o seu conceito e classificação são essenciais para obter os agrupamentos de natureza semelhante. Compreende-se custo como gasto necessário para produção de outros bens ou serviços, podendo ser classificados em custos fixos e custos variáveis, ou em custos diretos e custos indiretos (Martins, 2018). Este estudo está utiliza-se da classificação de custos fixos e variáveis, apropriados pelo método de custeio variável. 
Conforme Pereira (2014). Os custos fixos são os gastos que a empresa tem independentemente da quantidade de bens produzidos ou serviços prestados, como salário de empregado permanente, telefone residencial/internet, honorários de contador, entre outros. Nesse cenário, caso a empresa não tenha nenhuma atividade produtiva os custos permanecem inalterados. Enquanto os custos variáveis oscilam de acordo com a produção ou prestação de serviço, logo quanto maior a produção maior será o gasto, exemplo: insumos, mão de obra temporária, energia, água, entre outros, considerando a especificidades e características do que é produzido (Bacic, Megliorini, Oliveira \& Yomura, 2011; Martins, 2018). Ainda para esses autores, a identificação dos gastos com aquisição de bens ou serviços que não estão relacionados com os custos de produção, mas afetam as receitas, também, são relevantes e denominados de despesas.

As despesas podem ser classificadas em três grupos: despesas administrativas, despesas comerciais e despesas financeiras (Ferrari, 2012). As despesas administrativas compreendem os desembolsos realizados para o pagamento que não estão diretamente vinculadas ao processo produtivo, mas que dão suporte para sua realização, como por exemplo: telefone, honorário do contador, material de escritório, etc. Por outro lado, as despesas comerciais, abrangem os gastos envolvidos na comercialização, distribuição, embalagens, propaganda e comissão dos vendedores (Ferrari, 2012). E, ainda as despesas financeiras, que se referem aos dispêndios gerados a partir da captação de recursos de terceiros, que financiam a atividade da instituição, incluindo pagamento de juros e despesas bancárias (Ferrari, 2012).

De acordo com Martins (2018) para realizarmos uma análise gerencial de custo devemos obter informações acerca dos custos de materiais, mão-de-obra e gastos gerais de fabricação utilizados para a formação daquele bem. Após a coleta desses dados é possível extrair informações que serão utilizadas para serem aplicadas as fórmulas objetivando dar apoio a tomada de decisão. Dentre os custos que devem ser levados em consideração, o custo de capital é um deles. Ele se caracteriza por se tratar do capital investido na empresa que poderia estar aplicado em outro empreendimento. 0 custo de capital, também chamado de custo de oportunidade, é valor que se deixa de receber por optar em realizar o investimento em outro setor (Ehrlich \& Moraes, 2005).

A apropriação dos custos pode ser realizada por diversos métodos, que neste estudo optou-se em trabalhar com o custeio variável, por se tratar de uma ferramenta de gestão, visto que apresenta abordagem gerencial, subsidiando o gestor à tomada de decisão, e por não ter a finalidade de atender ao fisco (Martins, 2018). 0 método de custeio variável apropria os custos, por meio da classificação em custos fixos e variáveis (Albuquerque, Seribeli \& Soares, 2017).

Outra abordagem gerencial apresentada por Matsunaga et al. (1976), utilizada com frequência para apropriar custos no setor agropecuário, classifica-os em desembolsos monetários efetivos ao longo do ano, denominados de Custo Operacional Efetivo (COE). São exemplos de COE os desembolsos com mão de obra, alimentação do gado, medicamentos veterinários, sementes, fertilizantes, herbicidas, locação de máquinas/equipamentos, assistência técnica, combustível, energia elétrica, insumos em geral, taxas, impostos, custos financeiros do capital de giro, despesas administrativas, manutenção de máquinas e benfeitorias, etc. 0 Custo Operacional Total resulta da soma do COE com a depreciação de máquinas, implementos, benfeitorias, matrizes, reprodutores, lavouras, forrageiras perenes, e o pró-labore.

O Custo Total de Produção (CTP) é obtido pela soma do COT acrescido dos custos de oportunidades relativos aos juros que remuneram o capital investido; juros sobre o capital circulante; e sobre o uso da terra, que nesse estudo foi considerado como o preço de locação de pasto (Barros, Silva, Santo \& Barros, 2020; CNA, 2020; Nascimento et al., 2017).

Quando a receita é suficiente para cobrir o COE verifica-se sustentabilidade produtiva e econômica em curto prazo. E se suficiente para cobrir COT, então terá acumulado fundos para reposição do capital investido em bens produtivos, que foram inutilizados pelo uso ou obsolescência, além da remuneração do gestor possibilitando avaliar a sustentabilidade em longo prazo. (Barros, et al., 2020).

\subsection{ANÁLISE DE PROJETO DE INVESTIMENTO}

A análise de investimentos utiliza-se com frequência a técnica de fluxo de caixa, com a finalidade de identificar as entradas e saídas de recursos, em determinado período de tempo. Essa movimentação pode ser analisada em relação a período passado, presente e futuro, com a finalidade de tomada de decisão em relação às atividades de administração financeira, inclusive com estimativas para análise de projeto de investimento (Assaf Neto \& Lima, 2017). O fluxo de caixa, como instrumento de análise de projeto, traz valor futuro das receitas, custos e resultados para valor presente, descontos à determinada taxa de juros (Brito, 2003). 
Nesse contexto, o projeto de investimento se caracteriza por envolver um conjunto de conhecimentos, que estruturados propiciam analisar e indicar opções, que sejam mais atraentes para investimento de recursos de capital próprio ou de terceiros. Contudo, para que seja realizado um projeto consistente deve-se possuir: a conceituação do planejamento, confecção do fluxo de caixa, compreensão das demandas do setor, entendimento das exigências fiscais e regulatórias, além de analisar os custos tributários, operacionais, e despesas. A importância do projeto se dá pela possibilidade de estimar o resultado futuro dessa atividade. 0 projeto é considerado viável, a partir do momento em que se constata com clareza sobre o retorno financeiro positivo para os investidores (Abreu Filho \& Cury, 2018; Guiducci, Lima Filho \& Mota, 2012).

De acordo com Rebelatto (2004), para se iniciar um investimento é preciso escolher parâmetro para a taxa de retorno esperada pelo capital investido, denominado de Taxa Mínima de Atratividade (TMA), considerada como benchmark que indicará ao investidor se o retorno do investimento é atraente em determinado período de tempo, subsidiando na tomada de decisão. Para analisar e identificar as melhores opções de projetos de investimentos utilizam-se alguns indicadores: Valor Presente Líquido (VPL), Taxa Interna de Retorno (TIR), Margem Bruta (MB), Margem Líquida (ML); e Ponto equilíbrio (PE).

O VPL tem por objetivo trazer o fluxo de resultados futuros para valor presente, para se calcular esse índice deve-se planejar o fluxo de caixa do período de duração do projeto, considerando como taxa de juros a TMA (Guiducci, Lima Filho \& Mota, 2012). Se o VPL, descontado pela TMA, resultar em valor igual ou superior a zero sugere que o fluxo de resultados será suficiente para cobrir o valor do investimento realizado, portanto, conclui-se que o projeto é viável. Caso contrário o projeto deve ser considerado inviável, do ponto de vista econômico-financeiro (Brito, 2003). 0 VPL é mensurado pela expressão:

$$
V P L=\sum_{n=1}^{n=15} \frac{F C n}{(1+i)^{n}}-\text { investimento inicial }
$$

Sendo $\mathrm{n}=$ período de tempo (1...15 anos); $\mathrm{FC}_{\mathrm{n}}=$ fluxo dos resultados anuais $(\mathrm{n}=1 \ldots 15) ; \mathrm{i}=\mathrm{TMA}$; e investimento inicial. Enquanto a TIR, aplicada como taxa de desconto financeiro, traz valores futuros para valores presentes, e por meio de diversas interações, define-se o seu valor que torna o VPL igual a zero, possibilitando assim a comparabilidade com a Taxa Mínima de Atratividade (TMA) (Guiducci, Lima Filho \& Mota, 2012). Portanto, caso o resultado seja maior que a TMA, o projeto é considerado viável, se por sua vez a TIR for inferior a TMA, o investimento é considerado inviável e por fim, caso o resultado seja igual à TMA, a decisão fica a cargo dos investidores e diretoria (Brito, 2003). A mensuração da TIR é expressa por:

$$
0=V P L=\sum_{n=0}^{N} \frac{F C_{n}}{(1+T I R)^{n}}
$$

Sendo, $\mathrm{FC}_{0}=$ Investimento inicial; $\mathrm{FC}_{\mathrm{n}}=$ Fluxos de Caixa $\left(\mathrm{FC}_{1}, \mathrm{FC}_{2}, \mathrm{FC}_{3} \ldots \mathrm{FC}_{15}\right) ; \mathrm{n}=$ cada período; $\mathrm{N}=$ Período Total (15); VPL = Valor Presente Líquido; TIR = Taxa Interna de Retorno. A Margem Bruta é um indicador utilizado na avaliação econômica do setor agropecuário, pois evidencia se a receita bruta cobre todos os efetivos desembolsos monetários realizados pelo produtor, sugerindo se a propriedade apresenta viabilidade em curto prazo (Guiducci, Lima Filho \& Mota, 2012; Oliveira \& Couto, 2019). Caso o resultado seja positivo o produtor consegue cobrir os custos variáveis que efetivamente incorrem em desembolso. Ainda, segundo esses autores, a mensuração da margem bruta é expressa por:

$$
\mathrm{MB}=\mathrm{RB}-\mathrm{COE}
$$

Sendo, $\mathrm{MB}$ = Margem Bruta; $\mathrm{RB}=$ Receita Bruta; $\mathrm{COE}=$ Custo Operacional Efetivo. Enquanto a Margem Líquida (ML) é de extrema relevância para compreender se a atividade agropecuária apresenta capacidade de cumprir com os efetivos desembolsos monetários e, também, com as reservas necessárias para repor bens, infraestrutura, matrizes, reprodutores, etc. que são utilizados no processo produtivo, que se tornam obsoletos ou perdem a capacidade produtiva por desgastes com o uso ao longo do tempo. Assim, a ML indica a capacidade de sustentabilidade econômica em longo prazo, assegurando a reposição da infraestrutura necessária para continuar produzindo (Guiducci, Lima Filho \& Mota, 2012; Oliveira \& Couto, 2019). A ML é expressa: 


$$
\mathrm{ML}=\mathrm{RB}-\mathrm{COT}
$$

Sendo, $\mathrm{ML}=$ Margem Líquida; $\mathrm{RB}=$ Receita Bruta; COT = Custo Operacional Total. 0 Ponto de Equilíbrio (PE) físico é outro indicador importante para avaliação econômica, pois indica ao produtor o volume necessário que deve ser produzido, para que as receitas sejam equivalentes aos custos (Martins, 2018). De acordo com Lopes e Carvalho (2002) e Assaf Neto e Lima (2017) o PE expressa a quantidade de arrobas que deve ser produzida em um determinado período para empatar com os custos totais, na produção de bovinos de corte.

Para encontrar o Ponto de Equilíbrio Físico da produção de bovinos, deve-se utilizar a fórmula abaixo:

$$
\mathrm{Q}=\frac{\mathrm{CF}}{\mathrm{P}-\mathrm{CVu}}
$$

Sendo, Q = Quantidade de carne (@); CF = Custo Fixo total; $\mathrm{P}=$ Preço de mercado do produto (R\$/@); CVu = Custo Variável Unitário. Por fim, a rentabilidade mede o quanto a empresa obteve de lucro sobre o capital investido para a realização da atividade, no caso na criação de gado de corte. Para a realização do cálculo, utiliza-se o lucro operacional por se permitir comparar com outros investimentos disponíveis no mercado. 0 resultado da rentabilidade pode ser apresentado em valores (medida absoluta) ou em índice (Nogueira, 2007; Oliveira \& Couto, 2019). Para se obter a rentabilidade de uma atividade pode-se utilizar a seguinte fórmula:

$$
\text { Rentabilidade }(\%)=\frac{\mathrm{LO}}{\mathrm{CTI}} \cdot 100
$$

Sendo, $\mathrm{LO}=$ Lucro Operacional; CTI = Capital Total Investido.

De acordo com Tracy (2004) para encontrar o valor do lucro operacional, coloca-se em prática a seguinte fórmula:

$$
\mathrm{LO}=\mathrm{RT}-\mathrm{CTP}
$$

Sendo, RT = Receita Total; CTP = Custo Total de Produção.

\subsection{CARACTERÍSTICAS DA ATIVIDADE DE BOVINOCULTURA DE CORTE}

A evolução do rebanho bovino conduziu ao predomínio da raça nelore, por todas as regiões do país, principalmente em função da adaptação às condições edafoclimáticas e relação custo benefícios para produção de carne, representando $85 \%$ do rebanho brasileiro, alimentado de forma predominantemente com pastagem Brachiaria brizantha cv. Marandu, principalmente no Bioma Cerrado (Carvalho; Zen, 2017; Garcia, Carvalho, Peres, Malafia, Souza, 2017). O Centro-Oeste é a região que possui o maior rebanho de bovinos no país, com liderança do estado de Mato Grosso, seguida por Goiás, de acordo com o Instituto Brasileiro de Geografia e Estatística [IBGE] (IBGE, 2018). 0 agronegócio composto por essa atividade gerou mais de 16 bilhões, representando cerca de $10 \%$ de todo o Produto Interno Bruto do estado, conforme Instituto Mauro Borges [IMB] (IMB, 2018).

O sistema de produção de bovinos de corte pode ser especializado, conforme a fase de desenvolvimento do animal, sendo eles: cria, recria, engorda ou ciclos conjuntos (cria-recria; recria-engorda; ou cria-recriaengorda) (Cezar, Queiroz, Thiago, Cassales \& Costa, 2005). 0 estágio de cria, período que compreende rebanho de fêmeas, com possibilidade de presença de touro, com monta natural ou uso de inseminação artificial. Esse sistema, também, engloba a recria de fêmeas com a finalidade de agregar matrizes ao rebanho e assim aumentar a quantidade de animais ou efetuar vendas. Os bezerros, logo que desmamados são vendidos com cerca de 7 a 9 meses de vida. Por sua vez, as novilhas e bezerras são vendidas para reprodução, ao mesmo tempo em que os touros e matrizes são descartados em função da redução de produtividade (Cezar et al., 2005).

Por sua vez, o sistema de produção caracterizado como cria-recria se distingue do sistema de cria, em razão do macho agora também chamado de garrote, ser mantido na propriedade até alcançar seus 12 a 18 meses de vida, dependendo do nível tecnológico adotado, sendo que a partir desse momento iniciam-se as vendas dos garrotes. Nessa sequência chega-se ao que se pode considerar sistema de ciclo completo de criação de bovino de corte, que somada às fases apresentadas nos sistemas de cria-recria adiciona, 
também, a fase de desenvolvimento do garrote até à condição de boi, com o ciclo de engorda. 0 ciclo produtivo completo do boi até o abate (boi gordo) pode ser realizado no período de 15 a 42 meses de vida, dependendo do nível de tecnificação aplicado ao sistema de produção (Cezar et al., 2005).

Existem também ciclos mais curtos, que consistem na compra do bezerro ou novilha após o desmame, conduzindo-os às fases seguintes (recria e engorda). Por fim, o estágio de engorda ou também denominado de terminação, tem como característica a compra de garrote ou boi magro fornecendo os suportes necessários para transformá-lo em boi gordo e em seguida vendê-lo para o abate (Cezar et al., 2005).

Contudo, o ganho de peso varia de acordo com o sistema de produção de cada propriedade e de sua localidade, tendo em vista o tamanho continental do Brasil, que possui variações de clima e principalmente de solo de acordo com a região em que a propriedade está estabelecida. E predomina no país a pastagem, como principal fonte de alimentação para aproximadamente 95\% dos sistemas de bovinocultura. No entanto, durante os meses mais secos do ano, período de estresse hídrico na região Central do Brasil, ocorre menor oferta de pastagem, ainda com menos quantidade de nutrientes, conduzindo à perda de peso animal, portanto nesse período recomenda-se a suplementação alimentar (Gomes, Nunes, Mariano \& Medeiros, 2015).

Nesse contexto, a suplementação que exige menor investimento financeiro é o sal mineral e ureia. Ela consiste em realizar o balanceamento alimentar do gado, variando entre pasto (que pode ser de baixo valor nutricional, porém deve possuir bastante volume) e o sal mineral com ureia (Gomes et al., 2015).

Por outro lado, existe outra opção com o custo-benefício melhor, no entanto com um custo mais elevado quando comparado ao sal mineral com ureia, que é denominada de sal proteinado, nesse caso já existe ganho de peso para o animal, que variam de $200 \mathrm{~g}$ a $400 \mathrm{~g} / \mathrm{cabeça/dia,} \mathrm{essa} \mathrm{dieta} \mathrm{exige} \mathrm{uma} \mathrm{atenção} \mathrm{maior}$ por parte do criador, pois os cochos devem ser reabastecidos sempre que possível, caso esse reabastecimento não seja possível por falta de mão-de-obra ou dimensão da propriedade, recomenda-se que seja feita a reposição num período inferior a uma semana. Para a elaboração do sal proteinado são necessários os seguintes ingredientes: Milho triturado, farelo de soja, sal mineral, sal comum (cloreto de sódio), ureia e sulfato de amônio (Gomes et al, 2015).

Com o objetivo de realizar a engorda mais intensiva do gado no período de seca, existem outras opções que demandam mais investimento. 0 primeiro deles e com um custo mais baixo é o semiconfinamento, esse método é cada vez mais utilizado pelos criadores por não necessitar de uma grande infraestrutura e por gerar bons resultados (Gomes et al, 2015). Ainda, para esses autores, exige um planejamento maior por parte do proprietário por demandar uma grande quantidade de acúmulo de pasto para o gado se alimentar, uma vez que estará atravessando um período de estiagem, quando o volume de forragem é baixo, tendo isso em mente, orienta-se que sejam colocados nesse regime alimentar os animais que estejam próximos de chegarem ao ponto de abate, pela razão do pasto acumulado ser limitado. Conforme Gomes et al (2015) a alimentação pode ser composta por milho triturado, farelo de soja e folhagem (pasto).

\subsection{ESTUDOS CORRELATOS}

De acordo com o projeto realizado por Garcia et al (2020), com o objetivo de analisar três sistemas de criação de gado de corte, almejando valorizar o capital imobilizado em unidades animais e o fluxo de caixa, tomando por base os resultados dos indicadores de desempenho econômico-financeiro de cada sistema. A abordagem metodológica utilizada foi de múltiplos casos, com amostra coletada em quatro fazendas, em regiões distintas, no período de janeiro de 2012 a dezembro de 2014, classificadas em 3 sistemas: "A" com 120 hectares de pastagens e 102 animais, equivalentes à 73,1 unidade animal (UA); "B" com 102 hectares de pastagem, com 145 cabeças e 96,8 (UA) e por último sistema "C", composto por duas fazendas que juntas equivalem à 1000 hectares com 1.392 animais e 1.096 (UA). Observa-se que há evolução crescente da taxa de lotação (UA/hectare) para esses três sistemas, respectivamente na ordem que se apresenta.

Esses autores utilizaram os dados oriundos desses três sistemas como parâmetros para elaboração do projeto. Os indicadores de margem bruta, margem líquida, lucratividade e rentabilidade apresentaram resultados negativos para os sistemas " $A$ " e "B"; e positivo apenas para o " $C$ ", que trabalha com maior escala. A rentabilidade anual obtida foi de $-6,60 \%$ para o sistema "A"; $-9,43 \%$ para o sistema "B" e de 6,10 para o sistema "C" (Garcia et al, 2020). 
Por sua vez, o estudo realizado por Cruz e Guzatti (2020), na propriedade localizada no município de Denise (MT), analisou os custos despendidos no sistema de criação de bovinos com ciclo completo, com alimentação exclusivamente por meio de pastagem. Utilizaram abordagem quantitativa e qualitativa, para descrever os processos e identificar gastos e receitas, por meio de estudo de caso. Os dados foram coletados por meio de aplicação de formulário em duas fases, ambas no ano de 2016, identificando que sistema é realizado em 640 hectares de pasto, com rebanho composto por 393 animais em diversas etapas de desenvolvimento. Constatou-se que a manutenção da atividade era viável em curto e longo prazo, com índice de rentabilidade (lucro dobre receitas) de 33,26\%.

Nessa perspectiva, a pesquisa realizada por Araújo, Sabbag, Lima, Andrighetto \& Ruiz (2012), também teve por objetivo verificar a viabilidade econômica de um sistema de produção de cria-recria-engorda, de propriedade no município de Camapuã no estado do Mato Grosso do Sul, com 784,5 hectares com pastagem em torno de $57 \%$ de brachiária brizantha cv. Marandú, com rebanho de 591 animais (nelores). Trata-se de estudo de caso, com apropriação dos custos conforme metodologia elaborada por Matsunaga et al. (1976), baseada no efetivo desembolso realizado pelo produtor. Os resultados indicaram que alimentação e mão-de-obra são predominantes no custo variável que responde por $71 \%$ do custo total. Os custos com alimentação envolvem suplementação (concentrado), sal mineral e manutenção de pastagens. Para mensuração do custo de oportunidade da terra foi observado o valor de arredamento na região. 0 custo de oportunidade da terra. Os principais resultados obtidos: $13 \%$ de TIR, ponto de equilíbrio físico de 1.431@; e lucratividade (lucro operacional sobre receita total) de 20,47\%.

\section{ASPECTOS METODOLÓGICOS}

\subsection{TÉCNICAS DE PESQUISA}

Os métodos estatísticos utilizados foram pesquisa quantitativa, descritiva, com coleta de preços dos fatores de produção realizados nos estabelecimentos agropecuários localizados no município de Ipameri (G0), conjugado com parâmetros técnicos obtidos por pesquisa meio de pesquisa bibliográfica, baseados em Oliveira e Couto (2019).

Trata-se de pesquisa quantitativa, pois foi utilizado tratamento matemático para elaboração de fluxos de caixa e mensuração de indicadores de viabilidade econômico-financeiros: valor presente líquido (VPL), taxa interna de retorno (TIR), análise do ponto de equilíbrio físico (PE), margem bruta (MB), margem líquida (ML) e taxa de rentabilidade, com uso de planilha eletrônica Excel. Segundo Gil (2008), a pesquisa quantitativa tem como característica organizar os dados coletados, categorizar e tratá-los por meio de mensuração matemática e ou método estatístico, com o intuito de corroborar para uma análise objetiva e imparcial.

Utilizaram-se características de sistema de produção de baixo consumo de suplemento, baseado em Oliveira e Couto (2019), inclusive parâmetros zootécnicos, considerando uma propriedade rural com apenas a terra nua, sendo necessários investimentos em infraestrutura, aquisição de rebanho nelore e insumos, considerando as especificidades de produção de bovinos de corte, no sistema de ciclo completo (cria-recria-engorda), no município de Ipameri, Goiás. Nesse sentido, a pesquisa descritiva possibilitou identificar e caracterizar as etapas produtivas, com vista à mensuração dos custos e despesas, que nesta pesquisa foram agrupadas em valor anual (Gil, 2008).

\subsection{CARACTERIZAÇÃO DO SISTEMA DE PRODUÇÃO}

Os preços da arroba do boi, animais vivos e demais fatores de produção foram obtidos por meio de levantamento, utilizando a técnica de painel de especialistas, consultados de forma individualizada, considerando três produtores rurais, que atuam na produção de bovinos de corte, veterinários, zootecnistas, lojas agropecuárias para obtenção de informações, que possibilitaram identificar os custos inerentes à produção, bem como a comercialização e animais, conforme Guiducci et al. (2012). 0 preço da terra nua, nesse município foi obtido por média aritmética simples entre o valor informado pela Prefeitura, utilizado para efeito de cálculo de impostos e duas informações obtidas por proprietários de terra na região. Os custos foram estimados para o primeiro ano, e mantidos para os demais anos, considerando o pressuposto do tamanho constante do rebanho com 1.548 animais.

A propriedade rural (terra nua) está inserida na região sudeste de Goiás, no município de Ipameri, com área total de 435,86 hectares (ha), sendo 331,47 destinado para pastagem, 9,69 ha designados à Área de Preservação Permanente (APP), 87,17 ha atribuídos à reserva legal e as benfeitorias ocupam a área de 5 
ha. Considerou-se produção de bovino de corte, com ciclo completo, com suplementação de até 500 gramas, por animal/dia em fase de terminação (3 meses antes do abate), exclusivamente no período de seca. A tecnologia utilizada para reprodução do rebanho é com monta natural planejada para uma duração de 90 dias de monta, nos meses de novembro, dezembro e janeiro. Os investimentos necessários envolvem: cercas da propriedade e pastos; formação de pastagens (brachiária brizantha cv. Marandú); benfeitorias, aquisição de rebanho e outros. Considerou-se, também, que além de dois empregados permanentes, o sistema é gerenciado pelo produtor, com presença predominante na atividade.

Os parâmetros técnicos: coeficientes zootécnicos, investimentos em infraestrutura produtiva, área de pastagem, alimentação e sanidade animal, foram referenciados por Oliveira e Couto (2019), com dados atualizados e contextualizados com a realidade produtiva do município de Ipameri - GO.

Utilizaram-se duas situações para realização da análise de viabilidade econômico-financeira: 1) considerou-se a necessidade de realização de todos os investimentos necessários, exceto a aquisição de terra nua, para iniciar a atividade de bovinocultura de corte (análise de implantação do projeto - entrada do investidor no sistema); e 2) considerou-se que a propriedade já se encontra com os investimentos realizados, conforme sistema produtivo proposto (análise da continuidade da atividade).

\section{RESULTADOS E DISCUSSÃO}

A Tabela 1 apresenta a relação de custos fixos, variáveis, receitas, custos de oportunidade, custo total de produção e resultado. Os custos fixos equivalem a 63,69\% da soma dos custos fixos e variáveis. Em geral, sistemas com custos fixos elevados exigem maior escala de produção, para redução do custo unitário.

Tabela 1. Fluxo de caixa constante em (R\$)

\begin{tabular}{|c|c|}
\hline Descrição dos Custos & Valores (R\$) \\
\hline 1. Custo Fixo (1) & $219.874,29$ \\
\hline 1.1 Remuneração de empregados + encargos & $66.712,80$ \\
\hline 1.2. Remuneração do produtor & $72.000,00$ \\
\hline 1.3 Depreciação & $59.509,32$ \\
\hline 1.4 Energia elétrica e telefone & $6.540,00$ \\
\hline 1.5 Manutenção e reparos de instalações/benfeitorias & $11.096,45$ \\
\hline 1.6 Serviços Gerais + Contador & $2.790,00$ \\
\hline 2. Custo Variável (2) & $197.816,05$ \\
\hline 2.1. Alimentação & $169.200,07$ \\
\hline 2.1.1. Manutenção de Pastagens (calcário+adubo+herbicida) & $92.951,45$ \\
\hline 2.1.3. Suplemento Mineral & $27.997,22$ \\
\hline 2.1.5. Concentrado & $48.251,40$ \\
\hline 2.2. Vacinas & $7.204,76$ \\
\hline 2.3. Vermífugos e outros medicamentos & $7.804,76$ \\
\hline 2.4 Impostos e taxas comercialização & $2.054,62$ \\
\hline 2.5 Aquisição de touros & $11.551,83$ \\
\hline 3. Receitas & 714.321,13 \\
\hline 3.1. Venda de boi gordo & $392.087,28$ \\
\hline 3.2. Venda de Vacas & $88.217,12$ \\
\hline 3.3. Venda de Novilhas & $230.507,40$ \\
\hline 3.4. Descarte de Touro & $3.509,33$ \\
\hline 4. Custos de Oportunidade (3) & $213.740,64$ \\
\hline 4.1 Terra & $82.182,64$ \\
\hline 4.2 Capital de Giro & $4.292,72$ \\
\hline 4.3 Investimentos & $127.265,28$ \\
\hline 5. RESULTADO [Receitas - Custos $(1+2+3)]$ & $155.362,65$ \\
\hline
\end{tabular}

Fonte: Dados da pesquisa, adaptado de Oliveira e Couto (2019). Elaborado pelos autores. 
Neste estudo os gastos com remunerações e encargos dos dois empregados e do produtor resultam em 63,09\% dos custos fixos, seguido por depreciações. Esses, também, são custos mais relevantes observados por Garcia et al (2020), no sistema "A", onde o custo total com pessoal correspondeu ao principal desembolso, seguido por depreciações, ao classificar os custos em fixos e variáveis, considerando empregados permanentes nessa categoria.

Ainda, conforme Tabela 1, com relação aos custos variáveis a alimentação apresenta maior proporção (85,53\%), exigindo do produtor gerenciamento mais eficiente. Ressalta-se que no grupo de alimentação estão inseridos custos com manutenção de pastagens (calcário, fertilizante, defensivo, sementes e adubos) equivalentes a 54,94\% do custo do mesmo; suplemento mineral 16,55\%; e concentrado 28,52\%. Esses resultados estão em conformidade com as proporções de custos identificados por Araújo et al. (2012), para produção de bovinos em pastejo, com suplementação (sistema “C”).

Ressalta-se que na literatura nessa área, custos com remunerações e encargos sociais em geral configuram em custos variáveis, considerando a soma dos gastos com trabalho temporário e permanente (Carvalho \& Lopes, 2002; Cruz \& Guzatti, 2020; Gonçalves et al., 2017) ou individualizando em custo fixo (mão-de-obra permanente) e custo variável (mão-de-obra variável), conforme exposto por Noronha et al., 2001. Enquanto autores que utilizam apenas a abordagem de COE e COT não passam por essa discussão (Araújo et al., 2012; Carvalho \& Lopes, 2002).

Em virtude da manutenção realizada anualmente com pastagens (R\$92.951,45), não foi considerada exaustão da mesma, conforme Charker, (2018); contrariamente ao praticado por Cruz e Guzatti (2020), que consideraram o custo com exaustão das pastagens, dado que não ocorria a manutenção.

No que tange as receitas obtidas com vendas de animais, predominam as obtidas com boi gordo (128/ano) e novilhas (116/ano) que juntas equivalem a $87,16 \%$ do total desse grupo. Observa-se que as receitas obtidas com vendas de novilhas cobrem todos os custos fixos da propriedade. Esses resultados estão em conformidade com o obtido por Oliveira \& Couto (2019), cuja estrutura foi adaptada para esta pesquisa.

Consta na Tabela 1 o custo de oportunidade da terra, capital de giro e investimentos, considerando o valor médio da área total em Ipameri (GO), capital de giro (valores aplicados ao custeio - COE) e valor total do investimento inicial, respectivamente, sendo os três remunerados pela taxa Selic (3\% ao ano). Entre os custos de oportunidade os inerentes aos investimentos são os mais representativos (59,54\%). Observa-se, que isso decorre do elevado investimento inicial para instalação da infraestrutura necessária, partindo do pressuposto da existência apenas da terra nua. Nesta pesquisa o total de custo de oportunidade equivale a $38,24 \%$ do total dos custos $(\mathrm{R} \$ 558.958,48)$. Essa tendência é confirmada por Gonçalves et al. (2017), com custo de oportunidade (terra e investimentos) representando em torno de 54\% do CTP (Custo Total de Produção). Destaca-se que o custo da terra é mais elevado no Rio Grande do Sul, quando comparado com Goiás, para essa finalidade de bovinocultura (Brathwaite \& Santo, 2002).

Os indicadores de análise de viabilidade econômico-financeira apresentados na Tabela 2 indicam que para entrar na atividade de bovinocultura de corte em Ipameri (G0), conforme estrutura proposta e preços vigentes, o Valor Presente Líquido (VPL) do fluxo dos resultados anuais, observados no período de quinze anos, não cobrem os investimentos iniciais, considerando a taxa mínima de atratividade (Selic - 3\% ao ano). Esse resultado é corroborado com a Taxa Interna de Retorno (TIR) abaixo da taxa mínima de atratividade. Portanto, com base no VPL e na TIR deve-se rejeitar a realização desse investimento, nas condições propostas. Observa-se que se fosse desconsiderado o custo de oportunidade do investimento, os resultados conduziriam ao VPL positivo $(\mathrm{R} \$ 683.478,10)$ e a TIR $(4,41 \%)$ superior à taxa de atratividade. No entanto, o produtor não estaria exercendo a melhor opção econômico-financeira para investir o capital. No entanto, alguns investimentos são realizados desconsiderando os custos de oportunidade, sendo norteados por outros aspectos, conforme exposto por Gonçalves et al. (2017). 
Tabela 2. Indicadores de eficiência econômica (2020)

\begin{tabular}{|l|l|}
\hline \multicolumn{1}{c}{ Indicadores } & \multicolumn{1}{c|}{ Valores } \\
\hline VPL (R\$) & $-835.806,59$ \\
\hline TIR (\%) & $1,27 \%$ \\
\hline COE (R\$) & $358.181,02$ \\
\hline COT (R\$) & $417.690,34$ \\
\hline Margem Bruta (R\$) & $356.140,11$ \\
\hline Margem Líquida (R\$) & $296.630,79$ \\
\hline Taxa de Lucratividade (\%) & $11,60 \%$ \\
\hline Taxa de Rentabilidade (\%) & $2,59 \%$ \\
\hline Custo variável unitário (em @) & 47,99 \\
\hline Preço médio (@) & 181,43 \\
\hline Ponto de Equilíbrio Físico(@/ano) & $3.249,55$ \\
\hline Produção estimada de carne (@/ano) & $4.121,88$ \\
\hline
\end{tabular}

FONTE: Dados da pesquisa. Elaborado pelos autores.

Ao considerar o sistema produtivo já implantado, observados os grupos de receita bruta, o COE e o COT, apresentados na Tabela 1 e Tabela 2 respectivamente, os demais indicadores de viabilidade econômica indicam sustentabilidade em curto e em longo prazo. O COE anual, considerando todos os efetivos desembolsos monetários com os insumos representam $85,75 \%$ do COT, sendo o restante $(14,25 \%)$ destinado para formação de fundo para reposição de infraestrutura e animais quando esgotado a vida útil ou capacidade reprodutiva. Conforme Gonçalves (2017), em estudo realizado no Rio Grande do Sul a variação do COE em relação ao COT foi de aproximadamente 82,56\%, semelhante ao resultado obtido nesta pesquisa.

A margem bruta assegura a sobrevivência da atividade agropecuária em curto prazo, pois a receita cobre todos os desembolsos monetários realizados ao ano, gerando excedentes mais que suficiente para, também, formar reserva necessária para fazer reposição dos bens que foram depreciados. Assim, a margem líquida positiva indica que a capacidade produtiva pode ser financeiramente mantida em curto e longo prazo. Essa mesma estrutura produtiva, localizada na bacia do Rio Vermelho (GO) apresentou margem líquida equivalente a 90,09\% da margem bruta, conforme estudo realizado por Oliveira \& Couto (2019), portanto, maior que esta atividade localizada em Ipameri (G0) com proporção 83,29\% da margem líquida em relação à margem bruta. Para Gonçalves (2017) essa relação foi de 81,31\% do COT.

Neste contexto, o processo produtivo gera 872,33 arrobas ao ano de excedente em relação ao ponto de equilíbrio físico, indicando que o volume de carne produzida gera receita mais do que suficiente para cobrir os custos anuais. Quanto à lucratividade (11,60\%; Tabela 2), determinada pela razão entre o resultado e as receitas, constantes na Tabela 1, indica que as receitas geram retorno de aproximadamente $\mathrm{R} \$ 116,00$ de lucro, para cada mil reais com venda de animais, com todos os custos cobertos, inclusive remuneração do produtor e custos de oportunidades. Araújo et al. (2012) apurou lucratividade de 20,47\% na produção de bovinocultura ciclo completo em Camapuã (MS).

Porém, quando analisada a taxa de rentabilidade, mensurada pelo resultado em relação ao total de investimentos, observa-se que essa taxa (2,59\%) está abaixo da taxa mínima de atratividade $(3,0 \%)$, tendo em vista o elevado investimento vertido na propriedade. Enquanto estudo desenvolvido por Gonçalves et al. (2017) apresentou taxa negativa de rentabilidade de 0,19\%, em virtude de ter observado prejuízo no sistema de criação de bezerros.

\section{CONSIDERAÇÕES FINAIS}

Ao verificar a viabilidade econômico-financeira da implantação de sistema (cria-recria-engorda) de bovinos de corte, no município de Ipameri - Goiás, com duração prevista para 15 anos, considerou-se duas possibilidades a inserção de investidor nessa área, partindo do pressuposta apenas da existência da terra, sem nenhuma benfeitoria; e a manutenção da mesma, considerando que os investimentos já estivessem sido realizados, avaliando portanto sua continuidade. 
Os resultados desta pesquisa revelam não ser recomendada a inserção do investidor nessa área, com base neste projeto, considerando os indicadores VPL negativo (R $\$-835.806,59)$ e TIR $(1,27 \%)$. Os investimentos iniciais propostos se mostram elevados, pois os respectivos fluxos de resultados anuais, previstos para 15 anos, descontados à taxa mínima de atratividade, não cobrem o capital aplicado. Ressalta-se que estão inclusos todos os custos de oportunidade ( $\$ 213.740,64)$, relativos ao capital investido $(59,54 \%)$, valor da terra $(38,45 \%)$ e capital de giro $(2,01 \%)$.

O maior investimento inicial está na aquisição do rebanho $(\mathrm{R} \$ 3.195 .067,76)$, considerando plantel de 1.548 animais em diversas fases de desenvolvimento. Outra opção para se pensar em investir nesta atividade seria a composição do rebanho inicial com menor número de animais e aumentar o rebanho pelo processo natural de reprodução do mesmo.

No entanto, se for analisar a viabilidade econômico-financeira considerando o valor anual para um sistema já implantado, com vista a observar se ele apresenta sustentabilidade em curto e longo prazo verifica-se por meio dos indicadores de margem bruta $(\mathrm{R} \$ 356.140,11)$, margem líquida $(296.630,79)$, ponto de equilíbrio físico excedente (872,33 arrobas) e taxa de lucratividade (11,60\%), que o sistema apresenta viabilidade produtiva e econômica em curto e longo prazo, com condições financeiras para formação de reserva para reposição de bens que forem depreciados ao longo de sua vida útil. No entanto, a taxa de rentabilidade $(2,59 \%$ ao ano) está abaixa da taxa mínima de atratividade.

Na prática, a manutenção do sistema de produção de bovinos de corte já implantado é viável, pois consegue cobrir todos os desembolsos monetários, inclusive com remuneração do produtor, depreciação, custos de oportunidade da terra e do capital de giro, possibilitando inclusive a ampliação da sua capacidade produtiva. No entanto, a taxa de rentabilidade evidencia que essa opção não é a que maximiza o ganho financeiro do produtor, em virtude do elevado investimento inicial.

Esse estudo contribui para que investidores que desejam entrar nessa atividade, ao observar parâmetros técnicos, bem como para os que já estão atuando e precisam concentrar o foco de atenção gerencial aos principais custos, ressaltada a importância do preço da arroba do boi para obtenção dos resultados esperados.

É importante ressaltar que nessa análise foram considerados preços constantes para análise de viabilidade econômico-financeira, o que se torna uma limitação ao estudo, pois variações nos preços de venda e ou de compra de insumos afetam esses resultados. Para pesquisas futuras recomenda-se trabalhar com a inclusão de análise de risco de preços.

Ressalta-se o caráter multidisciplinar empregado na elaboração deste projeto de viabilidade econômicofinanceira, pois foram necessárias consultas a diversos profissionais para obtenção de informações técnicas com vista a estimar valores de custos e receitas, possibilitando ao contador elaborar o projeto com vista a subsidiar a tomada de decisão do investidor.

\section{REFERÊNCIAS}

[1] Associação Brasileira das Indústrias Exportadoras de Carne. (2019). Beef Report: perfil da pecuária no Brasil. Recuperado em 9 março, 2020, de https://bit.ly/2ZOI0xv.

[2] Abreu Filho, J. C. F. \& CURY, M.V.Q. (2018). Análise de projetos de investimento. Rio de Janeiro: FGV Editora.

[3] Albuquerque, G., Seribeli, G. \& Soares, M. C. P. (2017). A importância do custeio variável e custeio por absorção na gestão empresarial. ETIC 2017 - Encontro de Iniciação Científica. São Paulo. Recuperado em 10 abril, 2020, de https://bit.ly/207XW8B.

[4] Araújo, H. S., Sabbag, O. J., Lima, B. T. M., Andrighetto, C., \& Ruiz, U.S. (2012). Aspectos econômicos da produção de bovinos de corte. Pesquisa Agropecuária Tropical (Agricultural Research in the Tropics), 42 (1), 82-89. Doi: https://doi.org/10.1590/S1983-40632012000100012.

[5] Assaf Neto, A.\& Lima, F. G. Fundamentos de administração financeira (3. Ed). São Paulo: Atlas.

[6] Bacic, M. J., Megliorini, E., Oliveira, E.CM. \& Yomura, C.N. (2011). Manual de Técnicas e Práticas de Gestão Estratégia de Custos nas Pequenas e Médias Empresas. São Paulo: CRC.

[7] Barros, A., Silva, A.,Santo, P. \& Barros, O. (2020). Investimento e custo de produção de peixes nativos em sistema de policultivo e monocultivo-estudo de caso. Brazilian Journal of Development. 6, 16342-16359. Doi: $10.34117 /$ bjdv6n3-489.

[8] Brathwaite, C.W.D. \& Santo, B.R.E. (2002). Boletim do agronegócio e do desenvolvimento rural. Instituto Interamericano de Cooperação para a Agricultura. Recuperado em 17 maio, 2020, de https://bit.ly/2TeDUMz. 
[9] Brito, P. (2003). Análise e viabilidade de projetos de investimentos. São Paulo: Atlas.

[10] Capetti, E. (2017). Ministério da Agricultura quer elevar de 7\% para 10\% a participação do Brasil no agronegócio mundial. Exame, Paraná, 08 mai. Recuperado em 12 setembro, 2019, de https://bit.ly/2ZcbNAY.

[11] Carvalho, T. B. \& ZEN, S. (2017). A cadeia de Pecuária de Corte no Brasil: evolução e tendências. Revista iPecege, 3 (1), p. 85-99. Doi: https://doi.org/10.22167/r.ipecege.2017.1.85

[12] Centro de Estudos Avançados em Economia Aplicada \& Confederação Nacional da Agricultura e Pecuária. (2020). PIB do agronegócio brasileiro de 1996 a 2018. Recuperado em 26 abril, 2020, de https://bit.ly/2ZTKo6l.

[13] Cezar, I.M., Queiroz, H.P., Thiago, L.R.L.S., Cassales, F.L.G. \& Costa, F.P. (2005). Sistemas de produção de gado de corte no Brasil: uma descrição com ênfase no regime alimentar e no abate. Campo Grande, MS: Embrapa Gado de Corte.

[14] Charker, A. (2018). Depreciação rural: aprenda três formas de fazer as contas e evitar o ciclo da miséria. Jornal Giro do Boi, 8 fev. Recuperado em 17 maio, 2020, de https://bit.ly/2Ccrcs9.

[15] Cruz, A.M. \& Guzatti, N.C. (2020). Custos e lucratividade na produção de bovinos no sistema de pecuária extensiva, no município de Denise-MT. Revista UNEMAT de Contabilidade, 8 (16), 155-179. Recuperado em 06 maio, 2020, de https://bit.ly/2037AcK.

[16] Ehrlich, P. J. \& Moraes, E. A. (2005). Engenharia econômica: avaliação e seleção de projetos de investimento (6a ed.). São Paulo, SP: Atlas.

[17] Ferrari, E. L. (2012). Contabilidade Geral (12a ed.). Niterói, RJ: Impetus.

[18] Garcia, F. Z., Carvalho, C.A.B., Peres, A.A.C., Malafia, P. \& Souza, P.M. (2017). Análise dos indicadores de desempenho econômico-financeiro de sistemas de cria de gado de corte. Arq. Bras. Med. Vet. Zootec., 69 (4), 1030 1038, Doi: 10.1590/1678-4162-9194.

[19] GIL, A. C. (2008). Métodos e Técnicas de Pesquisa Social. São Paulo: Atlas.

[20] Gomes, R.C., Nunes, A.J.C., Mariano, C.T. \& Medeiros, S.R. (2015). Estratégias alimentares para gado de corte: suplementação a pasto, semiconfinamento e confinamento. Embrapa Gado de Corte-Capítulo em livro científico. Campo Grande: BDPA.

[21] Gonçalves, G.V.B., Vaz, R.Z., Vaz, F. N., Mendonça, F. S., Fontoura Júnior, J.A.S., \& Castilho, E.M. (2017). Análise de custos, receitas e ponto de equilíbrio dos sistemas de produção de bezerros no rio grande do sul. Ciência Animal Brasileira, 18, 1-17. Doi: http://dx.doi.org/10.1590/1089-6891v18e-46329.

[22] Guiducci, R.C.N., Lima Filho J.R. \& Mota M.M. (2012) Aspectos metodológicos da análise de viabilidade econômica de sistemas de produção. In: Guiducci R.C.N, Lima Filho J.R., Mota M.M. (Organizados). Viabilidade econômica de sistemas de produção agropecuários. Brasilia, Embrapa, p17-78. Recuperado em 28 junho, 2020, de https://bit.ly/38QpJEf.

[23] Instituto Brasileiro de Geografia e Estatística. (2018). Rebanho bovino predomina no Centro-Oeste e Mato Grosso lidera entre os estados. BeefPoint, 28 de set. Recuperado em 22 março, 2020, de https://bit.ly/2ZLfdtI.

[24] Instituto Mauro Borges. (2018). Produto Interno Bruto Goiano. Goiânia: IMB. Recuperado em 12 fevereiro, 2020, de https://bit.ly/2ZU2d4Y.

[25] Lopes, M. A. \& Carvalho, F.M. (2002). Custo de produção do gado de corte. Lavras: UFLA. Recuperado em 25 abril, 2020 de https://bit.ly/303XIKI.

[26] Martins, E. (2018). Contabilidade de Custos (11a ed.). São Paulo: Atlas.

[27] Matsunaga, M.; Bemelmans, P.F.; Toledo, P.E.N.; Dulley, R. D.; Okawa, H.\& Peroso, I. A. (1976). Metodologia de custo de produção utilizado pelo IEA. São Paulo: Instituto de Economia Agrícola de São Paulo, 23 (1), 123-139. Recuperado em 04 março, 2020, de https://bit.ly/305gwUx.

[28] Mendes, L. (2018). O que é administração rural e como usar em sua propriedade. AEGRO, São Paulo, 28 mar. Recuperado em 14 setembro, 2019, de https://bit.ly/2080Nyk.

[29] Nascimento, M. F.A., Taveira, R.Z., Carvalho, F. E., Amaral, A.G., Silva, R.M \& Campos, J.C.D. (2017). Viabilidade econômica de dois sistemas de produção de bovinos de corte. Revista Espacios, 38 (37), 10-25. Recuperado em 02 maio, 2020, de https://bit.ly/2Cb0MHs.

[30] Nogueira, M. P. (2007). Gestão de custos e avaliação de resultados: agricultura e pecuária. Bebedouro: Scot Consultoria. Recuperado em 08 abril, 2020, de https://bit.ly/3etQ3oG.

[31] Noronha, J. F.; Nunes, C. L. M; Geraldine, D. G.; Silva Júnior, R. P. (2001). Análise da rentabilidade da atividade leiteira no Estado de Goiás. Goiânia: Ed. UFG.

[32] Oliveira, E.R. \& Couto, V. R.M. (2019). Productive and Economic Viability of Raising Beef Cattle in the Savanna of the Brazilian State of Goiás. Revista de Economia e Sociologia Rural, 56 (3), 395-410. Doi: 
http://dx.doi.org/10.1590/1234-56781806-94790560302.

[33] Pedrozo, J. (2016). Gestão financeira é tão importante quanto a própria produção no campo. Santa Catarina: Sociedade Nacional de Agricultura, 06 dez. Recuperado em 12 setembro, 2020, de https://bit.ly/3gHMihc.

[34] Pereira, M. S. A. (2014). Gestão de Custos. São Paulo: IOB.

[35] Rebelatto, D. A. N. (2004). Projeto de Investimento. Barueri (SP): Editora Manole. 


\section{Capítulo 13}

Vantagens e desvantagens do home-office: Um estudo com profissionais da contabilidade

\section{Suzete Antonieta Lizote \\ Jessica Henequim \\ Julia Regina Martins \\ Luana Lia Schmitz. \\ Shirley Vargas Vicente}

Resumo: A necessidade de isolamento social com a chegada da pandemia do Covid-19, para diminuição das taxas de contágio do vírus, tornou o home-office uma das melhores alternativas para manutenção das atividades das organizações. 0 objetivo deste estudo foi identificar as vantagens e desvantagens do home-office na percepção dos profissionais das empresas de contabilidade. A pesquisa, de natureza básica, teve abordagem quali-quantitativa e de acordo com seus objetivos foi descritiva. A amostra esteve composta por 102 funcionários de empresas de contabilidade localizadas nos municípios da Associação dos Municípios da Região da Foz do Rio Itajaí (AMFRI). Para a análise dos dados foram aplicadas técnicas estatísticas descritivas. Quanto aos resultados, em relação as vantagens do home-office destacou-se a redução de custos, seguida pela flexibilidade de horários e menos exposição, violência/stress em deslocamentos. No que tange às desvantagens, à falta de socialização e à facilidade de distração foram as asseverações que obtiveram maiores pontuações. Portanto, estudar as vantagens e desvantagens do home-office revelam potencial de colaborar com subsídios para criação de políticas e práticas de gestão de pessoas, com foco na promoção de bem-estar no trabalho.

Palavras-Chave: Recursos Humanos. Home-office. Trabalho Flexível. 


\section{INTRODUÇ̃̃O}

Em dezembro de 2019 a Organização Mundial da Saúde (OMS) foi alertada sobre um novo vírus na cidade de Wuhan, na China que estava causando pneumonia na população. Logo após, foi declarado pela OMS que o surto deste novo vírus chamado Covid-19 consistia em uma Emergência de Saúde Pública de Importância Internacional, com isso em 11 de março de 2020 com o vírus já espalhado entre vários países a OMS caracterizou como uma pandemia (OPAS, 2020).

Dentre as ações de enfrentamento à Covid-19, o governo decretou estado de calamidade pública, com aplicação de medida de isolamento social, de fechamento de comércio e de fronteiras entre países, fato que atingiu diversas empresas, assim como as contabilidades, que serão objetos deste estudo. Dados do Cadastro Geral de Empregados e Desempregados (CAGED), divulgados pelo Conselho Federal de Contabilidade (CFC) apontaram que a área contábil esteve entre as seis profissões que mais contrataram no ano de 2018 no Brasil, com quase 17 mil vagas abertas e preenchidas no mercado de trabalho, estando ainda como a quarta carreira mais bem remunerada no País (CFC, 2019). Nesta perspectiva, Santos e Amorim (2021) afirmaram que este segmento da economia é responsável por gerar emprego, cidadania e autoestima para os cidadãos e pode ser considerado um alicerce da livre iniciativa e da democracia brasileira, pois atuam como agente de inclusão econômico-social gerando postos de trabalho e renda para os envolvidos.

Com a finalidade de reduzir o contágio e aumento do vírus, restrições objetivando o distanciamento foram impostas por autoridades mundo afora. Entre medidas, cita-se quarentena, lockdown, encerramento de atividades como comércio e escolas e a regra mais importante seria o uso obrigatório de máscara, por todos. Ressalta-se que o surto do coronavírus, transformou vidas e rotinas de toda a população. Uma das transformações que mais se utilizou foi a mudança da forma de trabalho.

Com o distanciamento social imposto e afim de evitar o aumento do vírus, as empresas, estão aderindo procedimentos de trabalho home office. Essa modalidade, segundo a Agência Brasil (2020), vem crescendo e se destacando entre os brasileiros nos últimos anos, entre 2016 e 2017 o número de adeptos aumentou 16,2\% e entre 2017 e 2018 cresceu 21,1\%. Importante ressaltar que, em 2018 os dados de uma pesquisa executada pela Sociedade Brasileira de Teletrabalho e Teleatividades (SOBRAT, 2018), apontaram que $45 \%$ de uma amostra das empresas pesquisadas já adotava regularmente o home office no referido ano e $15 \%$ planejavam implantá-lo. No entanto, argumentos sobre execução do teletrabalho ganharam diversas discussões no Brasil em tempos de combate à Covid-19 (VILARINHO, PASCHOAL, DEMO, 2021).

A percepção sobre o novo modelo de trabalho remete ao estar em casa, acompanhado da família, 24 horas por dia. Se antes da pandemia de Covid-19 esta frase era a realização de um sonho para alguns, a realidade que se presencia desde meados de março de 2020 mudou significativamente a perspectiva dos profissionais a seu respeito (SEHNEM, et al, 2021).

Diante do exposto, esta pesquisa procurou respostas ao seguinte questionamento: quais as vantagens e desvantagens do home-office na percepção dos profissionais das empresas de contabilidade? Para tanto, foi estabelecido como objetivo geral identificar as vantagens e desvantagens do home-office na percepção dos profissionais das empresas de contabilidade e como objetivos específicos: apresentar a importância dos recursos humanos nesse regime de trabalho; demonstrar as vantagens e desvantagens do home-office nos escritórios de contabilidade; e verificar a percepção dos trabalhadores contábeis em relação ao homeoffice.

O presente estudo justifica-se por buscar responder questões de como o home-office tem sido estudado no contexto brasileiro, quais pontos vêm se destacando e quais precisam ser melhor explorados. Essas respostas são essenciais na medida em que poderão auxiliar no processo de utilização e adaptação dessa modalidade de trabalho nas organizações, no caso específico deste estudo, as empresas contábeis, buscando potencializar seus resultados positivos e minimizar possíveis resistências e riscos em sua implantação. Para os acadêmicos e futuros contadores, a relevância está no fato de poder estudar e conhecer sobre a legislação e de mais aspectos que versam sobre a o home-office, ampliando o conhecimento na área pesquisada.

Trata-se de uma pesquisa básica, descritiva e com procedimentos bibliográficos e descritivos. Sua abordagem foi quali-quantitativa. Os dados foram coletados através de questionários enviados aos funcionários de escritórios de contabilidade localizados nos municípios da Associação dos Municípios da Região da Foz do Rio Itajaí (AMFRI). Os resultados mostraram que em relação as vantagens do home-office destacou-se a redução de custos, seguida pela flexibilidade de horários e menos exposição, 
violência/stress em deslocamentos. No que tange as desvantagens, a falta de socialização e a facilidade de distração foram as asseverações que obtiveram maiores pontuações.

Este artigo está organizado em cinco partes, iniciando com esta introdução; a parte dois se encontra a fundamentação teórica; em seguida teremos os aspectos metodológicos. $\mathrm{Na}$ parte quatro terão os resultados e a parte cinco as considerações finais da pesquisa, e por fim está disponibilizado as referencias bibliográficas citadas.

\section{FUNDAMENTAÇÃO TEÓRICA}

Esta seção aborda sobre a fundamentação teórica, iniciando pelos recursos humanos, o qual tem a função de adaptação frente às situações que se apresentam, enfatizando o bem-estar do colaborador e alinhando o objetivo da empresa como um todo. E, por fim, apresenta sobre as vantagens e desvantagens do homeoffice.

\subsection{RECURSOS HUMANOS}

Atualmente, os novos modelos de negócios e formas de trabalho, têm exigido das organizações um papel diferenciado em sua atuação, uma visão mais voltada para a sustentabilidade e um pensamento direcionado para a preservação e valorização dos funcionários. Neste contexto, Lesener, et al. (2021) destacam que os recursos humanos (RH) apresentam grande influência no desenvolvimento da organização para o alcance dos resultados.

Conforme Toledo (1986, p. 8), recursos humanos é “[...] um conjunto de princípios, estratégias e técnicas que visa contribuir para a atração, manutenção, motivação, treinamento e desenvolvimento do patrimônio humano de qualquer grupo organizado". Segundo o mesmo autor (1999), o RH é a área de estudos que trabalha com o elemento humano, em geral. A área que trata dos problemas e convivência do coletivo.

Nesta linha de pensamento, Tachizawa, Ferreira e Fortuna (2001, p. 127) destacam que

[...] a importância de a organização estabelecer um relacionamento adequado com seus colaboradores, em bases sólidas que só podem ser conseguidas com valores positivos, com políticas e diretrizes compatíveis com a realidade de mercado, com práticas de relações trabalhistas justas e bem aceitas e com um ambiente seguro e agradável.

Chiavenato (2003), por sua vez, define que recursos humanos é uma área que possui mais de um ramo de conhecimento que abrange conceitos de diversas áreas, pelo fato de atuar diretamente com o ser humano, que são pessoas com personalidades diferentes, onde será requisitado de qualquer profissional nesta área uma experiência e uma boa capacidade de conhecimentos em diferentes áreas. Ainda o mesmo autor, (1999, p. 6) salienta que

A área de gestão de pessoas é uma área muito sensível à mentalidade das pessoas que predomina nas organizações. É contingencial e situacional, pois depende de vários princípios, as características do contexto ambiental, o negócio da organização, a tecnologia utilizada, os processos internos e uma infinidade de outras variáveis importantes.

Em se tratando das políticas de RH, Chiavenato (2009, p. 124) coloca que "[...] se referem às maneiras pelas quais a organização pretende lidar com seus membros, e, por intermédio deles, atingir os objetivos organizacionais". Assim sendo, Sehnem, et al. (2021) evidenciam que em tempos de crise, instituições precisam mudar a administração dos recursos humanos conforme instabilidades da economia.

Ribeiro (2003, p. 124), por sua vez, salienta que "[...] que os objetivos devem caminhar junto com as mudanças, tanto de colaboradores, quanto da organização. É preciso sempre estar compatível com a realidade existente no mercado de trabalho". Chiavenato $(2004$, p. 16) complementa discorrendo que "[...] novas formas e modelos de organização serão necessários, bem como uma nova mentalidade dos administradores será imprescindível para os novos tempos".

Com base no exposto, se verifica que um dos setores mais importantes para a organização é o de recursos humanos, pois é responsável por administrar os relacionamentos internos, efetuar o recrutamento de colaboradores que tenham os mesmos objetivos que a empresa, auxiliar no desenvolvimento profissional, orientando o colaborar no cumprimento das metas estipuladas e trazer incentivos como treinamentos, 
promoções, bonificações, entre outros.

\subsection{HOME -OFFICE}

Ambiente virtual, de acordo com Silva et al. (2019) é estabelecido como área eletrônica, onde trabalhos, que habitualmente eram em papel, são virtuais. Esta temática, denominada teletrabalho, home office, entre outros termos. Seu termo designa longitude, crucial para classificação da modalidade de trabalho. Tem como propósito ajudar o trabalho com os recursos de tecnologia existentes, sem dependência de um espaço fixo e físico para sua existência.

O home-office já era uma prática realizada em diversas organizações pelo mundo e, com a pandemia do novo coronavírus (Covid-19), conforme apontam Silva, Silva e Santos (2021) passou de exceção para regra devido à necessidade de isolamento social para diminuir as taxas de contágio da doença em vários países.

Por um lado, afirmam Losekann e Mourão (2020), o home-office durante a pandemia foi uma das alternativas encontradas para a manutenção dos empregos para uma parcela da população mundial, de outra perspectiva, a sua intensificação chegou acompanhada de grandes dificuldades e desafios, tanto para as empresas quanto para os trabalhadores e familiares.

Nesse contexto, Lizote, et al. (2020) apontam que surge a necessidade de descobrir novas maneiras de exercer as tarefas, exigindo assim que os gestores pensem na modificação e adequação de estratégias, de modo a explorar meios de atender às novas exigências, assim como a adaptabilidade às novas formas autônomas de trabalho.

No Brasil, com a promulgação do Decreto-Lei №. 5.452, de 1o de maio de 1943, criou a Consolidação das Leis do Trabalho (CLT), que regulamenta as relações trabalhistas no território nacional. A CLT previu a proteção do trabalho a distância na modalidade de trabalho a domicílio, em seu Capítulo II-A, que considerou o 'teletrabalho' uma modalidade em que o funcionário trabalha "[...] preponderantemente fora das dependências do empregador, com a utilização de tecnologias de informação e de comunicação que, por sua natureza, não se constituem como trabalho externo" (BRASIL, 1943, p.).

No entanto, somente em 2011, com a alteração do art. 6 da CLT pela Lei no 12.551 de 2011 permitiramse aos trabalhadores externos os mesmos privilégios e regalias do trabalhador tradicional, no que corresponde a subordinação de procedimentos pessoais e práticos, na área de trabalho e suas formas de controle. A modificação do novo artigo $6 \stackrel{\circ}{\circ}$ da CLT deixou evidenciado que o trabalho a distância, trabalho presencial e trabalho em domicílio podem caracterizar o vínculo empregatício, desde que demonstrados todos os quesitos necessários para tal.

Conforme a Sobratt (2013), o home-office apresenta vantagens, financeiras, econômicas e sociais. É validado que existe melhora na execução de tarefas, aumento de produtividade e redução de inúmeros gastos existentes, podemos citar como, consumo de energia, água, auxílios (vale transporte e combustível). Bem como para o meio social, existe a diminuição da quantidade de pessoas nas ruas, resultando assim em menos chances de acidentes e colaboração com o ambiente. Ao colaborador, cita-se a confiança da empresa em lhe proporcionar trabalhar em casa, colocando a qualidade de vida em primeiro lugar.

Essa modalidade de trabalho, também apresenta desvantagens, que, segundo Barros (2016), seriam os prejuízos, citando o forte investimento nos equipamentos utilizados, que são necessários para o trabalho dos funcionários em suas casas, falta de controle e autonomia dos trabalhadores. 0 empregado fica sem proteção social sindical, conflitos em casa devido aos horários de trabalho, entre outros.

0 home-office, de modo geral, apresenta diversos aspectos positivos e negativos para os colaboradores e as empresas. No Quadro 01 se exibe alguns dos referidos aspectos fundamentais para o funcionário que o pratica. 
Quadro 01 - Principais aspectos positivos e negativos do home-office para o empregado

\begin{tabular}{|l|l|}
\hline \multicolumn{2}{|c|}{ Aspectos positivos } \\
$\begin{array}{l}\text { Economia nas despesas, principalmente com } \\
\text { deslocamento, alimentação e vestuário. }\end{array}$ & Isolamento social e profissional \\
\hline Flexibilidade das horas de trabalho. & Possível perda de status do trabalhador. \\
\hline $\begin{array}{l}\text { Eliminação do tempo gasto no trajeto } \\
\text { escritório/casa, casa/escritório. }\end{array}$ & Diminuição do espaço em casa. \\
\hline $\begin{array}{l}\text { Maior facilidade na combinação de } \\
\text { responsabilidades caseiras e de trabalho. }\end{array}$ & Aumento dos custos pessoais. \\
\hline Ganhos na saúde devido a menor estresse. & $\begin{array}{l}\text { Possível perda de benefícios trabalhistas (transporte } \\
\text { subsidiado, refeição no local de trabalho, entre outros). }\end{array}$ \\
\hline $\begin{array}{l}\text { Melhoria na qualidade de vida pela flexibilização do } \\
\text { horário e local de trabalho, permitindo conciliar vida } \\
\text { profissional e familiar. }\end{array}$ & $\begin{array}{l}\text { Falta de contato e interação social com os colegas de } \\
\text { trabalho. }\end{array}$ \\
\hline $\begin{array}{l}\text { Relativa autonomia, com a diminuição de uma } \\
\text { presença hierárquica constante. }\end{array}$ & $\begin{array}{l}\text { Aumento de gastos com energia e infraestrutura doméstica } \\
\text { (residência convertida em escritório). }\end{array}$ \\
\hline Aumento de motivação. & \begin{tabular}{l} 
Dificuldade de separar a vida pessoal da profissional. \\
\hline A produtividade do trabalhador aumenta.
\end{tabular} \\
\hline
\end{tabular}

Fonte: Elaborada pelas autoras com base em McNerney (1995); Andreassi (1997); Nilles (1997); Fusco, Lima e Riça (2003); Domingues e Guedert (2006) e Matlin (2008).

Os principais aspectos positivos e negativos do home-office na visão dos empregadores se apresentam no Quadro 02.

Quadro 02 - Principais aspectos positivos e negativos do home-office para o empregador

\begin{tabular}{|l|l|}
\hline \multicolumn{1}{|c|}{ Aspectos positivos } \\
$\begin{array}{l}\text { Maior atração e retenção de trabalhadores } \\
\text { qualificados. }\end{array}$ & Acesso a uma força de trabalho global. \\
\hline $\begin{array}{l}\text { Acesso a um mercado de trabalho doméstico mais } \\
\text { amplo (idosos ou deficientes). }\end{array}$ & $\begin{array}{l}\text { Demanda por novas capacidades de administração, } \\
\text { perante a incapacidade de controlar } \\
\text { permanentemente os empregados. }\end{array}$ \\
\hline Redução do espaço empregado. & Complexas questões de saúde e segurança. \\
\hline Redução do absenteísmo. & $\begin{array}{l}\text { Elevados investimentos em equipamentos de } \\
\text { informática, telefonia e tecnologia de informações. }\end{array}$ \\
\hline Rápido crescimento da empresa. & $\begin{array}{l}\text { Menor identificação do trabalhador com a empresa } \\
\text { ou, pelo menos, dificuldade na implementação e } \\
\text { extensão da cultura empresarial. }\end{array}$ \\
\hline $\begin{array}{l}\text { Diminuição de custos, transformando fixos em } \\
\text { variáveis. }\end{array}$ & $\begin{array}{l}\text { Enfraquecimento do espírito de grupo ou da cultura } \\
\text { empresarial. }\end{array}$ \\
\hline $\begin{array}{l}\text { Melhoria dos serviços ao cliente, em particular pelo } \\
\text { aumento da capacidade de resposta. }\end{array}$ & $\begin{array}{l}\text { Possível diminuição da identificação do empregado } \\
\text { com o grupo de trabalho e com a empresa. }\end{array}$ \\
\hline $\begin{array}{l}\text { Maior flexibilidade das pessoas e das estruturas de } \\
\text { trabalho. }\end{array}$ & Possível isolamento social do empregado. \\
\hline $\begin{array}{l}\text { Possibilidade de o teletrabalho ser visto como } \\
\text { benefício pelo trabalhador. }\end{array}$ & \multicolumn{2}{|l|}{\begin{tabular}{l} 
Aumento de produtividade e qualidade do trabalho. \\
\hline Fonte: Elaborada pelas autoras com base em McNerney (1995); Andreassi (1997); Nilles (1997); Fusco, Lima e Riça
\end{tabular}} \\
\hline
\end{tabular}


No quadro dos aspectos positivos e negativos do home-office para as organizações, é citada uma possível dificuldade de controle das funções dos trabalhadores por responsabilidade do empregador. Entretanto, outros estudos recomendam que, no teletrabalho, não é que o controle de funções seja inviável e sim a forma de trabalho que é diferente do tradicional, ou seja, de trabalhar presencialmente.

\section{METODOLOGIA}

A metodologia é o instrumento que favorece e desenvolve o trabalho de pesquisa, descrevendo o ambiente estudado (GIL, 2002). Desta forma, serão apresentados os métodos e os procedimentos utilizados para alcançar os objetivos desse estudo.

Esta pesquisa, em relação a sua natureza foi classificada como básica. Segundo Marconi e Lakatos (2015, p. 6), "É aquela que procura o progresso científico e a ampliação de conhecimentos teóricos, sem a preocupação de utilizá-los na prática. É a pesquisa formal, tendo em vista generalizações, princípios, leis. Tem por meta o conhecimento pelo conhecimento".

Do ponto de vista da abordagem do problema, se classificou como quali-quantitativa, ou seja, recursos estatísticos serão aplicados, abrangendo perguntas com indicadores numéricos, assim quanto mais informações e dados, melhores os resultados da pesquisa realizada, sendo esses lógicos e imparciais. De acordo com Gil (2002, p, 46), “[...] a pesquisa quantitativa considera que tudo pode ser quantificável, o que significa traduzir em números opiniões e informações para classificá-las e analisá-las".

Quanto ao objetivo, se enquadrou como um estudo de caráter descritivo. Nesse método utiliza-se do máximo de entendimento sobre o tema, visando informações completas sem estimativas e preposições. Segundo Silva e Menezes (2000, p.21)

[...] a pesquisa descritiva visa descrever as características de determinada população ou fenômeno ou o estabelecimento de relações entre variáveis. Envolve o uso de técnicas padronizadas de coleta de dados: questionário e observação sistemática. Assume, em geral, a forma de levantamento.

Em relação aos procedimentos, foi classificada como uma pesquisa de campo, sendo conduzido um levantamento com auxílio de questionário com perguntas fechadas. Leão (2017) cita que o levantamento é mais conveniente para as pesquisas que serão realizadas por meio de estudos descritivos. 0 tipo de pesquisa, também chamado de estudo de campo, tem como finalidade coletar dados, investigando seus objetivos.

O conteúdo para o estudo foi obtido através de um questionário de autopreenchimento enviado via correio eletrônico com auxílio da ferramenta do Google Docs, aos funcionários de empresas de serviços contábeis localizadas em Santa Catarina O período de coleta foi o mês de junho de 2021.

As empresas que fizeram parte da população foram aquelas localizados nos municípios da Associação dos Municípios da Região da Foz do Rio Itajaí (AMFRI) no estado de Santa Catarina. A AMFRI é formada pelos municípios de Balneário Camboriú, Balneário Piçarras, Bombinhas, Camboriú, Ilhota, Itajaí, Itapema, Luiz Alves, Navegantes, Penha e Porto Belo. Justifica-se esta escolha porque esta associação tem como objetivo promover o estabelecimento da colaboração intermunicipal e intergovernamental e de aumentar e reforçar a capacidade administrativa, econômica e social dos municípios que a integram (AMFRI, 2021).

A amostra foi composta pelos 5 maiores escritórios de cada município, levando em consideração o número de funcionários. A relação foi obtida junto ao Conselho Regional de Contabilidade de Santa Catarina (SC). O critério de seleção para o número de funcionários teve como base a determinação do Sebrae (2013): Microempresas (ME) até 9 empregados; Empresa de Pequeno Porte (EPP) de 10 a 49 empregados; Empresa de médio porte de 50 a 99 empregados e grandes empresas 100 ou mail. Para este estudo foram selecionadas as ME e EPP. A população esteve composta por 254 funcionários resultando em uma amostra de 102 respondentes, representando 40,15\% da população.

Este instrumento de coleta de dados contemplou as vantagens e desvantagens do trabalho em home-office e foi elaborado com base McNerney (1995); Andreassi (1997); Nilles (1997); Fusco, Lima e Riça (2003); Domingues e Guedert (2006) e Matlin (2008). Todas as asseverações foram respondidas com uma escala Likert de concordância de 7 pontos, partindo de discordo totalmente (1) até concordo plenamente (7).

Para análise dos dados, à cada afirmativa atribuiu-se uma pontuação, sendo a pontuação mínima de 102 e máxima de 714 pontos para cada pergunta. Este valor foi obtido pela multiplicação da menor e maior valoração possível por questão pelo total de respondentes apurados (102). Para efetuar as análises 
descritivas com base na frequência das respostas, os dados coletados foram digitados em uma planilha eletrônica Excel®.

\section{RESULTADOS E ANÁLISE DOS DADOS}

Neste tópico estão descritos e analisados os dados levantados, conforme detalhado anteriormente na metodologia.

\subsection{PERFIL DOS RESPONDENTES}

Inicialmente, para melhor compreensão do público que está sendo analisado, foi levantado o perfil dos respondentes, referentes ao sexo, faixa etária, escolaridade e tempo de serviço. Os resultados estão apresentados no Quadro 03.

Quadro 03 - Perfil dos respondentes

\begin{tabular}{|l|c|c|c|}
\hline \multirow{2}{*}{ Questionamento } & Opções e Faixas & № de Respondentes & $\%$ \\
& Feminino & 75 & $73,53 \%$ \\
\cline { 2 - 4 } & Masculino & 27 & $11,76 \%$ \\
\cline { 2 - 4 } & Até 20 anos & 12 & $47,06 \%$ \\
\cline { 2 - 4 } Faixa Etária & De 21 a 25 anos & 48 & $25,49 \%$ \\
\cline { 2 - 4 } & De 26 a 30 anos & 26 & $15,69 \%$ \\
\hline \multirow{2}{*}{\begin{tabular}{l} 
Escolaridade \\
\cline { 2 - 4 }
\end{tabular}} & De 31 a 35 anos & 16 & $0,00 \%$ \\
\hline $\begin{array}{l}\text { Quanto tempo } \\
\text { trabalha na área }\end{array}$ & Acima de 35 anos & 39 & $38,24 \%$ \\
\cline { 2 - 4 } & Especialização & 63 & $4,76 \%$ \\
\hline
\end{tabular}

Fonte: dados da pesquisa (2021).

Ao analisar o Quadro 03, se verifica que, em relação ao sexo, há predominância de mulheres, com um número de 75 respondentes, representando $73,53 \%$ da amostra. Já, a faixa etária com a maior porcentagem de respondentes, (47,06\%) é entre 21 e 25 anos, desta forma, salienta-se que o público respondente é relativamente jovem, pois não teve nenhum com idade superior a 35 anos.

Sobre a escolaridade, percebe-se que a maioria, ou seja, 63 respondentes $(61,76 \%)$ completaram ou estão completando o ensino superior, o que pode estar relacionado com a idade, por ser a maioria jovens. Por fim, no que tange ao tempo que desempenha suas atividades na área contábil, os resultados apontaram que $95,10 \%$ da amostra, isto é 97 dos respondentes atuam há mais de 6 meses.

\subsection{VANTAGENS E DESVANTAGENS DO HOME OFFICE}

Na sequência, os participantes da pesquisa foram questionados sobre as vantagens percebidas no homeoffice, conforme se evidencia os resultados no Quadro 04. 
Quadro 04 - Vantagens do home-office

\begin{tabular}{|l|c|c|c|}
\hline \multicolumn{2}{|c}{ Vantagens } & Pontuação máxima & $\begin{array}{c}\text { Pontuação } \\
\text { alcançada }\end{array}$ \\
\hline Redução de custos & 714 & 632 & $\begin{array}{c}\text { \% pontuação } \\
\text { alcançada }\end{array}$ \\
\hline Flexibilidade de horários & 714 & 615 & $88,52 \%$ \\
\hline $\begin{array}{l}\text { Menos exposição, violência/stress em } \\
\text { deslocamentos }\end{array}$ & 714 & 615 & $86,13 \%$ \\
\hline Maior praticidade no dia a dia & 714 & 608 & $85,13 \%$ \\
\hline Aumento da produtividade & 714 & 559 & $78,29 \%$ \\
\hline Melhor qualidade de vida & 714 & 539 & $75,49 \%$ \\
\hline
\end{tabular}

Fonte: Dados da pesquisa (2021).

Verificando os resultados do Quadro 04, se observa, de modo geral, alta pontuação em todas as afirmações. Nota-se que a maior vantagem da modalidade do home-office para os respondentes foi a redução de custos, tendo uma pontuação de 632 , equivalente a 88,52\%. Em seguida, consideram que há menos stress em relação ao deslocamento, muitas vezes por conta do trânsito e há uma maior praticidade no dia a dia, equivalentes a $86,13 \%$ e $85,15 \%$, respectivamente.

Esses resultados convergem com a pesquisa de Filardi, Castro e Zanini (2020) que revelou como benefício do home-office o melhor aproveitamento do tempo e a redução de custos. Zerbini e Zerbini (2020), por sua vez, destacam que, quando o trabalhador executa suas tarefas diárias de trabalho em sua própria residência, geralmente despende menos tempo para realizá-las, comparando com o tempo que levaria para desenvolvê-las na empresa. Um dos motivos é o tempo que ele economiza no deslocamento da casa para o trabalho.

Por fim, nota-se que os respondentes relataram, com pontuações um pouco menores, o aumento de produtividade e a melhora na qualidade de vida, sendo 78,29\% e 75,49\%, respectivamente. Neste sentido, esses achados corroboram com os estudos de Costa (2013) e Mello, et al. (2014) que identificaram ganhos para o home-office, como melhora qualidade de vida, autonomia e motivação.

De maneira complementar, o Quadro 05 apresenta pontuação das afirmações dos participantes da pesquisa referentes as desvantagens do home-office.

Quadro 05 - Desvantagens do home-office.

\begin{tabular}{|c|c|c|c|}
\hline & Pontuação máxima & $\begin{array}{l}\text { Pontuação } \\
\text { alcançada }\end{array}$ & $\begin{array}{l}\text { \% pontuação } \\
\text { alcançada }\end{array}$ \\
\hline Falta de socialização/isolamento & 714 & 714 & $100,00 \%$ \\
\hline Facilidade de distração & 714 & 708 & $99,16 \%$ \\
\hline $\begin{array}{l}\text { Dificuldades em estabelecer limites entre } \\
\text { casa-trabalho }\end{array}$ & 714 & 607 & $85,01 \%$ \\
\hline Aumento da carga de trabalho & 714 & 577 & $80,81 \%$ \\
\hline Menor exposição profissional & 714 & 540 & $75,63 \%$ \\
\hline Custo de manutenção do home-office & 714 & 376 & $52,66 \%$ \\
\hline
\end{tabular}

Fonte: Dados da pesquisa (2021).

Os resultados do Quadro 05, também evidenciaram pontuações altas nas asseverações. Todos os respondentes concordaram que a maior desvantagem do home-office é a falta de socialização/isolamento. Nesse sentido, Aderaldo, Aderaldo e Lima (2017), apontam que o isolamento social do indivíduo, pode fazê-lo sentir-se desmotivado, sem vontade de desenvolver suas tarefas; além disso, ele pode ter suas 
oportunidades de aprendizado reduzida. Complementam os estudos de Oliveira e Pantoja (2020), os quais mostraram que, as pessoas em trabalho remoto indicavam o isolamento social e profissional como uma dificuldade, considerando também os entraves para ascensão profissional, problemas em relação à comunicação e integração, e ainda sobrecarga de trabalho e conflitos entre vida profissional e pessoal.

Também foi relatado que existe facilidade de distração e dificuldade em estabelecer limites na hora do trabalho remoto, com 99,16\% e 85,01\% respectivamente na pesquisa. Neste sentido, Paschoal, Torres e Porto (2010) já sinalizavam que trabalhar em casa não é uma atividade caseira amadora e sim uma atividade de trabalho que exige um bom planejamento e dedicação. Esses resultados convergem daqueles encontrados por Rocha e Amador (2018) que ressaltam os riscos quanto a intensificação do trabalho, à dificuldade de separação do espaço e tempo de vida laboral, familiar e pessoal, e o risco do trabalho se estender indefinidamente por meio dos dispositivos digitais móveis.

Por fim, a menor pontuação alcançada, como desvantagem foi custo do home-office, atingindo a porcentagem de 52,66\%. Esta questão relaciona-se com os resultados das análises anteriores, haja visto que o item que teve maior pontuação na vantagem desta modalidade de trabalho foi a redução de custos.

\section{CONSIDERAÇÕES FINAIS}

O home-office, de um modo geral, influenciou diretamente processos informacionais na conjuntura da comunicação organizacional, automatizando e viabilizando a conectividade entre sistema, computadores e redes. Além disso, com uso das tecnologias da informação e comunicação possibilitou a flexibilização de tempo e do local de trabalho, ocorrendo a substituição do deslocamento do trabalhador ao posto de trabalho, na sua organização.

Este estudo buscou identificar as vantagens e desvantagens do home-office na percepção dos profissionais das empresas de contabilidade. Os resultados, em relação as vantagens do home-office destacou-se a redução de custos, seguida pela flexibilidade de horários e menos exposição, violência/stress em deslocamentos. No que tange as desvantagens, a falta de socialização e a facilidade de distração foram as asseverações que obtiveram maiores pontuações. Importante destacar os apontamentos de Pereira Júnior e Caetano (2009), que já argumentavam que a identificação das vantagens e desvantagens do home-office está intrinsicamente interligado as várias responsabilidades e os vários papéis exercidos pelo indivíduo para o equilíbrio entre vida profissional e pessoal.

A tendência atual, no contexto da globalização econômica, apresenta um grande desafio, que é fazer com que as corporações tenham capacidade de se organizar, alcancem metas cada vez mais ousadas, em um ambiente mutável, onde a organização está inserida e é obrigada a lidar com esta subjetividade intrínseca aos comportamentos humanos e seus reflexos no ambiente empresarial. Portanto, corroborando ao tema, Oliveira e Pantoja (2018) retratam a necessidade de agregar valor à organização e ao desenvolvimento das pessoas, através do emprego das inovações tecnológicas, aliadas com a capacidade humana de compatibilizar a redução de custos, o aumento da produtividade e a satisfação pessoal. Diante disso, se faz necessário avaliar o programa com cautela, adoção medidas que mitiguem os eventuais pontos negativos e contar com pessoas comprometidas com as adversidades vinculadas à importância da adoção de novas formas de gerir a entidade, a fim de torná-la mais competitiva.

Para pesquisas futuras, se sugere a ampliação do estudo junto a outras atividades, para que se tenha maior entendimento dos impactos da adoção do home-office nas empresas, em diversos contextos.

\section{REFERÊNCIAS}

[1] ADERALDO, I. L.; ADERALDO, C. V. L.; LIMA, A. C. Aspectos críticos do teletrabalho em uma companhia multinacional. Cadernos EBAPE.BR, v. 15, ed. esp., p. 511-533, 2017.

[2] AGÊNCIA BRASIL. Home office foi adotado por 46\% das empresas durante a pandemia. (2020). Disponível em: https://agenciabrasil.ebc.com.br/economia/noticia/2020-07/home-office-foi-adotado-por-46-das-empresasdurante-pandemia Acesso em: 26 jul. 2021.

[3] ANDREASSI, T. Virtualização das organizações: o caso do teletrabalho em uma consultoria. RAUSP. Revista de Administração, v. 32, p. 77-83, 1997.

[4] BARROS, A. de. Curso de direito do trabalho. 10. ed. São Paulo: LTr, 2016.

[5] BRASIL, Lei no 13.467, de 13 de julho de 2017. Altera as Consolidações das Leis do Trabalho. Disponível em: <http://www.planalto.gov.br/ccivil_03/_Ato2015-2018/2017/Lei/L13467.htm\#art1> Acesso em: 15 de maio de 
2021.

[6] BRASIL. Decreto-Lei no 5.452, de 1o de maio de 1943. Aprova a Consolidação das Leis do Trabalho. Brasília, DF: Presidência da República. Disponível em: http://www.planalto.gov.br/ccivil 03/decreto-lei/Del5452.htm Acesso em: 26 jul. 2021.

[7] BRASIL. Lei no 12.551, de 15 de dezembro de 2011. Altera o art. 6o da Consolidação das Leis do Trabalho (CLT), aprovada pelo Decreto-Lei no 5.452, de 1ํ de maio de 1943, para equiparar os efeitos jurídicos da subordinação exercida por meios telemáticos e informatizados à exercida por meios pessoais e diretos. Diário Oficial da União, Brasília, DF, 16 dez. 2011. Disponível em: www.planalto.gov.br/ccivil 03/Ato2011-2014/2011/Lei/L12551.htm. Acesso em 26 jul. 2021.

[8] CHIAVENATO, I. Administração de recursos humanos: fundamentos básicos. 5. ed. São Paulo: Atlas, 2003.

[9] CHIAVENATO, I. Introdução à teoria geral da administração. 2. ed. Rio de Janeiro: Elsevier, 2004.

[10] CHIAVENATO, I. Recursos humanos: o capital humano das organizações. 9.ed. Rio de Janeiro: Elsevier, 2009.

[11] CONSELHO FEDERAL DE CONTABILIDADE (CFC). Carreira Contábil está entre as que mais geraram empregos em 2018 e promete crescimento para 2019, 2019. Disponível em:

https://cfc.org.br/noticias/\%EF\%BB\%BFcarreira-contabil-esta-entre-as-que-mais-geraram-empregos-em-2018-epromete-crescimento-para-2019/. Acesso em: 26 jul. 2021.

[12] COSTA, I. S. A. Controle em novas formas de trabalho: teletrabalhadores e o discurso do empreendedorismo de si. Cadernos EBAPE.BR, v. 11, n. 3, p. 463-474, 2013.

[13] DOMINGUES, C., GUEDERT, L. Teletrabalho em empresas desenvolvedoras de software: Um estudo Multicaso, In: III COVINBRA 2006 - CONGRESSO BRASILEIRO DE ADMINISTRAÇÃO.

[14] FILARDI, F.; CASTRO, R. M.; ZANINI, M. T. F. Vantagens e Desvantagens do Teletrabalho na Administração Pública: Análise das Experiências do Serpro e da Receita Federal. Cadernos EBAPE.BR, v. 18, n. 1, p. 28-46, 2020.

[15] FUSCO, P. A. J., LIMA, U. F., RIÇA, R. A Tecnologia transforma o teletrabalho domiciliar em diferencial de competitividade. In: XXIII ENCONTRO NACIONAL DE ENGENHARIA DE PRODUÇÃO - Ouro Preto, MG, Brasil, 2003.

[16] GIL, A. C. Métodos e técnicas de pesquisa social. 5. ed. São Paulo: Atlas, 1999.

[17] LEÃO, L. Metodologia do estudo e pesquisa: facilitando a vida dos estudantes, professores e pesquisadores. Petrópolis, RJ, Vozes, 2017.

[18] LESENER, M.; et al. Análise da gestão de recursos humanos sustentável: um estudo em uma multinacional. Revista Gestão Organizacional, v. 14, n. 3, p. 6-30, 2021.

[19] LIZOTE, S. A. et al. Tempos de pandemia: bem-estar subjetivo e autonomia em home office. Revista Gestão Organizacional, v. 14, n. 1, p. 248-268, 2021.

[20] LOSEKANN, R. G. C. B.; MOURÃO, H. C. Desafios do teletrabalho na pandemia COVID-19: quando o home vira office. Caderno de Administração, v. 28, n. 1, p. 71-75. 2020.

[21] MARCONI, M. de A.; LAKATOS, E. M. Técnicas de pesquisa: planejamento e execução de pesquisas, amostragem e técnicas de pesquisa, elaboração, análise e interpretação de dados. 7. ed. São Paulo: Atlas, 2015.

[22] MATLIN, J. Telecommuting benefits outweigh negatives. Offshore, v. 68, n. 12, special, 2008.

[23] MCNERNEY, D. J. Telecommuting: an idea whose time has come. HR Focus; v. 72, n. 11, 1995.

[24] MELLO, A. A., et al. Teletrabalho como fator de inclusão social e digital em empresas de Call Center/Contact Center. Revista de Administração da UFSM, v. 7, n. 3, p. 373-388, 2014.

[25] NILLES, J. M. Fazendo do teletrabalho uma realidade: um guia para telegerentes e teletrabalhadores. São Paulo: Futura, 1997.

[26] OLIVEIRA, M. A. M.; PANTOJA, M. J. Desafios e perspectivas do teletrabalho nas organizações: cenário da produção nacional e agenda de pesquisa. Revista Ciências Administrativas, v. 26, n. 3, p. 1-12, 2020.

[27] OPAS. Folha informativa - Covid-19 (Doença causada pelo novo coronavirus). Disponível em: https://www.paho.org/pt/covid19. Acesso em 04 abr., 2021.

[28] PASCHOAL, T.; TORRES, C.; PORTO, J. B. Felicidade no trabalho: relações com suporte organizacional e suporte social. Revista de Administração Contemporânea, v. 14, n. 6, p. 1054-1072, 2010.

[29] PEREIRA JUNIOR, E.; CAETANO, M. E. S. Implicações do teletrabalho: um estudo sobre a percepção dos trabalhadores de uma região metropolitana. Revista Psicologia Organizações e Trabalho, v. 9, n. 2, p. 22-31, 2009.

[30] RIBEIRO, A. Teorias da administração. São Paulo: Saraiva, 2003. 
[31] ROCHA, C. T. M.; Amador, F. S. O teletrabalho: conceituação e questões para análise. Cadernos EBAPE.BR, v. 16, n. 1, p. 154-162, 2018.

[32] SANTOS, L.; AMORIM, D, A. Compras governamentais: a importância das micro e pequenas empresas para o desenvolvimento econômico local. RAGC, v. 9, n. 40, 2021.

[33] SEHNEM, S.; et al. Capacidade de adaptação das empresas em um cenário de crise. RGO - Revista Gestão Organizacional, v. 14, n. 1, p. 33-53, 2021.

[34] SILVA, E. L; MENEZES, E. M. Metodologia da pesquisa e elaboração de dissertação. Rev. Atual. 3 ed., Florianópolis: Laboratório de Ensino à Distância da UFSC, 2001.

[35] SILVA, I. C. M.; SILVA, M. H.; SANTOS, M. L. Condições de trabalho em casa durante a pandemia: uma análise do discurso do sujeito coletivo dos trabalhadores do setor de agências de turismo. Revista Brasileira de Pesquisa em Turismo, v. 15, n. 1, p. 1-18, 2021.

[36] SILVA, S. S. da., et al. A gestão estratégica na prática em um laboratório de aprendizagem vivencial online. Rev. Iberoam. Estratég. v. 18, n. 3, p. 382-396, 2019.

[37] SOBRATT - Sociedade Brasileira de Teletrabalhos e Teleatividades: Estudo de Estratégias de Gestão de Mobilidade via Teletrabalho no Estado de São Paulo. Resolução SMA no 24, 10 de abril de 2013. Disponível em: https://www.sobratt.org.br/10082013-estudo-de-estrategias-de-gestao-de-mobilidade-via-teletrabalho-eteleatividades-no-estado-de-sao-paulo-resolucao-sma-n-24-de-10-de-abril-de-2013/ Acesso em: 26 jul. 2021.

[38] SOBRATT - Sociedade Brasileira de Teletrabalhos e teleatividades: Pesquisa home office. 2018. Disponível em: http://www.sobratt.org.br/index.php/01122018-pesquisa-home-office-2018/_ Acesso em: 26 jul. 2021.

[39] TACHIZAWA, T; FERREIRA, V; FORTUNA, A. Gestão com pessoas: uma abordagem aplicada às estratégias de negócios. 2. ed. Rio de Janeiro: FGV, 2001.

[40] TOLEDO, F. Administração de pessoal, desenvolvimento de recursos humanos. 7. ed. São Paulo: Atlas, 1999.

[41] TOLEDO, F. O que são recursos humanos? São Paulo: Brasiliense, 1986.

[42] VILARINHO, K. P. B.; PASCHOAL, T.; DEMO, G. Teletrabalho na atualidade: quais são os impactos no desempenho profissional, bem-estar e contexto de trabalho? Revista do Serviço Público, v. 72, n. 1, p. 133-162, 2021.

[43] ZERBINI, T.; ZERBINI, T. Home-office: o papel da ciência, orientações médicas e cuidados com o ambiente. In: Orientações para o home office durante a pandemia da COVID-19. Artmed Editora, 2020. 


\section{APÊNDICE A - QUESTIONÁRIO}

\section{QUESTIONÁRIO}

Somos alunos do Curso de Graduação em Ciências Contábeis da Universidade do Vale do Itajaí e temos como objetivo identificar as vantagens e desvantagens do home-office com funcionários de empresas de contabilidade. A pesquisa é orientada pela Prof. Drạ. Suzete Antonieta Lizote. O instrumento está apresentado em duas sessões, sendo: dados demográficos e home-office. Sua sinceridade é muito importante. A pesquisa é de cunho científico e não lhe trará nenhum prejuízo. Os dados obtidos serão analisados de forma que mantenham em sigilo as respostas individuais, e seu nome não será solicitado no instrumento.

\section{Perfil sociodemográfico e funcional}

1. Sexo:

( ) Feminino ( ) Masculino

\section{Idade:}

\section{Estado Civil:}

( ) Casado (a) / Mora junto / União Estável

( ) Solteiro (a) / Separado (a) / Desquitado (a) / Viúvo (a)

\section{Grau de Instrução / Escolaridade:}

( ) Superior

( ) Especialização

( ) Mestrado

( ) Doutorado

\section{Há quanto tempo está trabalhando de forma remota:}

\section{Possui Filhos:}

( ) Sim

( ) Não

\section{Renda mensal}

( ) De $R \$ 1.500,00$ a $R \$ 3.500,00$ ( ) De $R \$ 3.501,00$ a $R \$ 5.000,00$

( ) $D e R \$ 5.001,00$ a $R \$ 8.000,00$ ( ) Acima de $R \$ 8.001,00$ 


\section{Home Office}

Com o distanciamento social, as empresas, como medida de prevenção e buscando evitar a propagação ainda maior do vírus, estão em sua maioria, adotando o regime de home office. Esta modalidade apresenta alguns desafios. Marque com um x o seu grau de concordância com as seguintes afirmações: A escala de respostas vai de 1 (discordo totalmente) até 7 (concordo totalmente).

\begin{tabular}{|c|c|c|c|c|c|c|c|c|}
\hline \multicolumn{9}{|c|}{ Vantagens do Home Office } \\
\hline 1 & Flexibilidade de horários & 1 & 2 & 3 & 4 & 5 & 6 & 7 \\
\hline 2 & Menos exposição violência/stress em deslocamentos & 1 & 2 & 3 & 4 & 5 & 6 & 7 \\
\hline 3 & Redução de custos & 1 & 2 & 3 & 4 & 5 & 6 & 7 \\
\hline 4 & Aumento da produtividade & 1 & 2 & 3 & 4 & 5 & 6 & 7 \\
\hline 5 & Melhor qualidade de vida & & & & & & & \\
\hline 6 & Maior praticidade no dia-a-dia & 1 & 2 & 3 & 4 & 5 & 6 & 7 \\
\hline \multicolumn{9}{|c|}{ Desvantagens do Home Office } \\
\hline 1 & Falta de socialização/Isolamento & 1 & 2 & 3 & 4 & 5 & 6 & 7 \\
\hline 2 & Facilidade de distração & 1 & 2 & 3 & 4 & 5 & 6 & 7 \\
\hline 3 & Dificuldade em estabelecer limites entre casa-trabalho & 1 & 2 & 3 & 4 & 5 & 6 & 7 \\
\hline 4 & Menor exposição profissional & 1 & 2 & 3 & 4 & 5 & 6 & 7 \\
\hline 5 & Custo de manutenção do home-office & 1 & 2 & 3 & 4 & 5 & 6 & 7 \\
\hline 6 & Aumento da carga de trabalho & 1 & 2 & 3 & 4 & 5 & 6 & 7 \\
\hline
\end{tabular}




\title{
Capítulo 14
}

Estudo comparativo dos modelos de gestão das Unidades de Atendimento Integrado (UAI) em Minas Gerais

\author{
Laura Cecília Rodrigues Reis \\ Luis de Paulo Costa \\ Carolina Gabarra Marques Gonçalves \\ Polyana Rodrigues do Carmo Silva
}

Resumo: A evidenciação de um arranjo que combina o modelo de execução direta e a adoção de parcerias público-privadas (PPP), como alternativa para a gestão das Unidades de Atendimento Integrado (UAI), tem fomentado a discussão sobre qual modelo se mostra mais adequado à consecução dessa política pública no estado de Minas Gerais. Nesse sentido, o presente estudo objetiva investigar e compreender em que medida as PPPs contribuem para a qualidade, eficiência e continuidade dos serviços, em comparação com o modelo de gestão direta das UAIs. Para a metodologia, o estudo quali-quantitativo esteve fundamentado na realização de entrevistas semiestruturadas e na análise dos indicadores que refletem a realidade dos modelos de gestão direta e de gestão por parcerias público-privadas. Os resultados da análise qualitativa evidenciaram aspectos positivos e negativos de cada um dos modelos com destaque a um melhor desempenho do modelo de gestão por PPP em especial, no que tange à infraestrutura das unidades. Já os resultados da análise quantitativa demonstraram que a gestão direta possui desempenho intermediário entre as duas concessionárias PPPs.

Palavras-Chave: Unidades de Atendimento Integrado; Atendimento ao Cidadão; Parceria Público-Privada; Estudo comparativo; Serviço Público. 


\section{INTRODUÇÃO}

O uso de parcerias público-privadas (PPPs) para implementação de políticas públicas e investimento em infraestrutura é uma das soluções para a redução do gasto público, a partir da cooperação entre autoridades públicas e empresas (Comissão das Comunidades Europeias, 2004, p.3 apud SANTOS, 2016, p. 24). No entanto, para que tais parcerias alcancem sucesso, é preciso se atentar para as questões legais e institucionais envolvidas no processo.

Atualmente, parte das Unidades de Atendimento Integrado (UAIs) são administradas diretamente por meio da empresa pública estadual Minas Gerais Administração e Serviços S.A. (MGS), enquanto outra parcela é gerida por parcerias público-privada por meio de duas concessionárias. Nesse sentido, este artigo se propõe a fazer um estudo comparativo entre os modelos de gestão. Dessa forma, será possível compreender em que medida as PPPs contribuem para a qualidade e continuidade dos serviços, a sustentabilidade econômica e a responsabilidade fiscal dos contratos.

Considerando este objetivo, será realizada análise qualitativa e quantitativa. Quanto à análise qualitativa, foram realizadas entrevistas semiestruturadas com gestores responsáveis pelo acompanhamento das unidades de modelo PPP e gestão das unidades de modelo direto. Quanto à análise quantitativa, foram utilizados indicadores de 2019 e 2020, que refletem a eficiência e a qualidade do serviço prestado. Maiores informações acerca dos aspectos metodológicos utilizados em cada uma das análises serão apresentadas pela seção "Das comparações entre os modelos".

Sendo assim, esse estudo se divide em quatro seções. A primeira delas é intitulada "As parcerias públicoprivadas" e visa introduzir o funcionamento, o surgimento das PPPs e a sua aplicação no estado de Minas Gerais. Na segunda seção, será discutido o surgimento das UAIs, além da implementação do modelo de gestão PPP. A terceira parte ilustra qual é a distribuição das unidades entre os modelos de gestão. A quarta seção é a comparação propriamente dita dos modelos apresentados na seção anterior, incluindo, conforme acima explanado, aspectos qualitativos e quantitativos. Por fim, é apresentada a conclusão deste estudo, elucidando os resultados a partir da análise realizada e da teoria discutida na primeira seção.

\section{AS PARCERIAS PÚBLICO-PRIVADAS}

A Parceria Público-Privada (PPP) despontou na Inglaterra em 1992, inserida no âmbito do programa Private Finance Iniciative (PFI), um programa do governo britânico que objetivava "encorajar a realização de obras e a gestão de serviços públicos mediante o apoio do setor privado". Ele foi definido como um conjunto de ações para aumentar a participação do capital privado na prestação de serviços públicos. A regulamentação da PPP inglesa, no entanto, ocorreu um ano depois do seu surgimento, com seu primeiro projeto implantado no final de 1994 (CARRARA, 2012). Nesse sentido, a onda de políticas privatizantes, observada à época, serviu como impulsionadora para uma participação do setor privado na realização de obras, produção de bens e prestação de serviços públicos, retrato do movimento neoliberal pertencente aos governos Thatcher no Reino Unido e Reagan nos Estados Unidos.

Ao pensar no cenário brasileiro, o termo Parceria Público-Privada representa, num sentido amplo, "os múltiplos vínculos negociais de trato continuado estabelecidos entre a Administração Pública e particulares para viabilizar o desenvolvimento, sob a responsabilidade destes, de atividades com algum coeficiente de interesse geral" (SUNDFELD, 2011, p. 24). No sentido mais restrito, por sua vez, a criação da Lei Federal no 11.079, de 30 de dezembro de 2004, instituiu normas gerais para licitação e contratação de parceria público-privada no âmbito da administração pública, antes inviabilizadas pela insuficiência normativa ou por proibição legal (SUNDFELD, 2011).

Conforme determinam MOREIRA \& CARNEIRO (1994), o modelo de parceria público privado serviria como uma forma de o Estado viabilizar a implantação de projetos, que não obtivessem recursos para a execução. E isso se daria mediante a concessão à iniciativa privada do direito de construção, de exploração e prestação do serviço por um período de tempo determinado (Build-Operate-Transfer) ou não (BuildOwn-Operate), sendo que neste último caso não haveria retorno do empreendimento ao Estado. É relevante pensar, sobretudo, nos entraves ou facilitadores que permeiam as políticas públicas sob a ótica das parcerias público-privada. JEGERI (1996) aponta que as parcerias público-privado não se limitam à contribuição para a produção de bens e prestação de serviços de melhor qualidade, mas funcionam também, por exemplo, como "um excelente instrumento gerador de empregos".

Em Minas Gerais, as PPPs foram regulamentadas em 2003, pela Lei Estadual $n^{\circ}$ 14.868/2003, demonstrando o pioneirismo do estado no âmbito desse tipo de parceria. Para Santos, o "marco legal das 
PPPs surgiu em um contexto onde o montante crescente das dívidas do Estado reduzia de maneira significativa sua capacidade de resposta ante o desafio dos investimentos públicos em infraestrutura" (2016, p. 54). Dessa forma, as diretrizes propostas pela lei são:

I - eficiência na execução das políticas públicas e no emprego dos recursos públicos;

II - qualidade e continuidade na prestação dos serviços;

III - universalização do acesso a bens e serviços essenciais;

IV - respeito aos direitos dos usuários e dos agentes privados responsáveis pelo serviço;

V - garantia de sustentabilidade econômica da atividade;

VI - estímulo à competitividade na prestação de serviços;

VII - responsabilidade fiscal na celebração e execução de contratos;

VIII - indisponibilidade das funções reguladora, controladora e fiscalizadora do Estado;

IX - publicidade e clareza na adoção de procedimentos e decisões;

$\mathrm{X}$ - remuneração do contratado vinculada ao seu desempenho;

XI - participação popular, mediante consulta pública.

(MINAS GERAIS, 2003)

A partir do arcabouço teórico discutido nesta seção, será possível compreender a aplicação do modelo PPP para a gestão das UAIs pelo governo mineiro, a ser explicada a seguir.

\section{DO SURGIMENTO DA UAI À ESCOLHA DO MODELO DE PARCERIAS PÚBLICO-PRIVADA}

As Unidades de Atendimento Integrado, objeto de pesquisa desse artigo, foram desenvolvidas a partir do antigo modelo de Postos de Serviço Integrados Urbanos (PSIU) instituído em 1996 pelo Decreto Estadual 38.303/1996. O PSIU foi o primeiro modelo de atendimento integrado em Minas Gerais e surgiu a partir de incentivos do Governo Federal para criação, em parceria com os Estados, das Centrais de Atendimento Integrado (CAIs) (ARAÚJO, 2018). As CAIs, por sua vez, foram inspiradas na tendência internacional de one-stop-shopping, que propunha a oferta de diversos serviços públicos em um único local de forma integrada e acessível para o cidadão (OLIVEIRA, 2014).

Com objetivo facilitar e desburocratizar a prestação dos serviços públicos foi identificada a necessidade de se rever o então modelo do PSIU, de modo que em 2007 o governo de Minas Gerais contratou a empresa Res Pública Consultoria em Qualidade de Serviços Públicos para realizar um diagnóstico da situação dos 26 postos do PSIU espalhadas pelo estado (NESSIM, 2015). A avaliação realizada pela consultoria destacou a falta de padronização nos atendimentos e a inexistência de indicadores básicos para medição de eficiência e qualidade do atendimento, como tempo de atendimento e tempo de espera. A conclusão da pesquisa apontou que a estrutura apresentada pelo PSIU tanto em termos de pessoal quanto de infraestrutura era inadequada, o que demandaria uma reestruturação total para implantação de um novo modelo (SOUSA et al, 2012).

Nesse contexto ocorria em Minas Gerais a Reforma Gerencial da Administração Pública denominada Choque de Gestão, que tinha como um dos projetos estruturadores o Descomplicar, que visava a desburocratização e simplificação das relações do Estado com Cidadãos, Empresas e o próprio Estado. 0 processo de reestruturação do PSIU foi parte integrante desse projeto, que propunha uma transição de forma gradativa em todos os postos do estado. Em 2008, por meio do Decreto Estadual 44.817/2008, foi criada a Diretoria Central de Gestão das UAI (DCGUAI) e mudou, oficialmente, a denominação de PSIU para UAI (NESSIM, 2015).

Para a operacionalização das UAIs foram realizados contratos entre a Secretaria de Estado de Planejamento e Gestão (SEPLAG) e a MGS, empresa pública estadual que tem como objetivo a prestação de serviços gerais de apoio administrativo. 0 modelo adotado foi considerado uma evolução em relação ao modelo de operação do PSIU, uma vez que no modelo anterior os atendimentos eram realizados por 
servidores públicos efetivos do Estado, funcionários cedidos pelas prefeituras municipais, de órgãos parceiros e aqueles terceirizados, não existindo critérios estabelecidos para o gerenciamento desse quadro (SOUSA et al, 2012).

Além do fornecimento dos recursos humanos necessários para prestar os serviços públicos ao cidadão, na época a MGS passou também a ser responsável pela adequação dos imóveis locados pelo Estado para implantação das unidades, além do fornecimento dos equipamentos, sistemas e insumos (SOUSA et al, 2012).

Apesar dos notórios avanços alcançados com essa nova forma de gestão, em comparação ao antigo PSIU, ainda existiam problemas significativos enfrentados pelo modelo UAI de gestão da MGS, que acabaram motivando o surgimento do modelo de gestão por parceria público privada. Um desses problemas era o alto custo de manutenção envolvido, uma vez que houve um aumento de $522 \%$ no custo médio de

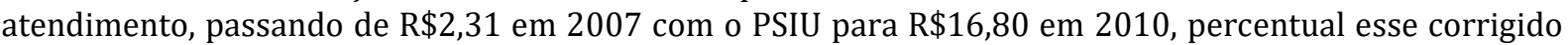
pela inflação (OLIVEIRA, 2014).

Mais especificamente no que diz respeito a gestão de pessoas, um dos problemas identificados no modelo MGS era a dificuldade na seleção de profissionais com habilidades específicas, uma vez que o meio de seleção dos colaboradores pela MGS eram "concursos padronizados" em que eram selecionados colaboradores com conhecimento generalista, com pouca ou nenhuma especialização para a atividade a ser exercida. Um segundo ponto negativo identificado na gestão de pessoas era a ausência de flexibilidade para a contratação de bons funcionários do antigo modelo PSIU. Por fim, o modelo MGS também não possibilitava a existência de um sistema de remuneração e progressão vinculados a avaliações de desempenho do funcionário, o que dificultava o incentivo para o desenvolvimento profissional dos colaboradores e a gestão para resultados (OLIVEIRA, 2014).

Outro ponto negativo identificado na gestão da MGS era a morosidade na aquisição de suprimentos e equipamentos, uma vez que, por se tratar de uma empresa pública, a MGS deve se submeter à Lei de Licitação e Contratos. Isso se aplica tanto para aquisições de materiais necessários para o funcionamento do dia a dia das UAIs quanto para outras despesas como reformas, adequações de acessibilidade, e identificação visual que também se submetem a essa legislação rígida, o que diversas vezes gerava atraso no fornecimento de vários itens (SOUSA et al, 2012).

Em 2017 a MGS deixou de ter a atribuição de realizar manutenções prediais preventivas e corretivas nos imóveis de funcionamento das UAIs. A modificação veio com o segundo Termo Aditivo do Contrato Unificado, fazendo com que a incumbência para realização desse tipo de serviço passasse a ser da própria SEPLAG. Essa mudança, apesar de trazer maior autonomia para o estado, não trouxe significativos ganhos de eficiência, uma vez que a realização desse tipo de serviço continua se submetendo à Lei de Licitação e Contratos, além das restrições orçamentárias dos cofres públicos.

Considerando todos os problemas operacionais e infraestruturais identificados no modelo UAI-MGS, realizou-se no ano de 2010 um processo licitatório que tinha como objetivo a implementação do modelo de parceria público-privada como especificado abaixo no trecho do edital em questão:

“O objetivo da presente licitação consiste na seleção de empresa ou consórcio de empresas para a implantação, gestão, operação e manutenção das UAI, nos municípios de Betim, Governador Valadares, Juiz de Fora, Montes Claros, Uberlândia e Varginha, sob a regulação e fiscalização da SEPLAG [...]" (MINAS GERAIS, 2010).

Segundo Souza et al (2012) a implementação do modelo PPP em 6 UAIs tinha como objetivo trazer para o atendimento ao cidadão em Minas Gerais pelo menos dois dos benefícios passíveis de serem obtidos pelas PPPs, sendo eles: a) melhor value for money (ganhos de eficiência e efetividade/qualidade) e; b) maior flexibilidade na gestão e execução. 0 novo modelo de gestão possibilitaria ao Estado se dedicar a ações estratégicas de gestão, e atividades colaborativas e de integração entre os parceiros, enquanto a empresa privada seria responsável por gerenciar as UAIs (OLIVEIRA, 2014).

Foi definido no edital da licitação que a remuneração da empresa ou consórcio vencedor ocorreria de acordo com o número de atendimentos e a qualidade desses. Para esse objetivo seria considerado o Valor Por Atendimento (VPA) definido durante a licitação e o COEF, índice de desempenho de qualidade que leva em consideração grau de satisfação do cidadão, senhas efetivamente atendidas e relação de senhas efetivamente atendidas em comparação com as senhas emitidas. (MINAS GERAIS, 2010). 
Em dezembro de 2010 o contrato foi assinado pelo prazo de 20 anos, podendo ser prorrogado por mais 15. A vencedora, responsável pela gestão de 6 municípios, foi a concessionária Minas Cidadão Centrais de Atendimento S.A. com o VPA de $\mathrm{R} \$ 11,60,31 \%$ menor que o preço por atendimento praticado na época pela MGS.

A partir do sucesso dessas 6 unidades que passaram a ser operadas por meio do modelo de parcerias público-privada, foi publicado em 2014 um novo edital para a concessão de outras 23 unidades por 17 anos. Essa nova licitação foi vencida pela empresa UAI Para Todos Gerenciamento de Unidades Mineira de Atendimento Integrado SPE Ltda com VPAs divididos em 3 lotes nos preços de dezembro de 2014: $\mathrm{R} \$ 12,07, \mathrm{R} \$ 11,21$ e $\mathrm{R} \$ 13,03$.

Apesar do contrato em questão ter sido assinado em dezembro de 2014, em março de 2015 houve uma suspensão administrativa para readequação quantitativa do objeto para otimização dos gastos públicos considerando a drástica alteração no contexto econômico. Essa situação se manteve até junho de 2016, data em que foi autorizada, por ato de Secretário de Estado de Planejamento e Gestão, a retomada da execução contratual, com autorização de implantação de apenas 11 unidades. Em novembro de 2016, a autorização de execução foi estendida para mais 02 unidades a serem implantadas pela Concessionária, totalizando 13. Essa alteração foi oficializada por meio do $1^{\circ}$ Termo Aditivo (2016) que modificou a previsão contratual de 23 para 13 unidades.

Com a redução do número de unidades a serem implementadas e geridas pela concessionária, houve o $2^{\circ}$ Termo Aditivo (2018) que modificou os VPAs que haviam sido previamente definidos em contrato. Os novos valores passaram a ser $\mathrm{R} \$ 11,92, \mathrm{R} \$ 10,00$ e 12,20 (preços de dezembro de 2014).

Em 2014 também houve a publicação do edital para concessão da UAI Praça Sete de Setembro (Belo Horizonte), a maior das Unidades de Atendimento Integrado em termos de número de atendimentos ${ }^{8}$. A licitação foi homologada e o contrato da Administração Pública com a Concessionária vencedora, Central de Cidadania Serviços de Atendimento ao Cidadão, foi publicado ainda em 2014. No entanto, com a troca de governo, em março de 2015 foi lavrado um ato administrativo de suspensão do referido contrato, por razões de interesse público. Dessa forma, o contrato se encontra suspenso até a data de elaboração desse artigo, sendo que essa unidade até então é administrada pela MGS.

A partir da implementação das Parcerias Público-Privada para a administração de 19 UAIs, a Coordenadoria Especial de Gestão (CEGUAI) - que posteriormente se tornaria Diretoria Central de Atendimento Presencial (DCAP) - deixou de fazer a gestão direta dessas unidades para exercer uma nova função: a fiscalização. Nesse sentido, para fiscalização das PPPs, passou a ser verificado o cumprimento das cláusulas contratuais e mantido os padrões de qualidade. 0 descumprimento do contrato pode levar a processos administrativos punitivos com a aplicação de multa, o que, até então, já ocorreu duas vezes com a concessionária Minas Cidadão.

Ademais, é importante mencionar que a pandemia de Covid-19 levou a uma grande redução do número de atendimentos em todos os modelos de gestão, como será detalhado ao longo deste estudo. Com o intuito de encontrar uma solução interessante para as concessionárias e para o poder concedente no que diz respeito a remuneração, foi firmado o $2^{\circ}$ Termo Aditivo para a Fase I e $3^{\circ}$ Termo Aditivo para a Fase II. Em ambos ficou estabelecida uma remuneração mensal fixa para os dois parceiros privados, independentemente da quantidade de atendimentos realizados durante o período em que durar a pandemia. Esses termos estabelecem também que o valor da diferença entre essa remuneração fixa e o valor correspondente à demanda real ficará como crédito ao Estado de Minas Gerais.

\section{DA ATUAL DISTRIBUIÇÃO DE UNIDADES ENTRE OS MODELOS DE GESTÃO}

A partir do histórico de concessão apresentado, o Estado de Minas Gerais conta atualmente com uma modalidade mista de gestão das Unidade de Atendimento Integrado, composta por: 12 unidades sob gestão direta do estado, por meio da empresa MGS; 6 unidades sob gestão da concessionária Minas Cidadão; 13 unidades sob gestão da concessionária UAI Para Todos. A tabela representativa desse arranjo segue logo abaixo:

\footnotetext{
${ }^{8}$ Em 2020, por exemplo, a UAI Praça Sete de Setembro foi responsável por 529.258 atendimentos, o que representa $18,4 \%$ do total de todas as 31 unidades.
} 
Tabela 1 - Distribuição atual das UAIs por município e modelo de gestão

\begin{tabular}{|l|l|l|}
\hline \multicolumn{1}{|c|}{ MGS (GESTÃO DIRETA) } & PPP MINAS CIDADÃO & \multicolumn{1}{c|}{ PPP UAI PARA TODOS } \\
\hline Araçuaí & Betim & Barreiro (BH) \\
\hline Barbacena & Governador Valadares & Contagem \\
\hline Caratinga & Juiz de Fora & Curvelo \\
\hline Coronel Fabriciano & Montes Claros & Diamantina \\
\hline Divinópolis & Uberlândia & Ipatinga \\
\hline Lavras & Varginha & Poços de Caldas \\
\hline Muriaé & & Pouso Alegre \\
\hline Paracatu & & Sete Lagoas \\
\hline Passos & & São João Del Rey \\
\hline Patos de Minas & & São Sebastião do Paraíso \\
\hline Ponte Nova & & Teófilo Otoni \\
\hline Praça Sete (BH) & & Uberaba \\
\hline & & Venda Nova (BH) \\
\hline
\end{tabular}

Fonte: Elaboração própria

\section{DAS COMPARAÇÕES ENTRE OS MODELOS}

Tendo em vista o objetivo desse estudo, a comparação entre os modelos de gestão foi realizada a partir de duas frentes: análise qualitativa e quantitativa. Foram comparados indicadores de 2019 e 2020 que refletem a realidade dos 2 modelos de gestão citados: gestão direta (empresa MGS), e gestão por parcerias público privadas (concessionárias UAI Para Todos e concessionária Minas Cidadão).

Para avaliação qualitativa foram realizadas entrevistas semiestruturadas com 2 gestores da DCAP/SEPLAG, responsável pela administração estadual de todas as UAIs. Os principais aspectos considerados para elaboração do roteiro de entrevista perpassam pelas principais vantagens apontadas anteriormente para o início do processo de concessão, são eles: flexibilidade na gestão e execução (manutenções do cotidiano, gestão de pessoas, serviços e materiais); infraestrutura das unidades; e ganhos em termos de padronização do serviço ofertado nas UAIs, de maneira semelhante ao proposto por Souza et al (2012).

No que se refere à comparação quantitativa, foram analisados índices e indicadores que refletem a eficiência e a qualidade do serviço prestado. Para análise da eficiência considerou-se o valor médio de atendimento, ou seja, o custo total para o Estado de cada um dos modelos de gestão dividido pelo número total de atendimentos. Aqui vale ressaltar que, apesar de ambos os contratos de PPP preverem um Valor por Atendimento (VPA), optou-se por fazer o cálculo explicitado acima de modo a considerar também valores pagos às concessionárias que não estariam contemplados no VPA contratual. Um exemplo disso são as indenizações que foram pagas durante o ano de 2020 devido a queda no número de atendimentos durante a pandemia de Covid-19.

Para mensuração da qualidade do atendimento, considerou-se o tempo médio de atendimento; o tempo médio de espera; o índice médio de satisfação do cidadão e o $\operatorname{COEF}^{9}$, sendo esse último o coeficiente de eficiência que considera os seguintes aspectos: grau de satisfação do cidadão, senhas efetivamente atendidas e relação de senhas efetivamente atendidas em comparação com as senhas emitidas. Com o intuito de padronizar a comparação, tornando-a mais justa, optou-se por restringir a análise apenas aos dados relativos a um único serviço. 0 serviço selecionado para análise foi o de emissão de carteira de identidade, já que é atualmente o serviço com número de atendimentos mais relevante e está presente em todas as 31 unidades.

\footnotetext{
${ }^{9}$ O COEF compõe a contraprestação mensal ao parceiro privado, a Parcela Mensal por Atendimentos. Sendo assim, é um índice importante para os consórcios, já que afeta o valor repassado a eles.
} 


\section{DO RESULTADO DA ANÁLISE QUALITATIVA}

\subsection{FLEXIBILIDADE NA GESTÃO E EXECUÇÃO}

No que se refere às diversas manutenções do cotidiano, como reparos elétricos ou hidráulicos, demandadas constantemente por todas as unidades, nota-se grande dificuldade na cobrança e fiscalização da execução desse tipo de serviço nas unidades de gestão direta.

As UAIs de gestão direta, em um momento anterior, contavam com a presença de artífices que eram responsáveis por realizar tais reparos. Entretanto, com a necessidade de corte de gastos, houve uma redução significativa no número desses profissionais, de modo que hoje são apenas dois colaboradores com essa atribuição que ficam alocados na unidade Praça Sete. Quando há a necessidade de fazer esse tipo de reparo nas unidades do interior é preciso planejar o deslocamento desses dois artífices ou contratar o serviço por meio de dispensa de licitação, o que demanda a realização de três orçamentos e torna o processo de conservação das unidades MGS moroso e burocrático.

Já no que se refere às unidades mantidas pelas concessionárias Minas Cidadão e UAI Para Todos, esse processo de reparo e manutenção é mais simples e eficiente. A partir do momento que se percebe alguma irregularidade e os pontos focais são comunicados, nota-se que os problemas são resolvidos de maneira mais rápida na comparação com as unidades mantidas pela MGS, uma vez que, por se tratar do setor privado, os procedimentos para realização de compras são muito mais simples. Assinala-se também que determinadas manutenções sequer chegam ao conhecimento do Estado, sendo resolvidas pelos próprios consórcios.

Sobre o tema da gestão de pessoas, constatou-se dificuldade de reposição de colaboradores quando necessário no caso da gestão direta. Essa complexidade advém, em partes, da dificuldade de a MGS dispor de pessoas aptas a assumirem as vagas nos municípios, de forma que isso tem se mostrado um problema ao longo dos anos.

No caso das concessionárias, é mais fácil a solução de problemas com os colaboradores das unidades. Foi relatado que, por diversas vezes, tais problemas com a gestão de pessoas nem chegam para a DECAP/SEPLAG, de forma que os próprios consórcios já fazem os procedimentos de adequação que julgam necessários.

Entretanto, um ponto negativo da Minas Cidadão e, mais ainda, da UAI Para Todos é que, diante da alta rotatividade dos colaboradores (bem menor na gestão direta), a prestação dos serviços por vezes é prejudicada, haja vista a necessidade de treinamento constante dos novos colaboradores. Uma das possíveis explicações para tamanha rotatividade no modelo de parceria público-privada são os salários pagos aos seus colaboradores que são inferiores em comparação à remuneração feita pela MGS.

\subsection{INFRAESTRUTURA DAS UNIDADES}

As unidades mantidas pelas concessionárias Minas Cidadão e UAI para Todos se destacam no que diz respeito à infraestrutura e conservação em comparação com aquelas de gestão direta pela MGS. Segundo os entrevistados, essa situação pode ser claramente observada ao se adentrar nas unidades mantidas diretamente pelo Estado e nas unidades PPPs. No primeiro grupo é comum encontrar imóveis pouco iluminados e cadeiras em mau estado de conservação, o que não acontece com tanta frequência no segundo grupo.

Dentre as possíveis explicações para essa discrepância está a burocracia imposta pelo modelo de comprar públicas exigido nas unidades de gestão direta tanto para a compra de novos materiais como longarinas, computadores, mas também para realização de manutenções prediais como pinturas, reparos elétricos, dentre outros. Além disso, o modelo de gestão direta está mais suscetível a sofrer corte de gastos, como tem ocorrido nos últimos anos, o que acaba contribuindo para que as unidades fiquem, de certa forma, sucateadas.

\subsection{PADRONIZAÇÃO DO SERVIÇO OFERTADO NAS UAIS}

Um dos aspectos de grande relevância na análise da qualidade das UAIs é a padronização dos serviços, uma vez que foi esse o grande problema que motivou a transformação do modelo do PSIU para o atual, da UAI. Como resultado da pesquisa qualitativa, não foram relatadas diferenças no que se refere à prestação 
dos serviços nos 3 grupos analisados, o que indica que a padronização do atendimento ao cidadão é igualmente preservada nos três modelos.

Essa manutenção de um padrão único para prestação do serviço se deve, principalmente, ao trabalho desenvolvido pela equipe de servidores da DCAP. A Diretoria é responsável pela interlocução com os órgãos públicos responsáveis pelos serviços prestados - como a Secretaria de Estado de Desenvolvimento Social, Departamento de Trânsito de Minas Gerais e Instituto de Identificação - e, quando há a necessidade da inserção de um novo serviço na UAI, a diretoria desenvolve fluxogramas e Procedimentos Operacionais Padrão (POPs) para adequar os serviços dos diversos órgãos ao padrão de atendimento UAI.

\subsection{DIGITALIZAÇÃo}

Além dos tópicos abordados acima, outro tema ressaltado foi a tendência de digitalização dos serviços. Nos últimos anos, notam-se grandes esforços no sentido de facilitar o acesso da população aos serviços públicos, seja tornando seu fluxo menos burocrático, exigindo menos documentos do que o necessário e até mesmo possibilitando que o cidadão tenha o serviço prestado de sua casa, sem exigir seu deslocamento até uma unidade de atendimento.

Tendo em vista que as unidades mantidas pelas concessionárias são remuneradas pela quantidade de atendimentos realizados nos guichês, pode-se supor que não há grandes movimentos no sentido de prestação de serviços nos terminais de autoatendimento ou mesmo de propor alternativas para que a população consiga acesso aos serviços de casa. Por outro lado, como as unidades mantidas pela MGS não possuem essa limitação, nota-se menos resistência na implementação de alternativas de digitalização dos serviços.

\section{DO RESULTADO DA ANÁLISE QUANTITATIVA}

A análise quantitativa foi realizada a partir da extração de diversos dados do Sistema de Gestão de Atendimento utilizado nas unidades. Os quadros foram coloridos seguindo a lógica em que a cor verde representa o melhor resultado, amarelo o resultado mediano e vermelho o pior dentre os 3 grupos que foram comparados. As informações foram consolidadas no quadro a seguir:

Quadro 1 - Consolidado dos indicadores da UAI nos anos de 2019 e $2020^{10}$

\begin{tabular}{|c|c|c|c|c|c|c|}
\hline INDICADOR & MGS (2019) & $\begin{array}{c}\text { PPP MINAS } \\
\text { CIDADÃO } \\
(2019)\end{array}$ & $\begin{array}{l}\text { PPP UAI PARA } \\
\text { TODOS (2019) }\end{array}$ & MGS (2020) & $\begin{array}{c}\text { PPP MINAS } \\
\text { CIDADÃO } \\
(2020)\end{array}$ & $\begin{array}{l}\text { PPP UAI PARA } \\
\text { TODOS (2020) }\end{array}$ \\
\hline $\begin{array}{l}\text { Total de } \\
\text { despesas (em } \\
\text { reais) }\end{array}$ & $30.137 .136,83$ & $28.368 .610,67$ & $21.586 .407,67$ & $27.813 .808,56$ & 19.688.737,91 & $24.540 .893,51$ \\
\hline $\begin{array}{l}\text { Total de } \\
\text { Atendimentos }\end{array}$ & 2.667 .230 & 1.925 .118 & 1.961 .523 & 1.001 .098 & 930.594 & 952.082 \\
\hline $\begin{array}{l}\text { Valor médio por } \\
\text { atendimento }\end{array}$ & $\mathrm{R} \$ 11,30$ & $\mathrm{R} \$ 14,74$ & $\mathrm{R} \$ 11,00$ & $\mathrm{R} \$ 27,78$ & $\mathrm{R} \$ 21,16$ & $\mathrm{R} \$ 25,78$ \\
\hline $\begin{array}{l}\text { Tempo Médio de } \\
\text { Atendimento - } \\
\text { Carteira de } \\
\text { Identidade }\end{array}$ & 00:09:16 & 00:11:01 & 00:08:45 & 00:09:38 & 00:11:02 & 00:08:21 \\
\hline $\begin{array}{l}\text { Tempo Médio de } \\
\text { Espera - Carteira } \\
\text { de Identidade }\end{array}$ & $00: 04: 57$ & 00:08:19 & $00: 04: 24$ & $00: 03: 24$ & 00:07:03 & $00: 02: 45$ \\
\hline $\begin{array}{l}\text { Índice Médio de } \\
\text { Satisfação - } \\
\text { Carteira de } \\
\text { Identidade }\end{array}$ & 99,316 & 97,434 & 99,484 & 99,535 & 97,96 & 99,766 \\
\hline $\begin{array}{l}\text { Coeficiente } \\
\text { médio de } \\
\text { Eficiência das } \\
\text { UAI (COEF) - } \\
\text { Carteira de } \\
\text { Identidade }\end{array}$ & 0,980 & 0,938 & 0,986 & 0,985 & 0,967 & 0,989 \\
\hline
\end{tabular}

${ }^{10}$ Especificamente sobre as despesas, os valores foram obtidos por meio de registros de faturamento da DCAP 


\subsection{TOTAL DE DESPESAS E TOTAL DE ATENDIMENTOS}

Como os três modelos de gestão administram um quantitativo distinto de UAIs com demandas de atendimentos também diferentes, entende-se que comparar o número absoluto de "Total de Despesas" e "Total de Atendimentos" não é a melhor forma de comparar a eficiência entre os modelos de gestão. Essas duas informações, entretanto, são fundamentais para compreender o Valor Médio por Atendimento.

Primeiramente, no que se refere ao número de atendimentos, pode-se perceber que houve uma significativa queda nos atendimentos dos três modelos de gestão na comparação entre o ano de 2019 e 2020, explicada pela pandemia de Covid-19 que começou no Brasil em março de 202011. Essa redução ocorreu da seguinte forma: 51\% em ambos consórcios e 62\% nas unidades administradas pela MGS, levando a uma redução global de 56\% no número de atendimentos feitos pelas UAIs de todo o estado.

Em relação às despesas do Estado com as UAIs, houve uma queda de $10 \%$ na comparação dos anos de 2019 e 2020, valor não proporcional a queda (de 56\%) encontrada para o número de atendimentos. Comparando os três modelos de gestão individualmente, percebe-se que na gestão direta houve uma queda de 7,7\% de despesas; na remuneração da Minas Cidadão houve uma queda de 30,6\%; e na remuneração da UAI Para Todos houve um aumento de 13,7\%.

A queda no total de despesas do modelo de gestão direta pode ser explicada pelos cortes na quantidade de colaboradores, além da redução de gastos com água e energia, relacionados com a brusca queda no número de atendimentos causada pela pandemia. Essa redução de custos, no entanto, foi muito inferior à queda do número de atendimentos, levando a crer, portanto, que custos fixos têm maior impacto nas despesas.

Já no que diz respeito aos parceiros privados, uma das explicações para a redução da remuneração ter sido menor que a redução de atendimentos é o Termo Aditivo assinado com cada um dos dois parceiros em que ficou definida uma remuneração fixa desvinculada do número real de atendimentos que passaria a ser aplicada durante a pandemia. 0 Termo aditivo com o parceiro Minas Cidadão definiu as remunerações mensais fixas no valor de $\mathrm{R} \$ 1.696 .714,39$ e de $\mathrm{R} \$ \mathrm{R} \$ 1.399 .987,26$ a partir de julho, já para a UAI Para Todos foram fixados os valores de $\mathrm{R} \$ 2.096 .484,19$ para os meses de março a junho e de $\mathrm{R} \$ 1.474 .423,97$ a partir de julho. Como já mencionado anteriormente, é importante destacar que os dois Termos Aditivos definem que a diferença entre essa remuneração fixa e a demanda real ficará como crédito do Poder Concedente a ser abatido posteriormente.

Dos três modelos de gestão, apenas a UAI Para Todos apresentou aumento na remuneração recebida $(13,7 \%)$ apesar da grande redução do número de atendimentos. Isso ocorreu devido ao pagamento de 3 Parcelas Anuais Complementares (PACs) no ano de 2020 realizadas pelo Estado de Minas Gerais, totalizando $\mathrm{R} \$ 10.017 .688,37$. Esse valor, que possui previsão contratual, visa resguardar o parceiro privado diante do atendimento de menos cidadãos do que aquele inicialmente previsto. Apesar da PAC ter sido suspensa com o Termo Aditivo mencionado anteriormente, a UAI Para Todos possuía parcelas relativas a meses do final de 2019 e começo de 2020 - que já tinham atingido seu período aquisitivo antes da assinatura do aditamento, portanto foi mantido o seu direito de recebê-las.

\subsection{VALOR MÉDIO POR ATENDIMENTO DAS UNIDADES}

A comparação entre as despesas por atendimento realizado nas unidades é uma medida de eficiência, conforme definição de Gomes: "emprego de recursos de forma a obter a melhor relação custo-benefício entre os objetivos estabelecidos e os recursos utilizados" (GOMES, 2009, p. 19). Nesse sentido, o Estado de Minas Gerais emprega recursos financeiros com o objetivo de realizar atendimentos aos cidadãos: aquele modelo que atende mais pessoas com menos recursos pode ser considerado mais eficiente em termos de custos.

Sobre este tópico, é interessante notar que houve uma mudança na distribuição das unidades entre os anos de 2019 e 2020. No primeiro ano, a concessionária Minas Cidadão tinha o maior Valor Médio por Atendimento ( $R \$ 14,74$ ) e passou a ter o menor valor ( $R \$ 21,16$ ) em 2020. As unidades geridas diretamente, pela MGS, apresentavam tal valor intermediário $(\mathrm{R} \$ 11,30)$ e passaram a ter o maior valor

11 Diante das recomendações de órgãos de saúde sobre a necessidade do distanciamento social como medida de prevenção à contaminação pelo vírus, houve diretriz da DCAP para redução dos quantitativos de atendimentos. 
(R\$ 27,78) em 2020. Já a concessionária UAI Para Todos possuía o menor valor (R\$ 11,00) em 2019 e passou a um valor intermediário em 2020 (R\$25,78).

Nota-se que houve aumento no Valor Médio por Atendimento na comparação entre os 2 anos, em todos os 3 grupos analisados. Entretanto, foram variações diferentes: a menor variação entre os grupos foi da concessionária Minas Cidadão (44\%); a concessionária UAI Para Todos teve seu valor por atendimento aumentado em 134\%; por fim, a maior variação foi das unidades de gestão direta, tendo aumentado em $146 \%$.

\section{3 ÍNDICES DE SATISFAÇÃO DOS USUÁRIOS}

Esse índice é calculado a partir das avaliações que os cidadãos fazem após os atendimentos nos terminais de autoavaliação, e escolhem entre as opções "Ruim", "Regular", "Bom" e "Ótimo". O cálculo refere-se à relação entre a quantidade de avaliações boas e ótimas pela quantidade de avaliações ruins e regulares; dessa forma, quanto mais próximo de 100, melhor é o indicador, refletindo que os atendimentos estão sendo bem avaliados.

Com relação a esse índice, não foram encontradas grandes variações entre os anos de 2019 e 2020, apesar da variação expressiva no número de atendimentos nas unidades. Percebe-se que a concessionária UAI Para Todos auferiu a melhor nota nesse quesito na comparação com MGS e com Minas Cidadão nos dois anos analisados.

Percebe-se também que há pouca variação entre os 3 grupos, sendo que esse índice variou somente no intervalo entre 97,43 e 99,76. Esses resultados demonstram que as UAIs, no geral, possuem qualidade elevada na oferta dos serviços, de modo que a percepção da qualidade do serviço por parte do cidadão não sofre grandes variações a depender do modelo de gestão.

\subsection{TEMPO MÉDIO DE ATENDIMENTO (TEMPO TOTAL DECORRIDO ENTRE O INÍCIO E A FINALIZAÇÃO DO ATENDIMENTO DO CIDADÃO)}

Na comparação entre os 3 grupos, a concessionária UAI Para Todos obteve o menor tempo de atendimento para o serviço de emissão da carteira de identidade nos dois anos analisados, atendendo, em média, com maior rapidez do que a MGS e a Minas Cidadão.

\subsection{TEMPO MÉDIO DE ESPERA (TEMPO DECORRIDO DESDE QUE A SENHA É EMITIDA NO SISTEMA ATÉ O MOMENTO DO INÍCIO DO ATENDIMENTO DO CIDADÃO)}

Na comparação entre os 3 grupos, a concessionária UAI Para Todos obteve o menor tempo de espera para o serviço de emissão da carteira de identidade nos dois anos analisados. Esse indicador mostra que os cidadãos nos municípios atendidos por essa concessionária precisam ficar menos tempo esperando do que nas unidades da MGS ou da Minas Cidadão.

\subsection{COEF (COEFICIENTE DE EFICIÊNCIA DAS UAI)}

Na comparação entre os 3 grupos, a concessionária UAI Para Todos obteve o melhor COEF, índice de desempenho de qualidade, nos dois anos analisados. Nota-se também que há pouca variação entre os valores mensurados nos dois anos, sendo o menor igual a 0,94 e o maior 0,99 .

De acordo com o trabalho de Sousa et al (2012), percebe-se que quanto mais o COEF mensurado aproxima-se de 1, melhores são as pontuações obtidas através do grau de satisfação do usuário, maior o percentual de senhas efetivamente atendidas, e maior também a relação entre senhas atendidas e senhas emitidas. Diante dos bons resultados relativos a esse indicador, nota-se que as UAIs possuem elevado grau de satisfação entre os cidadãos e poucos casos em que senhas são emitidas, mas os cidadãos não são atendidos.

Por fim, é interessante observar por meio das cores do Quadro 1 que houve um padrão nos dois anos analisados: a concessionária UAI Para Todos possui melhores indicadores do que a MGS que, por sua vez, possui indicadores melhores que a Minas Cidadão, sendo a única exceção o Valor Médio de Atendimento de 2020, que sofreu alterações já mencionadas nesse estudo fazendo com que os melhores resultados fossem da Minas Cidadão, seguido respectivamente pelos resultados da UAI Para Todos e MGS. 


\section{CONCLUSÃO}

$\mathrm{O}$ atendimento presencial ao cidadão em Minas Gerais passou por inúmeras alterações até chegar ao cenário atual. A mudança mais significativa dos últimos anos foi a transição do modelo PSIU para o modelo UAI que se iniciou em 2008 e tinha como objetivo a desburocratização e a padronização do serviço e do atendimento. Passada mais de uma década desde do início do processo de transição, destaca-se que a padronização do serviço de fato foi um grande mérito desse novo modelo. Mesmo com a diversidade de formas de gestão, o atendimento ao cidadão se mantém padronizado graças ao trabalho desenvolvido pela DCAP, que faz a articulação com os órgãos e a adequação do serviço ao padrão de atendimento UAI antes dele chegar na "ponta".

Ao longo da existência da UAI houve três processos de concessão para Parceria Público Privada, sendo que dois deles estão com contratos vigentes, enquanto o terceiro se encontra suspenso até a data de finalização deste artigo. Esse modelo de gestão foi regulamentado em Minas Gerais no ano de 2003 pela Lei 14.868/2003, que instituiu o Programa de Parcerias Público-Privadas e trouxe diretrizes de qualidade e continuidade na execução do serviço, além da eficiência no emprego dos recursos públicos. Nesse sentido, esse estudo realizou uma pesquisa qualitativa e quantitativa para avaliar em qual medida essas diretrizes de fato se apresentam no modelo de gestão das UAIs por meio de PPPs em comparação com o modelo de gestão direta.

Na análise qualitativa, de forma geral, o modelo de gestão por PPP se sobressaiu quando comparado com a gestão direta realizada por meio da Empresa Pública MGS, sendo um dos principais motivos de discrepância dessa comparação a qualidade da infraestrutura das unidades PPP. Por não se submeter a burocracia necessária para realização das compras públicas, o modelo de parceria público-privada tem maior eficiência e facilidade para realização de compras, o que se reflete de maneira explícita na infraestrutura das unidades, especialmente no estado de conservação do espaço, mobiliário e equipamentos.

Além da burocracia para a compra de materiais e contratação de serviços, há outra diferença significativa entre os dois modelos: o planejamento de desembolsos financeiros e a abundância de reservas de recursos públicos. Enquanto as PPPs possuem garantia da continuidade de fluxo orçamentário e financeiro para a remuneração das concessionárias, o que garante maior agilidade e qualidade para compra de materiais, equipamentos e manutenção do espaço onde o serviço é prestado, a gestão direta se sujeita a cortes orçamentários, o que pode acabar levando ao sucateamento dessas unidades.

É importante considerar que, no caso da gestão direta, a aquisição de materiais permanentes e a realização de serviços de manutenção não estão atrelados ao contrato da MGS, mas são executados por servidores da DCAP por meio de recursos próprios da Secretaria de Planejamento e Gestão. Nesse sentido, infere-se que a conservação dessas unidades fica sujeita à vontade política para a destinação de recursos públicos e para o direcionamento de esforços da equipe da DCAP para identificação e atendimento das necessidades de conservação das UAIs de gestão direta.

No que se refere aos pontos críticos do modelo de gestão de parceria público-privada, além da alta rotatividade de mão de obra causada pelos baixos salários pagos aos colaboradores das unidades PPPs, destaca-se que a grande dificuldade na gestão desse modelo acaba sendo a conciliação do interesse público do Estado com o interesse privado das concessionárias. Essa situação acaba exigindo da equipe da DCAP um grande esforço de fiscalização para garantir que o interesse público seja respeitado, os contratos cumpridos e a remuneração das concessionárias realizada de forma lícita.

Essa dificuldade de conciliação do interesse público e privado se reflete também na resistência apresentada pelas PPPs de se implementar estratégias de digitalização de serviço por meio, por exemplo, do incentivo ao uso dos totens de autoatendimento e dos telecentros presentes nas unidades. Apesar dessa digitalização de serviços ser do interesse do Estado e da população mineira, além de tendência global, acaba não sendo conveniente por parte das concessionárias, uma vez que representa redução da sua remuneração.

No que se refere à análise quantitativa, os resultados dos indicadores utilizados apontam que a gestão direta não apresenta desempenho superior ou inferior em comparação com o modelo PPP, mas sim intermediário entre as concessionárias UAI para Todos e Minas Cidadão. Diante do padrão observado, sugere-se que estudos posteriores busquem explicar os motivos dessa diferença observada entre as duas PPPs.

Dentre os dez indicadores utilizados, o único que rompeu com o padrão observado foi o valor médio por atendimento no ano de 2020 em que o modelo de gestão direta apresentou um custo médio por 
atendimento maior que os dois modelos de PPP. Isso ocorreu devido aos Termos Aditivos assinados com cada um dos consórcios que passaram a prever uma parcela mensal fixa como remuneração durante a pandemia de Covid-19. Portanto, pode-se dizer que, do ponto de vista dos cofres públicos, o modelo de PPP acabou se mostrando mais vantajoso que o modelo de gestão direta graças aos acordos firmados por meio dos Aditivos.

Por fim, com o intuito de fazer uma comparação entre a gestão direta das UAIs e a gestão por meio de parceria público-privada, esse estudo identificou os prós e contras de cada um dos modelos e, principalmente, os pontos de melhorias de cada um deles. Ressalta-se que as condições dos municípios, das estruturas e profissionais envolvidos na prestação do serviço são variáveis difíceis de serem mensuradas e inviabilizam uma comparação perfeita. Isso posto, destaca-se a importância de que outras pesquisas sejam feitas de modo a dar continuidade nesse estudo, contribuindo assim para a geração de mais evidências que favoreçam uma utilização íntegra e eficiente dos recursos públicos, além da manutenção de um atendimento de qualidade ao cidadão.

\section{REFERÊNCIAS}

[1] ARAÚJO, Lucas de Carvalho. Emissão de Carteira de Identidade: análise da implantação da obrigatoriedade de agendamento on-line prévio no estado de Minas Gerais. 2018. 187 f. Dissertação (Mestrado) - Curso de Administração, Universidade Federal de Minas Gerais, Belo Horizonte, 2018.

[2] CARRERA, Mariana Baleeiro Martins. Parceria Público-Privada na Saúde no Brasil: Estudo de caso do Hospital do Subúrbio de Salvador. Bahia. 2012. 105 p. Fundação Getúlio Vargas Escola De Administração de Empresas de São Paulo. São Paulo, 2012.

[3] GOMES, Eduardo Granha Magalhães. Gestão por Resultados e eficiência na Administração Pública: uma análise à luz da experiência de Minas Gerais. 2009. 187 f. Tese (Doutorado) - Curso de Doutorado em Administração Pública e Governo, Escola de Administração de Empresas de São Paulo, Fundação Getúlio Vargas, São Paulo, 2009.

[4] JEGERI, Ernesto. Ensaio bibliográfico: Parcerias público-privado. Revista do Serviço Público, 47, v. 120, n. 1. jan-abr, 1996.

[5] MARTINS, Felipe Ribeiro. Gestão da qualidade em Parcerias Público Privadas: a mensuração de desempenho na perspectiva agente-principal. 2018. 96 f. TCC (Graduação) - Curso de Administração Pública, Fundação João Pinheiro, Belo Horizonte, 2018.

[6] MINAS GERAIS. Edital de licitação por concorrência n 001/2010 [Unidades de Atendimento Integrado (UAI)]. Secretaria de Planejamento e Gestão de Minas Gerais, p. 44, 01 de jun. 2010.

[7] Edital de licitação por concorrência n ${ }^{\circ}$ 555/2013 [Unidades de Atendimento Integrado (UAI)]. Secretaria de Planejamento e Gestão de Minas Gerais, p. 72, 26 de jul. 2013.

[8] Primeiro Termo Aditivo do Contrato Unificado CEGUAI de prestação de serviços. Belo Horizonte, Minas Gerais, p. 108, 14 de mar. 2018

[9] Lei Estadual $n^{\circ} 14.868$, de 16 de dezembro de 2003. Dispõe sobre o Programa Estadual de Parcerias Público-Privadas. Disponível em: https://www.almg.gov.br/consulte/legislacao/completa/completa.html?num=14868\&ano=2003\&tipo=LEI. Acesso em: 06 mai. 2021

[10] MOREIRA, Terezinha; CARNEIRO, Christina Fontainha. A parceria público-privada na infraestrutura econômica. Revista do BNDES. Rio de Janeiro, v. 2, n. 1, p.27-46, dez. 1994.

[11] NESSIM, Pérola Hana. Gestão da informação na apuração e análise da satisfação dos usuários de serviços nas Unidades de Atendimento Integrado de Minas Gerais. 2015. 81 f. TCC (Graduação) - Curso de Administração Pública, Escola de Governo Professor Paulo Neves de Carvalho da Fundação João Pinheiro, Belo Horizonte, 2015.

[12] OLIVEIRA, D. R. Unidades de Atendimento Integrado (UAI): um estudo de políticas públicas para o fortalecimento da cidadania no Estado de Minas Gerais. 2014. 156f. Tese (Doutorado) - Faculdade de Economia, Administração e Contabilidade de Ribeirão Preto, Universidade de São Paulo, Ribeirão Preto, 2014.

[13] SANTOS, Pollyana Joanes Oliveira. Arranjo Institucional de Governança na Coordenação e Implementação de Parcerias Público-Privadas em Minas Gerais. 2016. 123 f. TCC (Graduação) - Curso de Administração Pública, Fundação João Pinheiro, Belo Horizonte, 2016.

[14] SOUSA, A. A. et al. Pioneirismo em Parcerias Público-Privadas: o modelo alternativo de atendimento ao cidadão no governo de Minas Gerais. In: CONGRESSO CONSAD DE GESTÃo PÚBLICA, 5. 2012, Brasília. Painel 04/015. Brasília: -, 2012. p. 1-28. Disponível em: http://www.sgc.goias.gov.br/upload/arquivos/2013-03/pioneirismo-em-parcerias-publico- privadas-o-modelo-alternativo-deatendimento-ao-cidadao-no-governo-de-minas-gerais.pdf. Acesso em: 22 abr. 2021. 


\section{Capítulo 15}

\section{Aplicação de Metodologia Ágil de Gestão de Projetos em pesquisa industrial aplicada}

\section{Caio Moldenhauer Peret}

Resumo: As pesquisas industriais trazem, por definição, a descoberta de dados inesperados, que se apresentam como novas questões a serem respondidas, ou oportunidades a serem exploradas. As Metodologias Ágeis de Gestão de Projetos representam vantagens em relação à adaptabilidade e aceitação de mudanças, porém têm sido aplicadas sobretudo para desenvolvimento de software. 0 presente artigo apresenta uma experiência real de aplicação desse tipo de metodologia, baseada em SCRUM, para o desenvolvimento de uma nova tecnologia para a empresa, que consistia de um sistema de controle bivolt de alta potência. 0 projeto incluiu o desenvolvimento de três conceitos alternativos de tecnologia, a definição de uma metodologia de validação e sua aplicação para os conceitos em questão. Os três conceitos mostraram-se viáveis, e a metodologia empregada estimulou o atingimento dos resultados, tendo sido empregada em seguida em outros projetos da empresa, mesmo sem a presença do responsável pela implantação.

Palavras-Chave: Metodologias ágeis; gestão de projetos; pesquisa industrial 


\section{INTRODUÇÃO}

\subsection{MÉTODOS ÁGEIS DE GESTÃO DE PROJETOS}

Em uma grande parte das empresas, assim como nas universidades, a gestão de projetos de pesquisa e desenvolvimento de tecnologias e produtos físicos ainda segue um modelo tradicional, baseado em um planejamento prévio detalhado, que inclui a preparação de uma estrutura analítica de projetos, seguida de um cronograma detalhado. Busca-se prever o máximo possível os resultados e problemas potenciais, e minimizar as alterações de escopo. Uma dificuldade que se apresenta nesse tipo de abordagem convencional, entretanto, é o fato de a pesquisa, por definição, criar resultados por vezes inesperados, que se apresentam como novas questões a serem respondidas, ou a oportunidades a serem exploradas.

As Metodologias Ágeis de Gestão de Projetos são diversas abordagens que tem em comum alguns pontos relacionados à capacidade de adaptação e aceitação de mudanças ao longo do projeto. Ao invés de evitar qualquer alteração, as Metodologias Ágeis entendem que as mudanças são parte intrínseca da execução do projeto, e são vistas como oportunidades de ampliação da entrega de valor para as Partes Interessadas.

Tais sistemáticas foram concebidas inicialmente para o desenvolvimento de software, como uma reação às fraquezas das abordagens convencionais, como o previamente aclamado Waterfall, criticado basicamente pela sua falta de reação face a mudanças. Uma das principais diferenças entre essas duas abordagens é a utilização de iterações na abordagem Ágil, com pequenas entregas de valor ao longo de todo o projeto, no qual o planejamento de cada sprint ou iteração leva em consideração os aprendizados oriundos das etapas anteriores (Figura 1).

Figura 1 - Comparação entre sistemáticas tradicionais e ágeis de gestão de projetos

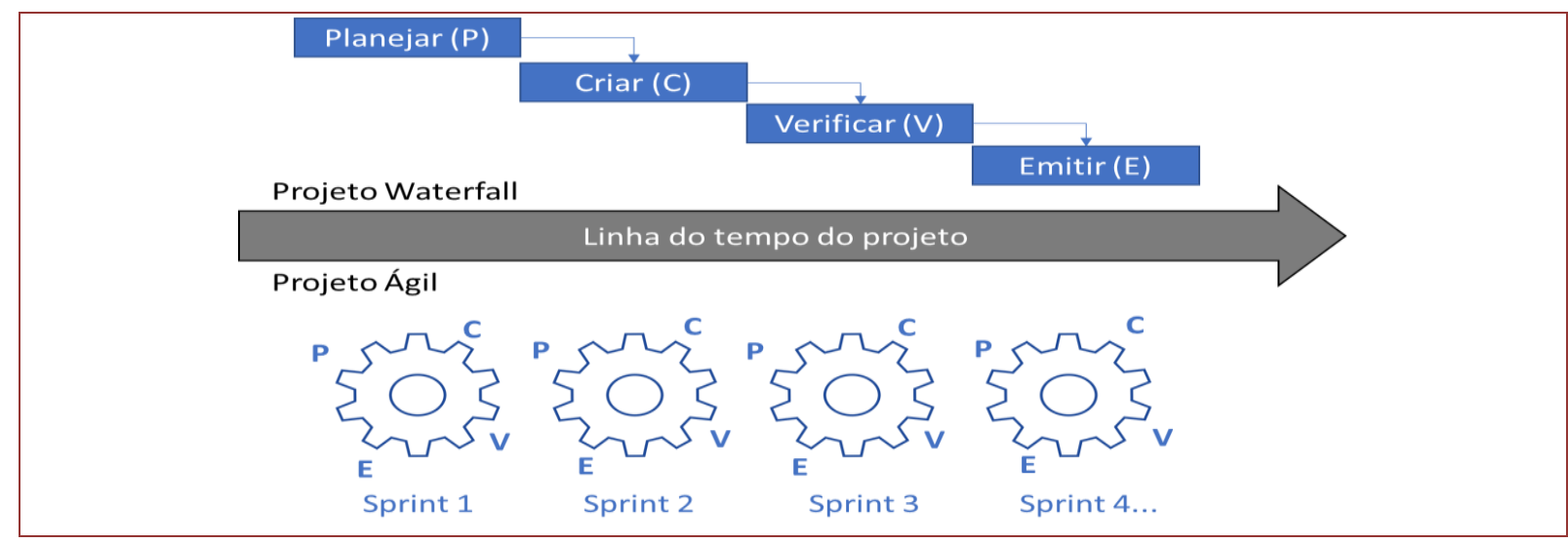

Um dos primeiros documentos que buscaram descrever as necessidades de projetos em um ambiente complexo e em mudança acelerada foi o Agile Manifesto (Beck et al., 2001), cujos princípios são apresentados na Figura 2; 
Figura 2 - Princípios do Manifesto Ágil (Beck et al, 2001).

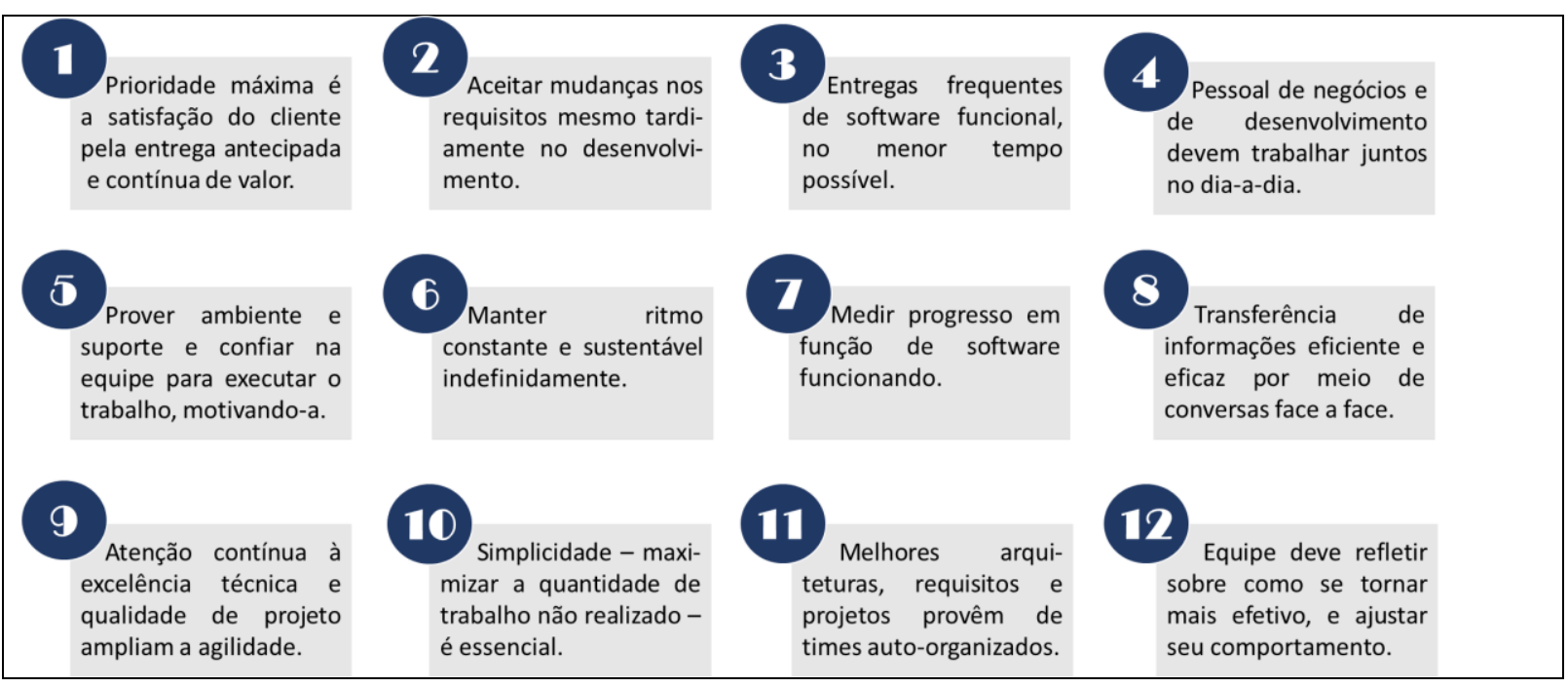

\subsection{CARACTERÍSTICAS DA METODOLOGIA SCRUM}

Baseado nesses princípios e na observação de empresas líderes em seus segmentos nos Estados Unidos e no Japão, Nonaka e Takeuchi (1986) compilaram as principais características de gestão de projetos bemsucedidos, e suas diferenças para a abordagem convencional. Segundo eles, na abordagem antiga, o processo de desenvolvimento de produtos movia-se como uma corrida de revezamento, em que um grupo de especialistas passava o bastão para o próximo, e assim sucessivamente, de fase a fase: desenvolvimento de conceito, teste de viabilidade, design do produto, processo de desenvolvimento, produção piloto, e produção. As funções eram especializadas e segmentadas, com diferentes responsáveis. Eles então compararam a nova gestão proposta ao Rugby, onde o processo de desenvolvimento nasce da interação constante de um time multidisciplinar, cujos membros trabalham juntos do início ao fim, sem uma estruturação rígida entre etapas, e com uma reavaliação constante de sua posição e das decisões tomadas, até o final do desenvolvimento.

Nasceu assim a metodologia Scrum, aplicada nos últimos 15 anos de forma bastante disseminada sobretudo no desenvolvimento de software, porém que aos poucos vai ganhando espaço também em outras áreas. De forma geral, a Gestão de Projetos Ágil tem sido aplicada em desenvolvimento de produtos (Nonaka e Takeuchi, 1986; Lehnen et al., 2016; Stare, 2014), projetos educacionais (Grimheden, 2013), construção civil (Demir e Theis, 2016), capital de risco (Sutherland e Altman, 2009), processos de inovação (Hannola et al., 2013), dentre outros.

Os resultados obtidos têm demonstrado benefícios significativos na maior agilidade de entregas, na obtenção de resultados com maior qualidade e valor percebido, e no aumento da assertividade na comunicação dentro das equipes de projeto, e desta com os stakeholders.

As principais características do Scrum - e de várias das metodologias ágeis como um todo - incluem:

- Alto grau de liberdade para a tomada de decisões de projeto pela equipe, e metas desafiadoras;

- Equipes auto-organizadas e autogerenciadas;

- Fases de desenvolvimento sobrepostas, dando ênfase à flexibilidade e velocidade;

- Cooperação e responsabilidade compartilhada pelos membros da equipe em relação às decisões do projeto;

- Processo contínuo de aprendizagem, aceitando os erros como parte do processo de desenvolvimento, tanto no nível individual, quanto de equipe, quanto institucional;

- Controle sutil, com checkpoints para prevenir instabilidades, ambiguidades e tensão, e controle por pressão de pares;

- Transferência organizacional do aprendizado;

- Emprego de um facilitador para assegurar a aplicação das sistemáticas da metodologia. 
Tanto no Scrum quanto em outras abordagens ágeis, é comum a divisão do projeto em iterações, cada qual com todos os elementos necessários para a agregação incremental de valor. No caso do Scrum, cada iteração é considerada um sprint, com duração de 1 a 4 semanas, dependendo do tipo e complexidade do projeto. Dentro desse período, pacotes de entregas priorizadas pelo Product Owner são executadas completamente, agregando valor gradativamente ao projeto final e antecipando ao máximo as entregas.

Após cada sprint, todas as atividades remanescentes - incluindo aquelas executadas parcialmente - são repriorizadas de acordo com os novos conhecimentos resultantes dos sprints anteriores e da evolução da visão do cliente. Isso faz com que o máximo de valor seja entregue o mais cedo possível.

As metodologias ágeis têm por objetivo minimizar os riscos decorrentes das mudanças, que são consideradas intrínsecas à maioria dos projetos. A filosofia Lean, por sua vez, objetiva a otimização dos recursos limitados para a produção (Womack e Jones, 1996). Apesar dessa diferença de finalidades, seus métodos se aproximam e por vezes se complementam, na redução de retrabalho, foco nas atividades de maior valor agregado, e atuação em pacotes de trabalho de tamanho reduzido. Com efeito, o Scrum se apropriou de certos elementos da prática Lean para apresentar um controle com gestão à vista da evolução do sprint e do projeto, e também para limitar a quantidade de trabalho executado simultaneamente. Em especial, um elemento crítico para aumentar a velocidade das entregas tem sido a utilização do Scrum Board, como uma ferramenta para a visualização da evolução do sprint, identificando tarefas aguardando execução, já iniciadas, e finalizadas.

Uma das características do Scrum são seus eventos, ou ritos que auxiliam na manutenção dos conceitos e fundamentos (Schwaber e Sutherland, 2020). O projeto inicia com um Kick-off Meeting, em que a visão do projeto é apresentada, e uma avaliação macro da sequência do projeto é discutida com a equipe e a direção da empresa. Define-se as responsabilidades e o tempo de cada sprint. No início de cada iteração, é realizada uma reunião de planejamento (Sprint Planning), que ocupa cerca de 5\% do tempo total, e diariamente são realizadas reuniões de cerca de 15 minutos, o Scrum Diário, para a verificação de quais atividades foram realizadas, de quais serão realizadas nos próximos dias, e quais os obstáculos e riscos que podem impedir a realização do que foi previsto.

Ao final do sprint, é realizada uma reunião de Sprint Review - onde são avaliadas as atividades finalizadas e compilados os aprendizados e resultados, seguida de uma Retrospectiva, que consiste de uma avaliação periódica do processo Scrum em si, a fim de incorporar melhorias na execução do projeto.

O Scrum Master é a figura responsável pela facilitação desses eventos e pela remoção dos obstáculos que porventura surjam, permitindo à equipe focar o máximo possível na agregação de valor aos entregáveis do projeto.

\subsection{CONTEXTO DA IMPLEMENTAÇÃO}

A intervenção apresentada neste trabalho ocorreu em uma empresa de médio porte, brasileira, de grande penetração de mercado no fornecimento de equipamentos eletroportáteis de uso por profissionais e pelo público em geral.

A empresa possui uma área de Engenharia, que tradicionalmente foi responsável pela execução de testes de controle de qualidade, Engenharia de Aplicação de tecnologias já existentes para a montagem de novos produtos, porém que tinha, até então, pouca expressão no desenvolvimento de tecnologias próprias para desenvolvimento de novos produtos.

A maior parte dos produtos eram desenvolvidos por fornecedores de componentes, e que de fato dominavam os processos de cálculo e dimensionamento de componentes, pesquisa de novas tecnologias, e desenvolvimento de produtos. Essa característica deixou a empresa em uma situação de dependência tecnológica, e levou a um aumento do poder de barganha dos fornecedores, que passaram a elevar cada vez mais os preços de seus componentes, que em última análise definiam o grau de competitividade da empresa, frente aos lançamentos cada vez mais frequentes de produtos da concorrência.

Um desses fornecedores críticos acabou optando pela integração para frente, e fabricação dos produtos acabados com marca própria, o que causou seu afastamento da empresa, e uma grande instabilidade. Isso levou à necessidade de aumento urgente do nível de capacitação de sua Engenharia interna para o desenvolvimento de produtos, bem como da modificação do pipeline de projetos, incluindo produtos mais avançados. 
Após encerrar a parceria com a empresa, esse antigo fornecedor lançou no mercado um produto bivolt automático, de alta potência, característica até então inexplorada no Brasil pela falta de tecnologia desenvolvida, e também no exterior, pela predominância, em outros países, de apenas uma voltagem na rede pública. A ação do novo concorrente incluiu a proteção da tecnologia desenvolvida por meio de patente registrada no INPI.

Como resposta competitiva, a empresa decidiu realizar o desenvolvimento de tecnologia para criar um produto bivolt automático de alta potência através de um fornecedor de produtos acabados do exterior e, em paralelo, de um pesquisador brasileiro. 0 texto de patente do antigo parceiro foi apresentado a ambos os fornecedores, para que desenvolvessem um produto cuja tecnologia não colidisse com aquela já protegida.

Em ambas as iniciativas, pelo menos seis meses se passaram até que as primeiras provas de conceito fossem entregues. A tecnologia proposta por cada fornecedor foi testada e comparada com o desempenho do produto do concorrente, e foi analisada do ponto de vista de potencial colisão com a patente.

Em ambos os casos, percebeu-se pequenas variações em relação ao produto patenteado, criando um risco considerável para a empresa em caso de comercialização. Além disso, ambos os protótipos apresentaram defeitos após pouco tempo de uso, e considerou-se que os defeitos, além de gerar insatisfação do cliente, poderiam colocar em risco sua segurança no momento do uso. 0 resultado de cada teste e da análise da tecnologia foi compartilhado com os respectivos desenvolvedores, que tiveram mais oportunidades para alterar seus protótipos, porém em nenhum caso foi possível a obtenção de um conceito estável, e os fornecedores não conseguiram desenvolver seus produtos baseado em outra plataforma tecnológica que reduzisse os riscos ao negócio.

A partir de então, a empresa decidiu desenvolver internamente a tecnologia, utilizando recursos humanos já existentes na área de Engenharia. Em função da urgência na resposta competitiva, e por se tratar de algo desconhecido para a empresa, optou-se pela aplicação de um método de gestão de projetos baseado em Scrum, porém modificado para a realidade da empresa.

\section{INTERVENÇÃO PROPOSTA}

A equipe de Engenharia da empresa era reduzida, de forma que o desenvolvimento da tecnologia elétrica e eletrônica ficou a cargo de um Analista de Engenharia Elétrica Júnior, orientado por um Engenheiro Sênior e pelo Gerente de Engenharia.

Houve a necessidade de adaptar a metodologia para emprego por um único desenvolvedor, ajudado pelo Engenheiro Sênior (que também tinha outras responsabilidades). Ao Engenheiro Sênior, coube o papel de Scrum Master, e o Gerente de Engenharia supervisionou a execução do método e atuou como Product Owner no projeto.

Antes do início do projeto, a equipe foi instruída em relação à metodologia, e foi ressaltada a necessidade de que, em cada sprint, fosse gerado um valor incremental. No Scrum, isto significa o atingimento de um marco completo em direção à meta do produto, desde o esclarecimento de um conceito teórico a ser utilizado, até a preparação de um protótipo que será utilizado em múltiplas avaliações posteriores (Scrum.org, 2021).

Definiu-se um sprint de duas semanas de duração, sendo que no último dia do sprint era realizada uma reunião única englobando Sprint Review, Retrospective e Planning.

Todas as manhãs, uma reunião entre o pesquisador e o Engenheiro Sênior era realizada, em que as atividades realizadas e a realizar eram rapidamente discutidas, bem como os eventuais obstáculos. Nesse momento, o Engenheiro Sênior também orientava tecnicamente o pesquisador, direcionando-o em suas atividades teóricas e práticas (embora fossem de especialidades distintas).

No início do projeto, foi realizado um planejamento macro, e foi definido que o escopo incluiria uma revisão bibliográfica envolvendo pesquisa de patentes relacionadas às tecnologias que teriam potencial como resolução do problema proposto, bem como estudo de livros da área e conversa com especialistas; com base nessa revisão, seriam estabelecidas algumas possibilidades de controle para a comutação automática de potência, desde que elas não colidissem com a patente do concorrente. Em seguida seriam selecionadas algumas alternativas mais promissoras, e seriam criados circuitos testes, utilizando componentes disponíveis em lojas de materiais eletrônicos, para se obter rapidamente protótipos de circuitos que pudessem ser conectados a um produto padrão usado como base para a validação. 
Juntamente com o desenvolvimento e teste dos protótipos desenvolvidos, a equipe adquiriu e testou alguns exemplares do equipamento comercial desenvolvido pelo concorrente, o que serviu como benchmarking de desempenho.

Em todos os Sprint Reviews, manteve-se a filosofia de selecionar pacotes de trabalho de forma que uma geração de valor incremental de fato ocorresse após cada sprint. Por exemplo, ao invés de, em uma fase, fabricar simultaneamente diversos protótipos de conceitos distintos, e testá-los juntos em um momento posterior, optou-se por construir um protótipo de um primeiro conceito, efetuar seu teste, e somente então, com base nos novos conhecimentos adquiridos, partir para o protótipo e testes de um segundo conceito. Também se optou pela execução primeiramente dos protótipos mais simples, que pudessem ser realizados de forma mais ágil, antecipando a geração de valor.

\section{RESULTADOS OBTIDOS}

Estabeleceu-se o objetivo de completar a pesquisa em 12 semanas - equivalentes a 6 sprints - ao fim das quais, tencionava-se decidir pela tecnologia a ser utilizada no produto, após testes de validação. Seria necessário que ela não colidisse com a patente do concorrente, e que tivesse um comportamento técnico estável. Foi definido como base para os testes um equipamento da empresa com potência próxima da qual se tencionava aplicar a tecnologia, cujos sistemas de potência seriam conectados à placa controladora, que permaneceria externa ao equipamento. Não era escopo do projeto o desenvolvimento de uma placa de circuito impresso miniaturizada, com dimensões apropriadas para o produto, por se entender que tal escopo seria específico para o desenvolvimento do produto em si, e não do conceito tecnológico, e pelo fato de que, uma vez definido o funcionamento do circuito, a fabricação de uma placa miniaturizada não apresenta dificuldades técnicas significativas.

0 primeiro sprint consistiu de uma pesquisa bibliográfica em patentes, artigos e livros, bem como de discussões do Engenheiro com especialistas, com o objetivo de identificar possibilidades de controles utilizadas em outros tipos de produtos e indústrias, mas que poderiam ser adaptadas para a situação em questão. A tendência inicial dos Engenheiros envolvidos com o projeto foi de explorarem um único conceito que julgavam possível. Em função disso, a equipe foi orientada a permanecer na busca de soluções de tal forma que pelo menos três conceitos distintos e viáveis fossem apresentados.

Essa pressão colocada sobre a equipe assemelha-se à "Instabilidade Incorporada" identificada por Nonaka e Takeuchi (1986), criando um "elemento de tensão na equipe (...) definindo requisitos muito desafiadores". Além disso, trabalhos anteriores (Ayag, 2005) demonstram a importância de se considerar múltiplas alternativas viáveis para a obtenção de resultados com maior nível de inventividade e potencial de sucesso de mercado. Após a obtenção das alternativas, é possível a seleção da mais adequada estabelecendo-se um conjunto de critérios ponderados.

Assim, a equipe conseguiu identificar três alternativas de conceitos possíveis, sendo um baseado em um relé elétrico em miniatura, e outros dois baseados em circuitos eletrônicos, controlados por PLC. Nenhum desses conceitos assemelhava-se em qualquer sentido com aquele empregado pelo concorrente.

No Sprint 1, ainda foram definidos os testes necessários para a comparação entre os diferentes conceitos. Como o que se estava buscando era uma caracterização do sistema de comutação automática entre tensões, foi necessário desenvolver uma giga de testes específica para a ciclagem entre tensões, que seguisse a sequência abaixo:

1) Habilitação de $127 \mathrm{~V}$ durante um intervalo de tempo pré-definido;

2) Desligamento da tensão de saída para o protótipo;

3) Habilitação de 220 V durante o mesmo intervalo de tempo;

4) Desligamento da tensão de saída para o protótipo;

5) Retorno ao passo 1.

Um número mínimo de ciclos sem falha foi definido como condição para um sistema estável. Além disso, outras medidas foram realizadas, incluindo a estabilidade da tensão de saída, durante um intervalo prédeterminado, dentre outros.

Foram testados o produto da concorrência e os conceitos inicialmente desenvolvidos externamente pela empresa, confirmando a instabilidade dos protótipos desenvolvidos, e a adequação do modelo comercial desenvolvido pelo concorrente. 
Ao término do Sprint 1, as alternativas desenvolvidas foram apresentadas, e discutiu-se qual seria a alternativa mais simples para que fosse criado um protótipo e testado de forma imediata. 0 Sprint 2 concentrou-se então na compra de componentes, preparação do circuito em placa de ensaio e testes do primeiro conceito, que não necessitava de programação. Além disso, sabendo-se que os sprints subsequentes envolveriam a programação de PLC, o Engenheiro responsável tomou a iniciativa de estudar a linguagem de programação que se faria necessária.

A realização dos testes no protótipo mais simples revelou, de forma antecipada, a necessidade de adaptações de instrumentos e métodos, que mais adiante puderam ser modificados antes da preparação dos demais protótipos, evitando perda de dados e retrabalhos, e minimizando o tempo de projeto. Assim, pela forma em que o Sprint 2 foi planejado, o valor agregado transcendeu as conclusões sobre o conceito específico estudado, mas se aplicou ao método de pesquisa em si.

Um aspecto importante na autogestão da equipe foi a utilização de um Scrum Board físico (apesar da disponibilidade de plataformas digitais que poderiam ser usadas para essa finalidade). A visibilidade contínua desse quadro proporcionou uma lembrança constante do status das atividades esperadas até o fim do sprint atual, que um quadro virtual não permitiria, pois só seria visto quando acessado (exceto se houvesse um monitor ou TV continuamente exibindo-o). Diariamente, a reunião da equipe era feita em frente a esse Scrum Board, que também era atualizado nesse instante. Com o objetivo de zelar para que a equipe o mantivesse atualizado a todo momento, de tempos em tempos, o Gerente de Engenharia chamava uma reunião rápida para entender a evolução do trabalho. Ainda mais em se tratando de uma equipe pouco experiente com a metodologia, essa ação permitiu que a equipe conseguisse a todo instante explicar suas decisões e justificá-las, mantendo uma consistência lógica.

Figura 3 - Ilustração do Scrum Board

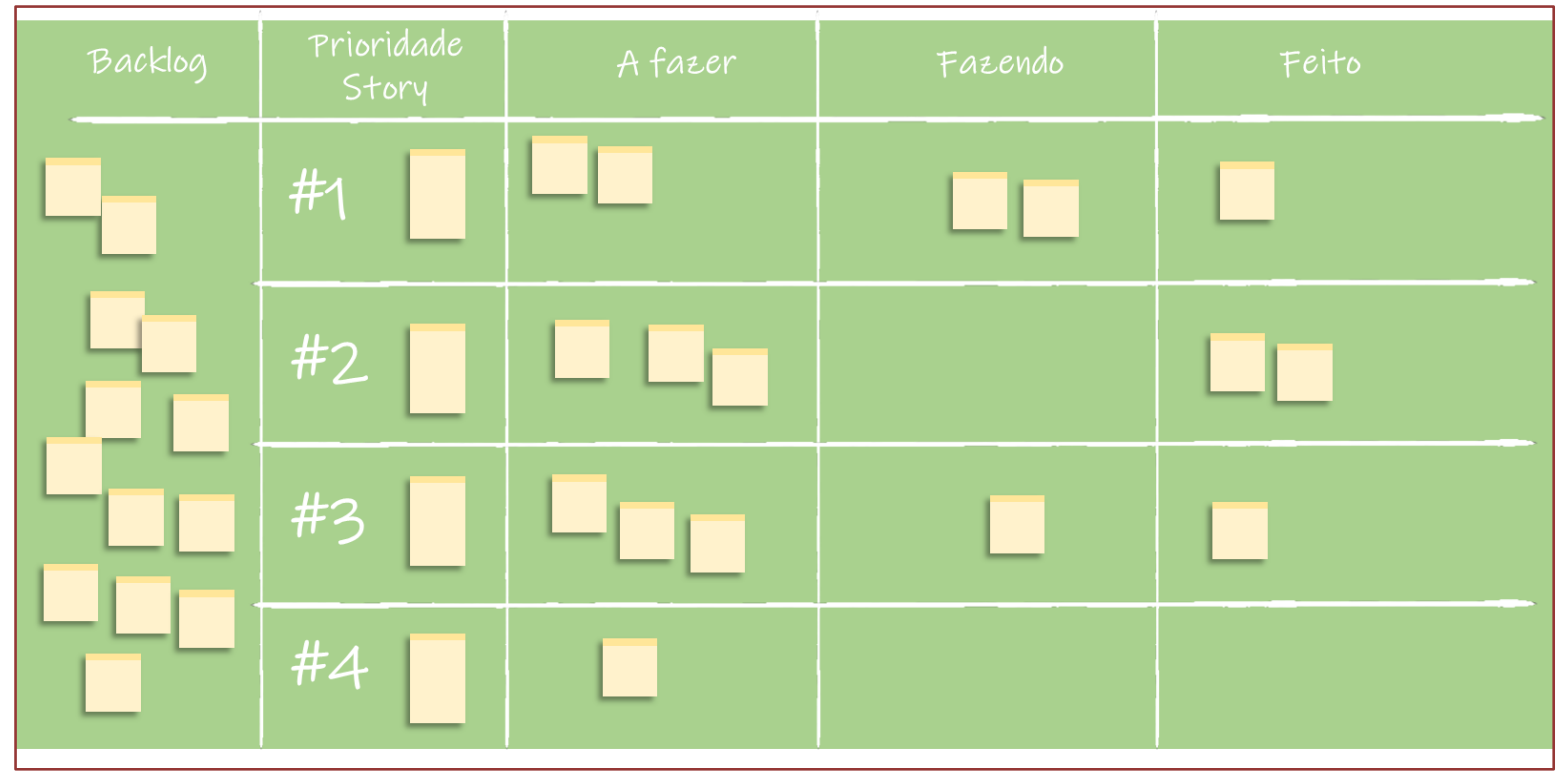

Uma melhoria em relação ao uso do Scrum Board apenas como uma ferramenta de gestão à vista foi a introdução de um limite de Work in Progress (WIP Limit). Esse limite evita a abertura de várias frentes para cada membro da equipe, de forma a assegurar que uma atividade somente seja iniciada após a finalização de outra aberta previamente, como em um sistema de produção puxada. Essa iniciativa foi executada na forma da diretriz apresentada na Figura 4. No exemplo, a story de maior prioridade é composta por três atividades com intervalos de tempo entre elas (por exemplo, o tempo de entrega de componentes para a fabricação de um protótipo). As atividades da segunda prioridade são alocadas nos intervalos entre as atividades de maior prioridade, desde que estas não sofram atrasos. 0 mesmo ocorre para a terceira prioridade, e assim por diante. 
Figura 4 - Ilustração da diretriz de alocação de stories dentro do sprint considerando limite de Work-InProgress (WIP Limit).

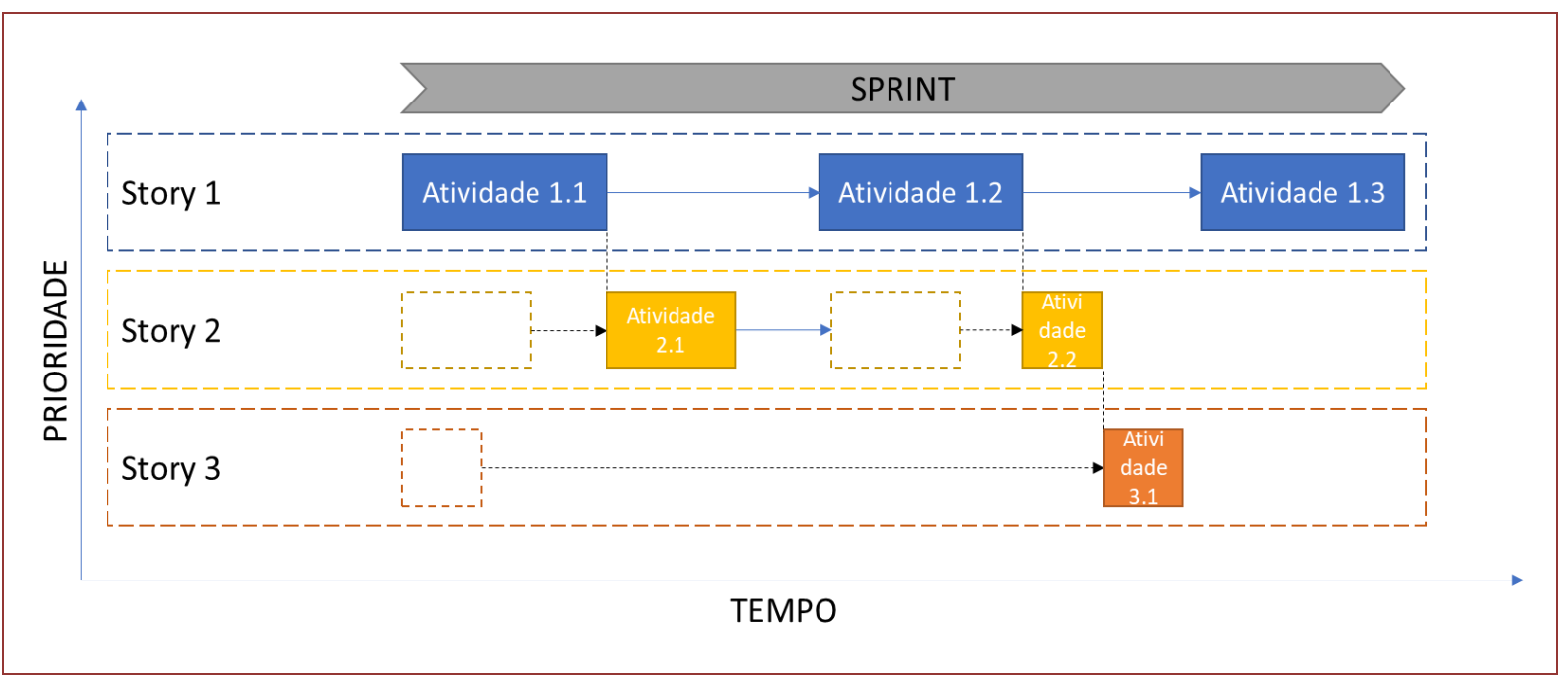

Os Sprints seguintes se concentraram na preparação dos dois outros protótipos e seu teste. 0 Protótipo 2, apesar de ser controlado por PLC da mesma forma que o Protótipo 3, era mais simples, por isso foi elaborado já no Sprint 3. Como ele demandava conhecimentos até então não disponíveis na equipe, seu desenvolvimento demandou várias adaptações até que o protótipo fosse considerado estável. Dessa forma, os novos conhecimentos adquiridos pela equipe durante a experiência também agregaram valor ao projeto, indo além do valor do protótipo final, pois criaram know how. A construção do Protótipo 3 usufruiu desse conhecimento e, apesar de ser mais complexo em termos de programação e calibração de parâmetros, seu desenvolvimento ocorreu de forma mais rápida.

Diferentemente de um projeto de desenvolvimento de software, onde as user stories são em grande medida independentes entre si, um projeto de desenvolvimento tecnológico ou de desenvolvimento de produto tem um nível elevado de dependência entre as atividades, o que limita a ordenação das atividades conforme o valor agregado ao produto final. No presente trabalho, houve a necessidade de um planejamento macro dos sprints levando em consideração essas dependências. Por exemplo, antes de se iniciar o desenvolvimento dos protótipos, houve a necessidade de realizar a pesquisa bibliográfica para identificação dos conceitos principais que deveriam ser utilizados como base, e em seguida de adquirir os componentes e preparar a infraestrutura necessária para a montagem das placas de ensaio. Essa foi uma adaptação necessária, e que é fundamental na utilização de metodologias ágeis em áreas industriais e de pesquisa e desenvolvimento.

Após a fabricação e testes dos protótipos dos três conceitos, foi preparada uma matriz apresentando os resultados e uma análise estimativa do custo de cada solução, a fim de selecionar a tecnologia mais adequada para implementação posterior nos produtos.

Para a seleção da tecnologia, foi feito um workshop com a liderança do departamento e os demais integrantes da Engenharia - incluindo os que não estavam diretamente envolvidos neste projeto. Com isso, esperava-se ter um questionamento mais aprofundado sobre os benefícios e restrições de cada uma alternativa.

Os seguintes critérios foram estabelecidos para a comparação entre as alternativas desenvolvidas:

1) Tempo sem falha na comutação entre as tensões;

2) Número de componentes no sistema de controle;

3) Potencial de miniaturização;

4) Custo estimado dos componentes. 
Ao final das discussões, entendeu-se que as duas primeiras alternativas seriam mais viáveis para incorporação no produto, e optou-se pelo conceito do primeiro protótipo, pela simplicidade e custo mais reduzido. Ressalta-se que esta foi a última alternativa identificada, e que a equipe não acreditava inicialmente em seu potencial, o que demonstra a importância de forçar o limite da criatividade pela imposição de necessidade de um número mínimo de conceitos possíveis.

0 projeto gerou como resultado a seleção de uma tecnologia de controle para a comutação automática bivolt, mas também o domínio de conceitos fundamentais de controle por meio eletrônico, o treinamento dos engenheiros em desenvolvimento de circuitos e da programação de PLC's, bem como das rotinas de programação específicas para controle de potência, e o treinamento da equipe em uma nova forma de trabalho que se mostrou muito vantajosa.

0 atingimento dos objetivos do trabalho nesse projeto inicial gerou um aumento da confiança da equipe no desenvolvimento de outros produtos de maior complexidade. Isso levou à aplicação da metodologia proposta em outros trabalhos, conforme reportado por um membro da equipe.

\section{CONTRIBUIÇÃO TECNOLÓGICA-SOCIAL}

A competição entre alternativas conceituais é essencial para a obtenção de uma solução inovadora, porém a competição entre os conceitos somente deve ser estabelecida após a proposição de soluções viáveis sem restrições (sejam elas orçamentárias, de desempenho ou de expectativa de solução). Essa ausência de restrições iniciais estimula a criatividade e evita o cancelamento de opções, antes que elas tenham a chance de ser desenvolvidas o suficiente para serem viabilizadas.

A liderança de um facilitador com mais conhecimento na utilização de métodos ágeis, sobretudo que esteja no papel de Product Owner, além de coach da equipe, foi fundamental para que a sistemática fosse bem implementada e que gerasse resultados, pelo foco na geração de valor a cada iteração, e por zelar para que os ritos do Scrum fossem mantidos. Além disso, a utilização de um Scrum Board físico - e não virtual possibilitou uma maior visibilidade da evolução dos trabalhos, e serviu como pano de fundo para as discussões diárias, mas também para eventuais intervenções da gestão do departamento, levando a equipe a um empenho maior na consistência lógica de suas argumentações e na manutenção da atualização desse quadro. Essa conclusão provavelmente é mais importante no caso de equipes pouco experientes nesse tipo de abordagem, já que com o tempo a equipe é capaz de criar uma rotina padronizada, permitindo a utilização de um ambiente virtual.

Mesmo no caso de um desenvolvimento tecnológico no qual há um encadeamento mais intenso entre algumas atividades, é importante que os sprints sejam definidos como pacotes de atividades com o atingimento de determinadas conclusões. Em Pesquisa, a geração de conhecimento é de fato o valor agregado. Assim, a organização dos pacotes incluindo a concepção, fabricação e teste de um elemento do problema como um todo permite o aprendizado antecipado que caracteriza as metodologias ágeis de gestão de projetos, e que pode ser utilizado nos pacotes subsequentes.

A imposição de um WIP Limit, que seja definido em função da disponibilidade de tempo sem que haja atraso das atividades prioritárias, foi também essencial para orientar o foco da equipe, minimizando o tempo para a realização das atividades, e antecipando a entrega de valor.

Neste trabalho, foram definidos alguns critérios de seleção entre as alternativas, porém tais critérios foram considerados de forma subjetiva, por meio da discussão e da busca por uma concordância entre a equipe. Um refinamento desse método seria a consideração de uma metodologia de seleção baseada em AHP - Analytic Hierarchy Process (Saaty, 1980; Ayag, 2005), no qual a importância relativa entre cada parâmetro é avaliada, gerando uma ponderação à qual as avaliações são submetidas, trazendo um resultado mais próximo da expectativa das partes interessadas. 


\section{REFERÊNCIAS}

[1] Ayag, Z (2005). An integrated approach to evaluating conceptual design alternatives in a new product development environment. International Journal of Production Research, 43(4), 687-713.

[2] Beck, K. et al. (2021) Manifesto for Agile Software Development. http://agilemanifesto.org

[3] Demir, S. T.; Theis, P. (2016). Agile design management - the application of Scrum in the design phase of construction projects. In Annual Conference of the International Group for Lean Construction, 24.

[4] Grimheden, M.E. (2013). Can agile methods enhance mechatronics design education?. Mechatronics, 23(8), 967-973.

[5] Hannola, L.; Friman, J.; Niemimuukko, J (2013). Application of agile methods in the innovation process. International Journal of Business Innovation and Research, 7(1), 84-98.

[6] Lehnen, J.; Schmidt, T.S.; Herstatt, C (2016). Bringing agile project management into lead user projects. International Journal of Product Development, 21(2-3), 212-232.

[7] Nonaka, I.; Takeuchi, H. The new new product development game (1986). Harvard Business Review, jan-fev, 137-146.

[8] Schwaber, K. \& Sutherland, J (2021). The Scrum Guide: The Definitive Guide to Scrum: The Rules of the Game. https://scrumguides.org/index.html

[9] Saaty, T.L (1980). The Analytic Hierarchy Process. Ed. McGraw-Hill.

[10] Stare, A. (2014). Agile Project management in product development projects. Procedia - Social and Behavioral Sciences, 119, 295-304

[11] Sutherland, J.; Altman, I. (2009). Take no prisoners: how a venture capital group does scrum. In Agile conference (pp. 350-355). IEEE.

[12] What is an Increment in Scrum? (2021). In Scrum.org. https://www.scrum.org/resources/what-is-anincrement

[13] Womack, J.P.; Jones, D.T. (1996). Lean Thinking: Banish Waste and Create Wealth in Your Corporation. Ed. Productivity Press. 


\section{Capítulo 16}

A abordagem da gestão por competências para alocação de servidores técnico-administrativos recémconcursados em uma instituição federal de ensino superior

\section{Phelipe Augusto Marins \\ Fernando de Oliveira Vieira}

Resumo: Com o tempo, cada vez mais novas ferramentas têm sido utilizadas na administração pública. Uma dessas práticas, a Gestão por Competências, implantada através do Decreto $\mathrm{n}^{\circ}$ 5.707, em 2006, busca a adequação das competências requeridas dos servidores aos objetivos das Instituições Federais. Verifica-se que a administração pública possui características próprias, diferentes da particular, e que têm impacto no modo de gerir seus recursos humanos. Uma dessas peculiaridades é a forma de ingresso dos seus profissionais, que deve ser levada em consideração para aproximar as expectativas dos ingressantes aos interesses dessas instituições. Nesse contexto, a presente pesquisa pretende verificar como a adoção da gestão por competências pode impactar na alocação de servidores públicos recém-concursados. Esta pesquisa tem como objetivo analisar o modelo de alocação de servidores técnico-administrativos recém-concursados implantado por uma Instituição Federal de Ensino Superior. A metodologia utilizada caracteriza-se, principalmente, por uma pesquisa descritiva, bibliográfica e documental, com aplicação de um questionário aos servidores técnico-administrativos ingressantes em 2019 para obter a percepção acerca do referido modelo. Os principais resultados em discussão apontam que a gestão por competências teve um impacto positivo para alocação dos servidores recém-concursados na instituição estudada.

Palavras-chave: Competências, Gestão por Competências, Gestão de Pessoas, Administração Pública, Alocação de Pessoal 


\section{INTRODUÇÃO}

A gestão de pessoas nas organizações tem sofrido alteração na forma de abordagem ao longo dos anos, passando a ter um contexto estratégico em que se alinha a sua gestão ao planejamento da organização. A Gestão por Competências (GPC) pode ser considerada uma das práticas que tem ganhado destaque nesse contexto. Sua implantação formal na administração pública brasileira ocorreu em 2006, por meio do Decreto ${ }^{\circ} 5.707 / 2006$, que instituiu a Política e as Diretrizes para o Desenvolvimento de Pessoal (BRASIL, 2006).

As ações relacionadas à implementação da abordagem de competências fornecem importantes subsídios para as atividades de gestão de pessoas em organizações públicas. Podem auxiliar na formatação de concursos, agilizar ações de recrutamento e seleção interna e otimizar os processos de lotação e de movimentação de pessoal. Isso permite a definição de critérios claros para as iniciativas de avaliação de servidores, de estruturação de planos de desenvolvimento pessoal e profissional e de remuneração, promovendo maior integração dos subsistemas de gestão de pessoas (PIRES et al., 2005).

Pode-se dizer que o setor público possui características próprias, distintas das organizações particulares, que influenciam na forma de gerenciar seus recursos humanos. Como os cargos no serviço público são definidos por lei, as atribuições, muitas vezes, são descritas de forma genérica, não se levando em consideração a definição clara das funções, as competências, nem o perfil do funcionário, necessários a sua ocupação. A forma de seleção de pessoal no serviço público, em sua maioria, não consegue avaliar as habilidades e atitudes de um candidato, que são fatores importantes para se definir a alocação de um novo servidor (SOUZA, 2019). Entretanto, cabe ressaltar a importância do concurso público na democratização do processo de recrutamento e seleção das instituições públicas.

Cargos podem ser plurais e genéricos, isto é, um mesmo cargo pode possuir atribuições completamente distintas conforme a natureza da área de atuação. Para a gestão por competências funcionar de forma efetiva é preciso que sejam identificadas e especificadas as atribuições que um servidor lotado em um determinado setor deve realizar (LEME, 2011, p. 4).

Em teoria, um servidor bem alocado exercerá suas atividades com mais eficiência, possuirá maior qualidade de vida no trabalho, estabelecerá uma relação mais próxima com a instituição, estará menos propenso a processos de movimentação para outras áreas e necessitará de menos capacitações para se adaptar à função (PIRES et al., 2005).

Nesse contexto, esta pesquisa se propõe a analisar o modelo recém-implantando de alocação por competência de servidores técnico-administrativos recém-concursados de uma Instituição Federal de Ensino Superior brasileira. Para isso, o objeto de estudo consiste na percepção dos técnicosadministrativos ingressantes em 2019 que se submeteram ao processo de alocação de pessoal por competências na referida instituição.

\section{REVISÃO DA LITERATURA}

\subsection{COMPETÊNCIAS}

Autores como Carbone et al. (2016) afirmam que os estudos organizacionais que se desenvolveram relacionados à competência podem ser agrupados em duas correntes teóricas relacionadas à localidade em que se originaram: a americana e a francesa.

0 termo competência ganhou destaque com suas primeiras pesquisas na década de 1970, passando a ser ser objeto de estudo teórico em várias áreas áreas de interesse, como no campo da administração, psicologia, economia e sociologia do trabalho. Conforme Dutra (2017), a primeira proposição de forma estruturada foi feita por David McClelland em 1973 com a publicação do artigo Testing for competence rather than for "intelligence" nos Estados Unidos. Nessa sequência referente à corrente americana, Boyatzis (1982), observando os dados de estudos realizados sobre as competências gerenciais, identificou um conjunto de traços e características que, de acordo com ele, são responsáveis por um desempenho superior (FLEURY E FLEURY, 2001, p.185). Pode-se dizer que o foco de análise dessa abordagem está no indivíduo e no alinhamento às necessidades estabelecidas pelos cargos ou posições organizacionais. Segundo Carbone et al. (2016), essa análise, que considera o alinhamento das competências ao desempenho desejado para a ocupação de posições dentro das organizações, marcou de forma significativa a literatura norte-americana sobre o tema. 
Por outro lado, a corrente Europeia, representada por autores como Zarifian (2001), Le Boterf (2003), contesta a definição americana de competência, associando-a às realizações das pessoas, àquilo que elas produzem ou entregam, adotando uma visão para além da qualificação (FLEURY e FLEURY, 2001, p. 186). Nessa linha, Dutra (2000, p.163) aponta que o fato da pessoa possuir as qualificações para determinado trabalho não garante que ela irá entregar o que lhe é demandado.

Nesse sentido, Fleury e Fleury (2001, p. 186) afirmam que o trabalho não é mais o conjunto de tarefas associadas de forma descritiva ao cargo. Ele se torna o prolongamento direto da competência que a pessoa mobiliza em razão de uma situação profissional cada vez mais complexa e mutável.

Uma terceira corrente tem recebido destaque na medida em que procura adotar uma perspectiva integradora, definindo a competência como somatório dessas duas linhas. Em outras palavras, como sendo a entrega e as características da pessoa que podem ajudá-la a entregar com maior facilidade (MCLAGAN, 1997; PARRY, 1996; CARBONE et al., 2016; DUTRA, 2017). Pode-se dizer que articula as concepções das vertentes americana e francesa, destacando a competência como a combinação de conhecimentos, habilidades e atitudes expressos pelo desempenho de contextos organizacionais.

Brandão e Guimarães (2001), ao apontar os propósitos da gestão por competências, afirmam que ela orienta esforços para planejar, captar, desenvolver e avaliar nos níveis individual, grupal e organizacional as competências necessárias para o alcance dos objetivos da organização. Seguindo essa linha de pensamento, Silva et al. (2014, p.103) apontam que o modelo de gestão de competências tem sido inserido aos poucos nas organizações na tentativa de alinhar as competências individuais dos colaboradores às metas da empresa.

Trata de um processo contínuo, que possui como etapas a formulação da estratégia organizacional, o mapeamento de competências, a captação ou o desenvolvimento de competências, o acompanhamento e avaliação e, por fim, o sistema de retribuição e incentivos (CARBONE et al., 2016).

\subsection{MAPEAMENTO DE COMPETÊNCIAS}

Segundo Brandão e Bahry (2005), o mapeamento de competências objetiva identificar o gap de competências, que é a diferença entre as competências necessárias para concretizar a estratégia definida e as competências internas já disponíveis na organização.

O primeiro passo para o mapeamento de competências se baseia na identificação das competências organizacionais e profissionais necessárias ao alcance dos objetivos da organização (BRANDÃO e BAHRY, 2005). Para isso, poderá ser realizada uma pesquisa documental que abrange a análise do conteúdo da missão, da visão de futuro, dos objetivos, atos constitutivos, regimento interno e demais documentos estruturantes da organização relacionados ao planejamento estratégico (CARBONE et al., 2009). Carbone et al. (2016) indicam que a observação, a entrevista, os grupos focais, a aplicação de questionários e a análise documental estão entre as principais técnicas utilizadas para mapear competências.

Após a análise de conteúdo das respostas, ocorre a descrição das competências profissionais consideradas relevantes. Percebe-se que as competências podem ser descritas e identificadas de diferentes formas. Carbone et al. (2009) recomendam descrever as competências profissionais sob a forma de referenciais de desempenho, isto é, por meio de comportamentos objetivos e passíveis de observação no ambiente de trabalho. Pode ser acrescentada uma condição na qual se espera que o desempenho ocorra e um critério que aponte um padrão de qualidade ou nível de desempenho considerado satisfatório (BRANDÃO E BAHRY, 2005, p. 183).

Outros autores procuram descrever as competências através de seus elementos constitutivos, isto é, os conhecimentos, habilidades e as atitudes necessárias para que o indivíduo apresente determinado comportamento no trabalho (MARQUES, 2013).

É importante realizar periodicamente o mapeamento e planejar a captação e o desenvolvimento de competências, uma vez que as próprias competências internas disponíveis na organização podem ganhar ou perder relevância com o passar do tempo. Ademais, o ambiente complexo no qual as organizações estão presentes faz com que sejam necessárias cada vez mais novas competências. Recomenda-se que a organização estime a relevância futura de suas competências, possibilitando agir de forma proativa para desenvolver no presente competências que serão importantes no futuro (BRANDÃO E BAHRY, 2005).

Uma outra opção para mapeamento de competências foi desenvolvida por Leme (2014) através da metodologia do Inventário Comportamental. Caracteriza-se como uma lista de Indicadores de 
Competências que traduz a conduta do comportamento ideal desejado e necessário para que a organização consiga agir alinhada à Missão, Visão, Valores e a Estratégia da Organização (MVVE). A sua proposta é trabalhar com os indicadores de competências comportamentais, que são os comportamentos que podem ser observados nas pessoas. Após a sensibilização das pessoas na organização, os funcionários recebem orientações para o preenchimento de uma folha com três colunas denominadas como "Gosto", "Não Gosto" e "O Ideal Seria". Devem ser envolvidas pessoas de todas as funções da organização. Uma boa amostra pode girar em média de $10 \%$ a $20 \%$ dessa população.

Elas devem pensar em cada pessoa com as quais se relaciona na organização. Na coluna “Gosto”, ao pensar em uma das pessoas, devem ser anotados os comportamentos que sejam admirados e que contribuam para a organização. Posteriormente, devem ser registrados os comportamentos que não julgue apropriados na coluna "Não Gosto". Na coluna "O Ideal Seria", são anotados os comportamentos que precisam ser desenvolvidos para que a organização alcance o MVVE. Assim, as duas primeiras colunas revelam os comportamentos que serão transformados em competências do presente, enquanto a última coluna se refere aos comportamentos necessários para o futuro. Esses indicadores são consolidados no infinitivo de forma afirmativa. Por fim, cada indicador é associado a uma competência, resultando em uma lista de competências e cada uma com uma quantidade diferente de indicadores. Com isso, são encontradas as competências organizacionais (LEME, 2014).

Após o mapeamento das competências organizacionais, Leme (2014) aponta que são identificadas quais e quanto dessas competências são necessárias para cada função. 0 superior da função, juntamente com um representante da função, analisa cada indicador e classifica a sua necessidade como "muito forte", "forte", "normal" ou "não se aplica". Os três primeiros são autoexplicativos, enquanto o "normal" é marcado caso o comportamento não sinalize nenhum destaque especial. Os comportamentos classificados como "normal" e "não se aplica" são desprezados e aqueles marcados como "muito forte" e "forte são os comportamentos necessários para a função.

\subsection{GESTÃO POR COMPETÊNCIAS NO SERVIÇO PÚBLICO}

A gestão por competências, na administração pública federal, foi implantada por meio da publicação do Decreto no 5.707, de 23 de fevereiro de 2006, que instituiu a Política Nacional de Desenvolvimento de Pessoal (PNDP), trazendo como uma de suas finalidades a adequação das competências requeridas dos servidores aos objetivos da instituição e o sistema de gestão por competência como um de seus instrumentos (BRASIL, 2006).

0 referido decreto focaliza aspectos ligados à capacitação de servidores como principal ferramenta para implantação da Gestão por Competências no serviço público federal brasileiro. Importante ressaltar que, para parte significativa dos autores que estudam este assunto, não se deve menosprezar a utilização da GPC em todas as áreas de Recursos humanos, isto é, utilizá-la no momento de captação, seleção e de alocação de novos servidores (BERGUE, 2010; CARVALHO et al. 2009; PIRES et al. 2005).

Verifica-se que houve a sua revogação pelo Decreto ${ }^{\circ}$ 9.991, de 28 de agosto de 2019, que relata que a PNDP possui como objetivo promover o desenvolvimento de servidores públicos nas competências necessárias ao alcance da excelência na atuação dos órgãos e das entidades da administração pública federal direta, autárquica e fundacional (BRASIL, 2019).

Destaca-se que o Tribunal de Contas da União (TCU) tem realizado cobrança pelo correto cumprimento dessa legislação. O TCU tem acompanhado e fiscalizado a situação da governança e da gestão de pessoas da Administração Pública Federal. Com o objetivo de promover melhorias nessa situação, proferiu o Acórdão $\mathrm{n}^{\circ} 3.023 / 2013$, de 13 de novembro de 2013, indicando a GPC como instrumento da governança estratégica de pessoas (TRIBUNAL DE CONTAS DA UNIÃO, 2013).

De acordo com Giudice (2012, p. 200), apesar do modelo de gestão por competências estar associado, em grande parte, à entrega dos funcionários conforme os objetivos da organização, isso ainda não ocorre com muita frequência, no setor público, devido à ausência de efetividade na legislação que normatiza o processo de desempenho e cobrança de resultado na administração pública.

No relatório elaborado pela Organização para Cooperação e Desenvolvimento Econômico (OCDE) para avaliar a gestão de recursos humanos do governo brasileiro, a Gestão por Competências é apontada como uma ferramenta potencialmente poderosa, devendo representar uma prioridade para a administração brasileira. Além disso, segundo o relatório supracitado, a finalidade da utilização das competências é "alterar radicalmente a forma como as pessoas são geridas e aumentar a utilização de competências para 
todo o ciclo de gestão de pessoal: seleção, alocação, treinamento e desenvolvimento, e sua avaliação de desempenho" (OCDE, 2010, p. 134).

Segundo Amaral (2014, p. 551), a administração pública brasileira possui traços peculiares, historicamente construídos. Nesse sentido, Leme (2011) destaca que é importante que a escolha do modelo metodológico relacionado à gestão de pessoas por competências seja compatível com a realidade, a cultura da instituição pública e que seja flexível, podendo ser aprimorado com a evolução da organização e da Gestão de Pessoas.

De acordo com Camões (2010), estudos feitos em órgãos públicos sugerem que os principais obstáculos para a adoção do modelo de gestão por competências são a inexistência de um sistema de informações bem estruturado, as barreiras culturais, a falta de incentivo à participação em programas de treinamento e a ausência de oportunidade de aplicar o conhecimento adquirido na prática.

\subsection{GESTÃO POR COMPETÊNCIAS NAS IFES}

Romano (2016) aponta que as IFES, em geral, esperam posicionamento e orientações do Órgão Central do Sistema de Pessoal Civil da Administração Federal (SIPEC) no que se refere ao modo de conduzir suas ações para implementar a gestão por competências em suas rotinas gerenciais. Nesse contexto, algumas dessas instituições se destacam pela construção prévia de modelos de gestão e se empenham para colocálos em prática.

Perseguino e Pedro (2017) realizaram uma pesquisa para analisar o estágio de adoção do modelo de gestão por competências (GPC) em universidades federais (UFs). Do universo de 60 UFs pesquisadas, 50 instituições responderam ao questionário. Verificou-se que oito instituições adotaram a GPC como parâmetro para a gestão de pessoas e quarenta e duas ainda não. Considerando as universidades que não adotaram a GPC, onze declararam estar em fase de estudo para compreensão das premissas presentes no modelo. Em relação às UFs que adotaram, a maioria indica que a GPC se encontra incorporada ao nível estratégico, uma vez que há a previsão no Plano de Desenvolvimento Institucional (PDI). No entanto, observou-se que nenhuma delas implantou integralmente o modelo em todos os subsistemas de gestão de pessoas.

Montezano, Marques, Silva e Isidro-Filho (2019) identificaram como dificuldades para implantação da Gestão por Competências nas Instituições da Rede Federal de Educação Profissional, Científica e Tecnológica os seguintes fatores: restrições de pessoal para implementação, falta de apoio da gestão, resistência dos servidores, problemas estruturais e de gestão, restrições de recursos orçamentários e tecnológicos, falta de planejamento para implantação, ausência de referências positivas da implantação em organizações públicas, resistências à mudança da cultura organizacional, e limitações conceituais e metodológicas.

\subsection{ALOCAÇÃO E SELEÇÃO DE PESSOAL}

Destacam-se como principais ganhos esperados com a implantação da Gestão por Competências a possibilidade de melhorias no desempenho individual e organizacional e na alocação de pessoas (MONTEZANO, 2019).

Treff (2016, p.45) aponta que há quem afirme que a alocação procura selecionar/escolher "a pessoa certa para o lugar certo". Entretanto, a complexidade e o dinamismo do mundo do trabalho e dos negócios fazem com que esse objetivo seja quase impossível de ser alcançado, embora essa seja considerada a situação ideal. Mesmo assim, os gestores devem procurar adotar metodologias e técnicas que aproximem o máximo possível as características e competências dos servidores às necessidades da instituição.

Rabaglio (2004, p. 96) aponta algumas vantagens da seleção por competências. Exemplo disso é uma seleção com mais foco e consistente na identificação de comportamentos relevantes para a vaga; melhor adequação do profissional à empresa e à função a ser desempenhada, possibilitando uma possível rotatividade de funcionários dentro da empresa mais baixa; fortalecimento da parceria entre a área de seleção e clientes internos; maior clareza na coleta de dados sobre a situação do candidato, com maior veracidade das informações relatadas por ele.

Para Leme (2014), todo processo seletivo é realizado mediante a seleção por competências no que se refere às competências técnicas. Nesses casos, investiga-se os conhecimentos adquiridos e experiências vividas relacionadas ao passado do candidato. Deveria haver o mesmo procedimento para identificar a 
parte comportamental, investigando um comportamento já ocorrido. Isso não quer dizer que o candidato agirá da mesma maneira, porém ele terá uma forte tendência a fazê-lo.

\subsection{ALOCAÇÃO E SELEÇÃO DE PESSOAL NO SERVIÇO PÚBLICO}

A seleção de pessoas na Administração Pública, em sua maioria, não consegue avaliar as habilidades e atitudes de um candidato (SOUZA, 2019). Leme (2011, p. 104) menciona que as competências técnicas podem ser avaliadas objetivamente com provas e testes. 0 conhecimento pode ser avaliado por meio de uma prova teórica, como ocorre em um concurso público.

Pires et al. (2005) consideram que a formação de um quadro de servidores adequado deve se apoiar na contratação de funcionários que não apenas demonstrem o domínio de conhecimentos técnicos acerca de determinadas matérias, mas possuam também habilidades e atitudes compatíveis com suas atribuições futuras.

Pode-se afirmar que há uma grande dificuldade em aplicar técnicas voltadas pra o perfil psicológico e transformar elementos considerados subjetivos em critérios objetivos de avaliação para seleção no serviço público. Sendo assim, a seleção pública acaba por admitir candidatos muito capazes intelectualmente, porém, nem sempre, com o perfil comportamental adequado para um bom desempenho em sua função.

Carvalho et al. (2016) argumentam que diversos instrumentos de seleção podem servir de auxílio à identificação das características de cada candidato para posterior associação com as competências necessárias ao perfil estabelecido como referencial. Segundo Leme (2011), o serviço público pode utilizar técnicas de seleção com os aprovados em concurso que foram convocados.

A entrevista por competências se baseia na premissa de que os comportamentos revelados podem indicar comportamentos futuros. Dessa maneira, adota-se como instrumento de trabalho uma pesquisa de comportamentos e resultados passados com a finalidade de prever comportamentos futuros que podem, ou não, colaborar com o sucesso do servidor para o setor.

De forma diferente das empresas privadas, que utilizam a entrevista como fator de exclusão de um candidato, o serviço público busca a inclusão ao usar esse instrumento. Isso ocorre porque deve-se chamar o próximo da fila do concurso no serviço público e é necessário determinar em qual setor o servidor terá a menor necessidade de capacitação (LEME, 2011, p. 93).

Nesse sentido, a alocação de servidores por competências pode ser considerada como a distribuição de pessoal nos diversos cargos após aprovação e convocação no concurso público, através do levantamento do perfil do servidor, o que inclui conhecer suas experiências anteriores, suas aptidões, sua identificação com os valores da organização, suas competências técnicas e comportamentais. Esse processo busca a conciliação entre o perfil exigido para o cargo ou função e o perfil do profissional ingressante.

As dinâmicas de grupo, quando aplicadas à seleção, são praticadas para identificar e analisar a interação de cada candidato com os demais participantes. Além disso, possibilita observar a inter-relação do perfil do candidato com o perfil de competências estabelecido para o cargo. Isso ocorre a partir da observação direta do comportamento dos candidatos pelo profissional responsável pela seleção (CARVALHO et al., 2016).

Almeida (2004) ressalta que houve o cuidado do legislador em instituir o concurso público como obrigatório com o propósito de democratizar o processo de seleção. Pode-se afirmar que busca a igualdade de oportunidades a todos os candidatos e a transparência no processo. Desse modo, exames escritos e, em determinados casos, a comprovação de títulos são exemplos de critérios objetivos mais aceitáveis por estarem menos sujeitos a influências políticas (MARCONI, 2003).

Marconi (2003) acrescenta que as descrições das atividades a serem exercidas pelos ocupantes de cada cargo estão incluídas de forma genérica nas leis que criam as carreiras e cargos. Segundo Pantoja (2010), a forma que é realizada a descrição de cargos limita o escopo de atuação dos servidores.

Observa-se a presença de cargos generalistas no serviço público que podem estar presente em quase todos os setores dessas instituições. Com isso, as competências técnicas e comportamentais que os servidores desses cargos precisam possuir podem variar de acordo com esses setores.

Nesse contexto, Leme (2011, p. 69) recomenda que não se deve atentar apenas ao cargo que os profissionais possuem quando falamos em competências em instituições públicas. 0 referido autor 
aconselha realizar a descrição da função no lugar da descrição de cargo. A função corresponde ao conjunto de atribuições a serem desempenhadas no dia a dia do servidor. Pode-se afirmar que é a junção entre o cargo e a área de atuação.

Pires et al. (2005), inspirados em processos similares aplicados por países que fazem parte da OCDE, sugerem a realização de cursos de formação e ambientação, entrevistas, testes psicológicos e exames de saúde como novas fases no concurso público. Com isso, buscam viabilizar a identificação de competências interpessoais, gerenciais e estratégicas que não conseguiriam ser analisadas através de provas e comprovação de títulos.

No entendimento de Pires et al. (2005), uma alternativa interessante consiste em realizar avaliação de perfil em cursos de ambientação não mais como etapa de concurso. Desse modo, propõe que seja como uma fase de socialização para observar, avaliar e desenvolver comportamentos, servindo de base para orientar a lotação futura dos servidores.

Cabe destacar que as estratégias de seleção, os tipos de provas e conteúdos programáticos, podem ser mais focalizados, considerando o perfil profissional que se deseja para o cargo (ALMEIDA, 2004).

\section{METODOLOGIA}

Realizou-se, preliminarmente, um estudo sobre a literatura em questão através da investigação de pesquisas de autores consagrados no que se refere a temas como Competências, Gestão por competências no serviço púbico, Gestão de Pessoas, seleção de pessoas e alocação de servidores. Com isso, buscou-se obter suporte teórico para melhor avaliar o processo de alocação de servidores técnico-administrativos recém-concursados da IFES estudada e elaborar o instrumento de coleta de dados. Posteriormente, foram encaminhados questionários aos técnico-administrativos que ingressaram em 2019 na referida IFES.

Esta pesquisa utiliza a classificação proposta por Vergara $(2016$, p. 48) que qualifica a pesquisa quanto aos aspectos relacionados aos seus fins e meios. Em relação aos fins, esta pesquisa pode ser classificada como descritiva. Quanto aos meios, apresenta-se como bibliográfica, documental, estudo de caso e pesquisa de campo.

Caracteriza-se como descritiva, uma vez que buscou descrever a percepção dos servidores técnicoadministrativos recém-concursados da IFES estudada.

Bibliográfica porque consistiu em pesquisa em periódicos, artigos, livros, dissertações. Considera-se documental, pois foram utilizadas leis, decretos, relatórios e o formulário para mapeamento da vaga da instituição. Ademais, verifica-se como pesquisa de campo ao utilizar questionários para levantar a percepção dos técnico-administrativos recém-concursados.

A coleta dos dados foi realizada com caráter anônimo através de questionários online. As respostas foram padronizadas conforme a escala Likert, desenvolvida por Rensis Likert (1932) para medir atitudes no contexto das ciências comportamentais. Conforme sugere Mattar (1997), observa-se que os respondentes são solicitados não só a concordarem ou discordarem das afirmações, mas também a afirmarem qual seu grau de concordância, ou discordância. A cada célula de resposta, é atribuído um número, que reflete a direção da atitude do respondente a cada afirmação.

Para efeito desta pesquisa, o questionário aplicado foi apresentado com uma série de cinco proposições, em que o respondente teve que selecionar apenas uma. As afirmações eram "concordo totalmente"; "concordo"; "não concordo, nem discordo"; "discordo"; "discordo totalmente".

A consulta foi realizada pela equipe de análise de lotação da instituição. Antes de aplicar o questionário aos servidores, um teste foi realizado com um pequeno grupo de pessoas selecionadas por conveniência, uma vez que fazem parte da própria equipe. Após retificações, houve o reteste com a coordenadora e com a diretora da unidade responsável pela lotação de pessoal técnico-administrativo da instituição. As sugestões dos envolvidos refinaram as perguntas, e deixaram o questionário mais claro e objetivo para ser aplicado.

O questionário foi encaminhado a 343 servidores técnico-administrativos admitidos por concurso em 2019 na IFES em estudo e esteve disponível para resposta entre fevereiro e agosto de 2020. 0 presente trabalho conta apenas com a parte objetiva do questionário, que apresenta 8 perguntas fechadas. Oportuno ressaltar que apenas a questão 6 não tinha caráter de resposta obrigatória. Isso ocorre porque a questão 6 foi direcionada apenas aos servidores dos cargos que passaram por dinâmica de grupos com base em competências. 


\section{ANÁLISE DOS RESULTADOS}

A IFES contava com um número de técnico-administrativos superior ao de docentes, em setembro de 2020, destacando a importância desses servidores para o bom desempenho da instituição. Eles ingressam na IFES mediante concurso público e são submetidos ao regime jurídico único dos servidores públicos federais sob a lei 8.112 de 1990.

A Divisão de Gestão de Lotação faz parte da Pró-Reitoria de Gestão de Pessoas da instituição. Dentre outras responsabilidades, compete à supracitada Divisão gerenciar as atividades relacionadas à lotação dos servidores técnico-administrativos, tendo como fundamento à política de gestão de pessoas por competências adotada pela instituição. Uma das equipes responsáveis pela alocação dos servidores técnico-administrativos é a equipe de análise de lotação.

A instituição procurou se alinhar ao decreto 5.707/2006 que instituiu a Política Nacional de Desenvolvimento de Pessoal - PNDP, a qual previa, dentre outras ações, a implementação da gestão por competências pelos órgãos e entidades da administração pública federal direta, autárquica e fundacional. Em 2010, ocorreu o I Seminário Interno de Recursos Humanos, pela então Superintendência de Recursos Humanos, atualmente Pró-Reitoria de Gestão de Pessoas. Seu objetivo era a elaboração do planejamento estratégico para o próximo quadriênio, incluindo a realização do mapeamento de competências.

Inicialmente, o projeto de mapeamento de competências contou com a realização de um projeto-piloto, em 2011, executado na atual Pró-Reitoria de Gestão de Pessoas. Seus resultados foram apresentados à alta gestão da IFES e obteve aprovação para implementação, em toda a organização, em 2012.

Para isso, uma equipe de trabalho foi composta para ser responsável pelos estudos a respeito das diversas abordagens possíveis para a implementação de uma metodologia relacionada à GPC que contemplasse as características técnicas e culturais da Instituição. Optou-se pela adoção da proposta concebida por Rogerio Leme como ferramenta central para a implementação do modelo. Essa escolha foi justificada em razão da metodologia trazer uma proposta de operacionalização mais clara e prática, diferente de outras que são mais teóricas.

Essa metodologia separa competências em dois grupos: competências técnicas e competências comportamentais. Conforme Leme (2014), as primeiras se associam aos conhecimentos e habilidades, enquanto as segundas estão vinculadas às atitudes.

Cabe ressaltar que foram realizadas algumas adaptações necessárias à realidade da instituição. Essas adequações corroboram com Leme (2011, p. 9) que faz críticas a respeito da aplicação de referências teóricas na íntegra. Para o autor, as questões culturais que envolvem a região, a organização, o funcionalismo público e o setor devem ser consideradas na prática.

Na IFES, a ausência de mapeamento anterior de funções, que garantisse a eficácia da utilização desse conceito, fez com que houvesse uma adaptação em relação à metodologia. Com isso, os cargos foram considerados como referência para a descrição das atribuições dos servidores em seus locais de trabalho ao invés da função. Tais atribuições, vinculadas ao Plano de Carreira dos Cargos Técnico-Administrativos em Educação - PCCTAE (Lei 11.091, 2005), foram utilizadas como base para a definição de competências técnicas, além de nortearem a análise em relação à pertinência e à intensidade dos indicadores de competências comportamentais em cada um dos setores da instituição.

$\mathrm{Na}$ etapa relacionada ao mapeamento das competências organizacionais, a metodologia do Inventário Comportamental de Rogerio Leme foi utilizada para mapear as competências comportamentais. Segundo Leme (2014), essas necessitam estar alinhadas com a missão, visão, valores e estratégia (MVVE). Observase que a IFES contemplou os $20 \%$ de representatividade de todos os cargos, conforme a amostra prevista na metodologia.

Cabe afirmar que, no projeto de mapeamento de competências, foram considerados apenas os técnicoadministrativos e as respectivas chefias para definir quais e quanto das competências eram necessárias de cada cargo em cada setor.

Importante destacar que determinados cargos mais genéricos, como Assistente em Administração, podem requerer atribuições e competências completamente distintas conforme a natureza da área em que atuam.

Nesse contexto, para realizar a alocação por competências de servidores técnico-administrativos recémconcursados, a instituição criou o Formulário para mapeamento da vaga, que inclui o Mapeamento de Atribuições e Processos (MAP) e o Mapeamento de Competências (MC). Sua construção se baseia nos 
conceitos de mapeamento de competências (LEME, 2014), análise do trabalho (SPECTOR, 2010) e análise e descrição de cargos. Esses mapeamentos realizados na instituição são realizados através da função do cargo em cada setor.

Além dos conceitos mencionados, o Mapeamento de Atribuições e Processos (MAP) utiliza como referência o Inventário de Atribuições por Produto (IAP) e o conceito de descrição da função de Rogerio Leme. Importante destacar que foram efetuadas algumas adaptações ao construir esse instrumento por considerar que não era viável lidar com o conceito de entregas naquele momento na instituição.

O MAP tem como objetivo auxiliar o gestor da área a definir com clareza as atribuições do cargo no setor sob sua responsabilidade. Além disso, são solicitadas informações adicionais relacionadas às condições do trabalho, como o turno estabelecido, exigência de disponibilidade para viagens, composição da equipe. 0 foco está em especificar "o que fazer" através da identificação do conjunto de atividades necessárias para realizar uma determinada entrega ou produto com base no cenário atual. Leme $(2014$, p.12) esclarece que a descrição da função deve se concentrar na essência das tarefas, sem detalhar processos e procedimentos. Isso ocorre porque estes podem possuir um nível médio e alto de mudanças, enquanto aquelas apresentam um nível baixo. Observa-se que o PCCTAE esclarece os limites das atribuições relativas a cada cargo. A chefia imediata deve usá-lo como referência para não extrapolar os limites dispostos no Plano de Carreira.

O Mapeamento de Competências (MC) abrange o mapeamento de competências técnicas e comportamentais. O mapeamento de competências técnicas foi baseado no PCCTAE a partir do levantamento das atribuições dos cargos técnico-administrativos. Dessa forma, buscou-se mitigar riscos de desvios de função. O PCCTAE descreve os cargos técnico-administrativos em educação, seus requisitos de qualificação e suas atividades típicas. Para cada atribuição, foram descritos conhecimentos e habilidades necessários para a sua execução, definindo as competências técnicas de cada cargo. Leme (2011, p.70) aponta que a descrição de cargos descreve o macro de atividades abarcadas por determinado cargo e não tem como finalidade descrever atividades específicas de suas funções derivadas.

Com a finalidade de considerar à função do cargo no setor, a partir das competências técnicas definidas para cada cargo, procurou-se identificar com os servidores ocupantes do cargo e chefes dos setores quais e quanto dessas competências são necessárias para cada cargo de acordo com os seus setores de atuação. Cabe ressaltar que tal fato ocorreu no projeto de mapeamento de competências e atualmente essas informações são validadas ou atualizadas com as chefias imediatas quando uma vaga está para ser provida. Isso acontece através do mapeamento de competências técnicas que está presente no formulário de Mapeamento de Competências (MC). Essa parte possui três colunas. Leme (2014, p. 28) considera que formulários para coleta de dados podem ser utilizados para mapear competências técnicas. A primeira coluna aborda as competências técnicas identificadas. Caso seja necessário, o gestor pode incluir outras consideradas importantes para o cargo no setor. A segunda consta o nível de conhecimento exigido para a admissão do servidor na função e se refere ao conceito de requisito de acesso de Leme (2014). A terceira se refere ao desempenho a ser atingido após período de adaptação e desenvolvimento no local de atuação, baseada na definição de requisito de função de Leme (2014). Em outras palavras, o referido autor aponta que requisito de acesso é o mínimo aceitável que um funcionário iniciante em sua função necessita ter e requisitos de função são as condições ideais que o colaborador deve possuir para desempenhar suas atividades na plenitude.

O mapeamento de competências comportamentais foi gerado a partir de uma lista de 65 indicadores comportamentais, usando como referência o conceito do Inventário Comportamental descrito por Leme (2011, p. 40). Esses indicadores refletem os comportamentos que podem ser observados nas pessoas. Além disso, o referido autor argumenta que esse inventário consiste em uma lista de indicadores de competências que traduz o comportamento ideal desejado e necessário para que a instituição atue de forma alinhada à missão, visão, aos valores, e à estratégia da organização.

Na IFES, esses indicadores deram origem a uma lista de 15 competências comportamentais. Dessa forma, cada indicador é associado a uma competência. Liderança, comunicação e sociabilidade são alguns exemplos dessas competências. Observa-se que, para a alocação de técnico-administrativos recémconcursados, houve uma adaptação na metodologia. Dentre a lista de 15 competências comportamentais mencionadas, foram excluídas as competências ética e comprometimento, passando a trabalhar com 13 competências. Atualmente o gestor informa quais são as 5 mais importantes para o cargo no setor à equipe responsável pela alocação de novos servidores concursados por meio do formulário de Mapeamento de Competências (MC). 
Antes da convocação dos candidatos, esses mapeamentos são realizados em cada unidade que possui previsão de ingresso de novos servidores. Inicialmente, a equipe de análise de lotação identifica as vagas desocupadas e solicita aos gestores máximos dessas unidades que indiquem o setor de exercício, nome e chefia imediata do futuro servidor. Cabe a essa equipe atuar na definição da lotação dos servidores recémconcursados, tendo como premissa a análise da compatibilidade entre o mapeamento das vagas disponíveis, considerando os cargos e as demandas dos setores previstos de exercício, e a identificação do perfil do novo servidor.

Após as repostas com esses detalhamentos, o Formulário para mapeamento da vaga é encaminhado às chefias imediatas dos novos servidores. Soma-se a isso, o envio de materiais de apoio como tutoriais e glossários para facilitar o entendimento e posterior preenchimento do instrumento para mapeamento por esses gestores. Caso o cargo já tenha sido mapeado no setor, solicita-se que seja feita a validação ou atualização das informações. Nesse momento, as principais atribuições do cargo no setor, bem como as competências técnicas e comportamentais esperadas são levantadas.

Em seguida, a equipe realiza a análise do formulário preenchido pelas chefias e verifica a compatibilidade dessas informações com a descrição do cargo no PCCTAE. Essa ação busca evitar casos de desvio de função. Caso o cargo não seja compatível com a realidade atual do trabalho do setor, recomenda-se a sua permuta internamente ou pelo Ministério da Educação.

Importante destacar que a instituição tem buscado alinhar o conteúdo programático de seus concursos para cargos técnico-administrativos com o perfil profissional que se deseja para as vagas as serem providas.

Após a convocação, os candidatos se submetem a entrevistas individuais por competências. Para a uniformização do processo, todos os entrevistadores são capacitados previamente em Entrevista de Seleção por Competência (ALMEIDA, 2004; LEME, 2014). Além disso, são realizadas dinâmicas de grupo com base em competências para determinados cargos. A escolha em complementar o processo de avaliação com dinâmicas de grupo é baseada na quantidade de convocados e de vagas disponíveis para esses cargos com o intuito de obter mais subsídios para a indicação da lotação (SPECTOR, 2010).

Todas as informações coletadas com os formulários MAP e MC são utilizadas nas entrevistas e dinâmicas de grupo para identificar perfis compatíveis com a demanda do posto de trabalho a ser ocupado. Destacase que essas atividades não possuem caráter eliminatório.

Os principais diferenciais da nova metodologia se referem à parceria da equipe responsável com as unidades para o mapeamento das vagas desocupadas, considerando a lotação de exercício do futuro ocupante; inclusão da etapa de desenho do perfil da vaga; utilização do mapeamento de competências como instrumento para o provimento da vaga; revisão dos cargos a serem repostos conforme as atribuições mapeadas; realização de entrevistas e dinâmicas de grupo com base no MAP e MC; reuniões com equipe multidisciplinar para definição de lotação; alocação dos novos servidores nos setores de exercício.

Cabe salientar que é elaborado um Relato da Entrevista para cada candidato, que juntamente com o currículo entregue na convocação, integram o material a ser utilizado como subsídio para a indicação da lotação. A decisão de alocação do novo servidor fica a cargo da Divisão de Gestão de Lotação após reunião entre as suas equipes. No entanto, os gestores das unidades possuem autonomia para movimentar seus servidores dentro de suas unidades, apesar de não ser indicado agir assim.

Verifica-se que 151 servidores responderam o questionário, o que representa um percentual de retorno de 44,02\%. Como não possuía caráter obrigatório e estava direcionada apenas aos cargos que passaram pela dinâmica de grupo, a questão 6 obteve 93 respostas válidas.

Para realizar o estudo das respostas do questionário encaminhado aos técnico-administrativos recémconcursados, verifica-se que foram utilizadas as frequências, os percentuais, a moda e mediana relacionadas a cada pergunta. A descrição geral das análises de cada assertiva está demonstrada na tabela 1. 
Tópicos em Administração - Volume 43

Tabela 1 - Respostas do questionário

\begin{tabular}{|c|c|c|c|c|c|c|c|}
\hline Questão & $\begin{array}{l}\text { Discordo } \\
\text { totalmente }\end{array}$ & Discordo & $\begin{array}{l}\text { Não concordo, } \\
\text { nem discordo }\end{array}$ & Concordo & $\begin{array}{l}\text { Concordo } \\
\text { totalmente }\end{array}$ & MEDIANA & MODA \\
\hline $\begin{array}{l}\text { 1) Considero possuir } \\
\text { conhecimentos e } \\
\text { habilidades compatíveis } \\
\text { com as atividades } \\
\text { desenvolvidas no meu } \\
\text { setor de lotação. }\end{array}$ & $1,99 \%$ & $2,65 \%$ & $7,28 \%$ & $32,45 \%$ & $55,63 \%$ & $\begin{array}{l}\text { Concordo } \\
\text { totalmente }\end{array}$ & $\begin{array}{l}\text { Concordo } \\
\text { totalmente }\end{array}$ \\
\hline $\begin{array}{l}\text { 2) Considero apresentar } \\
\text { comportamentos } \\
\text { compatíveis com as } \\
\text { atividades desenvolvidas } \\
\text { no meu setor de lotação. }\end{array}$ & $1,32 \%$ & $0,00 \%$ & $3,97 \%$ & $21,19 \%$ & $73,51 \%$ & $\begin{array}{l}\text { Concordo } \\
\text { totalmente }\end{array}$ & $\begin{array}{l}\text { Concordo } \\
\text { totalmente }\end{array}$ \\
\hline $\begin{array}{l}\text { 3) Estou satisfeito com a } \\
\text { minha lotação. }\end{array}$ & $7,95 \%$ & $7,28 \%$ & $9,93 \%$ & $22,52 \%$ & $52,32 \%$ & $\begin{array}{l}\text { Concordo } \\
\text { totalmente }\end{array}$ & $\begin{array}{l}\text { Concordo } \\
\text { totalmente }\end{array}$ \\
\hline $\begin{array}{l}\text { 4) Estou exercendo } \\
\text { minhas atividades na } \\
\text { lotação indicada no Ofício } \\
\text { de Apresentação }\end{array}$ & $4,64 \%$ & $3,31 \%$ & $4,64 \%$ & $17,88 \%$ & $69,54 \%$ & $\begin{array}{l}\text { Concordo } \\
\text { totalmente }\end{array}$ & $\begin{array}{l}\text { Concordo } \\
\text { totalmente }\end{array}$ \\
\hline $\begin{array}{l}\text { 5) Considero que o } \\
\text { modelo da Entrevista } \\
\text { individual utilizado foi } \\
\text { relevante para a } \\
\text { definição da minha } \\
\text { lotação. }\end{array}$ & $11,92 \%$ & $6,62 \%$ & $20,53 \%$ & $27,15 \%$ & $33,77 \%$ & Concordo & $\begin{array}{l}\text { Concordo } \\
\text { totalmente }\end{array}$ \\
\hline $\begin{array}{l}\text { 6) Caso tenha participado } \\
\text { da dinâmica de grupo } \\
\text { conduzida pela Equipe de } \\
\text { Análise de Lotação, } \\
\text { considero que a dinâmica } \\
\text { utilizada foi relevante } \\
\text { para a definição da minha } \\
\text { lotação. }\end{array}$ & $11,83 \%$ & $13,98 \%$ & $18,28 \%$ & $32,26 \%$ & $23,66 \%$ & Concordo & Concordo \\
\hline $\begin{array}{l}\text { 7) O processo de análise } \\
\text { de lotação contribuiu } \\
\text { para o alinhamento entre } \\
\text { o meu perfil profissional } \\
\text { e as necessidades da } \\
\text { Universidade. }\end{array}$ & $5,30 \%$ & $10,60 \%$ & $14,57 \%$ & $35,10 \%$ & $34,44 \%$ & Concordo & Concordo \\
\hline $\begin{array}{l}\text { 8) As orientações } \\
\text { prestadas na Entrevista } \\
\text { individual pela Equipe de } \\
\text { Análise de Lotação foram } \\
\text { suficientes. }\end{array}$ & $3,31 \%$ & $7,95 \%$ & $18,54 \%$ & $31,79 \%$ & $38,41 \%$ & Concordo & $\begin{array}{l}\text { Concordo } \\
\text { totalmente }\end{array}$ \\
\hline
\end{tabular}

A primeira pergunta direcionada aos servidores está associada ao conceito de competências técnicas de Leme. Ao considerar competências como Conhecimentos, Habilidades e Atitudes (CHA), Leme (2011, p.11) considera que as competências técnicas são a união do Conhecimento e Habilidade, ou seja, o $\mathrm{CH}$ do $\mathrm{CHA}$. Observa-se que o uso dessa maneira é justificado pela desnecessidade e, em muitos casos, da impossibilidade de se avaliar o conhecimento desassociado da habilidade.

Pires et al. (2005) consideram que a formação de um quadro de servidores adequado deve se apoiar na contratação de funcionários que demonstrem o domínio de conhecimentos técnicos acerca de determinadas matérias compatíveis com suas atribuições futuras.

Verifica-se que $88 \%$ dos servidores concordam totalmente ou concordam que possuem conhecimentos e habilidades compatíveis com as atividades desenvolvidas em seus setores de lotação. A moda e a mediana corresponderam ao item "concordo totalmente".

A segunda questão está relacionada à definição de competências comportamentais de Rogério Leme. Leme (2011, p.13) afirma que as competências comportamentais representam as atitudes de um profissional, isto é, o A do CHA. Para o autor, as atitudes orientam os comportamentos das pessoas. Comportamento é o 
conjunto das reações que podem ser observadas em um indivíduo. Sendo assim, o desafio é desenvolver as atitudes das pessoas para que seus comportamentos estejam adequados (LEME, 2011, p.15).

Pires et al. (2005, p. 23) consideram que a formação de um quadro de servidores adequado deve ser apoiar na contratação de funcionários que não apenas demonstrem o domínio de conhecimentos técnicos acerca de determinadas matérias, mas também possuam atitudes compatíveis com suas atribuições futuras.

Do total de respostas, 95\% dos servidores concordam totalmente ou concordam que apresentam comportamentos compatíveis com as atividades desenvolvidas em seus setores de lotação. Além disso, a mediana e a moda representaram a proposição "concordo totalmente".

Sobre a terceira pergunta, 75\% dos servidores concordam totalmente ou concordam que estão satisfeitos com a lotação. A mediana e a moda representaram a afirmação "concordo totalmente".

Em tese, um servidor bem alocado trabalhará com mais eficiência, terá qualidade de vida no trabalho, estabelecerá um vínculo maior com a instituição, estará menos propenso aos processos de remoção e não necessitará de um grande número de capacitações para se adequar à função (PIRES et al., 2005).

Na quarta pergunta, buscou- se avaliar se os servidores estão exercendo as suas atividades no local indicado pela equipe responsável pelo processo de alocação de pessoal. Cabe destacar a relevância dessa pergunta, pois o gestor possui autonomia para movimentar o servidor dentro da sua unidade. Vale ressaltar que esse tipo de prática não é recomendada.

Observa-se que apenas 8\% dos servidores discordam totalmente ou discordam que estão exercendo as suas atividades na lotação indicada no Ofício de Apresentação. Isso revela que a maior parte dos gestores respeita as indicações feitas para alocação de servidores recém-concursados. A moda e a mediana estão relacionadas à afirmação "concordo totalmente".

Diferentemente das empresas privadas, que utilizam a entrevista como fator de exclusão de um candidato, o objetivo no setor público é o oposto, justamente o da inclusão. Verifica-se que essa questão é importante, visto que o serviço público tem que convocar o próximo da fila que foi contratado. Com isso, deve-se identificar em qual setor o servidor possui o perfil com menor gap em relação as suas competências (LEME, 2011, p. 93).

A instituição utiliza a entrevista por competências para alocar seus novos servidores. Nesse tipo de entrevista, pressupõe-se que os comportamentos revelados podem dar indícios de comportamentos futuros e, por isso, adota-se como instrumento de trabalho uma pesquisa de comportamentos e resultados anteriores, objetivando a previsão de comportamentos futuros que podem, ou não, colaborar com o sucesso do servidor para o setor. Isso não significa que as pessoas sejam estáticas e seus comportamentos também. Muito pelo contrário, essa premissa é a melhor indicação encontrada, até o momento, para prever comportamentos futuros (RABAGLIO, 2004, p.37).

Leme (2014, p.76) aponta que a finalidade desse tipo de entrevista consiste em investigar o comportamento passado do profissional, uma vez que uma pessoa tende a apresentar o mesmo comportamento quando exposta ao mesmo estímulo já vivenciado no futuro. No entanto, isso não deve ser considerado uma verdade absoluta, pois as pessoas podem amadurecer e modificar seus comportamentos com a experiência adquirida. 0 ideal é que se busque exemplos mais recentes e não vivências distantes do candidato.

Nota-se que $61 \%$ concordam totalmente ou concordam que consideram que esse modelo de entrevista utilizado foi relevante para a definição de sua lotação. A mediana e moda das respostas da questão foram "concordo" e "concordo totalmente" respectivamente.

A sexta questão não foi direcionada a todos os servidores recém-concursados, uma vez que as dinâmicas de grupo com foco em competências foram realizadas em apenas determinados cargos. Com isso, 93 servidores que participaram dessas atividades responderam a essa pergunta do questionário.

Percebe-se que 56\% concordam ou concordam totalmente que a dinâmica de grupo com base em competências foi relevante para a definição da lotação. A mediana e a moda representaram a afirmação "concordo".

Rabaglio (2004, p.80) afirma que "o jogo com foco em competências permite investigar melhor os comportamentos dos indivíduos e identificar com mais eficiência as competências, uma vez que estamos com o candidato diante dos nossos olhos, vendo-o atuar e se comportar dentro de situações preestabelecidas estrategicamente." 
Para Leme (2014, p.112), as dinâmicas de grupo com foco em competências buscam visualizar as competências dos candidatos "ao vivo". Para isso, o objetivo da sua utilização é observar os comportamentos do candidato, analisando se são compatíveis com os comportamentos requisitados para a vaga, o que levará a enxergar as competências.

A sétima questão busca avaliar se o servidor considera que o processo de alocação de pessoal por competências contribuiu para o alinhamento entre o seu perfil profissional e as necessidades da Universidade.

Aproximadamente $70 \%$ concordam totalmente ou concordam com a afirmação. Este processo evidencia a conciliação entre o perfil do profissional e o necessário ao cargo ou função. 0 resultado corrobora com Carbone et al. (2016) que afirma que a seleção externa por competências minimiza o risco de contratar funcionários com perfis de competências diferentes dos desejados. Além disso, ressalta que as organizações públicas apresentam, em grande parte, servidores com boa formação, e, por conseguinte, basta direcionar esforços para alinhar as competências individuais de cada servidor às necessidades da organização.

Para gestão por competências funcionar efetivamente é necessário que sejam identificadas e especificadas as atribuições que um servidor, lotado em uma gerência, seção, coordenação ou secretaria específica, deve realizar (LEME, 2011, p. 4).

Oportuno ressaltar que a mediana e a moda da questão corresponderam ao item "concordo". Houve uma pequena diferença de percentual entre os que concordaram, totalmente e os que concordaram. 0 primeiro apresentou $34 \%$ e o segundo $35 \%$.

A última questão procurou analisar se as orientações prestadas pela equipe responsável pelas entrevistas individuais foram suficientes. 70\% concordaram totalmente ou concordaram com a afirmação. A mediana e a moda corresponderam à "concordo" e "concordo totalmente" respectivamente. Observa-se que por ser um dos primeiros contatos do servidor com a universidade, pode ser considerado um passo inicial para a sua integração à Instituição.

\section{CONSIDERAÇÕES FINAIS}

Observa-se que, se bem conduzidas, as atividades de recrutamento e seleção, fazem com que as organizações tenham maior probabilidade de trazer talentos alinhados com a sua estratégia e missão.

Ao longo da pesquisa buscou-se construir o referencial teórico através das temáticas relacionadas à Gestão por Competências e Alocação de Pessoal, dando ênfase ao contexto do serviço público. O presente artigo procurou avaliar o processo de alocação por competências dos técnicos-administrativos recémconcursados utilizado pela IFES através da percepção de seus servidores admitidos por concurso em 2019.

Percebe-se que o serviço público possui suas particularidades. Após a aprovação em concurso público, a instituição deve definir em quais setores seus novos servidores devem atuar. Uma de suas especificidades decorre do fato de que o processo de alocação lida com um universo limitado de possibilidades de lotação, uma vez que correspondem aos setores com vagas disponíveis no momento da convocação, e de candidatos, que incluem apenas aqueles que foram aprovados no concurso. Com isso, nota-se que nem sempre é possível atender a todas as necessidades das áreas.

Considerando as peculiaridades do serviço público, os resultados apresentados sugerem que, em geral, a instituição alocou servidores com conhecimentos, habilidades e atitudes compatíveis com as atividades dos setores de exercício. Em geral, os servidores respondentes consideram que as suas competências são compatíveis com as atividades desenvolvidas e que o processo de análise de lotação contribuiu para alinhamento entre o seu perfil profissional e as necessidades da universidade. Além disso, apontam satisfação com a lotação e consideram os instrumentos utilizados para análise do perfil dos servidores, tendo como base a gestão por competências, relevantes para a definição da lotação. Esses resultados sugerem que o processo de alocação por competências adotado teve uma avaliação positiva por parte dos servidores que ingressaram na instituição nesse período.

A ausência de análise de percepção de outras partes envolvidas no processo, como os gestores das vagas e os usuários que são atendidos pelos servidores recém-concursados, podem ser consideradas limitações desse estudo. Dessa forma, recomenda-se que sejam realizadas análises com esses públicos como sugestões para estudos futuros. 
Por fim, considerando todas as informações apresentadas, este trabalho desenvolvido na instituição pode indicar que a gestão por competências pode impactar positivamente ao ser utilizada como ferramenta para alocar servidores recém-concursados no serviço público.

\section{REFERÊNCIAS}

[1] ALMEIDA, W. Captação e seleção de talentos: repensando a teoria e a prática. São Paulo: Atlas, 2004.

[2] AMARAL, H. K. do. Desenvolvimento de competências de servidores na administração pública brasileira. Revista do Serviço Público, [s. l], v. 57, n. 4, p. p. 549-563, 2014.

[3] BERGUE, S. T. Gestão de pessoas em organizações. 3. ed. Caxias do Sul: Educs, 2010.

[4] BOYATZIS, R.E. The competent manager: a model for effective performance. Nova York: John Wiley, 1982.

[5] BRANDÃO, H.P.; GUIMARÃES, T.A. Gestão de competências e gestão de desempenho: tecnologias distintas ou instrumentos de um mesmo constructo? Revista de Administração de Empresas, São Paulo, v. 41, n. 1, p. 8-15, 2001.

[6] BRANDÃO, H. P.; BAHRY, C.P. Gestão por competências: métodos e técnicas para mapeamento de competências. Revista do Serviço Público, Brasília, v. 56, n. 2, p. 179-194, 2005.

[7] BRASIL. Decreto no 5.707, de 23 de fevereiro de 2006. Disponível em: <http://www.planalto.gov.br/ccivil_03/_ato2004-2006/2006/decreto/d5707.htm> Acesso em: 06 jan. 2020.

[8] BRASIL. Decreto no 9.991, de 28 de agosto de 2019. Disponível em: <http://www.planalto.gov.br/ccivil_03/_Ato2019-2022/2019/Decreto/D9991.htm> Acesso em: 07 mar. 2020.

[9] BRASIL. Tribunal de Contas da União. Acórdão no 3.023, de 13 de novembro de 2013. DOU: Diário Oficial da República Federativa do Brasil, Brasília, seção 1, 21 nov. 2013, página 89. Disponível em: http://www.jusbrasil.com.br/diarios/61945559/dou-secao-1-21-11-2013-pg-89. Acesso em: 02 ago. 2020.

[10] CAMÕES, M. R. Suporte à transferência de treinamento: estudo de caso na administração pública. Brasília. ENAP, 2010.

[11] CARBONE, P.P.et al. Gestão por competências e gestão do conhecimento. 3. ed. Rio de Janeiro: Fundação Getúlio Vargas, 2009.

[12] CARBONE, P. P.et al. Gestão por competências. 1. Ed. Rio de Janeiro: Editora FGV, 2016.

[13] CARVALHO, A.I. et. al. Escolas de governo e gestão por competências: mesa-redonda de pesquisa-ação. Brasília: ENAP, 2009.

[14] CARVALHO, I. M. V.; PASSOS, A. E. V. M.; SARAIVA, S. B. C. Recrutamento e Seleção por Competências. Rio de Janeiro: Editora FGV, 2016.

[15] DUTRA, J.S; HIPÓLITO, J.A.M; Silva, C.M. Gestão de pessoas por competências: o caso de uma empresa do setor de telecomunicações. Revista de Administração Contemporânea, Curitiba, v.4, n.1, p 161-176, abr. 2000

[16] DUTRA, J. S. Competências: conceitos, instrumentos e Experiências. 2. ed. São Paulo: Atlas, 2017

[17] FLEURY, A.; FLEURY, M.T.L. Construindo o conceito de competência. Revista de Administração Contemporânea, Curitiba, v.5, n. spe, p. 183-196, 2001

[18] GIUDICE, R.C. Desafios da gestão de pessoas por competências na Administração Pública Federal Brasileira. Revista Brasileira de Planejamento e Orçamento, Brasília, v. 2, no 2, p. 188-204, 2012

[19] LE BOTERF, G. Desenvolvendo a competência dos profissionais. Patricia Chittoni Ramos Reuillard (Trad.). Porto Alegre: Artmed, 2003.

[20] LEME. R. Gestão por competências no setor público. Rio de Janeiro: Qualitymark Editora, 2011

[21] LEME, R. Seleção e entrevista por competências com inventário comportamental: guia prático do processo seletivo para a redução da subjetividade e eficácia na seleção. Rio de Janeiro: Qualitymark, 2014.

[22] MARCONI, N. Diagnóstico do sistema de serviço civil do governo federal no Brasil. In: VIII CONGRESSO INTERNACIONAL DEL CLAD SOBRE LA REFORMA DEL ESTADO Y DE LA ADMINISTRACIÓN PÚBLICA. Panamá, 2003. Anais. Panamá, 2003.

[23] MARQUES, F. Guia de mapeamento e avaliação de competências para a administração pública poder executivo. Brasília, jun. 2013.

[24] MATTAR, F. Pesquisa de Marketing. São Paulo: Altas, 1997.

[25] MCLAGAN, P. Competencies: the next generation. Training and Development, p. 40-47, 1997. 
[26] MONTEZANO, L.; SILVA, N. B.; MARQUES, F. B.; ISIDRO-FILHO, A. Aspectos determinantes da implantação da gestão por competências em institutos federais. Revista GUAL, Florianópolis, v. 12, n. 3, p. 21-44, setembro-dezembro 2019.

[27] ORGANIZAÇÃo PARA A COOPERAÇÃo E DESENVOLVIMENTO ECONÔMICO - OCDE. Avaliação da Gestão de Recursos Humanos no Governo. Relatório da OCDE: Brasil: Governo Federal, 2010.

[28] PANTOJA, M. J.; CAMÕES, M. R; BERGUE, S. T. Gestão de pessoas: bases teóricas e experiências no setor público. Organizado por Marizaura Reis de Souza Camões, Maria Júlia Pantoja e Sandro Trescastro Bergue. Brasília: ENAP, 2010.

[29] PARRY, S.B. The quest for competencies. Training, p.48-54, July, 1996

[30] PERSEGUINO, S. A.; PEDRO, W. J. A. Análise crítica da gestão por competências em universidades federais. Revista Tecnologia e Sociedade, v. 13, n. 29, p. 22-44, set./dez. 2017.

[31] PIRES, A. K. et al. Gestão por competências em organizações de governo. Brasília: Escola Nacional de Administração Pública - ENAP, 2005.

[32] RABAGLIO, M. O. Seleção por competências. 4. ed. São Paulo: Educator, 2004.

[33] ROMANO, J.M.T. Benchmarking para implementação do modelo de gestão de pessoas por competências na Universidade Federal de Goiás: Multicasos. Dissertação de Mestrado, 2016. 320 p. - Mestrado Profissional em Administração das Faculdades Alves Faria. Goiânia, 2016.

[34] SILVA, A. C. et al. A gestão por competência na busca de uma organização eficaz: estudo de caso em uma universidade brasileira. Journal Globalization, Competitiveness and Governability, Georgetown, v. 8, n. 2, p. 102-120, 2014.

[35] SOUZA, V. R. Alocação de pessoas por competência em instituições federais de ensino superior: estudo de caso na Universidade Federal de Goiás. Dissertação de Mestrado do Programa de Pós-Graduação em Administração Pública. UFG. Aparecida de Goiânia. 2019.

[36] SPECTOR, P. E. Psicologia nas organizações. 3 ed.São Paulo: Saraiva, 2010.

[37] TREFF, M. Gestão de pessoas: olhar estratégico com foco em competências. 1. Ed. Rio de Janeiro: Elsevier, 2016.

[38] VERGARA, S. C. Projetos e relatórios de pesquisa em administração. 16a ed. São Paulo: Atlas. 2016.

[39] ZARIFIAN, P. Objetivo competência: por uma nova lógica. Maria Helena C.V. Trylinski (Trad.). São Paulo: Atlas, 2001. 


\section{Capítulo 17}

Primeiros passos em busca da vantagem competitiva: Construção da identidade organizacional para pequenas empresas

\section{Cássia Jaqueline Theobald}

Resumo: Este trabalho buscou delinear a construção do histórico da identidade organizacional a partir da ideia de um constructo social, interligando-a à teoria de vantagem competitiva a fim do uso dessas informações para planejamentos empresariais e tomadas de decisão, e possibilitar que a empresa desenvolva vantagem em relação a seus concorrentes a partir do conhecimento sobre suas características e diferenciais. Para isso, realizou-se uma revisão de literatura sobre identidade organizacional e vantagem competitiva à luz de ideias vindas de diferentes autores, para estabelecer com o desenvolvimento e atrelamento das duas teorias, como o processo criativo de delimitação de identidade organizacional se forma, dando ênfase em empresas pequenas. Dada a relevância do tema, procurou-se através dos autores e desenvolvimento de ideias incitar o interesse nas organizações em conhecer e definir suas identidades, enfatizando-a como importante ferramenta para exploração do entendimento e conhecimento organizacional, além da identificação do que pode ser uma fonte de vantagem competitiva.

Palavras-Chave: Identidade Organizacional; Vantagem Competitiva; Empresas Pequenas. 


\section{INTRODUÇÃO}

Identidade organizacional é um estudo que possui várias vertentes e integrações com diferentes áreas de pesquisa acadêmica. Dentre as várias ideias desenvolvidas sobre o tema, este trabalho optou por seguir pelo caminho da identidade sendo vista como um constructo social que é formado a partir de um ciclo de influência que integra o público interno e externo a empresa. Tem-se por fim, elucidar sua importância e construir uma discussão teórica que permita como contribuição, uma melhor aplicação do tema a empresas reais, especificamente pequenas, ao proporcionar uma base de estudo com histórico e ideias de como se forma a identidade, juntamente a atrelá-la com a estratégia organizacional pela vantagem competitiva.

O desenvolvimento de identidade pelos ramos da psicologia e ciências sociais, trouxe definições do termo "Self" como identidade que se diferenciava entre pessoal ou como o integrante de um grupo (Caldas e Wood Jr, 1997). Com as empresas tomando espaços perante a sociedade, estudos organizacionais passam a aplicar como metáfora essa visão de identidade que era tida como algo do indivíduo (Corley et al. 2006). 0 aumento crescente de interesse no tema contribuiu para várias linhas de estudos, que seguiram por diferentes vertentes disciplinares (Corley et al., 2006).

Foi com o trabalho dos autores Albert e Whetten (1985) que o termo adquiriu suas primeiras delimitações de teorias. Eles possuíam o objetivo de atingir uma definição que seria usada tanto na teoria como na prática, já que a conceituação anterior era muito dispersa e distante de um consenso. Sua principal contribuição, foi o estabelecimento de três critérios que norteavam a seleção de características que delimitavam a identidade organizacional, eram estes: centralidade, distintividade e continuidade temporal.

A partir disto, passou-se a adotar uma diferente abordagem que via a identidade organizacional como um constructo social que se formava a partir do entendimento de coletividade e interação social entre o público interno e o público externo (Corley et al., 2006). Essa visão surgiu com a problemática de utilizar características de um ser individual para uma identidade coletiva (Gioia; Schultz; Corley, 2000).

Pela nova exposição enfrentada na era da informação e seus diversos meios de comunicação, as organizações se viram condicionadas às reações do público e este se tornou formalmente parte do processo de identificação e constante mudança na identidade (Hatch e Schultz, 1997, 2002). A partir disso, as autoras Hatch e Schultz (2002) estabeleceram um ciclo de influência que leva em consideração a cultura, imagem e a identidade, e associa que cada um deles influencia na constante interação entre o público interno e externo a partir de um processo de quatro etapas.

O conhecimento sobre a própria organização e sobre a sua identidade é de extremo benefício, levando em consideração que o aprendizado organizacional sobre as visões da empresa em relação a si mesma e em relação ao seu público externo, eliminam ambiguidades e ajudam a alinhar essas duas visões. As autoras Hatch e Schultz (2002) acreditam que quando a dinâmica entre imagem e cultura está bem balanceada, gera uma definição da identidade que considera todos os grupos relevantes de stakeholders. Além de estabelecer uma base para planejamentos a curto, médio e longo prazo, estratégias, e o eixo de como a organização age e toma suas decisões.

A partir da visão baseada em recursos, o trabalho de Barney (1991) discute a utilização de ativos diversos na empresa que permitem ações estratégicas em relação aos seus competidores, e desenvolve a teoria em torno dos critérios de definição desses recursos. Para uma melhor aplicação prática, adotou-se em conjunto a visão de vantagem competitiva de Ma (2000) que trabalha com a ideia de um constructo que relaciona qualquer par de rivais em um contexto específico, dimensionados em um ambiente focal observado.

Dado o entendimento da construção social trabalhado principalmente pelas autoras Hatch e Schultz $(1997,2002)$ e outros citados e mais explorados no decorrer do trabalho, a identidade organizacional pontua-se como um constructo social que se forma a partir da interação social entre o público interno e externo que cerca a organização. É interessante que se desenvolva esse conceito a fim de estabelecer sua relação com a imagem e cultura organizacional e sua adaptação ambiental, por sua vez, explorados na seção 3. Na seção 4, a vantagem competitiva é trabalhada com os autores Barney (1991) e Ma (2000) a fim de entender a utilização de recursos como fonte de estratégia organizacional e seu atrelamento com a identidade. E por fim, na seção 5, se estabelece a relação positiva e de benefício recíproco entre os dois termos, como fator fundamental para o posicionamento estratégico das organizações num contexto de constantes mudanças e ainda, através de diferentes relatos de autores, como se dá o processo criativo prático de delineamento da identidade dentro das organizações. 


\section{METODOLOGIA}

No presente trabalho teórico, realizou-se uma pesquisa na literatura existente a partir dos temas de identidade organizacional com foco em delimitação da construção da teoria a partir da visão de um constructo social; e vantagem competitiva, interligando-o ao primeiro em justificativa pela busca de diferenciação de mercado a partir do conhecimento organizacional. 0 levantamento bibliográfico sucedeuse a partir de buscas online sobre os assuntos em plataformas nacionais e internacionais com amplitude para fontes e com foco em trabalhos de diversas linhas temporais, a fim de trazer conteúdos já estabelecidos e ideias desenvolvidas, escolhidos com o uso de filtros por palavras chaves e a partir da relevância e complementação com os temas.

\section{CONCEITOS DE IDENTIDADE}

Neste primeiro tópico contemplaremos em uma representação das pesquisas em torno da identidade organizacional e seu desenvolvimento a partir do envolvimento com outras epistemologias e estudos sob o olhar de diferentes áreas. Enfatiza-se a ideia de que a identidade organizacional é uma construção a partir de um fenômeno social que ocorre pela interação entre os stakeholders e além disso, é discutido a teoria da interdependência entre imagem, cultura e a própria identidade da empresa.

\subsection{IDENTIDADE}

O termo "identidade" foi muito citado nos ramos da psicologia e ciências sociais, em disciplinas que lidavam com o "self" e a construção da identidade pessoal, seja ela vista individualmente ou como integrante de um grupo. "O conceito mais popularizado de identidade define-a como uma classificação do self que expressa o indivíduo como reconhecidamente diferente dos demais, e como similar a membros da mesma classe" (Caldas e Wood Jr., 1997, pg.10). "A noção psicanalítica de identidade individual tornou o sentido de unicidade e continuidade, de um processo localizado no indivíduo, porém influenciado pelo seu meio e pela sua cultura" (Caldas e Wood Jr., 1997, pg.10).

A partir disso, usou-se essa visão como uma analogia para as empresas que passaram a ser mais influentes e adotarem características de verdadeiros atores sociais, e autores como Weber, Marx, Durkheim e outros, iniciaram os estudos organizacionais (Corley et al., 2006). Com o desenvolvimento do tema, houve uma explosão de trabalhos acadêmicos sobre o assunto na década de 90 e início dos anos 2000, mas ainda assim, a conceituação ainda é muito teórica e possui pouca aplicação prática (Corley et al., 2006). Surgiram muitas abordagens, pela amplitude da teoria, juntamente aos precedentes de várias vertentes e linhas de estudo, porém, seguindo para o ramo organizacional, utilizou-se mais a teoria psicológica do "Self' assumindo características pessoais e até mesmo traços de personalidade que a empresa teria.

\subsection{IDENTIDADE ORGANIZACIONAL COMO UM CONSTRUCTO SOCIAL}

A primeira e mais popular contribuição conceitual para a definição de identidade organizacional foi com o trabalho dos autores Albert e Whetten (1985) que trouxeram as definições e teorias iniciais sobre o tema. Esses autores estabeleciam as características da identidade organizacional a partir do estabelecimento de três critérios: Centralidade que são as características vistas como essência da organização e que a distinguem como importante e essencial; Distintividade que são as características que diferenciam a organização das outras do mesmo ramo e incluem a ideologia, gerenciamento da filosofia, cultura, rituais e até estratégias que a empresa utiliza; e Continuidade Temporal que são as características que mostram estabilidade no tempo. Essas definições sofreram algumas alterações com o passar do tempo e conforme os estudos foram sendo aplicados por outros autores.

Albert e Whetten (1985) tinham por objetivo definir o conceito de identidade para os cientistas conheceram e construírem os aspectos das organizações, e para as próprias empresas utilizarem na compreensão de suas características. Eles comentam que tinham o foco de fazer as definições iniciais sobre identidade organizacional, considerando que a literatura anterior oferecia apenas uma diversidade de ideias e conceitos distantes. Antes desses autores, não existia definição sobre o assunto e era estabelecido o que é ou não identidade organizacional a partir do conhecimento empírico e o que se aplicava em cada caso (Albert e Whetten, 1985).

A medida que as teorias iniciais foram exploradas por outros campos científicos, surgiu uma diversidade de conceitos, Caldas e Wood Jr. (2006) citam que o ramo de identidade organizacional é um aglomerado de 
pesquisas distintas que vêm de backgrounds teóricos muito diferentes que influenciaram vários seguidores e suas pesquisas. A partir disso, inicia-se as definições de identidade organizacional, mesclando diferentes visões que se complementam para a construção da teoria.

Ruão (2001) descreve a identidade organizacional como um:

Concentrado de informação que integra os sentidos dominantes, duradouros e consensuais, instituídos como narrativas que projetam a imagem da organização no sentido que lhe é mais favorável. É sua função orientar as realizações simbólicas das empresas, promovendo a harmonização de princípios e intenções, junto dos públicos internos ou externos. E será este papel da identidade, enquanto suporte basilar de qualquer estratégia de comunicação e institucionalização nas organizações (Ruão, 2001, pg. 3).

Minguez (2000) elucida o conceito de identidade organizacional por ser "a trajetória experimentada pela organização desde sua fundação e do acúmulo de êxitos e fracassos ao longo de sua história, está relacionado com aquelas características que os membros da organização consideram definidoras e duradouras dentro da empresa" (pg.2). Essa visão contempla a ideia da trajetória da empresa como um grande formador da identidade e de suas características através do tempo e fazem com que o "grupo social" da organização adquira um formado. Ruão (2001) afirma também que a "identidade deve ser usada como filosofia de toda a atividade organizacional" (pg. 4).

A partir da aplicação da identidade pessoal citada anteriormente como uma metáfora para a identidade organizacional, adotou-se a perspectiva como constructo social formado a partir do entendimento compartilhado de coletividade, que abrange não apenas aos integrantes formais da organização, mas também outros stakeholders que tem interações sociais com a empresa (Corley et al., 2006, pg. 86). Essa abordagem surgiu a partir do problema de utilizar características de um ser individual para uma identidade coletiva, que encontrou solução ao ver este conjunto como um fenômeno social experienciado por todos ligados à organização (Gioia; Schultz; Corley, 2000). E este poderia ser "modelado por seus antecedentes e consequências de outros processos e resultados sociais" (Corley et al., 2006, pg. 89). Com isso, o tema deu abertura para a discussão do comportamento organizacional fora da visão antiga, da empresa como máquina ou como sistema aberto (Corley et al., 2006).

As instituições organizacionais passam a adquirir características que "surgem aos olhos dos públicos, como pessoas, dotadas de personalidade ou carácter, expressão última da sua forma de atuar e interpretar o "ambiente relevante" (Ruão, 2001, pg. 5). Esses traços são formados a partir de uma relação entre seu público interno (integrantes da empresa) e o público externo (audiência de fora e outros stakeholders), elucidados por Hatch e Schultz (2002) ao comentarem que "(a identidade organizacional) é um conjunto de processos dinâmicos nos quais o "eu" da organização é continuadamente socialmente construído pela troca entre definições organizacionais internas e externas, oferecidas por todos os stakeholders" (pg.128).

"Identidade organizacional é a resposta compartilhada dos membros para a pergunta 'quem somos nós como organização?' (Jeyavelu, 2007, pg. 2 APUD Gioia, 1998) que traz a reflexão para os membros sobre o propósito da existência da organização e a natureza do contexto organizacional. Essa reflexão permite a noção de existência e indica que a organização possui interação com o público externo, e sua dinâmica entre o contexto externo e interno estão alinhados (Jeyavelu, 2007). Essa dinâmica garante que a empresa consiga clareza em seus objetivos e naturalmente, seja suscetível a ter adaptação ao ambiente em que atua, mesmo em condições de mudança (Jeyavelu, 2007).

A identidade toma forma através dos "valores e crenças compartilhados, na missão, na estrutura e processos, nos objetivos, no clima organizacional, entre outros" (Barbosa \& Cesar, 2003, pg. 2), e por isso, adquire uma profundidade de significado, ligado a interação entre os públicos. Ela é vista como mais do que "apenas um manual de normas gráficas ou um quadro de princípios éticos de atuação, mas sim a forma do indivíduo e do social empreenderem uma dialética de relacionamento, em que a dominação de públicos internos e externos surge como o caminho da vantagem competitiva" (Ruão, 2001, pg. 10).

As autoras Harquail e King (2003) criticam que tanto a academia quanto os administradores tentam ver a identidade organizacional como um fato que existe independente da definição de qualquer indivíduo ao invés de um conjunto de crenças tidas por eles, além disso, que a identidade organizacional é apenas percebida pelos membros ao invés de ser construída por eles (pg. E4).

Portanto, a identidade organizacional norteia as decisões empresariais, e serve de base para o significado de todas as ações que são feitas na empresa. Ela se forma a partir dessa dinâmica social de interação entre 
o público interno e externo, que será melhor aprofundada posteriormente. Harquail e King (2003) comentam que a identidade fornece um ponto de referência para os membros da organização e estabelecem um significado para o passado, presente e futuro da mesma.

\subsection{IDENTIDADE ORGANIZACIONAL E SUA ADAPTABILIDADE AO AMBIENTE}

A teoria tradicional aponta que as mudanças na identidade organizacional vinham de pressões externas que causam reações passivas internas em resposta (Sillince, 2006). "As organizações estão deixando de ser sistemas relativamente fechados para tornarem-se sistemas cada vez mais abertos. Suas fronteiras estão se tornando mais permeáveis e, em muitos casos, difíceis de identificar" (Caldas e Wood Jr., 1997, pg.15). Isso acontece pela mudança no ambiente competitivo e principalmente pela globalização, que aproximou as empresas aos fornecedores e clientes pela busca na vantagem competitiva trazida pelo mercado global.

Caldas e Wood Jr (2006) defendem que a organização precisa manter características passíveis a constantes mudanças ao invés de distintivas e duradouras, proporcionando a possibilidade de melhor adaptação às solicitações das demandas no meio em que a organização está inserida. 0 axioma de centralidade passou a ser definido e os outros dois conceitos (distintividade e durabilidade no tempo) aceitam abordagens questionando a apropriação no contexto da transformação organizacional em ambiente voláteis (Caldas e Wood Jr, 2006). Sillince (2006) cita ainda sobre "uma maneira de ver a mudança da identidade como tendo uma orientação endógena, na qual as conexões percebidas entre identidade e recursos geram pressões internas para a mudança" (pg 189).

Os autores Gioia, Schultz e Corley (2000) discutem sobre instabilidade adaptativa da identidade, necessária como resposta a demandas ambientais e por isso, a identidade organizacional não pode ser estritamente duradoura, por mais que possua continuidade em suas características. Deve existir fluidez para enfrentar a estagnação. Em congruência com esta ideia, eles apresentam o termo "continuidade" que representa mais corretamente a interpretação das características da identidade que permanecem durante o tempo, além de englobar a mudança e adaptação (Gioia; Schultz; Corley, 2000).

Os autores Caldas e Wood Jr. (1997) comentam que a imagem externa da organização altera sua autoimagem e origina mudanças na mesma. Essas mudanças modificam e afetam a percepção do grupo que geram então outras mudanças. Essa dinâmica complexa que integra os vários atores organizacionais define e redefine as percepções de realidade e assim, faz com que a identidade da empresa necessite assumir várias formas que se articulam de acordo com as solicitações do ambiente (Caldas e Wood Jr., 1997, pg.8). "A identidade consiste numa constelação de características e rótulos apropriados para diferentes contextos e interações" (Gioia; Schultz; Corley, 2000, pg. 74).

\subsection{IDENTIDADE CORPORATIVA E VISUAL}

0 termo "corporativo" vem das vertentes de estudo do Marketing, Comunicação e do Design que trabalham com a dinâmica de manifestação da identidade organizacional pela imagem e divulgação da empresa, ao ter a interação com o público externo e suas reações como objeto focal. Machado (2003) comenta que a "identidade corporativa é frequentemente chamada de identidade visual, pois utiliza de formas visuais e a identidade organizacional, por meio da palavra" (pg 61). Além disso, "a identidade organizacional cria um senso de identificação entre os membros da organização enquanto a identidade corporativa estimula a diferenciação da empresa no mercado" (Machado, 2003, pg 62). "Podemos definir imagem corporativa como o conjunto de significados que uma pessoa associa a uma organização, e as ideias utilizadas para descrever o que lembram dessa organização" (Minguez, 2000, pg.4).

Na Administração é discutido como esses meios de comunicação são geridos estrategicamente para fins de um determinado resultado desejado e planejado pela empresa, e como o feedback dessas interações influencia na percepção de necessidade de mudanças na identidade organizacional. "Quem nós somos é refletido no que estamos fazendo e como os outros interpretam quem nós somos e o que estamos fazendo" (Hatch \& Schultz, 1997, pg. 54).

As autoras Kiriakidou e Millward (2000) trazem ainda a importância de como na atualidade, com a larga exposição das organizações pela comunicação, temos uma preocupação com como a empresa se representa em relação ao que ela verdadeiramente é. Quanto maior a discrepância dessas duas ideias, maior é a tendência na geração de conflitos dentro da organização, considerando que a empresa passa a manifestar por sua comunicação e marketing algo que não é, e prejudica sua identidade e cultura interna (Kiriakidou e Millward, 2000). 
Colnago (2007) comenta sobre como a comunicação organizacional pode ser usada de maneira estratégica na construção da imagem institucional das organizações ao divulgar positivamente pontos que podem lhe trazer vantagem e melhorar os pontos considerados negativos. "Verifica-se, que quando inexiste a comunicação, consequentemente inexistem meios adequados de expressão da identidade, e assim, a imagem não possui mecanismos formais de controle" (Colnago, 2007, pg.5) o resultado disso é que a imagem e os significados do que a empresa transmite ficam condicionados à reação e percepção própria do público sem qualquer possibilidade de intervenção, o que pode prejudicar a organização (Colnago, 2007).

As autoras Hatch e Schultz (1997) comentam que os estudos até agora têm separado a organização de seu ambiente e que a interdisciplinariedade neste sentido, considera várias vertentes (design, marketing, estratégia e outros) e apaga essas separações ao construir um novo caminho para a compreensão organizacional.

\subsection{IDENTIDADE, IMAGEM E CULTURA ORGANIZACIONAL}

Com o desenvolvimento da informação pela era digital, as organizações passam a enfrentar uma maneira de constante exposição ao participarem deste meio, e consequentemente, se condicionam às reações do público. A comunicação se tornou então uma atividade rotineira de todos os integrantes da empresa, levando em consideração a visibilidade e exposição que as organizações enfrentam pelos meios de comunicação (Kiriakidou e Millward, 2000). As autoras Hatch e Schultz $(1997,2002)$ abordam muito em seus trabalhos, a associação entre identidade, cultura e imagem organizacional. "A mídia está tendo mais e mais interesse na vida privada das organizações e expondo quaisquer divergências que encontram entre a imagem corporativa e as ações organizacionais" (Hatch e Schultz, 2002, pg.116) ou seja, o que empresa divulga para seu público em relação às práticas diárias. Com o aumento da exibição das empresas pela mídia, passamos a ter muitas fontes de onde o público tem informações para formular suas impressões, e opiniões sobre a empresa. Através da nossa cultura, expressamos e apresentamos a imagem da empresa, mas as pessoas que interpretam essas projeções, se baseiam em sua própria cultura (Hatch e Schultz, 1997) e por isso é enfatizado a gestão dos meios de comunicação.

Hatch e Schultz (2002) ainda complementam que os "empregados são também clientes, investidores, membros da comunidade local, da mesma maneira que estão cada vez mais conectados pelo mundo, eles carregam conhecimento sobre as práticas internas do negócio além dos limites da empresa, e ajudam a expor a organização" (pg.116). Por isso, as organizações direcionam seus esforços para alinhar os ideais da visão empresarial com a visão pessoal dos stakeholders, a fim de demonstrar que seus princípios são seguidos de acordo com o que divulga (Hatch e Schultz, 2002).

A autora Machado (2003) traz o conceito dos simbolismos nos comportamentos e na comunicação, presentes da cultura organizacional que definem a identidade da mesma. "A cultura provê o material simbólico com o qual as imagens serão construídas e comunicadas. Todavia para os autores a identidade organizacional sofre também influência externas por meio do processo de formação de imagem" (Machado, 2003, pg. 61). Machado (2003) comenta que a imagem tem influência da formação da identidade organizacional. A identidade remete ao que é interno, e a imagem ao externo, o segundo influência no primeiro por ter as reações e opiniões do público geral consideradas em suas ações.

Hatch e Schultz (2002) definem imagem organizacional como o conjunto de visões daqueles que agem como os "outros" para a organização, seguindo práticas da estratégia, comunicação e marketing. Além disso, elas definem a cultura organizacional como "o entendimento tácito organizacional que contextualiza empenho para ter significado, incluindo a definição de si mesma. A cultura organizacional não considera os "outros" e sim, o significado, valores, crenças e suposições internas da própria empresa sobre o que ela acha de si, enquanto a imagem considera o que os "outros" pensam da empresa e qual a reação do público interno com as reações do público externo. "Assim como os indivíduos formam suas identidades em relação às definições tanto internas quanto externas, organizações formam suas relações com cultura e imagem (Hatch e Schultz, 2002, pg.122).

Estas mesmas autoras esquematizaram o ciclo de influência entre imagem, identidade e cultura e demonstram essa interdependência através de quatro processos: internamente, a identidade expressa entendimentos da cultura e reflete nela a incorporação de elementos da própria identidade; externamente, a identidade se expressa e deixa uma impressão nos outros através da imagem, e espelha ao somar essa imagem que deixou nos outros às suas definições dentro da própria identidade, em uma constante conversação entre esses três termos. Em outras palavras, a imagem afeta a identidade pelo processo de 
espelhamento, onde os acontecimentos e opiniões públicas fazem a empresa questionar o seu "verdadeiro eu", desse modo, empresa escolhe considerar ou não essas opiniões externas quando se define para o público e então, a imagem passa a afetar a cultura e a identidade (Hatch e Schultz, 2002). Além disso, o que a corporação compreende por cultura é refletido pela identidade ao público geral e por isso, afeta a imagem (Hatch e Schultz, 2002).

Ainda, Barbosa \& Cesar (2003) citam que:

A auto percepção da organização é possibilitada pela visão de seus membros enquanto a identidade pública é percebida pela visão de clientes, agências reguladoras, competidores, instituições financeiras, entre outros, e nem sempre as expectativas e percepções desses agentes externos se apresentam congruentes com a imagem que os membros organizacionais têm internamente do que fazem e de sua responsabilidade perante o meio externo (Barbosa \& Cesar, 2003, pg. 6).

Hatch e Schultz (2002) consideram que a identidade é definida pela imagem que o público externo tem de si (imagem), além de considerar o que a empresa entende pela sua diferenciação dos outros, ou seja, sua "personalidade" e características que a fazem única (cultura). A imagem formada e mantida pelas organizações é derivada da percepção e visão de pessoas de fora que mais tarde são trazidas para a identidade pelos processos de acesso e exposição (Hatch e Schultz, 2002). Machado (2003) exemplifica a construção da identidade ao dizer que "é o equilíbrio entre o que os outros esperam de nós e o que realmente somos" (Machado, 2003, pg 54).

Nesta área, os estudos da Administração focam em compreender como os gerentes vão reagir e tomar decisões em relação às suas observações e interpretações feitas em relação às informações que são expostas pela mídia sobre as empresas (Barbosa \& Cesar, 2003). "O modo como vão observar, interpretar e agir em face do ambiente depende do conjunto de crenças, valores e padrões legitimados pelo tempo e experiência" (Barbosa \& Cesar, 2003, pg. 4).

Ruão (2001) retrata que "tal como as pessoas, as instituições teriam, na verdade, não uma identidade própria, mas diferentes identidades, que se podiam transmitir aos públicos de forma inteligente, sem que isso gerasse problemas de incoerência", pg. 6). "Em cada uma as operações, a organização leva a cabo uma projeção ou uma representação de si mesma para os distintos grupos de pessoas com que se relaciona" (Minguez, 2000, pg. 2).

\subsection{BENEFÍCIOS DE CONHECIMENTO SOBRE A IDENTIDADE ORGANIZACIONAL}

Com base no que foi apresentado anteriormente, observamos que o conhecimento sobre a própria organização e sobre a sua identidade é de extremo benefício, levando em consideração que o aprendizado organizacional sobre as visões da empresa em relação a si mesma e em relação ao seu público externo, eliminam ambiguidades e ajudam a alinhar essas duas visões, estabelecendo demarcações bem definidas da identidade em um diálogo entre sua cultura e imagem. Hatch e Schultz (2002) acreditam que quando a dinâmica entre imagem e cultura está bem balanceada, gera uma definição da identidade que considera todos os grupos relevantes de stakeholders. A importância de conhecer a identidade empresarial se encontra, portanto, no alinhamento dessas visões, que geram o que a empresa expressa ser. As autoras ainda definem que conhecendo sobre a dinâmica de identidade, a empresa evita disfunções e ainda acrescenta sua efetividade (Hatch e Schultz, 2002).

Machado (2003) retrata a importância de reconhecer a identidade organizacional e ainda, analisar e compreender sua profundidade por melhorar as ações individuais, o cooperativismo e trabalho em grupo e como consequência, estímulo da criatividade e o comportamento participativo, pela união entre o indivíduo, grupo e organização.

Considera-se que a identidade estabelece base para planejamentos a curto, médio e longo prazo, estratégias, administração de recursos humanos e ainda define o eixo de como a organização lida com as situações rotineiras ou mesmo em momentos de tomada de decisões mais complexas. "Identidade organizacional não é apenas a expressão coletiva de cultura organizacional. Ela é também fonte de identificação simbólico material que pode ser usado para impressionar os "outros" para demonstrar simpatia (conexão) ao estimular seu conhecimento, atraindo sua atenção e interesse, e encorajando seu envolvimento e suporte" (Hatch e Schultz, 2002, pg.126). 
Além disso, a identidade ajuda a definir as demarcações da imagem e como a empresa quer se apresentar ao público, bem como a sua própria administração que traz benefícios de compreensão e constante melhoria nesta interação. Ela ainda aumenta as possibilidades de sucesso de comunicação com os públicos externos e internos ao alinhar a identidade com a imagem. Considerando que a informação rápida e de fácil acesso faz parte da sociedade na atualidade, progressivamente a comunicação integra as atividades diárias das organizações e expõe dados antes consideradas apenas de cunho interno. "Quanto maior a discrepância entre o jeito que a organização vê a si mesma e o jeito que ou outros a veem, tendo essa ambiguidade na identidade mantida, mais ela tende a ser prejudicada". (Albert e Whetten, 1985).

Ao conhecer a si mesma através da definição da sua identidade, a empresa possibilita identificação dos seus pontos fortes e potenciais recursos que podem ser explorados, desenvolvidos e melhorados de uma maneira positiva interna e externamente a fim de constante aprimoramento e ainda, geração de vantagem competitiva. "Utilizar a estratégia como meio de focalizar esforços apresenta vantagens a partir do momento que concentra os esforços individuais em objetivos comuns, impedindo o caos e conflito" (Barbosa \& Cesar, 2003, pg. 3). A identidade deve sempre nortear as ações da empresa e da imagem a partir da consideração dessas características descobertas que a definem, consolidando uma imagem em coerência com sua identidade. No próximo tópico, abordaremos algumas ideias que cercam a teoria da vantagem competitiva.

\section{VANTAGEM COMPETITIVA}

O termo vantagem competitiva tem um começo ainda um pouco indefinido, porém os autores Brito \& Brito (2012) citam as primeiras noções datando em meados do início da década de 1930. Com o desenvolvimento da indústria, a ideia do termo passou a ser mais citada e a abranger a estratégia e competitividade do ambiente, ainda que sem uma demarcação estabelecida de definição aceita por todos (Brito \& Brito, 2012). 0 autor Michael Porter, populariza para os acadêmicos e consultores o termo Vantagem Competitiva em seu trabalho de 1985, que assume um forte atrelamento a estratégia e adquire a posição central como objeto de pesquisa no tema (Brito \& Brito, 2012).

A evolução do tópico trouxe o desenvolvimento de estudos por vários autores que passaram a adotar diferentes definição do que significa vantagem competitiva (Brito \& Brito, 2012). "Vantagem Competitiva é provavelmente o termo mais usado em administração estratégica, porém ainda, continua com uma definição e operacionalização deficiente" (Ma, 2000, pg. 15). "No debate teórico, nem a definição nem a delimitação de vantagem competitiva são um consenso" (Brito \& Brito, 2012, pg. 362). 0 trabalho dos autores Brito \& Brito (2012) traz uma tabela que reúne várias visões a partir de diferentes trabalhos em relação ao termo vantagem competitiva, que possui uma larga divergência de assimilação a significados como: diferenciação e posição concorrencial em relação aos competidores; melhor utilização de recursos; criação de valor; desempenho e até ganhos financeiros superiores (pg. 363-364).

Considerando este histórico e a abrangência de significados retratada, a vantagem competitiva seguirá a definição do autor Ma (2000), à luz da visão baseada em recursos do autor Barney (1991), respeitando o que se encaixa com as ideias já desenvolvidas anteriormente sobre identidade organizacional e o objetivo estabelecido do trabalho.

A partir da visão baseada em recursos, o trabalho de Barney (1991) discute a utilização de ativos diversos na empresa que permitem ações estratégicas, em relação aos seus competidores, e desenvolve a teoria em torno dos critérios de definição desses recursos. Ele considera que recursos empresariais abrangem todo o tipo de ativos, e os classifica em três categorias: Recursos de Capital Físico que incluem a tecnologia usada na empresa, equipamentos, localização geográfica e etc.; Recursos de Capital Humano que incluem treinamentos, experiência, inteligência, relacionamento e insights dos gerentes e trabalhadores da empresa e etc.; e Recursos de Capital Organizacional que incluem o planejamento formal e informal, controle e sistema de coordenação, relações informais entre grupos dentro da empresa e entre a empresa e outro no ambiente e etc. (Barney, 1991, pg. 101).

Barney (1991) ainda complementa que dentro da variedade de recursos que todas as organizações possuem, nem todos podem ser explorados de maneira estratégica e relevante. Para isso, o autor estabelece quatro critérios de definição: 1. Recursos Valiosos que "permitem a empresa a criar ou implementar estratégias que aperfeiçoam a eficiência e efetividade da empresa; ajudam a explorar oportunidades e neutralizam ameaças no ambiente da empresa" (pg. 105); 2. Recursos Raros que "são únicos entre um conjunto de empresas e potenciais competidoras" (pg. 107); 3. Recursos Imperfeitamente Imitáveis que representam recursos que foram obtidos através de situações e oportunidades 
extremamente específicas e únicas e que por isso, são de difícil imitabilidade da parte dos competidores (pg. 107); 4. Substituibilidade que "são recursos similares que permitem conceber e implementar as mesmas estratégias” (pg. 111), (Barney, 1991).

A importância no estabelecimento desses critérios, é justamente a identificação do que pode ou não ser fonte de vantagem competitiva através do levantamento de perguntas empíricas que ajudam a elucidar o entendimento da empresa em relação a seus recursos (Barney, 1991). "Empresas obtêm vantagem competitiva sustentável implementando estratégias que exploram suas forças internas, através da resposta para oportunidades ambientais, enquanto neutraliza ameaças externas e evita fraquezas internas" (Barney, 1991, pg. 99).

Porém o modelo Barney (1991) apresenta um ponto negativo, ao considerar que apenas uma empresa em todo o mercado pode ser dotada de vantagem e que por exemplo, em um mercado de empresas que gozem de recursos idênticos, caracterizadas como homogêneas, não é possível adquirir vantagem competitiva "porquê essas empresas implementam as mesmas estratégias, todas elas vão melhorar sua eficiência e efetividade do mesmo jeito, e na mesma medida" (Barney, 1991, pg. 104). Ou seja, "apresentada em sua maneira mais forte: você tem ou não tem. Aqueles que tem (heterogeneidade), possuem vantagem competitiva; aqueles que não tem, não possuem" (Ma, 2000, pg. 19). Essa ideia acaba por representar uma restrição grande na aplicabilidade e desenvolvimento teórico-empírico no sentido de consideração de mercado e competição da empresa focal. Por isso, adotou-se a visão de Ma (2000) que desenvolve a partir da visão baseada em recursos a vantagem competitiva relativa a uma situação observada.

Ma (2000) trabalha a ideia de que vantagem competitiva é um constructo que relaciona qualquer par de rivais em um contexto específico, dimensionados em um ambiente focal observado. Podemos ver essas definições elucidadas nos trechos: "vantagem competitiva é um termo relacional. É essencialmente uma comparação desenhada entre a empresa focal e sua(s) rival(ais) em uma certa dimensão(sões) de interesse na competição" (Ma, 2000, pg. 18), "o diferencial entre dois concorrentes em qualquer dimensão concebível, que permita a um criar mais valor para o cliente do que ao outro" (Ma, 2000, pg. 18), e ainda "pontuação relacional de uma empresa em uma dimensão competitiva particular em comparação a seus rivais que pode contribuir para a performance superior" (Ma, 2000, pg. 18).

Ao discutir sobre vantagem competitiva sem performance superior, Ma, (2000) dialoga sobre a importância de saber desenvolver um determinado recurso, pois por mais que este seja dotado de características que o consideram como potencial originador de vantagem competitiva, sem total ciência de como trabalhar o devido afloramento deste potencial, a oportunidade não poderá será eficientemente utilizada. A empresa pode possuir inúmeros recursos potenciais, porém sem a aplicabilidade correta, ele não se transforma em vantagem competitiva.

Ma (2000) complementa que a vantagem competitiva pode vir de outras características que a organização pode ter como velocidade, flexibilidade, entre outras, e ainda, potenciais recursos que geram múltiplas vantagens competitivas (Ma, 2000, pg. 16).

\section{ANÁLISES E RESULTADOS}

Diante das discussões retratadas na revisão de literatura anterior, podemos pontuar que a identidade organizacional é um constructo social que se forma a partir da interação social entre o público interno (integrantes da organização) e o público externo (outros stakeholders e audiência externa). Além disso, é composta pelo dinamismo do ciclo de influência entre a cultura (características que definem a empresa e seu público interno), e a imagem organizacional (reflexão da identidade para o público externo) e a partir deste, os três integrantes se aprimoram, desenvolvem e se alteram de acordo com a necessidades do mercado. A importância do conhecimento sobre essa dinâmica e como a identidade organizacional se forma, vê-se de extrema importância, pois possibilita que a organização conheça mais sobre suas características e recursos e saiba identificar quais deles podem ser utilizados como fonte de vantagem competitiva em relação aos concorrentes, também identificados neste processo, na busca por diferenciação e aumento de ganhos financeiros.

A partir deste tópico, será discutido então a união e atrelamento das teorias de vantagem competitiva e identidade organizacional, que utilizam reciprocamente suas informações para exploração de conhecimento e formulação e aperfeiçoamento de ideias já existentes na organização. Além disso, propõese no último tópico em uma construção a partir de vários autores, como na prática se define a identidade organizacional. 


\subsection{IDENTIDADE ORGANIZACIONAL A BENEFÍCIO DA VANTAGEM COMPETITIVA E VICE-VERSA}

Com a identidade já definida, a empresa pode utilizar este material para por exemplo, construir o marketing, direcionar o relacionamento com o cliente, e mesmo a venda de um produto ou realização de um serviço seguindo os conceitos da identidade organizacional que compõem o que a empresa verdadeiramente acredita. "Utilizar a estratégia como meio de focalizar esforços apresenta vantagens a partir do momento que concentra os esforços individuais em objetivos comuns, impedindo o caos e conflito" (Barbosa \& Cesar, 2003, pg. 3).

A identidade deve sempre nortear as ações da empresa e da imagem a partir da consideração dessas características descobertas que a definem, consolidando uma imagem em coerência com sua identidade.

Barbosa \& Cesar (2003) comentam que:

A necessidade de integração entre a identidade e a estratégia organizacional deriva do próprio conceito de posicionamento competitivo (Porter, 1998) no qual a organização que pretende se posicionar no mercado apoiada em uma vantagem sustentável deve definir uma estratégia genérica que vise o foco ou a diferenciação, o que de todas maneiras indica também a determinação de um olhar focado em um ponto específico do mercado. Esse foco determinado pela estratégia irá criar as condições para a definição de sua identidade a partir dos significados gerados em torno do que ela faz (Barbosa \& Cesar, 2003, pg. 10).

Ao conhecer a si mesma através da definição da sua identidade, a empresa possibilita identificação dos seus pontos fortes e potenciais recursos de diferenciação no mercado através da vantagem competitiva. "A identificação da competência central de uma organização pode tanto contribuir para o desenho de sua identidade... como pode também permitir que a definição a priori de uma estratégia fundada nessa competência passe a delinear a identidade organizacional" (Barbosa \& Cesar, 2003, pg. 6). Porter (1979) cita alguns exemplos como "solidificar o relacionamento com cliente favoráveis, diferenciação de produtos que pode ser substantivamente ou psicologicamente pelo marketing, estabelecendo liderança tecnológica" entre outros. (Porter, 1979, p.145).

Sillince (2006) aponta sobre a importância da gestão da imagem e sua representação perante o público como vantagem competitiva: "a principal fonte de vantagem competitiva não imitável, são os recursos intangíveis como cultura organizacional, a questão de como as empresas apresentam através da retórica essa vantagem competitiva para a audiência interna e externas tem sido negligenciada" (pg.188).

0 autor Jeyavelu (2007) destaca que a identidade organizacional pode ser uma fonte de vantagem competitiva, "por permitir a organização fazer coisas que seus competidores não conseguem, fazer algumas coisas melhor que seus competidores e prevê que seja não sucumbida a modismos" (Jeyavelu, 2007, pg. 81 APUD Reger, 1998). Ele desenvolve esse pensamento ao comentar que:

A identidade organizacional mantém dimensões críticas de seu propósito e contexto dentro dele, além disso, providencia esclarecimentos para manifestações de identidade em termos de características organizacionais. Esse esclarecimento nas manifestações possibilita a organização a sustentar sua vantagem competitiva pelo tempo, e sob condições de mudanças ambientais" (Jeyavelu, 2007, pg.4).

Ainda, Porter (1979) define que o "conhecimento das capacidades da empresa e as causas das forças competitivas vão evidenciar as áreas onde a companhia deveria confrontar a competição e onde evitar" (p.143). Mas o verdadeiro desafio encontra-se na habilidade em utilizar esse conhecimento efetivamente como alavancagem competitiva, "acredita-se que as raízes do problema estão na inabilidade do gerenciamento em ativamente criar, comunicar e explorar esse domínio como um recurso para a organização conseguir liderar e alcançar superioridade competitiva" (Chowtupalli and Rafi, 2013, pg.2).

A partir do que foi definido neste tópico, conclui-se que a identidade organizacional é fonte de vantagem competitiva por fornecer conhecimento para decisões e ações estratégicas, recursos que podem ser utilizados como vantagem competitiva em relação ao mercado e ainda, nortear a imagem da organização a partir dos seus princípios. "As empresas mais bem-sucedidas combinam um processo integrado e uma cultura apoiadora para criar uma vantagem competitiva sustentável" (Chowtupalli and Rafi, 2013, pg.2). 


\subsection{DEFINIÇÃO E CONSTRUÇÃO PRÁTICA DA IDENTIDADE ORGANIZACIONAL}

A identidade organizacional estabelece uma base de conteúdo para estratégias, tomada de decisões, e um eixo de comportamento para as atividades rotineiras, e ainda define, junto a imagem como ela se representa aos seus públicos (Ruão, 2001). Nota-se que o processo de formação e delimitação da identidade no contexto organizacional é muito característico de cada caso e "o planejamento do modelo comunicacional adequado a cada empresa, exige, por isso, a definição da identidade organizacional, como o ponto de partida do necessário processo de institucionalização (regulamentação e estabelecimento de regras)" (Ruão, 2001, pg. 10).

O'Donnell, Gilmore, Carson e Cummins (2002) em seu trabalho de pesquisa aplicada, buscaram reconhecer a maneira como as organizações de pequeno e médio porte definiam sua vantagem e estratégia competitiva, e constataram que ao contrário do que a maior parte da literatura define, o processo é muito diferente do modelo retratado pelas grandes empresas, em relação a escala econômica. Um dos motivos do porquê isso acontece, é que a literatura estabelece modelos impraticáveis para organizações de porte pequeno, que possuem uma visão mais simplificada do mercado e considera apenas alguns competidores com o mesmo comportamento (pg. 206), e além disso, o foco é em clientes mais apropriados para o que seu produto ou serviço oferece, caracterização que é mais específica e aproximada de nichos ao invés de englobar o mercado por completo (pg. 217).

Whetten, (2006) comenta que os esforços para compreender uma identidade organizacional devem começar no topo através de um brainsstorm feito pelo time de administradores que saberão nomear os possíveis aspectos tidos como centrais, duradouros e distintivos. Além disso, ele complementa que esse processo "pode envolver o requerimento de um exercício de escolha forçada desafiando eles a provar a uma pessoa cética que cada nomeação satisfaz as três características e corresponde a indicadores fenomenológicos" (Whetten, 2006, pg 230).

A autora Fascioni (2009) descreve que "o processo de definição (da identidade) se inicia com reuniões com a alta cúpula administrativa onde ocorrem debates, entrevistas e questionamentos sobre onde a empresa deseja chegar, sua identidade desejada e até definições de missão e visão" (Fascioni, 2009, pg.5). "Para caracterizar uma identidade organizacional em termos de seus valores centrais, é necessário primeiro que o alcance de valores relevantes seja identificado, e então que uma avaliação seja feita para saber sobre o consenso entre os integrantes da empresa sobre esses valores" (Kiriakidou e Millward, 2000, pg.3).

Albert e Whetten (1985) estabelecem algumas perguntas que elucidam as reflexões principais no processo de idealização da identidade: "Quem somos nós como organização?" e "Quem nós pensamos que deveríamos ser?". Em paralelo, Gioia, Schultz e Corley (2000) consideram também as perguntas que devemos fazer em relação a resposta do público: "Quem eles pensam que nós somos?" e "Quem eles pensam que nós deveríamos ser?".

Harquail e King (2003) acrescentam como etapa a comparação com outras organizações do mesmo ramo: "As características atraídas para comporem a construção da identidade organizacional serão baseadas no conjunto de organizações referentes contra quais indivíduos estão tentando distinguir ou definir sua organização" (pg. E3). Esse processo de comparação ajuda a reconhecer os traços que definem as características distintivas da empresa (Harquail e King, 2003).

Se a organização já está em atividade "pode-se também definir a identidade da empresa com um longo período de convivência, observando detalhes, relacionamentos, atitudes, reações e históricos" (Fascioni, 2009, pg.9). Além disso, "estruturas sociais podem ser entendidas como coleções padronizadas de caraterísticas organizacionais que tenham sido selecionadas da experiência organizacional" (Harquail e King, 2003, pg. E3).

A partir da delimitação das características da identidade, desenvolve-se a imagem que receberá um feedback ao se comunicar para o público interno e externo, e o ciclo de influência de identidade, imagem e cultura se inicia (Gioia; Schultz; Corley, 2000; Hatch e Schultz, 1997). Os autores Gioia, Schultz e Corley (2000) apontam a importância do feedback do público (interno e externo) como resultado da divulgação da imagem oriunda da identidade, que contempla a comparação com outras empresas do mesmo ramo. Esse processo desencadeia o desenvolvimento e até redefinição dos parâmetros do que se consideram características da identidade e as respostas a perguntas como "quem nós somos somo empresa?" (Gioia; Schultz; Corley, 2000). 
A "identidade 'desejada' (idealizada) é então comunicada através do simbolismo mais adequado com o objetivo de se obter a imagem mais favorável no mercado e promover uma vantagem competitiva" (Fascioni, 2009, pg.5). 0 uso da vantagem competitiva entra em ação e a empresa passa a determinar e manipular o que pretende ou não demonstrar através de sua imagem em uma gestão estratégica que leva em consideração os benefícios e malefícios dessas ações. Os "administradores precisam se tornar conscientes de como ou outros interpretam eles e suas organizações e reagem a este feedback de uma maneira estratégica" (Hatch e Schultz, 1997, pg.363).

Fascioni (2009) alerta sobre a ideia errônea de que a identidade organizacional é apenas composta pela missão, visão e o planejamento estratégico, sem considerar a profundidade que ela representa, como discutido nos tópicos anteriores. Ela comenta que sem um conhecimento prévio sobre a identidade, esses termos estão suscetíveis a "idealismo, visão parcial, confusão entre desejos e fatos" (pg. 9) e que a missão, visão, planejamento estratégico e outros termos definidores da empresa, podem ser muito melhor trabalhados se tiverem o conhecimento empresarial da identidade como base, direcionando a perspectiva para a realidade da cultura e identidade presente na organização, do que o ideal do que a empresa quer ser, elaborado pelo alto escalão (Fascioni, 2009). Neste sentido, Ruão (2001) comenta que "identidades bem geridas dão maior flexibilidade à organização, que se apresenta de forma adequada aos interesses dos públicos a que se dirige" (pg. 9). Além disso, ela "permite ainda desenvolver organizações mais criativas e inteligentemente adaptativas, pela variedade de facetas que pode incluir no seu carácter ou forma de atuar nos negócios" (Ruão, 2001, pg. 9).

Ruão (2001) evidencia a importância da volatilidade na identidade organizacional, a fim de se adequar e adaptar às mudanças e solicitações do mercado e ao ritmo das transformações ambientais. Ela complementa que:

A identidade sendo um fenômeno subjetivo e socialmente construído, exige modernização e atualização. Por isso, as empresas devem ciclicamente questionar a sua identidade, procurando nela um fio condutor, responsável pela estabilidade, mas também buscando eventuais conteúdos ou processos obsoletos, que convém renovar, promovendo uma imagem sempre jovem da empresa (Ruão, 2001, pg. 8).

O trabalho de O'Donnell, Gilmore, Carson, Cummins (2002) ainda trouxe que a visão dos empresários sobre vantagem competitiva foca mais na criação e manutenção de uma boa nextworking que inclui um relacionamento muito personalizado com os clientes (pg. 214), além das competências deles mesmos e dos outros integrantes da empresa (pg. 212). Além disso, os autores comentam que existem diferença no processo da vantagem competitiva, na identificação dos competidores, percepção de recursos vantajosos e na posição da vantagem e na performance dos resultados (pg. 218).

\section{CONSIDERAÇÕES FINAIS}

O estudo em questão buscou apresentar um histórico de construção da identidade organizacional e sua delimitação a partir da ideia de um constructo social, a fim do uso dessas informações como primeiros passos para a institucionalização. Ainda, interligou esta à teoria de vantagem competitiva por recursos organizacionais que possibilita a empresa, o desenvolvimento de vantagem em relação a seus concorrentes a partir do conhecimento sobre suas características e diferenciais. Utilizou-se para isso uma revisão de literatura do histórico de identidade organizacional e vantagem competitiva, para estabelecer com o desenvolvimento e atrelamento das duas teorias, como o processo criativo de delimitação de identidade organizacional se forma, dando ênfase em empresas pequenas.

Diante do que foi retratado anteriormente, nota-se que identidade organizacional é um estudo que possui várias vertentes e integrações com diferentes áreas de pesquisa acadêmica. Trata-se de um tema muito importante quando falamos sobre os primeiros passos em busca da formalização e geração de conhecimento sobre o que a organização considera como sua identidade. Com isso estabelece uma base de informações para todas as ações realizadas na mesma, mas principalmente para o processo de tomada de decisão, além de ajudar a elucidar através deste conhecimento, características que podem ser desenvolvidas e utilizadas como vantagem competitiva e formação da imagem organizacional. Esta última representa uma grande importância, pois reflete a organização para seus públicos e promove através desse processo o aprimoramento da identidade por demonstrar com o seu feedback, as necessidades do mercado. 
Buscou-se através dos autores e desenvolvimento das ideias estabelecidas neste trabalho, incitar o interesse das empresas pequenas em conhecerem mais sobre si mesmas e buscarem definir seus conceitos de identidade, levando em consideração que sua aplicação traz muitos benefícios em diversos âmbitos e ainda, possui uma forte e importante relação com a estratégia e vantagem competitiva.

Considera-se como principal contribuição, a união de diversos cortes de autores que corroboraram neste trabalho, com a demonstração de como na prática se delimita a identidade organizacional dentro de uma empresa, e como ela pode ser utilizada e trabalhada, demonstrando a realidade no estudo. Em complementação, considerou-se também a junção de um histórico linear para a teoria sobre identidade organizacional como constructo social, considerando sua abrangência e diversidade de ideias, e difícil acesso para o público brasileiro pela barreira da língua e poucos trabalhos que relatam o assunto dentro do país.

Por último, este artigo visou contribuir com o crescimento e ampliação do tema, a partir do atrelamento dos termos identidade organizacional e vantagem competitiva e ainda, estabelecer como o processo criativo de delimitação de identidade organizacional se forma, dando ênfase em empresas pequenas. Espera-se que estes conteúdos possam servir de base para desenvolvimento prático, diante da compreensão desta importante ferramenta para exploração do entendimento e conhecimento organizacional. Recomenda-se também que estudos futuros realizem a aplicação dessas ideias e exploração do desenvolvimento da identidade organizacional como ferramenta de gestão, com a finalidade de validar sua eficiência.

\section{REFERÊNCIAS}

[1] Albert, S., \& Whetten, D. A. (1985). Organizational identity. Research in Organizational Behavior, 7, 263-295.

[2] Barbosa, S., \& Cesar, P. C. (2003). Estratégia e Identidade Organizacional: Uma Aproximação Mais Que Conceitual

[3] Barney, J. (1991). Firm Resources and Sustained Competitive Advantage. Journal of Management, 17, 99-120.

[4] Brito, R. P. de, \& Brito, L. A. L. (2012). Vantagem competitiva e sua relação com o desempenho: uma abordagem baseada em valor. Revista De Administração Contemporânea, 16(3), 360-380.

[5] Caldas, M. P. \& Wood Jr., T. (1997). Identidade Organizacional. RAE-Revista de Administração de Empresas, $37(1), 6-17$.

[6] Caldas, M. P., \& Wood Jr., T. (2006). Legacy identities during organizational change: the case of an Enron Subsidiary.

[7] Chowtupalli, Y., \& Rafi, S. (2013). Achieving Sustainable Competitive Advantage Through Resource Configuration and Organizational Identity: An Empirical Study.

[8] Colnago, C. K. (2007). A Comunicação Organizacional como Elemento Estratégico para a Construção da Identidade Corporativa e da Imagem Institucional das Empresas. XXX Congresso Brasileiro de Ciências da Comunicação.

[9] Corley, K. \& Harquail, C. \& Pratt, M. \& Glynn, M. \& Fiol, C. \& Hatch, M. (2006). Guiding Organizational Identity Through Aged Adolescence. Journal of Management Inquiry - J MANAGE INQUIRY. 15. 85-99.

[10] Fascioni, L. (2009). Método Participativo de Definição da Identidade Corporativa.

[11] Gioia, D. \& Schultz, M. \& Corley, K. (2000). Organizational Identity, Image, and Adaptive Instability. The Academy of Management Review.

[12] Harquail, C. \& King, A. (2003). Organizational Identity and Embodied Cognition: A Multi-Level Conceptual Framework. Academy of Management Proceedings. 2003. E1-E6.

[13] Haslam, S. \& Postmes, T. \& Ellemers, N. (2003). More Than a Metaphor: Organizational Identity Makes Organizational Life Possible. British Journal of Management. 14. 357 - 369.

[14] Hatch, M. \& Schultz, M. (1997). Relations Between Organizational Culture, Identity and Image. European Journal of Marketing. 31. 356-365.

[15] Hatch, M. \& Schultz, M. (2002). The Dynamics of Organizational Identity. Human Relations - HUM RELAT. 55. 989-1018.

[16] Jeyavelu, S. (2007). Organizational Identity and Sustainable Competitive Advantage: Combining Resource Based View and Configuration Approach. International Journal of Management Practices \& Contemporary Thoughts, Vol. 2, No.2, July-December 2007. 
[17] Kiriakidou, O. \& Millward, L.J. (2000). "Corporate identity: external reality or internal fit?", Corporate Communications: An International Journal, Vol. 5, No. 1, pp. 49-58.

[18] Ma, H. (2000). Competitive advantage and firm performance. Competitiveness Review: An International Business Journal incorporating Journal of Global Competitiveness. 10. 15-32.

[19] Machado, H. V. (2003). A identidade e o contexto organizacional: perspectivas de análise. Revista De Administração Contemporânea, 7(spe), 51-73.

[20] Minguez, N. (2000). Un marco conceptual para la comuncación corporativa. Zer: Revista de estudios de comunicación = Komunikazio ikasketen aldizkaria, ISSN 1137-1102, №. 8, 2000.

[21] O'Donnell, A. \& Gilmore, A. \& Carson, D. \& Cummins, D. (2002). Competitive advantage in small to mediumsized enterprises, Journal of Strategic Marketing, 10:3, 205-223

[22] Porter M.E. (1979). How Competitive Forces Shape Strategy. In: Asch D., Bowman C. (eds) Readings in Strategic Management. Palgrave, London.

[23] Ruão, T. (2001). o conceito de identidade organizacional: teorias, gestão e valor.

[24] Sillince, J. (2006). Resources and Organizational Identities: The Role of Rhetoric in the Creation of Competitive Advantage. Management Communication Quarterly - MANAG COMMUN Q. 20.186-212.

[25] Whetten, D. (2006). Albert and Whetten Revisited: Strengthening the Concept of Organizational Identity. Journal of Management Inquiry - J MANAGE INQUIRY. 15. 219-234. 


\section{Capítulo 18}

Planejamento estratégico em uma empresa de armazenagem de grãos no município de Amambai Mato Grosso do Sul

\section{Deisivani Carol Lima dos Santos \\ André Felipe Queiroz. \\ Lesley Soares Bueno \\ Valéria Sun Hwa Mazucato}

Resumo: A armazenagem de grãos é um importante elo da cadeia produtiva agrícola, que representa um nicho de crescentes oportunidades no qual o agronegócio tem sido extremamente favorecido pelo potencial produtivos das regiões em que se localiza, contexto este que tem implicao ao planejamento estratégico um papel cada vez mais importante na gestão de empresas armazenadoras de grãos. Com o intuito de contribuir com essa área de estudos, este trabalho assume como objetivo geral avaliar estrategicamente o ambiente organizacional e o posicionamento competitivo de uma empresa de armazenagens de grãos localizada no município de amambai no mato grosso do sul, a partir da análise do ambiente interno e externo (matriz swot) da organização e a análise das 5 forças de porter. A metodologia adotada foi um estudo de caso, com coleta de dados por entrevista estruturada, observação in locco e análise documental, sendo que todos os dados coletados foram analisados conforme a proposta das ferramentas escolhidas. A análise de 5 forças de porter permitiu constatar que apesar da grande concorrência na região, a empresa se destaca frente a seus concorrentes, possuindo grande potencial de crescimento no mercado, embora existam ameaças importantes a serem observadas. A matriz swot evidenciou os aspectos positivos se sobressaem aos negativos, sendo favorável a manutenção da estratégia adorada atualmente pela empresa, que se caracterizou como de crescimento, porque é a que mais se enquadra ao posicionamento competitivo atual da empresa, sua relação com os concorrentes, clientes e demais stakeholders e, principalmente, ao cenário local do agronegócio que apresenta imporantes oportunidades.

Palavras-chave: Agronegócio. Planejamento Estratégico. Matriz Swot. 5 forças de Porter. 


\section{INTRODUÇÃO}

O planejamento estratégico é primordial para a definição das estratégias organizacionais e modelos adequados de gestão para que uma determinada empresa alcance seus objetivos. Especialmente no agronegócio, que sofre de forma acentuada os impactos de situações inesperadas, visto a dependência do clima e da perecibilidade de seus produtos, o planejamentoestratégico assume um papel muito importante.

Nas empresas de armazenamento de grãos, por exemplo, o planejamento estratégico se expressa na delimitação dos objetivos organizacionais sim, mas além disso, também é percebido nas atividades cotidianas, responsáveis por garantir a qualidade dos serviços prestados e do produto final vendido. É de extrema importância o gerenciamento de qualidade na rede de armazenagem, sabendo então, para que o produto armazenado chegue ao consumidor com as devidas exigências padrões de qualidade, e que não perca produto com má gestão é necessário que sejam adotados métodos para que tenha menor custo e obtenha um melhor resultado.

Devido a esta importância, tem se tornado cada vez mais numerosos os trabalhos publicanos na área da gestão estratégica, inclusive voltados para o agronegócio (POLACINSKI et al., 2021; COSTA et al., 2020; GASPERIN, 2017; SOUZA et al., 2017). Soares et al (2016), por exemplo, discutiram em seu estudo, a viabilidade econômica de trabalhar no setor de apicultura. Seus resultados indicaram que planejamento estratégico é um fator determinante para a saúde e sustentabilidade dos negócios. Silva (2018), por sua vez, estudou como demonstrar a viabilidade do planejamento estratégico em pequenas propriedades rurais e constatou que a falta de planejamento e uso de ferramentas de gestão podem trazer a ineficiênciade produtividade. Ele também concluiu que por meio da implantação planejamento estratégico, foi possível aumentar cerca de $70 \%$ da produtividade.

Outros tantos trabalhos tem se dedicado a compreender como o planejamento estratégico contribui na prática das empresas. Ainda assim há uma enorme lacuna para a compreensão de como as peculiaridades de cada empresa interferem no planejamento estratégico e suas etapas, bem como seus resultados. Especialmente na armazenagem de grãos, são escassos os estudos na área de planejamento estratégico. Para contribuir com este ramo do conhecimento, este trabalho tem como objetivo geral avaliar estrategicamente o ambiente organizacional e o posicionamento competitivo de uma empresa de armazenagens de grãos localizada no município de Amambai em Mato Grosso do Sul.

\section{FUNDAMENTAÇÃO TEÓRICA}

\subsection{O PLANEJAMENTO ESTRATÉGICO}

O planejamento estratégico nas organizações tem como objetivo principal moldar os negócios e produtos de uma empresa, de modo que eles possibilitem os lucros e o crescimento almejados (KOTLER, 2000). Barros (2012) afirma que diante desta ferramenta de gestão, as organizações conseguem atingir uma percepção melhorada, assim podendo alcançar um possível crescimento econômico e financeiro.

Entre os diversos modelos didáticos de planejamento estratégico, o proposto por Chiavenato (2007) contempla seis principais etapas que estão apresentadas na figura 1. Partindo da identidade da empresa, a primeira etapa é a definição dos objetivos, partindo então para a analisar o ambiente externo, evidenciando fatores que possam influenciar nas tomadas de decisões da organização.

A análise de ambiente externo é basicamente observar em qual cenário atual em que a empresa se encontra ou em qual posicionamento comercial estratégico ela atua, isso facilitará para qualquer tomada de decisão. Já a análise interna consiste no diagnóstico de aspectos como cultura e clima organizacional, qualidade dos produtos, organização das pessoas, entre outros, visa obter um diagnóstico de como é o funcionamento da empresa, quais pontos específicos devem ser melhorados ou corrigidos. 
Figura 1: Etapas do Planejamento Estratégico.

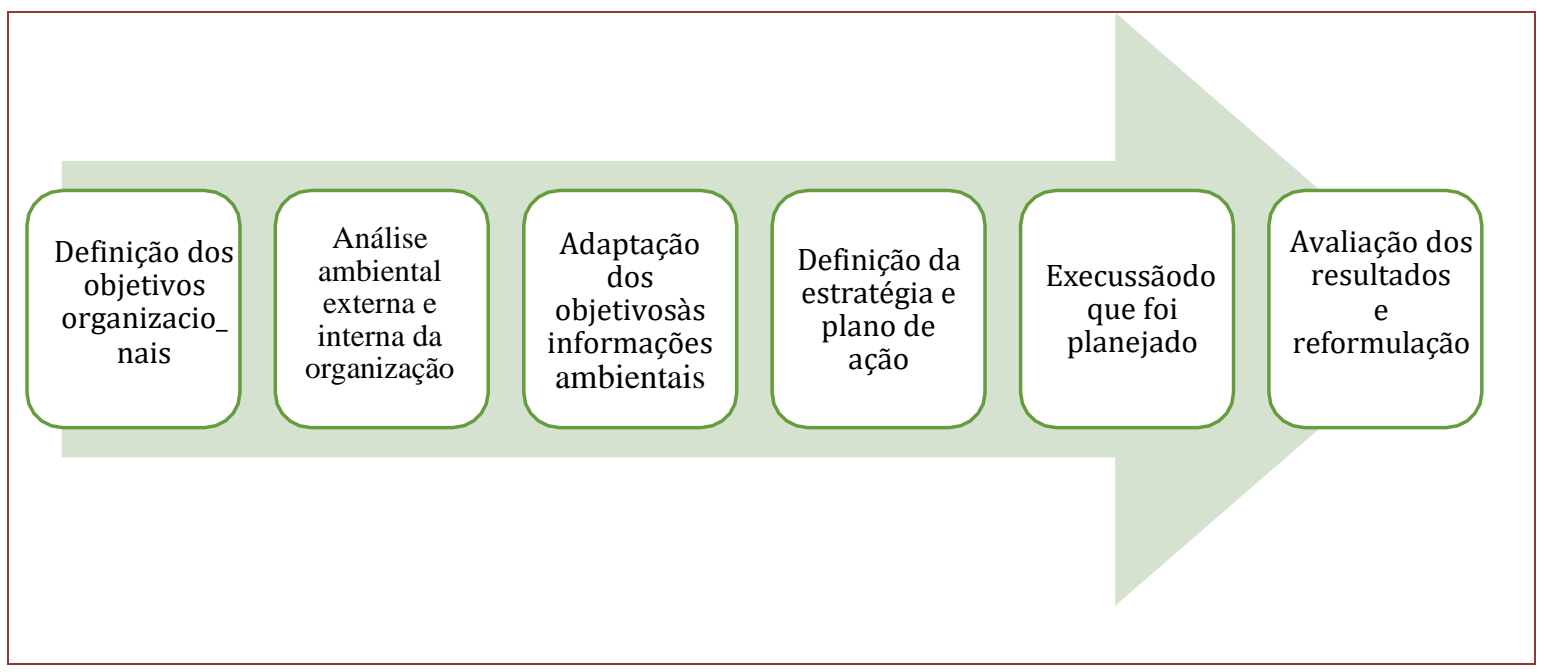

Fonte: Adaptado de Chiavenato (2007).

Com base na análise do ambiente organizacional, se dá a próxima etapa que é a adaptação dos objetivos diante o cenário do ambiente externo, e interno. A quarta etapa é o estudo de como será implantado o plano de ação, quais estratégias serão necessárias adotar para o cenário atual que a organização se encontra. Na etapa seguinte é a fase onde seráconstruído todo o plano de ação e por fim tem-se a avaliação dos resultados, através da avaliaçãopode ser determinado se houve êxito nos resultados desejados.

\subsection{MATRIZ SWOT: UMA FERRAMENTA DE ANÁLISE DO AMBIENTE ORGANIZACIONAL}

Ao decorrer da evolução do planejamento estratégico como área de estudo, diversos especialistas acadêmicos e gerenciais observaram a aplicação do planejamento estratégico nas empresas e desenvolveram diversas ferramentas para auxiliar cada uma das etapas deste processo. Especialmente a etapa de análise do ambiente interno e externo da organização tem sido foco de diversas ferramentas, dentre as quais uma das mais conhecidas é a Matriz Swot.

A Matriz Swot foi criada pelo pesquisador Albert Humphrey, o qual liderou um projeto de pesquisa na universidade de Stanford responsável por cruzar dados das maiores corporações da época. A ferramenta desenvolvida pela pesquisa logo se tornou conhecida e utilizada por varias empresas para auxiliar nas elaborações de suas estratégias, por conseguir simplificar o diagnóstico da situação organizacional.

A Matriz Swot estuda o ambiente interno e externo de uma organização a partir de quatro elementos, sendo eles: Strengths (Forças), Weaknesses (Fraquezas), Oportunities (Oportunidades) e Threats (Ameaças). Por meio deles se obtém a Matriz Swot ( $\mathrm{S}$ - trengths; W- eaknesses; 0 - portunities; T hreats).

Também conhecida como Análise Swot, esta ferramenta é cada vez mais utilizada em grande escala pelas organizações. Contudo é uma ferramenta simples, que traz grandes resultados quando aplicada, ela visa situar em qual posição tática a empresa ou organização está, entretanto evidencia os pontos fortes e fracos, internos e externos da instituição. Para Serra et al. (2004, p. 28) "a função primordial da Matriz Swot é possibilitar a escolha de uma estratégia adequada, para que se alcancem determinados objetivos, a partir de uma avaliação crítica dos ambientes internos e externos".

Para Chiavenato (2007), a Matriz Swot constitui a ideia de junção entre a análise ambiental e a análise da organização, para analisar a condição da instituição em um certo período de tempo. 0 confronto da análise de ambiente externo e interno, possibilita a visão e desenvolvimento de estratégias que possam melhorar, e desenvolver suas vantagens competitivas, ou até mesmo diminuir os contrastes de suas deficiências internas e intervençõesexternas.

No agronegócio, a Matriz Swot tem sido intensamente utilizada para análises estratégicas e tomadas de decisões (POLACINSKI et al., 2021; COSTA et al., 2020). Gasperin(2017), por exemplo, aplicou esta ferramenta para diagnosticar o ambiente interno e externo em propriedades rurais familiares no Rio Grande do Sul, como forma de analisar os custos de transação e os recursos estratégicos e, 
consequentemente, identificar os aspectos de impacto competitivo a estes produtores.

Souza et al. (2017) fizeram uso da Matriz Swot para diagnosticar o cenário do agronegócio de Santa Catarina como forma de blindar a proposta de uma nova empresa contra possíveis ameaças. Neste caso específico a Matriz Swot fez parte do planejamento estratégico de abertura da empresa. Já Behnen (2020) utilizou Matriz Swot para avaliar a gestão de custos do plantio de grãos de uma propriedade rural, enquanto que Costa et al. (2020) aplica a Matriz Swot como parte da análise da utilização de sistemas de gerenciamento de armazéns no Agronegócio do Distrito Federal, e sua relação com os Condomínios de Armazéns Rurais.

Nota-se que, no contexto que se refere ao agronegócio, a aplicação da Matriz Swot tem permitido a diagnósticos interessantes, que contribuíram para a melhor tomada de decisão por parte dos gestores. Percebeu-se também a preocupação em explicitar as evidências analisadas, de forma que a tomada de decisão seja embasada em circunstâncias e fatos corretos.

\subsection{A ANÁLISE DAS 5 FORÇAS DE PORTER}

A Análise das 5 forças de Porter podem ser definidas como uma ferramenta de análise ambiental, que pode ser utilizada como complemento à Matriz Swot ou em análises singulares.A Análise das 5 Forças de Porter tem o objetivo de ajudar a análise do ambiente organizacionalque está inserido, assim obtendo estratégias eficazes que colaboram com o crescimento da mesma (PORTER, 2004). Para Proença (1999), o foco desta ferramenta consiste em detectar quem está com vantagem e porquê. Pode ainda resolver os problemas verticais da empresa, sua forma e direção.

A Análise das 5 forças de Porter contempla cinco dimensões de análise, sendo elas os clientes, os concorrentes, os produtos substitutos, os fornecedores e a ameaça de novos entrantes no mercado de atuação da empresa.

Os produtos substitutos são aqueles que possuem como principal característica desempenhar a mesma função que o produto ou serviço oferecido possui (SERTEK et al., 2007). Porter (2004) diz que os produtos substitutos é um meio de limitação da lucratividade, pois quanto mais atrativo e de menor valor do produto, consequentemente maior será a ameaça sobre os preços ofertados pela empresa. A ameaça de entrada de novos concorrentes observa quais são as chances de novos concorrentes no mercado em qual atua, qual as chances de crescimento e lucratividade. 0 poder de negociação dos clientes, refere-se à capacidade do cliente em barganhar maneiras de pagamentos. 0 poder de negociação dos fornecedores, trata-se da empresa onde contrata seus fornecedores, negociar prazos e preços, onde a organização que depende desses serviços, fica à mercê de seus provedores, e por fim a rivalidade entre os concorrentes, visa destacar que por mais que um mercado que possua muitas empresas prestando o mesmo serviço a rivalidade e concorrência será maior.

No contexto do agronegócio esta ferramenta tem sido aplicada em diversas análises sobre vantagem competitiva, como é o caso de Coutinho e Chaves (2009) que aplicaram a Análise das 5 Forças de Porter como parte de um sistema de informações do mercado proposto ao produtor de arroz, ou Pedrozo et al. (2005) que a aplicaram para avaliar o ambiente de negócio, a estrutura competitiva e o comportamento estratégico da agroindústria avícola.

Mattos et al (2010) utilizaram a Análise das 5 Forças de Porter como ferramenta para diagnóstico estratégico nas unidades de produção primária, o qual obteve como resultado significativo a identificação do cenário das empresas estudadas, com predominância de pontos fortes e oportunidades para a propriedade rural estudada. Martinez (2020), por sua vez, buscou estender a proposição de forças competitivas no agronegócio incluindo as questões da sustentabilidade.

\subsection{ESTRATÉGIAS ORGANIZACIONAIS}

As estratégias organizacionais consistem no ato de planejar e executar medidas para quea empresa alcance seus objetivos. Embora as estratégias organizacionais possam ser de incontáveis particularidades, dependendo da empresa, seus objetivos e cenário de atuação, nestetrabalho serão consideradas as quatros principais vertentes de estratégias propostas por Oliveira(2007), que são de sobrevivência, manutenção, desenvolvimento e crescimento.

Estratégias de sobrevivência são aquelas em que a empresa opta pela redução de alguns custos e o desinvestimento. Normalmente é adotada quando uma determinada empresa passapor um momento de 
crise, seja por questões internas, seja por questões externas, como umarecessão econômica do país ou alteração do comportamento de compra de seus consumidores.

Na estratégia de manutenção, por sua vez, a empresa já alcançou patamar considerável e pretende manter sua posição no mercado, assim ela busca novas aberturas em especializações, dominando apenas uma área específica, assim valorizando seus pontos fortes.

A estratégia de crescimento é adotada quando a empresa possui caráter de ambiente externo comercial favorável, no entanto a empresa busca aliados de mercado, aproveita essas oportunidades para fazer algo novo, diversificação. Ela pode optar por fazer algo novo, lançar algum produto ou serviço que ainda não foi lançado, ou também poderá fazer transações comerciais, optando pela estratégia de exportar seus produtos ou serviços.

Também é bastante comum dentro da estratégia de crescimento, optar pela estratégia de joint venture, quando a empresa quer entrar em um outro ramo de mercado, então ela busca uma outra organização para ser aliada, onde cada uma colabora com um item necessário, seja ele tecnologia ou capital, para que seja produzido o produto. Ela pode também optar pela estratégia de expansão que deve ser planejada minunciosamente, pois a análise de mercado ter que ser criteriosa, pois a não expansão ou a expansão em momentos incertos pode lavar a possíveis perdas.

Por fim, a estratégia de desenvolvimento é utilizada quando ela possui características de pontos fortes e quer utiliza-las. Diante disso, ao que diz respeito a estratégia de desenvolvimento, essa técnica busca escolher um mercado que já atua comercialmente e tenta aperfeiçoar o serviço prestado, ou também usa de um produto ou serviço que já é destaque em sua linha comercial e leva para outro mercado.

\section{METODOLOGIA}

Em vista dos objetivos propostos, este trabalho se caracteriza como um estudo qualitativo de nível descritivo, que tem por objetivo a descrição das características de determinada população ou fenômeno ou, então, o estabelecimento de relações entre variáveis (GIL, 2002, p. 45). 0 delineamento adotado foi o de estudo de caso, no qual o objeto de estudo foi estudado de forma extensiva e aprofundada (Gil, 2002). Foram coletados dados por meio roteiro de entrevista estruturada com pessoas chave dentro da organização, totalizando três respondentes e contemplando o processo operacional da empresa. Foram também feitas investigações em documentos organizacionais e observação diária in locco ao longo dos meses de outubro a dezembro do ano de 2020.

Os dados provenientes das entrevistas e das anotações de campo foram analisados a partir do seu conteúdo, de acordo com as ferramentas escolhidas neste trabalho: a Matriz Swot e a Análise das 5 Forças de Porter. Dessa forma, foi possível a avaliação das características da empresa e do seu ambiente interno e externo, de forma a elucidar o cenário atual da empresa e evidenciar possíveis escolhas estratégicas mais vantajosas.

\section{RESULTADOS}

Os resultados do trabalho permitiram a caracterização do cenário competitivo da empresa, visto suas características estratégicas e seu ambiente interno e externo. Primeiramente destaca-se que, assim como o proposto na literatura, o planejamento estratégico partiu da identidade da empresa.

Averiguou-se então que a empresa objeto deste estudo é um armazém de grãos que pertencente a uma família que atua também com serviços de abatedor de bovinos, frigorifico, onde é fonte de renda de aproximadamente 200 famílias da região. Os proprietários da empresa atualmente se dedicam ao frigorifico que é localizado em frente ao armazém, deixando como responsável e filho mais novo do casal.

A empresa foi inaugurada em junho de 2019 e partir do sucesso alcançado nesta atividade os proprietários decidiram abrir em um futuro próximo, uma nova filial em um ponto estratégico. Até o momento da realização deste estudo e delimitando-se a análise apenas ao armazém já em funcionamento.

No que tange aos demais elementos da identidade organizacional, como missão, visão e valores, a organização ainda não possui elementos bem estabelecidos. Não foram constatadas declarações de missão, visão e valores aos funcionários ou aos clientes, refletindo a recém entrada no mercado e o pouco uso de ferramentas de gestão que fortaleçam a identidade organizacional. 


\subsection{PROCESSOS E OPERAÇÕES DA EMPRESA}

A empresa conta com oito funcionários, sendo que cinco deles trabalham no setor operacional e três no setor administrativo. Cabe ao gerente o contato com os clientes e as atividades de venda dos serviços, além da gestão dos colaboradores. Ao setor administrativo cabem as tarefas auxiliares à venda, como emissão de notas fiscais e gestão de documentos, bem como as atividades referentes a gestão de departamento pessoal. Já ao setor operacional da empresa cabe todo o processo de recebimento e gestão dos grãos, detalhado na figura 2 .

Figura 2: Fluxograma do Recebimento dos Grãos na Empresa

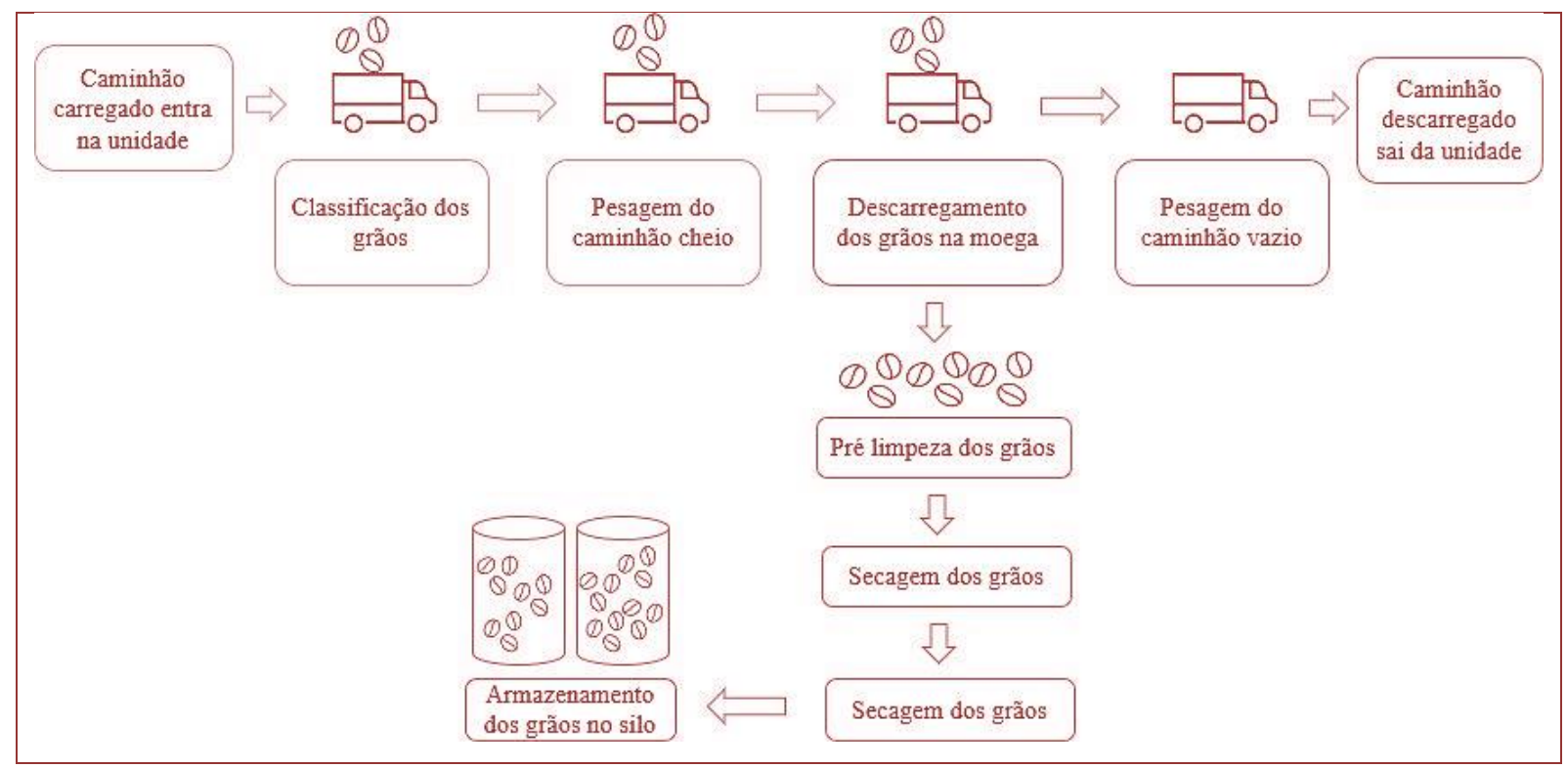

Fonte: Dados da pesquisa.

Como descrito pela figura 2, o caminhão contendo os grãos entra na unidade e os grãos passam por um processo de classificação, no qual o profissional classificador de cereais vai determinar a qualidade do produto e por meio desta classificação será possível determinar a melhor técnica de manejo necessário para aquela carga específica.

Após esta primeira etapa, o caminhão carregado com o produto passa pela balança, para pesar o peso bruto, e segue para a moega onde vai descarregar o cereal. Para os grãos descarregados vem a etapa de pré-limpeza, secagem e limpeza do grão, onde na pré-limpeza ena limpeza provém os grãos quebrados, e aqueles grãos menores chamados também de resíduos, onde podem ser usados para o consumo animal.

Para realizar o processo de secagem de grãos, o produto passa primeiramente na pré- limpeza e depois é submetido a secagem do grão onde esse produto é exposto a uma temperatura especifica até chegar à umidade desejada, após a secagem, o produto passa na limpeza, posteriormente à secagem pode haver algumas quebras devido o produto estar seco, por isso é necessário a temperatura ideal, depois de todo esse processo o produto é armazenado no silo.

No entanto o veículo volta novamente na balança e pesa vazio assim será possível saber a quantidade de produto que ele armazenou, através do peso e da classificação. De acordo com a qualidade dos grãos é feito uma porcentagem de descontos para o produto com umidade, impureza e outros requisitos de classificação acima do permitido, lembrando que o produto só será submetido a secagem se ele não estiver com umidade padrão estabelecido pelas normas do armazém. Ao serem armazenados a empresa é responsável por cobrar um valor, devido a prestação de serviço da mesma, porém esse valor só vai ser acertado no momento em que o cliente efetuar venda ou fazer retirada do produto estocado. Tendo em conta que as taxas de serviço correm mensamente, para que seja designado um preço para a prestação de serviço é feito uma tabela com a porcentagem com o grau e valor que será cobrado por sacas.

A empresa opera com três taxas de prestação de serviços, a taxa de recebimento, taxa de armazenagem, e a quebra técnica que é a diferença da sobra do grão, todo armazém ou cooperativa tem um grau de 
porcentagem que define a quantidade que será descontado ao final da armazenagem do produto. Entretanto há também os descontos de impureza e umidade que tais são descontados no peso líquido do caminhão, se no entanto o caminhão obteve um peso x, com os descontos através de tabelas ele obterá um peso y, já descontado as impurezas e outros itens de classificação de acordo com a qualidade do produto, é descontado uma porcentagem tanto de impureza como de umidade e outros elementos se necessário , porém com descontos diferentes, não é usada a mesma tabela para obter a taxa de porcentagem da mesma. Essas tabelas podem variar de uma unidade armazenadora para outra, não são todas unificadas.

\subsection{DISCUSSÃO DA ANÁLISE DAS 5 FORÇAS DE PORTER}

Pela aplicação da ferramenta Análise das 5 Forças de Porter, foi possível caracterizar a relação da empresa com os seus clientes, fornecedores, concorrentes, além da ameaça de novos entrantes no mercado e produtos substitutos.

A gama de clientes da empresa está localizada na região da cidade de Amambai, porém as propriedades onde se concentra os produtos é localizada em áreas rurais, algumas em localidades mais próximas outras mais distantes em média de 20 à $60 \mathrm{~kg}$ da empresa destino onde irá ser entregue o produto. A faixa etária dos clientes de 35 a 65 anos de idade, com alguns casos mais raros de herdeiros mais novos. A maior parte são homens, com idade media de 50 anos. Os clientes moram na cidade, mas possuem área de atuação no meio agrícola, especificamente na produção de grãos.

A região de entorno possui duas culturas fortes, a soja e o milho, consequentemente a empresa conta com a colheita dos mesmo em duas épocas do ano. No entanto, os clientes trabalham o ano inteiro na produção dessas duas culturas, para que na colheita a empresa em destaque preste seu serviço. Comumente esses produtores rurais, são responsáveis pela supervisão do trabalho de seus funcionários, onde eles possuem em sua propriedade pessoas capacitadas para desenvolver os serviços de antes da porteira e depois da porteira, contudo elesestão sempre monitorando para que haja uma boa produção.

A comercialização desses grãos pode ser feita por intermédio da empresa, que também compra de seus clientes os produtos armazenados, porque é de interesse dos proprietários para consumo animal, ou também por venda direta, do produtor para a empresa que comprou o produto. Atualmente o preço para armazenar os grãos correspondem a uma taxa de recebimento, e possui outro valor, que corresponde com tempo armazenado do produto que por ventura ficarecebendo os devidos cuidados para garantir a qualidade.

Um grande diferencial que a empresa possui é a forma de receber e atender os clientes, desde os produtores aos servidores dos produtores, a empresa sempre se preocupando com o bom atendimento, sempre presando que seus clientes se sintam bem ao estarem ali, esse item éde extrema importância para os gerenciadores da organização, sempre em reuniões é mencionado a importância do bem estar dos clientes. Um outro grande fator de vantagem da empresa é a facilidade de comercialização já que eles também atuam como fortes compradores dos produtos para seus clientes, evidenciando uma posição confortável da empresa com os clientes.

No setor agrícola de cereais há grandes cooperativas armazenadoras. Essas empresas atuam diretamente como concorrentes fortes no mercado, inclusive tendo como diferencial o fato de fornecer insumos para os produtores e, em troca, os produtores devolvem na maioria das vezes como forma de pagamento uma quantidade em sacas de grãos no valor correspondente ao valor adquirido aos insumos.

Estas empresas concorrentes atuam há anos no mercado trabalhando para o reconhecimento e fidelidade dos clientes, por tanto já tem uma rede de clientes fiéis. Além disso, as cooperativas fornecem insumos para a produção.

Entretanto, mesmo com a forte concorrência e pouco tempo de atuação já possui uma grande linha de clientes. Para que os clientes conheçam o armazém, tem sido feito uma estratégia de prestação de serviços para duas cooperativas das cidades, sendo assim ambas as partes são favorecidas, a cooperativa por ter uma aliada ao ter mais espaço para depositar seus produtos fazendo assim um contrato com a empresa, garantindo um lucro fixo para a organização.

A localização é um fator de extrema importância nesse ramo, pois uma rede armazenadora não pode estar localizada no centro da cidade, pois seria extremamente fora de acesso aos produtores, sabendo que o principal foco é as fazendas onde é produzido os grãos, portanto é estratégia que os receptores de grãos sejam localizados nas saídas das cidades, ou em áreas rurais próximos a fazendas, onde é de fácil acesso aos que entregaram o produto ao armazém. 
Os principais produtos substitutos no caso da empresa estudada são os silos bags, que possuem valor muito mais inferior aos silos metálicos, e com qualidade não garantida pois ficam apenas armazenadas em grandes bolsas, assim ficando vulneráveis a intempéries temporais, bichos roedores, e entre outras diversificações de vulnerabilidade, e com poucos recursos para manter a qualidade. Porém é de baixo custo, entretanto o produtor não tenha alternativa é um meio bastante acessível e barato.

Outro grande produto substituto que vem crescendo ao decorrer dos anos, é os silos de fazenda, alguns produtores tem optado por construir silos em suas propriedades, assim é possível que seja armazenado todo o seu produto em sua própria localidade. Os benefícios paraquem possui um silo em sua propriedade são imensos, pois o produtor não terá custo algum com taxas de armazenagem, terá apenas o custo para que o produto seja armazenado com qualidade, e para que a qualidade se mantenha ao perpassar o tempo.

É fato que ainda não é muito forte esse meio de silos de fazenda, pois o custo é muito alto, porém se todos os produtores adquirissem esse produto substituto, seria sim um fator de risco para a empresa pois teria muita demanda de armazéns e pouca oferta de produtos para armazenar, se levarmos em conta é um fator de risco se todos adquirissem essa modalidade.

Quanto aos fornecedores, a empresa conta com fornecedores locais e não possuidependência de somente um fornecedor, pois os produtos necessários são de fácil acesso. Entãoas compras são feitas por cotação de preços para buscar o melhor lugar com preços mais acessíveis. No que abrange os novos entrantes no mercado, é relevante ressaltar que os armazéns metálicos são de custo elevado e, consequentemente, é alto o investimento para abertura de novos empreendimentos, sendo um aspecto positivo para a empresa.

\subsection{DISCUSSÃO DA MATIZ SWOT}

A análise do ambiente interno e externo por meio da Matriz Swot permitiu um diagnóstico detalhado, cujos pontos mais importantes estão destacados na figura 3.

Figura 3: Principais aspectos destacados na Matriz Swot

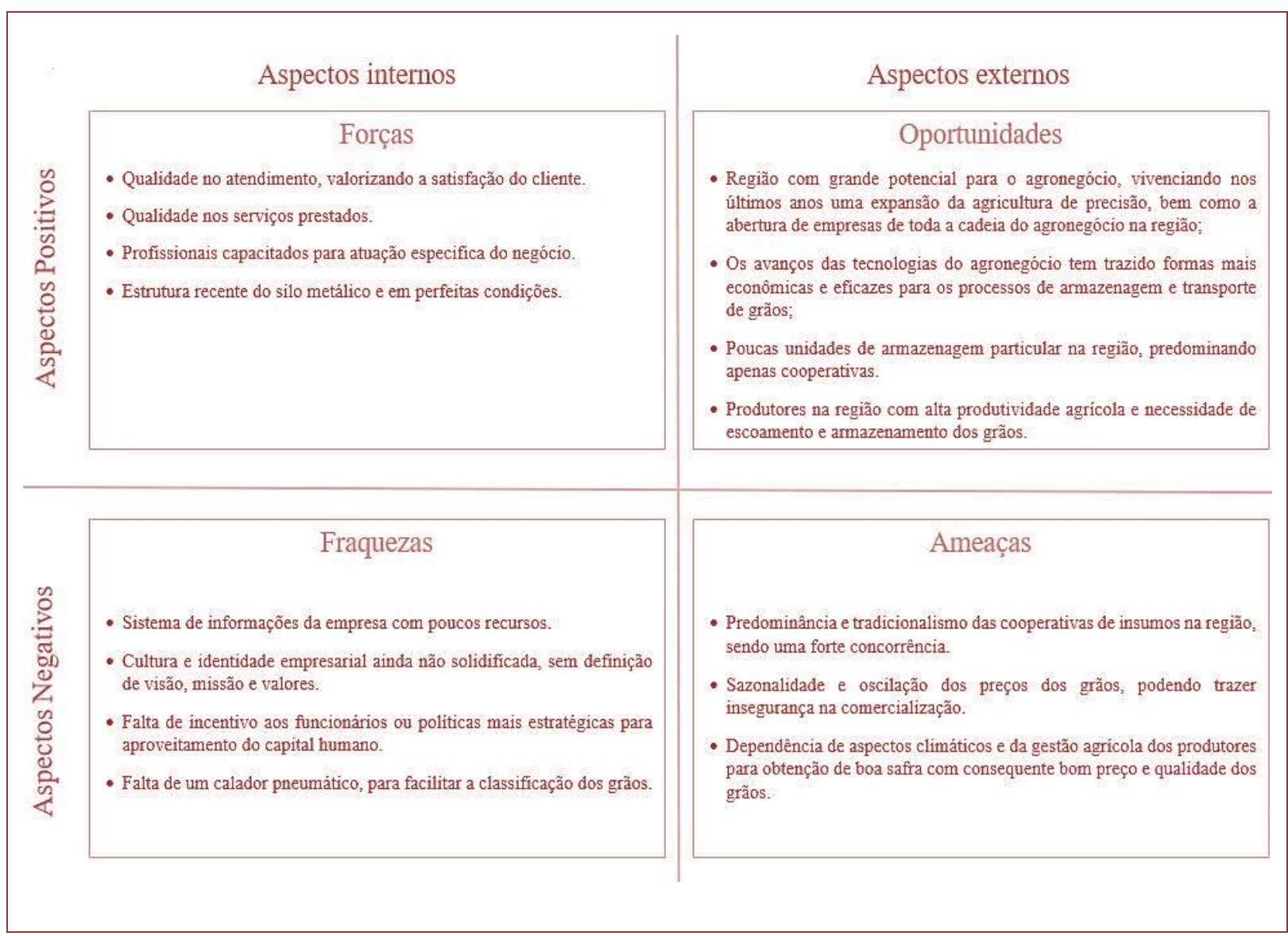


Observando a figura 3, observa-se que a empresa possui como principais forças a qualidade no atendimento e nos serviços prestado, além de boa infraestrutura e disponibilidade de recursos para continuar se desenvolvendo. Para garantir que essa infraestrutura esteja sempre em boas qualidades é necessário que seja feito a manutenção dele periodicamente assim garantindouma maior durabilidade do mesmo. Também destaca-se como ponto positivo do cenário interno a qualificação dos funcionários, uma vez que todos os funcionários possuem capacitação para executar os serviços que lhes cabem.

Entre os aspectos internos negativos mais relevantes destaca-se o sistema de informações da empresa, pois o programa utilizado conta com poucos recursos e escassas atualizações, possuindo inclusive alguns itens básicos e necessários, porém inoperantes.

Já as oportunidades que mais se destacaram são o crescimento do agronegócio da região e o fortalecimento da cadeia produtiva como um todo, permitindo que a empresa tenha suporte e os parceiros necessários. De fato, a região sudoeste do Mato Grosso do Sul tem tido desenvolvimento voltado ao agronegócio, os grandes avanços da tecnologia no setor do agronegócio, e terras com grandes potenciais agricultáveis na região. Esses avanços tem ajudado a evitar desperdícios de insumos e garantir a qualidade das safras, tendo como grande aliado as tecnologias de precisão, que vem assessorando através de coleta de dados, assim melhorando o potencial produtivo. 0 potencial da qualidade das terras na região é uma ótima chance de o mercado de armazenagem crescer, pois quanto mais produto, maior será a receptividade dos armazéns, além das terras já possuírem alto índice produtivo, as deficiências são preenchidas através da agricultura de precisão, sendo assim cada vez mais a qualidade da produção vem se aprimorando.

Quanto as ameaças, destaca se a forte concorrência sofrida por parte das cooperativas, que juntamente com o serviço de armazenamento, costumam fornecer insumos para os produtores, fortalecendo a relação com o produtor. Entretanto, a politica das cooperativas também inflingem diversos pontos negativos como a falta de flexibilidade e valores de compra pré-determinado, que são desfavoráveis para produtores rurais que busquem mais autonomia. Alem disso, nada impede que a empresa foco deste estudo adote estratégia de prevenção a essa concorrência, colocando em prática ações que fidelizem os produtores e os ajude a ter mais segurança. Com base em todas essas observações, constata-se que a análise feita apresenta uma atuação positiva da empresa, pois de acordo com os dados levantados na pesquisa, a posição atual que ela se encontra no mercado é positivo, isso significa que ela possui muitos aspectos favoráveis que poderão contribuir para o desenvolvimento da mesma.

\subsection{PROSPECÇÃO DE CENÁRIOS E ESCOLHA ESTRATÉGICA}

Considerando o resultado das ferramentas aplicadas, é possível estimar alguns cenários possíveis para a empresa. De forma sintética é possível prever que a empresa, sustentada pelo bom atendimento prestado aos clientes e pelo pessoal capacitado, tem condições de continuar acompanhando o desenvolvimento do agronegócio no Mato Grosso do Sul. Entretanto, para evitar as ameaças mais impactantes do cenário atual da empresa, é imprescindível que ela continue investindo em soluções tecnológicas para competir de forma vantajosa com os concorrentes deste mercado tão dinâmico. Além disso, é preciso estar atenta as novas tecnologias específicas às atividades da empresa.

Por conseguinte, os resultados deste estudo parecem indicar que a estratégia de crescimento, que é atualmente empregada pela empresa, seja de fato a mais adequada, uma vezque permitirá que a empresa faça uso dos ganhos atuais para investimentos em atividadesfuturas e aumentem sua capacidade de atendimento. Nesse sentido, é preciso manter um olharainda mais vigilante na qualidade dos serviços e do capital humano disponível para a empresa.

A estratégia de crescimento envolve a expansão da empresa e implica na capacidade de arcar com esse crescimento sem afetar a qualidade de seus serviços. Além disso, essa estratégia se baseia no potencial de mercado, com oportunidades a seu favor, como é o caso do agronegócio na região da organização. É notável que a empresa possui grande potencial de crescimento, pois se ela prosseguir na mesma direção poderá aproveitar oportunidades vantajosas e obter importantes resultados futuros.

\section{CONCLUSÃO}

Em virtudes dos fatos mencionados, o objetivo do trabalho foi fazer um estudo de casoda empresa, onde através das ferramentas de planejamento estratégico, Matriz Swot e Análise de 5 forças de Porter foi possível analisar o cenário atual da empresa. 
Esses procedimentos metodológicos permitiram que o objetivo fosse alcançado, por meio da avaliação estratégica da empresa. A Análise de 5 forças de Porter permitiu constatar que apesar da grande concorrência na região, ainda sim a empresa se destaca frente a seus concorrentes. Portanto, empresa possuigrande potencial de crescimento no mercado, onde através da ferramenta foi possível observarque a organização também possui aspectos de ameaça aos concorrentes.

Por sua vez a Matriz Swot evidenciou os grandes pontos fortes e fracos da empresa, naqual a organização possui indicativos que ressaltam os aspectos positivos que se sobressaemaos negativos onde é possível perceber que a empresa não se encontra em situação prejudicial.

Deste modo a organização se enquadra na estratégia de crescimento na qual o ambiente externo é favorável para que ela possa aproveitar esses aspectos e transforma-los emoportunidades. A estratégia de crescimento é a que mais se enquadra devido aos indicadores serem de crescimento sendo que a empresa já possui projetos de ampliação em uma nova região, assim podendo levar seus serviços a outros clientes.

\section{REFERÊNCIAS}

[1] BARROS, A.M. Gerenciamento da produção visando o crescimento da propriedade rural. Disponível em:< http://rehagro.com.br/plus/modulos/noticias/imprimir.php?cdnoticia=2373> Acessoem 04 de Abril de 2012.

[2] BEHNEN, B. Custos do plantio de grãos na fazenda Quero Quero. Pontifícia Universidade Católica de Goiás. Trabalho de Conclusão de Curso. Dezembro de 2020. Disponível em: https://repositorio.pucgoias.edu.br/jspui/handle/123456789/1072

[3] CHIAVENATO, I; SAPIRO, A. Planejamento Estratégico: fundamentos e aplicações. 1. ed. $13^{\circ}$ tiragem. Rio de Janeiro: Elsevier, 2007.

[4] COSTA, L. M.; FILIPPI, A. C. G.; GUARNIERI, P. Sistemas de gerenciamento de armazéns no agronegócio e em condomínios de armazéns rurais no Distrito Federal. Informe Gepec, v. 24, n. 2, 2020. DOI: https://doi.org/10.48075/igepec.v24i2.24492

[5] COUTINHO, A. R.; CHAVES, M. O. Estratégia e planejamento de mercado para produtor dearroz irrigado tropical. In: Embrapa Arroz e Feijão-Artigo em Anais de congresso (ALICE). In:CONGRESSO BRASILEIRO DE ARROZ IRRIGADO, 6., 2009, Porto Alegre. Estresses e sustentabilidade: desafios para a lavoura arrozeira: anais. Porto Alegre: Sosbai, 2009., 2009.

[6] DUARTE, F. Planejamento Estratégico: uma contribuição para análise de resultados de implantação da média indústria, 2002. 95f. Tese (Curso de Pós-Graduação) - Programa de Revista Perspectiva em Gestão, Educação \& Tecnologia, v.4 n.8, julho-dezembroo/2015 Pós- Graduação em Administração de Empresas, Departamento ECA,Universidade de Taubaté 2002. Disponível em: . Acesso em: 27 maio 2012.

[7] GASPERIN, A. R. Competitividade da agricultura familiar na região central do Rio Grande doSul: um estudo de caso utilizando a Matriz Swot. Dissertação de Mestrado. UFMS. 2017.

[8] KOTLER, P.- Administração de Marketing - 10aㅡ Edição, 7ํa reimpressão - Tradução Bazán Tecnologia e Lingüística; revisão técnica Arão Sapiro. São Paulo: Prentice Hall, 2000.

[9] MARTINS, L. Marketing: Como se tornar um profissional de sucesso. 1. ed. São Paulo: Digerati Books, 2006.

[10] MARTINEZ, L. F. Uma proposta de ampliação do método de planejamento estratégico no agronegócio (ChainPlan) a partir de uma abordagem de sustentabilidade. Tese de Doutorado. Universidade de São Paulo. São Paulo: 2020. DOI: https://doi.org/10.11606/D.96.2020.tde- 26062020-142250

[11] MATTOS, P.; RODRIGUES, R. G.; Gomes, M A.; MATTOS, P.;GOLlO, S. S. O desenvolvimento do diagnóstico estratégico em propriedades rurais do agronegócio: análiseambiental em uma propriedade rural familiar. Revista InGEPRO. vol. 02, n. 06, 2010

[12] OLIVEIRA, Djalma de Pinho Rebouças de. Planejamento estratégico: conceitos metodologias,prática. 23. ed. São Paulo: Atlas, 2007.

[13] PEDROZO, E. Á.; BEGNIS, H. S. M.; ESTIVALETE, V. F. B. Análise do ambiente competitivo como determinante das escolhas estratégicas no agronegócio: um estudo de caso em uma unidade de produção. Contexto. Porto Alegre. Vol. 5, n. 8 (2. sem. 2005), p. 71-96, 2005.

[14] POLACINSKI, E., GESSI, N. L., ABEGG, D. R., WIETHOLTER, D. L., LAZZARETTI, L.

A. F., ESPANHOL, D. D., WALKER, R. Inovação e sustentabilidade no agribusiness: uma proposta de aplicação de plataformas digitais. Brazilian Journal of Development, v. 7, n. 1, p. 7658-7679, 2021.

[15] PORTER, M. E., Estratégia competitiva: técnica para analise de indústria e da concorrência /M. E. Porter; 
tradução de Elisabeth Maria de Pinho Braga. - 2.ed. - Rio de Janeiro: Elsevier; 2004.

[16] PROENÇA, A. Dinâmica estratégica sob uma perspectiva analítica: reinando o entendimento gerencial. Rio de Janeiro: Universidade Cândido Mendes, ARCHÉ, 1999. ano VIII, n. 23.

[17] SERRA, F.; TORRES, M. C. S. \& TORRES, A. P. Administração Estratégica. Rio de Janeiro:Reichmann e Affonso Editores, 2004.0LIVEIRA, Djalma de Pinho Rebouças de Planejamentoestratégico: conceitos, metodologia e práticas. In: Planejamento estratégico: conceitos, metodologia e práticas. 2002. p. 337-337.

[18] SILVA, Devanildo Braz da; PEREIRA, Marlos da Silva; SPROESSER, Renato Luiz. O planejamento estratégico como ferramenta para obter vantagem competitiva no agronegócio. Anais do Encontro Científico de Administração, Economia e Contabilidade, v. 1, n. 1, 2011.

[19] SILVA, N., A., C; Planejamento Estratégico no Suporte Gerencial de Pequenas Propriedades Rurais. Trabalho de Conclusão de Curso. Especialização em Gestão do Agronegócio. UFPR. Curitiba; 2018.

[20] SOARES, Danilo de Medeiros Arcanjo et al. O planejamento estratégico na apicultura: uma contribuição para a sustentabilidade. Informativo Técnico do Semiárido, v. 10, n. 2, p. 26-30, 2016.

[21] SOUZA, G. M.; AMBONI, N.; ORSSATTO, J. H. C. Planejamento Estratégico no Agronegócio: proposta de aplicação em uma empresa de Santa Catarina. Revista Espacios, v.38, n. 3, 2017.

[22] SERTEK, P.; GUINDANI, A.R.; MARTINS, S.T. Administração e Planejamento Estratégico. 20. ed. Curitiba: Ibpex, 2007. $131 \mathrm{p}$. 


\section{Capítulo 19}

Gestão e Estratégia: Os impactos da COVID-19 e os 10 passos para retomada

\section{Marielle Ferreira Figueiredo \\ Andriéli Ferreira de Araujo \\ Rossana Veiga do Canto}

Rsumo: Um dos papéis fundamentais dos gestores é planejar estrategicamente o seu negócio, independente do tamanho da empresa. Para isso, é preciso ter conhecimento aprofundado sobre o negócio, sobre o mercado e prever as situações, para uma tomada de decisão eficaz. De acordo com a teoria contingencial, baseada no princípio em que nas organizações tudo é relativo, o fator externo acarreta em diversas incertezas. Atualmente, é justamente o ambiente externo que apresenta uma maior ameaça, onde as organizações foram surpreendidas com a crise ocasionada pela pandemia de COVID-19. O objetivo deste estudo foi fazer uma análise da forma que as micro e pequenas empresas foram impactadas pela COVID-19. A pesquisa caracteriza-se como qualitativa e exploratória-descritiva, e os dados coletados em uma análise nos documentos do SEBRAE/RS, informações de um levantamento entre os meses de junho e agosto de 2020. Ainda foram entrevistados os presidentes das Associações Comerciais de Caçapava do Sul e Rosário do Sul, para inter-relacionar à realidade dos gestores. A partir da análise documental e da entrevista constatou-se que os gestores das MPEs pesquisadas, não tem planejamento financeiro adequado, a totalidade não faz reservas para contingências, evidenciando que trabalham no limite financeiro. Outra evidência é a falta de cooperação entre os setores para troca de informações sobre ações estratégicas. Sobre estratégias adotadas para manter os clientes, a maior parte delas não tinham domínio das plataformas digitais e estão em processo de adaptação. Conclui-se que em momentos como este, as empresas precisam inovar nos processos e buscar órgãos de apoio.

Palavras-Chave: COVID-19; Estratégia; MPEs. 


\section{INTRODUÇÃO}

No atual cenário vivenciado pelo o mercado econômico, onde a economia global deparou-se com uma crise econômica e sanitária, causada pela pandemia de COVID-19, visto que o distanciamento social foi necessário e urgente. Os gestores necessitam adaptar-se ao novo cenário e pensar em estratégias de gestão é fundamental, além de uma visão inovadora, empreendedora e adaptativa, para então garantirem a sobrevivência dos seus negócios, independente do tamanho da empresa e do seu segmento de mercado. Para isso, é preciso ter conhecimento aprofundado sobre a empresa, sobre o mercado e encontrar alternativas para prever possíveis situações, para uma tomada de decisão efetiva e eficaz.

De acordo com a teoria contingencial, baseada no princípio em que nas organizações tudo é relativo, o fator externo acarreta em diversas incertezas. Justamente é do ambiente externo que vem a maior ameaça, os empresários foram surpreendidos com a crise ocasionada pela pandemia de COVID-19, que tomou proporções mundiais e pegou os gestores totalmente desprevenidos. 0 objetivo principal deste artigo foi analisar de que forma as MPEs foram impactadas pela pandemia supramencionada.

Desta forma, pensando no momento em que vivemos e na forma como as organizações estão lidando com tamanha recessão econômica, surge o questionamento "Quais são os principais impactos ocasionados pela COVID-19 nas MPEs", o qual é o objetivo geral desse projeto. Para isso, os objetivos específicos são: a) Levantar junto ao Serviço Brasileiro de Apoio às Micro e Pequenas Empresas (SEBRAE/RS) sobre as principais dificuldades apontadas pelas MPEs; b) Relacionar as principais dificuldades apontadas pelo SEBRAE/RS à realidade da classe empresária das cidades de Caçapava do Sul e Rosário do Sul; c) Estimular a adoção de estratégias de adaptação das MPEs com base nas informações levantadas pelo estudo.

A pesquisa caracteriza-se como qualitativa e exploratória-descritiva, e os dados coletados através de uma análise nos documentos do SEBRAE/RS, que fez um levantamento importante nos meses de junho, julho e agosto de 2020. Ainda foram entrevistados os presidentes das Associações Comerciais das cidades de Caçapava do Sul e Rosário do Sul para inter-relacionar à realidade dos gestores locais. 0 estudo ainda apresenta a seguinte estrutura: referencial teórico, metodologia, análise de resultados, considerações finais e referências bibliográficas.

\section{TEORIA CONTINGENCIAL}

Para Chiavenato (2011, pg.: 468) a palavra contingência significa algo incerto ou eventual, que pode suceder ou não, dependendo das circunstâncias.

A teoria da contingência é uma variante que se posiciona dentro das teorias comportamentais, sendo sua principal característica de defender que o curso ideal de uma ação é contingente, ou seja, que tudo depende dentro de situações internas e externas em uma organização. Essa abordagem teve seu início com as pesquisas e o trabalho da socióloga Joan Woodward em 1958.

Diversas abordagens anteriores foram desenvolvidas ao mesmo tempo na década de 1960, elas relatavam que as teorias anteriores falharam e se descuidaram na observação das influências de vários fatores no meio ambiente, á nível de gestão e estrutura organizacional (COLTRO 2015).

Essa teoria estava baseada no princípio de que nas instituições nada é absoluto, tudo é relativo, dependente de algo, que é algo incontrolável pelas organizações, pois estão em um ambiente externo (OLIVEIRA 2012).

A teoria da contingência relata que o melhor estilo de gestão e as melhores decisões dependem de diversos fatores, como por exemplo, do ambiente em que a empresa se encontra, da sua equipe de trabalho e também da sua situação. Ela estimula os gestores a diagnosticar a situação antes da tomada de decisão (LACOMBE 2009).

A Teoria da contingência salienta o comportamento organizacional de forma teórica focando em como as contingências internas e externas, como tecnologia, gestão e o ambiente, afetam o desenvolvimento das organizações. Essa teoria deriva da Teoria Geral da Administração, e com relação a isso, a mesma é aplicada no contexto organizacional, sendo também utilizada como ferramenta de análise da gestão empresarial (MOLINARI; GURREIRO, 2004 apud MEDEIROS 2018).

A visão contingencial de uma organização e da administração consegue afirmar que uma empresa é um sistema composto por outros subsistemas, que é definido por limites que o identificam em relação ao 
ambiente. 0 método contingencial está dirigido como desenhos e sistemas organizacionais adequados para cada tipo de situação específica dentro da organização (CHIAVENATO 2011).

Conforme Chiavenato (2011, pg.: 473) a teoria da contingência enfatiza que não há nada de absoluto nas organizações ou na teoria administrativa. Tudo é relativo. Tudo depende.

A Teoria da Contingência nos proporcionou inúmeras contribuições, ao longo dos anos, para a administração das organizações, como:

- Maior conhecimento no estudo de assuntos administrativos. Essa contribuição foi de grande valia para o estudo e a prática da administração pelas empresas e seus colaboradores;

Nesse entendimento, a teoria também facilitou no processo de isolamento de determinantes situacionais que facilitam o processo decisório nas empresas. Com tudo, a teoria contingencial conseguiu, não somente, trabalhar o todo, mas também as partes, desde que devidamente identificadas.

Cada administrador contingencial sabe que cada empresa é única que precisa ter a sabedoria de antecipar a incerteza e o entendimento do futuro.

- Obrigatório conhecimento e uso de assuntos administrativos de forma global.

Essa contribuição é de uma incrível importância, pois se consolidou com a contribuição inicialmente proporcionada pela Teoria dos Sistemas.

- Contribuição para o desenvolvimento da adhocracia nas empresas (OLIVEIRA 2012).

Com tudo, desde os primórdios da humanidade, nós convivemos com organizações e por causa disso conseguimos adquirir conhecimentos administrativos. Porém, nunca se pode saber tudo sobre administração, os gestores e as empresas precisam estarem em constante aprendizado e evolução para trazer inovações para suas organizações.

A administração se faz, principalmente, com muito estudo, trabalho e uma constante dedicação. Cada situação é diferente da outra, e é por isso que a teoria da contingência é de imensa importância, já que nós mostra que mesmo que um gestor saiba como conduzir o seu negócio, o mesmo precisa estar em constante evolução e preparado para problemas que fogem do controle (LACOMBE 2009).

\section{ESTRATÉGIA}

Na visão de Maximiano (2015) estratégia é um termo usado no mundo contemporâneo com o significado de escolha de meios para realizar objetivos, significado esse que foi tomado do empréstimo do mundo militar.

Estratégia abrange situações de concorrência e também de colaboração. Organizações que são concorrentes uma da outra, fazem alianças estratégias para conseguir ganhar vantagens e assegurar seu desenvolvimento e sobrevivência no mercado altamente competitivo.

No início do século XX, Pierre du Ponto e Alfred Sloan foram os primeiros executivos a aplicar a administração estratégia em suas organizações, logo depois esse conceito se consolidou dentro das empresas, fazendo parte até os dias atuais (MAXIMIANO 2015).

Segundo Sloan (1965 apud Maximiano 2015) o objetivo estratégico de uma empresa é obter retorno do capital. Se, em um caso específico, o retorno em longo prazo não for satisfatório, o defeito deve ser corrigido ou a atividade de ser abandonada.

O pensamento estratégico tornou-se muito importante para que as instituições se mantenham firmes no ambiente de incertezas. As preferências dos consumidores, a economia e aos gostos dos consumidores, que estão sempre mudando, exigindo que as empresas se adaptem rapidamente. Com isso, o planejamento estratégico de ser torna indispensável para as organizações se manterem vivas no mercado atual (GUAZZELLI e XARÃO 2018).

\section{PLANEJAMENTO ESTRATÉGICO}

Para Certo (2003 apud Guazzelli e Xarão 2018), o planejamento é a atividade gerencial básica de uma organização, que deve anteceder todas as demais a ser a base para as ações dos gestores, que devem influenciar, organizar e controlar. 
Pfeiffer (2000) alega que o propósito do planejamento estratégico é tornar o trabalho de uma organização mais eficiente, buscando gerenciar de maneira mais eficaz, tomando decisões mais corretas.

Todo o planejamento vai contribuir para a criação de um norte para que a organização alcance suas metas e objetivos. A administração estratégica é uma contínua ação que tem como objetivo conservar uma organização como um todo (CERTO 2003 apud GUAZZELLI e XARÃO 2018).

Planejamento estratégico é a metodologia administrativa que proporciona sustentação para se estabelecer a melhor direção a ser seguida pela organização, visando ao otimizado grau de interação com os fatores externos não controláveis - e atuando de forma inovadora e diferenciada (OLIVERIA 2012).

Drucker (1998) nota que o planejamento estratégico é um conceito que planeja o futuro em longo prazo, fixando os principais objetivos globais, definindo os caminhos básicos para se atingir esses objetivos e proporcionando os meios para se ter os recursos necessários para essa realização.

Dornelas (2011, p. 85) apresentou um estudo que foi publicado pela Harvard Buisness School, elaborou um estudo que mostra que o ato de planejar aumenta $60 \%$ a probabilidade de sucesso nos negócios.

Chiavenato $(1987$, p. 447) afirma que o planejamento estratégico se refere à maneira que uma empresa pretende aplicar uma determinada estratégia para alcançar os objetivos propostos. É geralmente um planejamento que engloba toda a organização em longo prazo.

O planejamento estratégico em sua elaboração possui três dimensões operacionais: o delineamento, a elaboração e a implementação. 0 delineamento compreende a estrutura metodológica do processo, bem como o profissional que irá auxiliar na elaboração, podendo ser um consultor ou um executivo da empresa. A elaboração fica com a obrigação de identificar as oportunidades e as ameaças do ambiente, avaliar os pontos fortes e fracos e sua capacidade de retirar vantagens das oportunidades, explicitar os objetivos e as metas a serem alcançadas e também desenvolver maneiras para realização das estratégias. Enquanto que a implementação envolverá os assuntos organizacionais, o sistema de informação, orçamentário, sistemas de incentivos, o treinamento e liderança necessária para desenvolver o processo e colocá-lo em prática (OLIVEIRA, 2009 p. 39).

Todo plano requer um prazo para sua implantação. Se não planejarmos no presente, não teremos condições de implantarmos no que desejamos no futuro. 0 planejamento estratégico refere-se ao planejamento sistêmico das metas em longo prazo e dos meios disponíveis para alcança-los, ou seja, aos elementos estruturais mais importantes da empresa e a sua área de atuação, e considerada não só os aspectos internos da empresa, mas também, e principalmente o ambiente externo no qual a empresa está inserida (LACOMBE, 2003).

Os grandes navegadores sempre sabem onde fica o norte. Sabem aonde querem ir e o que fazer para chegar a seu destino. Com as grandes empresas acontece a mesma coisa: elas têm visão. É isso que lhes permite administrar a continuidade e a mudança simultaneamente (COLLINS e PORRAS, 1996).

Para Kotler (1993) planejamento estratégico é definido como processo gerencial de desenvolver e manter uma adequação razoável entre os objetivos e recursos da empresa e as mudanças de oportunidades de mercado. 0 objetivo do planejamento estratégico é orientar e reorientar os negócios e produtos da empresa de modo que gere lucro e crescimento satisfatórios.

Segundo Kotler e Keller (2012) as metas definem onde a unidade de negócio deseja alcançar, a estratégia é um plano de ação para chegar lá. Em seu livro eles apontam as Estratégias Competitiva de Porter que seriam as seguintes:

- Liderança em total custos. A empresa se esforça para produzir e distribuir a custos menores de modo que possa oferecer preços mais baixos que os concorrentes no mercado e conquistar uma grande participação no mercado. As empresas que adotarem essa estratégia não precisam de muita habilidade em marketing. 0 problema é que surgirão concorrentes com custos menores, assim prejudicando a empresa que fundamentou o seu futuro em baixos custos. 
- Diferenciação. A empresa se concentra em um desempenho em uma área importante de benefícios ao cliente, valorizada por grande parte do mercado. A empresa que busca liderança em qualidade, deve utilizar os melhores componentes, montá-los com habilidade, inspecioná-los com cuidado e comunicar efetivamente sua qualidade.

- Foco. A empresa se contra em um ou mais segmentos estreitos de mercado, passa a conhecê-los intimamente e busca a liderança em custos ou diferenciação dentro do segmento-alvo.

\section{METODOLOGIA}

Neste capítulo, apresenta-se o tipo de pesquisa realizada, a amostra selecionada, o instrumento de pesquisa, a forma de coleta dos dados e a análise dos mesmos, a fim de responder os questionamentos apresentados no começo da pesquisa. Quanto aos objetivos o presente estudo classifica-se como exploratório-descritivo e quanto à forma de abordagem do problema, como qualitativo.

A pesquisa exploratória proporciona uma maior familiaridade com o problema, com o objetivo de tornar explícito ou de construir possíveis hipóteses. E a pesquisa descritiva visa descrever as características de uma determinada população, fenônimo ou o estabelecimento de relações entre determinadas variáveis (LEAL E SOUZA, 2006).

Para Pereira (2019, p.86) quanto ao método qualitativo, pode ser entendido como:

No método qualitativo a pesquisa é descritiva, ou seja, as informações obtidas não podem ser quantificáveis. Por sua vez, os dados obtidos são analisados de forma indutiva. Nesse sentido, a interpretação dos fenômenos e a atribuição de significados são básicas no processo de pesquisa qualitativa.

O objetivo principal foi pesquisar "Quais são os principais impactos ocasionados pela COVID-19 nas MPEs" e para que este levantamento fosse possível, a coleta dos dados foi feita em duas etapas, a primeira foi fazer uma análise documental nos relatórios do Serviço Brasileiro de Apoio às Micro e Pequenas Empresas (SEBRAE/RS).

O órgão de apoio fez um levantamento importante com 522 MPEs atendidos pela consultoria e entrevistados ente junho, julho e agosto de 2020, trazendo pontos importantes sobre a situação atual das empresas e principais dificuldades enfrentadas no momento.

Para confrontar as informações que correspondem às realidades diversas do estado, a segunda etapa foi composta por uma entrevista estruturada com os representantes da classe empresária das cidades de Caçapava do Sul e Rosário do Sul/RS (identificados como E1 e E2 respectivamente). Escolhidos por conveniência.

As perguntas elaboradas a partir da revisão da literatura, e ainda com base nos principais desafios dos gestores apontados pelo documento do SEBRAE/RS, versaram principalmente sobre possível situação financeira, manutenção dos empregos, cumprimento de obrigações fiscais e com fornecedores, manutenção e comunicação com clientes, a relação com as entidades de apoio e ainda sobre possível cooperação entre os setores. 
Quadro 1 - Variáveis da coleta de dados

\begin{tabular}{|c|c|}
\hline $\mathbf{N}^{\circ}$ & Itens \\
\hline 1 & $\begin{array}{l}\text { De acordo com os relatos dos empresários da classe que representa, eles enfrentam alguma } \\
\text { dificuldade nesse momento? Quais a principais dificuldades relatadas? }\end{array}$ \\
\hline 2 & $\begin{array}{l}\text { Na sua opinião, as empresas estavam preparadas para enfrentar uma crise? Fazem ou faziam } \\
\text { algum tipo de planejamento estratégico e/ou reservas financeiras para momentos de } \\
\text { contingência e/ou recesso econômica? }\end{array}$ \\
\hline 3 & $\begin{array}{l}\text { Os empresários relatam ter precisado demitir funcionários ou aderiram ao programa do } \\
\text { governo de proteção ao emprego e renda? }\end{array}$ \\
\hline 4 & Os empresários relatam alguma dificuldade em cumprir as obrigações com fornecedores? \\
\hline 5 & Os empresários relatam alguma dificuldade em cumprir as obrigações fiscais? \\
\hline 6 & $\begin{array}{l}\text { Os empresários relatam dificuldades logísticas de entrega de produtos vendidos ou dificuldades } \\
\text { em receber materiais que precisem vir de outros lugares? }\end{array}$ \\
\hline 7 & $\begin{array}{l}\text { Na sua opinião, quais as principais dificuldades relatadas em relação a comunicação com os } \\
\text { clientes? }\end{array}$ \\
\hline 8 & $\begin{array}{l}\text { Na sua opinião, existe algum movimento empresário relevante para modificação dos processos } \\
\text { de comunicação com o cliente? }\end{array}$ \\
\hline 9 & $\begin{array}{l}\text { Existe algum movimento da classe empresária em relação a parcerias estratégicas com outros } \\
\text { setores ou seguimentos para garantir sobrevivência no momento atual? }\end{array}$ \\
\hline 10 & Os empresários tem buscado apoio nas entidades que os representa? \\
\hline 11 & $\begin{array}{l}\text { Na sua opinião, os empresários buscam entre os pares, empresários do mesmo segmento, apoio } \\
\text { para troca de ideias e experiências positivas? }\end{array}$ \\
\hline
\end{tabular}

\section{ANÁLISE DOS DADOS}

A partir da análise documental realizada nos relatórios emitidos pelo SEBRAE/RS, foi possível levantar as principais dificuldades dos gestores do estado do Rio Grande do Sul, para enfrentamento da pandemia. A partir disto e da análise qualitativa das entrevistas com os representantes da classe empresária das cidades de Caçapava do Sul e Rosário do Sul, escolhidos por conveniência, pode-se evidenciar os principais impactos nas MPEs ocasionados pela COVID-19.

De acordo com o levantamento do SEBRAE/RS, no universo das 522 MPEs pesquisadas, questionadas sobre o impacto no faturamento, observou-se uma redução em média de $62 \%$ no período.

Questionados sobre as principais dificuldades relatadas pelas empresas de Caçapava e Rosário do Sul, no momento atual?" R1: "As dificuldades são, inicialmente na queda de faturamento e manter em equilíbrio as suas contas, mas variam entre setores, uns setores mais afetados outros menos prejudicados". R2 "Fechamento do comércio, com a pandemia e agora a instabilidade nas vendas".

0 formato das empresas também precisou ser modificado 47\%, ou seja, 245 delas relataram que só continuaram operando em junho com estrutura adaptada, a necessidade da utilização de ferramentas digitais também cresceu. A importância do uso da tecnologia e das ferramentas digitais aparece nas 
respostas dos entrevistados também, pois quando questionado quais as principais dificuldades relatadas em relação a comunicação com os clientes? responderam "Não saber usar a tecnologia digital, muitos não tinham nenhuma forma de venda online e ainda tem pouco conhecimento de como fazer isso acontecer"(R1) e "Não estavam preparados para usar as mídias sociais"(R2).

Sobre qual tipo de apoio as MPEs mais precisam neste momento, 60\%, 313 empresas relatam a necessidade de uma consultoria em diversas áreas como gestão financeira, remodelagem do negócio, adequação de custos e gestão de crise, seguidos de 59\%, 307 que relatam a maior dificuldade é a falta de capital de giro.

Na sua opinião, as empresas estavam preparadas para enfrentar uma crise? Fazem ou faziam algum tipo de planejamento para momentos de contingência e/ou recessão econômica? R1: "Infelizmente não, poucos empresários fazem algum tipo de planejamento, nem mesmo um fluxo de caixa. Todos viviam no piloto automático ...não tinham reservas para aguentar o tempo de fechamento das empresas ... prova que nosso empresário trabalha sempre no limite, qualquer problemas leva ao desequilíbrio financeiro. A maioria não busca apoio nas entidades representativas, disponibilizamos um produto do Sebrae a custo quase zero, consultorias que ajudariam muito nesse momento, praticamente não houve adesão".

R2: “A maioria, pelos relatos não estavam preparadas, pelo contrário todos estavam com os estoques altos para a próxima estação".

A presente pesquisa, fez o seguinte questionamento, os empresários tem buscado apoio nas entidades que os presenta? R1: "Esse é um dos grandes desafios das entidades representativas no setor empresarial, conseguir convencer o empresário que ela pode ajudar, seja, pela defesa dos interesses junto aos setores competentes, ou seja, pela possibilidade de capacitação. Durante a pandemia disponibilizamos um produto de Sebrae a custo zero, consultorias que ajudariam muito nesse momento, praticamente não houve adesão". R2: "Sim, a título de informações".

Na sua opinião, existe algum movimento empresário relevante para modificação dos processos de comunicação coom o cliente? R1: "Algumas empresas começam a liderar esse processo, mas de forma isolada, não há um movimento fundamentado voltado a um novo processo de comunicação". R2: "Sim, diversas opções e informações".

Foi perguntado aos representantes se existe algum movimento da classe empresária em relação às parcerias estratégicas com outros setores ou seguimentos para garantir sobrevivência no momento atual? R1: "Se existe ainda não está plenamente divulgado". R2: "Sim, com instituições financeira".

Na sua opinião, os empresários buscam entre pares, empresários do mesmo segmento, apoio para troca de ideias e experiências positivas? R1: "Alguns seguimentos isso acontece, mas poucos, a grande maioria trabalha de forma individual, solitária mesmo, não conversa com ninguém sobe o seu ramo. Ainda existe o medo de falar com a chamada "concorrência" o que dificulta perceber que os problemas de um podem ser o de outros e que juntos poderiam buscar uma solução".R2: "Sim, com com certeza".

\section{CONSIDERAC̄̃̃ES FINAIS}

O presente estudo nos permitiu analisar quais foram os principais impactos ocasionados pela pandemia de COVID-19 nas MPEs nas cidades de Caçapava do Sul e Rosário do Sul, juntamente com a realização de uma análise comparativa com o material documental fornecido pelo SEBRAE/RS.

Diante do exposto, apresentado pelo estudo, foi possível concluir que os gestores das MPEs pesquisadas, independente do tamanho da empresa e do segmento de mercado, não tem um planejamento financeiro adequado, a totalidade não faz reservas para possíveis contingências, evidenciando que trabalham no limite financeiro.

Com a pandemia, empresas que não eram consideradas serviços essenciais precisaram ser fechadas, devido ao alto número de infectados pela doença. Com isso, muitos empresários tiveram que encontrar alternativas e inovar para poder continuar com o seu negócio. Na pesquisa, podemos observar que a utilização da tecnologia e de ferramentas digitais, foi uma das principais dificuldades encontradas pelos gestores.

Outra evidência é a falta de cooperação entre os setores para troca de informações sobre ações estratégicas, quanto a um possível aumento nas demissões, podemos concluir que houveram diversas demissões durante esse período, porém muitas empresas aderiram ao programa emergencial do governo de proteção ao emprego e renda e ao parcelamento de tributos, o que desonerou um pouco nesse período. 
Para poder auxiliar essas empresas nesse momento de crise, foi elaborado um e-book com principais estratégias de gestão para MPEs, entregue às entidades representativas para distribuição gratuita aos empresários. 0 e-book "10 PASSOS PARA ALAVANCAR SUA EMPRESA NA CRISE" aborda de forma clara e simples temas como:

\section{Repense sua missão;}

A missão de um negócio é muito importante para os gestores e seus funcionários, ela não só revela o "porquê" de a empresa existir, como também mostra o coração da mesma. É importante repensar a sua missão para que ela esteja sempre alinhada com os valores da empresa, e com isso, ser mais fácil de compreender o próprio negócio, de onde veio e de onde quer chegar.

\section{Crie diferenciais;}

O diferencial é sempre bem-vindo, ainda mais quando se trata de se destacar da sua concorrência, quem tem sempre um diferencial acaba, na maioria das vezes, sendo a principal opção do consumidor, além criar um diferencial competitivo e gerar inovação.

\section{Planeje;}

O planejamento não é a primeira função de um administrador, sem nenhum motivo, se planejar é de grande importância para a eficácia de uma boa administração, o gestor precisa ter metas e objetivos bem definidos para a sua empresa, e com isso, conseguir tomar as melhores decisões para a organização.

4. Aja;

Não se pode ficar parado enquanto seu negócio não está indo bem, por isso, é importante sempre ter um plano reserva para possíveis crises, que auxiliem o seu empreendimento a crescer, algumas coisas que lhe deixam no conforto, vão ter que ser deixadas de lado. Entretanto, o único passo para o sucesso é a inovação.

\section{Gestão do tempo;}

É de grande valia que um empresário saiba gerenciar o seu tempo, afinal ele precisa lidar com os negócios, e não perder tempo com tarefas que não agregam para a sua empresa. É preciso analisar quais tarefas diárias estão lhe custando mais tempo e focar nas prioridades, a tecnologia pode ser sua parceira, já que existe vários cursos on-line e gratuitos que podem ajudar muito no seu empreendimento.

\section{Gestão das emoções;}

Em meio a crises, uma das situações que mais afetam os microempreendedores são, com certeza, o medo e o anseio com seus negócios, para isso é importante cuidarmos da nossa saúde mental e emocional, para assim conseguir tomar sempre as melhoras decisões sobre os negócios.

\section{Gestão financeira;}

Além das gestões das emoções é preciso saber lidar com a parte financeira, por isso tente prolongar os prazos, reveja e analise seu fluxo de caixa e renegocie dividas para evitar os prejuízos, entre em contato com os seus fornecedores. Existem linhas de créditos para capital de giro procure uma que possa te auxiliar nesse momento.

\section{Gestão de pessoas:}

O desenvolvimento de uma empresa se dá através do esforço e dedicação do seu gestor e de colaboradores, gerir pessoas tem sido cada vez mais importante dentro das organizações, pois com funcionários satisfeitos, motivados e com o planejamento certo, a empresa consegue atingir seus objetivos.

\section{Networking;}

O networking de uma empresa é fundamental, ainda mais na crise em que estamos vivendo, procure negócios parecidos com o seu e forme parecerias para apoiar eles e eles lhe apoiarem, é importante ressaltar a participação de ações promovidas por entidades, principalmente as Associações Comerciais que são focadas em auxiliar e ajudar os empresários. 


\section{Presença digital}

Aprenda a usar o meio digital para promover e vender o seu produto, existem vários mecanismos que te ajudam, as mídias sociais são uma boa forma de fazer o marketing do seu negócio, poste fotos, faça stories e com certeza te ajudará a vender bem mais, aprenda a interagir com o seu cliente.

O e-book foi pensando e desenvolvido para ser um material de fácil leitura e compreensão, para que todos os gestores conseguissem utilizar e aplicar em suas respectivas empresas. 0 material encontrado no ebook pode auxiliar diversas empresas, independente do seu tamanho ou segmento de mercado. Porém, mesmo que este produto final tenha sido pensado para auxiliar as organizações durante a pandemia, o conteúdo contido é muito versátil e também pode ser usado em diversos outros momentos, principalmente na criação e no desenvolvimento de um novo negócio.

\section{REFERÊNCIAS}

[1] BRASIL. Medida Provisória nº 963 de $1^{\circ}$ de abril de 2020. Diário Oficial da União: Seção 1 - Extra, Edição 63-D, Brasília DF, p. $1,2020$.

[2] BRASIL. Lei n 14.020 de 6 de julho de 2020. Diário Oficial da União: Seção 1, Edição 128, Brasília - DF, p. 1, 2020.

[3] CHIAVENATO, Idalberto. Introdução à teoria geral da administração. $8^{\circ}$ ed. - Rio de Janeiro, Editora Elsevier, 2011.

[4] COLLINS, James Charles; PORRAS, Jerry I. Feitas Para Durar: Praticas bem sucedidas de empresas visionarias. 6.Ed. Rio de Janeiro: Rocco,1996.

[5] COLTRO, Alex. Teoria geral da administração. Edi. InterSaberes, Curitiba, 2015.

[6] DORNELAS, José Carlos Assis. Plano de negócios - seu guia definitivo. Rio de Janeiro. Elsevier, 2011.

[7] DRUCKER, Peter. Introdução à administração. 3a. ed. São Paulo: Editora Pioneira, 1998.

[8] GUAZZELLI, Arianne Menna; XARÃO, Jacqueline Cucco. Planejamente Estratégico, Editora Sagah, Porto Alegra, 2018. Disponível em: https://integrada.minhabiblioteca.com.br/\#/books/9788595026360/cfi/0!/4/4@0.00:38.1 Acesso: 08. Junh. 2020.

[9] KOTLER, Philip. Administração de Marketing - Edição Compacta. 1aa edição. São Paulo: Editora Atlas, 1993.

[10] KOTLER, Philip; KELLER, Kevin Lane; Administração de Marketing. 14. Ed. São Paulo: Pearson Education do Brasil 2012.

[11] LACOMBE, Francisco José Masset; HEILBORN, Gilberto Luiz José. Administração: Princípios e Tendências. 1. Ed. São Paulo: Saraiva, 2003.

[12] LACOMBE, Francisco José Masset. Teoria geral da administração. Editora Saraiva, São Paulo, 2009. Disponível em: https://integrada.minhabiblioteca.com.br/\#/books/9788502089181/cfi/3!/4/4@0.00:0.00 Acesso: 05 junh. 2020.

[13] LEAL, Alzira Elaine Melo; SOUZA, Carlos Eduardo Gerzson. Construindo o Conhecimento Pela Pesquisa: Orientações Básicas para Elaboração de Trabalhos Científicos. Santa Maria, Sociedade Vicente Pallotti, 2006.

[14] MARTINS, Gilberto de Andrade, THEÓPHILO, Carlos Renato. Metodologia da investigação científica para ciências sociais aplicadas. $3^{\circ}$ ed. São Paulo: Atlas, 2016. Disponível em: https://integrada.minhabiblioteca.com.br/\#/books/9788597009088/cfi/6/12!/4@0:0 Acesso: 08 junh. 2020.

[15] MAXIMIANO, Antonio Cesar Amaru. Introdução à teoria geral da administração. $3^{\circ}$ ed. - São Paulo, Editora Atlas, 2015. Disponível em: https://integrada.minhabiblioteca.com.br/\#/books/9788522495559/cfi/4!/4/4@0.00:0.00 Acesso: 20 junh. 2020.

[16] MEDEIROS, Victor Hugo Souza. Teoria da Contingência: um estudo sobre a evidência dos fatores contingenciais em empresas do setor de telecomunicação listadas na B3. Artigo apresentado à faculdade de Uberlândia como requisito para obtenção do título de Bacharel em Ciências Contábeis. Uberlândia - MG, 2018

[17] OLIVEIRA, Djalma de Pinho Rebouças; Planejamento Estratégico. 26aㅡ ed, São Paulo: Atlas, 2009.

[18] OLIVEIRA, Djalma de Pinto Rebouças de. Teoria geral da administração: uma abordagem prática. $3^{\circ}$ ed. Editora Atlas, São Paulo, 2012. Disponível em: https://integrada.minhabiblioteca.com.br/\#/books/9788522475018/cfi/4!/4/2@100:0.00 Acesso: 20 junh. 2020.

[19] PEREIRA, José Matias-, Manual de metodologia da pesquisa científica. $4^{\circ}$ ed. São Paulo: Atlas, 2019. Disponível em: https://integrada.minhabiblioteca.com.br/\#/books/9788597008821/cfi/6/10!/4/12@0:0 Acesso: 10 junh. 2020.

[20] PFEIFFER, Peter. Planejamento estratégico municipal no Brasil: uma nova abordagem. Brasília: ENAP, 2000.

[21] SEBRAE/RS. Monitoramento dos Pequenos Negócios na Crise, $3^{\circ}$ edição, 2020. 


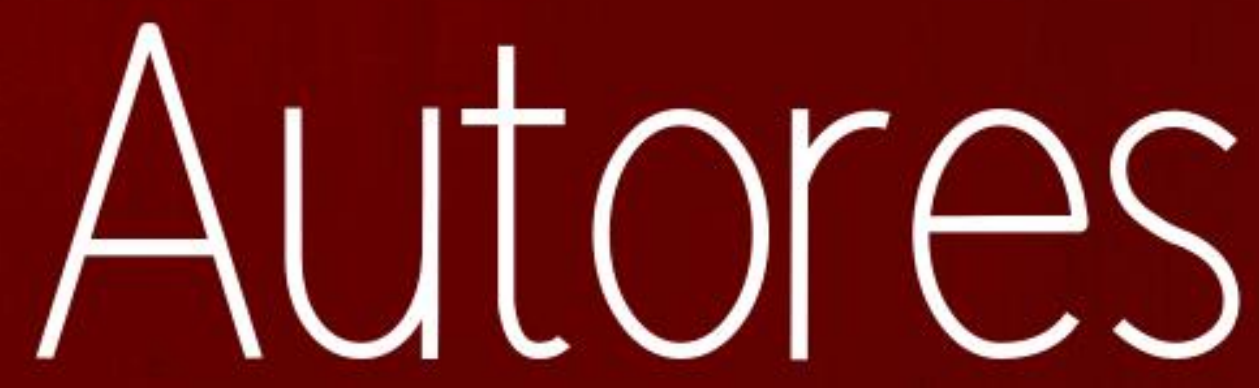




\section{ELIZÂNGELA DE JESUS OLIVEIRA (ORGANIZADORA)}

Professora Doutora da Universidade Federal do Amazonas. Doutorado em Administração pela UNIMEP - UNIVERSIDADE METODISTA DE PIRACICABA e Mestre em Administração pela FPL FUNDAÇÃO PEDRO LEOPOLDO DE MINAS GERAIS. Possui graduação em Administração pela UNIMONTES- Universidade Estadual de Montes Claros (2008). Especialista em Design Instrucional para Educação a Distância pela UNIFEI- Universidade Federal de Itajubál. Possui experiência como docente na Graduação Presencial dos cursos de Administração, Engenharias, e Cursos Superiores em Tecnologia de Logística, Comércio Exterior e Gestão Portuária e Gestão de Recursos Humanos. Estuda o tema felicidade no trabalho nas organizações e desenvolve consultoria na área de gestão de pessoas.

\section{RUTE HOLANDA LOPES (ORGANIZADORA)}

Pesquisadora e Professora Adjunto da Universidade Federal do Amazonas - UFAM/ ICET (Economia Rural, Introdução à Economia e Gestão Ambiental). Coordenadora do Núcleo de Economia, Tecnologia, Gestão e Inovação; Coordenadora Administrativa da Incubadora do ICET ICETech, Vice coordenadora do Curso de Engenharia de Produção, Coordenadora do COMEXI Comitê de Extensão do ICET. Doutora em Ciências do Ambiente e Sustentabilidade da Amazônia pela UFAM (2015). Mestra em Desenvolvimento Regional pela UFAM (2008). Graduada em Ciências Econômicas pelo CIESA (2001), MBA em Empresas e Negócios pelo CIESA (2003). Pesquisas na área de: Economia Rural, Economia Regional, Engenharia de Produção, Produção Agrícola, Cadeias Produtivas Locais e Agricultura Familiar, Gestão Ambiental, Sustentabilidade. Possui experiência como consultora econômica e ambiental com trabalhos técnicos em Diagnósticos, Prognósticos, Caracterizações e Análises de Contexto dos municípios da Região Metropolitana de Manaus

\section{MARIA ELIANE BARBOSA LACERDA (ORGANIZADORA)}

Administradora com especialização em docência do ensino superior. Foi Instrutora de cursos no CETAM e Senac. Administradora no ICET UFAM.

\section{LEIA MARIA ERLICH RUWER (ORGANIZADORA)}

Doutora em Serviço social pela UNESP/SP (2011), possui mestrado em Engenharia de Produção pela UFSC/SC (2004). É especialista em Administração pela UNIOESTE/PR (2000). Graduada em Administração pela UNIOESTE/PR (1994). Atua na Docência no Ensino Superior na Área de Gestão Estratégica de Pessoas e Marketing (graduação, pós-graduação, MBAs e educação corporativa). Possui ampla bagagem generalista de estudos em empresas de pequeno, médio e grande porte nacionais e multinacionais. Experiência profissional de 21 anos no mercado financeiro, e atua com Consultoria Organizacional e Desenvolvimento de Conteúdo; é avaliadora de cursos do INEP/MEC; é Membro de comissão científica de revistas e eventos diversos.

\section{OSVALDO SENA GUIMARÃES (ORGANIZADOR)}

Graduação em Engenharia Civil pela Escola de Engenharia Kennedy (1983), Ênfase em Engenharia de Transportes EEK (1983), Análise De Sistemas - UFMG(1985), Especialização em Gestão de Projetos de Engenharia IEC/PUC (2012), Mestrado em Estratégia FEAD (2005). Professor do curso de Engenharia Civil da Universidade do Estado de Minas Gerais (2015-2017 Divinópolis). Professor na Faculdade Senac Minas. Atua na área de ensino superior desde 1988 como Professor, Coordenador de Curso, Coordenador de Extensão, Coordenador de Iniciação Científica e de Préincubadora de base Tecnológica. Atua na área de Engenharia, Computação e Projetos desde 1984.

\section{ADRIANA GRESIELLY FABRINI}

Possui graduação em Administração com habilitação em Comércio Exterior pela Universidade Estadual de Ponta Grossa (2002), especialização em Gestão Industrial (2004) e Mestrado em Engenharia de Produção (2007), ambos pela Universidade Tecnológica Federal do Paraná, Doutora 
em Administração pela Universidade Positivo - Curitiba. Estágio Doutoral (Sanduíche) com apoio financeiro da Cooperação de Aperfeiçoamento de Pessoal de Nível Superior - CAPES, em 2017 na Aalborg University - Dinamarca sob orientação do Prof. Dr. Arnim Decker. Atualmente é professora adjunta da Universidade Estadual de Ponta Grossa para o curso de Administração com linha de formação em Comércio Exterior. Possui projeto de pesquisa na área de Gestão de Negócios Internacionais, especialmente na internacionalização de empresas instaladas em mercados emergentes.

\section{ALESSANDRA BANDEIRA DA ROSA}

Possui graduação em Ciências Contábeis pela Universidade Metodista de São Paulo(2005), especialização em Linguagens Verbais Visuais e suas Tecnologias pelo Instituto Federal Sul-RioGrandense(2012), especialização em MBA Gestão Estratégica de Negócios pela Universidade Federal de Pelotas(2018), especialização em Mídias em Educação pelo Instituto Federal Sul-RioGrandense(2018) e especialização em Pós graduação em Ciências Contábeis pela Universidade Federal do Rio Grande(2013). Tem experiência na área de Administração, com ênfase em Ciências Contábeis.

\section{ALEXSANDRA CAMILA ZAGULSKI IENSEN}

Graduada em Ciências Contábeis pela Universidade Estadual de Ponta Grossa (2021).

\section{ALISON SILVA FERREIRA}

Mestrando em Contabilidade pela Universidade Federal da Bahia (UFBA). Especialista em Gestão Ambiental pela Universidade Cândido Mendes e em Gestão Contábil e Finanças Empresariais pela Faculdade Católica Paulista. Graduado em Ciências Contábeis pela Faculdade Anísio Teixeira (FAT) e Graduando em Administração Pública pelo Instituto Federal Baiano (IFBA). Pesquisador na área de Contabilidade Ambiental, Finanças e Educação.

\section{AMANDA EDUARDA DA SILVA}

Graduanda em Administração com habilitação em Comércio Exterior pela UEPG - Universidade Estadual de Ponta Grossa. Formada como Técnica de Administração no ano de 2019. Participou do projeto de extensão de empresa Junior como Diretora de Marketing no ano de 2020.

\section{ANDRÉ FELIPE QUEIROZ}

Professor EBTT do Instituto Federal de Educação, Ciência e Tecnologia de Mato Grosso do Sul (IFMS). Graduado em administração e em ciências contábeis, especialista em gerência contábil, financeira e auditoria e mestre em administração. Atualmente é doutorando em administração pela Universidade Federal de Mato Grosso do Sul.

\section{ANDRIÉLI FERREIRA DE ARAUJO}

Graduanda em Administração pelo Centro Universitário da Região da Campanha (URCAMP) campus São Gabriel - RS. Atualmente desenvolve suas atividades junto ao Banco Bradesco S.A. no cargo de Escriturária.

\section{BRASILINO JOSÉ FERREIRA NETO}

Mestre em Controladoria e Contabilidade pela Universidade de São Paulo, especialista em Auditoria e Análise Contábil, pela PUC Goiás, graduado em Ciências Contábeis pela PUC Goiás. Professor Assistente do Curso de Ciências Contábeis da PUC Goiás. 


\section{CAIO MOLDENHAUER PERET}

Doutor em Ciência e Engenharia de Materiais pela UFSCar, além de possuir graduação e mestrado nessa mesma instituição. Possui MBA em Gestão de Negócios pelo IBMEC, e é certificado PMP pelo Project Management Institute, e Green Belt em Lean Six Sigma. É autor de diversos artigos publicados em eventos e revistas nacionais e internacionais, além de patentes no Brasil e exterior. Atua com consultoria empresarial, Gestão de Projetos e Portfólios, Engenharia e Desenvolvimento de Produtos e Processos. Tem grande interesse em utilização de conceitos de Agilidade em gestão de portfólios e de desenvolvimento tecnológico.

\section{CAROLINA GABARRA MARQUES GONÇALVES}

Formada em Administração Pública pela Fundação João Pinheiro e graduanda em Direito pela Universidade Federal de Minas Gerais. Atualmente, trabalha na Assessoria de Parcerias da Secretaria Estadual de Saúde.

\section{CÁSSIA JAQUELINE THEOBALD}

Formada em Administração pela Universidade Estadual do Oeste do Paraná e pós-graduada em Gestão Empresarial pela instituição Legale. Atualmente é administradora de uma micro empresa que trabalha com serviços de pet shop, atuando de uma maneira holística em todas as atividades da empresa. Trabalha também como voluntária em projetos que visam compartilhamento de experiências e aprendizados com jovens e ainda, se dedica no aprendizado de outras línguas. Atualmente, fala espanhol, inglês e coreano além do português.

\section{DEISIVANI CAROL LIMA DOS SANTOS}

Graduada em Tecnologia em Gestão do Agronegócio pelo Instituto Federal de Mato Grosso do Sul Campus Ponta Porã - 2021, há 5 anos trabalha na área de armazenagens de grãos, e atualmente à dois anos e meio trabalha no setor administrativo na empresa BL Armazéns.

\section{EDUARDO LEITE DE SOUZA}

Graduado em Administração, na Universidade Católica de Pelotas. Atualmente é graduando em Ciências Econômicas e mestrando em Desenvolvimento Territorial e Sistemas Agroindustriais na Universidade Federal de Pelotas, atuando na linha de pesquisa de Desenvolvimento Territorial. Integrante do Núcleo de Estudos em Economia e Agriculturas (NEA)/UFPEL. Tem interesse nos temas: Mercado Financeiro, Administração de empresas, Plano de negócios, Gestão de propriedade rural, Desenvolvimento territorial, Inovação, Transição e Sustentabilidade. (Texto informado pelo autor)

\section{ELIANE IARA BENDIX}

Professora e pesquisadora do curso de Ciências Contábeis da Universidade Estadual de Ponta Grossa desde 1999. Mestre em Controladoria pela Unopar. Especialista em Contabilidade Gerencial pela UEPG. Graduada em Ciências Contábeis pela UEPG. Experiência na área contábil com ênfase em controladoria. Atuante em projetos de extensão e pesquisa. Pesquisas voltadas às temáticas da contabilidade e o meio ambiente, Terceiro Setor e custos voltados para as micro e pequenas empresas. Atualmente participa do projeto de pesquisa 'Temáticas contemporâneas da contabilidade a partir de enfoques sobre a ética, compliance e sustentabilidade nos negócios'.

\section{ELINELSON PINHEIRO DE SOUZA}

Possui graduação em Engenharia de Produção pela Universidade Estadual do Pará (2003), especialização em Engenharia de Segurança do Trabalho pela Universidade da Amazônia (2005) e especialização em Formação Pedagógica na Área de Matemática pela Universidade do Vale do Acaraú (2008). Trabalhou dez anos em unidades de processamento de madeira serrada e de toras, também atuou como Técnico Florestal em Engenharia de Produção no Instituto de 
Desenvolvimento Florestal e da Biodiversidade do Pará - IDEFLOR-BIO, tendo contribuído com ferramentas e documentos para o monitoramento dos contratos de concessão florestal sobre gestão do IDEFLOR-BIO. Atualmente trabalha como Docente EBTT do IFPA - Campus Tucuruí e faz o Mestrado Profissional em Administração pela Universidade de Fortaleza. Tem experiência na área de Produção Industrial com ênfase em controles de produção, estoques e planejamento de capacidades produtivas e na área de Segurança do Trabalho com ênfase em controle de riscos.

\section{ELIS REGINA DE OLIVEIRA}

Doutora em Ciências Ambientais. Mestre em Agronegócios (UFG). Graduação em Ciências Econômicas (PUC Goiás) e Ciências Atuariais (UFRJ). Professora Assistente no Curso de Ciências Contábeis da PUC Goiás.

\section{EVELIN CRISTINA DE GOES}

Possui graduação em Gestão de Recursos Humanos - Faculdades Integradas Santa Cruz de Curitiba. Especialização em MBA em Gestão de Recursos Humanos - Faculdades Integradas Santa Cruz de Curitiba.

\section{EVELYN CRISTINA SILVA}

Graduada em Administração de Empresas pela Faculdade de Estudos Sociais do Espírito Santo. Pós-graduanda em Comércio Exterior pela Universidade Paulista. Pós-Graduanda em Gestão Empresarial e Inteligência Executiva pela Faculdade Sociais do Espírito Santo. Possui experiência em importação marítima.

\section{GABRIELITO RAUTER MENEZES}

Doutor em Economia Aplicada pela Universidade Federal do Rio Grande do Sul (2015). Atualmente é Professor Adjunto da Universidade Federal de Pelotas e Coordenador do LabReg (Laboratório de Economia Regional). Tem experiência nas áreas de Economia Regional, Empreendedorismo e Métodos Quantitativos.

\section{INÁCIO FERREIRA FAÇANHA NETO}

Mestre em Administração e Controladoria pela Universidade Federal do Ceará (UFC). Professor Assistente do Curso de Administração do Centro de Estudos Superiores de Codó - CESCD da Universidade Estadual do Maranhão - UEMA

\section{JESSICA HENEQUIM}

Bacharel em Ciências Contábeis

\section{JOCELINO ANTONIO DEMUNER}

Graduação: Engenharia Civil pela Universidade Federal do Espírito Santo (UFES). Especialização: Transformação Digital na Educação pelo Instituto de Gestão e Tecnologia da Informação (IGTI) . Mestrando em Tecnologias Emergentes em Educação pela Must University.

\section{JULIA REGINA MARTINS}

Bacharel em Ciências Contábeis 


\section{JULIANE ANDRESSA PAVÃO}

Professora do Departamento de Ciências Contábeis na Universidade Estadual de Maringá. Mestre em Contabilidade pela Universidade Federal do Paraná. Pesquisadora na área da Contabilidade Gerencial e Pública, Gestão Pública e Políticas Públicas.

\section{KERLA MATTIELLO}

Professora Adjunta do Departamento de Ciências Contábeis na Universidade Estadual de Maringá. Doutora em Administração Pública e Governo pela Fundação Getúlio Vargas - FGV/SP. Professora na Graduação em Ciências contábeis e Pós-Graduação Stricto Sensu em Políticas Públicas. Pesquisadora na área da Contabilidade Pública, Gestão Pública e Políticas Públicas.

\section{LAURA CECÍLIA RODRIGUES REIS}

Formada em Administração Pública pela Fundação João Pinheiro e pós-graduanda em Direito Administrativo pela PUC Minas. Atualmente, trabalha na Diretoria Central de Atendimento Presencial da Secretaria Estadual de Planejamento e Gestão.

\section{LESLEY SOARES BUENO}

Doutorado em Ciências Ambientais e Sustentabilidade Agropecuária pela Universidade Católica Dom Bosco-UCDB,Mestre em Zootecnia pela Universidade Federal da Grande Dourados-UFGD, Pós-Graduação em Administração Financeira e Controladoria, graduação em Administração de Empresas com ênfase no Agronegócio e Ciências Contábeis pelo Centro Universitário da Grande Dourados - UNIGRAN. Possui dezessete anos de experiência em agroindústrias nas áreas administrativas, controle operacional e planejamento estratégico na função de Programador de Produção. Atualmente é Professor do Instituto Federal de Educação, Ciência e Tecnologia de Mato Grosso do Sul, Campus de Ponta Porã.

\section{LETÍCIA RIBEIRO GASPARINI}

Graduanda em Ciências Contábeis, Universidade Estadual de Maringá

\section{LUANA LIA SCHMITZ}

Bacharel em Ciências Contábeis

\section{LUCIANE SILVA FRANCO}

Graduação em Administração - Universidade Estadual do Paraná (UNESPAR), Mestre em Engenharia de Produção - Universidade Tecnológica Federal do Paraná (UTFPR), Mestre em Desenvolvimento Comunitário - Universidade Estadual do Centro-Oeste (UNICENTRO), Doutoranda em Administração - Pontifícia Universidade Católica do Paraná (PUC-PR)

\section{LUCIANO TRENTIN}

Doutor em Ciências Contábeis e Administração pela Fundação Universidade Regional de Blumenau - FURB (2021); Mestre em Engenharia da Produção pelo Centro Universitário Tupy - UNISOCIESC (2017); Especialista em Controladoria e Finanças pela Pontifícia Universidade Católica do Paraná PUC (2011) e Gestão de Recursos Humanos pela Universidade do Oeste de Santa Catarina UNOESC (2000); Graduado em Administração pela Universidade do Planalto Catarinense UNIPLAC (1999). Professor convidado da Universidade do Vale do Itajaí - UNIVALI do curso de Pós-Graduação Lato Sensu em Especialização em Engenharia de Segurança do Trabalho e Engenharia de Manutenção Industrial; Professor conteudista no Centro Universitário Leonardo da Vinci - UNIASSELVI. Experiência de 20 anos nas áreas de Gestão Executiva de Recursos Humanos, Qualidade e Administração Geral em empresas de grande porte, em processos de crescimento, 
transformação, fusão e aquisição. Foco em posicionamento estratégico, gestão eficiente dos recursos, gestão fabril e operações, inovação, tecnologia e finanças, tendo atuado em empresas como: Klabin, Teleperformance, Univali, Unoesc, Arxo e CMJ Têxtil. Atua com pesquisa e ensino principalmente nos seguintes temas: gestão de recursos humanos; gestão da qualidade; lean manufacturing; modelos de maturidade organizacional; higiene ocupacional.

\section{LUÍS DE PAULO COSTA}

Formado em Administração Pública pela Fundação João Pinheiro e pós-graduado em Gestão de Projetos pela PUC Minas e também em Liderança e Desenvolvimento de Equipes pelo Centro de Estudos de Especialização e Extensão. Atualmente, trabalha na Diretoria Central de Atendimento Presencial da Secretaria Estadual de Planejamento e Gestão.

\section{MARIA PAULA FERREIRA MACHADO}

Graduada em Ciências Contábeis pela Universidade Estadual de Ponta Grossa (2021). Atualmente atua como Analista Contábil Trainee em um Escritório Contábil. Tem interesse em Auditoria e Controladoria.

\section{MARIELLE FERREIRA FIGUEIREDO}

Graduanda em Administração pelo Centro Universitário da Região da Campanha (URCAMP) campus São Gabriel - RS.

\section{MIRIAN GOMES CONCEIÇÃO}

Mestra em Contabilidade pela Universidade Federal da Bahia (UFBA), Professora do Departamento de Ciências Sociais Aplicadas (DCIS) da Universidade Estadual de Feira de Santana (UEFS) e do Curso de Ciências Contábeis da Faculdade Anísio Teixeira (FAT). Membro da Comissão de Contabilidade Aplicada ao Setor Público do Conselho Regional de Contabilidade do Estado da Bahia (CRCBA), Pesquisadora em temas ligados, principalmente, à Contabilidade Social e Ambiental, Educação e Pesquisa Contábil, Diversidade e Inclusão em Contabilidade e Gestão de Resíduos Sólidos. Co-autora de livros e autora de artigos científicos.

\section{MONIKA FRITZ}

Graduada em Administração pela Faculdade Moraes Junior Mackenzie Rio. Mestrado em Tecnologia na área de Gestão em Tecnologia, pelo Centro Federal de Educação Tecnológica Celso Suckow da Fonseca-Cefet-RJ. Doutoranda em Projetos (Resolução de Conflitos e Mediação) pela FUNIBER - Fundação Universitária Iberoamericana.

\section{NATÁLIA DO AMARAL}

Graduanda em Administração com linha em comércio exterior pela UEPG (Universidade Estadual de Ponta Grossa). Atua como assistente de gestão estratégica e marketing do escritório de contabilidade, Delta Assessoria Contábil. Realizou diversos cursos da área de empreendedorismo, financeira e marketing. Participou do projeto de extensão de empresa Júnior como vice presidente no ano de 2020.

\section{PEDRO DA SILVA SOUSA}

Bacharel em Administração pela Universidade Estadual do Maranhão - UEMA, Centro de Estudos Superiores de Codó - CESCD 


\section{PEDRO ZORZETTI DE PAIVA}

Graduado em Ciências Contábeis (PUC Goiás), com experiência de intercâmbio. Atua na Empresa Bayer (SP).

\section{POLYANA RODRIGUES DO CARMO SILVA}

Formada em Administração Pública pela Fundação João Pinheiro, pós-graduanda em Gestão de Projetos pela PUC Minas e graduanda em Letras pela Universidade Federal de Minas Gerais. Atualmente, trabalha na Diretoria Central de Atendimento Eletrônico da Secretaria Estadual de Planejamento e Gestão.

\section{ROBERTO RIVELINO MARTINS RIBEIRO}

Professor Adjunto do Departamento de Ciências Contábeis na Universidade Estadual de Maringá. Doutor em Administração Pública e Governo pela Fundação Getúlio Vargas - FGV/SP. Professor na Graduação em Ciências contábeis e Pós-Graduação Stricto Sensu no Mestrado Profissional em Rede Nacional em Propriedade Intelectual e Transferência de Tecnologia para Núcleos de Inovação Tecnológica - PROFNIT. Pesquisador na área da Contabilidade Pública, Gestão Pública e Políticas Públicas.

\section{RONIVALDO ALCEBÍADES FERREIRA}

Doutorando e Mestre em Ciências Contábeis pela Fucape Business School, especialista em Auditoria e Perícia Contábil pela PUC Goiás, especialista em SPED pelo IPOG, Graduado em Ciências Contábeis pela PUC Goiás, professor de graduação na Escola de Gestão em Negócios PUC Goiás.

\section{ROSALY MACHADO}

Professora de Contabilidade na Universidade Estadual de Ponta Grossa (PR); doutora no Programa de Pós-Graduação em Administração da Universidade Positivo - Curitiba (PR); mestre em Engenharia de Produção pelo Programa de Pós-Graduação da Universidade Tecnológica Federal do Paraná; Especialista MBA, Contabilidade, Finanças e Auditoria pela Faculdade Uniandrade; graduada em Bacharelado no curso de Ciências Contábeis (UEPG). Atualmente coordena o projeto de pesquisa Temáticas contemporâneas da contabilidade a partir de enfoques sobre a ética, compliance e sustentabilidade nos negócios.

\section{ROSSANA VEIGA DO CANTO}

Mestre em Engenharia da Produção pela UFSM, Bacharel em Administração pela UNIFRA, atualmente coordenadora do Curso de Administração no Centro Universitário da Região da Campanha (URCAMP) campus São Gabriel - RS.

\section{SÉRGIO HENRIQUE ARRUDA CAVALCANTE FORTE}

Graduado em Engenharia Civil pela Universidade Federal do Ceará (1982) e em Administração de Empresas pela Universidade Estadual do Ceará (1984). Mestre em Administração de Empresas pela Fundação Getulio Vargas - SP (1988) e Doutor em Administração de Empresas pela Fundação Getulio Vargas - SP (1995). Professor titular da Universidade de Fortaleza-UNIFOR desde 1996, lotado no Programa de Posgraduação em Administração (PPGA) e no Centro de Comunicação e Gestão (CCG) da UNIFOR. Atua como professor, pesquisador e consultor na área de Administração, com ênfase em Estratégia Empresarial, Cenários, Governança Corporativa, Negócios Internacionais, Empreendedorismo e Métodos de Pesquisa. Foi coordenador do curso de Mestrado em Administração da UNIFOR de 1996 a 2008) e coordenador do Núcleo de Pesquisa do Centro de Ciências Administrativas da UNIFOR de 2001 a 2008). Foi coordenador de Área de Gestão Internacional da Anpad de 2006 a 2009. Foi membro do comitê de avaliação da Capes da área 027 de Administração, Contabilidade e Turismo e é Consultor Ad hoc da CAPES, CNPq, FUNCAP e Universidade Mackenzie. É coordenador de temas e parecerista de eventos de destaque na área, e 
ainda membro do comitê e parecerista de principais periódicos nacionais qualificados pela CAPES. Foi coordenador do Tema Estratégia Corporativa e Stakeholders do Semead da USP de 2014 a 2018. Foi coordenador do Programa de Pós-graduação em Administração (PPGA) da UNIFOR de 2015 a 2017 . Foi editor chefe da Revista de Ciências Administrativas-RCA da UNIFOR de 2014 a 2018. Coordena o Grupo de Pesquisa em Estudos Avançados e Aplicados de Estratégia-ESAE no PPGA da UNIFOR.

\section{SHIRLEY VARGAS VICENTE}

Bacharel em Ciências Contábeis

\section{SONIA LUÍZA BERNET DA LUZ}

Graduação em Administração pela Faculdade de Ciências Administrativas e Comércio Exterior do Paraná. Pós-graduação em Qualidade \& Produtividade pela UFPR Pós-Graduação em Gestão Empresarial - MBA pela Fundação Getúlio Vargas. Mestre do Curso o Internacional em Administração e Direção de Empresas pela Universidad Europea del Atlántico.

\section{SONIA MARIA DA SILVA GOMES}

Professora Titular da Faculdade de Ciências Contábeis/UFBA, desde 1991, doutora em Engenharia da Produção, Co-fundadora da BRASFI, pesquisadora da área de contabilidade para sustentabilidade, com ênfase: em evidenciação de mudanças e riscos climáticos e educação contábil para sustentabilidade. Vice-presidente Técnica do Conselho Regional de Contabilidade do Estado da Bahia (CRCBA). Organizadora do livro Controladoria Ambiental: gestão social, análise e controle publicado pela Atlas/Gen. Autora e co-autora de outros livros e vários artigos científicos.

\section{SUZETE ANTONIETA LIZOTE}

Doutora em Administração e Turismo na Universidade do Vale do Itajaí, Biguaçu, Santa Catarina, Brasil. Docente na Universidade do Vale do Itajaí - Escola de Negócios, Mestrado Profissional em Gestão, Internacionalização e Logística (PMPGIL) e Mestrado e Doutorado em Administração (PPGA). Biguaçu, Santa Catarina, Brasil.

\section{VALÉRIA SUN HWA MAZUCATO}

Graduada em Administração pela Universidade Federal do Mato Grosso do Sul (UFMS), possui mestrado em Administração pela Universidade Municipal de São Caetano do Sul (USCS) e atualmente cursa Engenharia Sanitária e Ambiental. Atua como professora e pesquisadora do Instituto Federal de Educação Ciência e Tecnologia de Mato Grosso do Sul e coordena a unidade de incubação de empresas do IFMS (TecnoIF) no Campus de Ponta Porã MS.

\section{VIRGILIUS DE ALBUQUERQUE}

Doutor em Administração pela FGV-EBAPE/RJ com intercâmbio acadêmico na University of North Carolina at Chapel Hill. Mestre em Relações Internacionais pela PUC/RJ. Pós-Graduação em Engenharia de Produção pela COPPE/UFRJ. MBA em Finanças pelo IBMEC/RJ. MBA promovido pela COPPEAD/UFRJ e VALE. Graduação em Engenharia de Produção pela UFRJ. Empregado da VALE. Atuação profissional na ex-Rio Doce International S.A., Bruxelas. Atividades didáticas nas instituições IBMEC-RJ, ESPM-RJ, EBAPE/FGV, UNIRIO e UFRJ, campus Macaé. Atualmente, servidor público do Tribunal de Contas da União e professor adjunto da UERJ, na Faculdade de Administração e Finanças. Experiência nas áreas de administração pública e empresarial, economia, finanças, estatística multivariada, modelo de equações estruturais, ciência política, economia política, comércio internacional e relações internacionais. 


\section{WENDELINO FANG}

Possui graduação em Gestão de Cooperativas pelo Instituto Federal Sul-Rio-Grandense (2015). Especialista Controladoria e Finanças - Universidade Católica de Pelotas, Mestrando no Programa Desenvolvimento Territorial e Sistemas Agroindustriais - UFPEL. Piloto de Aeronaves. Instrutor de Voo. Atuou como Instrutor de Voo em curso de Extensão da Universidade Federal de Pelotas UFPEL. 


\section{www.poisson.com.br contato@poisson.com.br}

@editorapoisson 